\title{
$\begin{array}{llll}3 & 1822 & 00852 & 1502\end{array}$
}

\section{The came}

of

British Last Arrica

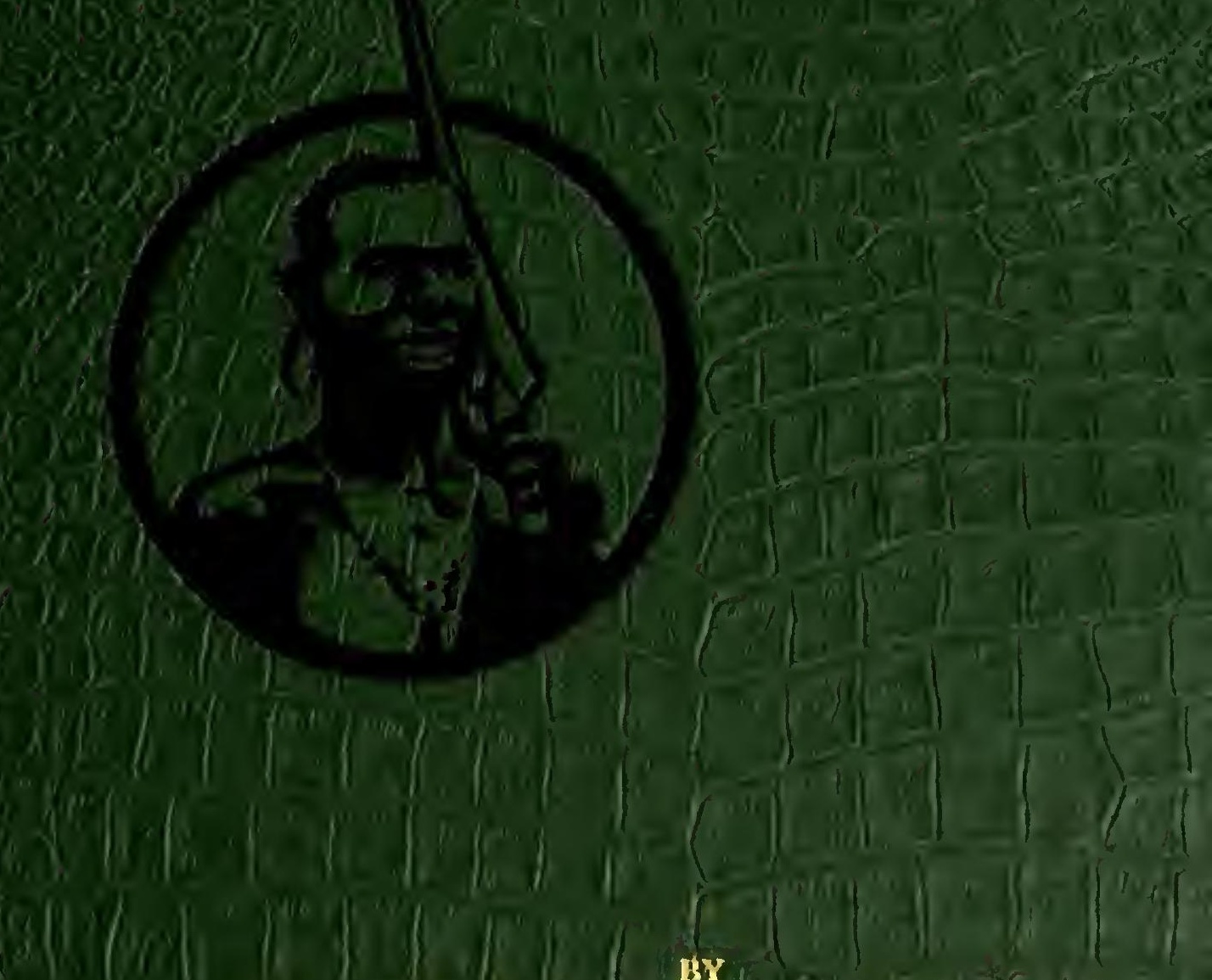

bY

Capt. C. H. Stigand, F.R.C.S., F.Z.S. 


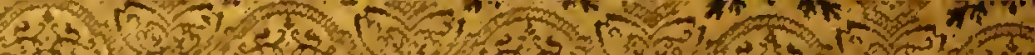

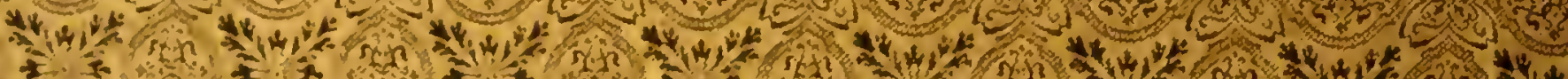

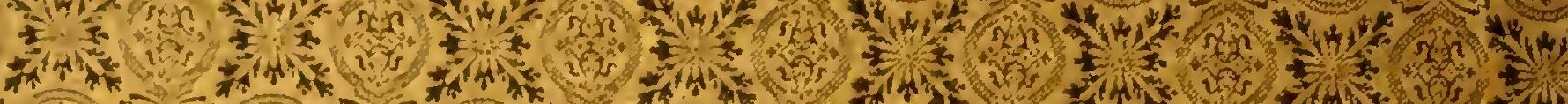

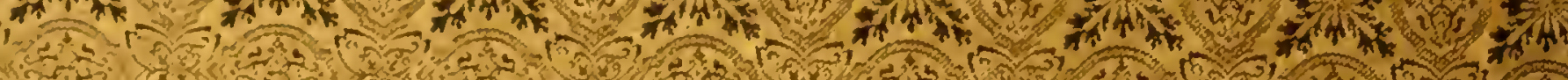

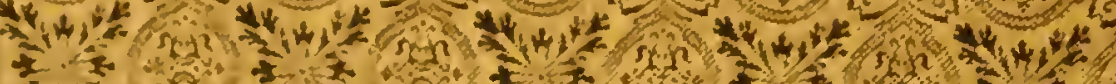
*)

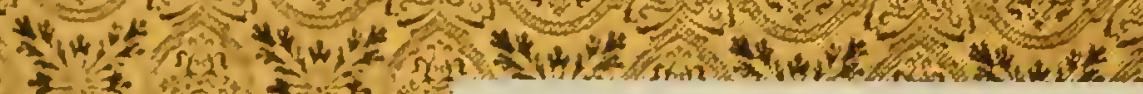 tintint
H(w)

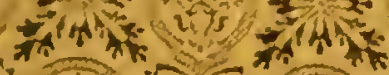

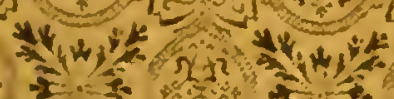 * ${ }^{2}+x^{2}$ if

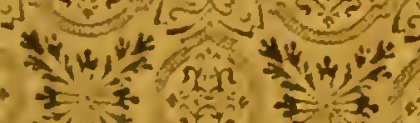 * हn
O. AR LIBRTS J. (n)
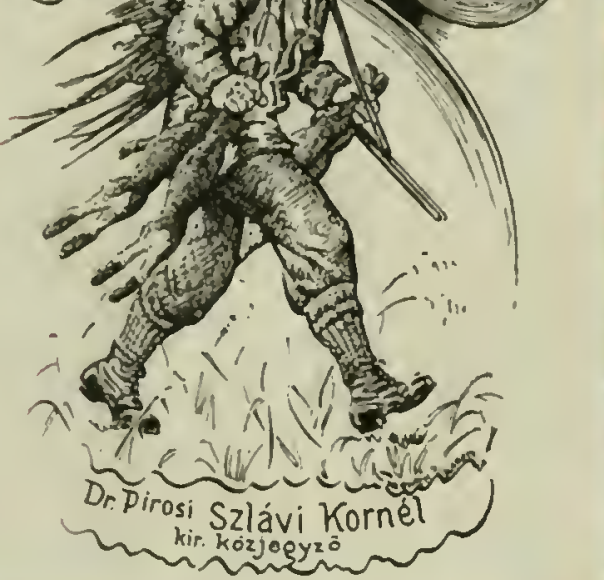

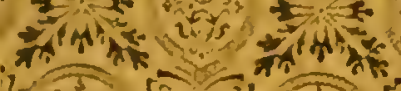

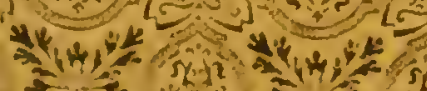
$\frac{1}{1}$

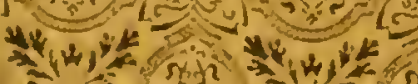
है: $\leqslant$ क्रम 난 Fin

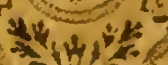
tw

(1)

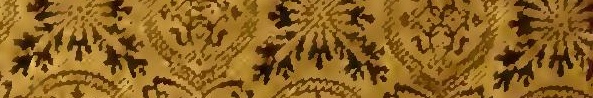

morrot

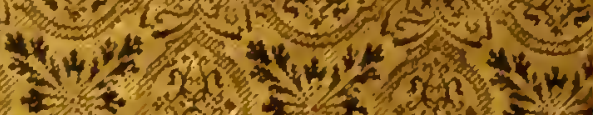

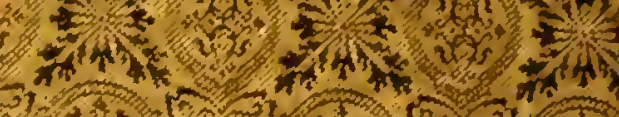

\section{$3 x^{5}$}

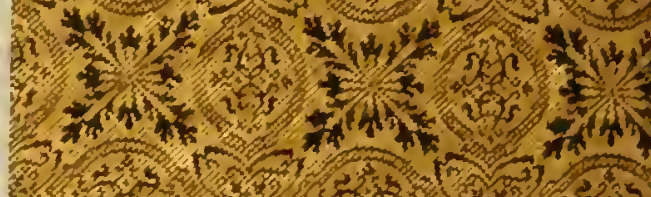

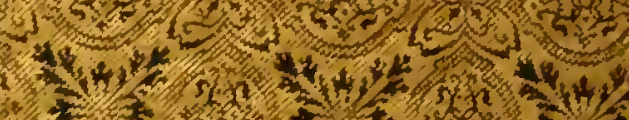

If

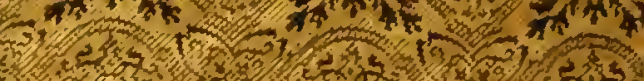

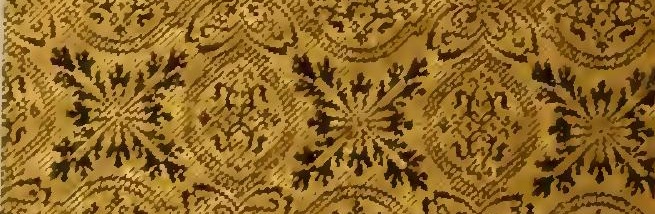

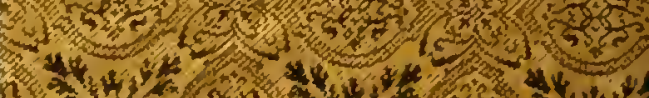

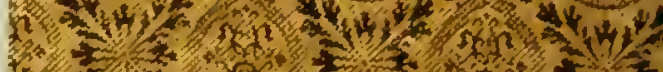

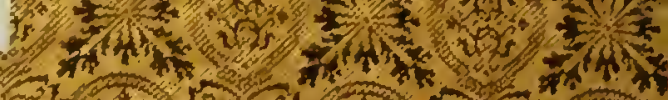




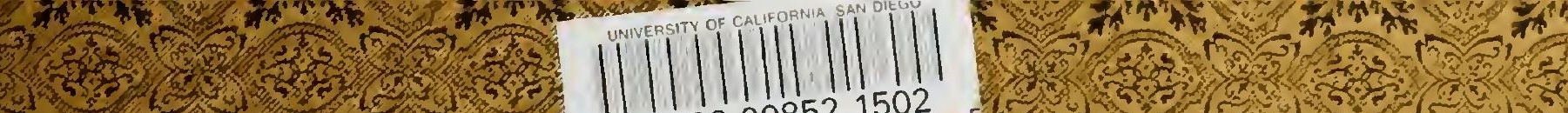
NHw

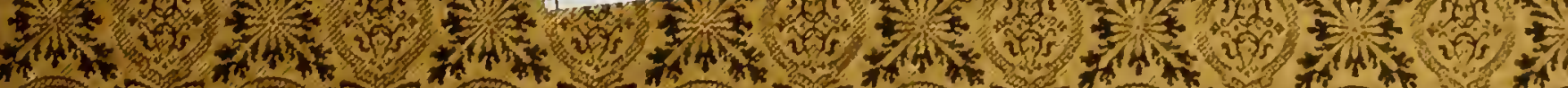
( .

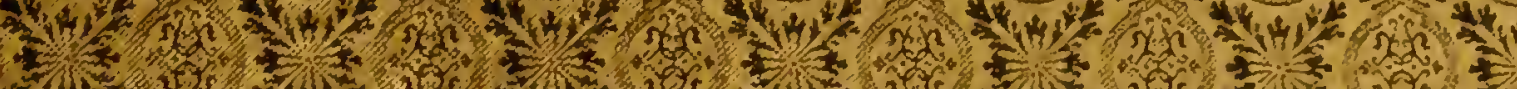
4.

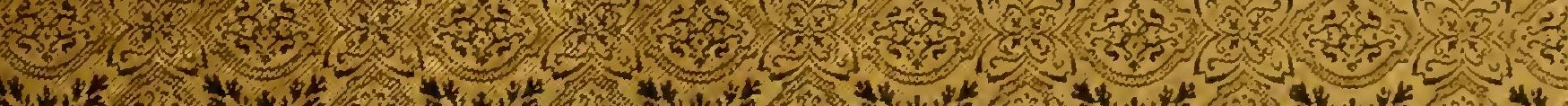

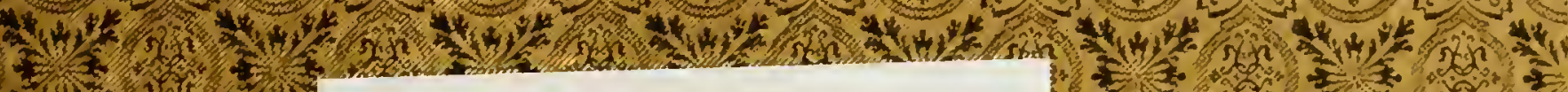

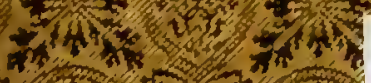

Central University Library

University of California, San Diego

Note: This item is subject to recall after two weeks. SEP 081992 Date Due

$3\left(1+2, x^{2}+2\right.$ n

C.

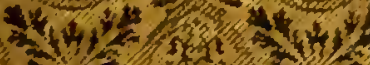

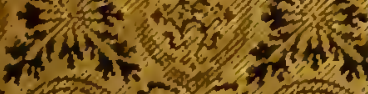

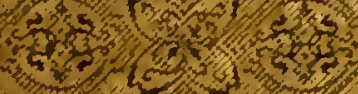

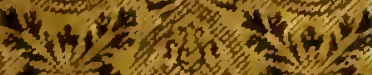

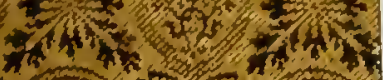

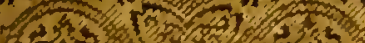

- $45-24$

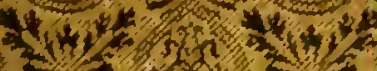

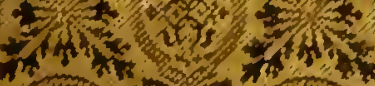
fist

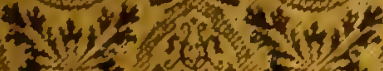

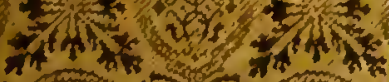
Cl39(1/91) 092
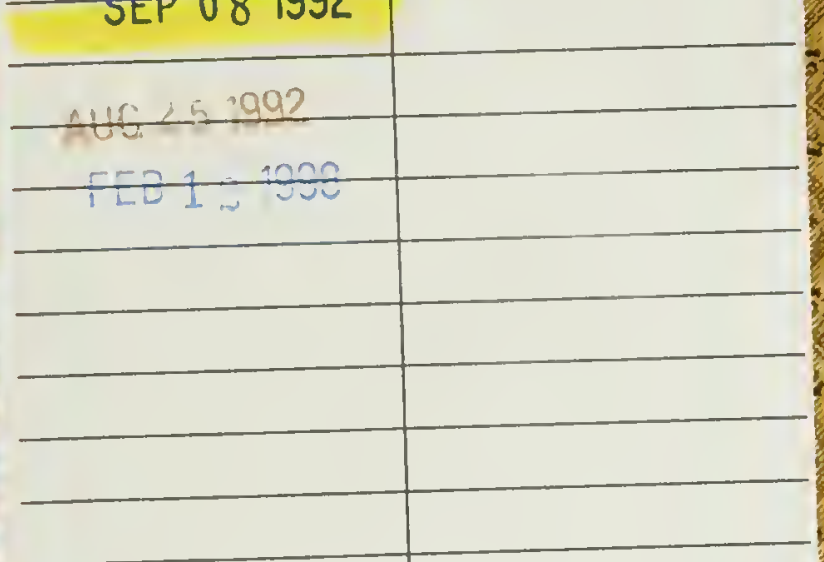

(1) $y^{2}$ sin

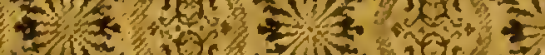

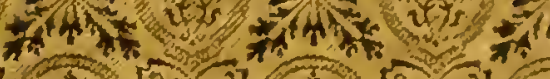

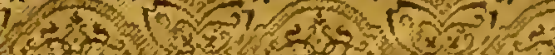

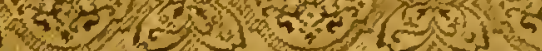

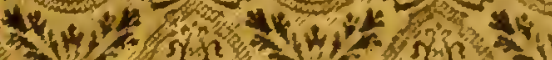

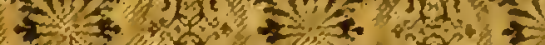

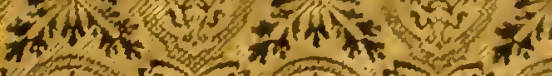

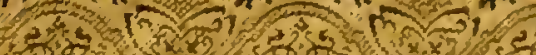
E.

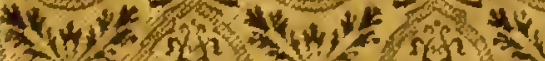

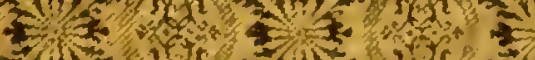

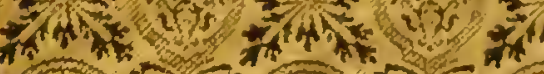

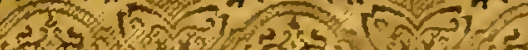

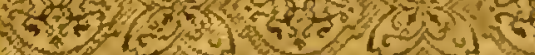

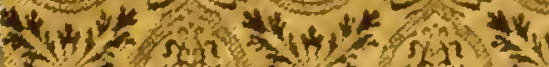

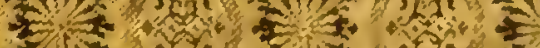

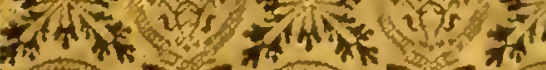

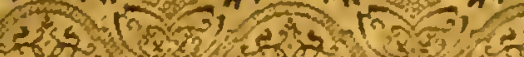

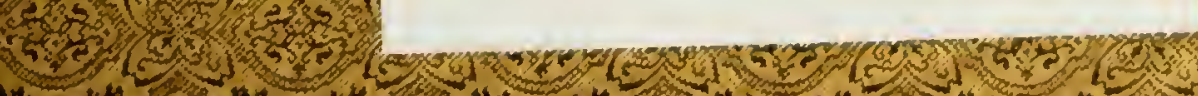

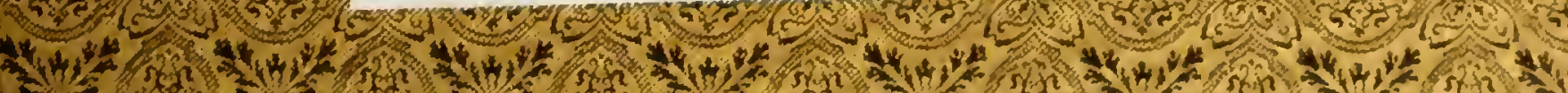

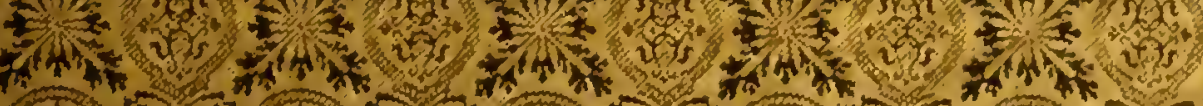
7. . . . ? *

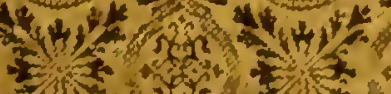





\section{Oversize

G/C

\section{THE GAME OF BRITISH EAST AFRICA.}





\section{THE GAME}

OIi

\section{BRITISH EAST AFRICA}

BY

CAPT. C. H. STIGAND, F.R.G.S., F.Z.S.

PROFUSELY ILLUSTRATED

WITH PHOTOGRAPHS.

Ionison:

HORACI: CON,

"Field" OfFich, Windsor Housh, Brlin's BuHmings, b.C. 



\section{PREFACE.}

$1 \mathrm{~T}$ is civilised weapons alone, especially when in the hands of irresponsible black men, that irreparably upset the balance of Nature. The black hunter, armed with primitive weapons, and the beast of prey, take their toll of life, but appear never to exterminate or even sensibly diminish the number of game.

Civilisation is advancing with such rapid strides in British East Africa that year by year it becomes more difficult to find and observe game still undisturbed by the sportsman and hunter.

Another generation and perhaps there will be little or no opportunities of observing these animals as they existed before the net of civilisation had been drawn round them.

It thus behoves anyone who has had the fortune to be thrown much with wild and unsophisticated animals to leave as careful a record as possible of their ways and manners of living while there is still opportunity, and to study them in their natural state.

It is this consideration which has induced me to attempt the task of describing the wild life of the country to the best of my ability.

I quite realise that I am not specially qualified for the work, and that there are many with greater experience of the comntry and game than 1 possess.

However, I hope that perhaps in later years, when the lion no longer roars over the plain and the rhino has ceased to wander in the open, that this book, in conjunction with many others of a similar nature, may be of some little value in reconstructing what will then be past natural history.

If the deficiencies of this book only bring home to any more experienced sportsmen, who have not yet done so, the necessity for recording their obscrvations, it will not be without its value. 
I regret that I have been unable to grive the book a more scientific aspect. The whole of it wats written in the field, and so books of reference were an impossibility.

I must here acknowledge my indebtedness to those friends who have given ine photographs or rendered me other help.

Especially are my most grateful thanks due to my aunt, Mrs. Edgar Clark, for the paticuce and skill with which she has cajoled my ill-taken films into revealing whit they really saw through the camera's eye. I feel sure that whatever success this book may achire will largely be attributable to her valuable aid in connection with it.

I'nfortunately my friend, D. D). Lyell, with whom I collaborated in my book on Central Ifrican Game, has been unable to work with me again. He has very kindly, however, made out the reduced drawings of spoor to be found in Chapter V1Il.

C. H. STIGANI).

Contr) FrRE: STATE,

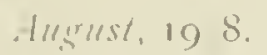




\section{CONTENTS.}

CHAPTER I.

PAGE

Introductory

\section{CHAPTFR II.}

Animal Life of the Country

CIIAPTER 11 .

Coloration of Game Animals

$\begin{array}{llllllll}\text {.. } & \ldots & \ldots & \ldots & \ldots & \ldots & 40\end{array}$

CHAPTER IV.

"Ilunting" versus "Shooting" $\ldots$

CHAPTER V.

The Plains

$\begin{array}{llllllll}\text {.. } & \ldots & \ldots & \ldots & \ldots & \ldots & 8_{9}\end{array}$

CHAPTER VI.

Stalking Gam

\section{CHAPTER VII.}

$\begin{array}{lllllllll}\text { The River of the Plains } & \ldots & \ldots & \ldots & \ldots & \ldots & \ldots & \ldots & 126\end{array}$

CHAP'TER VIII.

What is learnt from Spoor

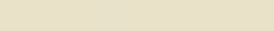

CHATER IX.

The Bush
CHAPTEK X.

The Came of Uganda and the Eastern Congo

CHIJTER XI.

The Forest 
lirk and Camp

$$
\text { -.. }
$$$$
\cdots
$$

('IIATTER XIII.

The l'rescrsation of liame ...

… $\quad$-..

Ivi) 


\section{ILLUSTRATIONS.}

A Morning's Bag-Reedbuck, Leopard, and Bushbuck, by Capt. C. R. Bacon ... 160

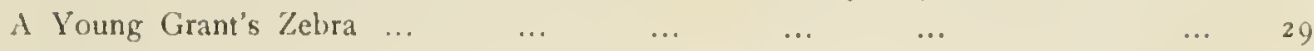

$\begin{array}{llllllllll}\text { Abnormal Tusker } & \ldots & \ldots & \ldots & \ldots & \ldots & \ldots & \ldots & 223\end{array}$

$\begin{array}{lllllllll}\text { lilack-maned Lion } & \ldots & \ldots & \ldots & \ldots & \ldots & \ldots & \ldots & 6\end{array}$

$\begin{array}{lllllllllll}\text { Bongo } f & \ldots & \ldots & \ldots & \ldots & \ldots & \ldots & \ldots & \ldots & 171\end{array}$

$\begin{array}{llllllllllll}\text { Buffalo o } & \ldots & \ldots & \ldots & \ldots & \ldots & \ldots & \ldots & \ldots & 7\end{array}$

$\begin{array}{llllllllll}\text { Burchell's Rhino } & \ldots & \ldots & \ldots & \ldots & \ldots & \ldots & \ldots & \text { I } 68\end{array}$

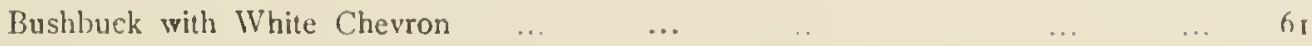

$\begin{array}{llllllllll}\text { Chanler's Reedbuck } & \ldots & \ldots & \ldots & \ldots & \ldots & \ldots & \ldots & 29\end{array}$

$\begin{array}{lllllllllll}\text { Cheetah } & \ldots & \ldots & \ldots & \ldots & \ldots & \ldots & \ldots & \ldots & 87\end{array}$

$\begin{array}{lllllllllll}\text { Congo Buffalo } \& & \ldots & \ldots & \ldots & \ldots & \ldots & & \ldots & & \ldots & 167\end{array}$

$\begin{array}{llllllllll}\text { Crocodile } & \ldots & \ldots & \ldots & \ldots & \ldots & \ldots & \ldots & \ldots & 44\end{array}$

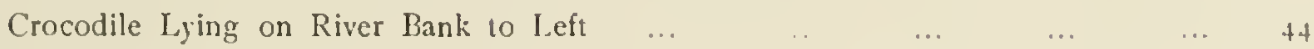

$\begin{array}{llllllllll}\text { Curious Rhino Horns } & \ldots & \ldots & \ldots & \ldots & \ldots & \ldots & \ldots & 128\end{array}$

$\begin{array}{lllllllllll}\text { Eland Bull } & \ldots & \ldots & \ldots & \ldots & \ldots & \ldots & \ldots & \ldots & 207\end{array}$

$\begin{array}{llllllllll}\text { Elephant } \delta & \ldots & \ldots & \ldots & \ldots & \ldots & \ldots & \ldots & 5\end{array}$

$\begin{array}{lllllllllll}\text { Elephant } & \ldots & \ldots & \ldots & \ldots & \ldots & \ldots & \ldots & \ldots & \ldots & 80\end{array}$

$\begin{array}{lllllllllll}\text { Elephant } & \ldots & \ldots & \ldots & \ldots & \ldots & \ldots & \ldots & 8_{7}\end{array}$

$\begin{array}{llllllllll}\text { E.lephant Country } & \ldots & \ldots & \ldots & \ldots & \ldots & \ldots & \ldots & 5\end{array}$

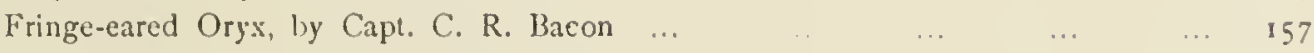

$\begin{array}{llllllllllll}\text { Gaboon Viper } & \ldots & \ldots & \ldots & \ldots & \ldots & \ldots & \ldots & \ldots & \ldots & 65\end{array}$

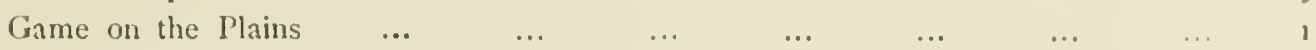

Girafte, by Captain C. R. Bacon, Serengeti Plains, British Fast Africa ... ... 37

$\begin{array}{lllllllll}\text { Grant's Gazelle } & \ldots & \ldots & \ldots & \ldots & \ldots & \ldots & \ldots & \ldots\end{array}$

Grant's Gazelle (Northern Form), by Capt. C. R. Bacon _.. $\quad \ldots \quad 105$

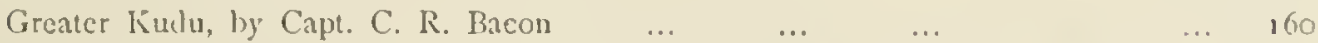

IIerd of 'Thomson's Gazelle Seen in Single File Between the Two $x$ Marks ... ${ }_{236}$

$\begin{array}{llllllllll}\text { Hunting Leoparl } & \ldots & \ldots & \ldots & \ldots & \ldots & \ldots & \ldots & 48\end{array}$

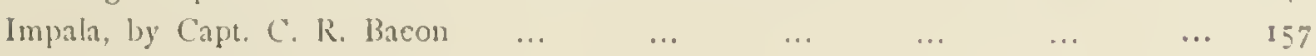

$\begin{array}{lllllllllll}\text { Jackal, liy K. G. Stone } & \ldots & \ldots & \ldots & \ldots & \ldots & \ldots & \ldots & 95\end{array}$

$\begin{array}{llllllllll}\text { Jackson's llartebeest } & \ldots & \ldots & \ldots & \ldots & \ldots & \ldots & \ldots & 63\end{array}$

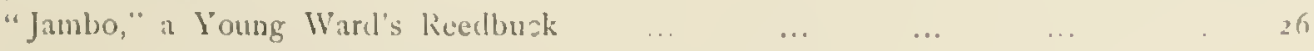

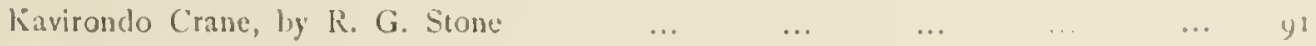

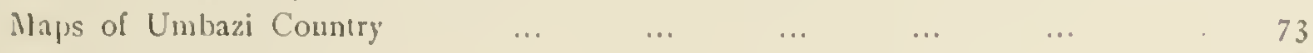

$\begin{array}{llllllllll}\| & \| & \ldots & \ldots & \ldots & \ldots & \ldots & \ldots & 7+\end{array}$ 
Map of Umbazi 'ouniry

Neumann's Ilartelieest

(II) an! loumg lioneis

(Ine Jusher. In 11 ․ W'riglit

Oryex Betsa, by Capt. I1. W. 13. Thorp

Ostrich Xiest

Porcupine

Real-mane I Lion

Klisuo

Rlino

Khıno Charging ...

Rhinn : with Broken Ilorn

sali-1.1ck

Sing-Sin, Waterbuck, by Capt. C. R. Bacon, Uasen-Gishu Plateau, British East Africa

FACE PAGE Sioor:-

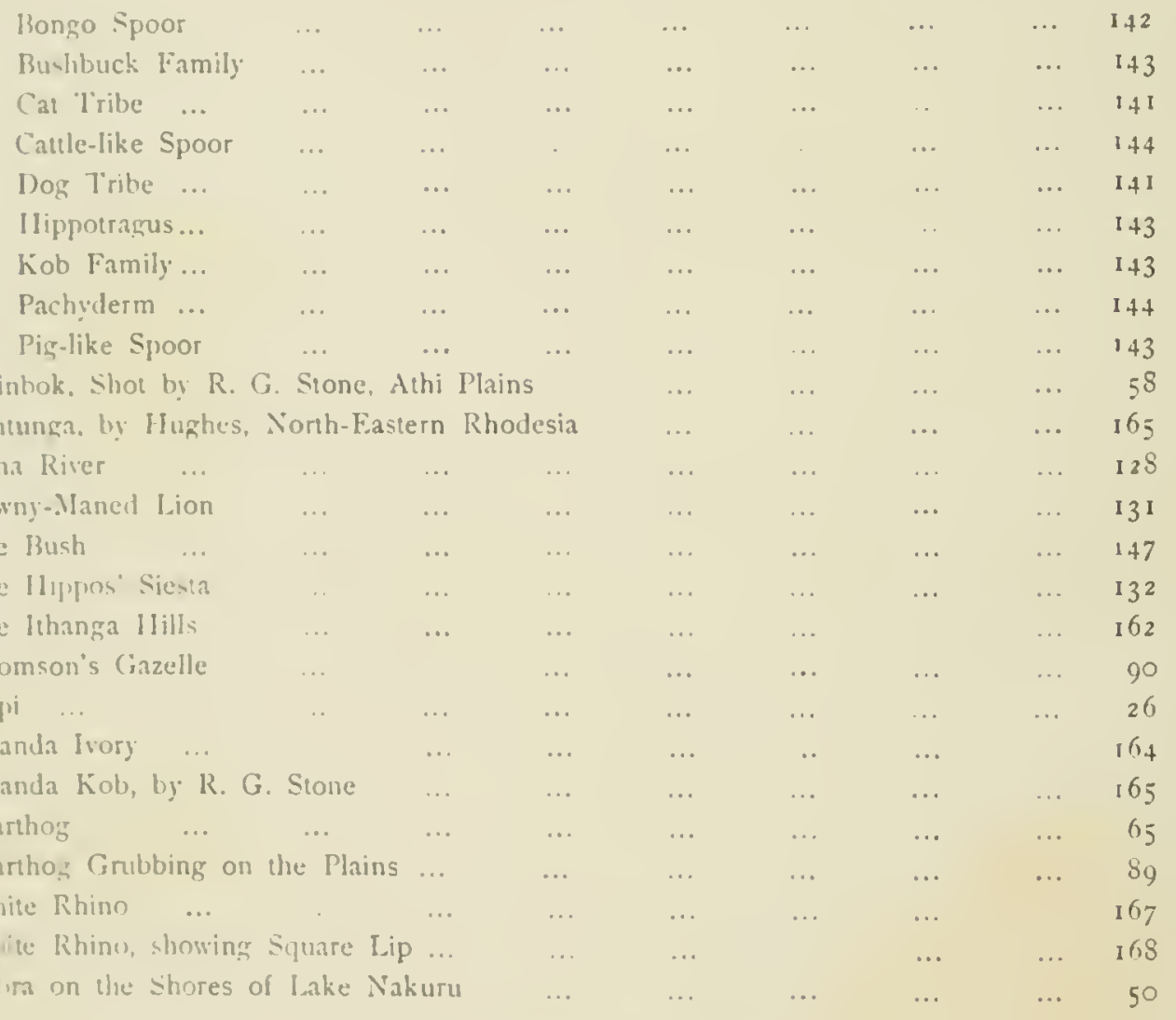




\section{E R R A T A.}

OWING to being unexpectedly delayed on a journey through Abyssinia, I returned home to find the printing of this book so far advanced that it was impossible to make certain corrections in the first half. It is, therefore, necessary to insert a few corrections here.

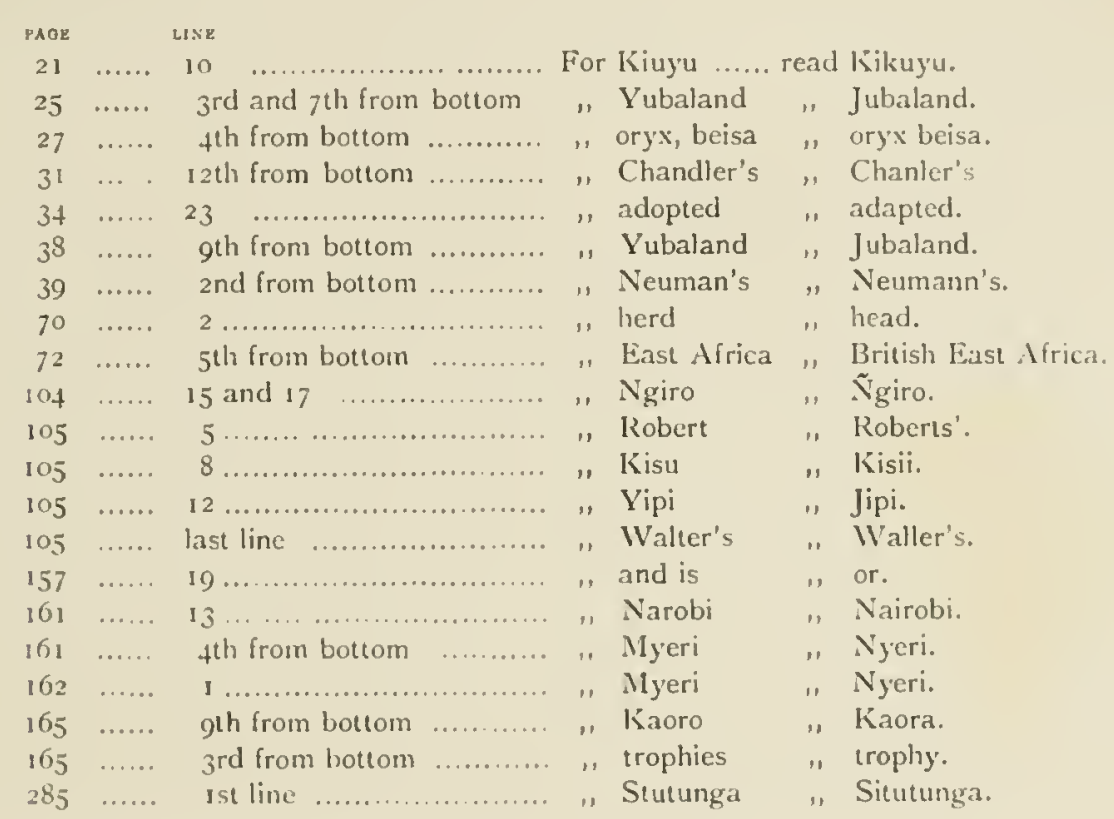

\section{ILLUSTRATIONS.}

Illustration opposite page 91, for G. R. Stone read ..... Illustration uppusite pange 95, fur G. R. Stone read Illustration opposite page 165, for G. R. Stone sead Illustration opposite patge 223 , for W'right reach
R. G. Stune.

R. (i. Stonc.

R. G. Sture.

II. S. IIright. 




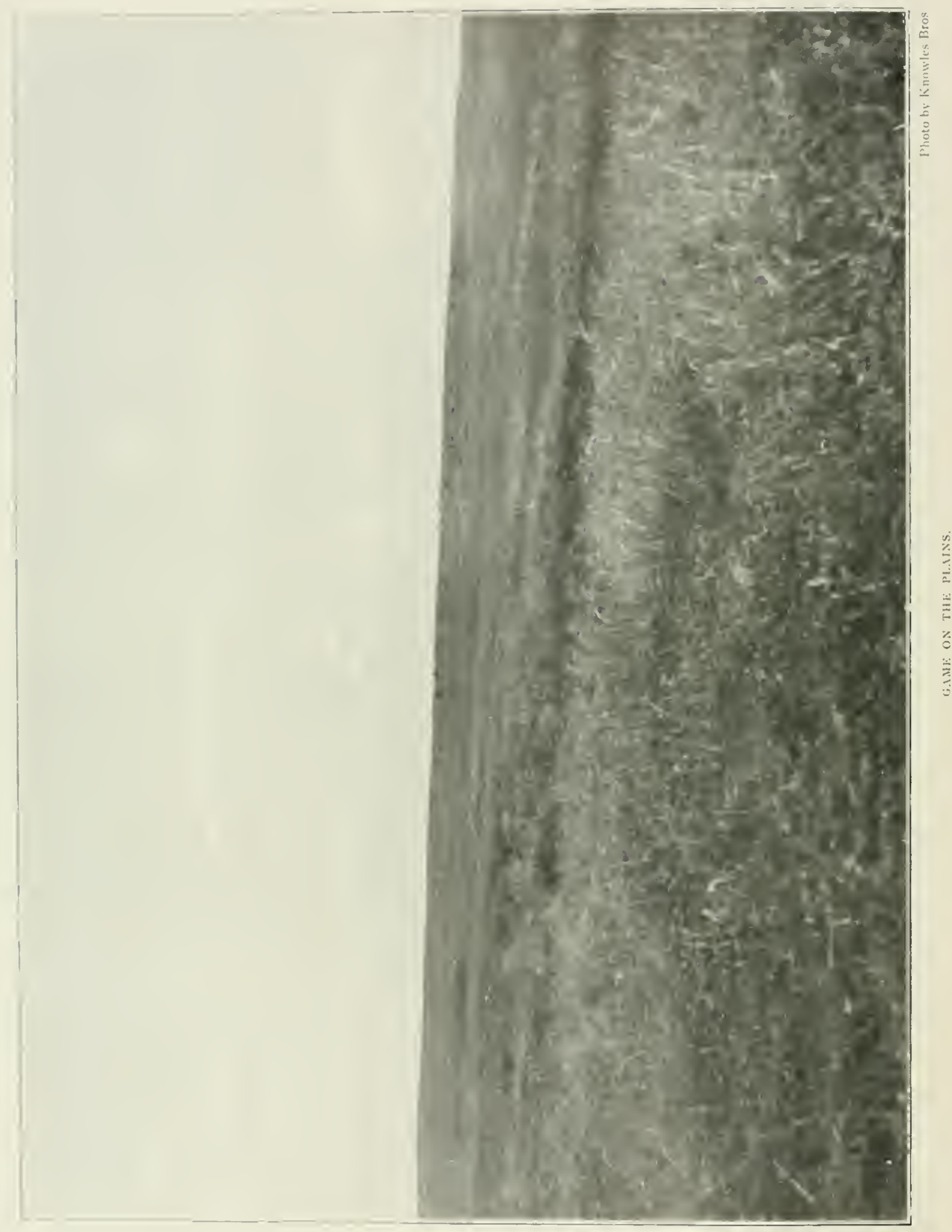




\section{THE GAME OF BRITISH EAST AFRICA.}

\section{CHAPTER I.}

\section{INTRODUCTORY.}

BEFORE setting to work to describe the game of East Africa, it would be as well to set forth one's attitude towards the game in question. By so doing the reader will be able to judge for himself how much credence to give to any views or ideas that may be set forth.

At one time I used to be a keen sportsman. That is to say, I was always anxious to secure a specimen of some animal I had not yet shot, and was always on the look-out for good heads.

In those days I used to shoot for heads and nothing else.

Why I wanted these heads, or why I was so keen on getting a horn half an inch bigger than one shot by someone else, is not quite clear to me. Since coming to East Africa all this desire for tape measurements and new specimens has quite vanished, as regards the commoner and easily shot game. The reason for this is that in the countries in which I laad shot before, practically every animal has to be hunted and tracked with the utmost care before being brought to bag.

In East Africa, on the contrary, the majority of the game wander about in a semi-tame state, and live on the open plains where all the world can look at them.

So in this country, any townsman who can hold a rifle straight, or, in lieu of that, will expend vast quantities of ammunition, is able to procure all the common varieties of game without any knowledge of liunting or bush lore.

It was then that I realised more than before that it was the hunting and tracking that interested me, and that the mere shooting was a matter to which I was indifferent. Many men let their native trackers have all the best part of the fun by allowing them to do all the tracking and interesting work single-handed, reserving themselves for the shot. 
Is for measurements, where same abound in such numbers, it scems to me that, in the Inngr run, the man who slaughters the most should have the best average lengths of horns. This, of course, is provided he uses a litule discrimination in picking out a decent head every time he fires.

It cimnot be denied that luck also plays an important roble in the obtaining of a big head. One has heard of many instances of records or exceptionally line heads being obtained by beginners or by men "browning" herds or resorting (n) other unsporting practices. To quote a couple of instances in point: the first kudu I ever shot was such a magnificent specimen that, if I hunted for a hmondred years, I would, in all probability, never shoot another within many inches of it. The first time I found myself in country inhabited by the little Zanzibar Suni I went out and picked up a record head which had been killed by a leopard. So it would appear that the possession of one or two exceptionally fine heads in no way proves that the owner is a hard-working sportsman or one gifted in bush lore.

Putting aside chance, however, it is granted by most sportsmen that, in the field, it is impossible to judge the length of a long horn to within an inch or wo. Some animals are notoriously more difficult to judge than others. Thus, in the long run, a man who shoots a vast quantity of heads, as long as he selects what lic imagrimes to be good heads, should obtain better measurements than a man who shoots, say, two heads only of one species, however carefully he may select them.

So on these East African plains, swarming with game, I do not consider that measurements in inches are so much a proof of a man's skill in selection; they are more a testimony to the number of animals he has slaughtered. A small bag containing all fairly average heads is far more an achievcment to be proud of than the amassing of a big bag of poor heads with here and there an exceptional head.

British East Africa is the happy hunting-ground of the town-bred sportsman, and one meets him elerywhere amassing great piles of worthless and immature heads, 99 per cent. of which are only fit to be thrown on the dust-heap.

Ithen one really good head is found amongst all this rubbish it is evident that a pure fluke has been responsible for its being brought to bag. For this reason I luave neter made any serious attempt to secure abnormally good heads in this country, for it would only mean that one would shoot many animals not really required before one is likely to obtain anything near the record.

Nor have I ever made any special efforts to secure species new to me from amongst the ranks of these plain-dwellers, for the sport does not appeal to me.

By this, I do not wish to infer that I never shoot such common animals, for 
there is always the meat problem to deal with. I have been mostly on trek while in this country, and my dislike to killing these animals does not induce me to carry about expensive and distasteful tinned meats when there is game to be had easily for the shooting. Nor should 1 feel justified in curtailing my marches so as to be able to drive a flock of sheep about with me. Life has to be sacrificed to the needs of a man's stomach (unless, indeed, he be a vegetarian), and there is not any great difference between killing a small buck or a sheep for this purpose.

So one kills a small buck when one can, and derives a certain amount of satisfaction from supplying the table with one's own rifle. However, one does not gloat over the performance, nor does one think it other than boring when such necessary slaughter is described in glowing terms with all the setting of a sporting adventure. For the purposes of the pot one can get practically all that is wanted on the line of march, and one seldom need go out of the way when in game countries. When one kills a bigger beast, such as eland, gnu, hartebeest, etc., much of it goes to the porters, and some of it is made into biltong to tide over any gameless region met with.

This brings me to another consideration, and that is the porters.

The usual porter's ration of a "kibaba" of beans or grain is not really sufficient to keep a man in perfect health for any lengthy period carrying a 6olb. load the while. He will do much better work, keep fitter, and be more cheerful for a meat ration every now and then.

Moreover, professional porters, accustomed to accompany shooting parties and to eat their glut of meat, think very poorly of you if nothing is forthcoming.

During a whole-day march, if there is no meat, the men have to go foodtess throughout the day, for their usual ration of "mbaazi" or "malualagwe" takes about two hours cooking before it is ready for consumption, and such a lengthy halt as this would entait is frequently unfeasible. If they have some dried meat with them this can be brought out and eaten in the course of a few minutes, and the men will last out through the day much better. Thus the porters, too, must have their toll of life, and this is arranged for by an occasional rhino, zebra, or hartebeest shot in place of one's small buck. In fact, if one is constantly trekking about the country, one is practically forced to do a certain amount of this plain-shooting.

When so doing, one generally selects a male, and a gond head in preference to a bad, and a new species in preference to an old, so is to hate an opportunity of examining him at close quarters; but, one does not necessarily go out of one's way to hunt for an extra grood head.

This much for the actual shooting of these plainedwetlers. 
On the other hand, although I have been at no pains to secure specimens new to me, or grood measurements, I have never failed to observe the doings of these plaims-folk with interest. Wherever aninals new to me are to be met with, I make a point of studying their habits and peculiarities. This is a never-failing source of interest, and where the actual shooting may be tame and uninteresting the study of animal life is never without charm.

Besides "shooting," however, there is also good "hunting" to be had in East Africa, and this is the more interesting as all the sportsmen go for the plains and lewie any animals difficult to bag severely alone.

Ilunting and tracking game difficult to bag is still a sport which appeals to me as much as ever. So, although I would not leave the path to shoot a plain-dweller, unless he is very necessary for the pot, I am always willing to go far in search of some shy and wary denizens of the bush and forest. Such animals as still have an interest for me, from the sportsman's point of view, are the elephant, lion, buffalo, the kudus, the bongo, and a few others.

Having referred to the former animals as conmon, it may be inferred that these latter are very rare animals, and that I an doing my best, amongst others, to hasten their extinction. I have referred to the plain-dwellers as common chiefly because they are the commonly seen and commonly shot animals. As such most of them will, in all probability, be the first to become exterminated. These others are all so difficult to get that their death-roll is comparatively small, and, owing to the difficulty attending the hunting, shooting, and locating of them, they are generally given credit for being much rarer than they really are.

In point of fact, there are great numbers of these animals in East Africa, with the exception, perhaps, of the greater kudu. Even he, I believe, is considerably more numcrous than is generally supposed.

I might have added bushbuck to this list, if it had not been that on several occasions I have found him quite easily. Having shot several, I do not consider that he justifies any further execution, unless I am actually in quest of provisions. He is, however, as a rule, although very common, exceedingly hard to obtain, and so is quite worthy of being hunted by those who have not shot many.

In these days of short shooting trips, when countless parties come out to this country with vast batterics of rifles and boxes of ammunition and shoot more heads of common animals in a few months than I have clone in as many years of constant trek, it might seem unnecessary to try to justify myself for shooting at all. Owing to the wholesale slaughter of harmless animals indulged in by such people, many critics are nowadays apt to regard all forms of big-game shooting as iniquitous and 



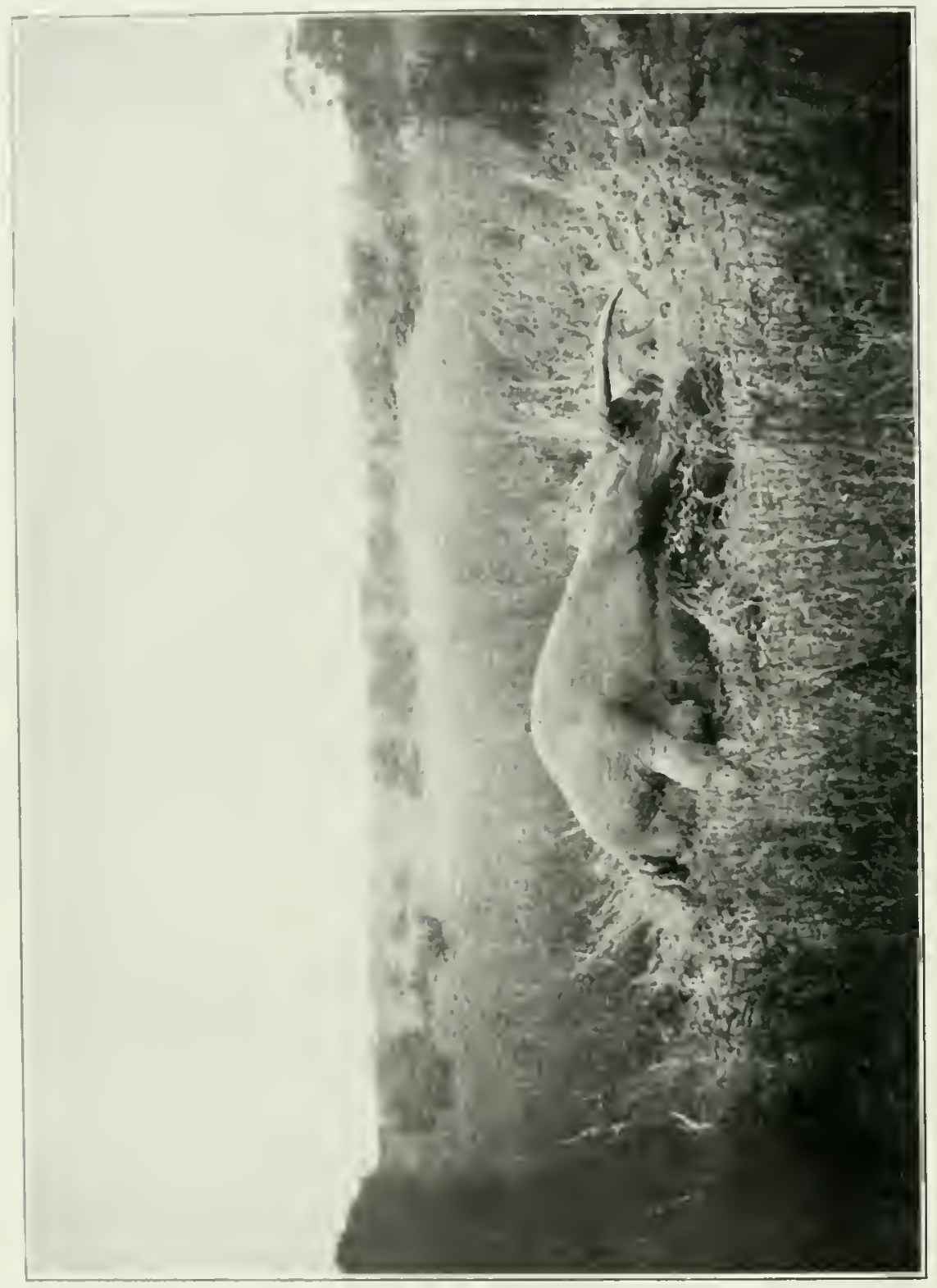

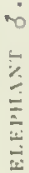




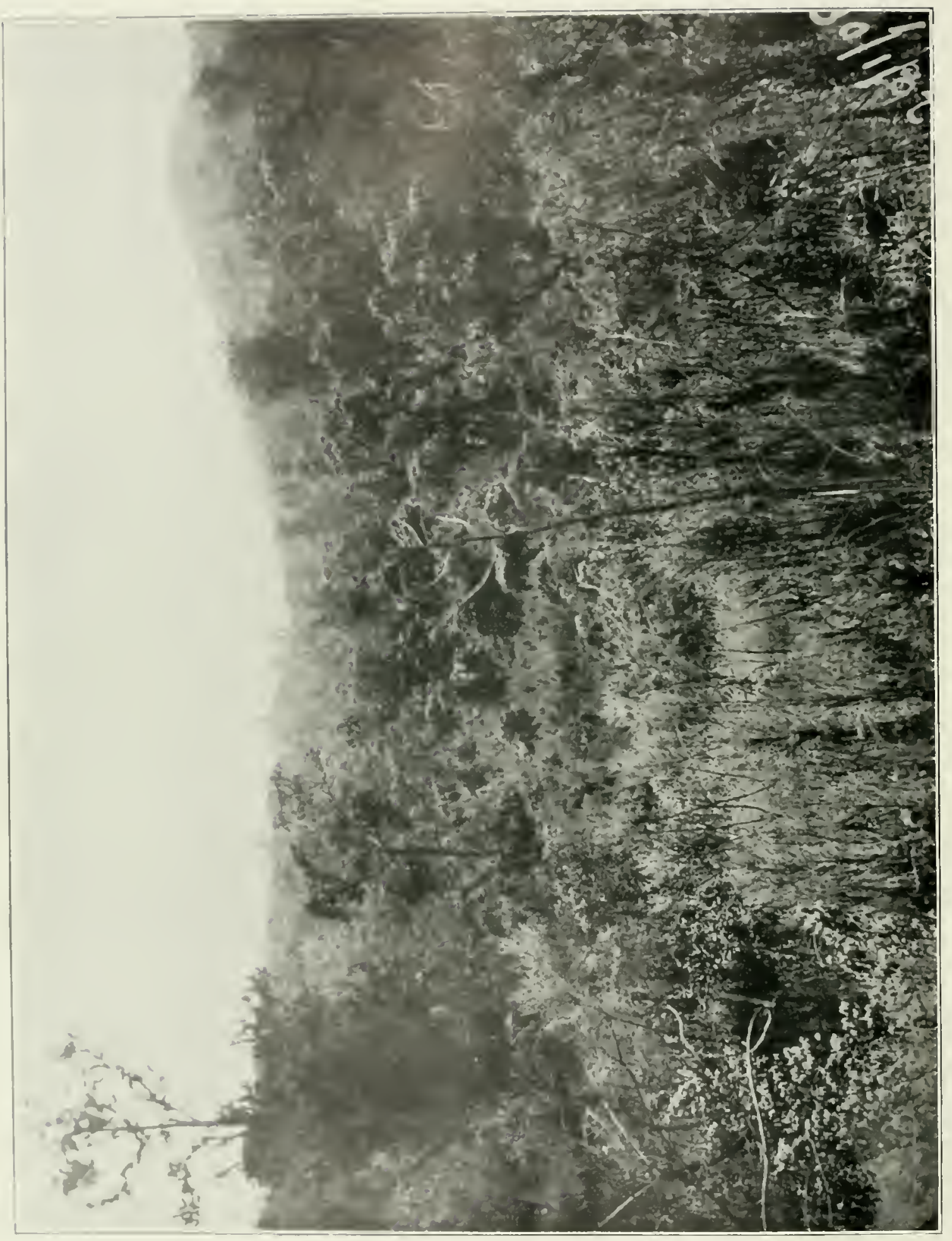


unsporting. So it may serve to whitewash the character of true sportsmen to state the grounds on which I consider the hunting of the animals I have selected, as sport and not butchery.

To begin with, all these animals-elephant, lion, buffalo, the kudus, the bongo, and a few others-give you a lot of fun for your money. That is to say, whereas one might go and shoot ten of the plain-dwelling buck in a morning, should one be so evilly disposed, the chances are that one may hunt many days after each of the others without getting a single animal. Indeed, every animal brought to bag has had a very good sporting chance of escape, which can hardly be said of the plain-folk. This alone should remove the sport beyond the criticism of a race whose boast it is that they like to see fair play.

It would have been interesting if I had kept a record of the many miles I have tramped after elephant. Very seldom have I had to walk less than a hundred miles to bag one elephant, and often I have been very considerably farther. With lion I have estimated that I have had seven to eight blanks to every one success. This is, of course, hunting on foot.

I count as a blank either an excursion of several days, made without success to a place in which lions have been reported, or an occasion on which I have found a fresh kill and sat over it, or seen lion and been unable to get close, or when I have had some other very good reason for imagining I might get one.

I will now take these animals selected in turn and endeavour to offer my justification for wanting to shoot them.

Elephant-shooting is a kingly sport; there is nothing on earth to touch it. Once one has tasted of its excitement he can never return to the shooting even of a lion or buffalo with the same zest.

The clephant nowadays is almost invariably found in the most atrocious country, so thick that you can seldon see him till you are close on him, and even then you will hardly ever be able to see what size his tusks are till you have watched him from close quarters for some tine and seen him throw up his head. Even then you get but a momentary glimpse. Hunting him takes you through thick grass reaching far over your head, and through which a way has to be broken in a blazing sun without a breath of air to cool you. It takes you through thick, tangled, and matted bush, through swamps waist-deep, through virgin forests choked with creepers and undergrowth, up steep hills to chilly heights of 10,000 feet and over, and through every conceivable kind of bad country. It is prodigiously hard work, includes tracking, most careful and minute attention to wind, and compels one to be constantly on the qui arive, with eyes, ears, and even nose to catch sight, sound, or 
Whiff of the ammitl. In addition to this, the element of danger is very great. In short, there is 10 man who works harder for his living or better deserves his profits than the much-abused ivory-hunter. Nany must have been the times that such an one has grone hungry, weary, thirsty, and fever-stricken throughout the long day's fight against moxious regetation and natural obstacles, and many the times he must have bivnacked cold and comfortless by night. Many the disappointments caused by treacherous winds, ague shaking the finger on the trigger when the critical moment is reatched, or by other circumstances beyond his control. At last comes the supreme moment for which all these hardships have been endured, the bull elephant staggers and falls, and the rest of the herd rush screaming past, while he tries to shrink out of their way. Then a brief rest, and the cutting-out of the tusks, the weighing of the ivory, and a rapid calculation of the profits iersus the expense of porters, presents to chiefs, expense of stores, expense of transport back to the coast, and various other itcms. Then once more to work again.

Next as to the lion. No apology should be needed for shooting him in the sporting way; that is, by tracking him up or hunting him unaided on foot. If one is to meet with any measure of success, this requires both hard work and a considerable knowledge of his habits, while disappointments are the rule and not the exception. There are, however, more lordly ways of shooting him entailing little danger or trouble to the sportsman. Such are, having him located and rounded up by mounted sumalis, after which word is sent in, and the sportsman finishes a late breakfast and starts out with a party of rifles to shoot him where he sits. Should he try to break away, he is at once rounded up by horsemen; or should he get crusty he goes for a horse, and the Somali rider skilfully aroids him.

Another way is to have him located in cover, such as a thick reed bed. The sportsmen, with multitudinous gunbearers and a large battery, post themselves in advantageous positions, white naked savages with spears are sent in to drive him out. It must be said that it is very rarely any of the spearmen get hurt, as they make such a prodigrious noise that the lion always tries to get out of their way. Ilowever, I find that it requires all the courage I can collect to go myself with a rifle into a thick reed bed after a lion, and so it is distasteful to send others to do what one shrinks from oneself, however cheerfully they may go about it.

Neither of these last two ways of obtaining lion seem to be very sporting, as nearly all the risk is incurred by the beaters and the horsemen, and very little is incurred by the sportsman. Of course, if one rides down the lion oneself the case is very different, although still much easier than hunting on foot.

East Africa has become a so-called white man's country; that is to say, that 


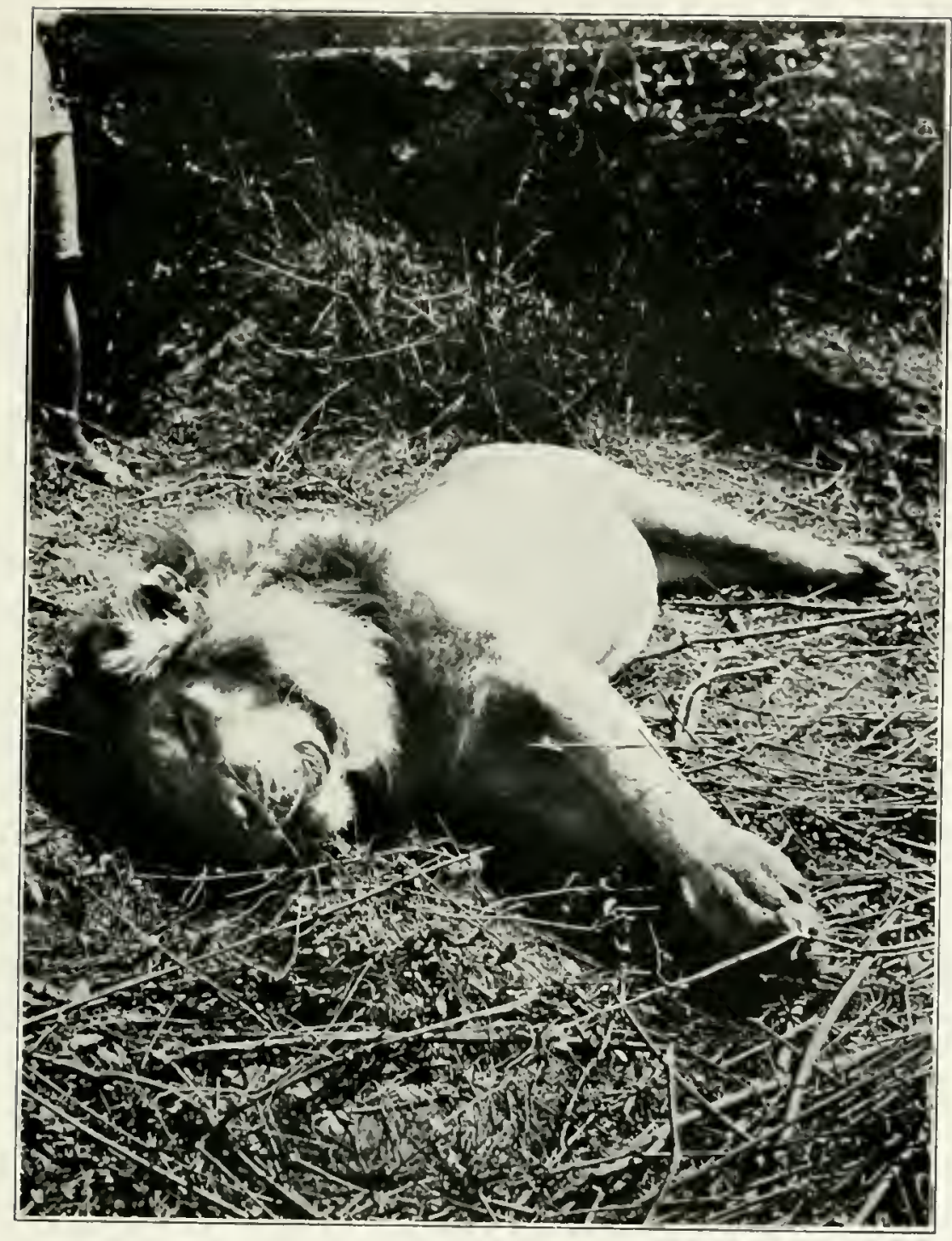

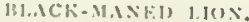






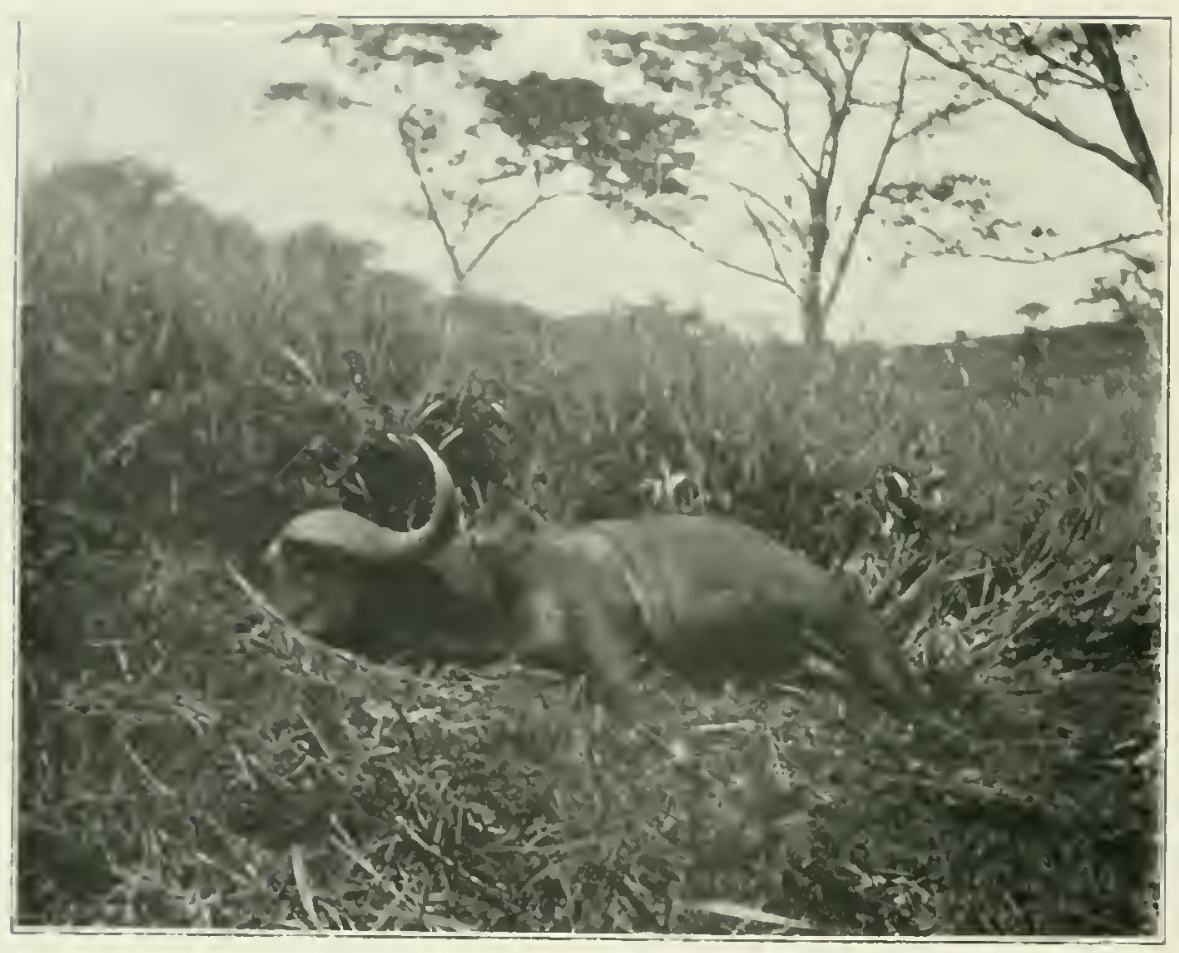

Photo by R C. Strine 
settlers are taking up land all over the country. Although a few of these settlers try to shoot lion, a great number of them wage war against him with poison and traps in spite of the very minute damage he appears to do to their stock. For the usual lion of East Africa is a plain-dwelling and game-feeding lion, and very rarely even attacks the cattle of the native, and practically never if the cattle are enclosed at night in a proper stockade. It is generally the men who are too lazy to build for their cattle any better protection than a fence of twigs, who resort to poison.

As this state of things exists, I do not think that the sportsman who shoots a number of these fine animals has any cause to reproach himself. For if the lion had the option of being killed by a bullet, with a fair chance of a dash at the shooter, or of being taken unawares by a dose of strychnine, there is little doubt that he would choose the former. Moreover, one only shoots full-grow specimens and males for preference. I have never shot, and hope never to shoot, young and halfgrown lion. The poison bottle is unable to discriminate between young and old, and even some sportsmen, it must be admitted, are equally indiscriminate.

Now as to the buffalo. One bull is at present allowed to be shot on a licence in British East Africa. Considering the tough customers they are, the thick country they inhabit, and when one remembers that they are among the cutest of game in secing, hearing, scenting, and bush tactics, no sportsman could be considered greedy or barbarous if he endeavoured to shoot his one per annum.

In Uganda they have been found to do so much damage that they have been removed from the list of protected animals, and there, at least, the sportsman has rery good excuse for wanting to shoot one or two.

Concerming the bongo, he is really a fairly common animal in certain parts of the country. He lives in such thick jungle and is so wary that all the sportsmen who live in the country, together with the many who visit it on shooting trips, do not account for one in a year. In fact, I believe that I am about the only white man who has tracked up and shot this animal without other aid than my rifle. The native hunters obtain them by trapping them or hunting them with dogs.

As for the kudus, they are also very wary bush customers, and their death-rate is very low. The lesser kudu, at any rate, is common enough, so a few superfluous males thinned off can do no harm; on the contrary; it is probable that it is beneficial to their rate of production. The females, being hornless, would not be shot. The greater kudu is scarce enough to make it a pity to molest it, and it is very wisely. protected in the only area in which it oceurs at all commonly, viz., the Baringo district.

Of the other animals oceasionally hunted, one's reasons for shooting them would be much on the same lines as those above. 
Some people may be astonished that rhino do not come under my heading of sporting animals to shoot. That he is an excecdingly dangerous animal in thick bush I am quite ready to testify. In such a country as North.Eastern Rhodesia he is a most exciting and interesting animal to hunt. In East Africa, however, people do not, as a rule, go into bush to look for him.

in many places in this country, directly one gets off the beaten track, rhino are common and in many localities swarming. On the plains or in a park-like country of thorn trees and short grass he is so easy to locate and approach that there is no such thing as lounting and stalking him. On a licence two are allowed, and by choosing a farourable moment these two can always be shot with much more ease than could two hartebeest under similar circumstances. Add to this a little caution and he can be shot with little more danger than the latter animal. Having shot your two, if you go rummaging about in thick bush the chances are that you will have to shoot a third and fourth at considerably more personal risk, and, moreover, you will have to hand in the trophies to the Government.

So much for one's point of vicw as a sportsman, and apologies for being a hunter. After this I hope to bore the reader as little as possible with the actual slaying of animals, my intention being to try and describe the game, and game countries as they appear to the naturalist and sportsman. I do not pretend to be a scientific naturalist, but only a rough-and-ready field naturalist recording his observations. As regards such observations, it will have been noticed that different writers' accounts of the game inhabiting a certain country are often singularly at variance. A discussion on the habits of the tsetse fly which recently took place in the columns of the Field will serve as an instance in point as to the different views people take of the habits of the same creature.

The reason for such divergence of observation is sometimes hard to discover. Some men are more imaginative than others and unconsciously fill in a lot of detail from some small observation actually made. As it is impossible to observe game as closely as one might some domestic animal, most observations of game in their wild state must be supplemented to a certain extent by deductions drawn from spoor, sound, or inference.

Other men are apt to jump at conclusions and stick to them whether they are proved wrong or not by subsequent experience.

Others are liable to generalise too much from some one or two incidents observed. I have often heard men lay down infallible rules as to the conduct of certain animals, when to my own knowledge they have only seen the animals in question once or twice. 
Again, two men will perhaps visit a certain area at different seasons, and each one will be convinced that what he saw when he was there holds good for the remainder of the year.

I do not know how it is some people are always meeting with certain animals, while others are unable to get some quite common animal after, perhaps, several years of trying. A common instance is the lion. There are, undoubtedly, lion men and non-lion men. Some men, after a few months spent in East Africa, have been fortunate enough to secure several lion, and have seen many more.

Again, one constantly meets other men who have been many years in the country and are still bemoaning their fate that they have never even seen one out of a cage.

Apart from the different manner of observation of the individual, 1 cannot help thinking that some writers are apt to record habits and other notes concerning the behaviour of game on rather flimsy evidence.

Most men-and I am no exception-are liable to be led into making rash statements in the course of conversation. When writing, however, on the habits of any animal there is no excuse for so doing, for one has ample time to consider over every statement made. In revising it only requires a scratch of the pen to cut out any doubtful or not sufficiently proved statement. Even in matters unrelated to the theme in hand it behoves one to be as accurate as possible in details, as constant inaccuracies are apt to make the reader doubtful of even the well-authenticated facts.

For instance, in a book on sport I recently read, I noticed, amongst many smaller inaceuracies in the first chapter, two very glaring mistakes, both, however, unconnected with the subject of the book. The first was the quite unnecessary introduction of the common Arabic expression for "Good morning," which was translated as "God bless thee" for the benefit of the reader-not quite the same thing! The second was an allusion to a small punitive expedition which lasted three weeks, and during which the enemy never put up a fight. This was described as a long and bloody warfare lasting many years.

Now, although most of the remarks on game were of a very superior quality, statements like those above must tend rather to shake the reader's confidence in the writer. After rounding up against them at the start it is impossible for the reader to peruse any new or unusual facts which may be described later with such trusting confidence as he might otherwise have done.

As to languages, many native languages have not as yet been reduced to a writing or vocabulary. When dealing with these, mistakes or differences in spelling to the forms subsequently adopted are liable to oecur, and such are unavoidable. 
With the less-known languages of the African continent many already have rocabularies, but these rocabularies are generally very weak in words for animals. It thus happens that, even in these, to obtain such words the traveller and sportsman must trust to his own researches. Where there are good dictionaries, however, I see no excuse for the writer of a book on game or travels giving his own incorrect versions of words and sentences for the benefit of a confiding public. If he has good grounds for believing the accepted dictionary word is wrong he should verify it carefulty before departing from it.

I could name many books in which the writers, evidently profoundly ignorant of the language they speak of, have endeavoured to put down their versions of different words and sentences. In each of the cases referred to, if they had copied the words they required out of a dictionary they would have saved themselves trouble and their readers mystification.

In recording matters connected with game here I hope to record only as facts such things as are matters of conviction, not of opinion. An opinion may be formed from two or three instances, but a conviction is an opinion confirmed.

When the evidence does not appear to be overwhelming I have always tried to qualify my remarks by such words as "perhaps," "possibly:" or "I imagine" so and so. Even as such, convictions are liable to be modified very often in the light of subsequent experience.

There are many' things which I have read about game that I am unable to reconcile with my own observations. Some of these things are recorded by so many different observers that it would be foolish to pretend that they are in error. Others appear to be mistakes made by some former writer and taken for granted and repeated by subsequent writers.

To quote a few of these:-

Several writers have observed, talking of countries known to me, that it is the invariable rule for rhino to return to their droppings half an hour or so after depositing them and to toss them with their horns. These same writers make no mention of his scratching over them with his hind.legs. I cannot agree that anything is the invariable rule of any animal, or that in this case that it is even the general rule.

Now, I have observed a rhino performing this function many times, and on most occasions he has immediately afterwards executed a back shuffle with his hind legs, just as a dog often scratches after this operation. This has generally been sufficient to break up the droppings or part of them.

Furthermore, I have seen the distinct marks of this scratching performance, I would not like to say whether hundreds of times or thousands. At any rate, I have 
often seen from ten to twenty of these rhino retiring-places bearing fresh signs of these scratching marks, in the course of a single day.

Now, it strikes me as very odd that anyone writing with such certainty as to the rhino's movements half an hour after this operation should omit any mention of what he actually does during this operation. That he occasionally tosses his dung, too, I am not prepared to deny, but that this is his invariable performance I cannot agree.

Again, I have often seen it stated, talking of the plain-dwelling lion, that he never roars before hunting, but only after he has fed. This would seem at first sight the most natural thing to do, as it would be supposed that he would frighten game and so warn them if he roared first. However, this again is absolutely contrary to my observations.

I often wonder if those who make the above statement have gone to the trouble of cutting out and examining carefully that wonderful apparatus in a lion's throat which produces his reverberating roars. I claim that Nature would never have troubled to endow him with such an organ for the useless purpose of roaring after he has fed.

Where he has been much shot at he naturally gets rather diffident about roaring much, and sometimes hardly roars at all. In places where he has not yet been molested, or where he has been shot at but little, he roars incessantly. I have been in places where lions can be heard roaring nightly directly dark sets in. Moreover, I have had the most direct evidence time and time again that he roars or grunts before and during lunting, in addition to roaring after feeding. Also that he roars when coming for stock. I do not say that he invariably does so, as that would undoubtedly be a misstatement. He roars or not, just as it suits his particular plan of action. In dealing with the lion later on, the uses to which he puts his roaring will be dealt witl..*

Talking of the same lion, the lion of the plains, it is commonly stated that he should not be sought for where game is plentiful. That is to say that, if lion were lying up in a certain spot, there would be no game for some distance. Even the native will persist in saying this. Yet 1 have time after time found lion lying up right in the lieart of game. The first plain-drielling lions I crer saw were drinking during the day, and a herd of zebra were playing a game of bo-peep with them the while.

I have seen a herd of hartebeest following two belated lions at less than

- I have also had an arlicle in the Field of February 22nd, 1908, on this subject. 
two hundred yards' distance, and appearing most anxious to have a good look at them. Meamwhile, the lions looked most embarrassed and self-conscious as they slunk away.

When one is looking for lion lying up, the probability is that they have already feed, and so game is not just then afraid of them. Thus, they may be found in close proximity to game, or they may be far away, all depending on the spot they have chosen.

Again, one luas read thrilling accounts of sportsmen stalking rhino, crawling and crouching after them as they would after any keen-sighted buck. I have also seen it stated that they have been seen and charged by rhino from something like two hundred yards distant. Now, I have never stalked a rhino in my life, and yet I have seldom had any difficulty in approaching within twenty to forty yards of one of these animals. If I could really believe that they would see me and come for me at two hundred yards, I would think more of rhino-shooting on the plains as a sport.

Where rhino have been much molested they are very jumpy and sometimes manage to become aware of the hunter's approach at long distances. Most hunters give the rhino birds the credit for imparting this information to their hosts. When approaching such a rhino I have often gone to the trouble of trying to stalk the rlino birds, generally with indifferent success. In most cases, however, wherever I have found the rhino at all unsophisticated, whether in bush or plain, and even if accompanied by birds, I have been able to walk up within at least fifty yards whout his becoming alarmed. This is, of course, only provided that the wind is righl. Many times when trekkingr with porters in country swarming with rhino have 1 found them in my direct path.

On many occasions have I had to inducc rhino, very dense and slow at taking a hint, that they were not wanted. On such occasions the porters are generally told to wait behind. Then one goes forward to within one hundred or fifty yards of the animal, according to the presence of trees or otherwise and their suitability for climbing, and shouts and blows whistles at him. He pricks up his ears and turns his wrinkled face round, peering in every direction, and trying to locate the unwonted sound.

Again one shouts at him, and he is confirmed in his opinion that there is something there. He wheels round and round, trying to make up his mind in which direction to go. Again one shouts at him, and finally he blunders off, generally speaking, upwind. Sometimes he takes the hint quickly and sometimes slowly, but this is the general method of procedure. 
On the treeless plain I have sometimes been trekking in places abounding with rhino. Here one has to make a detour to pass downwind of every rhino seen. When the rhino is some way downwind of the general direction and there are many scattered about, the constant trekking off the path becomes very boring and one is apt to cut down the distance at which to pass him.

Many times have I led a whole long caravan of porters past a rhino within two hundred yards upwind of us, only impressing on the porters to go silently.

Sometimes I have passed within one hundred yards, and other men have told me that they have done the same. I have never met with any misadventure in so doing, and generally the rhino has not taken the slightest notice of us when the porters were perfectly' silent.

Very scldom, in places where the rhino has not been much molested, has he show uneasiness, and then our presence was probably betrayed to him by the behaviour of the rhino birds.

This seems, to my mind, sufficient proof that the rhino is unable to see a long caravan of forty or fifty porters at one hundred yards' distance. It makes one inclined to doubt the stories one hears of his seeing and charging a single man at two hundred yards.

Sometimes it bccomes expedient to try to cross upwind of a rhino at long distances, such as four hundred yards. This may be either to avoid a very long detour on a long march, or because there are several rhino about, and it is impossible to avoid them all. On such occasions the sportsman would post himself in a good position till the caravan had passed.

I consider it a toss-up which direction the rhino takes when he smells the caravan: he may come straight for the caravan, go straight away or off to a flank, or at any angle to these directions. When disturbed by any cause other than scent he will, as a rule, make off upirind.

The above will show why 1 consider that the shooting of two rhinos on one's licence can be performed with as little danger and considerably more ease than, the shooting of two hartebeest.

First, wait till you find a rhino in a suitable place with a few trees about. Then walk upwind to a trce about thirty yards from him, without any pretence at a stalk, rest your rifle against a tree, and shoot. If you fail to kill or disable him, and lie comes your way, dodge behind a tree. In approaching him you may, it is true, give your wind to another you have not yet seen, but in stalking a hartebcest you might equally well give your wind to an unseen rhino.

I do not wish, however, to decry a gallant foe, so I inust qualify my remarks by 
saying that he is undoubtedly, on occasions, one of the most dangerous animals in Africa. First of all, on the plains, where you lave not your convenient and climbable trees, directly you fire, if he is not killed, he will as likely as not come straight for the sound of the rille.

In a rhino country one must be constantly on the alert. A fold of ground, bush, or anthill may conceal onc of these formidable beasts.

If you pass upwind of him he may come straight for your wind. On the open plain he mily even come "bald-headed" for you from a distance of five hundred yards doa'nind, as one has seen, but such cases are the exception. On such occasions, if you are alone, you can make a run across the wind with as much celerity as the country will permit.

If you can once make him lose your wind he is unlikely to pick it up again or cast for it, and he cannot pick you up by sight till he is within pcrhaps twenty-five or thirty yards of you.

If, on the other hand, you have a long tail of porters, loads are thrown down, your only bottle of whisky is broken, and other very boring breakages are apt to take place, while you have to see it out to restore confidence.

This latter is probably the most boring part of all, as you would much rather be up a trec beside the man who is carrying your ammunition, especially if you have already shot all you are entitled to. It is then that you will realise what a very difficult shot is a rhino coming straight towards you, his massive head protecting his heart, and his horns covering his brain. On such occasions if you can break a leg it will be of more use than placing a shot in the side of his body or head, as it will sufficiently impede his progress to permit of your skipping out of the way and finishing him at leisure from a flank.

However, where rhino are so very dangerous is in thick bush, grass, or thorn. Here you cannot possibly run or dodge, as the regetation is so dense, and you cannot see him till he is on top of you. You may walk within a few yards of a family of them, lying down, without being aware of their presence. It is in such places as these that the many rhino accidents which take place chiefly happen.

This leads me to another point on which many people have totally different views, namely, as to rhino-charging and their motives.

Some say that a rhino charges at every possible opportunity, or that directly he notices you he comes for you. If he does not hit you off, that is only his bad aiming. Others try completely to whitewash his character, and say that he practically never charges in the real sense of the word. It is only his fun or a mistake, or that he took the wrong turning, but he is really trying to run away. 


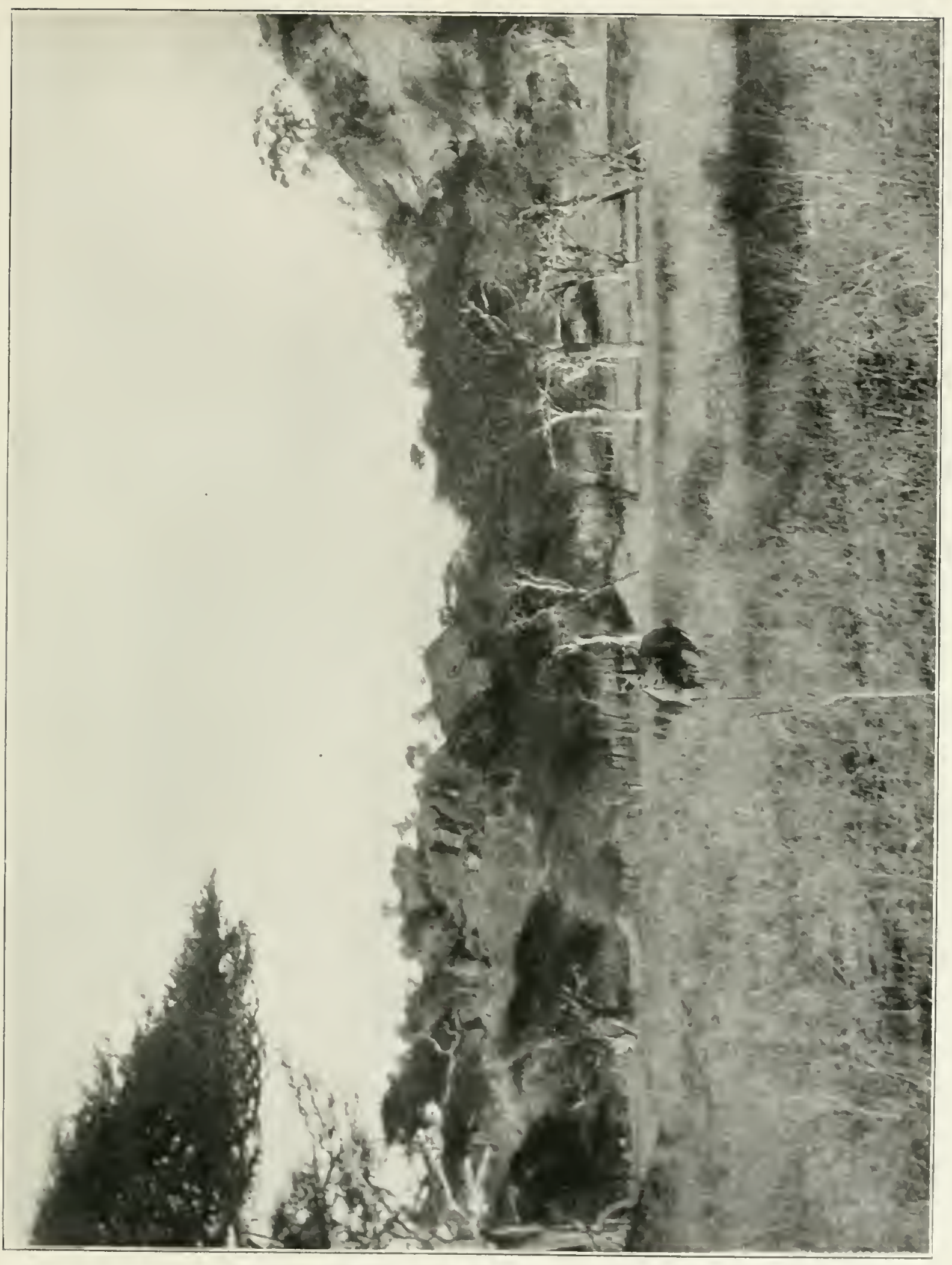



That he made a mistake would seem a poor consolation if one was the victim of that mistake.

Bctween these extremes there are all sorts of reasons offered as explanations for his conduct.

My view is somewhat as follows:-

First of all, there are the many rhino you see, but which do not perceive you either by hearing or smell. These can be practically put out of the discussion. So a man walking about in an open rhino country and having his wits about him may see many rhino, and meanwhile himself be only in the slightest danger.

But rhino often suddenly make up their minds to run in a certain direction, apparently for no object, and as suddenly decide to stop still or to run off somewhere else. Thus even some of these might have the appearance of coming for you, or might run across the wind of a sportsman after he had taken every precaution.

Putting aside these, however, we have to deal with the rhino which have been made aware of your presence either by sound, smell, or possibly sight. These will, as a general rule, run away from you. About one out of five, however, will make as if he was coming for you. Of those which do this, the greater part will subsequently think better of it, and so after coming towards you for a short distance will swerve away and make off, or will pass you at a distance to either flank.

But about one out of five, again, of these will press straight on. Thus out of twenty-five rhino which have got your wind or in some way perceived you, we have, on an average, one pressing home an attack. He may be shot coming at you and he may be wounded. If he is wounded it will probably alter his frame of mind according to the gravity or otherwise of the wound he has received and his individual temperament. He may also just miss you and then decide to go straight on without turning. Possibly, he never really intended to hit you off.

If rhinos were left alone and not fired at, I believe the greater number would be found to make a blind eliarge.

That is to say, they would come straight for your wind and, if they did not actually run up agrainst something or someone, they would then rush straight through and off the other side, still going upwind. If one met anything direetly in his way he would toss it. The chances are, however, that he would just miss you by a few yards and go straight on. W'hen you eame into his range of vision he might also not like the look of you and swerve so as t" pass you.

Out of these rhino who press home an attack I take it that, say, one in ten, again, are really bad rhino and mean to do harm. Instead of passing by at a few 
yards, they will, directly you come into view, whip round on you with surprising agility, and they really mean business.

So we gret out of every two hundred and fifty rhino about one which is a really bad rhino and which will, if lee gets your wind, without any act of aggression on your part, try his best to do some damage.

I do not claim any special value for my statistics, but I do claim that these calculations should be on these lines, rather than the usual procedure of laying down greneral rules, to which it is expected that every rhino will conform, whether he is wounded or unwounded, or of whatever temperament he may be.

One man, who has seen, perhaps, half a dozen rhino in his life, says that on setting your wind they will always run away. Another, who has shot one, says that they alway's charge, but that the charge is blind and that they are unable to turn. Even men of considerable experience are often apt to try to lay down such hardand-fast rules.

The only general rule, to the best of my belief, that can be said to apply to rhino, is that, if there are two rhino together, they will nearly always do exactly the same thing and go exactly the same way. The reason for this is that two together generally consist of a female and young. Even when male and female, however, they generally behave in exactly the same way.

To return, however, to our statistics above. Presuming that they are approximately or very roughly correct, let us make further deductions from them.

If we are in an open country the chances are that we will be able to walk about for a considerable time without betraying ourselves to any rhino, bad or otherwise. If, however, we are in a slightly wooded and bushed country, and are seeing at the rate of about ten or fifteen rhino a day (no uncommon quantity in some unvisited parts), the chances are that we are also passing close to another fifteen or so which we do not see.

Of these let us put half upwind and half downwind. That will leave an average of seven and a half per diem of unseen rhino getting one's wind. Thus, in such a country we have three false alarms every two days, a rhino pushing home to close quarters every three to four days, and a bad rhino about once a month,- - sufficiently alarming experiences should you stop long in such a country.

In thick thorn or elephant grass it would be still more alarming.

IIhere, however, white men have been a good deal, the chances are that the proportion of bad and charging-home rhino has been considerably reduced, as they have rather put themselves in the way of extermination. On the other hand, there 
might be wounded rhino about which would be feeling worse tempered than was their wont.

Men whose paths have only led them in pleasant places and in the usual shooting grounds of British East Africa might think that I have overstated facts. Those whose work or inclinations, however, have taken them much in rhino-infested bush and thick country' will, many of them, on the contrary think that I have underestimated the facts.

One's views are largely influenced by the sort of country one habitually traverses. For instance, I have heard the mountain reedbuck generally spoken of as quite an uncommon animal in this country. I am sure, however, that any surveyor, interested in animal life, whose work takes him up numberless hills will bear me out that it is both widely distributed and fairly common.

Before leaving the rhino altogether I cannot resist a word on the usual method of dealing with the name together with that of his congener the hippo. I generally call them by these abbreviated forms, as they seem more friendly appellations. In talking of them the singular will stand equally well for the plural, and "rhino" and "hippo" can equally well be applied to a number. Even "rhinos" and "hippos" do not sound out of place.

As to their full names, however, about the only recollections I still have left to me of a so-called classical education are centred about these animals. Therefore, whilst all other derivations have long since left me, I still dimly recall that these are of Greek, and not Latin, origin. How, then, they can form their plurals as rhinoceri and hippopotami I fail to see. Yet in almost every book, pamphlet, article, or licence concerning game I take up, these two words are always recurring in the forms given above. It would appear to me as if rhino, rhinos, rhinoceros, rhinoceroses, rhinocerides, hippo, hippos, hippopotamus, hippopotamuses, hippopotamoides, would all be legitimate plurals when talking of then as game, but never rhinoceri or hippopotami.

In dealing with different animals in the Appendix, wherever my observations have differed from those of others, I have generally appended a few instances as examples. I have not multiplied examples, as such multiplication could serve no purpose other than that of boring the reader mnecessarily.

I hope to avoid "animal anecdotes" and "huntingr exploits," concerning which there is always a glut of literiture, but in the absence of these the reader is asked to believe that all conclusions are based on numerous inciclents observed.

It is very difficult often, though, to arrive at correct conclusions as to the reasons which actuate any amimal's belaviour. The lumatn being is really so little in toucle 
wilh wild mature that he, as often as not, may assign quite wrong motives to its conducl. Here is an instance, purely hypothetical, of how different ideas may be gained from an observation of the same circumstance. When the grass is fired small birds collect round the spot and dart in and out of the flames. This we will suppose has been noticed by two observers, people of widely differing temperament, on several different occasions.

The first observer, a sentimentalist, might write:-

"Is the all-clevouring flames leapt forward, licking up the ground, a small bird rushed into their very midst. It was piteous to see this tiny fluttering mite, uttering the most forlorn and despairing cries, dash again and again into the flames, reckless of heat or smoke. It would seem as if she was bent on self-destruction from the way she braved the fiery tongues. What could it be that made this tender thing face llye awful furnace? Only one thing would lead her to be so daring, a mother's love fur lier offspring. The lambent flames were enveloping and destroying her little nest, her home and young, while she, with heart-rending screams, was darting hither and thither powerless to save them."

The next observer might write:-

"As the flames crept forward they doubtless drove multitudinous insects from their retreats. Now was the time for insectivorous birds to gorge themselves to repletion off their defenceless prey. Even as we watched, a bird flew down, darting hither and thither, uttering discordant and jubilant screeches as it fell on its helpless victims. Nothing could equal the audacity of this rapacious bird as it flaunted itself before the flames and dived into their very midst, insatiable in its lust of killing."

The reader must please pardon these effusions, but they may explain, better than 1 could otherwise do, how temperament may affect the quality of observations. Granting this, a very considerable divergence in any two men's conclusions on the habits of game or any other wild animal is quite likely to occur, and is to a certain extent explainable. 


\section{CHAPTER II.}

\section{ANIMAL LIFE OF THE COUNTRY.}

R RITISH EAST AFRICA is, as everyone knows, that large block of British $B$ territory which lies astride of the equator on the east coast of Africa. Its boundaries are, roughly, Ethiopia and Somaliland to the north, Uganda to the west, German East Africa to the south-west, and the Indian Ocean to the south-east.

Of this country, the area of which is, roughly, about 200,000 square miles, less than half is administrated at present, while the remainder is still little known and much as it was before the British occupation. The administrated portion consists, roughly, of the south-western part and the coast line. In this part is a game reserve of about 10,000 square miles called the Southern Game Reserve. In the unadministrated portion are game reserves the areas of which are together about double the extent of the former. At first sight it might seem that the game reserves, consisting as they do of about a sixth of the whole country, occupy too extensive an area. This is by no means the case, however, for reasons that will be gone into in another chapter. Suffice it to say here that the smaller, or southern, reserve is the only thoroughly administrated reserve, for at present it is impossible to subject the northern reserves to any careful supervision.

The greater part of British East Africa is, or was, rich in game, of which there is a great variety. The completion of the Uganda Railway, which renders the country, or at any rate the south-western portions of it, so accessible to the tourist and sportsman, must eventually change this state of affairs. Moreover, large tracts of this country have been found suitable for colonisation. So, with the immense numbers of sportsmen who visit the country year by year and the settlers who pour into the country and take up unoccupied land in all directions, the fate of the game is as good as sealed. It must eventually become an alternative of settlers or game, and there is little doubt that the former will win the day.

Already large areas of the country which used to be full of game are now but poorly stocked. That wonderful sight of miles and miles of game, seen from the carriages of the Uganda Railway, is confining itself year by year more to the south-west side of the line, that of the grame reserve. This is more marked with the 
less commun of the platu animals, such as rhino, eland, oryx callotis, and grou, and it must be saul that it is probably not entirely due to the thinning of the game by sportsmen.

Although most game in liast Africa are very local in their habits, presumably many animals find it healthier to change their quarters from the north-east to the south-west or reserved side of the railway line.

Of other places becoming more and more denuded of game many instances could be quoted, but one will perhaps suffice. Sir Harry Johnston mentions, in his work ors Uganda, the thousands of Grant's gazelle which kept the grass round Lake Nairasha cropped close as a lawn. Now, you will hardly see a head of this beautiful gazelle on the shores of the lake, and certainly you will not see a good head. If you take up a Land Office map of the district you will see that the whole of the shore round Lake Naivasha is cut up into little blocks and squares, denoting land allotted to various settlers. I do not wish to imply that the gazelle have all been shot, because it is more than likely that the greater part of them have moved elsewhere. Nor do I wish to decry the efforts of those pioneers who hope to make this country into a prosperous colony. It is only from the point of view of the animal-lover that it is so sad to feel the absence of game where once such enormous herds roamed. Nor, if the greater part of these missing animals have found their way into the southern reserve, is the case much better. For they can only serve to congest this sanctuary, giving it more animal life than it can well hold. In this case it were almost better if they had been shot, for overcrowding may result in disease sweeping off more animals than have been saved from the rifle.

Again, take up a Land Office map of the once wonderful Athi Plains, and you will see that these vast tracts are also theoretically divided up into the same little blocks and squares. It would appear at first sight that on all these huge plains there is not an acre on which the sportsman can shoot without being guilty of trespass. However, as yet it is not quite as bad as this. I said theoretically above, for, although nearly the whole of this area is private property, you may still walk many a mile without seeing a settler's fence or house. It seems that a greater part of this land has been taken up by people who have no intention of settling on their property or of doing anything to it. Apparently they are only waiting for an opportunity to sell at a profit. However, this state of things cannot exist much longer, for the Government, as soon as it gets breathing space, is sure to enforce intending settlers either to take up their land in a boná-fide manner or else return it to the State.

Althougl, the congrestion in the game reserve may be insignificant and hardly 
apparent at present, when this large area bordering on it is finally and effectually occupied its condition may be very different. For then the greater part of the game from these huge plains will probably be forced back into the reserve, while possibly a similar state of affairs will occur on its opposite side, the German boundary.

There are other influences, too, at work to reduce the grazing grounds of the game besides the inpour of settlers. One is the increasing growth of the agricultural tribes under the benign influences of the British Government, for now that there are no wars to thin down their numbers they have increased greatly, and are able to put under cultivation a larger tract of land, undisturbed as they are by external or internal troubles. I speak more especially of the Kiuyu tribe, which occupies a large area of some of the most densely populated and thickly cultivated country in Africa. Now that they no longer live in fear of Masai raids from the south and west or of the hostility of the Kenya tribes to the east, and now that they no longer indulge in inter-tribal warfare, it seems as if their outward expansion could know no bounds. Moreover, they are also among the most prolific of African natives.

This dense mass of humanity is slowly spreading outwards like a slow-moving but all-devouring stream of lava. Forests are cut down, bush is cleared, and gradually every place it touches is converted into a treeless expanse of little, bare, red hills covered with beans, sweet potatoes, and other vegetables. So, what with game reserves, native cultivation, and the enormous tracts of land taken up by settlers, the intending sportsman of a few years hence will find very little vacant ground on which even to camp. Wherever he wishes to shoot he will find wire fences and notice-boards warning him of the conscquences of trespass. Already in many parts it is overmuch like this. I an speaking of the healthier parts of the administrated portion of British East Africa. In the game reserves, unadministrated portions, and unhealthier parts of the coast and low country; however, it is hoped that the game will survive for many a long year to give pleasure to the nature-lover and he who likes to watch and study their habits.

A great part of the highlands is plain country. It consists of great, rolling, open, trecless plains stretching away as far as the eye can reach, corered with short grass. It is on these plains that the large herds of game are found. There is not the slightest difficulty in finding them, and, when disturbed, they merely move off a few hundred yards, so that the only quality requisite to kill such game is straight shooting and a little patience in approaching.

I came to this country direct from in place where it was necessary to work hard for nearly every animal brought to bag, where it must be sought for, tracked, and circumvented in bush or long grass, and where an animal, if once alarmed, puts 
several hours of difficult country beween itself and the hunter. After that kind of shooting, the usual shooting in this country, which consists of running about on an open plain after semi-lame animals, offers little or no attractions. However, to the mere trophy-hunter such country is a paradise, as, without the smallest knowledge of bushcraft, he cals obtain a large bag in a brief time.

Apart from the plains, there is much of the country, little visited by the average sportsman, in which the hunter can even now practise his art undisturbed.

On the plains there is, indeed, much to see of the different animals and their labits. There is a fascination in the intimate way one may watch their doings, which is impossible to enjoy in the forest and bush. Here I am, quite a reformed character, the desire to hunt and slay being wholly allayed, except very occasionally when driven hard by the exigencies of the pot.

So of the plain I will talk as a spectator and as an open-air naturalist, not as a slaughterer. In the forest and bush, perhaps, I may be pardoned for occasionally forgetting to play the rôle of a disinterested observer and being enticed into the chase. For here are animals requiring all one's wits to circumvent and which have all the odds in favour of escape. Here also are trophies seldom bagged, and animals seldom studied or even seen.

If every sportsman returned from this country with a selection of forest and thick bush dwelling animals in his bag much more would doubtless be known concerning them. As it is, their lives have much of mystery about them. What is it that prompts one to interest oneself in such animals and to neglect the homely hartebcest? First and foremost, it is the science and difficulty of the chase which attracts, which are interests wholly absent on the plains. $1 \mathrm{t}$ is also the desire to gret out of the common groove, to be away from the majority of mankind; and, again, it is prompted by the same feelings which, in Africa, make one move camp when one hears that there is another white man camping near.

The methods used in bagging game on the plain and in the bush are so rery different that I shall distinguish them by the two words, "shooting" and "hunting." It is to be understood that shooting will be used for the plain, and hunting for the bush. The difference between these terms will be explained in a subsequent chapter.

lirstly, it may be as well to endearour to show what are the chief influences at work affecting the characteristics of game. Secondlv, what effect, if any, these infuences have on the game of this country as compared with that of other parts of Africa.

It is wroll known that various influences cause the same species of animal in 



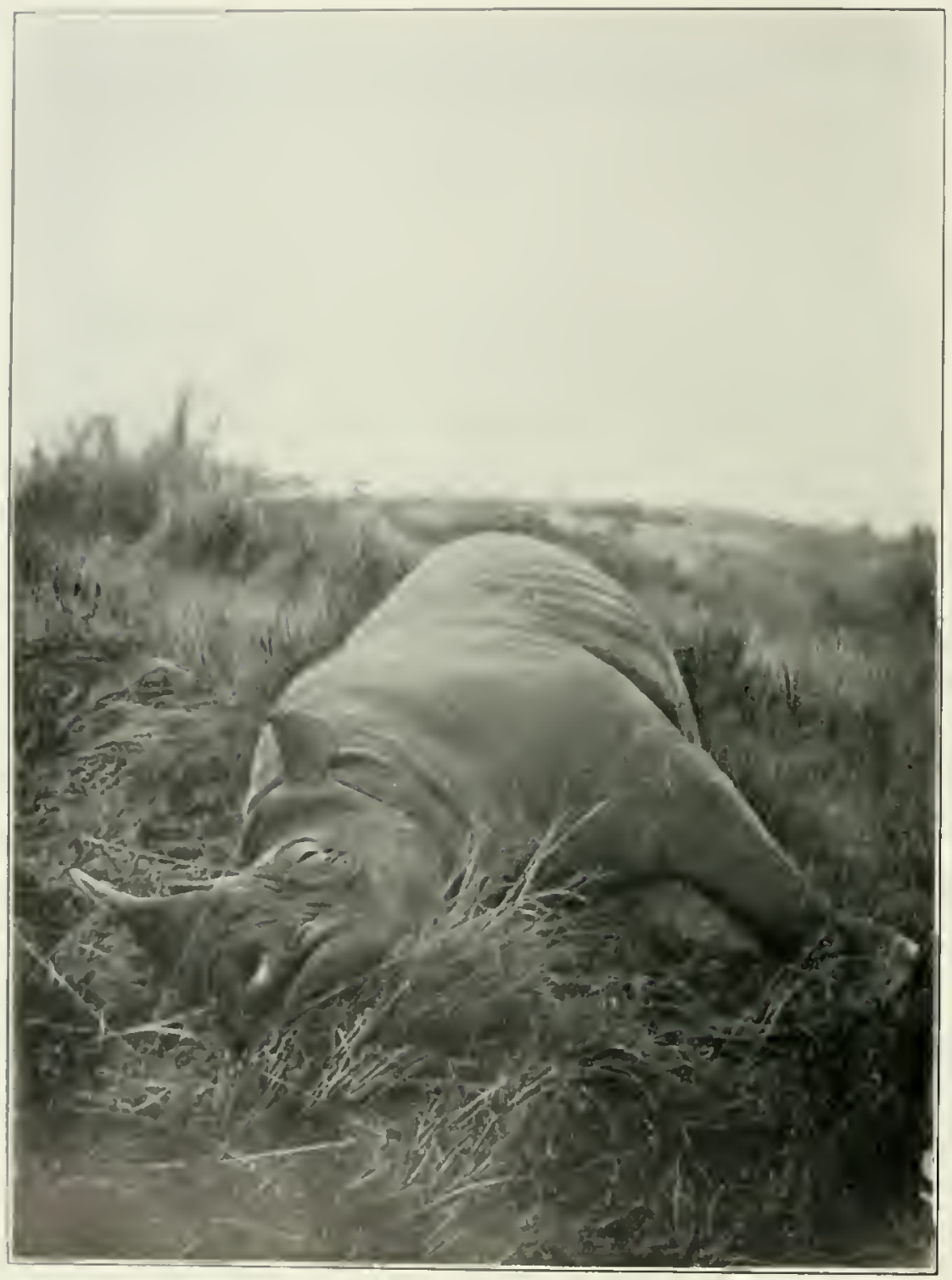

RHINo. 
different parts of the world to contract greatly differing habits. In many case's local or other causes, usually but imperfectly understood, are responsible for variations in colour, size, length of hair and horn, and other changes. These influences which tend to cause local variations are chiefly (i.) climatic; (ii.) pasturage and food supply; (iii.) kind of country; and (iv.) the habits of the other animals and human beings inhabiting such country.

It may be presumed that when a new species of animal gradually comes into existence its migrations are at first confined to such countries as are exactly similar to those in which it originated. Any spreading of the species into different kinds of country must be a slow process of gradually becoming accustomed to the altered state of living. To explain more clearly, I will suppose that the rhino in the highlands of East Africa is now passing through such a change. In East Africa the animal spends his time between plain and bush. In the plain he is easily brought to bag, as he can be seen from afar, and, owing to his defective eyesight, lie can be approached to within a short distance and often be shot dead before he is aware of his danger. In the bush things are much more in his favour, as, it being impossible to locate him by sight, he has the chance of winding or hearing an adversary. Moreover, most people are rather careful to avoid him there, for one might easily approach within a few yards of him without being aware of his presence. Then a rapid charge, and the chances are in favour of the rhino bringing the hunter to bag. The animal's weight also gives him a great advantage orer his pursuer in the bush, for he can crash rapidly through the thickest of bush and thus put a mass of difficult country between himself and the hunter. Following in his footsteps is no easy matter, as the stiff thorn branches which he has pushed aside so easily spring back into their old positions across his track and bar the way.

Again, if he has been disturbed by wind the chances are that he will make off downwind, and so you must either follow in his wake, with the certainty of giving him your wind again as soon as you get near him, or attempt to make a detour through previously unbroken bush and chance hitting him off.

Now, in process of time, if the rhino is spared long enough to effect the change, he should become, in this country, a pure bush aninal, shunning the open plains entirely. His pursuit will then be more or less akin to that of the Central African rhino.

It cannot be expected that such a change could be effected at once; it would be a long process.

The rhino is dependent on certain grasses and foods which he gets from the 
plains, and which are probably as necessary to his diet as are the thorns of the bush. In Central Africa he can get his grass diet under cover of the tall rank grasses, which conceal him as effectively as does the bush, and this allows him to move freely in any direction, his weight being sufficient to permit of his easily forcing a passage, while it offers to the sportsman a very serious obstacle.

There should therefore be wo processes at work to change the plain-wandering Irabits of the liast African rhino. The first is, that the rhinos which visit the plains least are those which, in the long run, will not suffer so much at the hands of the sportsman. Thus, of the survivors there will be always a greater proportion left of those which prefer the bush, and as it is the survivors which will propagate their species, the offspring in their turn will be, as time goes on, more and more of the bush-loving type. Again, the most frequent of these latter that visit the plains will again pay toll to the sportsman, and those then left will be still more of the bushdwelling type.

The second process at work should be the natural intelligence of the rhino, if, indeed, he possesses such a quality. He should learn by experience that there is danger awaiting him in the plains, and so curtail his visits there to the utmost of his powers. Thus, in time these animals may accustom themselves to do entirely without the food of the plains which now appears to form a considerable part of their diet, and adapt themselves to a pure bush diet. The above is, of course, a hypothetical case to illustrate the changes that are always in progress with animals, tending to accustom them to new environments, food, and habits.

The probable solution in the case quoted will be that the present plain-dwelling rhino will either be exterminated before he has accomplished any change so lengthy, or he will learn to visit the plains by night alone, and then only in close proximity to the bush.

In the Athi Plains, with the exception of that portion allotted to the reserve, and in the Rift valley, the rhino is now practically non-extant, although once plentiful. In plains farther afield he still roams, but the sportsman will soon follow him there and make it impossible for him to exist as he does now. Fortunately a large portion of the country is thick bush and grass intermingled, so the rhino inhabiting such strongholds will defy the sportsman for many years to come, for he can there get all the grass he wants under cover of the bush.

Apart from the persecution by human beings, natural changes are ever at work, to which some animals find it impossible to conform and so have to give way before them. Such a one might be an alteration in the character of the vegetation of, comparatively speaking, so rapid a nature that the game had not time to adapt 
themselves to it. It would then become necessary for them to gradually quit a country they once inhabited. Another of these natural changes might be the springingup and outward expansion of a new species, more able and better fitted to sustain life in the country, and before which the older inhabitants would have to give way.

When conditions such as these arise, a barrier is often put across, separating the area of the former distribution of the species into two or more parts, and it is conditions like these which account for the finding of a small isolated detachment of some species far removed from the country inhabited by the bulk of its own kind. An instance of this is found with the sassaby. The main country inhabited by this species is to the south of the Zambezi River. Passing northwards it is not again met with till away up by Lake Bangweolo, in which locality is found a small isolated settlement.

One can hardly credit this animal with a parallel case to the Angoni Zulus. That is, that, having suffered from internal strife and determined to endure no longer the tyranny of their paramount chief, a number broke off from the main body and took it long trek up to another country. The only feasible explanation to offer is that at one time there were sassaby distributed over the whole of the intervening country from Lake Bangweolo to the Zambezi, till something occurred to drive them away from the large intermediate tract. As the sassaby is a plain-loving animal, a reasonable theory to offer is that there were tracts of open plain at one time more or less connecting their present habitats. It must then have been the thick bush, which now covers this country, gradually spreading over the land that made it uninhabitable to these animals. At last the only retreats left were those great, open flats to the south of Bangweolo, and which are the only large, open spaces in the country.

Another explanation, but perhaps a less likely one, is that the coming of the Lichtenstein's hartebeest, an animal more suited to the intervening country, was the cause of the retirement of the sassaby.

There are similar cases of this broken distribution of species in British East Africa. One of these is that of the topi, an animal closely allied to the sassaby, and of rery similar halbits. He is found plentifully in the plains of Yubalind and the open country near the coast in Tanaland. Passing westwards from there he is not again met with till after the Rift valley is crossed and the shores of Iake Vietoria are approached.

It is true that he is screened off by dense bush which almost encircles his Tanaland and Yubaland habitats, but west of this bush many plains are met with that might have supported him. These are probably at too great an altitude or else deficient in some particular shrubs, and so do not suffice for his needs. 
Another example of this broken distribution is that of the roan, found in small numbers mear the lthanga llills and north-east of the Athi Plains. He next occurs on llue Guns Nigishu itt the other side of the Rift valley, and also plentifully on the German borcler. Between these spots, as far as I am aware, he is unknown.

Now as to the special causes, natural or otherwise, influencing the game of liast Arrica.

I have said that such causes are chiefly:-

(i.) Climatic; (ii.) pasturage and food supply; (iii.) kind of country; and (iv.) the habits of other animals and mankind. I will take these in order.

\section{(i.) Climatic Conditions.}

Climatic conditions may affect an animal indirectly in many ways, most of which are probably but imperfectly understood. The direct effects of heat and cold are often, however, obvious, especially in the mamer in which they affect hair in manmals and feathers in birds. As a general rule, animals inhabiting a tropical country are brilliantly coloured, while those of a temperate country are clad in more sombre hues. At the equat or there is a broad band of tropical vegetation running round the grobe. In this band the vegetation is rich and luxuriant, and there is a wealth of animal and bird life. It is in this equatorial belt that animal life and birds especially are found of such gorgeous colours. In Africa this belt contains the forest lands of liast Africa, Uganda, and the Ituri and Congo forests. The corresponding tropical belt in t!e American continents is Central America and the richly luxuriant regions of the Amazons.

North and south of the tropical equatorial band are intermittent belts of desert and barren countries, where there is but a paucity of animal life, usually of more sombre coloration, as befits the habitat. In Africa these desert regions comprise, amongst others, the llaud, Nubian, and Sahara deserts to the north, and the Kalahari to the south. The Rob al Khali of Arabia, the desert regions of India and China, and the salt lakes of Utah are amongst those that complete the northern bett; while to the south are the desert regions of Patagonia and Australia. Again, north and south of this necklace of deserts are found the semi-tropical and temperate belts. This is the gencral arrangement of the surface of the globe, though subject to local variations.

In addition to the effect of climate on the coloration of animals, the direct effect of cold is usually to increase the growtl of hair. This is generally, but not always, the case.

It appears that animals of the same species which inhabit both hot and cold 


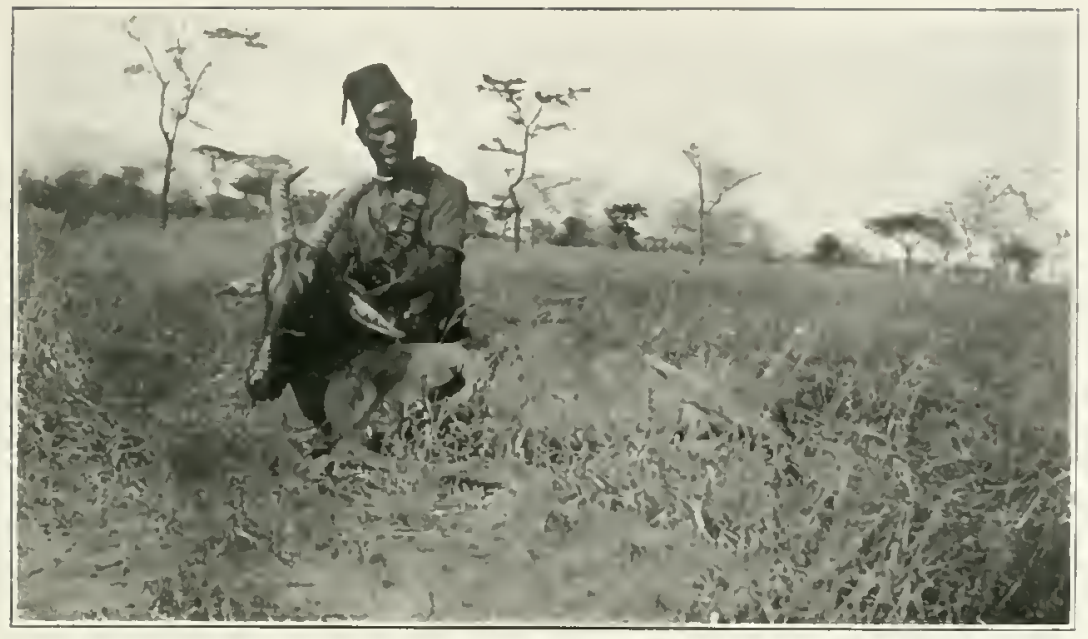

TกP.

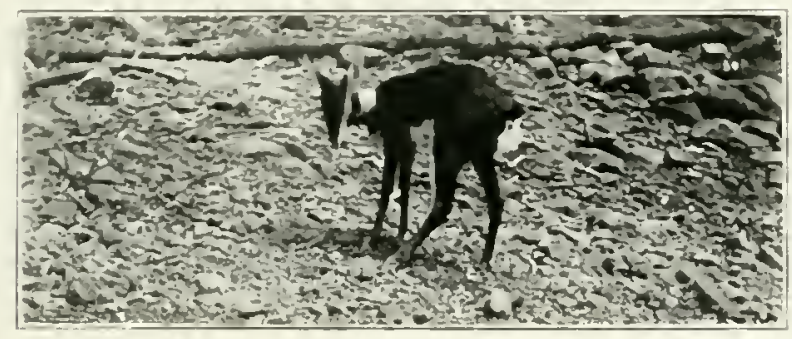

I.MBO, I รULNG W.IR|S'S REEDBLCK.

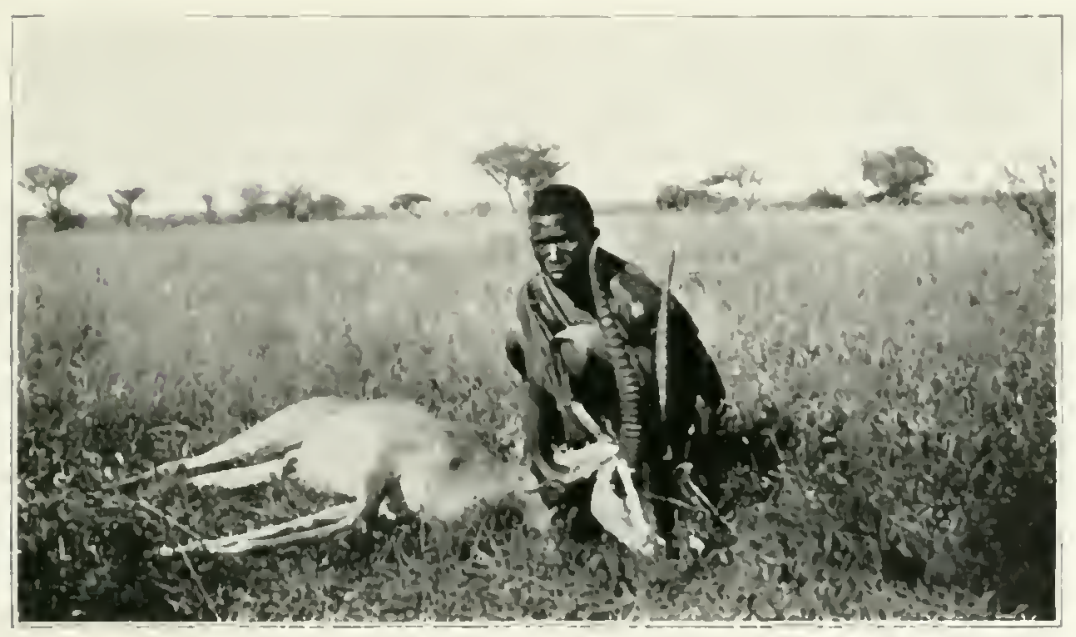

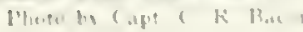



countries are found at their best in the latter. Thus, tigers from Siberia and Korea have much finer coats than those from Southern India and the Strats. Upland lions have generally better skins than those of the lowlands, and those from very hot countries are sometimes very lacking in mane. An apparent exception to this rule is the maneless or nearly maneless Masai lion, which inhabits the upland plains and also is found in the bush belt passed through before reaching the high country.

In the colder highlands it would appear that he ought to be furnished with a better mane, but on the Athi Plains, although at night it is cold, during the day the sun is very fierce, so possibly he finds his maneless coat better suited to the requirements of the country than would be a thickly maned coat. For during the cold of the night he is on the move, while during the heat of the day he is lying down. The best manes come from still higher and colder platcaux, such as the Guas Ngishu. Those animals which are only found in cold or only found in hot countries generally follow the rule of thicker and better coats in the former and thimner in the latter. With these, however, such a strict adherence to this rule is not so necessary as with animals inhabiting both countries, as they are presumably acclimatised to whichever country they inhabit.

For instance, the various goats and sheep that live in the Pamirs, llimalayas, Rockies, and other cold places are provided with ample coats, both species being essentially adapted for life in mountainous and cold regions.

Their only representatives amongst African game animals seem to be the sheep of Barbary and the ibex of Ethiopia and the Soudan.

In countries where there is a considerable difference in temperature between the cold and hot seasons animals are often provided with two coats-the summer and winter. The latter grows as the cold weather approaches and is slyed when it is over. An instance of such is the Bactrian camcl.

In East Africa a great part of the country is highland and often very cold.

There appears to be no evidence, though, of the highland game having anything unusual in the way of coats. The reason for this is that with the majority of the game different species inhabit the higher and the lower regions and do not pass between them. Thus, on the highland plains are found Grant's zebras, Cok's and Jackson's hartebeests, Grant's and Thomson's gazelles, in great numbers. As soon as the lower-lying hot and arid plains towards Lake Rudolf ate reached the Grevy's zebra, oryx, beisa, and Somering's gazelle take the place of the abore-named species.

With the rhino, as nearly all his hair-producing cnergy appears to be thrown into the formation of his horns, the cold-country animals should have longer and 
better horms than those of the hotter countries. Although most of the best horns recorded come from the highlands, there seems to be at present no definite proof that this result is actually the case. Elephants inhabit both some of the coldest parts of the country, viz, the mountain tops, 13,oooft. above sea level, and some of the hottest, viz., the coast line. I do not know if the skin of the former is any thicker than that of the latter, but temperature appears to have a decided infuence on the tusks, for, whereas the highland irory is close-grained and of good quality, that of the coast is poor and generally small. As the hair-producing power of the clephant is chiefly exercised in the production of his tusks, this is only the result one would expect from the difference of climate.

The effect of cold on the horns of buck and antelope does not appear to be as definite. Here it is possible that some quality in the grazing may be the cause of increasing the size of the horns, but even this theory does not seem quite satisfactory: It is not clear, for instance, why the horns of the East African impala should be so superior to those of the Central African, while, on the other hand, the horns of the East African eland are inferior to those of his Central African congener. In each of these cases there is a sub-specific difference between the animals of either country.

Again, in the province of Ankole, in Uganda, the cattle grow the most exceptional horns, and the buffalo are also noted for the size of theirs, while other game in the same district have smaller horns than the average. On the Semfliki River and on the west side of Lake Albert the waterbuck are noted for the tremendous size of their horns, while in East Africa they are usually small.

Climatic differences also are responsible for changes in the habits of animals. To take an instance: it is a most uncommon thing in most parts of Africa to find a lion out after seven o'clock in the morning. In the cold lighlands of East Africa, however, and especially on cloudy days, these animals may be seen out much later, and sometimes even at midday.

\section{(ii.) Pasturage and Food and Water Supply.}

The grazing over the greater part of the uplands of East Africa is extraordinarily rich and abundant. Moreover, there is no lengthy period of dry season as in other parts of Africa. In the highlands the rainfall is evenly distributed throughout the year. There are the yearly rains and the lesser rains, and there is never any long period during which there is no rain whatever. The dew also is very heavy.

Very different is the state of things in many other parts of the continent, where there are only the yearly rains and then no further fall till the next year. In 



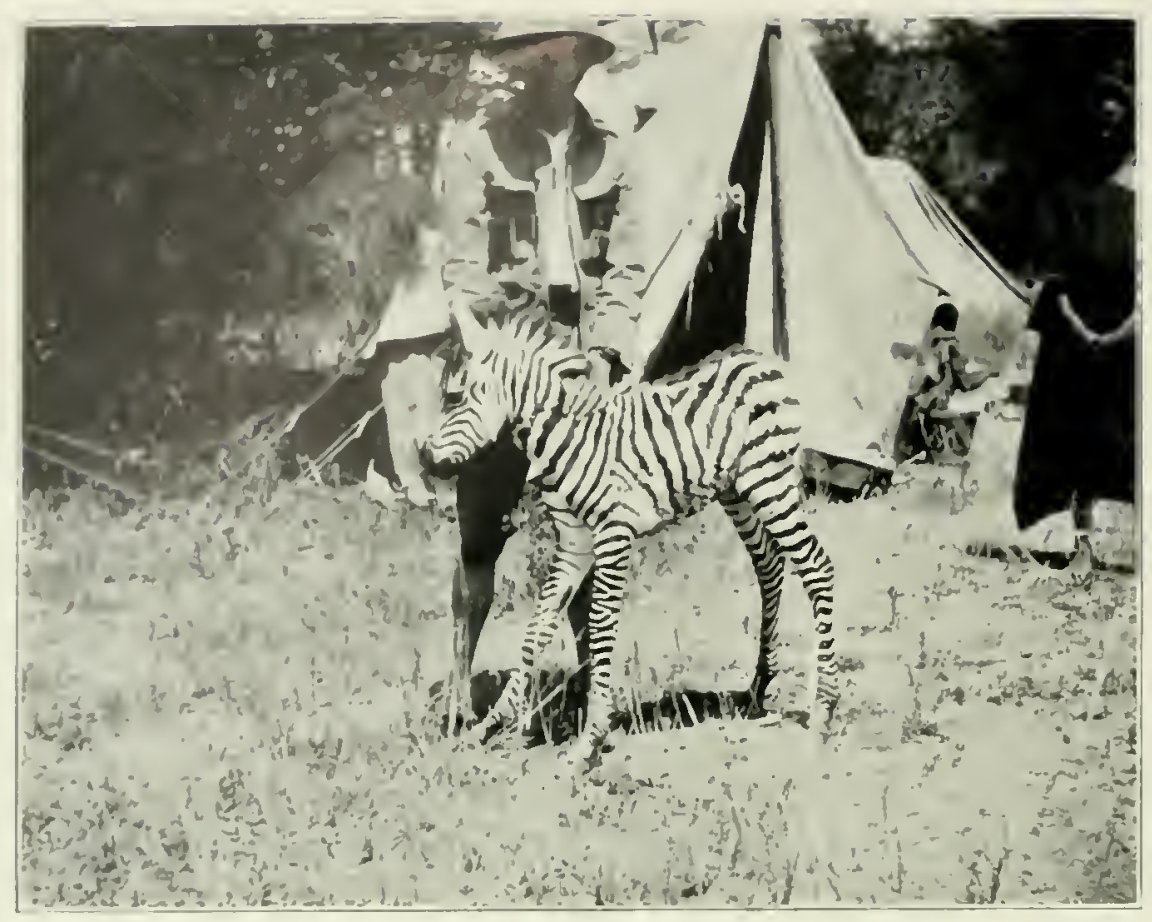

A VOUAR riRAXI'S ZEBRA.

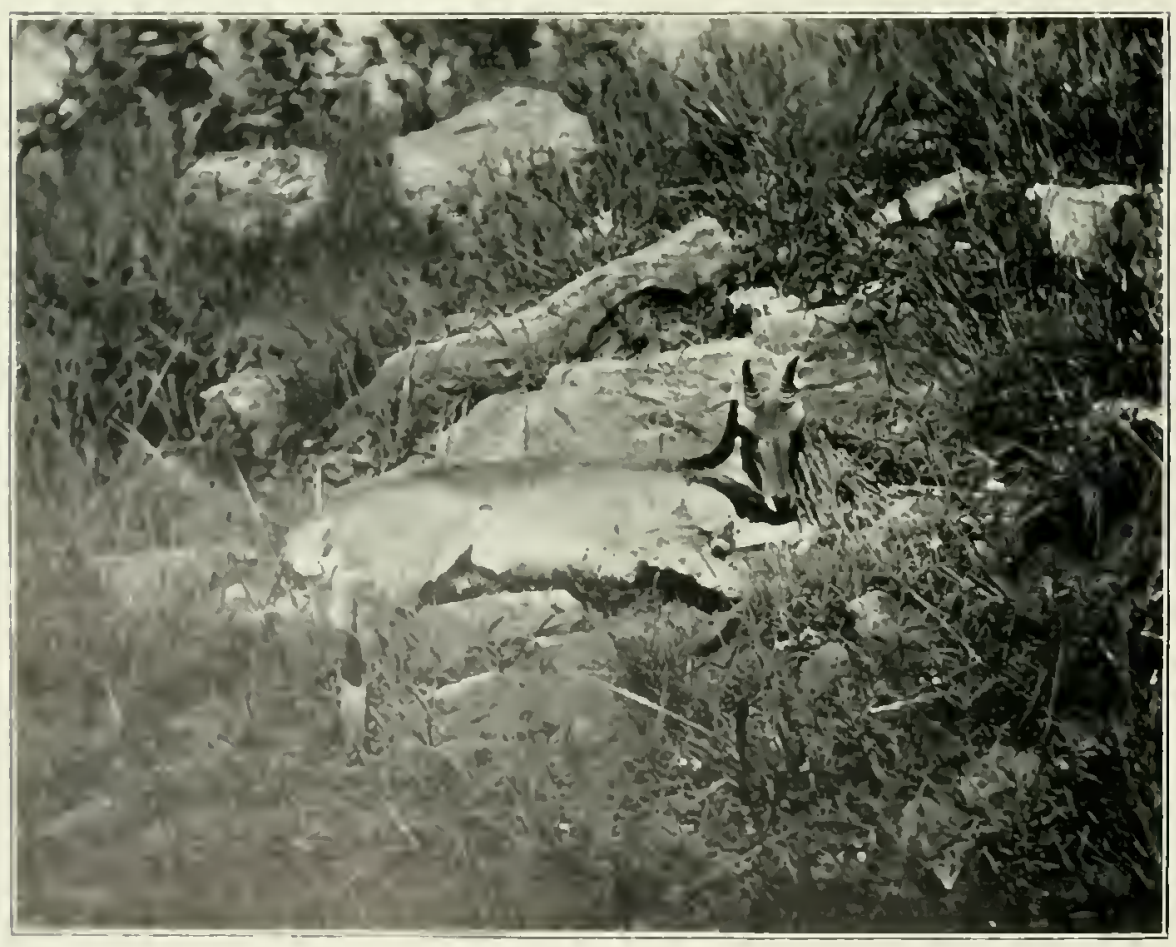

Photo by R, G. Stone, 
Nyasaland and North-Eastern Rhodesia the rains fall heavily for from four to six months. During this time every hollow, dip, and valley in the country is practically under water. During the remainder of the year there is no rain and the country becomes parched and dry, the grass is long since dead, and the grazing is of the poorest, so that the grass-feeding game have to subsist for months on the long, rank, dead grass.

In barren countries, like Somaliland and Southern and Eastern Abyssinia, the state of things is still worse, as the rainy season lasts but a brief while.

So the great feature of the East African highland pasturages is the luxuriancy of its grazing during the whole year, with but brief intervals. The grass here does not grow long and rank as in other parts, and during a great part of the year there are fresh and green grasses, and clovers. The immediate outcome of this state of things is that an enormous amount of game can support themselves on a comparatively small area. Another result of this abundance of grazing is that animals need never graze over any very extended area to eat their fill, neither is it expedient for them to leave their own pasturage to go to another where they will find other herds already in possession. In these rich uplands there is hardly such a thing as searching for food, although at the end of a dry season animals must necessarily walk a little farther and in places change grazing grounds so as to be near water. This engenders lazy habits in the game of the country, and so makes them very local in their habits. Animals may be found, clay after day, in exactly the same locality and grazing over the same ground and drinking from the same water-hole.

Very different is the state of things in such poor pasturages as Nyasaland and North-Eastern Rhodesia, where game must graze over an enormous area to get their day's fill. Thus, they are alway's on the move and are scarcely ever found twice in the same spot. Their habits are of the more energetic, wandering type, and they hardly ever return on two consecutive days to the same ground, and certainly never drink from the same place or use the same lying-up spot twice running. So if you see an animal in a certain place one day it is not worth while returning there to look for him on another day. On the contrary, if you once disturb him in a certain spot you might search the whole country side for him, but would never trouble to return to look for him again in the place from which he was frightened. In highland Last Africa, however, if you see an animal in a certain place at a particular time, or even if you frighten him away from it, you will know where to look for him again on the morrow or the next day. Exen in the less-favoured lowland gratying grounds game has it great tendency to become local in its habits, though, of 
course, not to so marlied a degree. This local endency of the game makes the sportsman's task ridiculously easy and rery uninteresting. For instead of being compelled to continually ferret out fresh grazing grounds and drinking places le contents himself with returning again and again to the same old places. Instead of laving to learn by hard experience the habits and peculiarities of his game, and to change camp every day, and hunt from morning till night, the East African sportsman goes out for a short morning's stroll, returns to lunch, and spends most of the aftermoon in bed. However, there are some kind of game which it is always difficult to bring to bag, and even in East Africa these do not entirely lose their cuming. They are recommended to the attention of those sportsmen who would be something more than mere shooters.

The local habits of the plain-dwelling game are not without effect on the carnivorous animals. For these carnivora things are made absurdly simple. A lair near a much-used water-hole and their food supply is assured. It is no matter for surprise, then, that they also are not up to the same standard of cunning and guile as the harder.working bush carnivora.

The last consideration under this heading is water. The greater part of the country, owing to the great mountain ranges, is well watered, and so no special adaptations in the manner of the living of its occupants is necessary. In the great waterless tracts towards Lake Rudolf and in the Taru Desert near the coast, howerer, special types of animals are required to go either for long periods without water or to do entirely without it. A certain amount of liquid sustenance is obtained from dew and the chewing of aloes and fibres. The peculiar regetations of such regions must affect the types of game dwelling there. Such types are many of the gazelles, oryx, dik-diks, and others.

\section{(iii.) Kind of Country.}

The different linds of country generally met with might be divided into:-

Bare and rocky mountains or hills.

Open plains.

Bush.

Swamps.

Thick forests.

Game is found in different parts of the world spccially equipped by Nature for life in any one of these kinds of country.

Then, there are also animals which can live in two or more of these countries, and others which pass from one to the other. By this I mean that there are animals 
which can live equally well in two or more kinds of country, but it is not necessary for them to wander backwards and forwards between these countries. Thus, bushbuck may live in bush country, and may also, equally well, inhabit forest. A hippo or lecluwe, however, spends part of its time in swamps or water and part in open or grass country. The Lichtenstein's hartebeest spends part of the day in bush and part in the operr.

In East Africa are found all the kinds of country mentioned. I will take the first, the bare mountains.

At any altitude above $1 \mathrm{I}, 000 \mathrm{ft}$. the forest and bamboo generally gives way to bare and rocky mountain. There are, however, no game animals like the ibex or the markhor, which make these rocky solitudes tlucir habitat, or, to speak more correctly, no game animal of this sort has up to the present been discovered in them. In fact, Africa is very poorly represented by members of the slreep and goat tribes, the only two representatives being as before mentioned, the ibex and the Barbary sheep.

By the way, it might also be of interest to mention that the only representative of the deer tribe in Africa is the Barbary deer, inhabiting the same part of the continent as does the sheep, viz., the Barbary States.

These high, bare mountain summits in East Africa are almost devoid of game life, except for the occasional visits of rhino and elephant coming up from the bamboo and forest levels, and a few small buck which also appear to be risitors. The rocky and stony kopjes of lower levels are the abodes of the little klipspringer, an animal specialised to this kind of country. This little buck is, perhaps, the most widely distributed buck in Africa, as he is found almost throughout the length and breadth of the continent, wherever the conformation of the hills suits his particular requirements. The mountain, or Chandler's, reedbuck is also often found on such hills, but he cannot be said to be specialised to the kind of country, as he is also found on lower and flatter grounds.

The characteristics of mountain animals are generally hardiness, long sight, sureness of foot, and the power of moving short distances over bad country at a rapid pace. The sides of stony hills form also the habitat of the greater kudu, and he possesses to a marked degree the last-mentioned characteristic, namely, the ability to move rapidly over bad country. He is, however, a bush-feeder, and so is hardly ever found on bare slopes, his farourite haunts being well-wooded, stony slopes. He is occasionally found in flatter bush country, but seldom far from steep hills.

To return to the mountain animals. They are generally of sturdy and compact 
build, and ane not, as at rule, used to travelling long distances; when disturbed they usually take to very difficult country, but do not go as far as many other animals such as ilephant, rhino, and sable.

The mext in order of the kinds of country is the open plain. The grass-eater of the plains is by far the least intelligent of game animals. He is endowed with great swiftness in short bursts and with long sight. His idea of safety is the centre of a treeless expanse, from whence every direction is under his observation. His sight is long, but not, as a rule, very quick. If there is only a little cover about he will be fund easier to stalk than is a bush animal where cover is plentiful. His intelligence is of the smallest, and he is taken night after night at the same drinking place, close to some famous lying-up place of lion, when a little thought would save him, whilst the remainder of the herd never seem to profit by experience. I liave often seen a herd of hartebeest coming down to drink within a few yards of nice little patches of reeds surrounded by bleached bones. There may be water-holes a hundred yards or so away, with open approaches, which they might perfectly well use instead. Moreover, if they always approached such places upwind there would be no danger, but they often fail to take even this precaution. I have concealed myself in patclies of grass that might have afforded cover to a dozen lions, and seen these innocent plain-dwellers come filing past within close range. In my case it meant the cxercise of a lot of patience in exchange for a possible camera shot.

For a lion, however, it is a very different matter. He has to sleep somewhere during the day, and so, for him, it only means that he must choose a resting-place near water or in the midst of game and lie there. Should anything come near he is immediately warned by scent and is ready for it.

It is hardly surprising that the plain-dweller should be very inferior in intellect to the bush-dweller, for the former has always abundant food at hand and has to exercise no thought or care in obtaining it. When pursued either by man or beast of prey he has no guile to display in escaping them. A short, sharp canter puts him out of range of the former's rifle and out of danger of the latter's claws. He then returns to the filling of his stomach without further thought of danger. There is, or should be, no danger to him from a seen foe. With man he has but to manceuvre out of range, and with beasts of prey he has only to gallop off. It is when taken unawares that he chicfly falls a vietim to the latter, but how little this care weighs on his mind may be seen from the way he deliberately puts himself into danger.

It is curious to note the different ideas of safety entertained respectively by the plain and the bush dweller. Let us say a Grant's gazelle and a bushbuck are grazing near each other on the edge of a plain when something occurs to alarm them. The 
bushbuck lopes quickly back into the bush, sure that in this lies his only ehance of safety. The Grant's turns and gallops from the bush as if it were some deadly thing, and not until he has put two or three hundred yards between himself and the bush does he breathe again and turn round to see what it was that frightened him.

The beast of prey boasts a greater intelligence and cunning than the grass-feeder. It is not strange that the beast which catches, should have greater guile than the beast which is caught. It is only natural that an animal which lives by hunting and stratagems for the outwitting of other animals should arrive at a higher state in the intellectual scale than an animal which merely stands to fill its stomach.

However, the plain-dwelling lion is much inferior in intelligence to the lion of the bush. The latter has to deal with cunning animals, while the former has only fools to circumvent. The plain-dwelling lion is, as a rule, superior to the bushdwelling lion in the size and quality of his mane. This is probably due to the fact that the plains are mostly highland plateaux, and it is the direct effect of cold which produces a greater abundance of hair. The best manes are usually found with well-kept zoo or menagerie lions. No wild lion's mane can touch these.

Now as to the bush-dwelling game. They have to walk about more than the plain-feeders to get their food, and so are not so local in their habits. When disturbed they do not move a few hundred yards, as do the latter, but travel some distance, perhaps going for several hours, before stopping. They are not, as a rule, long-sighted, but are very quick at picking up an object close by, even if almost concealed from view. Their sense of hearing is very acute, as is also their sense of smelling; many of them rely almost entirely on these two senses to detect an enemy. The unaroidable noise made by anyone approaching through bush is their safeguard against surprise, and for this reason bush-dwelling game have generally very big ears. The ears of the bongo are enormous when compared to those of the plains animals. The kudus also have very big ears. Curiously enough, some of the small buck have not big ears; but these little creatures rely on lying close for protection.

As the bush folk can locate anything by sound, so can they also be located themselves by sound. For this reason most of the larger bush animals wander by night, early morning, and late evening, lying down during the greater part of the day and listening for sounds. Of the smaller ones, some feed morning and evening and others are nocturnal; some of these, however, for fear of leopard, take to the open during the night, returning to the bush or forest in the early morning to lie up for the day. 
Bush animils generally have thicker hides than the plain-dwellers, especially athour the neck ind slunders, as it is these parts which come in contact mostly with the bush. The oryx has extraordinarily thick skin protecting the shoulders, so much so that his hide is much prized by the Somalis, who are able to cut a circular shield from each side of the shoulders.

The necks and shoulders of such animals as the kudu, bushbuck, etc., are genirally rubbed bare of hair, especially in old animals, through constant friction with the bush. Their horns are generally thick and massive, as it is by help of these that they force a way through thick country. They are generally laid back along the sides to protect the flanks, while the nose is inserted into any opening in the thick regetation, and the base of the horns serves to push back the branches and increase the opening. The branches and creepers then glide along the horns and slip off the animal's flanks. In passing through bush the whole body is crouched and, with the horns, forms a wedge shape, of which the nose of the animal is the point. In many kinds the females are hornless. With these, unlike most game, it is the custom of the male to precede and break the way, but when the females are travelling by themselves they push under and through the denser parts and do not attempt to crash through. They display a wonderful faculty for passing through, over, or under obstacles, seemingly without the use of any force.

Country inhabited by bush game is generally intersected with a network of paths broken by them, often impracticable for mankind, but quite good enough to enable the bush denizens to proceed at a great pace.

Some kinds of bush country produce animals specially adopted to get the greatest value out of the scanty feeding. Examples of such are the giraffe and Waller's gazelle, specialised for feeding off the tops of mimosa and other mushroomshaped thorn trees.

\section{Swamp and Water-dwelling Game.}

With the exception of the hippo, water-dwelling game is rare, for special shaping of the hoofs is required to serve as paddles. Such an animal, however, is the situtunga, built on the general lines of the bushbuck family, but possessed of long hair and enormously lengthened divided hoofs serving to give foothold on the papyrus roots. These hoofs pass on either side of the roots, after the manner of a two-pronged fork, and moreover, as the foot is very flexible when turned back, it acts as a paddle for the animal in swimming.

Native rumour states that in Lake Bangweolo there is a water rhino. Should this prove correct, it will be interesting to see what adaptation of the rhino's foot has taken place 10 fit the animal for an aquatic existence. 
The swamp-dwelling game of British East Africa appear to be confined to the hippo and situtunga, the latter being fairly common, though unattainable, in the papyrus belt round Lake Victoria, and it has lately been reported to exist in a swamp on the Guas Ngishu. It has, I believe, never actually been shot on the British East African side of the lake, and it is unlikely that even ardent sportsmen will attempt doing so, as, apart from the difficulty of locating and coming up with it in the swamps, its habitat is also the abode of sleeping sickness and other pestilential diseases. In Uganda the situtunga is fairly common in many of the swampy streams, but almost impossible to bring to bag by any other method than that of holding a big drive.

In parts of the Eastern Congo another water-dwelling and little-known game animal is found, and that is the chevrotain.

\section{Forest-daelling Animals.}

East Africa is rich in great forests, and from thence an intermittent line stretches westwards through Uganda and the Congo to the West Coast. Such forests are rare to the north or south of these countries, and in place is found wooded country of small, thin, and straggling trees, closely packed and reaching upwards for light and air at the expense of their lower portions.

The large equatorial forests stretching across the centre of Africa are the homes of many animals not known elsewhere. Such are the okapi, bongo, forest pig, gorilla, chimpanzee, certain kinds of duikers, and others. In East Africa the forests are not of the same extent as they are farther west, and are chiefly confined to altitudes over 6, oooft.

In these forests is a certain amount of undergrowth, and it is this that affords food to such animals as live on the floor of the forest. As this regetation is usually: of noxious quality, such as brambles and stinging-nettles, and the good foods are few, the floor of the forest does not appear to be capable of affording food to any great quantity of animals. It is the animals which are able to obtain the leaves of the trees which are found in greatest numbers.

Such are the elephant, and various species of baboons, monkeys, colobi, gennets, hyraces, and other tree-climbing creatures.

The "going" in the forest is bad, owing to the thick undergrowth, fallen trees, and the noxious plants which are able to exist with a minimum of light. Underfoot, dead and britte: sticks and twigs form a thick carpet, the crackling of which gives ample warning of the approach of an intruder to the denizens of the forest.

Ilithin the forest, however, is one of the most interesting fields for rescareh 
Fin whatever amimals dwell there are little known or quite unknown in more northern and southern Africa. Moreover, so difficult is it to penetrate into the heart of the great forests that these denizens are little studied and little known to science.

Before leaving the different types of country it may be remarked that those animals which inhabit indiscriminately two or more kinds of country generally take to the most difficult on being alarmed. Those animals that only know the plain leave the edges and seek the centre for safety. Those that inhabit both plain and bush generally leave the plain and take to the bush on being disturbed. Those that inhabit both bush and forest often leave the bush and make for the forest when come upon in the former. If come upon in the latter, they only push farther into the recesses. The water-dwelling animals, on being alarmed, will take to water or swamps.

\section{(iv.) Tho Effect on Game of the Habits of Other Animals and Mankind.}

The relations between animals living in the same country are chiefly:-

(A) The relations existing between the beast of prey and the beast preyed upon.

(B) The relations existing between animals which, although of different species, have one food in common.

To take the first of these.

Game have often to modify their habits considerably to aroid beasts of prey, and the latter have subsequently to modify theirs to meet these altered labits. Thus, in a wood abounding with leopard, it is seldom that baboon come down to the ground, or, at any rate, leave the trees for any distance. In other places they may be seen trooping out in the open hunting for centipedes and the other delicacies that they delight in. In places where lion have been much hunted they learn to roar little, and are sometimes almost completely silent, whereas in other and less-visited districts they usually roar incessantly. The leopard, having to deal with much more wary animals than has the lion, is correspondingly more cunning. Furthermore, the balance of nature is often so intricately arranged that the presence, or eren some peculiarity in habit, of some one animal may affect a number of others indirectly. Many instances of these are adduced by Darwin and Wallace, a well-known example being the case of the number of cats in a district affecting the honey supply.

The immediate result of two or more species of anmals having one food in common is to cause an unconscious rivalry betwen these species. This directly lends to the improvement of both species, unless one of these species improves so rapidly as 10 oust the other from the arena. When this takes place the inferior species dwindles and probably finally becomes extinct. It is prejudicial to any 



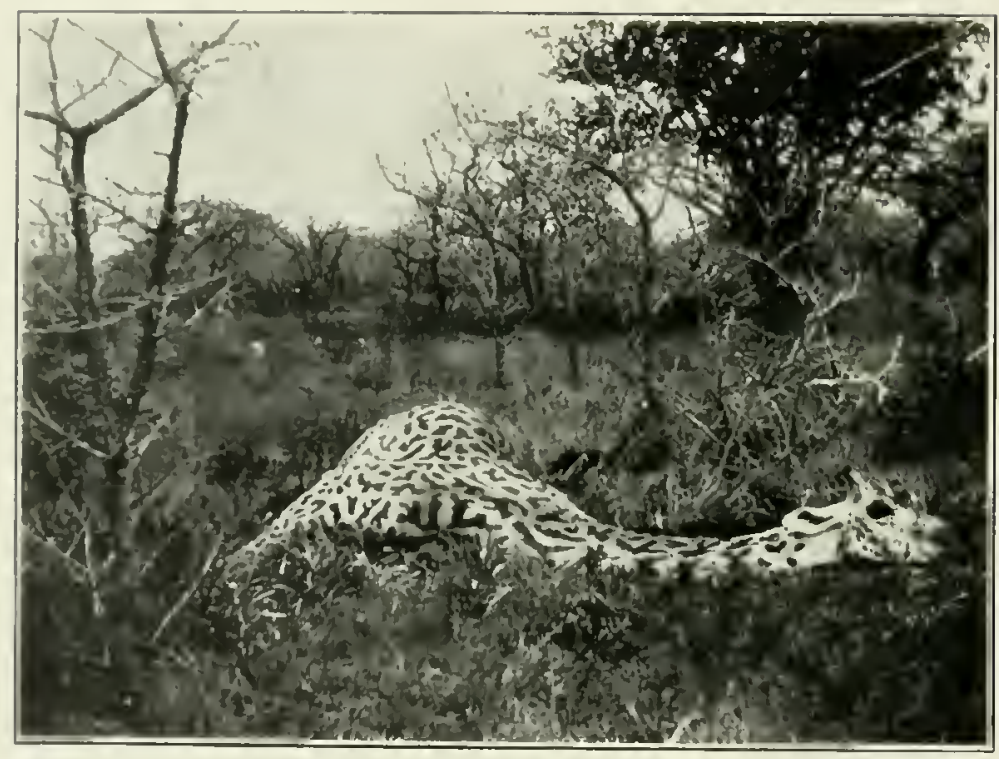

MIRIFFE, LY CAPTAIX C, R. B.ACON, SFRENGETI PL.IIS, BRITISH E.ISI AFRIC. 
animal to have a monopoly of one kind of regetable food, as it then has no stimulus to improvement. It grows stale and behindhand in the race for existence, and is then at the mercy of any new species which may crop up with more energy and vitality to throw into the struggle for existence.

Where any food is abundant, such as is the grass of the plains, then the struggle between species is almost nominal. Where, however, food is scarce and difficult to obtain, the struggle is keenly contested and causes rapid changes in the habits and forms of the contesting parties. Such a one has probably been continuing for eras between Waller's and Clarke's gazelle. Each has been trying to fit itself more and more for the scanty grazing off the mimosa and acacia tops. By the simple process of the least fitted of each of these species going to the wall for want of sufficient nourishment, their present forms have been produced. Each species has been unconsciously trying 10 grow longer legs and necks so as to reach the grazing untouched by its opponent. Apparently the Waller's has shown itself the more fitted to survive, and this probably accounts for its wider distribution. The Clarke's is gradually being ousted from the contest. Even now it is local and rare, which conditions are eventually followed by its extinction, unless, indeed, it can take up some new line before this entirely comes to pass.

The giraffe is in the same line of contest, but is hardly a serious rival to these gazelle, as it has grown out of their highest sphere of grazing and eats over their heads. Perhaps this animal is the survivor from a bygone contest similar to that now in progress between these gazelle. I can picture a prehistoric struggle between the ancestors of the giraffe, not yet atlained to its present size and form, and other giraffe or okapi-like animals; the gradual evolution to its present form and the gradual dying out and extinction of the other competitors. Having arrived at his present stature, he is now somewhat handicapped by finding himself saddled with an enormous body which it must take all his energies to fill.

Next, as to the effect on animals caused by their human neighbours.

It is very easy to imagine that animals living near a race of hunters learn to be of much more shy and retiring habits than those that live in an uninhabited country or near non-hunting tribes. In the plains of East Africa, the only tribe inhabiting these vast expanses is the Masai. They are a pastoral people, probably of northern origin. "To judge, however, from some of their cattle tracks, cut deep into rocky soil, they have for centuries been grazing these plains with their flocks and herds. Their food consists only of the meat, blood, and milk of their stock. Other meats and uther foods they never touch in the ordinary course of exents. Thus, they graze their cattle amongst the game, unleeding and unheeded by them. I'robably before the 
advent of the Masai these plains were uninhabited by human beings, for in all likelihood any inhabitants of this country before their advent were bush-dwellers, to whom cattle were unknown. It is unlikely; then, that even their hunters visited the plains; for armed with such short-ranged weapons as bows and clubs they would have found the bush a more suitable hunting-ground. To this probable state of affairs in the past I attribute the extraordinary tameness of the plain-dwelling animals which remains even to-day in spite of about a quarter of a century's rifle practice by pioncers and sportsmen. The game have, however, learnt to keep more or less out of range of the white man, but the Masai they often allow to pass them at fifty or one hundred yards. One of the most numerous tribes in the Protectorate, the Kikuyu, an agricultural people whose land borders on the plains, also possess the peculiarity of touching no game meat. These people also hardly concern themselves with the game at all.

Numbers of both the Masai and Kikuyu tribes, it is true, take to a hunting life, the former driven by loss of stock and eattle sickness, and the latter by poorness of crops and famine. It is noticeable, however, that both these peoples, when so compelled by hunger to take to a hunting life, as a rule take up their abode in bush and forests and do not visit the plains. Even their traps are set and game pits dug entirely in the latter country, and they appear to leave the plains animals absolutely unmolested.

It thus seems likely that this custom has always been followed by the bushmen and hunters of these parts in ancient times, so that the game of the plains have alway's been left in peace by human beings. No wonder, then, that they are peculiarly unsuspicious and guileless.

In the bush and forest, however, a very different state of things exists. For in the bush even at the present day live several tribes, some of whom are professional hunters, and others occasional hunters. It is also more than likely that from time immemorial hunters have lived in these localities.

In Tanaland and Yubaland are found the Waboni, who live by hunting; and there are also a few almost unknown tribes who gain a livelihood by the same means. They are what might be termed bush-hunters.

In the forests is also found a race of professional hunters. These people, generally known as Wandorobo, the Swahili form of their Masai name, call themselves the Ogieg. They live in the thick forests of the Kikuyu and Mau escarpments, and seldom emerge from them, living by hunting alone. The Masai who leave their pastoral life to become hunters join these people, and are henceforward known also as Torubo (Wandorobo) or Ogiegr. The Kikuyu who turn 
hunters form a different clan, called Kikuyu IVandorobo; but many of these appear to alternate between a hunting and an agricultural life. Their hunting-grounds are chiefly on the Kenya, Kinangop, and Aberdare forest-clad mountains. Members of other tribes also, such as the Nandi, hunt in the forests.

It is not surprising, then, that the forest animals should be, more than all others, wary and timid, for the tribes that hunt them are excessively cunning with trap, snare, and pitfall, poisoned arrow, and drop spear; and, moreover, they can walk silently enough in the forest, and make their way, almost naked, through the thickest of country. At tracking they are, however, surprisingly weak, and once away from their country they are but little use at any form of busheraft. But of these peoples more later.

\section{LIST OF EAST AFRICAN GAIHE ANIMALS.}

T:lephant.

Rhino.

Hippo.

Giraffe.

Buffalo.

Gnu.

Eland.

Kudu, Greater.

Kudu, Lesser.

Bongo.

Silutunga.

Bushbuck.

Salble.

Roan.

Oryx.

Orys, Fringe-eared.

Ilartebeest, Jackson's.

II artebeest, Coke's.

I Fartebeest, Neuman's.

Hunter's Antelope.
Topi.

Waterbuck, Common.

Waterbuck, Singsing.

Thomas's Cob.

Reedbuck, Bohor.

Reedbuck, Ward's.

Reedbuck, Chanler's.

Inpala.

Gazelle, Grant's.

Gazelle, Peters's.

Gazelle, WaIler's.

Gazelle, Thomson's.

Oribi, Ilaggard's.

Oribi, Abyssinian.

Duiker, Common.

Duiker, IIarvey's.

Duiker, Isaac's.

Klipspringer.

Steinbuck.

Suni, Zanzibar.
Dikdik, Cavendish's.

Dikdik, Gunther's.

Dikdik, Ilinde's.

Dikdik, Kirk's.

Lion.

Leopard.

Cheetah.

Serval.

Hyxna, Spolted.

Hyæna, Striped.

Hunting Dog.

Forest $\mathrm{Hog}$.

Wart Hog.

Bushpig.

Zebra, Granı's.

Zebra, Grevy's.

Colobus,

Ostrich. 


\section{CHAPTER III.}

\section{COLORATION OF GAME ANIMALS.}

I dealing with different types of country and their effects on the animals living there the subject of coloration was not touched upon.

It is undoubtedly the case that differences of climate, country, and regetation are determining factors in the colours, or at any rate part of the colours, of many game animals, but why this should be so or how it comes about is less clear. Wallace, that able follower and expounder of Darwin, has written much on the subject of coloration. He claims that practically the whole scheme of coloration of the animal world can be explained by his theories of protective coloration, recognition marks, danger signals, and sexual selection. Interesting and instructive as his works are, there is still much, especially as regards the larger game, that does not bear absolute conviction to the mind of the outdoor naturalist.

Darwin himself never considered the smallest of his points as proved until such time as he had produced an enormous and overwhelming bulk of practical evidence in its favour. I am sure that he would have been the first to allow that some of his disciples' theories and suggestions were as yet insufficiently proved by facts. Much as the ideas might have appealed to his imagination, a naturalist so practical as he was would never have committed himself to such statements before he had advanced the fullest and most ample proofs and field observations in their favour. For Darwin was not merely one of those whom President Roosevelt refers to as "closet naturalists" - he was rather at one and the same time a learned indoor, and an observant outdoor, naturalist.

I had read most of the accepted theories on animal coloration as a boy before I had come in actual contact with the larger game. In the light of my then very limited practical information these theories seemed to be convincing enough. The idea of accounting for all the markings of every animal by such simple principles seemed so perfectly in accord with Nature's scheme that one was compelled to accept them; but in recent years I have set myself to investigate these theories by the light of practical experience of the real habits and conditions under which the animals live, more particularly as regards the greater game. I am now compelled 
to admit that I am unable to find any very convincing practical proofs in farour of those theories, so fascinating when read in cirilised surroundings.

The rough copy of this chapter on animal coloration was written about the middle of the year 1907. I had then come to the conclusion that there were few defmite proofs that the colours of the larger game were of any service to them for protective purposes. Moreover, that neither could the majority ever hope to gain concealment, by means of their coloration, from their foes, nor did they ever seem to try to conceal themselves. Yet was the colour of many animals assimilated in great measure to their surroundings, but what benefit this was to them or exactly how this had come about it was impossible to imagine. Having arrived at these and several other conclusions, my observations seemed entirely opposed to those of Wallace and other eminent naturalists. I felt that it would be arrogant on my part to insist on opinions so different to those arrived at by distinguished men, but while in the act of revising this chapter a year later I received from England a copy of Selous's "African Nature Notes and Reminiscences," and in it I found some of the very conclusions I had arrived at myself, although very much more ably expressed and definitely explained. When I saw that he rejected many of the established theories with regard to animal coloration I no longer felt that it would be presumptuous on my part to do the same and differ with accepted theories. Since such a well-known naturalist and writer had disagreed with the old ideas I felt no hesitation in rewriting the present chapter and expressing more forcibly the views and observations which I had written on but diffidently before.

To touch first on animals lower in the scale. It is amongst these that the most wonderful likenesses to inanimate and other objects are found. Amongst insects in particular the marvellous resemblances to leaves of different kinds, both dead and green, singly and in bunches of two or three together, sticks, wigs, and other objects are most striking. Everyone must have noticed, even with European caterpillars, butterflies, and moths, what remarkable representations of certain objects many of these show, the rigid attitude of the wig-like caterpillars of some of the geometers standing out at an angle to the branch cannot have been developed by a mere accident, or the wonderful resemblance the undersides of many butterflies bear to the leaves of trees on which they are wont to rest, can hardly be considered as having been brought about by pure chance. Amongst British butterflies the green hairstreak show's, perhaps, one of the most beautiful imitations of a leaf. Nearly atl caterpillars bear an extraurdinary likeness to parts of the plants on which they feed, and many moths, too, when resting with their wings over their backs, are the exact representillim of a piece of the bark of those trees on the trunks of which they usuatly rest. 
"Yhe butterlives and moths cannot hope to avoid detertion when they move, and so it is only the undersides of butterflies' wings, and of most moths the upper side of the upper wings, which are so protectively coloured. The other parts of the wings and body, concealed while at rest, may be most gaudily coloured without this being apparent when the insect is at rest.

Amongst tropical insects even more wonderful imitations of leaves, twigs, bark, ctc., are noticeable. As I write now, an exact reproduction of a bit of dead grass stem and seed has just fallen on my paper and remains perfectly motionless. Now it runs across the paper and now remains still again. As I was writing a few days ago I saw the half of a dry seed-pod stir and then start walking into my tent. On examination I found a head, body, and legs attached to the underside of this extraordinary back.

As to butterflies and moths, considering that these resemblances are only marked in the larva and pupa stages or when the mature insect is at rest (the only time it can hope to pass unobserved), it seems as if these resemblances must be protective in origin and function, and unless a wealth of evidence is brought to bear on the subject proving conclusively that such imitation of their surroundings is of no use to these insects and nerer has been, it seems safest to assume that their present form has been arrived at by natural selection and survival of those less easily. detected by their enemies. It would be difficult to conceive of any other agency which has coloured the parts exposed during rest, to such perfect harmony with their surroundings, while bold and glaring colours run riot in other parts of their bodies. It appears to me, as far as the caterpillar is concerned, that the colours they assume cannot but be beneficial to them in escaping to a certain extent from the observation of eriemies.

It is supposed that even keen-sighted birds, in common with the majority of animals, possess the usual failings with regard to sight; that is, an inability to detect stationary objects, especially when these objects harmonise with their surroundings.

One can only assume that man, by virtue of his imagination and greater reasoning power, is more fitted to detect such objects as an explanation of how. seldom birds seem to find these protectively coloured insects.

Accepting the protective theory with regard to insects as explaining many things, there still remain, however, many small points which it is difficult to reconcile with this theory. W'hy should Nature hare been at such pains to render the butterfly and moth, protected during their preliminary stages and while at rest, yet so helpless and at the mercy of enemies when on the wing?

If these protective colours are chiefly a means of protection against birds, 
as is so often stated, the butterfly's aimless flights seem utterly in conflict with the idea of the necessity for these precautionary colours. Once the butterfly leaves its resting-place it flits about in the open, conspicuous to all, and never attempting to keep out of danger. It is, to all appearances, unsuspecting and perfectly indifferent to any foe which may attack it. The greater part of its life, during the sunshine, is spent in flitting about, sunning itself, and flapping its gaudily painted wings. It is difficult, then, to understand how the brief intervals of protected rest on tree-trunks, branches, or twigs can be of such infinite value to these insects as to be the sole cause of such a wonderful display of protective imitation.

As to the danger of these insects being devoured by birds, I think that this dinger has been greatly exaggerated by armchair naturalists.

It is very seldom, incleed, that I have actually seen a bird take a butterfly. On the few occasions I have witnessed the proceeding it has been after this manner :-

The bird swoops at the insect, taking, or missing, its body in transit without arresting its flight. The body appears to be gulped down almost immediately, while by the same act the four wings are severed and fall to the ground, or float away in the wind.

Now, although I have rarely witnessed this occurrence, I am frequently meeting with severed wings lying about. Only a few days ago while travelling along a road I noticed numbers of these severed wings, though chiefly of only two species of butterlly; and 1 also observed quantities of butterflies about.

Although one often notices single wings lying about, in many instances all four wings will be seen lying close together. It is thus almost a certainty that the butterflies to which these wings belonged were not taken by birds, but by some animal living on the ground, such as a field-mouse or lizard. Now, if such be the case that the chief enemies of butterfies are field-mice, slyrews, and the great variety of lizards which abound in the tropics, and if these animals are wont to catch their prey by sight rather than by smell, the necessity for protective coloration white at rest is obvious. However gaudily coloured are the parts exposed during flight it will not affect their safely from these animals.

Another point difficult to understand in Nature's scheme is with regard to numbers of short-lived insects, such as among the Neuroptera. Many of these are protected during the comparatively lengthy periods of their transformations, and even the perfect insect is perhaps protectively coloured, and all for what purpose? One or two short hours of life in the flying stage. Returning to the wealth and variety of colour displayed on the upper sides of the wings of butterllies-hats all 
this mlinite variation of colour and pattern been brought about solcly by sexual selection? It is an explanation that possibly accounts for part of these colours, but not as yet by any means is the theory proved beyond doubt. The action of climate and environment, it may be found some day, have had more to do with the formation of such colours and patterns than is generally suspected. How these conditions act on given organisms does not seem to be known at present, but that they do act in some way appears beyond a doubt.

There is an instance, well known amongst entomologists, of eggs from the same batch, hatched under different climatic conditions, producing the ordinary Brimstone butterfly of the British Isles (G. Rhamni) and the exotic, orange-suffused Brimstone (G. Cleopatra). Such an example is worthy of attention, and no doubt careful experiments would be productive of other like results. If varying climatic conditions can produce such difference in the products of the same batch of eggs, how very much greater must be the change produced by long residence in a different climate. However, it would be well to leave a subject on which one is so ill-informed.

Climatic influences and influences of environment have no doubt played a great part in the coloration of insects. Until, however, more definite information is to hand with regard to the effects of light and colour on living organisms, it seems that not much more can be said.

Next as to reptiles. These are generally bright-coloured, but very many appear to be protectively covered. It would appear as if the colours of some snakes, such as the green pit-viper and the puff-adder, are serviceable imitations of their surroundings, and should be of use in concealing them from the secretary bird and other foes, or of allowing them to remain undetected by their prey. The colour of the green tree-frog, too, should serve to conceal his presence amongst the leaves from the insects he wishes to catch. Other instances amongst reptiles are found, such as with chameleons and some of the lizards. As reptiles are in the habit of remaining perfectly stationary for long intervals, such protective coloration should be of great value to them.

The crocodile, although generally recognisable by the expert human eye, must frequently escape observation from other animals, remembering always the difficulty animals have in detecting any object remaining quite still. His likeness to a floating $\log$, perhaps, even deceives fishes upstream of him, for they are slow to see stationary objects, rapidly as they fly from any movements. I certainly think that the colour, and to a large extent the shape, of the crocodile is brought about for the purpose of enabling it to lie undetected by its prey. Putting aside, however, the 


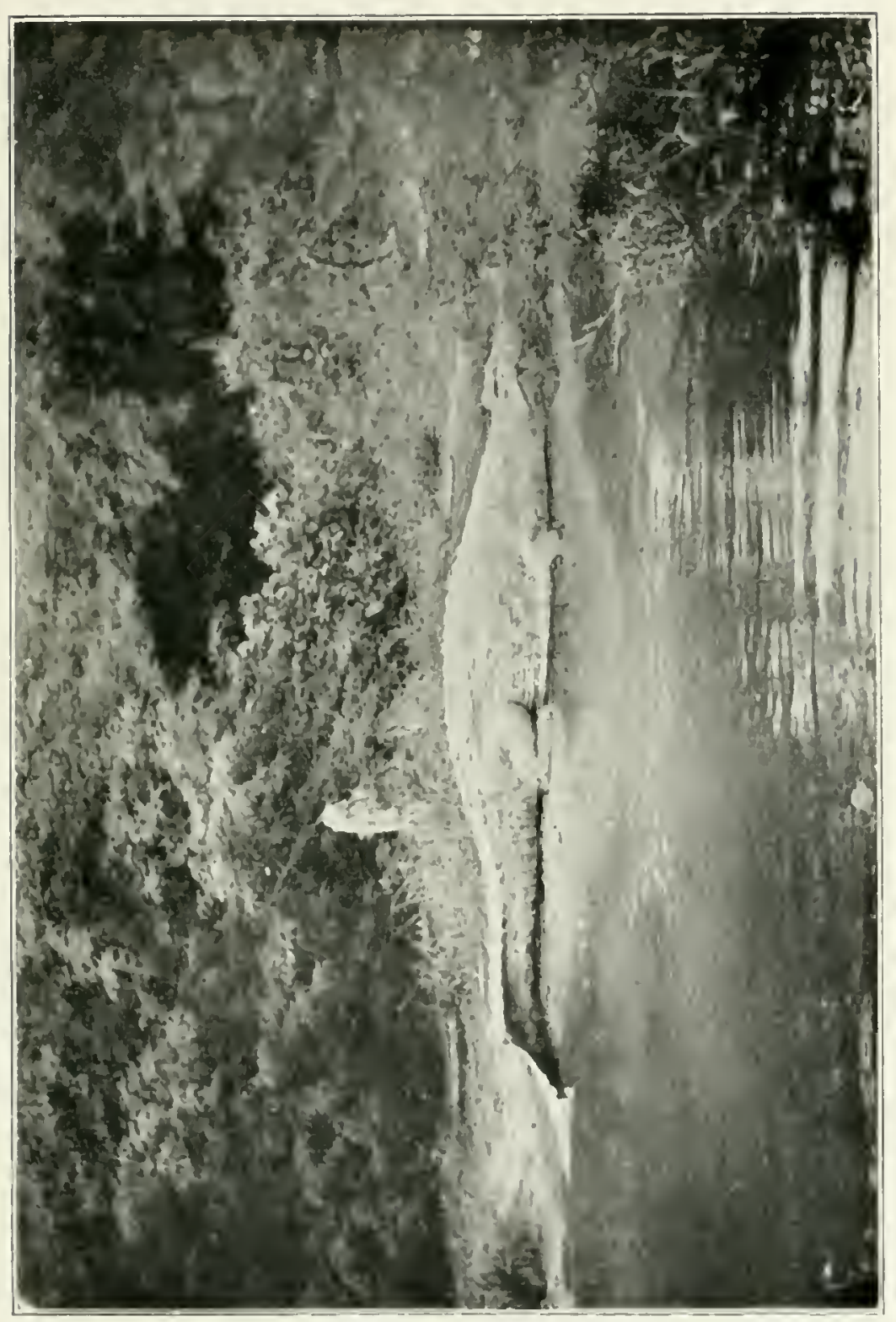





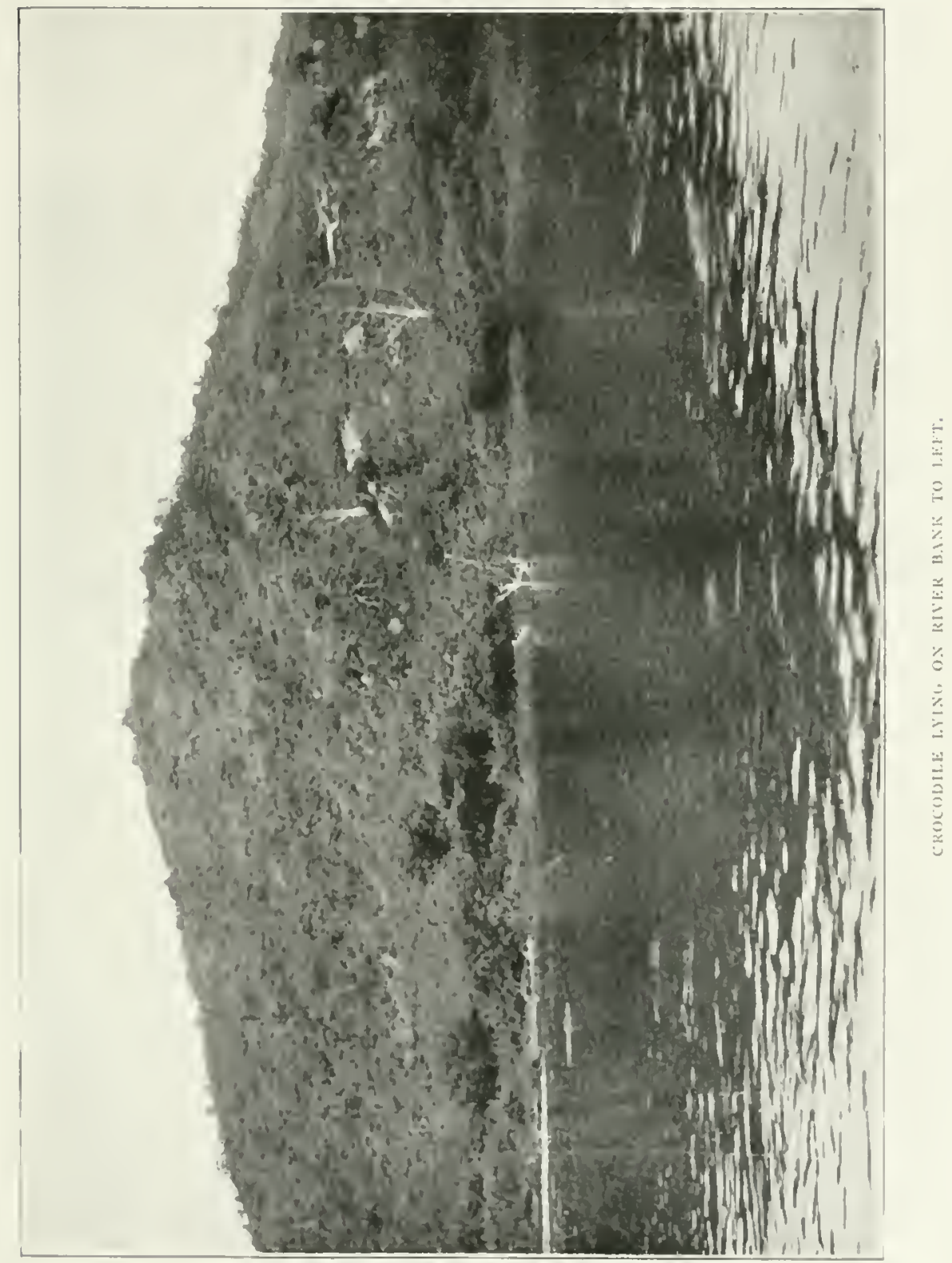



striking resemblances above referred to in the reptile world, there are still many more with which the theory of coloration does not altogether seem a satisfactory explanation, and which have every bit as much need of protective colours. In fact, there are a great number, such as the red frogs, iridescent blue and purple lizards, and others of striking hues whose coloration seems in direct opposition to this theory. I think that it would be safe to state that the theory of protective coloration, to whatever lengths it is carried, can only be made to apply to part of the reptile world. Some other theory or theories must be found to supplant or supplement it before all the vivid reptilian colours can be satisfactorily accounted for.

Let me now turn to the colours of birds for a moment. Here one finds colours most striking and conspicuous, as well as others in most perfect harmony with their surroundings.

The reasons generally given to account for the colours of birds are protection, utility, and sexual adornment. The first and last appear to be more or less in conflict, and the exigencies of the latter sometimes seem to throw to the winds the caution advocated by the former. However, in most cases this is not really so, as it is the male alone who beautifies and adorns himself to attract the female. This, as a rule, leaves the female free to adopt the precautionary colours which are more necessary to her during the anxious time of safely rearing her young. The young of both sexes usually take these protective colours of the female or are even more protectively coloured than is she. It is only when the young males are reaching maturity that they assume the more gaudy male colours.

With all animals it is the male which is the more ornate.

With savages, also, it is much the same. The young warrior reaching puberty decks and adorns himself as much to fascinate the woman more soberly clad as to make himself look fierce and awe-inspiring in the eyes of his enemy. II'th civilised races the exact reverse generally holds, as it is the woman who covers herself with feathers and ornaments to attract the man. She uses for this purpose the very same feathers that have already done duty for the cock bird in his advances to the hen. Lien with civilised races, however, traces of the barbaric ornaments used by the young varriors to impose on their enemies are still to be seen. The gaudy uniforms worn by soldiers are so wholly unfitted for modern warfare that they have long since been discarded for that purpose, but still appear in times of peace. Is not the busby, for instance, a survival of savage warfare in which every tribe endearoured to make its fighting men look as tall, big, and imposing as possible that they might terrify their adversaries?

The latter's warpaint, again, is man's improvement on such animal devices as 
rating bristles all uver the body in appear larger, or puffugs out the neck or raising a crest oll the head.

To return, however, to the hen bird. It is more sombre and duller coloured than the cuck, at times with good reason, but at other times it seems as if there was small need for such precautionary measures.

There seems to be little doubt that the eggs, young, and females of most of the sround-nesting birds are directly coloured for protective purposes. It is not, as a rule, that the hens themselves have any foes to fear. It is for the purpose of leting the eggs, when exposed, remain undetected, and for concealing the young from kites and hawks, while they themselves, if not also suitably coloured, would di close the presence of the nest. Examples of these protectively coloured birds and eggs are common, but nearly all those which might be termed wonderful adaptations to their surroundings occur among these ground-laying birds, birds which nest or merely scratch a hollow for their eggs on the surface of great open prairies, moors, fens, or beaches. Other birds, as a rule, seem to trust more to skill in concealing their nests than to any coloration of their own or of their eggs.

As to sexual selection, where the males alone have tufts, ornaments, crests, or other appendages or colours unpossessed by the female, no doubt this theory may be made to explain their presence. Apart from such ornamentation and the groundnesting birds and a few other instances of real protective coloration, it seems as if the theories of sexual selection and protective coloration can be made to account for the colours of but few birds. Where the colours of both sexes are the same it is difficult to explain them by the first theory. Still less can colours utterly out of harmony with their surroundings be accounted for by the second theory. Nor does any theory of utility seem to answer the question. What, then, were the determining factors in the coloration of such birds as rooks and crows, the snowy owl (for night work), flamingoes, egrets, and a host of others? No existing theory seems to fittingly explain them, but it seems very clear that there must be other agencies at work if the colours of the greater part of the bird world are to be accounted for by rule.

It is probable that conditions of climate and environment are amongst these agencies at work. For most of the more brilliantly coloured birds are found in tropical climes, and the more sombre-clad birds in colder countries.

The dull hues prevalent in desert bird and other life have often been noticed, and in many cases they are quite apart from any need for escaping observation or concealment.

Now to turn to mammals, and more especially to those known collectively as 
game. The usual theories offered as explanations for their coloration are, practically, protection, sexual and recognition marks. These theories possibly explain, more or less, the colours of some of the smaller mammals and little buck, but in no way satisfactorily explain those of all the larger animals. To commence with the human being, why does Europe produce white men, Africa black men, and Asia brown and yellow men? Why should Northern Europe produce people with fair hair and blue eyes, while Southern Europe produces men with dark hair and dark eyes? This can be neither caused for the sake of protection, mutual recognition, or sexual considerations, nor for any purpose of utility. Surely it must be the work of imperfectly understood influences of climate or cnvironment?

Admitting then that certain conditions of colour are induced by the action of climate or environment, we have the general reasons for different colours, as at present known, viz.:-

(i.) Utility. This includes assimilation with its surrounding for both beast of prey and beast preyed on. Possibly also recognition and other marks.

(ii.) Display, with which is associated sexual adornments.

(iii.) Considerations of climate and environment.

Utility may be utility of colour for the stalker or for the stalked. Both should aim at being inconspicuous. There is, in addition, utility in coloration to serve other purposes. For the stalker, one would instance first the lion, as being of one of the most useful colours. Anyone who has seen how conspicuously a lion stands out against green or burnt grass might at first doubt this. The lion, however, is coloured for night work, mostly in the open, and for this purpose khaki is a most perfect colour. If anyone doubt this let him walk out on a dark night with two men, the one dressed in khaki and the other in black. The latter will be seen ten yards away, when the former is invisible at five.

Much of the final stage of a lion's hunting consists of stalking an animal upwind as near as he can get undetected, then making a sudden rush and catching his victim before it is aware of its danger or can make use of its superiority in pace. For such purposes as these the lion's colour is admirably adapted. The only method used much for killing during the daytime-and even this is but seldom resorted to-is lying in wait, concealed by rushes or cover, mear some farouritc water-hole of same. From this cover the lion is ready to spring out on anglling coming within reach. Hare the very act of lying perfectly still is

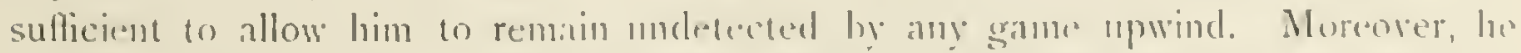
is generally wholly concealed from view. A limes, howerer, the luend is cautiously. poked out or raised up above the grass or reeds to recomnoitre. The black ears are 
skilful touches put in to break up the shape of the head when he is pecring out in this way.

For his particular walk in life the lion is perfectly coloured, and the scheme of coloration is absolutely simple and unlike the intricate and complicated coloration of many inimals which are exploited as being such wonderful instances of protective harmony with their surroundings. It may be argued that a full, black-maned lion must be greatly handicapped in his hunting if khaki is the best colour for night work. The black manc, however, does not cover his whole body, and so he is not as visible as if he were black all over. Moreover, it is generally the females which leat in attack and stalk. That only a small proportion of males bear this sexual adornment is perhaps a proof that it is not a serviceable colour to them.

The tiger is said to be of a colour suitable for his purposes also. I prefer, however, to speak only of animals 1 have observed intimately.

A leopard's usual habitat is bush or forest, where there is much of shadow, with but little patches of light peeping between branches and leaves. For this purpose a darker coat than that of the lion becomes necessary, and it is advisable to have it broken up into patches or blotches to represent the small patches of starlight or moonlight streaming through the trees.

Presumably this is also a good arrangement of colours for the purposes for which it is intended-that is, stalking at night in bush or forest. One would not imagine that it would be a good colour for concealment by day, yet it seems as if it is. I have often been in countries where leopard, by the spoor and other signs, are very plentiful. As the leopard lies very close and very seldom moves away when anybody comes near, I must have often been in their close proximity. Yet have I very rarely seen a leopard, and almost always only when he has been disturbed or frightened into moving.

The very limited number of times I have seen it has been generally over a hill, or when walked on accidentally, or when hunting away from cover late in the evening.

Nearly everyone who has been in leopard country remarks on the extreme rarity of seeing one.

This, I take it, is partly due to the animal's skill in taking cover and partly due to his coat harmonising with his surroundings to a greater extent than one would imagine possible.

Two other animals seem to find much the same arrangement of colour useful for bush-work. They are the serval cat and the spotted genet.

The spotted hyiena, too, is of a very serviccable colour for slinking in and out 


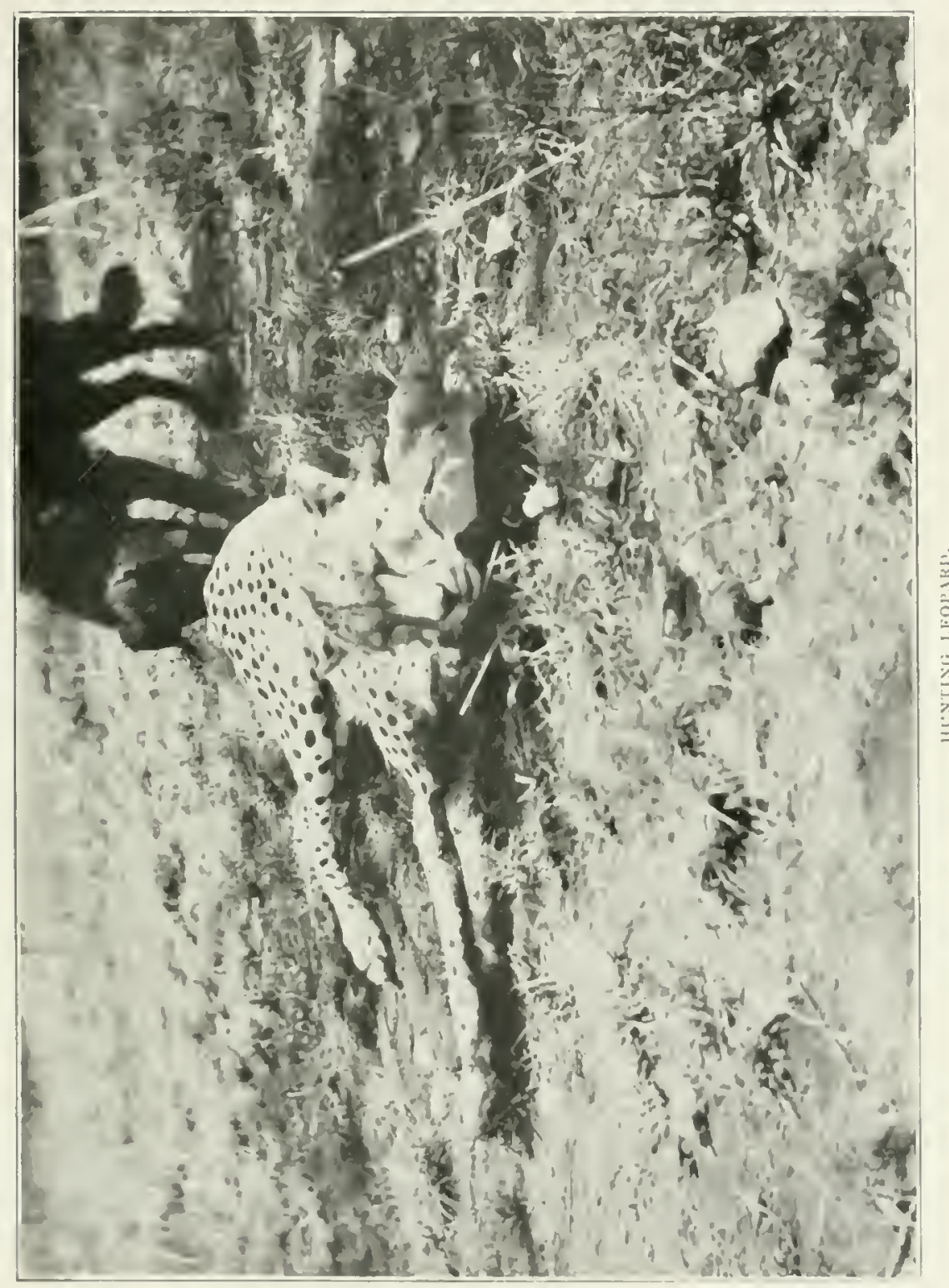



of shadows unobserved, but what purpose such protective coloration can serve him, I fail to see. The only time that it may be of use to him is in prowling round villages, and there he runs little danger, for almost all natives treat him with forbearance and even with veneration. As he takes the place of the family vault with many tribes, perhaps this respect for him is not out of place. Excepting, then, the very faint risk he runs from mankind, I do not see that he has anything to fear. For, so far as I am aware, there is no animal which he desires to avoid, nor is there any animal he habitually makes it his business to stalk or catch.

The hunting-dog is coloured very much in the same style as the spotted hyrna, and this for no apparent reason, for anything like a stalk is quite foreign to his nature.

Whatever the reason for the coloration of these two animals may be, it is most unlikely that their colours have been caused by any need for protection. It is, however, very possible that similar circumstances of climate or cnvironment may account for the fact that their schemes of coloration are much on the same principle.

Of other beasts of prey, the cheetah is an animal which neither has any cause for assuming an inconspicuous costume nor does his coat make any attempt at appearing inconspicuous. For the cheetah lives by running down his prey without much pretence at a stalk when once in the vicinity of his prey, and, indeed, his long legs are little adapted for anything in the nature of crouching and stalking. Seen hunting by day he is a most conspicuous animal. A possible explanation of his colour may be that his far ancestors were nocturnal, forest-dwelling animals. If this was so, he has since then changed his form and mode of living, while his coat has remained much the same, except that it has faded to a lighter colour in the sunlight. The fact that lion cubs are spotted scems to point to the conclusion that all African beasts of prey were originally spotted, and thereforc were also originally bush-dwellers.

To turn from the hunters to the hunted, very few game animals seem to rely on protective coloration as a means of escaping observation, however suitably they may be coloured. They appear to rely on neetness of foot, quickness of eye and ear, or on scenting powers, or in ability to pass rapidly through or over difficult or broken country, to escape their enemies, but hardly ever do they rely on sitting still and pretending to be a busls or an ant-lyill. In fact, the only game which regularly sit tiglat are the very small animils and little buck, as oribi, duiker, lrare, etc. These little animals will often lie perfeetly still and let one pass within 10 or zoyds. of them. If, however, one walks almost on the top of them they will spring up 
and dart off. A hen partridge or ground-nesting bird will, in like mamer, remain perfectly motionless on her nest until almost trodden upon.

The little buck, however, cannot be said to be very strikingly like any natural object. An oribi might pass in the long grass as a small red ant-hill, but no oribi would be foolish enough to sit on a bare patch and pretend to be an ant-hill. If he did, the difference in shade between his coat and the red soil would be rery noticcable. These little animals scem to rely more on cover and concealment or partial concealment than on any great similarity to natural objects.

If one admits that these little buck, and even some of the larger forest and bush game, have been coloured protectively to represent ant-hills it is still difficult to see how it can be claimed for the larger game of the plains that they have been coloured for the purpose of escaping observation. Even if they were perfect examples of protective harmony, which I do not admit, it would avail them little when their lives are spent in walking about in the open. For a moving object, even if it assimilates in colour to its surroundings, always catches the eye of the practised observer.

The two most absurd, but often quoted, examples of wonderful instances of protective coloration are the zebra and the giraffe. I sce that Mr. Sclous, in his book, ridicules the idea that these animals are endowed with their colours for the purpose of making them invisible at short distances. It is true that the zebra in very long grass is sometimes difficult to pick out, but so is any animal almost entirely concealed from view-even an elephant if the grass is long enough.

In their usual East African habitat (the plains) zebras are strikingly conspicuous, turning from black to white as they move and their sides are alternately in shadow or exposed to the sunlight.

All colours disappear in the far distance, and it is only at short distances, such as at two hundred yards at most, that the real colours composing an animal's coat can be seen clearly, so it is really only at that distance, or less than that distance, that colours, whether protective or the reverse, can have much significance.

A striking colour such as red or scarlet can be seen at much greater distances when exposed to light, but in shadow it soon becomes undistinguishable from black. In the far distance all colours appcar either as black or as shining surfaces. The glossy coats of animals, as a rule, shine in the sun and look dark in the shade. Zebras have particularly glossy coats, and so they shine out clearly in the far distance with the sun on them. When the shadow side only is visible they appear to be of immense bulk and quite black. Seeing one of these animals screral miles away with the shade on it, I have often been uncertain as to whether it was 


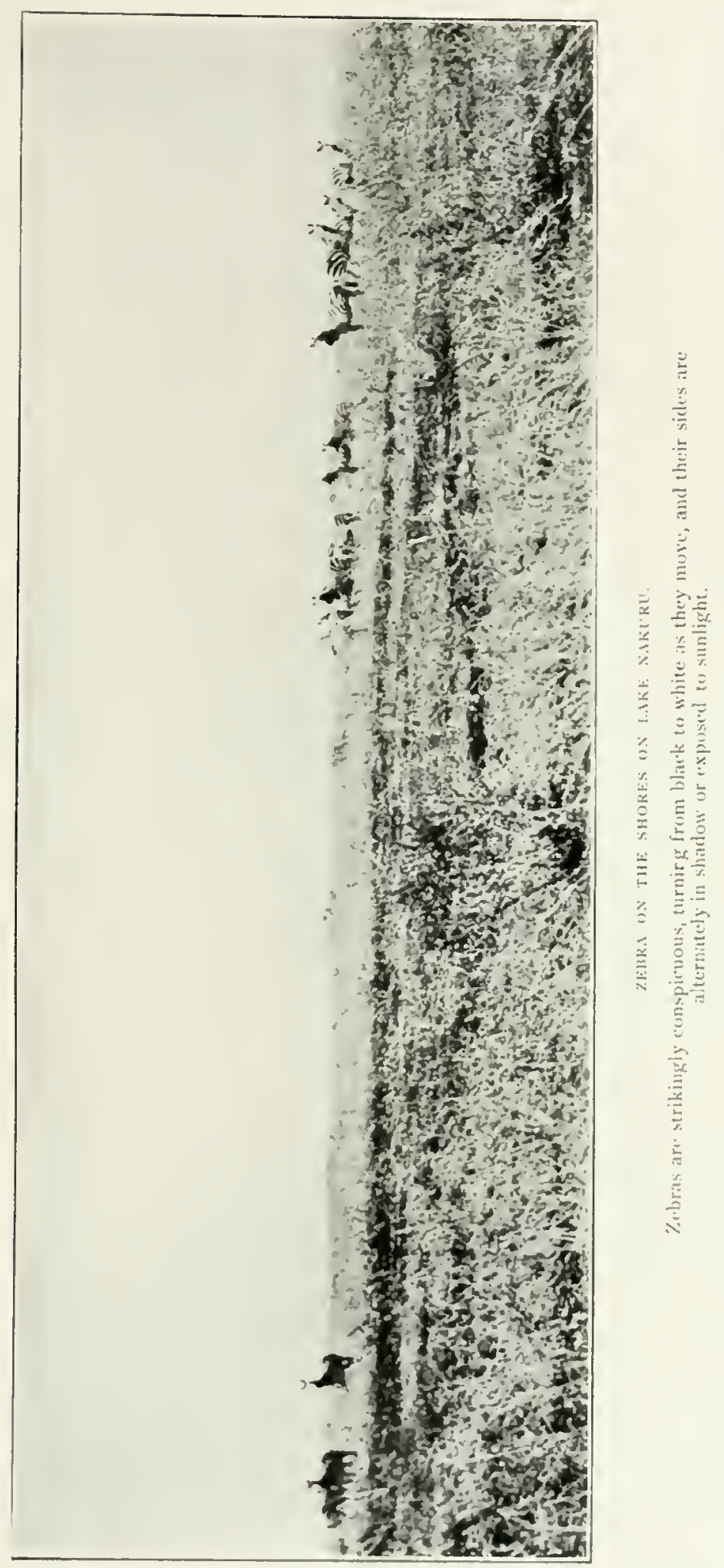



a rhino or not, owing to its bulky appearance, till glasses have been brought to bear on him.

Again, the giraffe, amongst trees and bushes in the very far distance, may be difficult to see, but this is only natural. Put a hut or a locomotive or a motor-bus in the far distance, and almost entirely screen it with trees and bushes, and it will not be easy to recognise. A giraffe near, or even in the far distance, when not screened from view, is a most conspicuous object to the practised eyc.

The men who write about these protective colours of game animals are men, as a rule, born and bred in towns and in civilised countries in which there is scarcely a square yard of land which does not bear some impress of man's handiwork. Even in the parts of our country which we call wild there is some trace of the human being at every step, the mark of the peat-digger's spade or the sportsman's cartridge on the moor, the stumps of undergrowth severed by the woodman's billhook or the gamekeeper's boot mark in the forest.

I have often stood in some such locality and looked round me to see if there were no traces of man, but there was always some sign of his presence-a match, a chip of wood, a scar on a tree, a cattle track, or the like mark. No wonder, then, when brought up in such surroundings, that at first the African bush seems strange to one, and that things so new to the eye are difficult to pick up.

The savage put down in London would have not the slightest chance of noticing everything which appeared to his eye till he had got used to his surroundings. He would see no difference between a Hammersmith and a Putney bus, nor would he be able to recognise a public from a private vehicle, nor a coffeestall from a van. The greater part of the things which passed before his eyes would entircly escape his observation. So is it at first in the bush. You think that you see a lot, but really are seeing little, and observing scarcely anything closely.

Game animals at first are very difficult to recognise in the bush, but as soon as you gret used to your surroundings they become easier of detection. 'They never become really easy to see in the thick bush, because so little of them is, as a rule, visible.

llowever, this has little to do with protective imitation.

Tlie reasons why game animals are often difficult to locate are that one is either looking for them in the far distance, where all objects are blurred by heat haze, or one is searching for them in thick bush, grass, or forest. In the latter places you have to pick up an animal by seeing only an ear, a horn, or a part of a leg between the foliagre.

On the other hand, the animals enjoy the advantage of being able to liear or 
scent your approach besides having a better chance of secing you than you have of sceing them.

On the plains the chief food of the lion consists of zebra and hartebeest, and there is no animal but the lion which habitually preys upon these animals. Therefore, to follow out the coloration theory, these two of all the plain animals should be the most protectively coloured. Now, if the zebra is coloured to suit its habitat, i.e., the plains, it is not likely that the hartebeest, whose colour is so different, is likewise adapted to the surroundings, yet both are equally in need of protection.

It is plcasant to be able to account for all the colours and combinations of colours occurring in animal life by a fow simple laws, such as those of protective coloration and recognition marks. These laws by no means, however, explain all the conditions of colour as scen by the eyes of the outdoor observer. In reality it will probably be found cventually that such laws are much more complex and intricate in their mode of operation. Personally, I think that many of the combinations of colour which may puzzle us now are reflections and alterations of or reversions to colours of bygone ancestors. We know from the fact that hybrid foals are liable to run to stripes that the ancestors of horses and donkeys were probably striped and possibly zebra-like animals. Much farther than this we cannot go. We cannot conceive what were the exact colours of far-distant ancestors of such ancestors.

Till one knows the protoytpes of any given animal for several geological ages, their colours and markings and the conditions of life under which they lived, it seems futile to try and lay down definite laws to account for their colours. At any rate, it seems unsound to assume that these colours have been entirely brought about by present prevailing conditions. For all that one knows to the contrary the zebra may be coloured in the most perfect harmony with the prevailing conditions of some fairly recent geological period, and these colours may have been of service to him then. Since that time conditions may have altered considerably. His old cnemies may have died out or a radical change in his own habits of life taken place; in spitc of which, his ancestral striping still holds good. With no vital influences at work to cause him to change his scheme of coloration he may have remained much the same, or reverted to a still older type, or have suffered but slight modifications. However, it is hard to believe that the stripes of a zebra have ever been of any use to it for protective purposes. The zebras and tapirs both come of the same ancient stock. Although the tapir is now no longer striped its young bear this marking, and are very striking-looking with their lateral stripes. There must have been some very strong cause of light or climate or other reason, quite apart from protective purposes, to have 
produced in these animals a tendency to become striped. This tendency has had its outlet in producing stripes, vertical in the zebras and horizontal in the ancient tapirs.

It is possible that the prototypes of many of the modern African buck were evolved during an epoch, and in a district, where red soil was prevalent, much as it is now in Africa. Also that for some purpose, protective or otherwise, it was beneficial to them to assume this colour. Should such a state of things have ever been, then, allowing for subsequent fading and intensifying of this colour, the ground colour of the coats of most African antelope and buck may be accounted for by the theory of a past utility. For the great majority of these are of some dark red or chestnut colour, viz., eland, giraffe, the hartebeests, the bushbucks, bongo, lechwe, puku, impala, and many kobs, gazelles, oribis, duikers, steinbuck, etc.

Assuming that this colour was protective in origin, the next step is to break up the outline so that the form of the animal does not stand out as a whole. With all animals and birds it may be noticed that the bellies and under parts are lighter coloured and often almost white. The lower part of an animal is almost always in shade. The sun never shines direct upon these parts, and so they do not show up as white or shining surfaces. The effect of this arrangement is to make the upper half of the body and also the legs stand out from the lower half and appear more definite in form, while the bottom half, being less distinct, appears to be at a greater distance from the observer. The idea conveyed to the eye by a rapid glance in a bad light is that there is an ant-hill, stone, or bush with a light patch of grass or ground seen below and through it. By this arrangement the whole shape of an animal's body seldom stands out in relief, untess against the sky-line.

This is Nature's principle in nearly all her protective coloration in bird life.

However, the mere fact of being in shade might account for the lighter colour, just in the same way as all parts of plants concealed from light, such as roots, bulbs, and banked celery, assume a white colour. By such conjectures as these we can account for the ground colour and the white or light-coloured bellies of the majority of game animals; but this is, after all, mere idle speculation, and is based on the assumption that conditions must have been very different to those now existing. Such a theory also must assume that the beasts of prey of former times liunted by sight, and not by smell. Those of the present day hunt almost entirely by scent.

It is quite possible that the white rumps of a great proportion of the buck family may have been, and in some cases may still be, as Wallace says, "dinger signals" like the rabbit's scut. White is the most conspicuous of colours, and a white patch in the distance means a nying buck, and lrence danger, a signal which all others 
in sight immediately profit by. It is possible that the other curious markings may atso be recognition or tribal marks, but it is unlikely. They certainly serve no useful purpose as such at present, but of these more later.

Because colours and marks are no longer of service, it does not prove that they have never been so. Before, however, such theories can be regarded seriously a certain amount of evidence must be shown in their favour, and at present there appears to be none.

The theory that plain-dwelling animals are coloured protectively for life on the plains under present conditions is absolutely untenable. The lion, looking out from his retreat in the reeds on the game swarming all over the plain, cannot imagine that they are all, or even that some of them are, bushes and ant-hills. Even if he did, his nose would warn him when any animal came within four hundred yards upwind of lis retreat.

There are many markings, however, which are undoubtedly sexual adornments. Of these ornaments some fit in with the general scheme of coloration, such as the dewlaps of certain antelopes. Others seem to be unchecked by any such consideration, such as the facial adornments of the males of certain monkeys.

Another point to be considered is as to whether man as a hunter has existed long enough to allow of game having undergone any very material changes in coloration for the purposes of escaping his observation. For, amongst creatures that prey on others, man is the only hunting creature who relies almost wholly on the sense of sight in pursuit. Carnirorous animals of the dog tribe hunt entirely by smell until but a few yards from their prey. It is a common event for a hare or fox, closely pursued by hounds, to make a sudden and sharp turn. In most cases the hounds go on a few yards beyond the spot at which the turn was made before they discover that the scent is lost. This shows that even when only a matter of twenty or thirty yards behind their quarry they are hunting by scent and not sight. Cat-like animals locate and approach animals chiefly by smell, but to them sight is of more service than to dog-like animals, as they often go in for an elaborate stalk, much of which is performed by sight. It remains, however, that man is the only creature whose success in the hunt depends on locating distant game entirely by sight. It seems hardly likely that game should have developed protective colours and yet maintained a very strong scent for the purpose of avoiding foes who hunt almost entirely by scent.

For the upholding of the protective coloration theories in regard to the ordinary game it seems necessary to prove first one of two things-either that when such colours originated conditions were prevalent very different to those 
now in existence or that these colours were developed to baffle man in his hunting. If the first proposition is to be upheld it must be proved that their colours were really protective in those days, for the majority are certainly not so now, and it must also be proved that they used to be preyed upon by animals which hunted by sight, unlike those of the present day. If the second proposition is to be upheld, it appears necessary to prove that man has been a hunter on the face of the globe long enough to permit of these changes taking place. In other words, it must be proved that these great changes in coloration have come about in a comparatively short period of time.

It is also necessary to prove, in the latter eventuality, that the eyesight of original man was very defective when compared to that of present-day man, or that the character of the country and vegetation was very different. For very few of the game can now be said to be in perfect harmony with their surroundings, and they certainly do not baffle the human hunter versed in busheraft. Considering man's slow gait and the methods primitive man used in hunting, it seems as if quickness of sight, scent, and hearing and a little intelligence are qualities all more useful for the aroiding of arrow, drop spear, and pitfall than any combination of colours, however wonderfully arranged.

Game has only the leeward side on which to fear a foe, anything to windward being automatically reported by scent. So game, in those days, had but to watch this side and try to locate anyone's approach before bowshot range was reached, generally under fifty yards, when its own overwhelmingly superior pace could have soon put it out of danger, once the danger was detected.

Last of all come animals which do not appear to go in for any sexual coloration, nor can they possibly be considered in need of any protective coloration. Such are the pachyderms.

It is a fact that rhino often look like rocks, and, when they have been haring a mud bath, they look like red ant-hills; and it is certain that elephant are often hard to distinguish. If these were animals regularly preyed upon it would no doubt be said that they were wonderful instances of protective coloration. As it is, however, the most sanguine supporter of protective coloration could hardly assert that these animals have assumed their present colour and the habit of mud-bathing for the sake of protection agrinst beasts of prey. Nor can it be said that they are protected against man, for I think that geologists will admit that these and similar animals wandered about primeval forests before man had assumed any distinction as a hunter, in much the same garb as they do to-day. Let has the hunter been deceived into uncertainty as to whether a rhino was an ant-hill or aice 
iersil, almost as often as he has been similarly deceived with a common animal like a hartebeest.

Presumably the primitive hunter and the beast of prey, if deceived in like manner, would, if very anxious to kill something, have behaved in the same way as the modern sportsman. That is, that instead of assuming that the object in doubt was an ant-hill, they would have made perfectly certain by a closer inspection before moving on elsewhere. It may seem unnecessary to try to pick holes in an old theory without substituting a new one in its place, but this theory of protective coloration, when carried too far, is in certain cases, to quote Mr. Selous, "so fantastic and extraragant as to be unworthy of serious consideration."

The theory of protective imitation within certain bounds, combined with a study of present climatic influences and past conditions of life and its coloration, opens up a wider, more interesting, and more scientific field of research. Among other points that bear on this subject is the coloration of young animals. The young, amongst game, though by no means wonderfully protectively coloured, are as it rule less obriously coloured than the adults, or else those of both sexes are coloured like the female. A sable is a good illustration of this, for it is only the adults which are black, and only the adult males which are charcoal black, while the young are brown. Yet such colour affords no protection to the young animal, for it is accompanied by its dark-coloured mother and the rest of the herd, anongst which will be at least one adult male that is coal-black in colour.

Mr. Sclous attributes to the influences of environment a great share in the determination of colours of game animals. It is, I believe, a medical fact that anything startling or striking-looking observed by an animal during the process of giving birth is liable to be reflected in some degree in the offspring. The conditions of game life which prevail on the plains of East Africa must be to-day much the same as those which prevailed half a century ago in South Africa. A great part of the rest of Africa, where there is neither bush nor forest nor swamp, is corered with long, rank grass, difficult to walk through and impossible to see through or over. In such parts the grass-eating game have all the advantages of concealment possessed by the bush-dweller. The habits of these animals, too, are more akin to those of the bush-dweller than to those of the plain-dweller. On the piains a very different type is met with, unintelligent, and apparently paying little heed to their self-preservation; tame, and not easily scared. All game are bad at picking up a stationary object, but these are especially so, however poorly the object may be concealed.

The sense on which practically all animals most rely, and man least, is the sense 
of smell. The usual procedure of wary game is to graze upwind. As long as they proceed in this way, and especially if they zigzag across the wind, they know that all the ground in front of them is clear of danger. As they are continually moving forward, anything wishing to approach them from behind must move after them, and their quickness in seeing a moring object should therefore enable them to detect anything downwind. It seems that the flanks are the chief source of danger, and for game that do not zigzag much a very real danger, for an enemy lying still on a flank may remain undetected. Bush animals are very quick of hearing, and so have an additional chance of locating anything approaching from an unguarded side. Moreover, anything moving through the bush must make a certain amount of noise.

Animals living in long, thick grass ought to be seldom or never surprised as, while they themselves are hidden from sight at only a few yards' distance, anything approaching can be heard by them for a long distance.

Their sense of hearing must serve the dwellers in bush and long grass in good stead during the night, when the plainsfolk are especially open to attack from downind.

As long as the plain-dweller can detect the lion at a reasonable distance it has no difficulty in outdistancing it. For lions are only capable of short bursts of great pace, and cannot run down game once the latter have any start. If when disturbed the game were to run straight upwind they would then avoid running into any other lion which might be lying in wait at a prearranged spot to have the game driven to them. However, these prearranged drives by lion must usually take the form of a party concealing themselves on a flank or downind, while the approaching lion drives from the other flank or upwind. On the plains matters are made easier for the lion than in the bush; it seems to me that they are made too easy, owing to the plain-dwellers being so lacking in intelligence and acuteness. They seem to take no precautions, and to be quite indifferent as to the fate in store for them. Unlike the bush game, they do not only graze upwind, but can be seen grazing downwind, and, what is even more reckless, approaching water and cover downind.

From careful observation of these plain-dwellers I feel certain that they are almost indifferent to the lion's roar and to the presence of lions in their midst. They seem to know when a lion is full fed, and will then let him approach within practically a few yards of them. It is only when he actually rushes at one of the herd that the rest turn and fy:

I often think that the nightly terror of beasts of prey, which animals are supposed to suffer from, is greatly exaggerated. The plain-dwellers exhibit no terror or panic 
until the lion is close on them. Then there is a moment of wild terror and panic as they rush away. Once out of reach, the fright quickly leares them, their flanks soon stop hearing, and they return again to their grazing as if nothing had happened.

Many people must have witnessed similar momentary terror on the part of a newly caged bird when suddenly approached. It flutters and cries, and throws itself against the bars in a frenzy of fright. Retire from it, and in a few seconds it is perfectly self-possessed and calm again.

The native, accustomed to hear the lion's roar, feels no fright. The white man, on the contrary, who is full of nerves and imagination, feels decidedly uncomfortable, though the danger is really distant and unreal. When the danger is actually at hand it is the black man, callous and self-possessed until then, who is all screams and panicstricken, whilst the white man is, to his own astonishment, cool and sclf-possessed. I do not here refer to such black fighting tribes as the Zulu, Masai, or Sudi, whose courage in a like emergency is probably considerably greater than that of the average European. I mean the ordinary Africans one has to make use of as porters, hangers-on, etc., when on trek. Such men as these show wild consternation for their own safety, and will leave a comrade in the lurch or let him die of wounds, starvation, or thirst, with the utmost sangfroid.

The extraordinary neglect of the simplest precautionary measures exhibited by the plain-dwelling animals will be referred to in other places. I have often wondered how they can have existed for so long and gained nothing by experience. The only feasible explanation which offers itsclf to me, my readers will probably think highly ridiculous, but it is that it is to the plaindwellers' advantage to let the lion catch his night's food quickly and without trouble.

The lion at present has a very soft time of it on the plains, and has to display but little skill to obtain as much food as he wants. Should his prey gain a little in intelligence he then must show a little more guile, and obtain his prey by taking more trouble. The more trouble the lion has to secure his food the longer will the hunt last and the hungrier will be the lion. If game ran all over the plain to avoid the lion they would always have a disturbed night and but little grazing. As it is, they set to work to graze peacefully as if nothing untoward could happen, there is one brief rush and a scuffle during the night, and they all return to grazing again. It may seem a very absurd idea, but it is equally absurd that game should have been living on the same plains as lions for untold ages and have learnt practically no caution from past experience.

There is another point about lion and other game that bears on the relations 


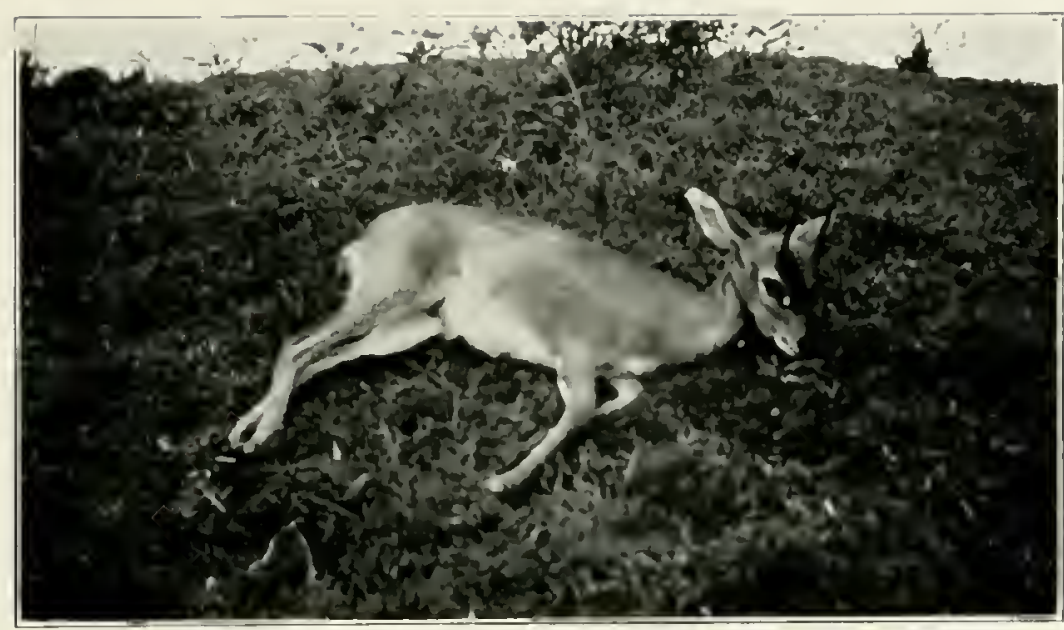

STEINBOK, SHOT HY R. (;. STONE, ATHI PLIXS.

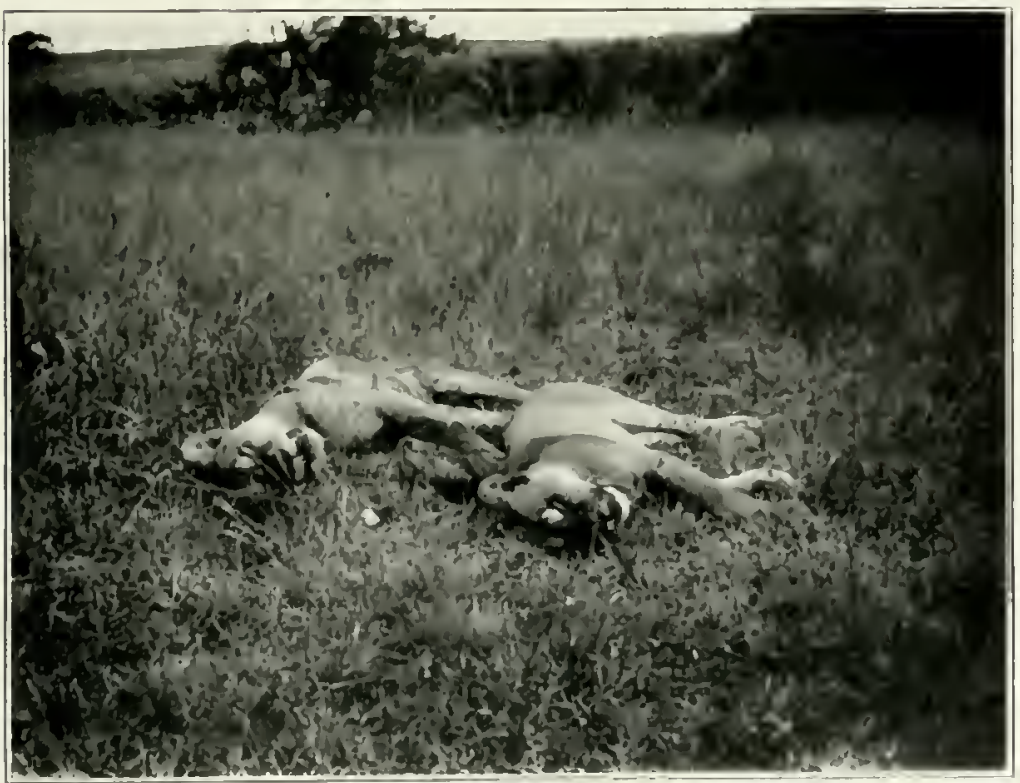

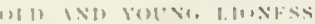



between them. By the way, I suppose that lion have been written about more than any other wild animal, and yet the subject appears far from being exhausted. The point in question is, How well can lion and other game really see in the dark? One hears that cats can see in the dark. I take it, though, that no creature can see in absolute and complete darkness. There must be some streak of light, however faint, before any one object can appear different to any other. If everything is of uniform shadow and blackness there can be no sight. Animals that live entirely in perfect darkness, as in the mammoth caves and on the floor of the deepest part of the ocean, are blind. Thus, with lion and cats there must be some faint light, reflected from stars or moon, to enable them to really see. It is only in their power of being able to see slightly by the faintest glimmer of light that they differ from us. On a dark night they probably can see but little; it is their wonderful sense of smell and touch which enables them to proceed with a minimum of light. In the bright moonlight, however, they can probably see almost as well as can we in the day.

Other game also must be able to see well in the dark, since they almost invariably graze at night. They are probably little, if anything, inferior to the lion in this respect. In spite of the wild stampedes which occur during the night I have never heard of an animal coming to grief by falling over a precipice or running full tilt against a rock or a tree. It would appear, then, that they are perfectly at home in the dark, in spite of being provided with no appliances like the lion's whiskers, or those of a cat.

There is another point which bears on the thcory of coloration, and that is to what extent animals are able to distinguish colours apart. They certainly notice quickly such colours as white or red, but I am not so certain that they see much difference between the remaining colours, excepting, perhaps, vivid green. The sense of colour is quite a civilised and cultivated sense, in which the ordinary savage is very defieient. In the dozen or so of African languages of which I have had a smattering at different times I have been greatly struck by the want of names for colours. It is only the most civilised of races whose langunges make any attempt to describe different colours. Tribes owning a large amount of stock often have a great variety of words describing the colours or markings of cattle; but excepting these, the remainder, comprising the great bulk of African raw natives, have practically no words for colours whatever. The general rule is that there are words for "white" (which usually also means "light" or "bright"), and "black" and "red." Occasionally one hears the term "like grass," which means "green." Beyond this they do not go. 
Now, although a native undoubtedly sees that there is a difference between other colours when placed side by side, his ideas about any other colours are blurred and hazy. He certainly cannot distinguish between shades, nor can he remember the sliade of anything. If one asked him to pick out the second volume of a book and showed him the first, he would probably go and bring you one of quite a different colour.

Now, I think that it is unlikely that game would have a greater discrimination in colour than the native, and the chances are that it possesses considerably less. It is probable, then, that to game all colours appear as either red or different shades of white and black, or call them light and dark, and also, possibly, green. Now, although the native has more discrimination of colours than this, his description of the colours the sees will probably describe fairly well what the game actually sees. The native calls white, silver, grey, yellow, light brown, pale green, and pale blue "white" or "bright." If pressed about the colour in question he might say that it was "very white," meaning that it was very pale or white.

Red, vermilion, magenta, scarlet, brown, and dark yellow he calls "red," and violet, dark blue, dark mauve, very dark green, dark brown, and chocolate he calls "black." Now, if game see colours something after this manner it will explain largely why they are so bad at picking out a stationary object. It will also explain how it is that they will often walk up without noticing to within a few yards of one when one is perfectly still.

You may imagine that you are not dressed in perfect harmony with your surroundings, but you may be dressed in just the same lightness or darkness of colour as your surroundings, although of a different shade.

There are many people who are colour blind, and the form this often takes is an inability to distinguish light blue from pink. Now, if you had a shirt made in stripes of light blue and pink of exactly the same depth of colour, to anybody else it would appear startling, but the colour-blind person would take it to be of one uniform colour. If, however, the blue was a darker blue than the pink was pink it would be apparent even to him that the shirt was in stripes, but he would not know if they were dark and light blue, dark and light pink, or light pink and dark blue, or dark pink and light blue stripes. This example may tend to explain how different colours may appear to game.

If this is so, protective coloration assumes quite a new aspect. For as long as an animal was black or white, or of the same lightness or darkness as the object to be imitated, the exact shade of colour would be immaterial. Then would many bush animals, which appear to us poor examples of protective imitation, be really protective 



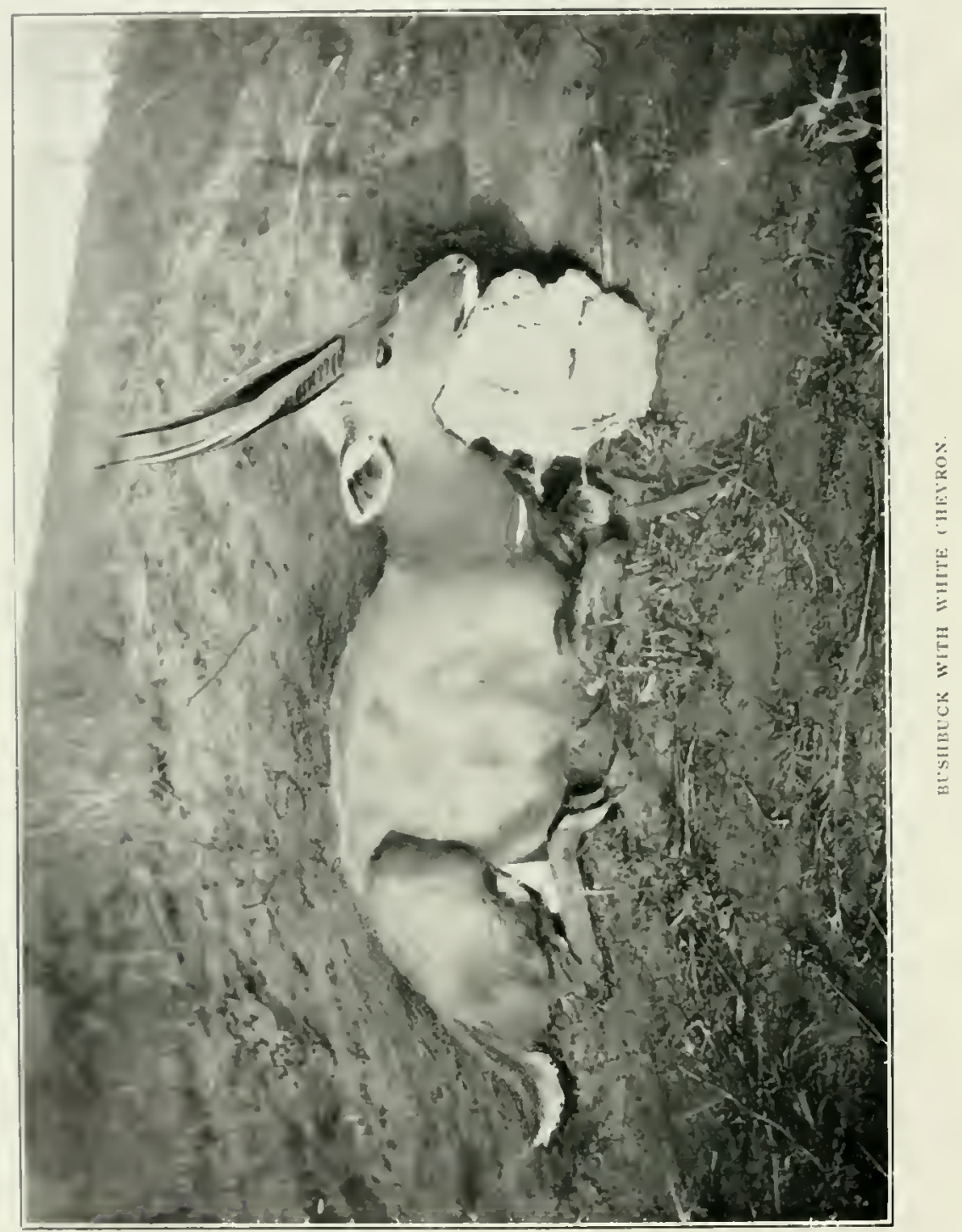


in coloration in an animal's cyes. However, in the plain it is different. There movement, light, and want of cover, besides many other considerations enumerated above, preclude the possibility of there being any such thing as protective imitation.

To leave the subject of colour and return to game grazing and hunting in the dark, one often hears that the eyes of beasts of prey "shine in the dark." I have never heard of any proof that this has been observed in complete darkness. Indeed, it seems impossible unless the creature's eyes were largely composed of phosphorus. Moreover, they would then be a warning to any animal they were endeavouring to stalk. When you open the door of a dark room and see a cat's eyes shining, they are not shining in the dark, they are reflecting the light from the open door. If you were to shut the door the light in them would die out. Similarly, all the cases I have heard of the eyes of wild beasts shining out from the darkness have been when the animal has been facing the camp fire or other light. I noticed one of Schilling's flashlight pictures referred to as proof of how animals' eyes "shine in the dark." It was obvious, however, that they were shining in the flashlight and not in the dark.

As to the theory of recognition marks, the only places such marks could be of value would be on the open plains, where the grass is short. The greater part of Africa, however, consists of forest, bush, swamp, and tall grass. Here there can be no possible object in game being able to recognise their own species at great distances, when the range of vision is limited to fifty or a hundred yards under favourable circumstances, and usually to but a few yards.

Animals seem to meet with no difficulty in finding one another, even when separated by distances greatly exceeding their range of vision. When animals become separated from their herds, or wish to meet for mating purposes, it is wonderful with what directness they proceed to join their own fellows even from a distance requiring several day's journey. When a troop of lions are disturbed suddenly they often disappear out of sight in several directions. If the spoor is followed it will be found that they have soon joined up again, although they were out of sight of each other. Elephant often leave a herd for long periods and then join it again.

When following the spoor of any animal it is common to notice that one animal or another has grazed off by itself, far out of sight of the herd, and then joined up with it several hours later.

Again, it is often the case that you find some animal apparently by iself, and when you disturb him he gallops off, and after following his spoor for a while you find that he has joined a herd.

The finding of one another for mating purposes or the finding of the herd 
appears to be chiefly done by scent and is rarely brought about by sight. There seems, then, to be bui little need for recognition marks.

When a herd breaks up on the plains and joins up in the course of an hour no doubt this is done by sight, but all joining up of animals from any distance is carried out by scent. It cannot but be noticed that many animals have a very strong and distinct smell. A few of the strong-smelling game are elephant, rhino, buffalo, eland, waterbuck, bushbuck, lion, hyæna, warthog, zebri. No doubt this powerful smell is of service to them in finding one another.

Most game animals possess peculiar glands, whose functions are imperfectly understood, but they are thought to be sexual in action and to aid in this scenting of one anotlier. Such is the peculiar gland under the eye of many buck, such as the gnus, hartebeests, gazelles, stcinbucks, duikers, oribis, and kilipspringer. This is supposed to exude moisture during grazing, which falls on the grass and leaves a permancnt trace, that can be scented and followed up by any member wishing to catch up the herd.

If such a gland is sexual in action it would serve the double purpose of leading an animal to its possessor, and also, if acted on by sexual emotions, showing the opposite sex that its presence was required. Other buck have glands in the groin, of which the functions are seemingly unknown. They may be found in reedbuck and in the gazelles, exuding a yellow, waxy secretion. Probably most or all of these glands are sexual in function, and it is very likely that they may serve to lead the sexes to each other when so required, by leaving a special scent on the path traversed. A suggestive fact about these glands is that the face-glands appear to be absent in animals having a very powerful smell. If this smell is for the purpose of locating one another by scent it is probable that these face-glands are for the same purpose, and supply the deficiency of a very powerful smell.

Reedbuck and impala neither have any very noticeable smell nor do they possess these face-glands, but in their place each appears to be endowed with a special arrangement. The former have bare glandular patches behind the ears, and the latter glands covered with hair on the pasterns.

There is another little theory, sometimes exploited by the armchair naturalist, in which I want to pick holes. I have often heard it remarked as wonderful how Nature has supplied every animal with horns exactly suited to its mode of living, and of the very best shape as a means of defence against its enemies.

Now, the horns of hollow-horned ruminants are so diverse, and display such a marvellous number of totally distinct forms, that they have practically exhausted every conceivable shape and fashion. It would be almost impossible to sit down with 



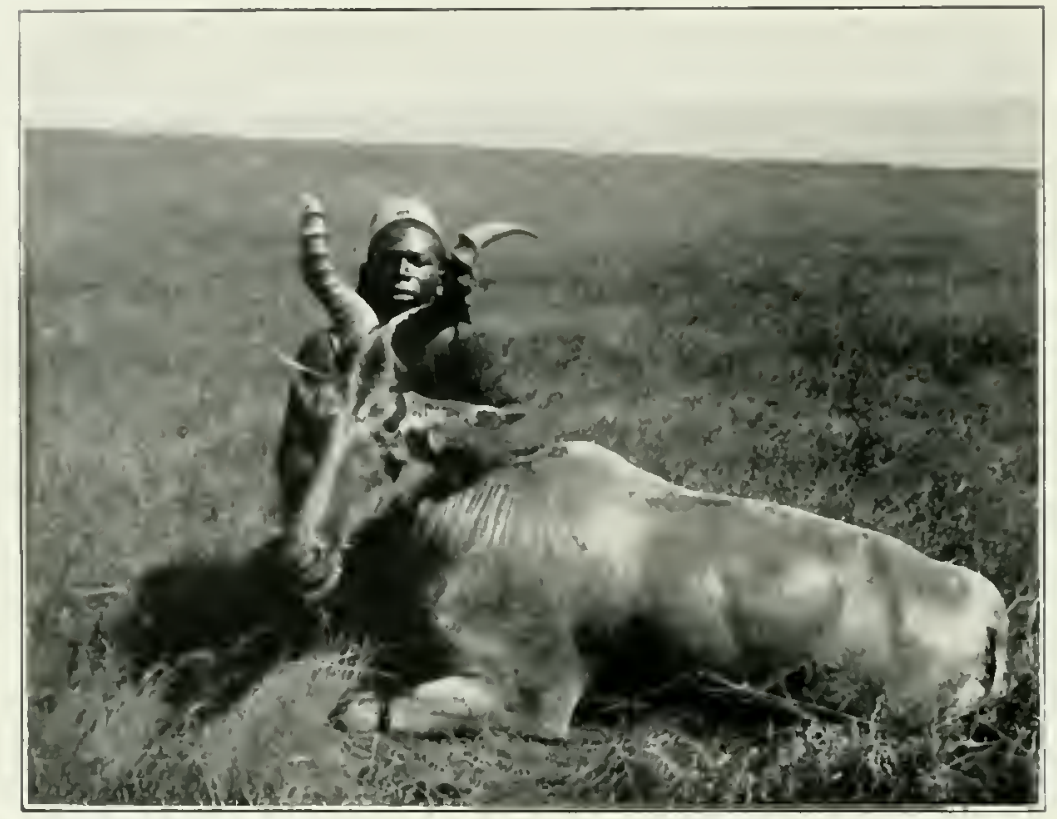

SEUMUN'S HARTHEFS 



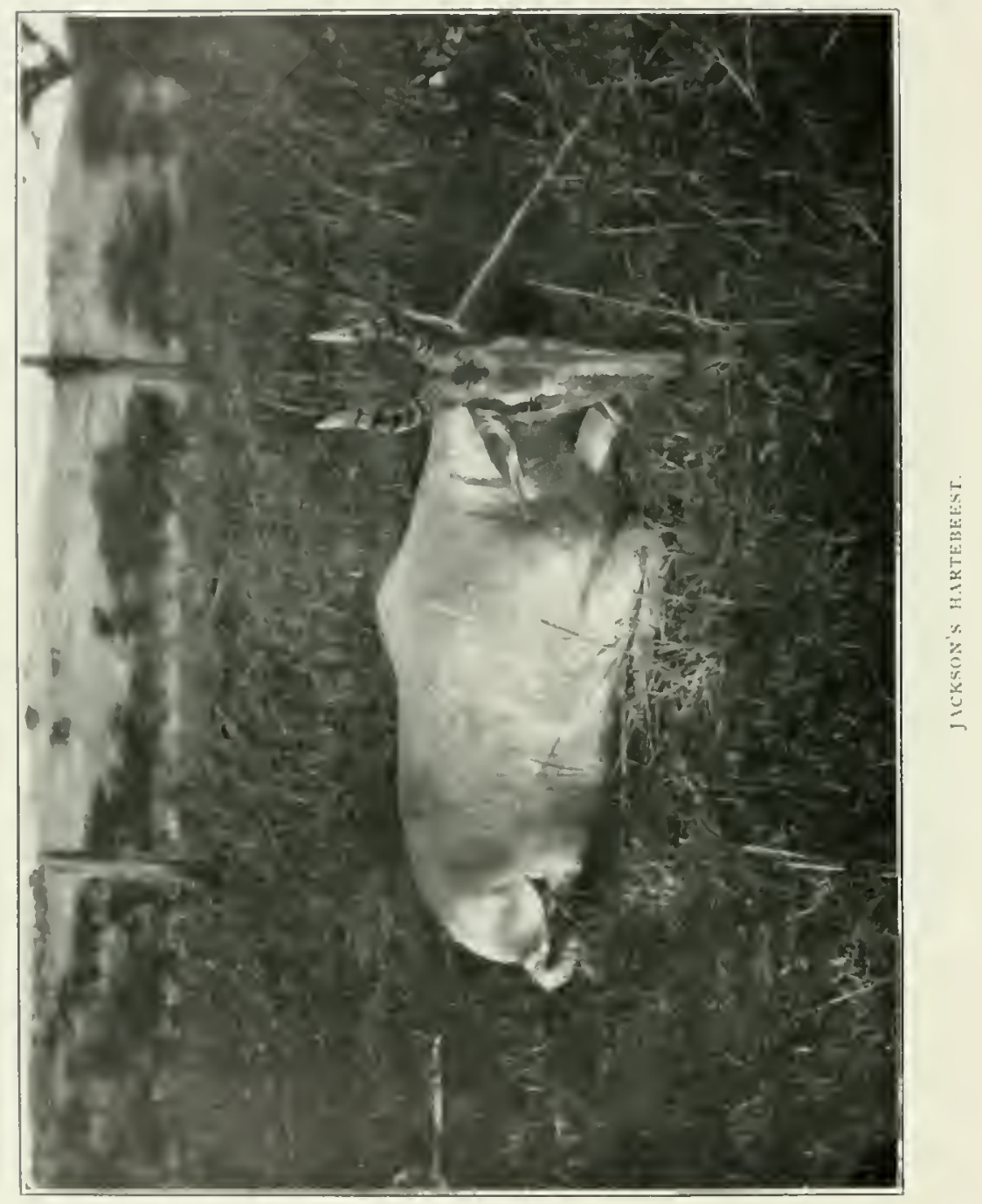


a pencil and piece of paper and devise a new shape of non-branching horn not already possessed by one of these animals. Every horn of this vast array of different forms and shapes cannot be the best possible defensive weapon with which it is possible to equip its possessor. Nor can each one be most peculiarly adapted to the animal's mode of life.

Take a gnu, a hartebeest, and a Crant's gazelle, living side by side on the same plain. Could anything be more diverse than the shape of their horns, while the mode of life of all is much the same?

A few horns form good weapons of offence, but most of them are clumsy and useless for either attack or defence, nor are they ever used by most game as offensive weapons except strictly for warfare inter se. This strife between males is, as a rule, clumsy in the extreme-a mere butting of foreheads together and pushing till one animal gives best and runs away. Sometimes a pugnacious animal like a roan may inflict a bad wound, but this is the exception rather than the rule. This strife is always of a ponderous nature, and is of no value in fitting an animal to tackle a formidable beast like a lion, leopard, or cheetah. Females, on the contrary, are much quicker and handier with their horns in tackling a beast when they are run down, or in defence of their young.

Amongst bush animals the form and shape of the horns has probably been influenced to a certain degree by the necessity for protecting head and flanks when passing through thick undergrowth. Another thing which has influenced their shape to some extent is the necessity that they should not be too deadly in inter-male strife. For it cannot be an advantage to a species if the majority of its males kill each other. On the other land, a few casualties in this way tends to the improvement of the general standard. The fact that one-horned or abnormal-horned males so often get the run of a large number of females seems to suggest what poor weapons they really are and how easily they may be improved on for offensive purposes. In the main, it is probable that horns are almost purely sexual ornaments in most of their present shapes, though their origin was probably in some way for defensive purposes.

One interesting point about horns is that their shape is such a good indication of specific difference or relationship. The exact species, and often sub-species, of most animals can be told by looking at the horn alone, and in many cases the horn is about the only outward sign of sub-specific variation. In cases where animals have interbred traces of both parents are almost always to be found in the horns. The horns of Neumann's hartebeest are almost exactly half-way between those of Coke's and Jackson's. These two latter species extend over wide areas, and are separated only by a narrow belt of Neumann's. On this border-line Neumann's are frequently 
seen consorting with herds of both species, and hybrids are from time to time reported. The coat of Neumann's is neither the richer colour of the one nor the lighter shade of the other, but a mean between the two. All these reasons, combined with the rery limited number and restricted area occupied by Neumann's, leaves no doubt in $m y$ mind that this species is the result of a mixture of these two forms, and that this mixture has occurred at only a very recent date. The thing appears so obrious that I cannot imagine how people can suggest that Jackson's hartebeest is a cross between Neumann's and Coke's, as one often hears, when all the facts point to its being Neumann's that has been derived from Jackson's and Coke's.

Touching on different species, it seems curious that some animals have split up into such numberless different species, while others have remained in the same form all over the continent. Thus, elephant, lion, leopard, kudu, klipspringer, and warthog, though nowhere teeming, as may be said of some other game, are yet most widely distributed over Africa, and wherever they occur are of practically the same form, though subject to slight variations. So also are the black rhino, hippo, and hyæna, which occur, practically, throughout Africa without change of form, with the exceptions of the square-mouthed rhino, inhabiting a small area, the pigmy hippo, also very local, and the allied and not very common species of striped and brown hycnas.

On the other hand, hunting-dogs, in spite of their comparative rarity, assume distinct types in different countries; for example, the Cape, Somali, and Abyssinian hunting-dogs. Even more marked is the case of many other animals which inhabit only some very local area, on leaving which an allied form is found, whilc the same form rarely occurs in two different localities. Such are the numberless different variations of hartebeest and the different types of zebra, oryx, duiker, eland, oribi, and reedbuck which occur in different localities.

In conclusion, to recapitulate the features of East African game resorts, there is the wonderful grazing, and hence the ability to support rast herds of game. The next feature is the amount of plain-land and the shortness of its grass, circumstances which make the shooting here different from most parts of Africa, though akin to the old conditions in South Africa. The conspicuousness of game on these plains and their want of protection by natural cover are circumstances which make the theory of protective coloration untenable on these plains. In most parts of Africa every would-be open space is covered with tall, rank grass reaching over the head. There the grass-feeder has all the advantages of cover and of detecting a foe's approach as possessed by the bush-dweller. 



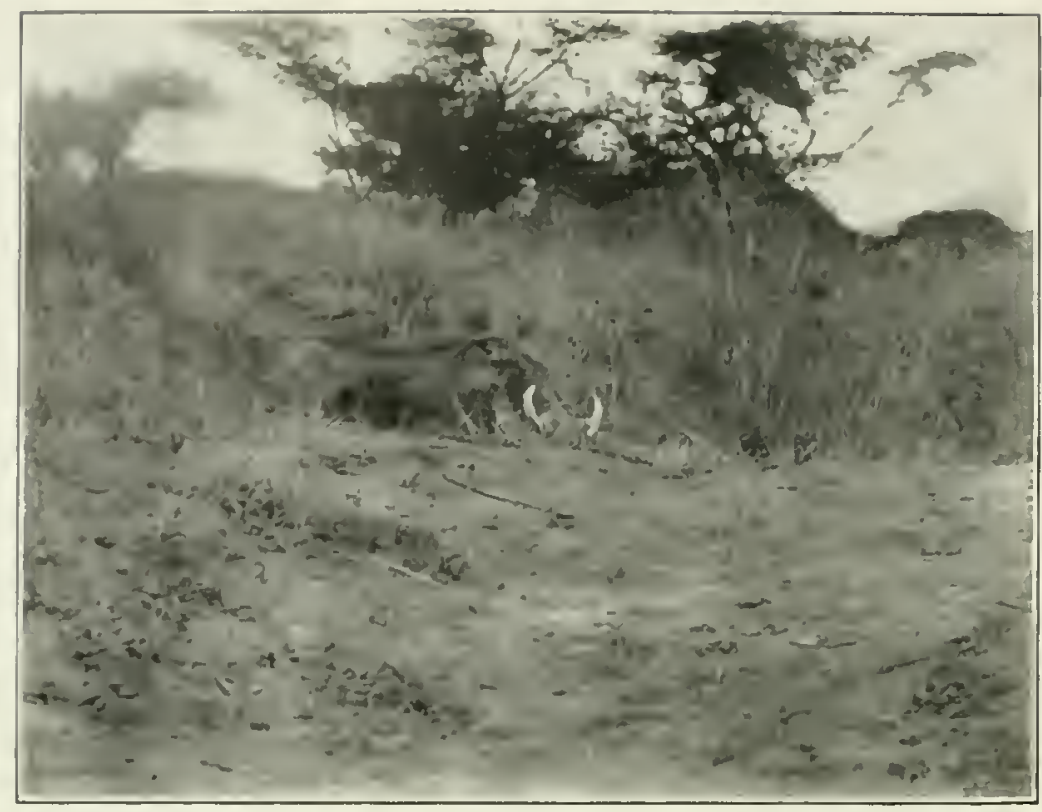

Photo by capt. R. S. llart.

W.IRTHOG.

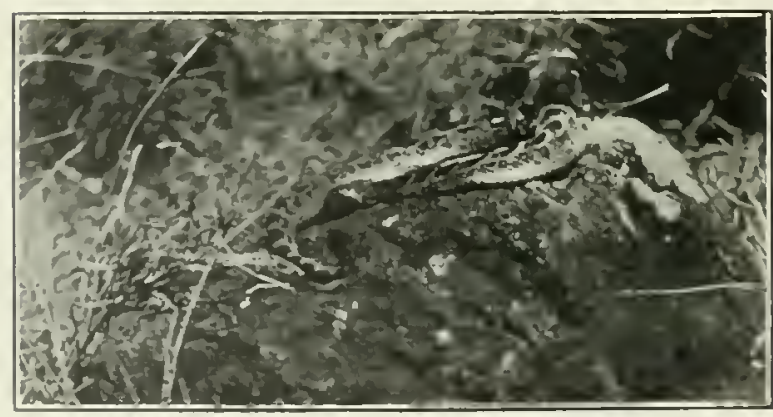

G.ABOON YIPER. 
Hence, in habits he is not much removed from the latter. Moreover, he is difficult to find and stalk. With the plain-dwellers of East Africa there is no difficulty in seeing an animal whatever. Also, owing to the non-hunting habits of the natives inhabiting the same country they are exceptionally tame and guileless.

Thus, the greater part of the hunter's art, detecting game difficult to see, picking up tracks of wary animals, and following them up, is not only unnecessary, but is even useless. With game so easily baggel as this, few take the trouble to learn the hunter's art so as to be able to obtain the bush animals, and the natives themselves are nearly all quite ignorant of spoor or tracking.

In a country like Nyasaland almost every native knows something of tracking. In East Africa there is hardly a native in the country, professional hunters included, who knows anything about it.

The wandorobo of the forest, it is true, follow certain animals by their spoors when wounded, but in forest places the ground is so soft and the undergrowth so thick that it would be almost possible for a blind man with a stick to follow the tracks. The most surprising people of all are the professional porters. Many of these inen have been on trek with exploring and shooting parties for the greater part of their lives. Yet, not only have they no knowledge of tracks and are unable to distinguish between those of an elephant and rhino, but they never notice tracks of any sort and seldom detect game difficult to pick up. When game is pointed out to them they do not know to what species it belongs. They have no idea of country, do not recognise paths, and if left to themselves lose themselves. When they see any animal their one idea is to shout and frighten it away. Yet are they ceaseless in their clamour for meat, their one idea of a sportsman being he who shoots zebra and hartebeest by the score.

These arre their defects, but for carrying loads and attending to the duties of camp life they probably have no equal in Africa. 


\section{CHAPTER IV.}

\section{THE DIFFERENCE BETWEEN "HUNTING" AND "SHOOTING" BIG GAME.}

"SHOOTING" game is the sport which is generally indulged in on the plains

$D$ of East Africa, and, from all accounts, it used to be so on the veldt of South Africa at the time when game was plentiful there.

The usual procedure is as follows:-The sportsman arrives on the plains and sees herds of game in every direction. He starts walking as if to pass by one of the nearest herds. When he gets to within $300 y d s$ or $400 y d s$. the herd gallops off for about 20oyds. and stands looking back at him. So he alters his course a little and walks rapidly on, still as if intending only to walk past, but really drawing nearer and nearer. Perhaps he succeeds this time in getting a little nearer before they mike off once more. After several manourres of this sort he may contrive to get near enough for a shot, which would be about zooyds. Then all depends on his straight shooting and his judgment of distance.

The latter is everything, and is not at all easy on these plains, especially to those unused to them, for the heat haze increases the difficulty.

A distance judged to be $200 y d s$. which in reality is $250 y d s$. is an error of sufficient magnitude to send the bullet below the animal's body. It may be, however, that the animal or herd will not let the sportsman get to within this distance. Then he either leaves in disgust to try for another herd or he risks a long shot, or, again, he may even "brown" the herd.

If, then, an animal is not hit vitally, but is only wounded, it soon gets mixed up with the rest of the herd, and it is difficult or impossible to distinguish it again from its many fellows. The herd will at last get bored with being dogged about and will gallop off and, probably, mingle with some other herd. When these combined numbers break up again into two parties which go off in different directions no one can tell which party the wounded one is among. If it is badly hit it will, perhaps, be left behind when the herd is stampeded by a lion; in which case its life will not be wasted uselessly, for it will take the place of the "night's kill" and so save the life of some fellow. On the other hand, it may aroid this fate and linger on for several days, growing weaker and weaker, eating little, and lying down a great 
deal, till some hyæna, growing bolder as the wounded animal grows weaker, makes a dash for its stomach and tears out its bowels.

The above two methods of "shooting" are those usually employed, but all sorts of variations in manœuvres are seen. Some sportsmen curtail the preliminary moves and at once bring a heavy fire to bear on their quarry, hoping by "power of fire" to compensate for the disadvantages of range. Others expect to be carried up to their game in a hammock, the exertion of walking being too great for them. Many people in England may think that such a statement is gross exaggeration. I can assure them, though, that not only have I seen this done, but I have also heard the sportsmen talk loudly of their sporting prowess or complain bitterly at their want of luck in getting near game in this way.

Other people walk over the flat, open, treeless plain in a crouching attitude, imagining that by so doing they will escape observation from the several hundred pairs of eyes watching their every movement. It is an amusing sight to watch with glasses a figure, dressed in khaki so as to be inconspicuous, crouching along with head close to the ground like the proverbial ostrich, while another part of the body is very much in evidence.

I remember watching such a figure from a distance, crouching about for the best part of an afternoon, occasionally stopping to fire a few rounds and then crouching on agrain. Behind him stalked erect three boys, carrying spare rifles and other belongings, possibly a spare casc of ammunition; but this may be imagination. One of these boys wore a red fez, and another a white coat!

However, it is only fair to admit that anyone who treks about the country much has occasionally perforce to resort to some: such manœuvres, for when crossing the plains, meat is no less a necessity than at other times and must be got, and, as I said previously, it cannot be expected that weighty timned meats should be carried wherever one goes, nor does one's work or objective allow of lengthy shooting excursions being made en route. It also seems rather absurd to take seriously to the pursuit of such an animal as the common Coke's hartebeest when all that is wanted is to secure meat.

Of the Coke's hartebeest I roughly estimate that there are at least a quarter of an million in the Southern Game Reserve and about the same number spread over the rest of the administrated portion of the country. The horms of this animal could hardly be considered as much of a trophy even if it were not so common. So there is no need to select one animal more than another, as long as a female or young orse is not slsot.

When travelling over the plains the best way to gret meat without trouble is 
to make a little detour to try to pass close to a herd near the line of march. If this is done it will be found, where game is plentiful, that a shot almost invariably offers itself some time during the course of the day, so that the march is not thereby delayed. For game is less suspicious of anyone passing on or near a path than it is when one leaves the track, which, as a rule, seems a signal for any herd near to get well out of range.

Such is the necessary "meat-shooting" of the plains-uninteresting enough. Some people, however, call this big-game hunting, and go to camp out on the plains for this purpose alone, returning with as many hartebeests and Grant's heads as their licences allow.

In places where the homely Coke is rather wild and difficult to approach a pretence at a stalk often allows one to get considerably nearer than one could do otherwise. There is no doubt that the animal either feels flattered at being thought worthy of anything in the nature of a stalk or else it is intensely curious about one's movements. For although the stalker may be perfectly visible the whole time he can generally get within range by the exercise of a little trouble.

Game vary very much on the plains as to the distance to which they allow anyone to approach. Sometimes a particular spot is crowded with game; at other times there are only a few animals scattered around. Sometimes game are extraordinarily tame and one is able to walk up to within range of any animal selected. At other times, for no apparent reason, all the game is wild and it is impossible to approach anything. This state of things seems to be unaffected by the amount they have been shot at, as far as I can see. I remember someone telling me about a special part of the Rift Valley he had just come from and how wild the game was. Even zebra, he stated, it was impossible to approach within many hundreds of yards. Some ten days or a fortnight later I had occasion to pass the very part referred to, and 1 just trekked through on the path. I heard shooting going on on both sides of me and saw two dead animals being eaten by vultures, both of which I judged had died of wounds and had not been killed by beasts of prey. In spite of all this, I do not think I have ever seen game tamer in my life. Some of the little Thomson's gazelle which strolled out of my way wagging their tails I believe I could have hit with a stone. Zebra, hartebeest, and Grant's stood staring at me from every side, many of them allowing ine to pass at a hundred yards' distance.

With the exception of the poor old rhino of the plains zebra are, as a rule, the easiest animals to approach, then come the Coke or kongoni. As the zebra's flesh is strong and unpleasant, the Coke's hartebeest is generally requisitioned to replenish the larder. Grant's and Thomson's gazelles are a trifle more difficult to 
obtain. The latter can often be approached to within 15 oyds., but their little bodies at that range are no very easy shot. The Grant's, as a rule, keep farther away, perhaps aware that their horns form one of the best trophies of the plains.

A step higher in the scale of shooting (than the above-referred to kongoni method) is that of watching game over a slight rise, and then hurrying after them. For this it is also necessary to keep the wind right. Dips, too, and little hollow valleys should be searched for game, while keeping just on the top of the rise and carefully out of sight. However, the plain-dwellers are generally wary enough to keep a good stretch of open country between themselves and the nearest dead ground. When the grass is at its longest it just affords enough protection to conceal anyone crawling flat on his stomach. In this way game may be approached closer, but the start has to be made out of their sight, so on the flat plains this generally entails a very long and dusty craw. Sometimes stream beds afford sufficient cover to keep one out of sight. When this is so it is often possible to locate a herd grazing close to the stream and approach them, this means the wind of course being kept right. Reed beds in valleys may be driven for lion, the guns posting themselves outside as if for a pheasant drive. In this a little knowledge of spoor is useful, as it is satisfactory to know before such a proceeding if there is anything inside, and this may be told by searching the ground all round. If the reeds are sufficiently dry they may be burnt, when a little knowledge of the habits of lion helps one to judge where the animal is likely to break, and hence to know the right spot to post oneself.

Lion-shooting, however, belongs more to the craft of the hunter, though the majority of these beast are found on the plains. For it is practically only at night that the animal stalks in the open. In the daytime, as great a knowledge of his habits and haunts is generally required to bring him to bag, as is knowledge of the habits of the wily denizens of the bush. It is only by studying his ways and looking for his tracks that any great measure of success can be met with, if hunting him on foot.

Another method of obtaining animals on the plains is by waiting at water-holes or concealing oneself behind tufts of grass. 'To do this a little study of the animal's ways helps one to select the right places. This is the most interesting of all occupations on the plains. An inspection of the spoor about water-holes will tell you exactly what animals are about and also much of their habits. Taking up a concealed position near some farourite haunt with a pair of good field-glasses, it is then that the charms of the plains are realised. Morever, on the plains there is always much to sec even if only on the march. But this comes into the province of the outdoor naturatist rather than that of the mere shooter, although it is true that when he wearies of being the latter he may become the former. 
In some parts of the plains are found rocks, bushes, and ant-hills. Here something real in the way of stalking may be done, and if the prize is such as a herd of the ory, small blame to the sportsman if he waxes enthusiastic over his sport, for to take advantage of the scanty cover that offers and approach unseen one of the lynx-eyed inhabitants of the plains will tax the skilled stalker to the limit of his powers. In the usual hunting-grounds of the sportsman in British East Africa this oryx trophy is the gem of the plain-dwellers' heads. Farther north, however, in the less-known parts, the animal is much more common, but still never quite easy to obtain.

I have now said about all that there is to say of "shooting" on the plains as a sport. In its ways it has charms, but it cannot be claimed for it that it ranks high as a sport. The "sport" in it consists practically entirely in the difficulty of shooting straight and estimating one's range correctly. No knowledge of tracking, spoor, or the habits of the game is generally necessary. Moreover, it entices people to use unsporting methods such as risking long shots, leaving wounded animals through inability to follow them up, killing larger quantities of game than is really necessary, and even more heinous offences.

For the pursuit of any animal not living on the plains, a knowledge of hunting is essential if you wish to reap any great measure of success. Where game is very plentiful in the bush it may be encountered accidentally. To maintain any consistent run of good luck, however, and to obtain good and not indifferent heads, and, above all, to meet with specimens of the rarer animals, a knowledge of hunting is necessary; that is to say, a knowledge of the spoors of the different game, ability to follow such spoor, quick eyesight and hearing, and above all a knowledge of the habits of game and the arts of bushcraft. Failing practice and experience in these subjects, they can be supplemented to some cxtent by the offices of a good native tracker; but, as I have before said, a skilled tracker is difficult or very ncarly impossible to obtain in this country, for few of the natives are of much use in the art. Moreover, as a pure matter of sport, there is no comparison between the excitement and interest when one is his own tracker, even if supplemented by a native, and that of being entirely dependent on the caprices of a professional tracker or native hunter.

Let me now try to detail the operations of a hunter in search of some particular specimen in bush and forest. Given a large tract of this sort of country, it may or may not contain the game wanted.

On the plains this doubt can be solved almost at a glance, but in the bush it can be determined only by research. This research is not so difficult as at first it inight appear. Given that you know the appearance of the spoor of the animal you 
require, it will not be long before you are able to detect its spoor if that part of the bush is one of its haunts. A single old spoor-mark on the banks of a stream, at a drinking-place, or on a soft patch of earth, provided that you can recognise it, is easily seen and gives the needed information. You then know that the animal in question is or has been in the locality, and you may assume it is so still, unless, indeed, by knowledge of its habits you know that something has occurred to change the state of affairs since it was there, such as the drying up of water or the absence of some particular food supply. A case in point might be the coming of animals to eat the pods of certain trees when they fell to the ground, which when the season was over the animals left for other pastures. This is but one instance of the use a knowledge of the habits of animals may be put to.

When I sce that some place is now deserted, whereas some time before animals have visited it in numbers, I always try to find the reason. Copious old spoor and no fresh spoor is a sign of this condition of things. I have often seen a place devoid of game, but pounded all over with tracks made during the wet season. It is obrious then that some change produced by this season accounts for their presence or absence. Perhaps it is some herbage which grows only during the rains or is at its best about that period. Or it may be that the animals have been driven to the spot by the worse conditions of their usually drier resorts.

It must be remembered that spoor made towards the end of the rains is very permanent in its nature and out of all proportion to the tracks made at other seasons. Thus, game may have been only a day or two in some place where the ground is mudly and yet have left it covered with tracks which remain to the year's end to testify to their presence. Subsequently, during the dry weather, they may have been much longer in some other place and yet nearly all signs of their tracks be obliterated by sand, dust, showers, growing of grass, and various other causes.

But to return to the spoor-mark which I am supposing you have discovered. It tells you that this spot is, or has been, the habitat of the animal wanted. If the spoor is fresh you know then that in all likelihood the quarry is close, but in any case that it cannot be very far away. It now becomes necessary to evolve a plan of campaign, for the game you want is presumably somewliere in the forest or piece of bush near. In it he must be found, but found in such a way that neither by scenting, hearing, nor seeing he mily get warning of your presence.

The great points are, to avoid all undue hurry and to think out the situation carefully. You take note of the direction the wind is blowing at the time and also the direction of the prevailing wind, the latter discovered by the various signs and traces it has left, such as bent grasses, moss on trees, and a multitude 
of other small signs easily recognised by the bushman. These considerations and the all-important question of water will, probably, influence you in the selection of a site for your camp. There may be a stream near the edge of the forest to the leeward. Somewhere there, then, should be the site for your camp, as your wind will not be blown into the recesses of the forest and so alarm animals. If you are afraid your porters will make too much noise you may then cainp outside the forest, or, at any rate, some distance from your intended hunting-ground. The noise made by the porters is not only ruinous to one's chances with wary animals, but it also gets on the hunter's nerves when he has been subjected to it for any length of time. If the porters are not dancing and singing they are shouting. Two men may be sitting sicle by side by the fre holding a quiet and confidential conversation, but every word spoken by them can be heard at a distance of perhaps a hundred yards. This is their subdued whispering, so the noise made when they raise their voices can be better imagined than described.

Having arranged your camp so that the men can do as little damage as possible, you next set out to investigate. If the animal wanted is only of a semi-wary kind and plentiful you will probably search round for him, hoping to see him before he sees you. If he is very wary or rare it is almost impossible to come upon him accidentally. It then becomes necessary to search about till you find fresh tracks and to follow them up with every precaution. The most fascinating part of such pursuit is that when you begin all is unknown, but as you proceed you gradually unravel the mystery which enshrouds the animal and its doings.

When you first arrived the country was unknown and the rivers, pools, and other features all hidden by bush. Bit by bit you piece together the lie of the land and the relative positions of different spots. Bit by bit you piece together information concerning the animal itself, its habits, haunts, foods, etc., until at last you "think" in the same vein as does the animal, or imagine that you do so.

This piecing together of a thick bush country in one's mind is, in my opinion, one of the most interesting points in bushcraft. I will try to give an illustration of how one picks up, little by little, the character of closed country, and 1 will endeavour to show how that, as time goes on, one becomes better equipped with information that may be turned to accounit.

An example that comes to mind, although it did not occur in East Africa, will do well enough to illustrate the subject. It took place in thick wooded country in Portuguese East Africa, but the principle is much the same in any thick country. The great distances travelled by game in that district, combined with the brevity of their stay in any one locality, made it difficult to locate them and added greatly to 


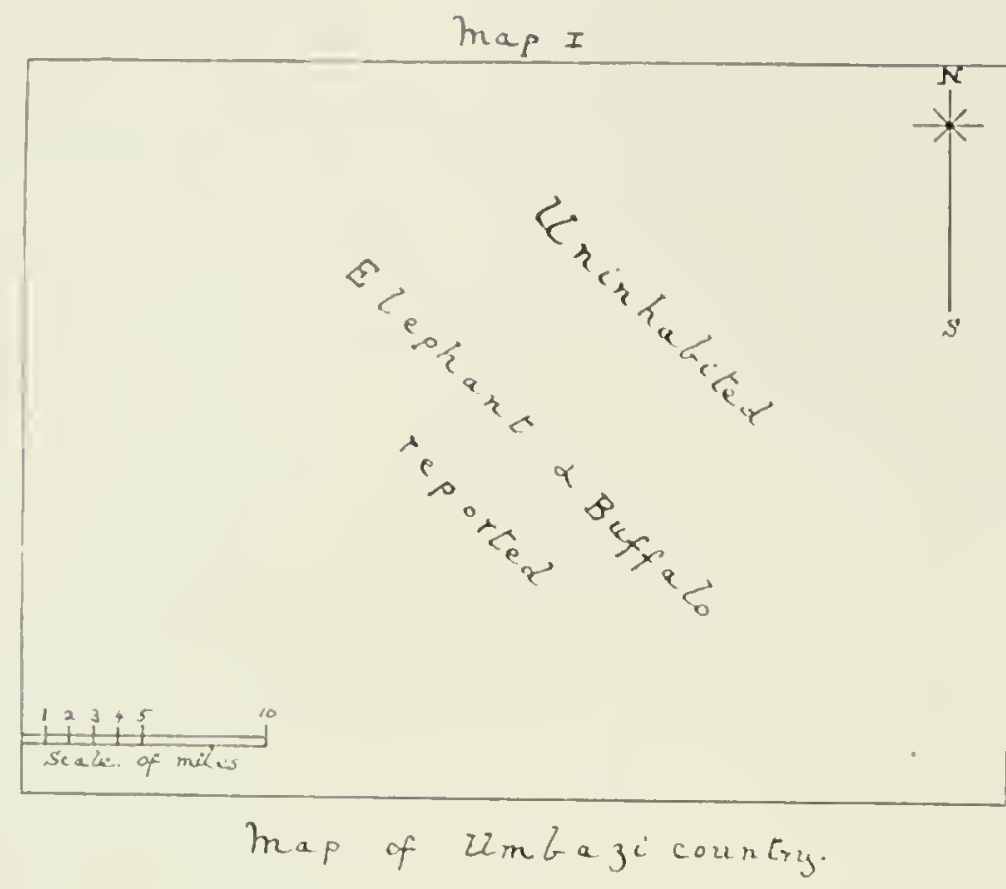

map II

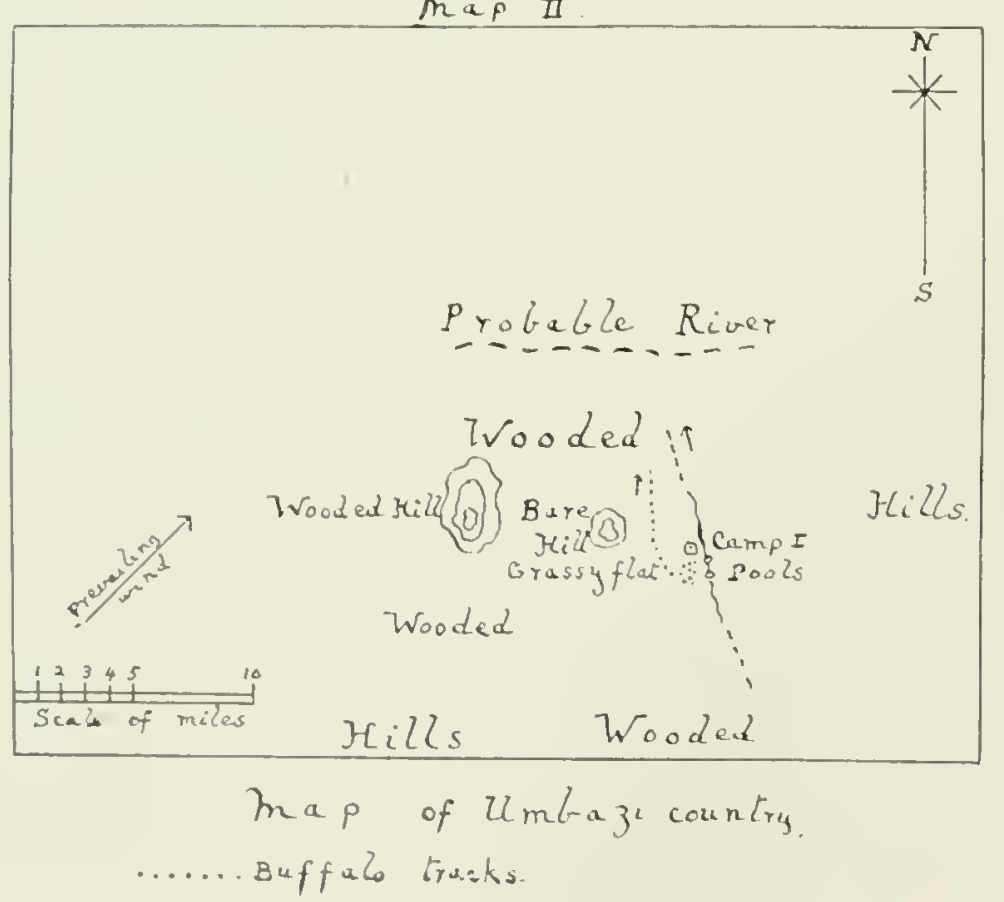


the interest of searching for them. There was a herd of buffalo, some elephant, and a few rhino which used to roam in an uninhabited part of that country, and it is to be hoped that they do so still. There were no villages or natives for a distance of two or three days' journey in any direction.

I will treat of the area hunted over as about forty miles long by thirty miles broad, and on Map $\mathrm{I}$ is shown the country as known to me before visiting it.

The names given thereon are fictitious, and $I$ have made an alteration in compass points, for convenience.

On the first day I arrived in this area I came the same evening to a little grassy flat, beside which was a smail watercourse. This watercourse contained two muddy pools of water growing small beds of reeds. Round this spot tracks of buffalo were plentiful, the age of which I estimated at three days.

The tracks about the water and grassy flat were confused and tortuous, as the animals had been grazing there. On searching a little farther, however, it was apparent that they were grazing towards the south, as once the grassy flat was left behind the tracks did not wind about so much. As the country made a gradual descent in the direction in which the animals were going I presumed that there was probably a river in that direction. For in these parts buffalo seldom wander very far from some big stream or river, as they like to drink its clearer water during the night.

That night I camped there. My knowledge of the country, as I made my plans for the morrow, is shown on my second map.

On the next day I followed the tracks and came to a river with steep and rocky banks, wooded on either side. As the season was the end of the dry weather this stream was no longer rumning, but in its rocky bed were a series of pools of clear water, some of which were several hundred yards in length; so it followed that when the animals were in this neighbourhood some spot in this series of pools was then their night's drinking-place. A brief inspection served to show that they had drunk two nights before not far from where I had struck the river. After selecting a site for camp I sent a man back to bring on the porters, while I followed the tracks still farther. These ascended the opposite bank and then took me up a gradual rise to the south-west for some six or eight miles, till I came to a water-hole in this higher ground, and there also discovered some old spoor of elephant.

The buffalo had evidently spent the day in the vicinity of the water-hole, and towards the evening made their way eastwards. I surmised that they had returned to the river to drink the night before, and that they had hit off the river below my camp, drunk there, and were spending this day at some other water-hole, but on which side of the river that might be or in what direction I could not guess. 
However, it seemed probable that it would be towards the higher ground away from the river, somewhere to the eastward.

I then returned to camp, making a detour eastwards so as to try to hit off their spoor again, either going to or coming from the river. 1 found some nullahs leading down to the stream, and noticed that a recent and very brief shower had been sufficient to fill up a few little holes with water in their beds. As these were very shallow and exposed to the sun it seemed certain that they would be dry again in the course of a couple of days. However, among these there was fresh spoor of buffalo. As it was then late in the day I followed these fresh tracks with more haste than caution, with the result that the buffalo got my wind in thick bush, where they were lying, and stampeded. I then returned to camp, arriving just after dark.

Next morning about dawn a lion roared from the westward. As this has nothing to do with the circumventing of the buffalo it will suffice to say that I followed him to some stony hills westward, and in so doing hit off an upper bend of the river, which had there swept round from the north. Above the bend was a little swamp and signs of old buffalo spoor. They had, probably, been there the day previous to that on which they had arrived at the grassy flat.

On the evening of the third day my knowledge of the country was as shown in Map 3 .

The following day, the wind being from the south, I followed a course parallel to the stream eastwards, in the hopes of hitting off some night spoor. In this I was successful, finding traces after I had gone several miles. This spoor led me south-east and then south. I followed it for ten miles or so and then gave up, as it was getting late. During the whole of this distance the animals had not stopped to feed, so it was obvious that they were trekking off to another grazingground. Just before I gave up, the spoor came to the river-bed again and crossed it twice. The channel here was perfectly dry, the steep, rocky bottom having given way to a shallow, sandy one. It was therefore apparent that the river's course had taken a bend to the south. It appeared, too, that there was no water here for the buffalo to drink, so they were, probably, going to follow the river to some part where it was again provided with pools. Having arrived at the spot they would, probably; take up their quarters in the neighbourhood for a few days until they had visited all the grazing-grounds in the vicinity.

It will be noticed that these wary animals, during the four days I followed them and the four preceding days (which latter knowledge I had gleaned from old spoor), had never watered or grazed twice in the same place.

My knowledge of the country up to date is contained in Map 4. 


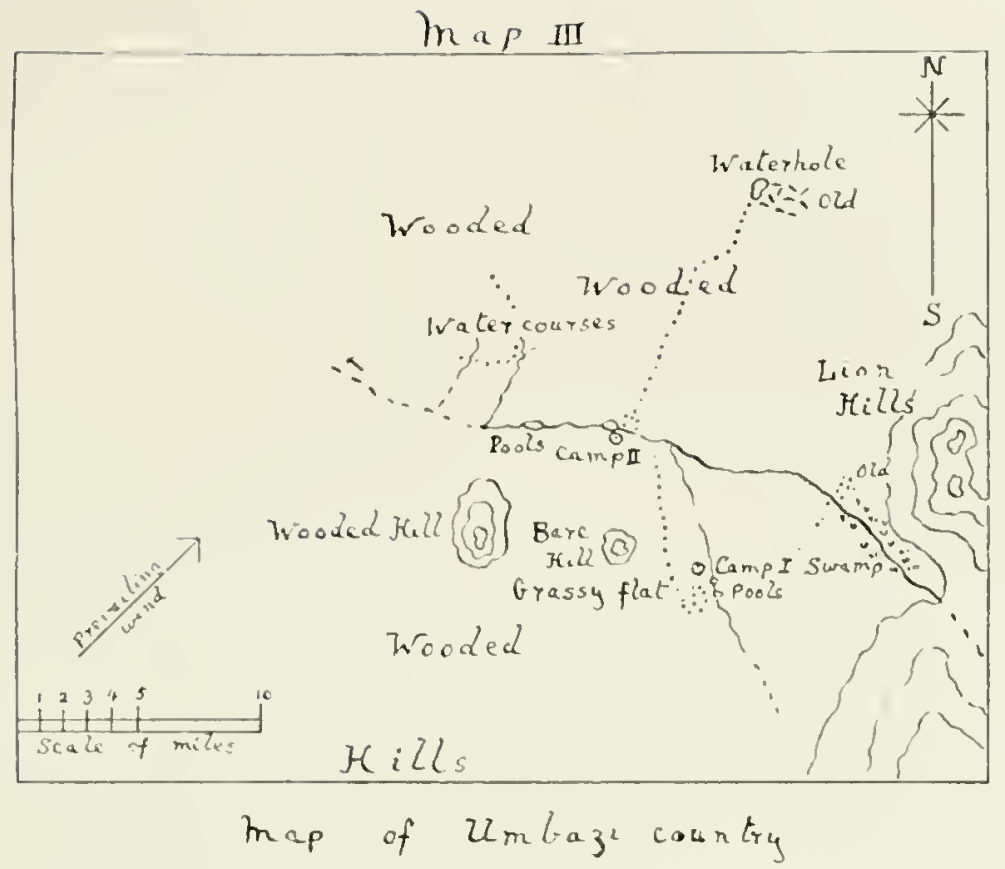

...... Buffalo tracks "old "means old spoor

..... El plant tracks

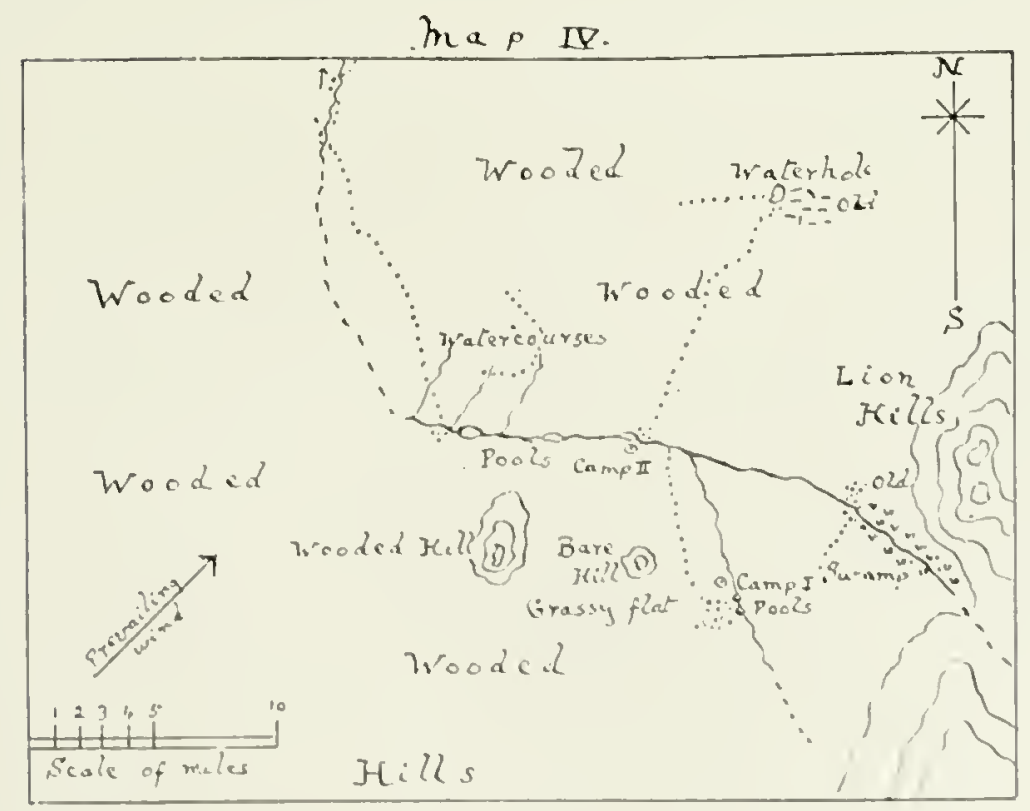

heap of $22 m$ braz i country.

Buffalo tracts "old" means ald spoor

- Elephant tracks 

This finished the first phase of my campaign, as after that I went off elsewhere.

However, a short time later I returned to see if the buffalo or clephant had revisited the spot. Equipped with the information on Map 4, I pushed on to the camp by the river. There I searched up and down for fresh spoor and visited the water-holes, but, finding none, moved camp on to the bend of the river. There was nothing there either, so, as I knew of no other spot away from the river where water was obtainable, a blind trek in any direction would be unlikely to hit off one of the few water-holes which, possibly, were concealed in the bush; I decided, under these circumstances, to follow the river down to try to find some more pools beyond the dry part of the watercourse.

The direction in which I had left the buffalo herd trekking on my last visit made me feel certain that there were some other pools to be found. With this intention I was proceeding downstream next morning when I came upon the fresh spoor of elephants crossing the river from west to east. They had probably come from the water-hole to the west.

Sending back word to my camp to follow up, I pushed on after the elephants. They were going straight on in a herd, and there were no signs of broken boughs or fallen leaves by the waly. After about four hours' going, I was brought out into an open glade with water-pools. The spoor had been growing older, and, as they had not even stopped to drink at these pools, it was evident that they also were on trek, and it secmed hopeless to follow them any farther. They had crossed the river early during the previous night, and so had fourteen hours' start of me.

I w.s interested to find a well-beaten thino path traversing the length of the glade, for these animals are not at all common in the country. There was also some fairly fresh buffalo spoor, which I followed, but did not succeed in coming up with the animals.

I passed and repassed the thino path, and also noted a spot where elephant seemed to be in the habit of coming to strip a certain kind of bark off the trees. A number of these trees were denuded of bark, and this was not the result of one visit from a large herd, as by the spoor it was apparent that elephants had been there on sceral occasions. Returning to the glade about sunset I was glad to find that my camp had caught me up and that food was ready.

Next morning I found fresh spoor by groing up the valley of the glite for a few miles. This spoor I followed and came up with some buffalo about noon, but bungled the shot. following them up once more across a broken country of ravines and nullahs, I came up with them at another set of pools and mud-holes about sundown. There I shot one and brouacked for the night, and next morning sent 
back for my camp. On looking around I found that elephant had drunk at the pools during the night, so 1 followed up these, and trekked off the locality of the map. Map 5 contains my present knowledge of the country.

All this description is not instanced as a very startling performance in the way of hunting. It is only intended to illustrate how it is that one pieces together gradually, under rather difficult circumstances, the chief features of a closed country and gets to know the habits of its game.

It must be remembered that even under the most farourable circumstances 1 could never see further than a few hundred yards.

The difficulties to contend with were many. Having no native with me who had ever visited the country before was a serious drawback. The lack of water and the impossibility of moring camp without having made fairly certain that there was a pool or hole in front was another drawback. The difficulty of locating these pools, and the great distances travelled by the game, and their very wary habits also tended to make things far from easy. It will be seen that without the help of spoor I could never have found any of these waterholes except by the purest fluke. The only chance would have been to walk aimlessly about in the thick bush and trust to luck in running up against the single herd of buffalo which were grazing over this large area, while camped always by the river.

If ever I get the chance to visit this country again, equipped with the information on Map 5, it should be a much easier matter to locate these animals if they are about, and it might also be possible to anticipate their movements when moving from one water-hole to another.

This learning of a difficult bush country is, to my mind, one of the principal charms of hunting, and is a charm that is altogether absent when shooting on the plain.

On the plain it is indeed an advantage, a great advantage, to know the country, but one learns its lie in large blocks at a time. There is no need to piece it together little by little, and fill in the unseen country between, from one's own imagination. The habits of the bush animal must also be learnt piece by piece, and this is chiefly done by watching and by making deductions from spoor. Bush animals' habits are not learnt in a day, and a knowledge of them is only the outcome of considerable experience. Another of the fascinations of the bush is the constant disappointments met with and the chances lost, or never made use of.

All these things take their share in the building up of the necessary experience. When at last success crowns the sportsman's efforts he feels that he has achieved no small thing, and that it has been worth all the trouble he has taken. 


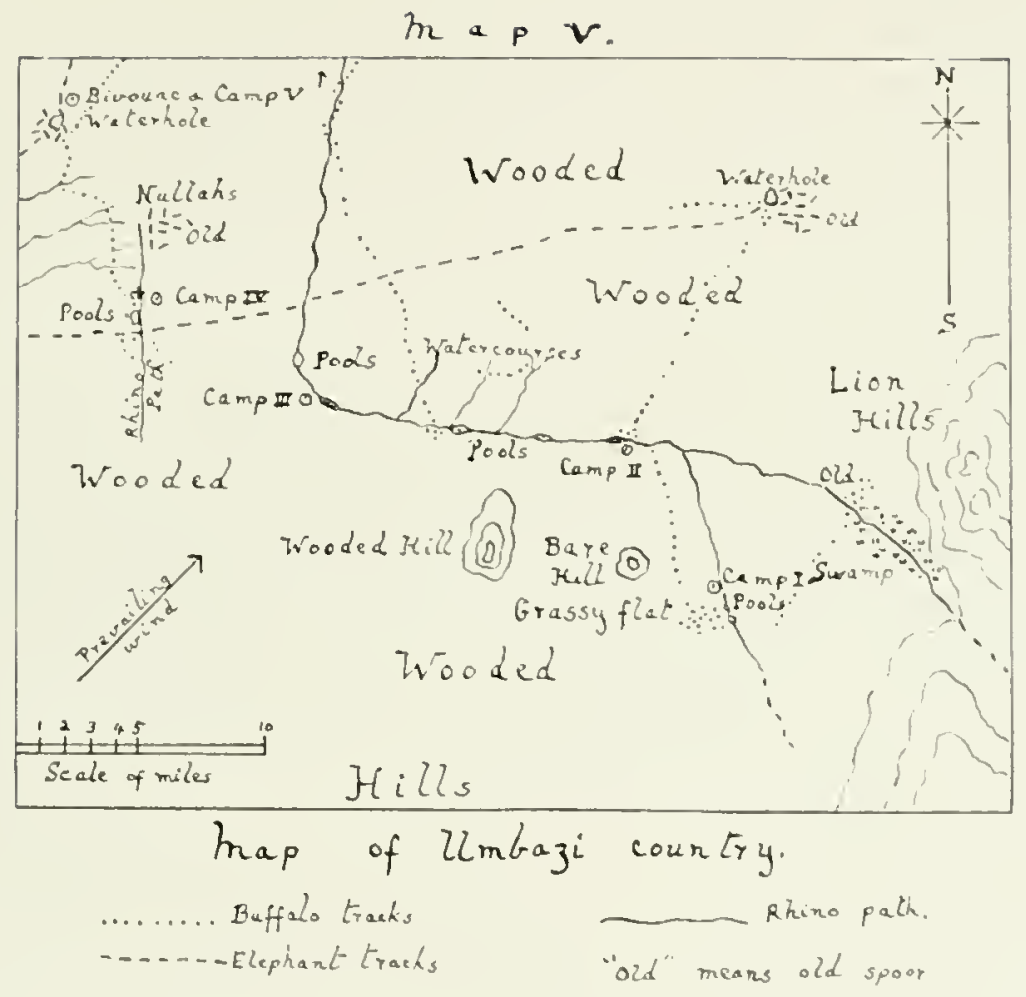



Sport is generally considered to rank in merit in proportion to the art required in bringing an animal to bag. About such ranking of sport different codes of etiquette spring up, as to what is "sporting" or what is not sporting; but the main idea of all such codes is that the sport which entails the greater skill and knowledge is more "sporting" than that which requires the lesser skill, for it gives the animal more of a "sporting chance." That is the only real difference between fly-fishing and float-fishing. The main ideas are the same, viz., that you catch a fish on a hook attached to a line and rod. Yet fly-fishing ranks much higher than float-fishing, because it requires far greater skill and so gives the fish a more sporting chance. It is not merely luck which counts towards success with the former, but a certain amount of luck combined with skill. In the same way, no reason can be given for the opprobrium in which the shooting of "sitting" birds is held, except one similar. The shooting of birds on the wing is more difficult, and thus gives the birds a greater chance; therefore it is sporting, whereas the other is not. Similarly then, the shooting of the wily bush animal should rank much higher than the shooting of the plains animal, for the former art requires varied skill, whereas the latter does not (i.e., not more than in the pulling of the trigger, for the shot is generally fired at very short range).

Bush-shooting requires more skill in the preliminary manouvres, and in this it corresponds to fly-fishing. For in fly-fishing the actual hooking of the fish, if it rises well to the fly, is not the difficulty; the chief difficulty lies in the preliminary mancuvres. The craft of the fly-fisher is in selecting his position and the likely places in the stream, and the choice and presenting of his lure; these are the things which enhance this sport. As for the playing of the fish, this in a measure corresponds to the difficulty of tracking a wounded animal in bush and finally bringing him to bag.

Likewise, in bush-hunting the game has more of a chance. How often does one get up near the quarry when the sudden crashing of branches tells that the wind has played you false. Or it may be that one slight error in judgment or the treading on one dead twig nullifies a whole day's work, or, again, it may be through no fault of the hunter's own, but through some quite unforeseen accident or through some ragary on the part of the animal, that the clanee is spoilt.

Moreover, the hunter of bush game can never be a butcher, whatever else he may be. When inexperienced he may be more likely" to shoot an immature animal or a female than he would if shooting in the plains. Even when experienced it is often impossible to see the size of the horns when only some small portion of the anmal is visible, besides which it may also be equally impossible to get any nearer.

On such an occasion there is the temptation to shoot and chance its being a grood animal, especially if it is of a species never before obtained. Howerer, such a 
shot on chance is almost invariably followed by disappointment; the beginner is then so mortified at the result that it will probably be a long time before he will again try such a shot.

It is so seldom that the bush-hunter is able to obtain more than one trophy in a day that he can never become a great killer of game. He cannot return, as does the hunter from the plains, with half a dozen or so of heads as the result of a day's work. In Central Africa I reckoned that it took anything from three days to a week's hard hunting to obtain one good bull sable, whilst every elephant shot meant at least a hundred miles of walking, and more often as much as two hundred, sometimes more.

When such work is done for one trophy it is not often that a hunter will take a risky shot and chance losing his trophy. Nor will he take a shot at an animal the head of which he is not certain is a good specimen.

Of course, something must be left to chance in the way of shooting. Sometimes the huntsinan may have every reason to believe that an animal only partly visible is the one which he has spoored up, and the size of the track of which has shown it to be an adult bull. If he shoots and afterwards finds that it is some other and smaller specimen which must have crossed the path of the first, he cannot be blamed for taking the shot, for the chances were all in favour of its being the animal desired, and he had, moreover, but a fraction of a second in which to decide whether to take the shot or let go the opportunity for which all his spooring up had been but a preliminary.

Even the oldest and most tried hunters make mistakes. I have had proofs of two of the most celebrated elephant-hunters in Africa shooting female elephants by mistake. Such shooting is considered by the framers of game-laws as one of the most heinous offences it is possible to commit. Yet that such a mistake can be made by a famous elephant-hunter only shows how impossible it is to entirely aroid making mistakes.

Much may be forgiven the young and keen beginner, for without experience many mistakes are easy to make. There are some people, though, who never seem to learn, however much experience they may have gained, for with them the sporting instinct is not, and they just kill for killing's sake. These are the real enemies of game, for they cannot resist a shot at anything they see moving, and so are constantly obtaining females and immature animals.

The pleasure derived from hunting in the bush and forest is mostly obtained in the successful outcome of the tracking and bushcraft so necessary to success. The actual shooting and killing is but the climax. It may be likened to checkmate in a game of chess, which is the result of manœurres successfully thought out. 
There would be no amusement to the chess-player to come up to the board and find the pieces so arranged that he could at once checkmate, and in the same way it gives the hunter little pleasure to walk out and find an animal waiting for his shooting.

In such a case the animal would not have had its sporting chance. If it was a much-coveted head the sportsman might shoot it, but he could not return and pat himself on the back for his skill.

The exercising of the bushcraft so necessary to be successful as a hunter is the enchanting part of hunting. It is a match between man and animal, each having to use all his wits and keep for ever on the alert. How different is the ordinary plainshooting, where, if the animal is only fool enough to stand until you get near enough, you may bag him.

"If all the pleasure is in the tracking and stalking," the humane reader will remark, "why shoot the animal at all?"

That 1 do not know. I have spent many interesting days in following tracks when I have had no intention of shooting and even when there has been no chance of coming up with the animal followed. At such times one just takes notes of the animal's habits and way's.

However, if one always spent long days following up animals and, after infinite trouble, came up with them and then just turned round and walked home again, there would seem to be something lacking. The fitting climax to the day's work would not have been reached; there would be nothing tangible to show for the pains endured. If one could hunt and stalk for a camera shot that would be a different matter. Such a proceeding is unfortunately seldom possible in the bush, unless the time at one's disposal is practically unlimited. There is hardly ever visible more than a small portion of a wary bush animal at any time, the bulk of its body being always concealed by bush wen when one is quite close. It almost invariably, 100, is in shadow, and thus but rarcly is depicted in a plotograph. Moreover, in most cases it would he necessary to smapshot it as quickly with the camera as one does with a rifle, for the animal must be approached very closely to be seen well, and at such close quarters part, at least, of the hunter must be visible to the animal. The slightest movement made then at this close range is almost certain to betray lis presence and so send the animal off in a flash. Again, even where the bush is more open, there is the inferiority of range of the camera as compared with that of the rifle, and always the shadow of bush and forest to contend with, for the denizens of the bush seldom let the sunlightit play upon them.

One's knowledge of the appearance of the bushfolk is generally confined to the 
feeting glimpse of a head or leg disappearing behind a tree, or of something indistinct, moving behind a bush, or perhaps a dark object which might be game or might be anything else. For this reason, when one has not yet shot some particular kind of animal, there is always a strong desire to shoot one, so as to be able to see what it is really like in the flesh. With the plain-dwellers a good pair of glasses suffices for this, but in the bush it is different.

However, to return to our reasons for wishing to shoot at all; there is one more I can put forward, and that is the fad for collecting heads, sometimes with the idea of comparing them, and at other times with the idea of using them as decorations. As the latter they serve for mementoes of many a pleasant day spent in the open air. The whole idea of displaying trophies of one's own shooting is, perhaps, a little bombastic, but it is this human weakness which is one of the chief reasons for indulging in shooting. This weakness for amassing a quantity of trophies may be best gratified on the plains, for on them roam numerous different kinds of animals, most of which are only waiting to be killed. Of these the trophy hunter can shoot with ease as many as his licence permits. The trophies from the bush and forest, however, are, as a rule, more striking.

On the plains the usual animals found are :-

Rhino.

Giraffe.

Eland.

Gnu.

Oryx beisa.

Roan.

Waterbuck.

Hartebeest, Coke's.

Hartebeest, Jackson's.
Hartebeest, Neumann's.

Topi.

Thonas's col.

Gazelle, Grant's.

Gazelle, Peter's.

Gazelle, Waller's.

Gazelle, Thomson's.

Impala.

Reedbuck.
Steinbuck.

Oribi.

Lion.

Cheetah.

Serval.

Hunting-dog.

Zebra.

Warthog.

Ostrich.

In the bush the usual kinds of game are :-

Eilephant.

Rhino.

Giraffe.

Buffalo.

Oryx beisa.

(Tryx callotis.

Sable.

\section{Greater liudu. \\ Lesser kudu. \\ Bushbuck. \\ Waterbuck. \\ Impala. \\ Waller's gazelle. \\ Duiker.}

Suni.

Dikdik.

Lion.

Leopard.

Hunting-dog.

Serval.

Bushpig.

In the forest are met with:-

Elephant.

Bongo.

Bushbuck.
Duiker.

Leopard.
Forest-hog.

Colobus.

It is not easy to draw a hard-and-fast line as to the habitat of most animals, as 


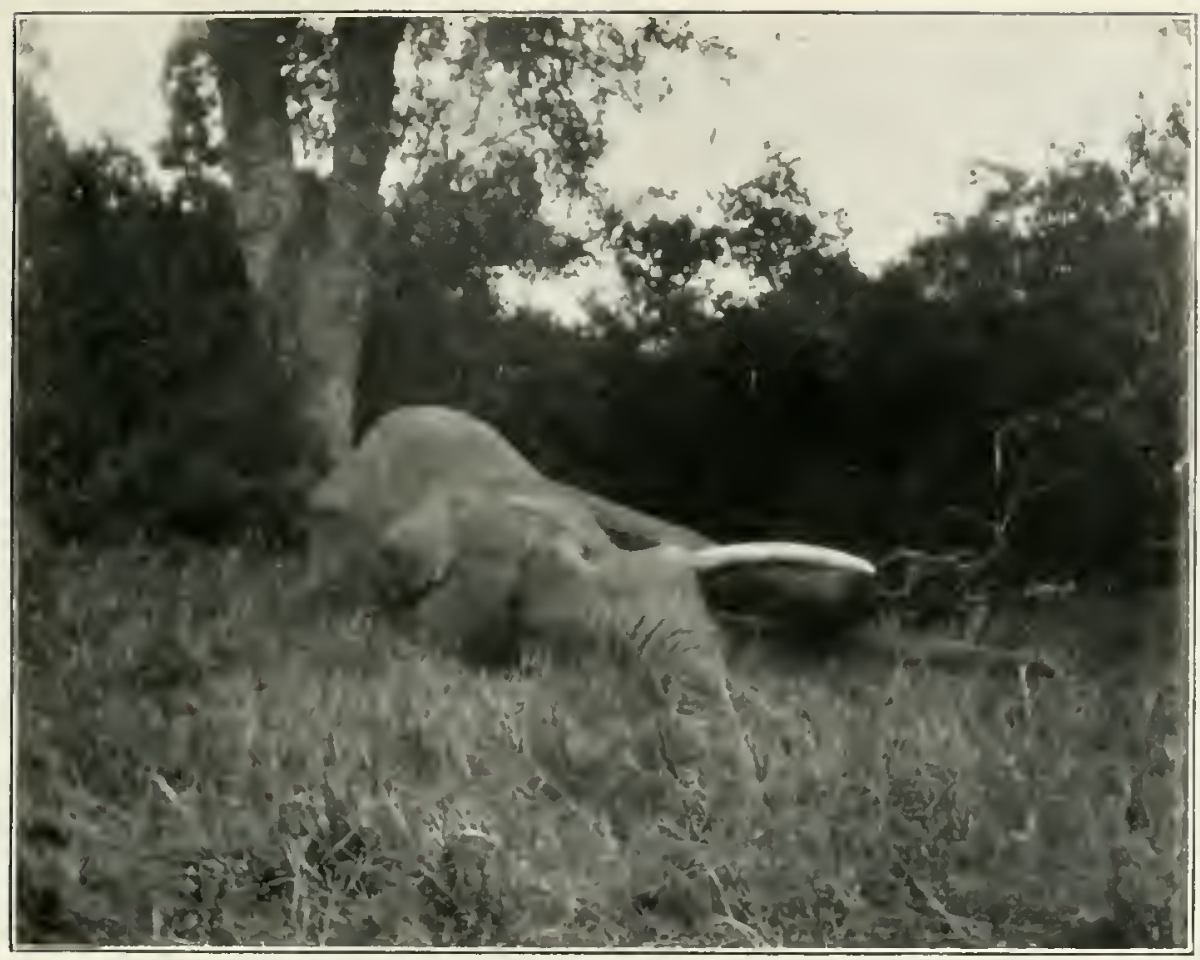

Phote lig G, R - inne.

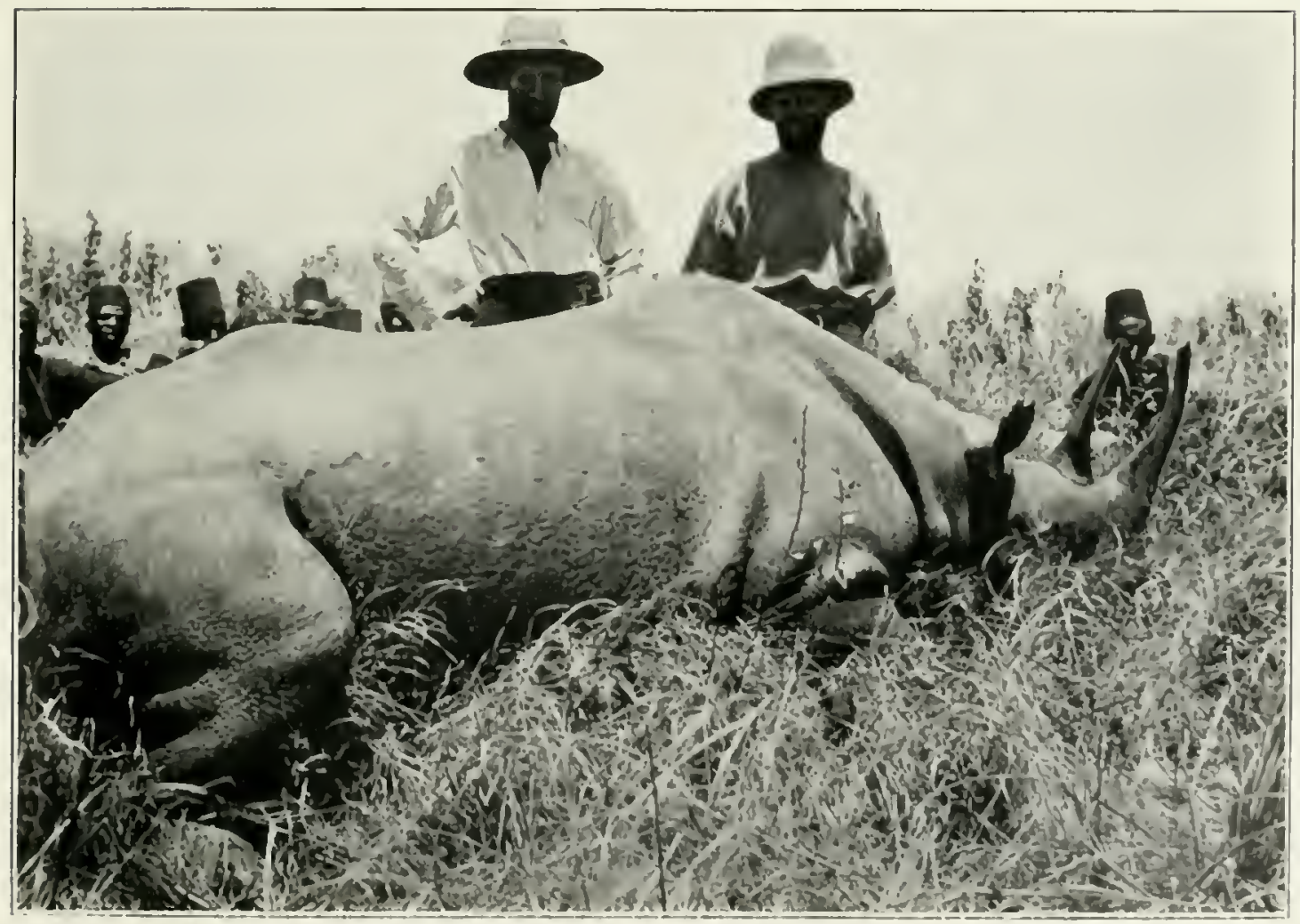

RIIXO, WIII URURFX MIIKS. 

they tend to wander to some extent between different kinds of country. Those grouped above are under their most general habitats.

Thus, an elephant is distinctly a forest animal, but it has at times been seen on the plains. On such an occasion it might either be passing from one forest to another, as these animals make periodical treks, or it might be going down for grass, as they sometimes do. However, where the grass is short, as in most parts of East Africa, it is the elephant's usual custom to graze by night.

In some instances in the above lists it will be noticed that an animal is given under two headings. In that case it may be that the animal wanders between the two kinds of country, or it may be that a distinet type of the animal, apparently not intermingling, is found in each of the two countries. With these latter it is probable that they are taking the first step in the change necessary to become a variation of species, and eventually a new species.

To return to the consideration of trophies; a grouping of the different heads obtainable in each of these types of countries shows that nearly all the best are found among the bush and forest animals. Although a greater number of heads fall to the lot of the shooter, by far the most striking trophies are obtained by the hunter. Even if these bush and forest animals were not more dfficult to obtain than the plain-dwellers, the former would, I think, take precedence for beauty and massiveness.

So far I have been talking of shooting and hunting almost solely with reference to inoffensive antelope and buck. These may be more or less interesting according to the difficulties in finding and shooting them.

When one turns to dangerous game however, a new factor is added to the procedure of hunting them. For with them, whether they are easy or difficult to find and come up with, there is always the chance of their turning the tables and hunting the hunter. Although the occasions on which they behave to all intents and purposes like other game are more numerous, still the occasions on which they do not are frequent enough to make the following of them exciting work.

There is often a tendency among people, who know little or nothing of the hunting of dangerous game, to underestimate the hazards run by the hunter, armed as he is with a long-range rifle of the greatest precision and accuracy of mechanism.

This under-estimation may be the outcome of sportsmen exaggerating the adventures they have met with and surpassing the bounds of credibility, or, on the other hand, it may be the roicing of the ideas which occur to many beginners when they 
find that they can account for big game easier than they had expected. Beginner's luck is proverbial in most sports, and big-game shooting is no exception. Many are the stories one hears of tyros who cannot shoot and who do not know where to aim or how to approach an animal, yet successfully drawing a bolt at a venture or meeting with an animal under almost unheard of favourable circumstances and securing a magnificent trophy:

The first sable bull I ever shot might have been deaf and blind, from his behariour. I walked suddenly on to him at close quarters, quite accidentally, in the bush. Several men were talking at the time and did not stop immediately. Y'et the sable strolled towards us quite unconcernedly and gave me a shot at thirty yards.

I have spent many long days following up sable since, but have never obtained a better head. If I had been a short-trip sportsman and returned to England after this performance, what a very wrong impression I might have carried home of the art, patience, and work required in bagging this particular animal.

A man who has bowled over a few lions as easily as if they had been so many rabbits goes back to England and dilates upon the cowardly nature of the king of beasts. If he had stopped to shoot a few more he might have changed his opinion. A sportsman has always an exaggerated respect for a dangerous animal before he has shot one, but if he manages to shoot one or two without mishap he experiences a revulsion of feeling, and the respect felt before gives place to a feeling something like contempt. The dangerous animal is never, perhaps, after that quite replaced on its old pedestal, but every one of its kind shot after the first two or three gives the hunter a slightly added respect for it.

A dangerous animal does not always rush for one on sight, as many people seem to think. If it did, there would now be either no dangerous animals surviving or else no hunters. It has, in fact, a natural tendency to try to avoid danger, though it can be formidable enough on occasions. A lion, for instance, however fierce he may be, cannot always be feeling ready to rush at a stranger with no provocation whatever; moreover, he may be feeling comfortable and replete after a heavy meal.

A famous duellist, comfortably asleep in a house and suddenly hearing a number of people, armed with rifles, and with whom he had no quarrel, clamouring for his life, would, if only armed with a sword, make a bolt for the back door. If he found on arrival there that his retreat was cut off he would probably then try to fight his way through. Similarly with the lion, found lying comfortably asleep in a reed-bed and suddenly hearing the clamour of armed people looking for him, he naturally slinks 
out at his back door. If he is then rounded up he turns formidable, but does not want to fight in the day any more than our duellist, cited above, wished to fight at night.

Neither the lion nor the duellist could be considered cowardly because he was not anxious to fight against heavy odds at a time when the conditions of darliness or light were unfavourable. During the night the lion is fearless enough.

With regard to the danger attending the shooting of the various dangerous game animals, taking into consideration the improvement in modern firearms, the chances of success are certainly very much more on the side of the hunter. This is no less than it should be, for if he were to have only equal chances with the animal, it is unlikely that he would ever bag two such animals before he was himself slain.

One hears much of the prowess of hunters of ancient times, who used to hunt and kill dangerous game with spears, swords, or bows and arrows. These hunters were undoubtedly very stalwart and brave men, but a point which is not generally brought to light when drawing the comparison is the following slight difference of method, viz.:-The modern and sporting way of hunting a dangerous animal, although it may not always be done, is for the hunter to go alone against the animal, or even against a number of them together. He will at most be accompanied by one black man carrying a spare rifle. In the ancient hunts the hunters were, it is true, only armed with primitive weapons, but as far as we can gather from accounts the hunters used to go in hundreds and sometimes even in thousands to surround an animal to kill it. The native hunters of to-day generally go in great crowds, and presumably their methods are much the same as those employed by the ancients.

However, there are native hunters who go in parties of two or three only, and these sometimes account for dangerous animals with primitive weapons. These men are undoubtedly braver with dangerous game than the average European. It must be remembered, however, that the savage is much quicker and more nimble in the bush than the white man. He cin throw himself into a tree with ape-like celerity, and thus escape unhurt where the white man would most certainly be killed. He can also run and dodge in the thick undergrowth where the white man gets hung up or trips and falls down.

The little scene I am about to describe will be the facsimile of one often witnessed by the hunter.

News comes in of dangerous game-sy, elephant. Much to your annoyance ten local natives insist on accompanying you to show you the game, instead of the 
two guides you want. Nothing will shake their determination to share the danger with you and be in at the death.

As you are to a large extent dependent on their good offices for bringing in news, you start off with your small army. All are laughing and talking and brandishing their spears and behaving in the most warlike manner. Some dash up from behind to lead the way, and others beckon you on, as you slowly plod through the thick undergrowth. At one moment you are surrounded on all sides by this bodyguard, safely protected in their midst, then there is a crashing of branches ahead and in a second there is not a native in sight. Not only are you quite alone, but to your bewilderment there is not even the sign of a flying figure anywhere. Not quite alone after all, though, for close behind you is your cook, who has accompanied you without orders, carrying your spare rifle, and, although he does not know how to fire it, he appears quite prepared to face any emergency.

However, it proves to be only a false alarm, and, after a short pause, the small army begins to reappear. Some lead the way again, and others beckon you forward. All are in high spirits and in no way ashamed of themselves or the worse for their sudden panic. The cook makes a few caustic remarks about the natives of these parts and comments on the superiority of his own tribe. They listen to these remarks with laughing good humour, and reply that they were "only frightened," an explanation which appears to them to be entirely satisfactory. When, however, you send eight of the young braves home they appear to be greatly hurt and grumble loudly. You then continue on your way with the other two, thinking how fearless you would feel if you knew that you were able to make yourself scarce even half as smartly as did they.

The black man does sometimes manage to kill dangerous animals in ways that astonish the European, but these cases are exceptional. The general methods employed are the use of such devices as poisoned drop spears, pitfalls, and shooting with poisoned arrows from safe positions up trees. Hunting in this way entails a great deal of patience, but little danger to the nimble savage.

To return to the rifle; the accuracy of the rifle puts a great advantage into the hands of the hunter, for he must, at close quarters, hit a dangerous animal through either brain or heart to account for it immediately. If he is using a small bore, even the heart-shot is not quite a certainty, as many an animal has lived with a shot through its heart long enough to severely damage or kill the man who fired it. A shot through most other parts of the body will only tend to make an animal more savage.

It may be as well to state that the range of a rifle has, as a rule, nothing to do 
with the safety of the hunter. A rifle may have a range of two thousand yards, but if you cannot see your game till you get within fifty yards this does not much help you.

Elephant are shot at from thirty to fifty yards, and in the thick grass and bush which they inhabit often cannot be seen farther than twenty yards. Rhino, in bush country, are generally shot at about the same range. Lion and buffalo, when they are wounded, and that is when they are most dangerous, are, as a rule, shot at twenty to thirty yards or under. I have only twice in my life shot leopard. On the first occasion I was firing through a zareba, and my rifle touched the animal; on the second occasion the animal was concealed in a small thorn bush, and 1 had to approach, with a single loading 303 , to within two yards before 1 could get a clear shot.

The mechanism of a magazine or double ejector is also tremendously in favour of the hunter; but if anything goes wrong at a critical moment, such as a jam or missfire, he will discover how entirely nature has failed to equip him with any natural means of defence. He cannot bite or scratch or sting or even run allay. He may have fancied himself as a runner with spiked shoes on a track, but in the bush it is all he can do to make his way through the thick and tangled undergrowth at a snail's pace.

In the old days the approaching of dangerous game with a muzzle-loader or single-loader must have been very much more dangerous work than is the presentday approaching with a rifle. However, I take it that the countries hunted over in those tines were far more open and favourable, as a rule, than the present huntinggrounds of Africa. Although there were patches of thick bush and grass, even these probably gave better "going" than the thick, matted and tangled country, with the rank and tropical growth of the present-day hunting-grounds. For instance, I have very seldom indeed seen elephants in a country in which it would be possible to follow them on horseback even for a short distance. I take it that in the very early days the hunting of elephant in South Africa was more akin to the present shooting of rhino on the East African plains, and quite unlike the following up of elephant in thick bamboo or tangled grass, where it is difficult to proceed on foot, and which has to be resorted to to-day. As years went by the elephant were pushed back into the more tropical and more thickly overgrown countries.

Lions may sonetimes be shot at long ranges on the East African plains, but at these distances it is generally difficult to do more than wound an animal. The wounded animal has either then to be followed up into such cover as he selects and there shot at close quarters-or left alone. 
The dangerous grame of Africa are: Lion, elephant, rlino, leopard, and buffalo. Hunting-dog and cheetah are by many included as dangerous game. These are undoubtedly very formidable animals, and the behaviour of the former, at any rate when encountered, is calculated to impress one with the idea that they needed but little provocation to induce them to attack human beings. However, in spite of their aggressive demeanour and the slowness with which they retire, it appears that they do not care about attacking mankind. In fact, I have been unable to hear of an authenticated instance of their ever having done so. The muchdespised hyæna is responsible for more damage to mankind than either hunting-dog or cheetah, for he will occasionally attack a sleeping manl.

Some people also include hippo and crocodile in the list of dangerous creatures. The former of these is generally harmless enough, though he may occasionally upset a canoe, sometimes in anger and sometimes as a joke. The latter reptile is only dangerous as a snake might be, that is to say, if you walk in the grass with bare feet you may tread on a snake, and if you bathe in a deep pool or fall overboard you may be taken by a crocodile. The shooting of neither hippo nor crocodile is attended by much danger.**

As to the really dangerous game, no hunter who has shot much will deny that there is considerable risk in hunting them. It would be difficult to find anyone who has hunted most of his life in Africa who had not at some time been damaged by some animal, besides having had many close shaves. It is, of course, quite possible for a man to have shot several dangerous animals and never to have been in much danger. He might be a very careful hunter and have let several chances go by, as safer left alone. A man who has seen a large troop of lions and thought it best not to fire may decry the hazards run by a brother sportsman, but he will never be able to convince himself that there is no real danger in shooting these animals. A "narrow escape" is an unmeasurable quantity. It assumes large or small proportions according to temperament. A most harmless event may, to some, assume the proportions of a very near thing, whilst others do not realise the danger run. Very few men can assess a "narrow escape" at its true value; moreover, it is a very difficult thing to judge what an animal's conduct rould have been if circumstances had been slightly otherwise, and speculations are no use in determining the relative amount of danger risked from each kind of animal. It is the long list of killed and wounded which proves the dangerous qualities of

* Since writing this a hippo in the Nile, unprovoked by me, lifted a large canoe that 1 was in, almost bodily out of the water, and a day or two later another seized a native close to my camp and nearly severed his arm with two enormous gashes. 



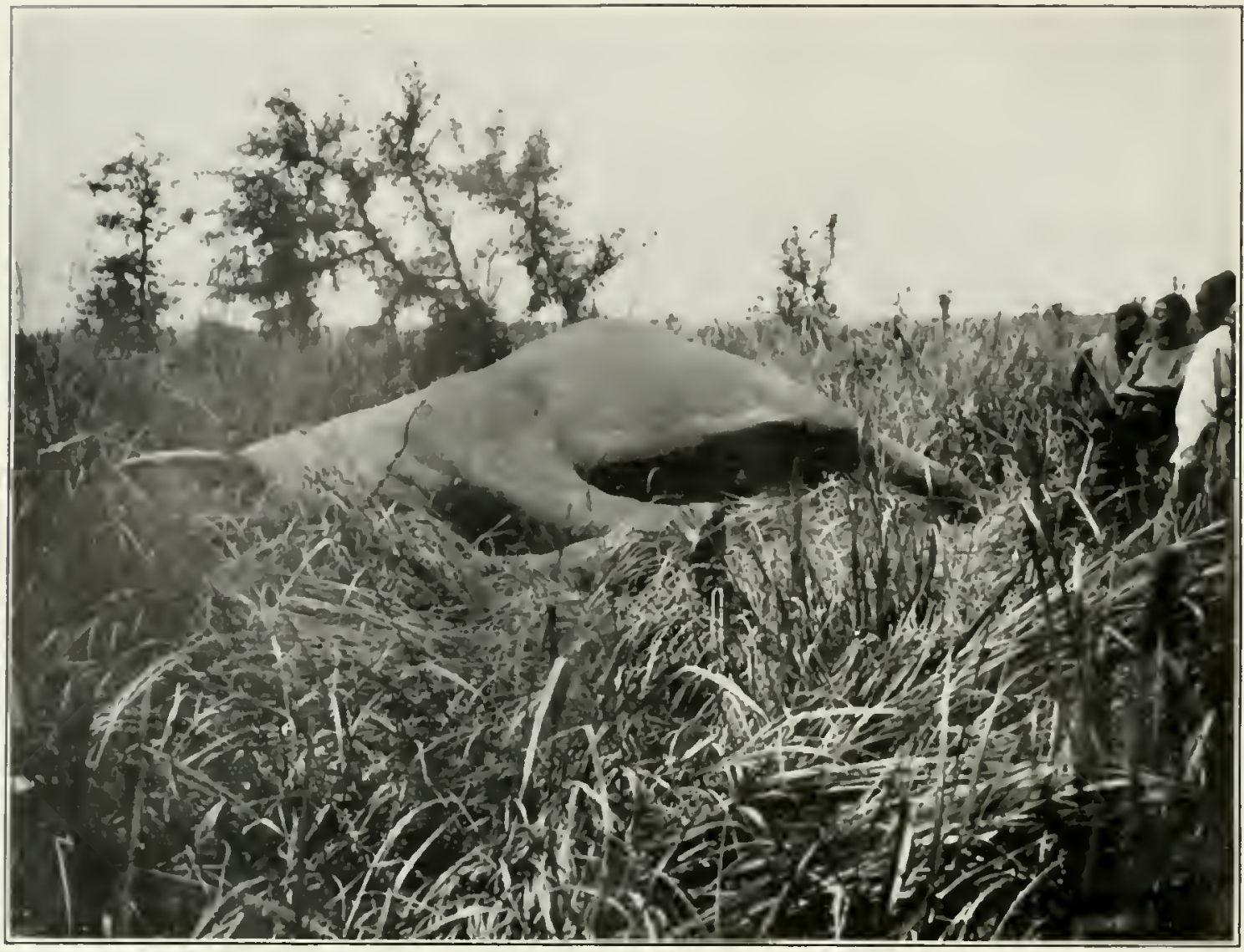

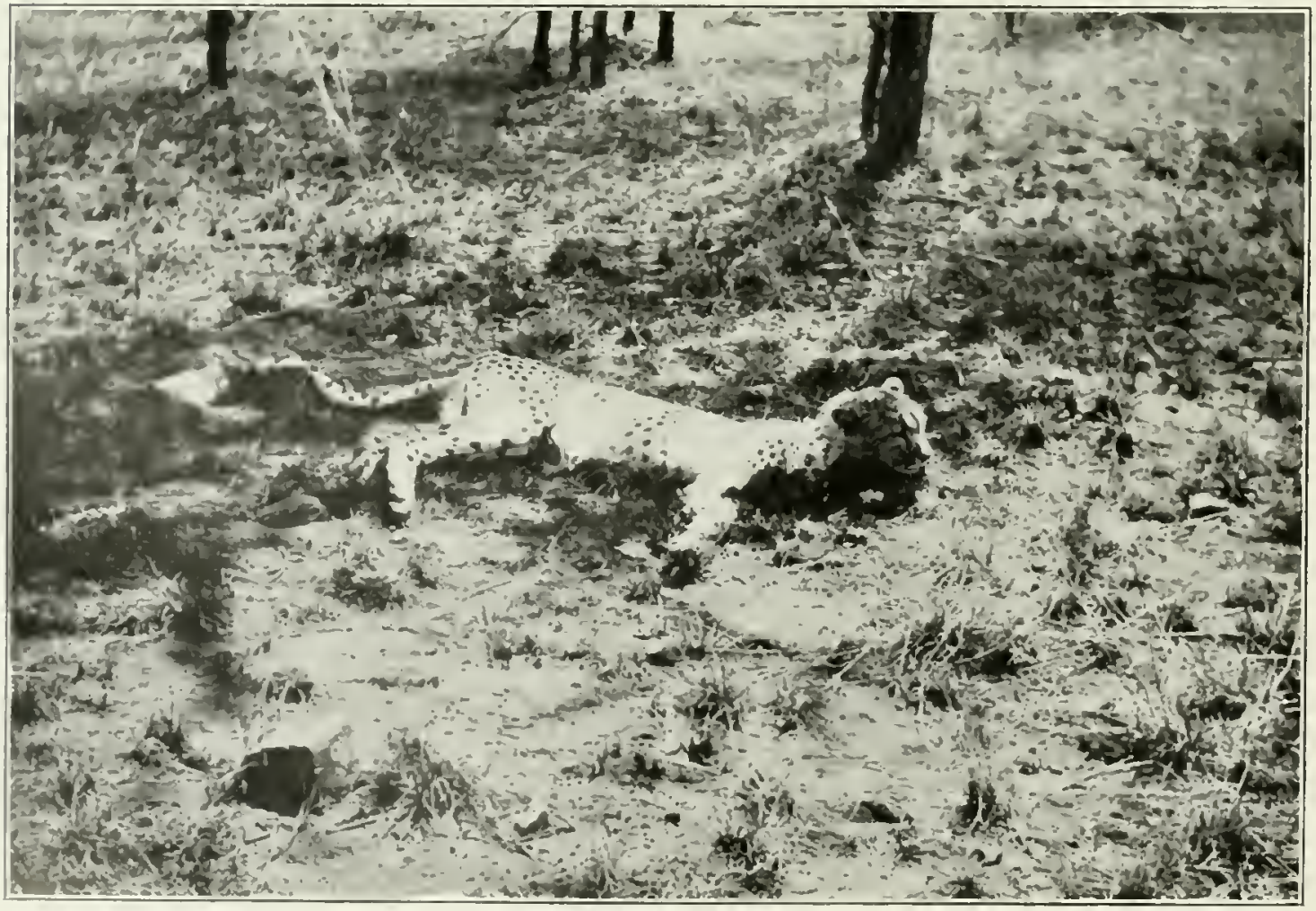


these animals, and it is by this that the relatively dangerous qualities of the various kinds should be compared.

A medical man in this country tells me that he has himself attended fourteen cases of Europeans mauled by lions.

The element of danger in the shooting of dangerous game can be increased or ininimised to some extent according to taste, but the risk run in shooting elephants it is difficult to reduce, for it is present every time one pulls the trigger and increases according to the numbers of the herd and the absence of any big trees. For the instant the shot is fired the herd stampedes, and, although an experienced hunter may forctell the direction they will be most likely to go in, no man can be quite certain on the point.

Although in cach individual case the risk is but small, the sum total of all these little risks assume fair proportions.

The shooting, then, of any of the dangerous game-lion, elephant, rhino, leopard, and buffalo-should rank high in the category of sport.

I have arranged these animals purposely in the order in which I believe that they are most dangerous, taking as the basis of comparison the instances of death and maulings by these animals that have come under my personal notice.

The reason why so very few cases of buffalo maulings have occurred in recent years is due to the fact that for some time past the animal has been either considered as royal game or has required a special licence for his shooting in most of the British protectorates and colonies. Now that he may be shot on the ordinary licence in East Africa and Uganda, doubtless more cases will occur and soon, perhaps, he will be able to rank higher in the scale. Mr. Selous ranks him much higher on the list of dangerous game. He uses the instances that have come under his observation as a basis of comparison. His long experience of game extended over a period when buffalo were, perhaps, the most numerous of any game animals. Since then things have, unfortunately, altered considerably, as now the buffalo is nowhere very common, and in most places rare. It is easy to understand how in those days he must have appeared very prominently in the light of a dangerous customer. The sportsman runs less danger from him now because, though his character is probably much the same, he is but seldom encountered.

Although the leopard is, probably, exceedingly dangerous to tackle face to face, he is so seldom encountered that accidents are few and far between.

In addition to the sporting clement in hunting dangerous game, there is the consideration that none of the animals on the list, with the exception of the rhino, is easy to obtain. The latter, because of his shortness of sight and, in this country, his 
love for the plains, is fairly easy to shoot. The elephant requires hard work and, where there is much spoor about, considerable nicety of tracking to bring him to bag. He is nearly" always found in very thick country where the winds are treacherous, and he travels immense distances by night. The remaining three on the list rank amongst the most alert and cunning of game. So of these five, four may be considered as belonging more especially to the province of the hunter, whilst the fifth, the rhino, is generally for the mere shooter's bag, but when found in bush country becomes a dangerous customer, and so may equally belong to the province of the bunter. 



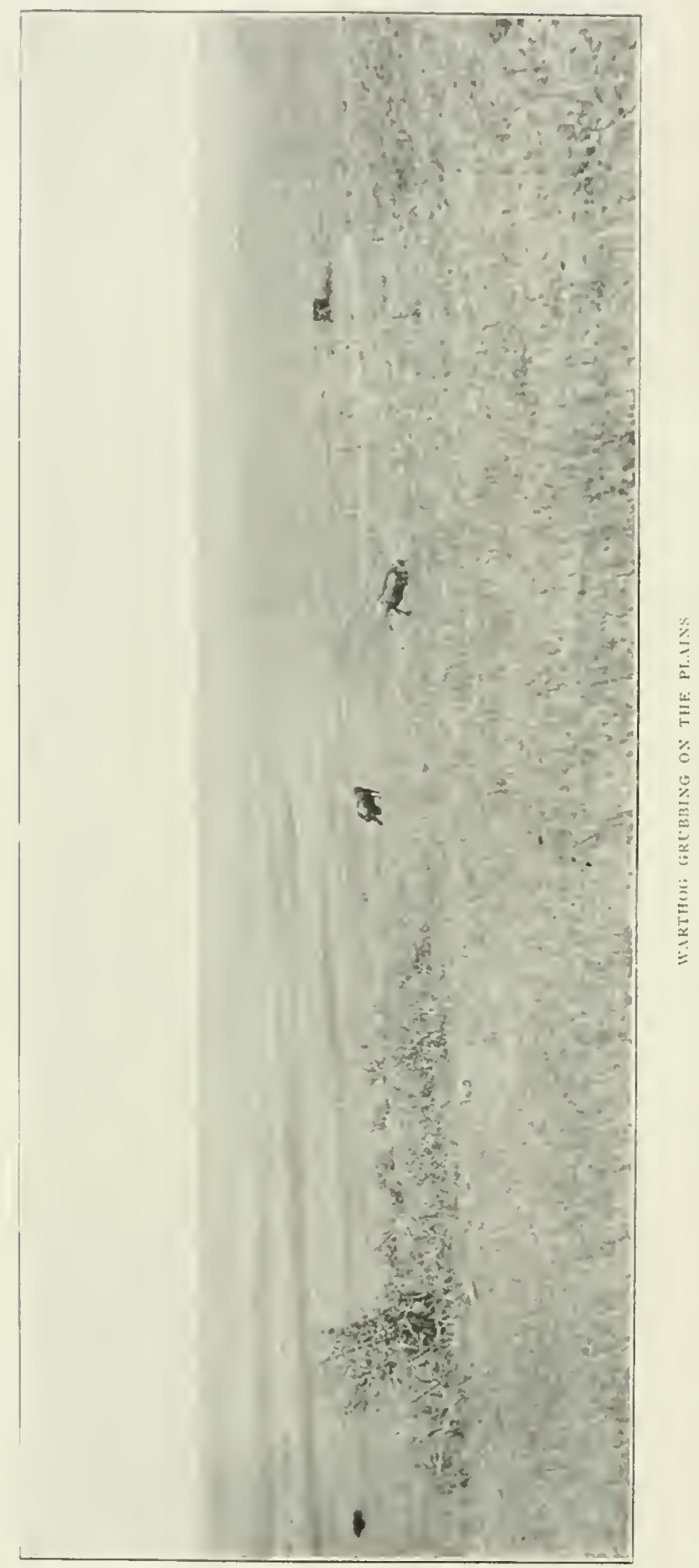




\section{CHAPTER $V$.}

\section{THE PLAINS.}

COMING up from the coast by train one first passes through the coast belt; this, for the first twenty miles or so, consists of cocoanut plantations and other cultivation. Shortly after, one enters on the dry bush country of the Taru Desert, ivith its unpleasant red dust-cloud that envelops the train. This thick and thorny country is passed through for most of the night's journey. As dawn breaks the scene has changed. As far as the eye can see, on both sides of the line, the great plains there reach and roll away, broken only by a few rocky hills and a few solitary and weather-beaten trees. The hills are more numerous at first, but grow less in number as the expanses of the Kapiti and Athi plains are reached. It is impossible to convey a correct idea of the seeming vastness of these great plains. The impression gained when standing on one of the little stony hills is that of being on some small island in the midst of a great sea of stationary billows stretching away in every direction. On the left of the line, going up country, is the game reserve, gently undulating to the German boundary. On the right the plains roll away to the foot of the Ukamba-land and Ol Doinyo Sapuk hills. Beyond these the country begins to get covered more and more with little thorn bushes, till it gires place to bush country. Game is seen in the foreground crawling about over the plains like little ants; beyond, the landscape becomes more and more blurred, till it finally merges into the haze.

I will now try to give a little sketch of how life on the plains must appear to the creatures that live there. Man, and especially the white man, is an animal not in touch with the rest; he is an outsider, and so cannot, except surreptitiously; see life on the plain as it really is. The scent or sight of him gires uneasiness to all the denizens of the plains. So we will try to watch the life on the plains for twenty-four hours, let us say in the guise of a zebra.

Dawn steals over the plains, and gradually objects begin to stand out from the darkness, weird in shape and as yet unrecognisable. All around us is the munch, munch of our busily feeding friends. A little farther off is a different munching sound coming from a herd of kongoni, as yet scarcely recognisable, although they 
cannot be far away, for their scent is strong. A little later, in the half-lights, a ghostly form steals through our midst, presently followed by two more. They neither heed us any more than we do them. They arc "those of the mane" returning home full after their night's kill. They wear a sheepish look and seem to feel uncomfortable in our presence.

Presently the leader of our herd starts walking slowly forwards, grazing herc and there as he goes, whilst we follow spread out at irregular intervals. We are going down to the pools to drink. At the same time we hear the movement of the kongoni travelling in the same direction. Some of the younger ones frisk up from behind, and the sound of their absurd up-and-down canter is unmistakable. Down by the pools are a few clumps of thorn trees and some long grass and reeds, where amid the longer grass of the bottom lie a few bleached skulls. By the smell around here we know that the three ghostly forms we saw, stopped to drink, but they have now moved on, probably going to the thick reed-bed a few hollows farther down. All round the pools is earth and mud deeply trodden in by other game. There is a great black object in the long grass making a lot of puffing and noise over his drink. He does not see us till we are close by, and we respectfully wait till he has finished. Down the opposite bank are coming a herd of graceful Grant's gazelle, and from far away behind comes the sound of roaring from a rocky nullah near the hills, that is another party of lions either settling down there for the day or pretending to settle down before going elsewhere to lie up.

Suddenly there is a sharp, spitting, cough-like sound from up the bank. All the kongoni look up and see one of their party above gazing intently at something. Some of the others slowly make their way up the bank and stare in the same direction, while all the game about waits on the alert. Even the old rhino cocks up his ears. After a long stare they all come down again. It is a false alarm, just like those kongoni to disturb everybody at their drink, but we will score off them later.

We have our drink and ascend the opposite bank, where are a couple of Thomson's gazelle, male and female, tearing round and round in circles. The kongoni are still at the pools.

It is now light, but the morning mists are hanging round the hollows. A couple of dark objects are crawling over the plain. They stand silhouetted for a moment against the sky-line before dropping over the edge. From their shape and sloping quarters and the even way they move it is easy, even at this distance, to recognise them as a couple of hyænas, belated scavengers of the plains. Presently a few more of these forms appear from different quarters and drop over into the same rocky gorge. For that is hyæna valley, a steep, rocky nullah, full of scrub, and the whole 


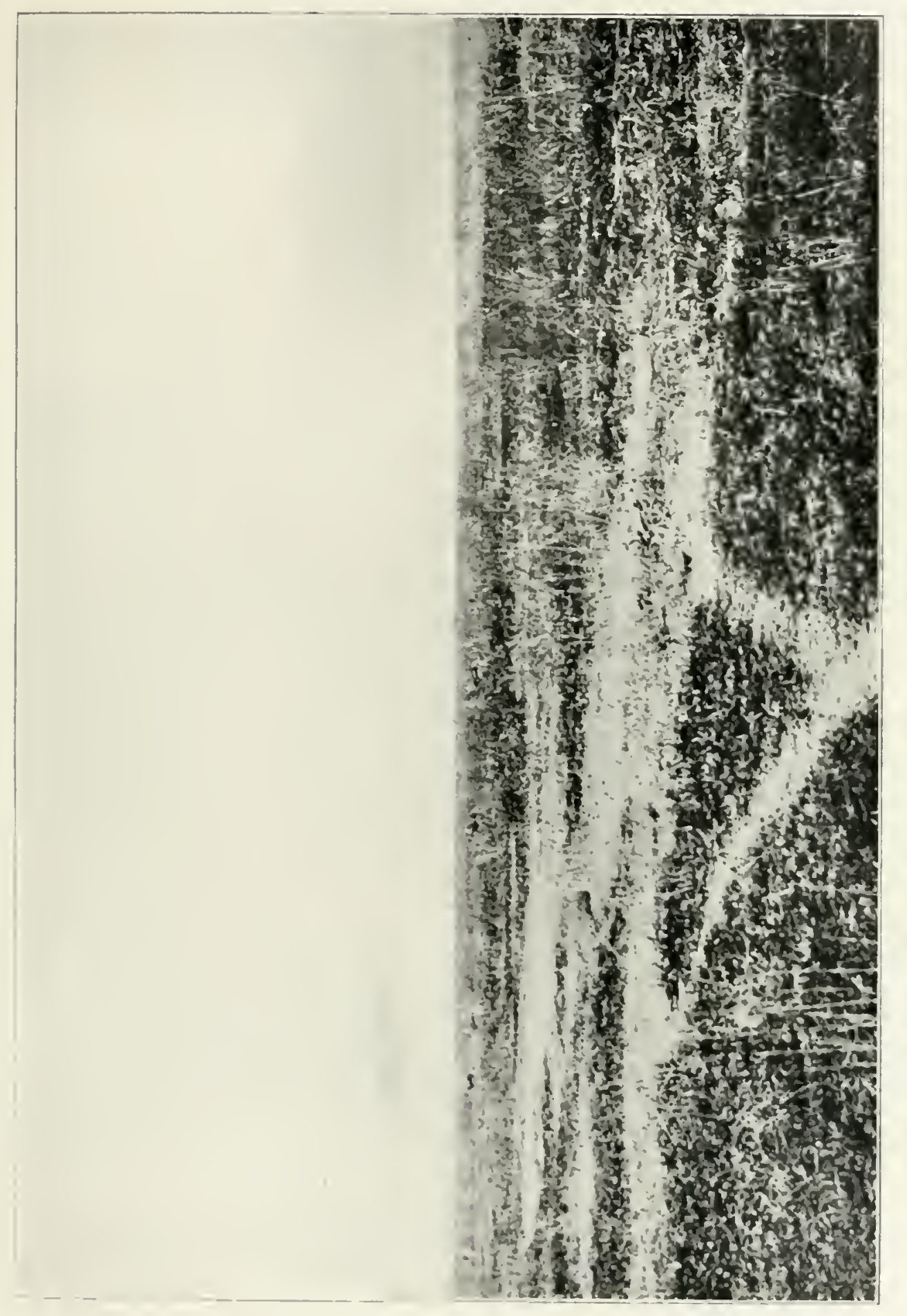






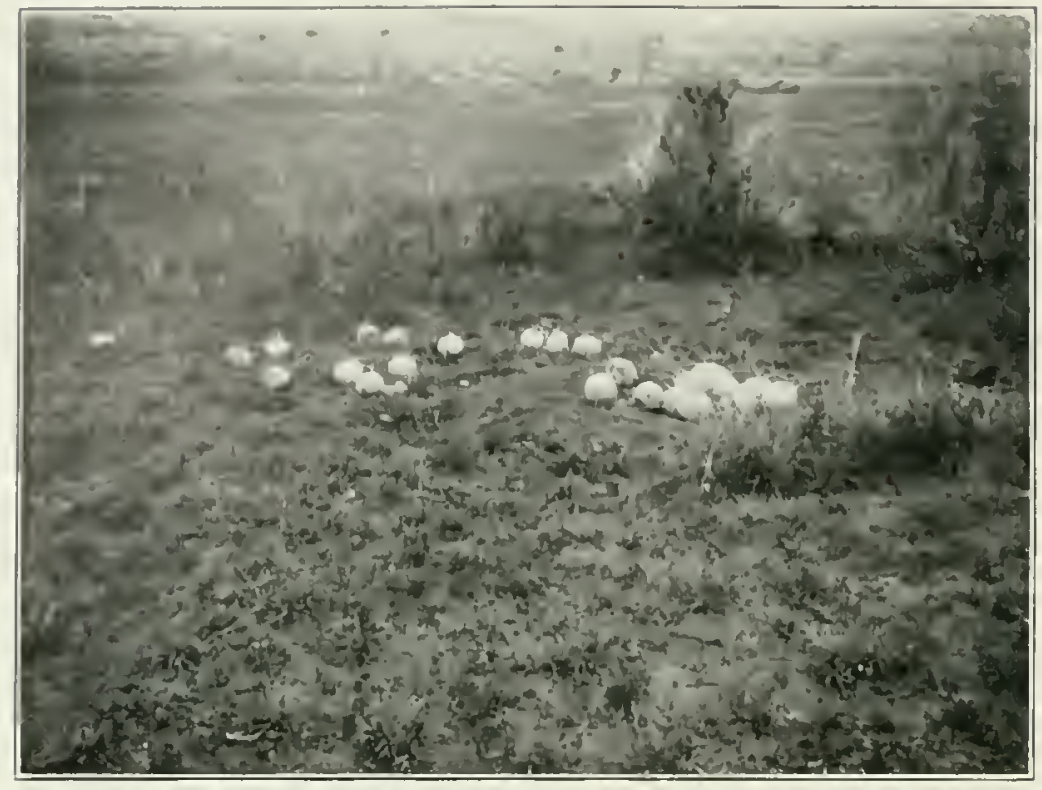

us lRICH NET

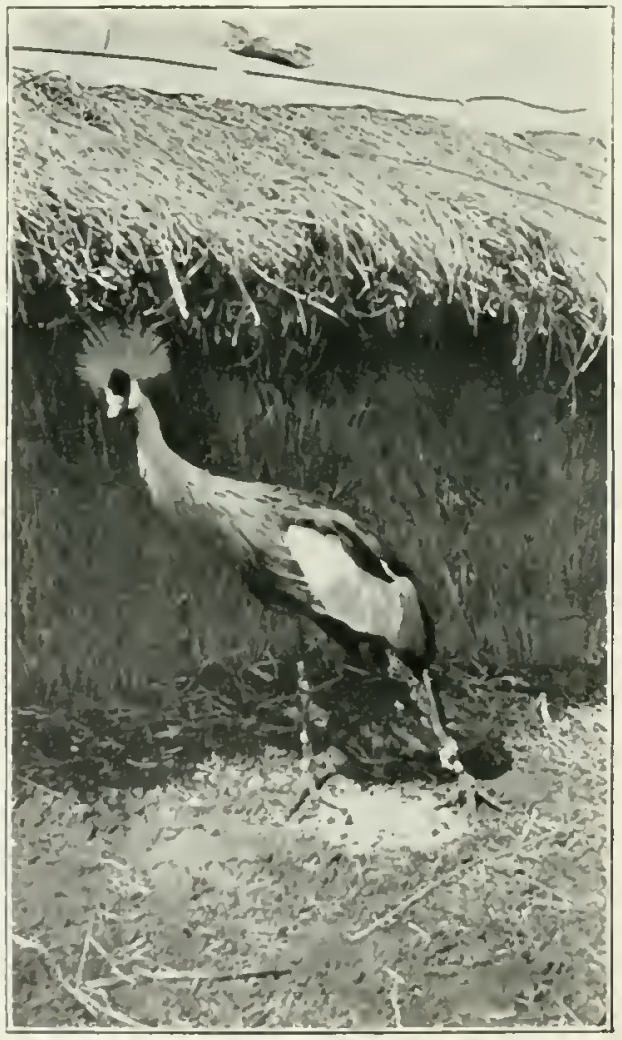

KAVIRONDO CRINE, BY G. R, STONE. 
place recks with their fetid odour. Under an overhanging rock, with its mouth blocked by thick undergrowth, is a cave. A few bits of gnawed bone and a kongoni's horns lie at its entrance. This serves as a retreat for any wounded or hunted hyæna but the greater number lie about the scrub and in other recesses in the valley.

Suddenly we all gallop off furiously for a few hundred paces and then stop again. The kongoni come pelting up from the pools and gallop off in their ungainly manner, scared to death, while we stop to laugh at them. They do not know what they are running from nor where they are running to; so after going for about half a mile they stop and look round to see what it was. There we leave them staring with their long silly faces, never realising that they have been badly scored off. We make our way over the rise and meet a solitary gnu standing on the next slope. This means that the herd is probably in the next bottom, and as we do not wish to interfere with their grazing rights we turn off and slowly wend our way to another dip. On the way we pass a cock ostrich grazing alone. In the distance is a thing like a stick standing up behind an ant-hill. This is the neck of the hen that is sitting.

A little farther on is a long, winding, broken line of tree-tops; these are thorn trees marking the course of the river in the dip below. We make our way to the banks of the stream, and there on the opposite bank we see a group of three female waterbuck, and a little apart is a male. The sides of the valley shelve steeply down, leaving a broad, flat expanse at the bottom of the valley. Just at the bottom of these walls a family party of mountain reedbuck are grazing. From among the thorn trees comes the soft cooing of the "dwellers at the wells."

Above this valley we start feeding, and graze away from the river, while the sun climbs up and dispels the last of the mist from the river-bed. Every here and there are flat, round, bare spaces; these were formerly termite hills, which now have been licked flat by the hartebeest and other game for the sake of the salt they contain.

As the sun climbs up the lieat haze begins to shimmer all over the plains, distorting objects at a distance and making bushes appear like game walking. As the heat of the sun increases, the game in all directions, we can see, are beginning to lie down; our friends the kongoni are all resting on the next rise, a few of them standing up as sentinels. The solitary gnu, outlined against the sky-line, still marks the near presence of the herd, which is probably resting in some bottom not far distant. The old rhino wanders past; he is making for a tree that stands alone in a sea of grass and gives the only shade obtainable within miles, excepting for that afforded by the small-leafed 
thorn of the river. Since his morning drink he has betaken himself to his mud bath and managed to smear himself all over with red earth. He now lies down to sleep, looking like an ant-hill, in the shade of the lone tree, twitching his cars irritably when the twitterings and attentions of a host of rhino-birds disturb his slumbers. Some of these tick-birds occasionally fly off for a while and return later. We follow the direction of their flight and see then settle on another ant-hill lying in a patch of thick grass some distance away. This is no less a personage than Mrs. Rhino, who wears the breeches in the rhino household. The old man is full of bluster and bluff when he is alone, but very meek and mild when his better half is about. It is perhaps by this wireless telegraphy of tick-birds that communication between them is constantly maintained, for they generally prefer to wander apart.

About noon we stroll down to the river for another drink. There is a herd of impala lying down, making the most of the scanty shelter afforded by the thorn of the river bottom. On a little bank a few feet above the stream a crocodile is lying, looking for all the world like a dead log. On our approach he softly drops into the water so as to try to pretend that he was not there, for he hopes that it is his dinner hour and, if lucky, that he may possibly get some small buck coming down to drink. It is the night time, however, which particularly favours him when lying in wait for prey of this kind. His chief food is fish, meat is only an extra.

Farther down the river we can hear the tired blowing of hippos. The reedbuck arc lying up under the rocks and steep walls of the valley and are difficult to distinguish, as they lie in shadow and pressed close up against the cliff.

As we take our drink the whole herd of gnu come clattering down the steep slope, making a prodigious noise of slipping hoofs and falling stones. They cross the river and ascend the opposite side. It is evident that they have been alarmed by something, so we retreat up the opposite bank and betake ourselves to a distance for our afternoon snooze. A "sounder" of warthog have also been disturbed and they make off in Indian file, the old sow leading and eight or ten young ones following in her wake. Every member of the party has its tail stuck straight up like a flag-pole, with the little tuft of hair at the end streaming out like the flag. As we come up the slope a party of three cheetahs come trotting past with long graceful strides. They, too, have taken the alarm from the gnu and are changing their quarters from the riverbed to some nullah near the hills. We see no cause for alarm, however, and so rest again just over the opposite slope. We do not like the close neighbourhood of the river, as things may stalk along the bottom unperceived. We have not the eyes of the impala which can see such things easily. So we lounge about through the rest of 



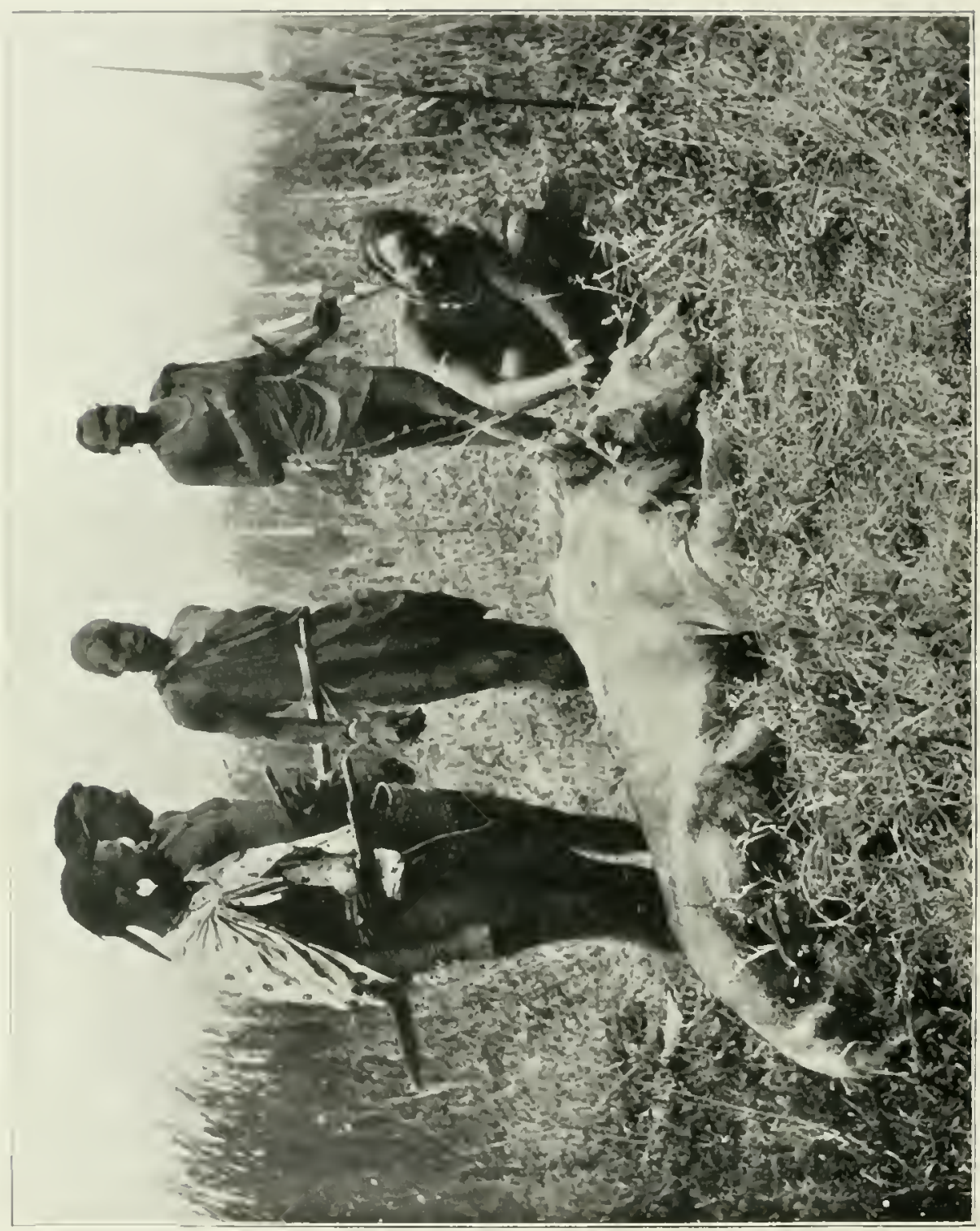


the heat of the day. As the afternoon advances we see a black bulky figure coming towards us. This is an old warthog, his tusks gleaming white as they catch the sun; he comes on slowly. He stops every now and again to go down on his fore knees and plough up the ground with his snout, while he propels himself forward with his hind legs. Presently some of the members of our herd begin to graze away again, and we rise one by one and follow suit, till we are all busy at work once more, our heads all pointing in the same direction. We feed in this way, advancing slowly a step or two at a time, till we cross a little rise and draw near a reed-bed in the next bottom. A female serval cat passes with a ground-rat in her mouth, carrying it carefully home to some young who are probably concealed in the reeds. This is an anxious time for her, and she advances stealthily from bush to bush and by a circuitous route so as not to betray the locality which she has chosen for the concealment of her offspring. As we pass close to the reeds there is suddenly a grunt and a roar. We turn to fly, but not before one of our number has been caught by the nostrils and his head pulled down between his legs. He falls forward on the top of his head, as he is trying to gallop away, and his neck breaks with a scrunching sound. We gallop off a short distance, but, finding that we are not being pursued, we watch for a while and then continue grazing. It is not long before a few kites come circling round, whilst higher up, like specks in the sky, are hovering vultures, but they will have to await till the morrow for their feed. On a small ant-hill are a number of litle figures busily popping in and out of their hole in a great state of excitement. It is a colony of the slender mungoose, that live there. They have killed a snake and are making passage way for the head, which they are carrying into their house to pick at leisurc.

Round the edge of the reed-bed a black object is running forward a few paces at a time and then stopping to look round and then running on again. This is the marsh mungoose out looking for his dimner of crabs. He is out early to-day, for it is seldom that he leaves his retreat till dusk. A large flock of sandgrouse come flying over, on their way back to the stony hills where they spend the night.

And now, as the sun slowly sinks, all things are preparing for the night's doings. The lions grive a few preparatory roars, and the great herds of game pack closer together for the night's grazing. But we feel safe enough to-night, for there is a blind kongoni, whose attempts to run away consist of going round in ever-narrowing circles. If we keep close enough to him we shall be safe enough, for he is cut out for a lion's kill. For this is the law of the plains, there is no place for the weak, the maimed, and the ailing, and they are given to the lion or the hy:ena. Even among some races of human beings their unfortunates 
suffer a similar fate or are left to perish of hunger. In the bush a wounded animal is driven from the herd to die or get well by itself, lest its blood-spoor induce beasts of prey to follow up the herd. On the plains a wounded or maimed beast is the safeguard of the remainder. With human beings there appears to be less excuse for such barbarous treatment of a fellow-creature.

All bird life, too, is preparing to roost; the stately old secretary bird has suddenly given a few gigantic hops along the ground to get up steam, and has sailed off to his night's lodging in a thorn tree. All day he has been leisurely stalking about on the plains as if he had no occupation other than that of being a perfect gentleman. A stork has already taken up a well-balanced position on one leg at the tip-top of a tree in the river-bed. A flock of crested or Kavirondo cranes fly overhead with their plaintive cry of "Come on! Come on!" The partridges are calling from the river-bed, and a party of ducks, with loud splashings and quacks, suddenly rise from the pool in the swamp and fly off in a V-shaped wedge. The guinea-fowl, who have been clank, clanking! in the river-bed, are flying one by one up to their perches and settling themselves for the night with tremendous flappings of wings and jostlings. Long after most of them lave settled down one or two can still be heard moving to different branches, having arrived at the conclusion that their position was not quite comfortable enough or that the company was not quite according to their taste.

As night closes, a great silence comes over the plain, now that all bird life has gone to rest, and there is no longer the hum and droning of insects except for an occasional chirrup of the cricket. During the day these sounds have been so continuous that they have almost passed unnoticed, whilst ever and anon from overhead came the rattling noise made by the lark of the plains, as he soared or descended with quickly shaking wings.

Suddenly there sounds the sharp bwe! bwe! of the jackal answered by another in the distance. Then from afar comes the mournful wail of the hyæna drawing nearer and nearer, as he unerringly makes his way to the scene of the lion's evening kill by the swamp. All is silent again, but as the wind veers round towards us and blows from the swamp, we hear the sharp crack of a crunched bone. Then of a sudden there is the sound of angry snarling and growls, finishing up with a howl. The hyæna has tried to get his portion prematurely and has been nipped or cuffed over the head for his temerity. He will not try to get any more now, but will sulk round, shuffling backwards and forwards in a great state of impatience. He will skulk up and down, every now and again coming up a little closer, but retiring quickly when the lion's eye meets his. If he is kept long waiting his impatience will know no 



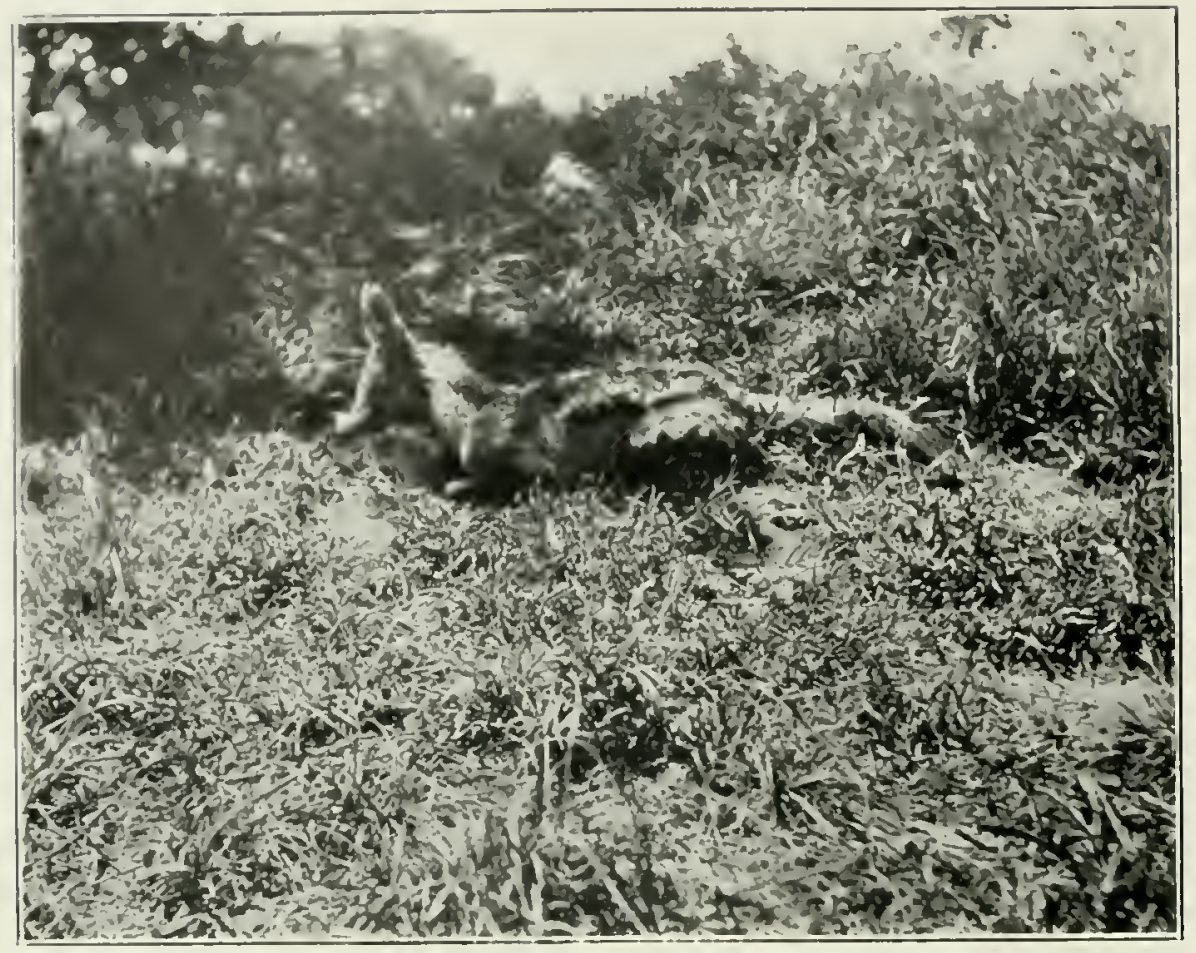

I.lCK.ı, BY G. R. STuNE

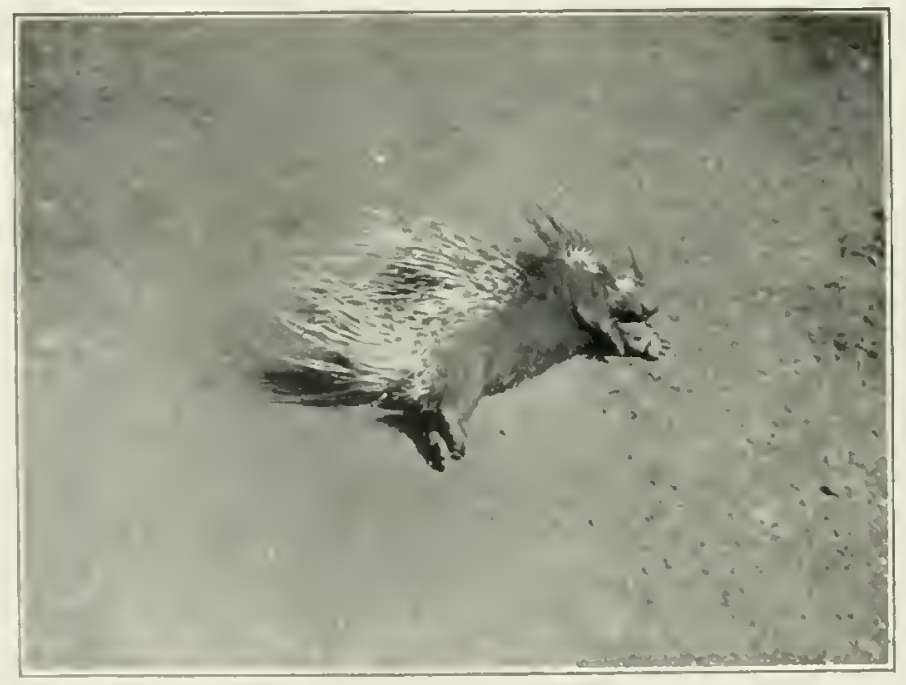

PORO:LPINE. 
bounds, and he will break out into that diabolical laughter so seldom heard in nature. Several jackal, too, must be pacing up and down, or running forward to look at the kill and running back again at intervals. They also will be all impatience. The wind dies down and all is still again; at intervals, however, a freshening of the breeze from some quarter of the plains brings with it some distant bark or howl. These sudden sharp cries and sounds coming over the plains seem to intensify the dead silence between whiles and make it all the more profound. This silence, as if no living thing was moving, is misleading, for now is the time of greatest activity amongst most animals. Many, indeed, whose very existence is hardly realised during the day, now come forth from their retreats. The little antbear is busy running from termite hill to termite hill and burrowing with frenzied energy. The porcupine is trotting up some pathway leading off the plains and into the little red hills, tilled and hoed by the hand of man, that he may pass the night in the cultivations, an unwelcomed visitor. The serval is prowling round on the look-out for rats and mice and patrolling paths and game tracks, as these at night are thoroughfares for many of the smaller mammals. The long-teethed ground-rats and the mole of these parts are busy burrowing and most of the game is grazing. The whistle of the owl can be heard passing overhead, for he, too, is on the look-out for the various mice, rats, and shrews of the plains. The giant-rat has come out from the stream-bed and is ferreting about after dainties. The spotted-necked otter has left the swamp and is wandering down the banks of the stream. It is difficult to recognise some of the more distant sounds coming over the plain. Nearer to the river we hear the occasional grunt of the otter and the louder gruntings of the hippos.

After a chorus of gruntings there is a great splashing, as they wade through the shallower water to reach land. Then a breaking of twigs and rushes, as they push through the undergrowth of the river bank to get to the thick reeds and grass beyond. After this all is quiet in their neighbourhood except for an occasional cracking of twigs, as one of them moves in the undergrowth. If you were nearer you would hear the comfortable sounding scrunch, scrunch of their great jaws. Presently there is a general movement among the game and then a stampede upwind. Blind old kongoni is left behind. As we hear the grunt, grunt of the pursuing lions we trust that they will not fail to see him. Meanwhile the kongoni runs round and round in circles, imagining that he is making tremendous progress. The grunting stops and there is a scuffe, so we know that now we are safe and so settle down to graze and sleep during the rest of the night with light hearts, for now both parties of lions are provided for. So the cold night gradually' passes as we keep packed close together for warmth and protection. About 
(wo or three o'clack in the morning we hear the lions go down to the river-bed for their drink and then come up again. Soon after this we rise to graze again, for we have been lying down for a while close huddled together. Then just before dawn we go off to the salt-lick.

This is a place trampled with the hoofmarks of many kinds of game. It has steep banks undermined and burrowed into by the generations of game that have come there for the salt earth. It is crowded this morning, and animals are busy pawing and digging with hoof and horn to loosen the earth, whilst others just lick up and down a smooth surface of grey earth bank. The place is cut deep with ravines and recesses, all made by animals either wild or domestic, and deepened by the surface drainage of water after heavy rains. By night this spot belongs to the wild animals, but by day the Masai bring their cattle and sheep at regular intervals to lick there.

Leaving the animated scene at the salt-lick we wander down to the pools again, as dawn is slowly redding in the east. The lions are roaring over the plain, as they settle down in their quarters, and day breaks once more, the birds come forth and sing, all is bright again, and the dangers of the chilly night are as things of another world. So the round of twenty-four hours starts once more, always much the same; a little danger, much eating, some sleeping, courting, and drinking, with no cares or troubles or worries. The dangers are the dangers of a moment and quickly forgotten. The joys are the joys of repletion and the delight in living, both fairly continuous. There are the seasons of the green grass and the dead grass, the bush-fires, and the rains. When the bush-fires have burnt much of the grass, grazing must be sought a little farther afield, but the season of the green grass is then near.

The daily round of animals covers, as a rule, but a small area, perhaps only a few square miles, and they may be found in exactly the same place for weeks on end, moving only farther afield for water.

There is a very prevalent idea that these plain-dwellers, where lion are plentiful, lead a miserable, hunted, and harassed existence. Nothing could be farther from the truth. Man is the only animal which hunts and worries them to excess. They seem to be aware that he is their worst eniemy, for they tolerate the lion and let it walk in their midst as one of themselves, whereas even the distant sight of a man makes them feel uneasy. Their apprehensions are well grounded, for man will never rest till he has exterminated then utterly from the face of the plains. The lion may live with them for all time, yet never diminish their numbers. The lion and even primitive man seem unable to upset the balance of 


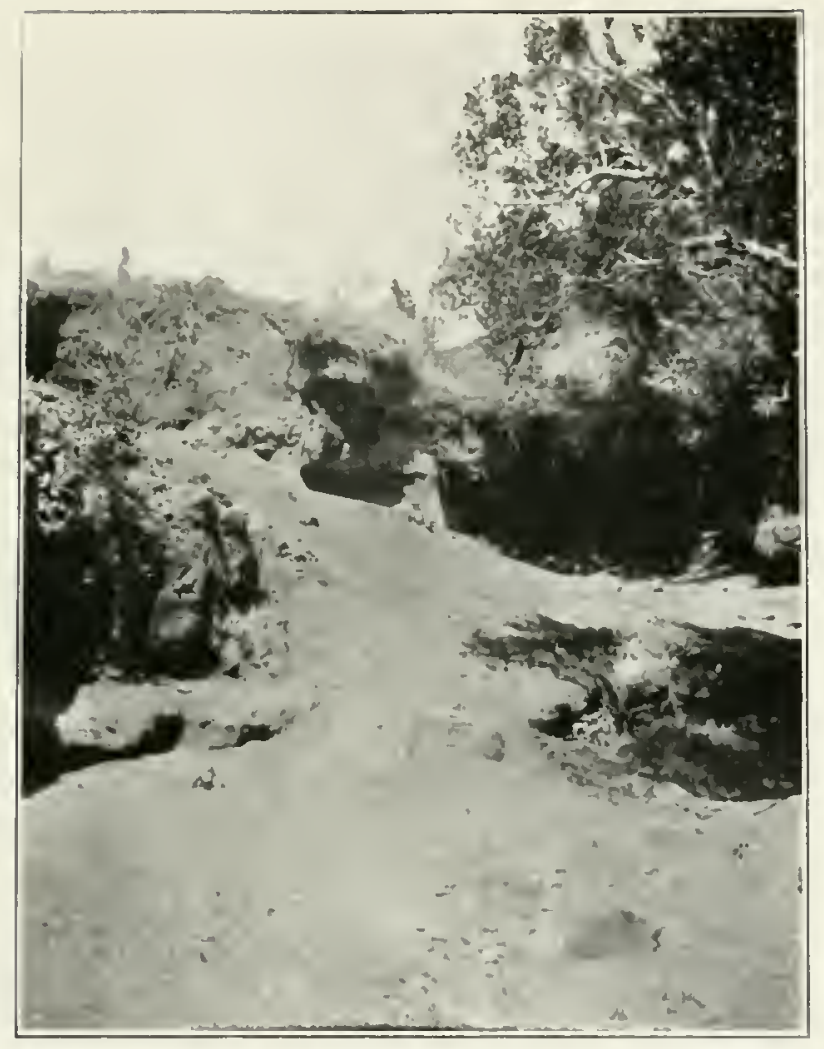

sit $1.16 x$ 

nature; they kill and kill, yet seem unable to kill in excess of nature's powers of reproduction, for the game remains the same in number. It is the rifle in the hands of civilised man or the trained native that so completely upsets the balance of nature.

As to the plain-dwellers, they rank lowest in intelligence of all game animals and lead the most commonplace of existences. They seem to be deroid of the imagination required to be able to dwell upon or brood over the dangers they run. When the danger is actually at hand they are, indeed, frightened enough, but the moment it is over their fright seems to vanish.

The sound of the lion's roaring, one would imagine, must be a terrible enough sound to them, but they generally take not the slightest notice of it. It is to them an oft-heard sound and conveys little to their imaginations. The more wary animals of the bush are apt to be startled at it or, at any rate, to take heed of it, but those of the plains are too stoical and too dull-witted to mind it. Moreover, there appears to be a perfect understanding between the lion and other game. When he is not on the war-path perhaps he can show a "nodanger" signal, for he may pass across a plain closely crowded with game and hardly an animal will take the trouble to so much as raise its head to look at him. At other times they seem to show quite a lively interest in lim, but such interest seems to have little of fear in it.

I have seen game following a lion at quite close quarters, for all the world as if they wanted to make friends or play with him. Perhaps they knew by his look or his last night's doings that he had fed and was no longer dangerous; whatever the reason of it some of them seemed to let him come perilously near.

Again, I have seen a lion pass so close to game that one spring could have landed him on the top of an animal. I could give a number of instances of lions not only passing close to herds of game, but actually passing through their midst and remaining unheeded. Sometimes I have seen one of the herd standing in his path give way a yard or two to let him pass, in just the same manner as one pedestrian makes way for another who is determinedly bearing straight down the middle of a parement.

Perlaps the lion is a chivalrous gentleman and never hunts without first giving warning, or it may be that by the tone of his roaring game are made aware of his intention to hunt or of his having successfully humted. Of course the lion practically never hunts by day, though he will occasionally wait at a water-hole to jump out on anything coming near his retreat. It may be then that game are so confident that they can outdistance him by day, or so sure that he will not 
try to pursue them that they do not mind his presence, whilst at night they only let him come close when they know that he has just fed.

The lion roars for a variety of purposes, as I shall endeavour to show under the heading of "his habits" in Part II., but the meanings of some of his roarings are not clear to me. I have often heard it stated, in excuse for his seeming folly at roaring and thus frightening or warning game of his presence, that he only roars immediately after he has fed. This is by no means the case, for I have repeatedly heard lions roaring at sundown and killing shortly afterwards. However, his loudest and finest roars are generally after feeding, or rather when drinking afterwards. I am unable to conceive what purpose this serves unless it is merely as practice in an accomplishment which serves him well at other times.

Others say that his roaring is a ventriloquial performance to confuse game. I do not believe in this statement either, as I have many times been able to locate lions with comparative ease by their roaring. I have heard lions roaring at sundown and located them with $\mathrm{my}$ glasses at no great distance from great herds of zebra, gnu, and hartcbeest which were grazing peacefully and perfectly unconcernedly. One would think that the game would at least move off to some little distance from the neighbourhood of danger. As to the rentriloquial performance, I certainly believe that they roar to drive game to one another, and that they also roar from one place and then move elsewhere to surprise the game. Roaring is ventriloquial in so far as it always sounds very much closer than it actually is, and may in this way turn game when they are trying to escape, so that they may fall into the clutches of other lions lying silent. This, I take it, is the chief purpose their roaring serves, i.e., the driving of game. Different parties roaring in different directions would also make the game undecided as to which direction to take when pursued, bui of this, more later. What I wish to show now is that the game of the plains are very callous as to the lion's roaring or to any risks they run of being caught by him.

Some of the actions of these plain-dwellers are positively foolhardy. You find in a little dip a row of pools apparently all equally good for drinking purposes. Some have thick grass and reeds near their brinks, and some bare earth or short grass. Round the former lie, perhaps, two or three bleached skulls. At what value is one to estimate the intellectual abilities of a herd of kongoni which innocently strolls downind to one of these reed clumps? If a lion was even to lie perfectly still in the open it is very likely that they would not notice him, but if they approached upwind they could not fail to scent him.

In this matter of scent the plain-dwellers are very lacking when compared 
to the bush-dwellers. The latter can wind human beings and animals at extraordinary distances, often in spite of the intervening bush, which holds the breeze to a certain extent. Inferior as are the buck of the plains in this sense of smell, still they could hardly fail, with a fair breeze, to wind anything over the open plains for a distance of one or two hundred yards, quite sufficient to safeguard them against most carnivora. To make up for this slight inferiority in scent they are gifted with very long sight and great quickness at picking up moving objects. With a stationary object, however, they are less perceptive than the bush-dweller. The difficulty of picking up any object perfectly stationary is well known, especially when this object is in shadow. It is wonderful how near some of the plain animals will approach without seeing you if you remain quite still, even if sitting in the open.

They rely on locating an enemy as a moring object in the distance more than as a stationary object close at hand. Any movement would attract their notice, but once they get close to a stationary object they seem to look everywhere past and beyond it. These grass-feeders of the plains lead too easy and sumptuous an existence, rery unconducive to the development of any great intelligence. As with mankind, the well-fed, fat-liver, who feels neither want nor care, seldom makes his mark in the world. The qualities of a man are called out by want, adversity, and poverty. So it is with animals, the well-fed, easy liver is reduced almost to the level of a domestic animal fattened for the table. He experiences no great joy's or sorrows, and scarcely any divertisements from the usual round of grazing and courting.

The zubra, however, is a little more intelligent than the remainder of the grass-feeders. He is also less callous than the others and occasionally shows a little anxiety for a stricken comrade.

A thing that always strikes one in watching these grass-feeders, is the immense amount of time devoted entirely to eating. An animal that spends twenty hours out of the twenty-four in doing nothing but eat has little leisure or opportunity to do anything else. Beasts of prey are both higher in the scale of intelligence and have more leisure at their disposal, they also often show very real sorrow at the cleath or misfortunc of a comrade. It is this which probably accounts for the fact that so often a lion is not shot singly, but usually two or three are shot together. With game, as a rule, the herd stampedes at the first shot, but with lions, if one member of the troop is bowled over at the first shot, the remainder generally stay with the body for a little while, or at least return to see what is the matter with their stricken fellow. They may also, of course, 
attack the shooter or premeditate doing so and then think better of it. This frequently gives the shooter a chance of bagging a second or even a third animal. However, even if they do not meditate an attack they will almost invariably come back to look at the body of a comrade or wait a little for the dead one to catch them up.

I have felt very brutal after shooting a lion when I have seen the anxious way in which the others came back to look at it and touched it with their paws to induce it to go away. The beasts of prey seem to hold closer family ties than do other game, they are more domesticated in their relations, and show greater solicitude for each other and for their offspring.

The male shows himself more in the light of the pater-familias. The female, as with most animals, has to bear the brunt of the hard work in connection with the young, but the male helps to catch food for them and performs various other little offices. The leader of a herd of buck, on the contrary, hardly seems to recognise the young as his own offspring. His only concern seems to be to drive away other males so as to keep as many females as he can for himself, and to drive the young males out of the herd as soon as they become adult.

No description of the plains would be complete without a mention of the Masai, the human inhabitants of these rolling tracts.

The Masai are a pastoral people who live on the produce of their own flocks and herds. As I hare before mentioned, they do not eat game-meat, and so the game is quite immune from destruction at their hands, herds of which may be seen grazing close alongside of herds of cattle on the plains, while the Masai appear to quite ignore the former's presence. The only animals which concern them much are the lions, on account of these animals' occasional attacks on their cattle. The buffalo also is of interest to them on account of its hide, which hide they prefer to any other for the making of their shields. The tail hairs of the giraffe are occasionally in request for the sewing of the ornamental patterns in kauris (cowries) on their gourds and other belongings.

Every warrior's desire is to obtain a lion's mane for a headdress, and, from the numbers of such headdresses met with, they must kill a very fair number. Nasai warriors are extraordinarily plucky in killing these animals and attacking them with spears. However, they usually go in large parties, but, from the number of men one meets who lave been mauled, it would seem that a lion is not often obtained before it has damaged some member of the party. Such wounds seem to heal up quickly, and these people do not appear to suffer from blood-poisoning or gangrene, as happens with Europeans. 
When a lion is heard roaring near a kraal at night a party of warriors will often go out and drive it away. The Masai probably regard the loss of a cow as something more serious than a warrior being wounded or damaged.

From their absolute indifference to game the Masai are the most admirable people it would be possible to have in a game reserve. Moreover, they can live in absolute harmony with the game, for both they and the game are dependent for their well-being on the grazing grounds remaining intact. They leave the country just as they find it save for a few cattle tracks and the grazing down of the grass. An agricultural people, on the other hand, with their cutting down of bush and forests and clearing and hoeing everywhere, make it impossible for any game to live, and only nocturnal animals like the bushpig and the porcupine thrive, which feed by night on the stolen products of the fields. The Masai, from their unsuitability to live side by side with Europeans, have been the cause of one of the greatest problems it has been the lot of the administration to have to deal with. They cannot be weaned from their pastoral life, and, indeed, could they be, it would be the death-blow to the organisation and independence of what is undoubtedly a fine people. They are inclined to be somewhat truculent, and they are inveterate cattle-thieves, but they have always played the game in their relations with us. From the time we first came into their country they have been our allies and never our enemies, although now and again some of their young bloods have given a little trouble. They have helped us in all our small expeditions against other tribes, and this has been in a measure an outlet for the martial feeling which is developed by their system.

Their organisation, for a savage people, is exceedingly good, and the allegiance of all the different clans and tribes to their paramount chicf, the Lunana, is unquestioned.

Secing how well they have behaved to us in the old days when East Africa was but a caravan route to L'ganda, and when they might have with impunity made themselves exceedingly objectionable to us, they deserve well at our hands. That they should be weaned from their pastoral life, as some suggest, and that their organisation should be broken up, thus reducing them to the level of the timorous non-militant tribus, is hardly a fitting reward. Suggestions such as these probably cmanate from white men who eny their grazing-grounds and wealth of stock.

Sir Donald Stewart's arrangement that certain areas, called "Masai Ruserves," should be absolutely and entirely devoted to the Masai, wis a very happy, and really the only fair, sulution to what was called the "Masai problem." In these 
reserves they can graze their cattle and wander at liberty, but outside they have no rights, and inside no white man or mative of another tribe has the right to settle or graze cattle. When the Masai agreed to remove themselves, so as not to clash with white settlers, from certain lands of which they were then in possession, these reserves were given to them and their clescendants for all time. This was in recognition of the ready way they agreed to remove themselves from certain lands which were required by settlers. That these Masai reserves also form admirable game reserves is another very happy state of affairs. They are almost identical with the northern and southern game reserves, and these two reserves between them contain representatives of a greater proportion of the species of game to be found in British East Africa.

Presumably the game and their descendants may, like the Masai, remain there for all time, and, unless the Masai change their habits very considerably, the game is safe from interference at their hands, besides which there can be no valid excuse for restricting or abolishing these reserves on the plea that the land is required for other purposes.

It is easy to foresee that at some future date attacks will be made on the Government or other responsible bodies with a view to the abolishment of any game reserve not so indisputably bound up, on the grounds that the land is required for settlers. It will be argued that game is being preserved at the expense of would-be settlers out of work, or that white men are being starved for the sake of the preservation of game. The agreement giving preserves to the Masai precludes any chance of these lands ever being settled over and denuded of game, for before such could take place it would be necessary to seriously break faith with these people.

The southern game reserve practically coincides with the southern Masai reserve, but only a small part of the northern game reserve is Masai reserve, the rest of it being outside the administrated portions of the Protectorate. However, in this portion of the northern game reserve outside the administrated parts of British East Africa live several stockkeeping tribes of very similar habits to the Masai. When these territories are taken over it will be necessary to make reserves for such tribes as the Rendile and Samburu, and there is no reason why these reserves should not likewise be game reserves, and thus ensure from extermination such northern game animals as differ from the southern The Masai, from the manner in which they spread themselves over the country, are met with in localities far apart, and thus give one the impression of their race being numerically stronger than it really is. Almost wherever there are plains, there also may the zarebas 
of the Masai be seen, with their little, long, skin and cow-dung covered huts, or failing any sight of these, then patches of grass of brighter green and a few stones, show where at some time zarebas have existed.

During the rinderpest the Masai were sadly reduced in numbers, many died of starvation on the loss of their cattle, others took refuge with different agricultural tribes, among the members of which occasional Masai types of features can now be traced, and many others joined the ranks of hunting tribes. Before this scourge passed over the country the Masai must have extended very much farther than they do at present. Remnants of old zarebas can be seen to the east of $\mathrm{Ol}$ Doinyo Sapuk and towards the Thika and Tana rivers, and also south of Embo, places in which the Masai have ceased to wander for many years.

As to their mode of living, their stock supplies nearly all their wants save the brass and iron wire used for ornaments, the iron for their spears, and the tobacco-snuff they are addicted to. Their food is the blood and milk of their cattle and oceasionally meat. As the first two items alone form the usual daily diet, there are seldom any arrangements for cooking, in the dark, low-roofed huts. Such fires as they have are merely for warmth at night. Their huts are made of a few gipsy poles, covered with hides and plastered hoth outsicle and in with cattledung. Very snug and warm these are too, of a cold night, for the window is confined to a hole about the size of two fingers' width, and there is but one outer door, which serves for many compartments. The darkness inside is absolute even on the brightest day, and were it not so, the dense smoke would blind the unaccustomed visitor.

When changing their grazing-grounds the loads are carried by the women and donkeys.

The warriors fight with spear, sword, and shield only; but the old men and boys carry bows and arrows. In times of cattle discase or drought they are sometimes driven by hunger to join the ranks of the Ogieg, a hunting tribe.

However, these Ogieg, or Wandorobo as they are generally called, from the Swahili corruption of their Masai name Torobo, usually hunt in the forests, so this does not affect the game of the plains. I am told that a Masai will become an Ogieg, but an Ogieg never a Masai. The two tribes do not marry except as between Ogrieg and naturalised Masai. There is a tradition, howcer, that these hunters originally sprang from the Masaj. Whether or not this is true it would be difficult to say, but they certainly spring from the same source as the Masai, their language being non-Bantu, and bearing many points of resemblance, but of these hunting people more later. 
I will now give a list of the commoner animals of the plains, and I will detail briefly the chief plains of the country and the game found thereon. In enumerating the different species to be met with the list will be treated as of the game likely to be found in each locality. Only such game as are in addition to, or absent from, this list will be remarked on.

\section{LIST OF COMIION ANIMALS OF THE PLAINS.}

$\begin{array}{lll}\text { Rhino. } & \text { Impała. } & \text { Warthog. } \\ \text { Eland. } & \text { Grant's gazelle. } & \text { I.ion. } \\ \text { Gnu. } & \text { Thomson's gazelle. } & \text { Cheetah. } \\ \text { Waterbuck. } & \text { Steinbuck. } & \text { Serval. } \\ \text { Coke's hartebeest. } & \text { Zebra. } & \text { Ostrich. }\end{array}$

The largest and most extensive plains are those generally known as the Athi and Kapiti plains. The south-western portion of these plains is in the southern game reserve. Its boundaries are, roughly, the Uganda Railway to N.E., the E-uaso Ngiro to the N., the German border S.W., and the Tsavo river and bushcountry to the $\mathrm{S}$.

North of the E-uaso Nyiro there is a certain amount of plain, and a big tract of open plain lies to the north-east of the railway line. On it are found all the usual forms of game, though in diminishing numbers as regurds the rarer and more sought-after animals, such as eland and rhino. Rhino are still fairly plentiful near Kiu, in a locality which has been made into a reserve for rhino. There, however, the country is more of a bush type. Rhino may occasionally be seen walking about in the reserve, but to the N.E. of the line, where once they used to be common on the plain, they are now no longer seen, but have been either killed off or driven into the bush-country east and south.

Beyond $\mathrm{Ol}$ Doinyo Sapuk the bush-country commences again, and there are found buffalo just outside the Ukamba province, these animals having been preserved in that province until quite recently. Buffalo are also found in the neighbourhood of Ngong Mountain, but they are generally just inside the reserve. The habitat of these animals is always in bush, so they are out of place under this heading, although they are only just on the edge of the plains.

Giraffe are found to the south of the reserve and also to the north-east of the plains near the lthanga Mountains.

I shall mention game indiscriminately whether they occur in the reserves or out of them.

I am writing of game themselves rather than of the shooting of them, as the reader may prefer to see and photograph them rather than shoot them. 



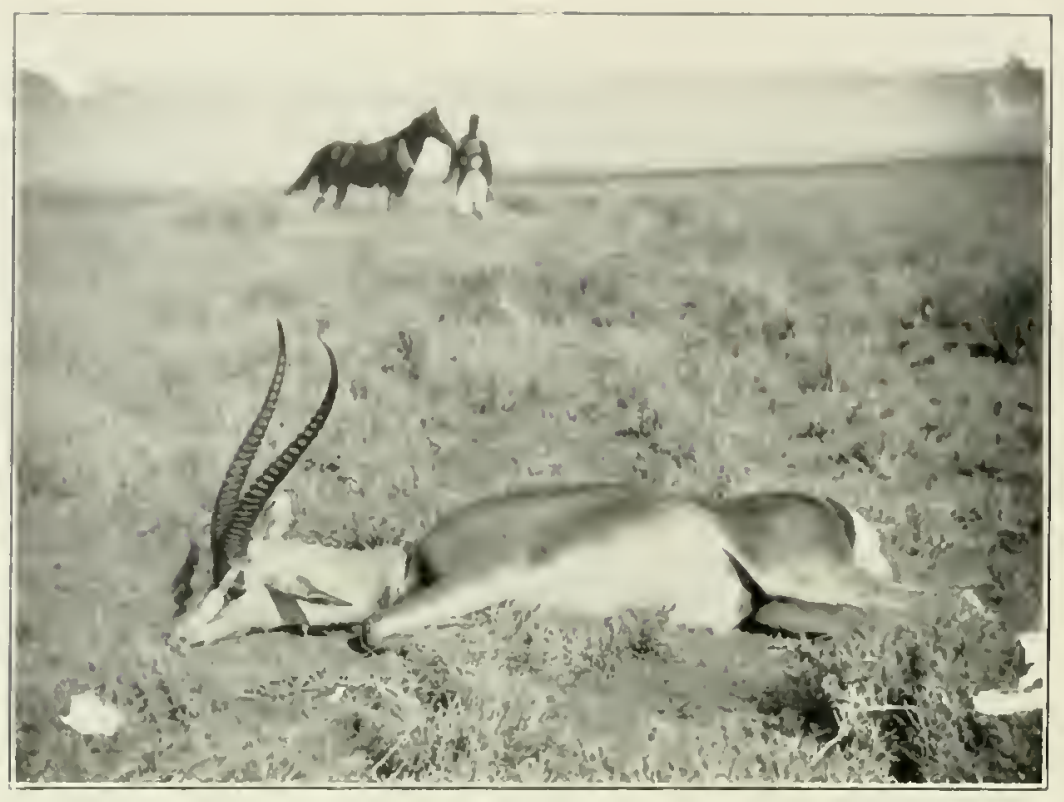

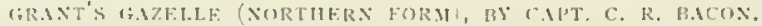

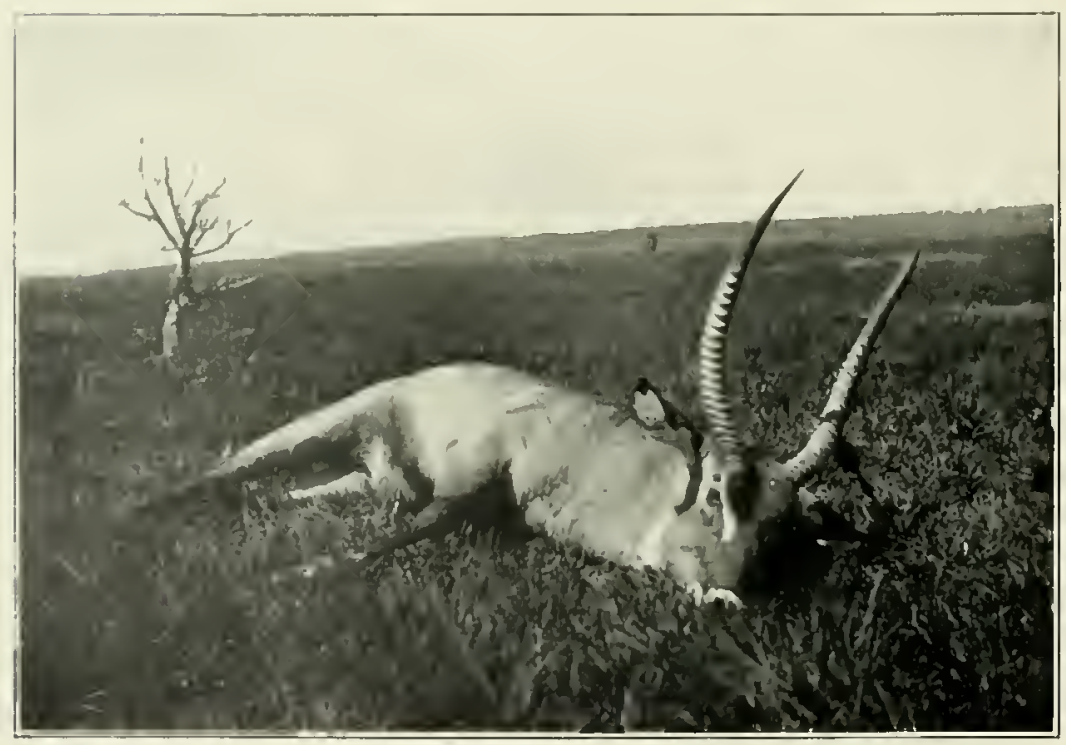

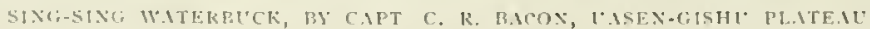
IЗRITISU E.IST IFRIC.. 
North of the reserve are the Lemek Planins, which many sportsmen visit. Here are found giraffe and occasionally elephant. These plains are usually. reached via the Sotik country, and west of them, on the German border, roan are plentiful, and it is not far from that part of the border that the Grant's gazclle, known as Robert Grant's gazelle, is found. These are by some considered as a sub-species of Grant's, and by others, owing to their very small distribution, as the offspring of one deformed horned buck. Near the border and west of the Kisu country are found plentifully roan, topi, and oribi.

Elephants have been shot on the Athi Plains, but I fancy that they must have been on trek from one locality to another.

Oryx callotis are to be seen in the reserve near Simba Station and along the German boundary, where they find their way as far northwards as the Yipi and Nyiri swamps. Roan, besides being plentiful on the German border, are found, in very small numbers, near Machakos, Punda Milia, and near the Chania Falls. Elephants, I am told, used at one time to be plentiful at Ngongo Bagasi, but there is no vestige of them there now. East of Ol Doinyo Sapuk occasional stretehes of plain break the monotony of the bush. Lions and the usual kinds of ordinary game are freely distributed there.

One of these stretches of plain between the Tana, or Sagana, River and the Embei country is called the Mwea Plain. Game is plentiful there, but restricted in variety. There are buffalo and eland in the open bush to the north, and rhino inhabiting these parts are noted for their small horns and their large feet. I have not seen any gnu in the plains east of the Athi River after it has left the Athi Plains and swept round Ol Doinyo Sapuk flowing southwards, nor have 1 seen the gazelles very plentifully scattered. To the west and north-west of Kenya there is an enormous plain including Laikipia and part of the northern reserve. $A s$ it passes northwards it gradually changes its nature to that of a thorn-bush and desert country. In the southern portion of this plain game is confined to zebra, impala, lion, and cheetah. Further northwards more game is found, till the E-uaso Nggiro (not the river of that name before mentioned) is reached. This river is the southern boundary of the northern reserve, and about these parts are found the much-soughtafter ory $x$ beisa and a northern form of Grant's gazelle, with horns straight and near together, and which form a link with the Peter's grazelle. Northwards of this again there is a fall in the country. At this lower level are situated the hot and arid plains of Rudolf. On them the game is almost entircly different to that of the southern plains and consists of ory'x beisa, Grevy's zebra, W'alter's gazelle, lion, and giraffe. 
Eastwards, towards the Lorian swamp, elephants are said to be plentiful. North-east, towards the Boran country, the reticulated or Somaliland giraffe is found.

Between the Aberdare range and the Kikuyu escarpment, to the north of Nairasha, is the Kinangop plateau. This is by no means rich in game, and at some seasons is nearly destitute. However, there can be obtained Neumann's hartebeest in addition to the ordinary Coke's. Elephants are occasionally rash enough to venture into these plains, coming down from the heights of the Aberdares, locally known as the Nguzeru and Simbara Mountains. However, they have been so peppered by sportsmen that I doubt if there is much shootable ivory left.

West of Naivasha are the Ndabibi Plains, which are really only a part of the Rift Valley, the greater part of which is plain country.

From these Ndabibi Plains and Lake Nairasha to the south, to Lake Solai up the Rift Valley to the north, is the habitat of the Neumann's hartebeest. The eastern and western boundaries of its habitat are the Aberdares and the Mau escarpment respectively. All this part of the valley has been taken up by settlers, and so, if this animal is to be preserved from future extermination, it will have to be by private enterprise. This part of the Rift Valley is sometimes full of game except near Lake Naivasha. The north and east sides of this lake seldom seem to have any game. Southwards, in the Kedong Valley, the skulls of many rhino show that once these animals were plentiful there, but now they seldom leave the steep and wooded side of the escarpment.

Still farther southwards where the boundary of the game reserve is reached, game are numerous again and remain so to Lake Magadi and the German boundary. In the Rift Valley to the north the country falls to Baringo, in which district the much-coveted kudu is found, but is preserved in these parts. I have seen this animal as far south as Lake Solai; however, this is a bush animal and never seen in the open plains. Beyond Baringo there is a drop again till the low-lying land is reached with its northern forms of game life.

To the east of Solai, after crossing the northern end of the Aberdares, which in that section are bare hills without the trees and bamboos which cover the range elsewhere, is the Laikipia plateau. This is the northern Masai reserve, and it joins, and is part of, the plains north of the E-uaso $\tilde{N}$ giro before referred to.

West of the Rift Valley is the high plateau of the Ngishu, surrounded and indented by thick and extensive forests. On this plateau, roan and oribi (Abyssinian) are found, in addition to the commoner game, and also the Bohor reedbuck. 
After passing Lake Solai the Jackson's hartebeest has been the only kind of hartebeest found, and from there, westwards, is plentiful both in East Africa and Uganda. The singr-sing waterbuck is also common in these parts and westward.

After crossing the Aberdares, this animal takes the place of the common waterbuck. North of the Ngishu plateau and towards Saragoi (Sirgoi) lions are plentiful, elephants also are found in the bush and forests adjacent. This part has, however, become such a favourite resort for sportsmen during the last few years that the best of the shooting is now over; moreover, great blocks of this plateau are being occupied by Boer settlers. In the lower country to the west are the slightly bush-covered plains of Lake Victoria. Game is plentiful near Muhoroni Station and south of the Nandi Hills. There are found roan, topi, Thomas's cob, and Ward's reedbuck, the last two of these not occurring in any of the ordinary shooting grounds of British East Africa. The country about is more of a bush country:

Striking in from Voi towards Taveta, one comes to the famous Serengeti Plains. On these are found giraffe and Waller's gazelle, in addition to the ordinary plain-dwellers, while in the surrounding bush are found oryx callotis and the lesser kudu. These plains are so dry that to shoot in comfort the sportsman must go during, or just after, the rains. Towards Shimba and Mount Kilibasi there is a certain amount of plain country, but the majority of the animals worth shooting, such as sable, buffalo, and lesser kudu, are found in the bush. On these plains and towards Kilimanjaro is found the little Zanzibar suni or Grave Island gazelle, so called because it was first discovered on Grave Island, off the town of Zanzibar. Haggard's oribi is also found in these parts and about the railway line near Samburu Station.

Following up the Tana River from its mouth a few patches of open country are crossed, and again near the coast in the Tana province. On these topi may be seen, and by going a little way up the Tana that very local animal, Hunter's antelope, may be found.

In Jubaland are many plains and much semi-buslr.plain country. This country is practically untouched by sportsmen, as it requires an escort of several hundred armed men before one is able to move about it in safety.

I have heard much of the Beskaya Plains as a shooting resort, and, according to accounts, oryx, buffalo, lion, Hunter's antelope, siraffe, and elephant are all conmon there.

Where I have mentioned elephant in connection with the plains it does not necessarily follow that these animals may be seen stalking about in the open, 
for they live in thick bush, grass, or forest on the edges of such plains, and, mostly, only at night venture into the open in search of grass.

If the reader has hoped to hear of some new plains as shooting resorts he will be disappointed. It is not possible to overlook such a thing as a large open plain when travelling through the country, and so all the plains at all close to the administrated portions of the Protectorate are well known and much frequented by the numberless sportsmen who visit the country.

Farther afield from these administrated portions are still many haunts of plain-dwelling game as yet little known or scarcely visited. To shoot in these, however, a combination of difficulties has to be overcome, such as providing armed escort, obtaining official sanction to proceed outside the administrated territories, and, lastly, arrangements for food and the finding of water. 


\section{CHAPTER VI.}

\section{STALKING GAIME.}

GALKING game belongs as much to the province of the outdoor naturalist as it $D$ does to that of the lunter. For if he wants to observe game it is necessary for him to approach them elosely, and if he would watch them in their natural state he must also remain unseen. Stalking for a camera shot is a very much more difficult process than stalking for a rifle shot, for with an ordinary hand-camera objects taken at forty yards look small enough and are sometimes quite invisible if they have a dark background, whereas at four and five times that distance an easy shot with a rifle is obtained. The average camera snap produces astonishingly poor results. After infinite patience and trouble let us say, you stalk an animal till at last you are as near as ever the animal is likely to let you get undiscovered. Or it may be that you lay in wait for him till he comes so near to you that you think at every moment he must see you, then in the excitement of the moment you forget to focus correctly, or omit to roll the film, or take two photographs on one plate, or any one of the thousand-and-one mischances that may occur. Finally, when the film is developed you find either a complete blank or else a very bad picture of some tuft of grass which has blocked the camera's eye! At best you get a photograph of a faint and hazy speck of an animal's body seemingly on the horizon, when you had imagined that its bulk would fill the plate. When you ate as close to an animal as it is necessary to get for a fairly successful camera shot, it is practicilly impossible to look to the focussing or through the finder, as at such elose quarters the slightest movement, even that of looking down at the camera, may betray one's presence. The only way is to arrange the probable focus beforehand and to trust to luck for the finding. Good conditions of light and shade, on which a successful picture so much depends, are rarely obtainable. When the sun is out there is a heat haze 10 contend with, and when it is in, the object is in 100 much shadow; but perhaps the greatest obstacte in the way of the photograpler is damp. The camera has often to pass day after day, during the first few hours of the morning, through long, dew-covered grass which soaks it quite as much as a heavy downpour of rain. After this the sun shines on it, which warps it. Then there are the healy thunderstorms which, without any warning, 
catch you on the march or drive rain into your tent whilst you are out, and, moreover, there are swollen rivers to cross and all manner of accidents to guard against. Finally, when the films are safely packed away in the bottom of a box, a porter will, perhaps, put the box down in a puddle while he is resting, turning it upside down or on its side. Then, even if the films are not among the things which actually get wet, the damp atmosphere which results inside the box for the next few days is quite enough to ruin them.

The difficulties of approaching game on the plains may be overcome to some extent by the use of a telephoto lense. This, however, with its expensive and cumbersome gear, is not within the scope of most travellers; moreover, the results they achieve in the field are generally remarkably poor. The photographs require a steadiness of the apparatus which is practically unobtamable in most cases out of doors, for the least tremor of the stand or movement of the animal spoils the picture entircly. I have seen a few very good telephoto results, but the majority of those taken are blurred and hazy and the animals are practically unrecognisable.

For stalking, two important things are requisite, namely, an appreciation of the lie of the country and a comprehension of the possibilities of cover. The plains, seen from a hill, look as bare and flat as a billiard table, but when walked over one realises how one's first impressions of then were very deceptive, for they are really a continuous stretch of folds, valleys, and bluffs, none very deep or high, but which practically never give way to a flat stretch of country. This being so, it is seldom that one is unable to take advantage of these folds of the ground to approach reasonably close to a herd of game before one's stalk begins. It is only a matter of time and patience, if one has enough of those priceless commodities to spare. For when a herd is marked down at a distance the chances are that the animals have also seen you. In such a case they must be given time to settle once more and forget your presence. When you have finished the preliminary approach, and are about to begin to stalk, it is certainly no advantage to have every animal on the plain staring at the place at which you are expected to make your appearance. A bush animal would never be content to see a figure in the distance and then let it pass out of sight in a direction which indicated a nearer approach to itself. It would either ascertain that the figure had passed on, or it would itself move away from the ricinity. Not so an animal of the plains; it stares at a distant object until the thing goes out of sight, and then continues to stare at the place where it was last seen, perhaps for half an hour. If the thing does not reappear during that time the animal assumes that it has gone on, and resumes grazing. 
In stalking, the lie of the land must be appreciated and committed to memory, and the line of the preliminary approach settled on. This must be worked out from a distance, and once it is embarked on should be performed, if possible, without again passing into sight of the game. This appreciation of the country, even to the experienced, is often a very difficult matter.

The folds of the plains are very deceptive, and from a distance it is often impossible to tell if a stretch of ground has a gentle slope upwards or clowwards. Even with a valley or a bottom it is sometimes equally difficult to determine in which direction lies the fall. I have been on the plains with an expert surveyor and sketcher when neither of us were able to tell which was the trend of a valley until we reached its bottom, and cren then it was only by the direction in which the grass was tangled that we were able to make certain. The plains are very like the Sussex or Wiltshire Downs, except that the slopes are much more gentle and the expanses more vast. As to comparative sizes, if one of the Wiltshire or Sussex Downs was set in the midst of the plains it would appear something like an oasis of greener grass.

It is only by actual practice on such plainslands that the requisite knowledge of country may be acquired for this preliminary part of stalking. It is only practice that enables one to realise the degrees of difference in the various slopes of ground and the relative heights and positions of one to the other. It is a very difficult matter to decide what exact objects lie in a direct line between any two distant points, and to gauge what is the probable risibility or invisibility of such objects when observations are made from either point. After laying one's plans, more often than not a valley or sudden sharp descent, impossible to see from one's first position, upsets all the calculations. No matter how good one's knowledge of country may be, it is impossible to base calculations on the things which lie screened behind other things. I might take as an example the hill of Lukenya, on the Athi Plains. As you pass this hill in the train at about Kapati Plains Station, it looks exactly like a round stony kopje rising alone out of the plains. This kopje is in reality the precipitous bluff at the end of a long saddle-backed range of hills stretching back some ten miles where it merges into the hills of Wakamba-land.

The preliminary part of stalking entails a knowledge which can alone be acquired by practice; if, in addition, the country itself is known this gives the stalker a tremendous pull. For then, besides the formation of the hidden parts of the country being includer in his calculations, the probable morements of the game may also be gauged, with possibilities for forestalling them. Sometimes, where the country is very 
farourable, this preliminary part of the stalk may lead within range of the game. Such occasions might be when the game is grazing near a deep-cut watercourse or above the banks of a stream, in which cases the valleys could be followed up to a point opposite the game.

Before doing so it would be necessary to note down and commit very carefully to memory the shapes and appearances of two or more trees, bushes, or other objects near the spot at which the watercourse is to be left. When these points are arrived at the stalker then knows that he is at the spot nearest the game, and so may crawl up the slope.

It is impossible to note too carefully the shapes or peculiarities of any objects chosen, as there will always be found a hundred similar objects when close quarters are reached; or, again, it may prove that some of the objects originally selccted are not visible from the new position.

If only one object has been chosen, and that has not been very carefully viewed from several different positions, then other objects of a similar nature near to it will afterwards be found very misleading. I remember a case in point, when I was sketching and wished to select a position on a hill a few miles off. Amongst all the trees and bushes on the hill was one conspicuous object which, with my naked eye, even at that distance, I could see was a candlearbra euphorbia, so I selected this as a mark, but when I arrived at the hill I was aghast to find that there were candlearbras at every few yards, in fact, that the hill was covered with them. Everywhere 1 went on that hill were lean, gaunt candlearbras standing up. The one that had appeared so conspicuous at a distance had had a white-looking background of open plain, caused by the dried grass. Against this my candlearbra had appeared almost as conspicuous as if it had been on the sky-line, whilst all the others, having had a dark background of thick bush and shade, had been quite invisible at my original range. Fortunately, I had noticed another point about my candlearbra, and that was that there was a little open space on the hill just abore it, and that the bush ran up in a $V$-shape, nearly bisecting this open space. In this tongue of bush stood the euphorbia. Of all the euphorbias on the hill, I found there was no other that grew in a similar position, though some had open spaces near them. So, through noting down in the first instance more points than seemed absolutely necessary, I saved myself from defeat or, at any rate, from a weary tramp back to the original point of observation.

Now to turn to the second part of stalking, the appreciation of cover.

There is perfect cover, such as a rock, tree-trunk, or ant-hill, giving a complete and opaque cover, and there is imperfect cover, such as bushes or grass, which can be 
seen through under favourable circumstances, but at other times appears quite as opaque as the first-named cover.

Of these two kinds, the imperfect cover is by far the more subtle in its uses.

In some sombre, old-fashioned London houses and in many old inns, hotels, and offices there is a device over the lower parts of the windows of the ground floor constructed of horsehair, wickerwork, or other material. This serves to screen the interior of the room from the inquisitive researches of the errand-boy and other gentlemen of leisure. I am not aware of the correct title by which these devices are known, but they must be familiar things to most of my readers.

Their uses are to permit the occupants of rooms to see out of the windows, whilst denying to the passers-by in the streets the privilege of gazing in. Nowadays these devices are largely superseded by muslin curtains and other less-forbidding excluders. I remember as a small boy I used to ponder on the merits of one such marvellous device, and wonder at its ingenuity. I used to try to puzzle out how it came about that from the inside of a certain room the excluder looked transparent, though things seen through it often appeared rather indistinct, while from outside in the street the excluder appeared perfectly opaque. When I went close to the window and looked very closely through this screen, objects no longer appeared indistinct, but quite clear, whereas the farther I went towards the other side of the room the more difficult was it to see things plainly. "Distance," then, made the screen sight-proof, or, at any rate, increased the difficulty of seeing through it. However, there was another point over which my childish mind pondered long. That was, why from the area railings (a distance of but a few yards from the window) should the interior of the room be invisible, when from the back of the room (representing a greater distance from the window) the area railings were quite visible, though somewhat indistinct. This problem afforded reflection for considerable periods during my temporary visits to the house that possessed this wonderful window. The problem was finally solved one night when I happened to be outside in the area when the gas inside the room had been lit, but the shutters had not as yet been closed. To my delight I found that I could see quite clearly into the room. So this, then, was the solution of the second problem-mamely, light-or, as I presently understood, the relative amount of light inside and outside the room. Whoever stood on the lighter side of the window was visible, whereas whoever stood on the darker was invisible. But my readers will be getting bored with the musings of a small child. Suffice it to say that a complete understanding of these two principles, namely, (i.) light and shidow, and (ii.) distance, practically sums up the art of using imperfect cover. 
The more shadow that there is under or behind imperfect cover, the less does it matter how imperfect the cover may be. The nearer that one is to such imperfect cover and the farther away the animal is from it, so much the greater, then, is one's advantage in being abte to see without being seen.

I have seen a man wait till a buck walked behind a bush, and then rush rapidly forward. After arriving at the bush, and pcering round only to find that the animal was not there, but had bolted, he seemed disappointed and to wonder how it had discovered his presence.

The fact was, the stalker had given the buck all the advantages similar to those possessed by the occupant of the room just described, while he had placed hinself in the position of an errand-boy hanging round the area rails.

In short grass country the advantages of imperfect cover between a tall and a rery short subject lie all with the shorter of the two. You may wonder how it is that a leopard or small buck in short grass always sees you first, while you generally only hear it disappearing. Well, in the first place, it can hear you moving, for you cannot pass through the grass without making a rustling sound. Even if the grass is sparse and in clumps, and you can pick your way between them without causing rustling, your footfall must be perceptible to a creature with its ears so close to the ground as are those of the animals referred to. As to the advantages of seeing, that lies with the short animal, as the following diagram will show.

The line of sight gives the line from the man's eye to that of the leopard, and also that of the leopard's eye to that of the man.

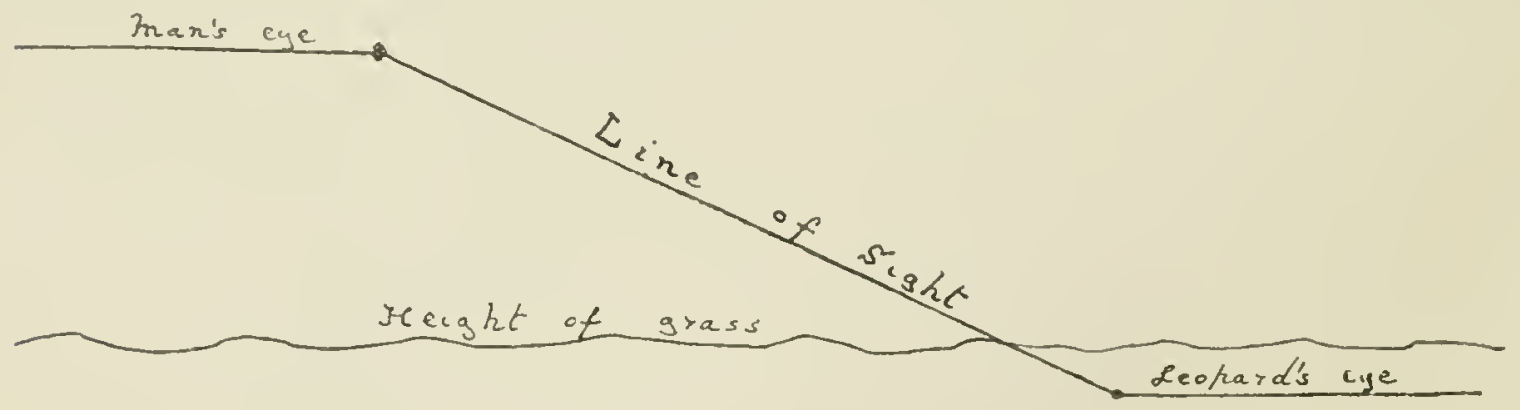

Ground Zone

See where this line cuts the line of the height of the grass, quite close to the leopard, therefore the leopard has the whole benefit of the imperfect cover. He can see through the grass, but cannot be seen through it. That is why imperfect cover is of no use to the stalker when it is quite near the animal and far from himself. 
The point to decide is, how far off must an animal be from a given bush or patch of scrub to be unable to see through it? That is a point which can only be determined by practice in noticing at what distance you yourself can see anything moving on the farther side of different kinds of bush.

Remember always that until you get very good at detecting an object in thick cover an animal, and especially a bush animal, will probably be able to see through imperfect cover at a much greater distance than can you. Remember, also, that an animal's eye, unless it be that of a giraffe or an elephant, is, as a rule, on a lower plane than your own, and therefore looks through the lower branches of a bush.

If it is at a distance of thirty or forty yards from a thick bush, the clances are that it is unable to see through it, but it may see your legs underneath; which latter point people are apt to forget, for it does not follow that because the bush or tree blocks your own view of the animal, that therefore it cannot see some part of your person. If the animal is stationary and you are utilising a bush or other cover by which to approach, you must fix on some object by which you can guide yourself in the right line. When the centre of the bush or other cover is between yourself and the animal you must then move straight onwards. If you leave this straight line you will get a sight of the animal again and will also be in the animal's range of vision. The best way to keep this straight line is to mark down small objects such as stones and tufts of grass in front of you that make a perfect line with the bush, then by keeping any one of these always in a straight line with the centre of the bush you will be able to steer a perfectly straight course, and so, as long as the animal does not move, you have the bush always covering the animal.

If the bush has been well chosen you will during these manouvres be always concealed from the animal, and the nearer you get to it the better will you be screened by the cover chosen. If the animal is walking to a flank the corering object must be approached in an elliptic curve so as to always keep it between yourself and the quarry. If the animal is grazing it will move very slowly, but its movements will be erratic and it will stop at intervals and may even reverse or move in any other direction. The best way to approach is to let it disappear behind the bush on one side and then go forward as rapidly as circumstances permit in what you take to be the right direction, keeping a little on the side on which the animal disappeared. By so doing, when part of it comes again into view that part should be its tail or rump and not its head, and so the chances of being detected are reduced. If after going for a short distance it comes into view unexpectedly, wait until it again disappears before you attempt another advance.

If you have made an error of judgment, and you see its head and not its 
flank come out on the farther side of the bush, wait till it has its head down grazing or turned away from you, or else take some other opportune moment, then crawl to a flank so as to get it covered again by the screening object. If in the first instance, after approaching for a short time, all remains satisfactory and you have not brought the animal into view, lean slowly outwards until you get a sight of its flanks, by which to readjust your bearings for a further advance. Directly the least portion of it comes into view lie perfectly still till it draws out of sight again; then make your next elliptic advance with the aid of the new data you have obtained. When you have reached the cover sought for your next step will be to ascertain the animal's exact whereabouts and how far distant it is. If you cannot see through the bush the branches may be lightly parted on the shady side, or you may look round the edge on the shady side, but not over the top.

If you always choose the side in shadow and make no sudden movement you will practically never be seen.

After untold exertions and precautions you will find on most occasions, on reaching the desired piece of cover, that the animal is still too far off, or that during your manœvures it has walked much farther than you expected and is as remote as ever. But do not give way to despair, so long as the quarry is still unaware of your presence, there is always a chance of coming up with it. If there is no cover immediately ahead which may be utilised, the only thing to do is to sit down and await developments. It is on the cards that the animal may turn round and walk back towards you, or it may pass over a rise or disappear into a dip, or get somewhere in line with another piece of cover, any one of which will give you the opportunity to make another forward movement. When there are several animals be careful that they have all moved on or are all out of sight, or otherwise provided for, ere you emerge. For this, glasses will be found invaluable. Glasses are also indispensable aids to the detection of game behind imperfect cover, as at once you are placed in the position of one looking through the insterstices of such cover from about a third or a quarter of the actual distance. Powerful glasses reduce to an enormous extent the advantages gained by imperfect cover on the part of animals.

When stalking one animal do not fail to keep a constant look-out in every direction for others, as they have an astonishing way of suddenly cropping up from behind cover, or from what is apparently perfectly visible open space, but which in reality contains some little hidden dip or fold. In this way you sometimes find yourself nearer some other animal which you had no pretensions of stalking, but which may do equally well for your needs. In any case, even if you do not want it, 



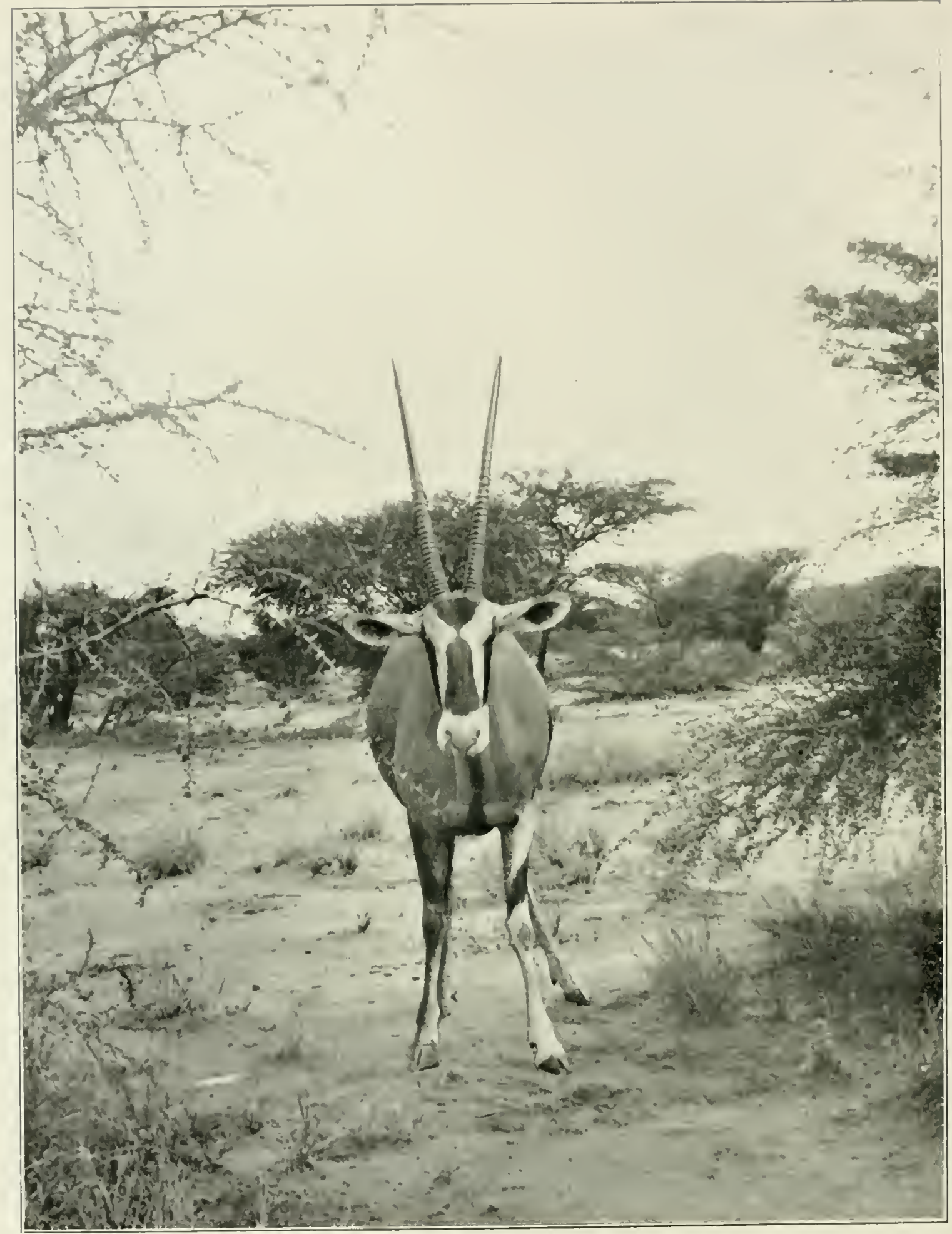


you may be certain that, had you missed seeing it, it would not have missed seeing you, and would probably have given warning of your approach to the one you were earefully stalking.

On the great open plains the whole secret of success in stalking lies in the giving of plenty of time and patience to the approach of one animal. This does not, of course, suit the man who desires to amass a great quantity of heads in a short trip, and lie usually prefers risking long shots in the hopes of some of them coming off, that he may bag his animals without trouble, but the man who goes in for plainshooting as a sport, and not merely as a rapid means of decorating his walls, will not grudge a certain amount of time spent on one head, more especially if the trophy is an eland or an oryx. If he wishes to make dead sure of his shot (that is, to get in one at about one hundred and fifty yards or under) he will find that, except under exceptional circumstances, such a shot will entail infinite patience.

The stalking will be very different to that obtained in more broken country, with its hill and ridges and numerous sharp contours. On the plains a stalk necessitates almost always a series of long crawls and the barking of knees and elbows, or long waits ensconced behind solitary small bushes or tufts of grass, with a fierce sun playing on the back all the while. When the grass is at its longest, then, with the requisite amount of patience and fortitude, it is possible to crawl almost anywhere and yet keep out of sight. The stalker then puts himself on a lower plane than the game, and so has the adrantage in point of sight of that possessed by the leopard, lately shown in the diagram. Crawling is, however, such fatiguing work, and makes one so breathless, that it is necessary to stop and rest every ten or fifteen yards, while before taking a shot another long pause is necessary to steady down. Leather kneepads are valuable for this kind of work, and should be made so that they can be easily strapped on before a stalk and taken off again when no longer required.

It is often possible to avail oneself of a line of tall grasses to make one's way from a bush already safely reached, to a position whence another will cover the animal stalked. When the grass is long it may be used similarly as a means of crossing over a very exposed place. A hand-and-knce approach under cover of a bush is much less tiring than an absolutely flat crawl which is the necessary manner of approach through the ordinary grass of the plains.

Of perfect cover, in distinction to the imperfect cover of grass and bushes I have been discussing, an ant-hill is about the most useful. Lnfortunately for the hunter, however, such is not often found on the plans.

When a bush grows on the top of an ant-hill it becomes an even more valuable objective to the stalker, for this will provide him with head cover if he wishes to 
recomoitre from its top. If an animal passes behind an ant-hill, however close it may be to it, it is unable to see through, and so, during an approach, silence and a correct wind are the only points really important.

Ant-hills may be used as look-out places as well as covers for approach, and so are doubly useful. In long grass country they are the only places, as a rule, from which it is possible to get a view at all without climbing a tree, and they also afford a raised platform from which to fire, and at their elevation a steady lying shot is often possible, whereas, below, a standing shot is more usual. Be careful, however, that your ant-hill is not in reality a rhino covered with red mud.

The stalker on the plains has so very little cover to hand of which to avail himself. There are the rises and dips and gentle slopes which enable him to get into a preliminary position for the stalk, but so flat-topped and shallow are they that he can seldom do more than that. There are, as a rule, no abrupt edges to these slopes, so that neither man nor animal can suddenly come into view or disappear from sight. It is rather a gradual process-an animal's head appears at perhaps four hundred yards, by crouching the stalker may be able to get another fifty yards nearer, and by crawling he may perhaps gain another fifty yards. This will still leave him three hundred yards from the animal, and if he then stands erect the animal's body will still perhaps be invisible or not clear, though its head has been in riew for the last hundred yards. So the ordinary dips and rises can, as a rule, be put out of the question for any further use they afford in the approach, once they have served their purpose as a preliminary.

For the stalk itself, there may offer a few tufts of long grass and a few ant-hills, besides a scattering of scanty thorn-bushes, the majority of which would hardly effectively conceal a hare. Then very occasionally there is a watercourse or riverbed. There is also at certain seasons the ordinary grass, but crawling through this is a laborious process, and apt to make a tremendous rustling. Care, also, must be taken that the grass is not unduly moved or shaken.

There is one great thing, however, in the stalker's favour, and that is the very local habits of the plain-feeders. They scarcely ever move very far during the day, so he has plenty of time to get near to them. There is practically no chance of their suddenly taking it into their heads to rush off to another grazing-ground, for, even when disturbed, they only move off a few hundred yards. Moreover, they generally go through much the same routine day after day for considerable periods, their migrations during the different seasons being a very slow change from one locality to another, and lasting over, perhaps, several months. Other gane, such as elephant and buffalo, trek off in a few hours to new grazing-grounds, often thirty or 
forty miles distant. The plain-dwellers do not seem to trek at all, but gradually graze their way from one locality to another. If their daily routine is carefully watched from a distance it may be possible for the sportsman to forestall them at some point in their daily round. For instance, it might be observed that they are usually seen in the early morning on the slopes above a big stream, and gradually graze over one or two rises, till at noon they come to a bottom with longer grass and muddy pools. In this case a central position near the pools would be obriously the best position to select, chosen so that movement could be made either to the right or left. Then, when the game began to come over the slope, it would be seen which part of the valley they were grazing towards, and one's position could then be changed for some place in the game's direct front, whilst as yet they were far distant.

Having said this, practically all that can be said about the art of bushcraft in plain-shooting has been said. At its best it is but a poor sport when compared to that of hunting. Practised as some people practise it, denying it the little art or bushcraft that might be spent on it, it can hardly be said to rank even as a sport at all.

About the plains themselves though, there is a fascination that seems to seize hold of people and compel them to go there whether they wish it or not. I have felt this impulse myself, and love to wander there. When embarking on their rolling wastes you feel as if it were some great unknown sea on which you are setting sail. In their midst you feel as absolutely out of touch with civilisation and all its horrors as if these sreat billows of plains rising and falling were truly miles and miles of wild waves separating you from the shore. Your tent is a little harbour on a desert island to which you steer back at the end of each day's sail. There is only one thing more wild and more fascinating than the plains, and compared to which they are but small and tame, that is the desert.

But to return to stalking on the plains. The whole art lies in the appreciation of the contours of the country and of the relative positions of distant objects, also the turning to account of the very scanty cover and the studying of the local habits of the game.

The stalker's true country is at the edge of the plains and in parts where the slopes get steeper and the ralleys turn into rocky nullahs ( 1 am presuming, of course, that the game condescends 10 graze there), then, by slowly topping the rises and reconnoitring carefully in every direction with glasses or telescope, it is often possible to locate animals in the distance and then stalk them to within one hundred and fifty yards or even less.

One great point to remember is to top every rise slowly, and if possible come up 
behind a rock or bush from which you may reconnoitre and mark down any game there is to be seen. Great care should be taken to sce that the coast is clear before appearing on the sky-line or on beginning to descend the next slope. One great advantage of stalking game in country at the edge of the plain is that there is not, as a rule, much game to be got, so with whatever docs chance to appear something satisfactory in the way of a stalk can be done. Moreover, the country lends itself to stalking, as its contours are sharper and there are generally more trees, rocks, and ant.hills to be found.

The greatest drawback to stalking in the plains is the amount of game present. If there is nothing else, there are sure to be a few herds of zcbra watching your efforts to stalk.

The stalking enthusiast who intends to turn the plains-shooting into a sporting pastime and to stalk to within close range every animal he shoots will soon give up in despair. He will soon betake himself elsewhere, or else resort to the usual long-range popping of the plains, for he will find that in most of his stalking attempts there are some hundreds of pairs of eyes, dotted all over the plains, watching his movements. Stalk he ever so wisely, it will be impossible in a country so bare to keep out of sight of every animal on the plains. Once any animal has located him it will not be long before all the animals on the plain are staring in his direction, including the one he is trying to stalk. The result of several such days of disappointment will be to drive him to less sporting methods or to the more thinly populated borders of the plains or to the bush.

For one whose pleasure in shooting is chiefly derived from the stalk, the klipspringer and the mountain reedbuck are recommended. Both have poor little heads, but these animals afford the stalker a most welcome exercise of his art as a change from the ordinary plains-shooting. Very difficult, too, are these little buck to hit. They are generally to be found on the rocky kopjes, although the mountain reedbuck is also found at lower levels. The best time to get them is, perhaps, about mid-day, when they may be seen from a distance lying out on a flat piece of rock sunning themselves and airing in the breeze. Then it is a matter of crawling over stones and dodging behind great rocks and boulders, wearing rubber-soled footgear, clinging to tree-roots to get down steep places, and treading carefully to avoid dislodging stones. Perhaps as you draw near, the little fellows will hear some slight sound and start up, standing on a rock-top to try to see what it is that has disturbed them. It will, as a rule, be as much as you can do to distinguish which of the group is the male, as you slowly bring your rifle to bear round the shady side of a boulder or rock. 
If only the trophy was something after the style of the ibex, now, or the markhor, or the ovis poli, what enjoyable days might be spent on these rocky ridges and terraces overlooking the plains!

Next in the order of stalking comes the thin, sparsely elad bush-country. This is really plain covered with patches of bushes in clumps and belts, and generally contains also innumerable termite hills. The charm of this country is that in it there may be all sorts of game or there may be none at all, and from an nutward inspection it is impossible to foretell which. Wandering about, and carefully rounding clumps and ant-hills, every turn may bring you face to face with something unexpected-or, as is more probable, there will be nothing there.

In this kind of country almost everything depends on quickness of eye. The animal is almost always in the shade, and often standing still, while, if it is grazing, it will be moving very slowly; so you must also keep in the shade and must not move about quickly, or you will increase the animal's chances of being able to see you first. As you walk there is always a tendency to look for game only in front of you, whereas it seldom appears in your direct front. I know of no reason why this should be so; I only state it as a fact that game generally appears on a flank. Nine cases out of ten in this sort of country the game comes into view, often close enough for a shot, on your right or left, but seldom in your front. Often the first warning you get of the proximity of some animal is a crashing of branches and the sound of galloping hoofs from a flank. So you must keep on the alert and look out well all around, but more especially notice the glades and recesses to your flanks, the back parts of which only will come into view as you draw level with them.

So for this kind of country quick eyesight is more necessary than anything else. If the game are grazing you are more likely to see them than if they are lying up, as in the former event they may be moving and therefore less concealed, or they may be at intervals completely in the sun. However, when grazing they only move a few steps at a time, while you are constantly on the move, so the advantage is still with them.

Once an animal is seen, if it has also seen you, as can generally be told from its attitude, you must decide at once whether it is worth the shooting, and if so you will need to take a snapshot. The action of bringing the rifle to the shoulder will, as a rule, be enough to scare the animal away, so the shot must be instantaneous.

If the animal sighted is a female or immature specimen, then stand ready, for you may get a glimpse of the male with her as they make off. If a female and young stand staring at you, as so often do the hornless femiles of such animals as kudu and bushbuck which are never fired upon, and if a few steps woukl permit you to see behind a bush or clump close to them, it would be as well to step forward and look. 
The first two animals will probably run off directly you move, but the male might be just behind the clump and you might get a look at him.

The instant you see anything moving in the bush it is as well to stand perfectly still until you have ascertained whether it is a single animal or a party. If you see that it, or they, have not noticed you, then either sink slowly down inch by inch till you are out of sight or else slowly make your way to the nearest cover or shade. A great point to remember about all such movements is that, if possible, cover should be sought by moving slowly directly towards the animal or directly away from it, such movements attract less attention than a lateral movement which is very quickly noticed.

With an object in the very far distance, such as a vehicle at the end of a long road, it is often very difficult to tell if it is coming towards you, or going away from you, or if it is stationary, but with an object moving across your front there is no such difficulty, as it is always easy to tell at a glance not only that it is moving, but in which direction it is moving. Therefore all lateral movements in the presence of game should be avoided. If it is not possible to move either directly forwards or backwards, then an oblique movement is the next best thing, but even this should be avoided if possible.

To stalk a member of a herd it is necessary to keep out of sight of all the animals of the herd, as any one of them may give the alarm. So before trying to stalk the one you want it is best to try to locate all the others when you are lying behind some convenient cover or in the shade of a bush. When trying to get near them you must remember to pass from bush to bush nearer to yourself than to them, so as to always have the advantages of imperfect cover resting with you. Never, if possible, expose yourself where there is a long, open space towards them, no matter how thick the bushes at their end may appear, for if they are close up to those bushes they are almost certain to see you through or under them. The open spaces that exist under many bushes are frequently overlooked, and you may be getting beautiful cover for your head and body, but if you stoop or lie down you will find that the lower parts of the bushes are not so thick and that your legs must show most of the time. The open spaces under bushes on their shady side are admirable places from which to reconnoitre, and also from which to shoot. It will often be found that in bush or sparsely wooded country, that the shorter a person is, or the more he stoops, the better can he sight game, for at a higher plane the foliage is thicker than below, where are mostly only bare trunks.

In heavily bushed country stalking is more difficult than in sparsely 
bushed country. In the former country it would seem as if it ought to be easy enough to approach an animal with so much cover about, but, as a matter of fact, this very cover makes it so difficult. For the cover that is good for the stalker is equally good for the animal, and if it has taken up a position behind some thick bush, while you are searching round and round trying to find a place from which you can spot it, it sees you through its bush and makes off.

The easiest country to stalk in is the rolling alternate valley and ridge country, with termite hills and single bushes dotted about. From the top of a ridge you can then often mark down the exact position of an animal and make all your plans for the approach and stalk.

In the really thick and tangled bush-country, such as round Voi and the lower Tana River, not only is it difficult to stalk, but it is difficult to make any progress through it at all. Moreover, in such country to move silently requires great patience and much practice.

Directly the country gets thick enough to make stalking at all difficult it is then that the sportsman should take to tracking, as it is the only way of coming up with an animal. Even in the very open bush, easy to make a way through, tracking is indispensable, as fresh tracks if followed will always lead to an animal, whilst aimless wandering about will probably result in little or nothing. Apart from this, directly the bush gets thick enough to make it difficult to move through, it is almost imperative to find the game by tracking alone. For it is impossible to go through a long day moving so silently and carefully amidst the thick undergrowth as to be perfectly noiseless the whole time, and chances may repeatedly be missed for want of sufficient warning.

Tracks may be looked for, and when found followed to a certain extent, using only average care in walking and passing through the bush silently and stopping to look and listen. When warned by the look of the tracks that the grame is in the near neighbourhood, then is the time to proceed with consummate caution and to be more than ever on the alert. It then becomes necessary, if there are leaves and twigs under foot, to tread on tiptoe in each footprint of the animal itself so as to avoid breaking any twigs or cracking any dry leaves. Where the animal has just trodden is the only safe place in which to tread, for in its footsteps nearly all twigs, leaves, etc., will have already been cracked or crushed. Even then the foot must be put down slowly, and, wherever it is impossible to tread in the animal's immediate track, you must test the ground at every step by putting the foot carefully down without at first bringing any weight to bear upon it, until you have ascertained if there is anything likely to make a noise. It is often necessary to remore trigs and leave's 
from the ground so as to leave a bare space on which to tread. Every branch across the path must be taken hold of and pressed gently back when passing it, so as to avoid rustling, and it must also be returned gently into its position again to prevent its springing back with noise.

When once a fair amount of experience has been gained in stalking and in knowledge of country and in marking down of a spot, then the methods to be employed and the manner of approaching any giren animal remains much the same. There is usually, when wind and other matters are taken into consideration, but one obvious line of approach, and the amount of success achieved depends on the patience and care with which that line of approach is taken.

Further experience does not tend to enable you to find other lines of advance, but further practice enables you to appreciate quickly which is the most feasible route to take and to put your plan into execution with all the despatch at your disposal. While the novice will probably choose in the end much the same route as the old hunter, he will take a considerable time in thinking it out. The latter, on the contrary, will appreciate the conditions of wind, cover, and lie of the country at a glance, and however unexpected the contingency that has arisen will decide on the plan of action and begin to put it into execution without a moment's delay.

When the animal is seen from afar there is, as a rule, no hurry, and it is as well to have a good look round first to see if there is anything else about at any point which might have escaped the first hurried glances. Where, however, you are suddenly confronted with game, or where the wind is bad, it is invaluable to be able to make up your mind in a moment as to the correct course to pursue, and the best and nearest cover available, and also the best places both for immediate and for future movements in which you will be safe from betraying your wind.

As an instance in point, a hunter might be in a thick, tall-grass country and in following an elephant path be suddenly confronted by a female or young elephant coming back along the track. His first thought would be to see if it was a bull or cow, and, if the former, whether of sizable ivory. If the latter, his next thought would be to run away, and his third thought would be of the wind. With practice all these three thoughts are realised and answered instinctively, and directly you see that it is a cow you dive out of the way downwind and in the direction of a tree if possible.

One of the most important factors in stalking is the dress worn by the stalker. For general use in East Africa I an of opinion that rather light colours should be 
worn. Mottled yellowish and light greenish colours are as good as anything for the coat, and a few patches of red-earth stains on these add to their effectiveness. The breeches may be of some lighter colour such as khaki. A pair of dark-coloured putties are a distinct advantage, on the same principle that an animal's legs are darker than the lower part of its body, and are often black or blackish. 'They may thus be easily mistaken for the stems of bushes or trees when the animal is not in a good light or is partly concealed.

The idea to bear in inind with regard to all clothes for stalking is to break up the appearance of the body into different pieces or layers of different colours and shapes, but all of which must be so coloured as to assimilate easily with possible surroundings. These different parts should convey the appearance of being at a distance from one another, and each one unconnected with any other.

This is accomplished by having the different layers of the body of different shades. It is only in insect and small animal life that it is usual for an animal to be of one uniform colour for the sake of concealment. As such they are coloured to represent some common inanimate object such as a stone, clod of earth, stick, or leaf. With larger animals this is not often feasible. It would be difficult to mistake a man standing erect for an ant-hill or a tree, however suitably coloured he might be.

However, if properly dressed his legs might appear as trunks or stumps of trees and the lower half of his body as grass, whilst the upper might be confused against background of bush.

When the hunter is coloured so as to blend with surrounding objects be may remain invisible, or at any rate undetected, almost anywhere so long as he does not move.

He may be sitting beside the thimest and scantiest of little bushes, but at a distance he will only appear to add to its size. He may even be sitting in the open, and if he remains perfectly still he may pass for a bush. He may move from behind a bush and sit down in its shade ready for a shot, and if only he gets into position slowly enough he will not be observed. To be quite certinin of keeping undetected lie must always, wherever practicable, remain in shade. Shadows falling on him of their own accord blend him with them-the darker they are, the nore is he protected. 


\section{CHAPTER VII. \\ THE RIVER OF THE PLAINS.}

THE cold mountain torrents coming down from the Nguzeru mountainous regions, and the clear snow-fed streams of Kenya, both pass through the hilly Kikuyuland before wending out on to the open plains. Where they first join the plains they cut deep nullahs and gorges, which afterwards give place to shallow valleys, on the banks of which grow a characteristic yellow-barked thorn-tree. In the upper gorges, however, the streams seem to have carried down with them to the plains some of their mountain vegetation, for massive forest and mountain trees grow on the banks, and a tangled belt of thick growth bars the approach to the river.

If you force a way through this thick vegetation to the banks of the stream you are at once transported into a world totally different from the arid and treeless plains a few yards back on either hand. By the river edge is cool shade and restful green, doubly welcome after the aching glare of the plains, whilst the swirling and bubbling of the stream is pleasant to listen to. The dead trunks of forest giants lie just as they fell, blocking the streain or forming natural bridges across it. Fish are plentiful, and many a pleasant day may be spent with rod and fly, or even with hook and string for that matter.

As your hearing grows accustomed to the swirl of the stream, a great quietude and peace seems to reign over the water-side, and this is all the more noticeable because the noise of the rushing torrent really drowns all minor sounds. Every now and then a pattering among the dead leaves lying on the banks breaks the stillness, as some little duiker, dikdik, or bird searches for berries fallen from overhead, or nibbles at the seed-pods which strew the ground. Then the patters die away into the distance, and all is quiet again.

This seeming hush is suddenly broken by loud chatterings and barkings, and violent rustlings and clashings of branches, drawing nearer and nearer till they pass overhead, and soon a baboon runs out to the end of a branch, bending beneath its weight, and hurls itself across the river into the midst of the thick branches on the opposite bank. These it nimbly catches and swings aloft into the tree, and runs down a big branch to the trunk. Then come after it a whole troop of baboons, large and small, throwing themselves recklessly across, 
but none failing to secure a hold on the opposite side. At last some forty have safely passed the stream, and only a small one is left on the ncar shore balanced at the extremity of the branch. Twice it makes as if it would jump, but both times holds back; perhaps this is its first attempt at such a big water-jump. Angry chatterings ring out from among its brethren perched in different forks of trees on the opposite bank, so our young friend makes up his mind and takes the desperate plunge and lands safely on the opposite side.

Something moving farther up the stream catches the eye; it is another party of baboons crossing, but these take an easier route by a fallen tree that lies from bank to bank. One after another they pass over, youngsters riding on their mothers' backs, old maned males, all ages and all sizcs. Suddenly the most piteous screams rend the air. Those of the troop already on the bridge fly across, and those about to cross leap back into the branches of the nearest tree, whilst a babel of alarmed cries fills the water-side. Recovering from their momentary panic, they leap down into the lower branches and crowd together, growling and barking at somcthing on the ground-and a formidable troop they look-but from below ficrce growls are returned, and as a heavy body springs towards them they scatter and skip up ligher for safety, the while keeping up an incessant babel of cries and barks. These tactics are repeated several times, but every time they come down to the lower branches, angry growls once more arise and a rush is made from below. At last the troop clear off, jumping from tree-top to tree-top, and branch to branch, till their harsh voices die away and the intruder is left with his prey. For even in this quict spot there are occasional tragedies, quickly consummated, and as quickly forgotten.

'To-day it is the crouching leopard, lying in wait by the baboons' bridgre, and assured that his chance must come sooner or later. To-morrow it will be a lurking crocodile, indistinguishable from one of the many half-sunken logs dotted in the stream, that will secure a victim.

But now let us follow this stream down many miles across the plain and into the bush-country beyond, where it has grown into a stately river several hundred yards across, enlarged with all the waters east of Niguzeru, and south of Kenya, where it flows between banks thickly lined with thorn-scrub, and bears the title of the Tana River.

Camp, let us say, is pitched on the edge of a bank dropping sheer down some twenty feet to the water edge. As you look out over the slow-flowing, muddy river, you instinctively liken it to the muddy. Thames as seen from the terrace of the Houses of Parliament. 
Although the highlands have been left far behind, the heat is not oppressive here, for a cool breeze sails up the broad expanse of waters, and the trees behind give grateful shade to the little camp. The sound of the blowing and puffing of hippos from somewhere downstream reaches your ears, and in the river just below camp is a little sandbank scattered with the fresh remains of one of these great beasts. The rusty head of a native's barbed arrow tells the tale of its death. The sun sinks and its fierce glare gives place to the bright, mellow light of a full moon. The hippos commence grunting with delight at the prospect of their excursion inland, and soon with a loud splashing and much noise they wade ashore. Then all is silent again except for the occasional splash of a fish or the crack of a branch, but if you were amongst the hippos you would hear the comfortable sound of their steady munch, munch.

Then comes a splash and a swirl from the opposite bank, followed by another and another; some animals are evidently taking to the water, and the nature of their splashes proclaims them to be tailed monsters. An egret or some other white river-bird sails silently up the river, and hovers over the sandbank before alighting in the shallow water at its edge. There it stands silent and expectant, for about this bank must be many fish attracted by the smell of the departed river-horse. Suddenly it starts forward and sails away upstream and out of sight, scared by a movement in the water close to the sandbank, and presently a long form, followed by others, glides up out of the water and on to the spit of sand. The sight of these constrains you to break the peace of the African night with a loud rifle report, and one of the forms throws itself high into the air and then falls back into the shallow water writhing in death struggles. The rest scuttle into the water with undignified haste, and when their swirlings and splashings have ceased, silence once more reigns supreme.

For the crocodile I have neither sympathy nor mercy, as it is an enemy to fish, game, and to mankind. Not that I wish to see it exterminated, for that would be as great a pity as the extermination of any other form of animal life. But for this creature there is no such chance until large towns and cities spring up on the banks of this at present uninhabited part of the river, and until excursion launches puff up and down well-dredged channels. Until that day arrives (and may it be a long time in coming) the isolated efforts of a few sportsmen are not likely to effect any great reduction in the numbers of these reptiles. What may be effected, however, is the instilling into this reptile of an increased respect for man, and for that reason I take a shot whenever occasion offers. It is possible to put up some sort of a fight with a lion or a leopard, but the victim of the crocodile is dragged down, all unawares, never to be again seen. 


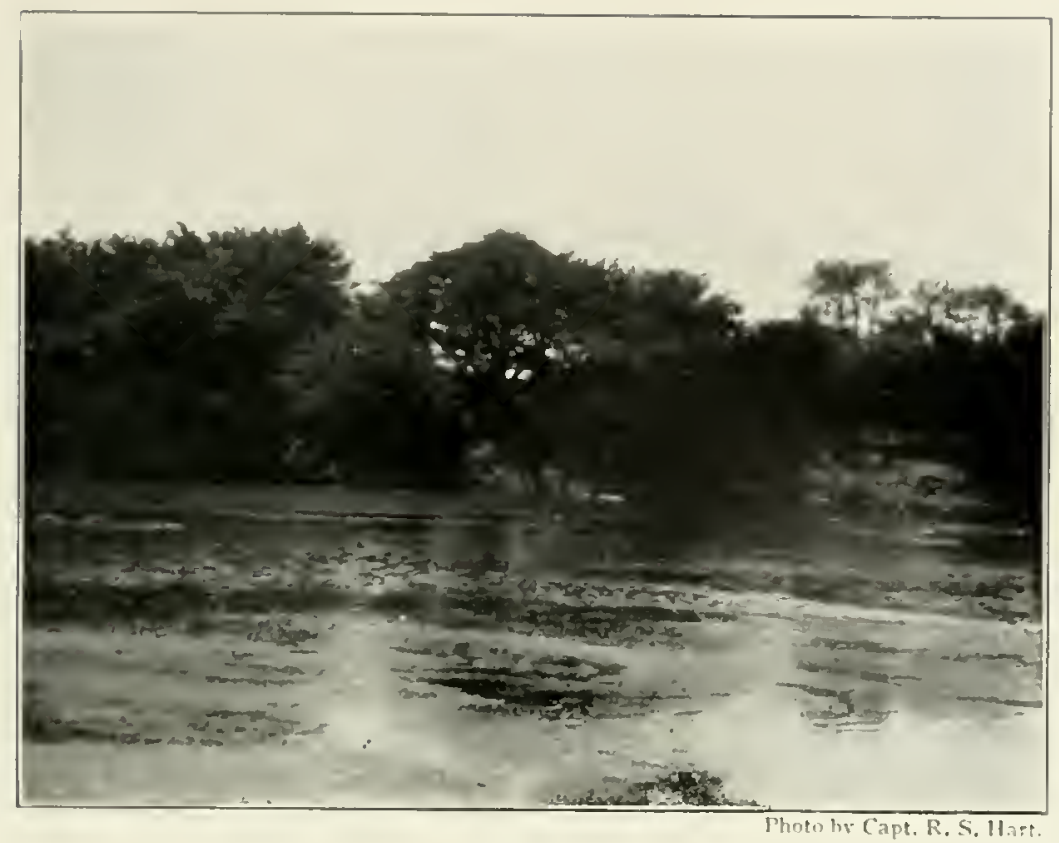

IXIA KIVER

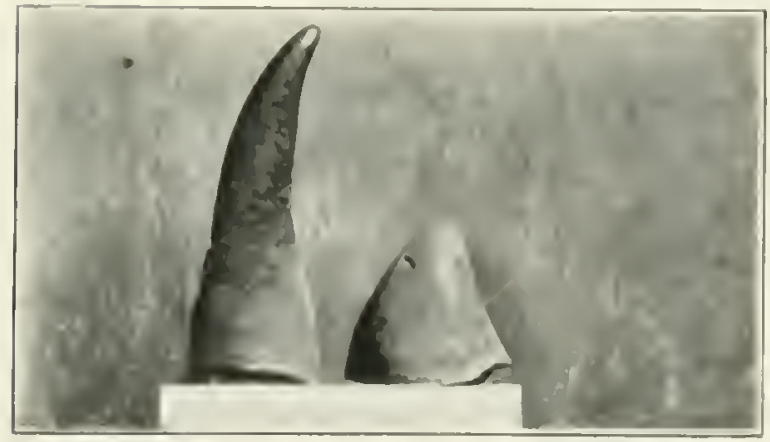

I. RIII, KHISU IIIKNS 
Now let us once more trek down this big Tana Rirer. For several days no human beings save a few Wakamba hunters have been met with, and they only few and far between. Marching downstream, and following the bank of the river in the shade of the narrow belt of trees at its edge, you occasionally disturb a little dikdik which scampers off. Before long the thorn-bush becomes denser, and you can no longer travel in the shade, but have to take to the open plains at its edge, and as you proceed, the thick thorn on either bank spreads farther and farther afield, and you have perforce to march farther away from the river. Two great forms, with shaggy heads, rise slowly up from under a tree and glare at you as you draw near. They are two old buffalo bulls which seem to resent your presence, but, after a brief stare, they toss their heads and gallop off into the bush. Much buffalo-spoor is about, and also that of giraffe. The former have left their wonted haunts some few days westward in the hills, and have wandered down to the big river, but they are not habitual visitors to these parts. Presently an alarm is given from behind, and some of the porters throw down their loads and hurriedly scramble up trees. The cause of the trouble is a buffalo cow which has been wandering by herself. Though wild enough looking as she tosses her head and tail, she intends no harm, but just gallops across, bent only on a return to the herd. Climbing on an ant-hill to watch her progress, you see her join a mass of wildly tossing horns and tails, which denote the presence of the herd.

Presently the whole herd makes off with a crashing of branches and rattling of hoofs against the loose stones lying on the red soil; then, having restored confidence among the porters, you once more proceed on your way. From high above a low thorn-tree a long-necked giraffe takes note of your approach, and soon, having satisfied itsclf as to your appearance, moves off and joins its family party, when, at a slow and stately gallop, the whole party makes off, with necks slightly extended, and easily recognised from their immense bulk and the height at which they stand above the low thorn-bushes. You watch them as they disappear into a dip, to reappear again on the far side and slowly make their way up to the top, where they are clearly defined against the sky, though they must be a couple of miles off.

A heavy shower in the afternoon fills up some of the little water-holes on the edges of the plain, and so permits you to camp there instead of having to dive through the thick thorn-bush back to the river. Soon after sunset you hear, that finest of all nature's sounds, the lion's roar, resounding over the plains, and your hopes run high with expectancy for the morrow. However, in the morning no roaring is to be heard, although anxiously listened for, and so trek is resumed, keeping just outside the thick thorn and among the more scattered bushes, which 
make a gradual transformation to plain-land. The wind is from behind, so you expect to see nothing, but on crossing a rise two light-coloured forms start up from the bottom and make for the opposite slope, which is dotted with thornbushes. It is a lion and lioness that have lingered over their meal till after sunrise.

It looks hopeless to bring them to bag, for they have your wind and are making good their retreat at something over three hundred yards. The lion stops for a moment and turns to look, standing broadside on. Now, although this shot would be unsporting with a buck, the case is different with a lion. For even if it is but slightly wounded it is almost certain to make for the nearest cover and there lie up. If you really intend to devote the day to following it up you are almost certain to come up with it sooner or later, whereas if it is unwounded it will make off none the worse. Very different is the case with a buck, which often manages to escape even when quite badly stricken. So you decide to take a shot at the lion at the distance offering, and hurriedly fire just as it has finished its momentary inspection and is again on the move. An answering roar tells that the bullet has gone home, and in a moment both lion and lioness are swallowed up in bush. You hurry after them and cross the bottom, where you see the shin-bone of a zebra gnawed off from the knee, and you run up the opposite slope. On arriving at the spot at which the lions were last seen you find a large thick clump of thorn. Passing quickly down one side of this for several hundred yards, till the thorn gets a little less dense, you enter there at right angles to try to discover if the animals have already passed the spot. Presently the native tracker discovers a spoor leading through the thinner thorn and then across a watercourse into the thicker bush beyond. He is all keenness, but the size of the spoor is mistrustful. However, it is but dimly marked on the hard ground, and you follow on for some distance till at last some clearer marks show up which are too small for those of a full-grown male, so must belong to the lioness. You decide to return, much to the chagrin of the tracker, who is convinced that your only chance is to forge ahead on the spoor. He is all keenness now, but if you were to follow the spoor for an hour or so he would soon get bored and want to give up. So you return to the spot where the lions were last seen, and after a brief search find where they entered. One of the spoors is much bigger than the other, and there are signs of a leg having been dragged, so your hopes run high again.

You follow the spoors into the thick thorn, bending almost double to pass beneath branches, thorns catch your hat and clothes and tear your face and arms and legs, but what matter? There is now blood on the spoor and signs that the leg has dragged heavily, so it is only a matter of time and patience. The lion is really quite close at hand, and in the first instance you had overshot 



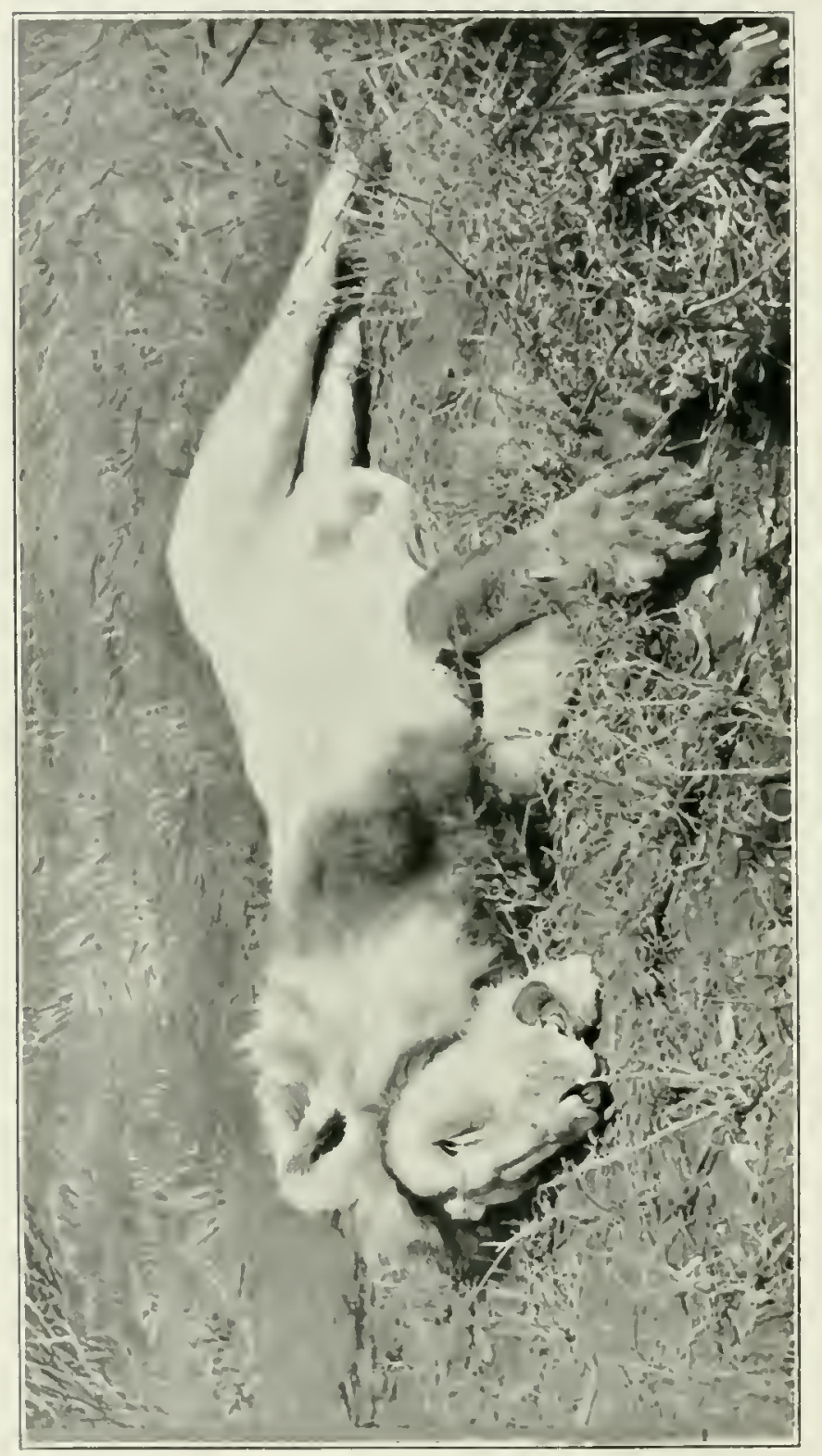

$\vdots$
$\vdots$
$\vdots$
$\vdots$
$\vdots$
$\vdots$
$\vdots$ 
him, for now he most considerately growls to show his whereabouts. You peer into the dense bushes, but can see nothing, so follow the spoor again, only more slowly and with greater caution, and with your rifle at full cock in front of you. Presently sounds another deep growl, so near that it makes you start, and there he is crouched under a bush not twenty yards off. As he tries to approach, you notice how badly the first shot has hit him, for he cannot move quickly. He raises his head to give another long reverberating growl, and taking the opportunity you put a bullet into the root of his neck. He turns and rushes blindly through the bush and is again lost to sight, but you can hear him struggling and beating the ground not very far off.

Advancing once more, you find he has gone but thirty yards and is now lying on his side, for the last bullet has pierced his heart, whilst the first long-range lucky shot hit him on the hip as he turned round to make off. He proves to be a tawny-maned lion and a fine specimen in his prime, and after the first feeling of exultant triumph is over you cannot help feeling sorry to have killed such a fine creature.

I do not know why it should be so, but I always feel more regretful over a stricken lion than I do over a buck. Perhaps it is that the killing of the latter is such a necessary performance for the table, whilst there is really no reason at all for the killing of the latter except that the sport is exhilarating.

But to resume; the same night you strike across another little pool, holding water from yesterday's rain, but very shallow, and there you pitch camp, and the following day you find, on trek, that the hot sun has dried up all other possible rainpools, so, as you are still near the river, though divided from it by a belt of thorn several miles thick, you decide to get your water there. On you march outside the thorn till, taking advantage of a grassy fiord running in towards the river, you begin to push through the thorny belt. Happily you come across rhino and hippo tracks in plenty, so the work is not so arduous as it might have been. Still, there are quite emough thorny branches left stragghing across the path to employ ten hands and arms to push them out of the way, were you blessed with that number.

Presently you hear the old familiar puff! puff! puff! of a rhino; he has got your wind; will be come your way or not? You wait anxiously, and are relieved to hear the sound of his crashing through the bushes grow fainter and fainter, and finally die away. Again you press onward, and again there is a puff! puff! puff! but this time supplemented by the crashing of loads hastily thrown down, and, before you quite know what has happened, a rhino followed by a calf comes tearing past and down the whole line of porters within three yards of them, and away into the bush. Going back to see how much has been broken, you find your porters getting down from 
thorn-trees and emerging from thorn-bushes, some scratched and torn, but all cheerful and laughing. So once more you push forward, but with a following train now jumpy and nervous. Something springs up in the bush quite close in front, and you start violently and prepare for the worst. A small dikdik scampers away, and you feel rather foolish. Fortunately the sun remains visible, or it would be very difficult to keep the right direction in this dense bush. Then you get into a watercourse, with steep banks on either side, and follow down its dry bed for some way. Again the puff! puff! puff! but this time it is on the bank above you. At last you reach the river concealed from the outside world by its dense belt of thorn. No white man that you know of has passed this locality since Carl Peters, and it is unlikely that he broke through the thorn at this identical place. It may well be that even the very few native hunters who come to this uninhabited part have never pushed through the thorn barrier at just this point. For there are no canoes on this part of the river, and no natives in these parts at all. The many canoes of the lower river and the few of the upper are prevented by falls and rapids from visiting this section of the stream.

Hopes run high that you are the first human being who has ever looked on this picture of wild nature or seen exactly this part of the river. It may be so; nature may have remained undisturbed, for there, quite close to the bank, and all unsuspecting, is a party of seven hippo peacefully sleeping half out of the waterseven big hippo and one baby nestled close to its mother. One of them is resting its head on a fellow's back, its eyes closed, and a serenely contented expression about the corners of its prodigious mouth. An occasional twitch of an ear or the hopping of a busy tick-bird are the only signs of movement about the party, otherwise they might be mistaken for dead creatures, and, as such a chance as this does not often fall to the sportsman's lot, it must be made the most of. The party are a little downstream from the place at which you have struck the river, so a detour in the bush must be made so as to get opposite them. There is a thick patch of thorn between yourself and the river-bank, so, taking your deadly weapon in hand you cautiously proceed, breathlessly pushing aside the branches and climbing through. Will they hear? Will a breaking twig give you away? At last you reach the river's edge safely. There, however, the foliage of the river-bank prevents a clear view, so you must perforce scramble half down the bank and support yourself on the roots of the trees washed bare by river floods. Having got there, you part the branches very quietly, clinging on as best you can to steady your precarious foothold. The hippos are just below, all unconscious of the fate that awaits them. Taking as steady an aim as the awkward position on the roots of the river trees permits, you 


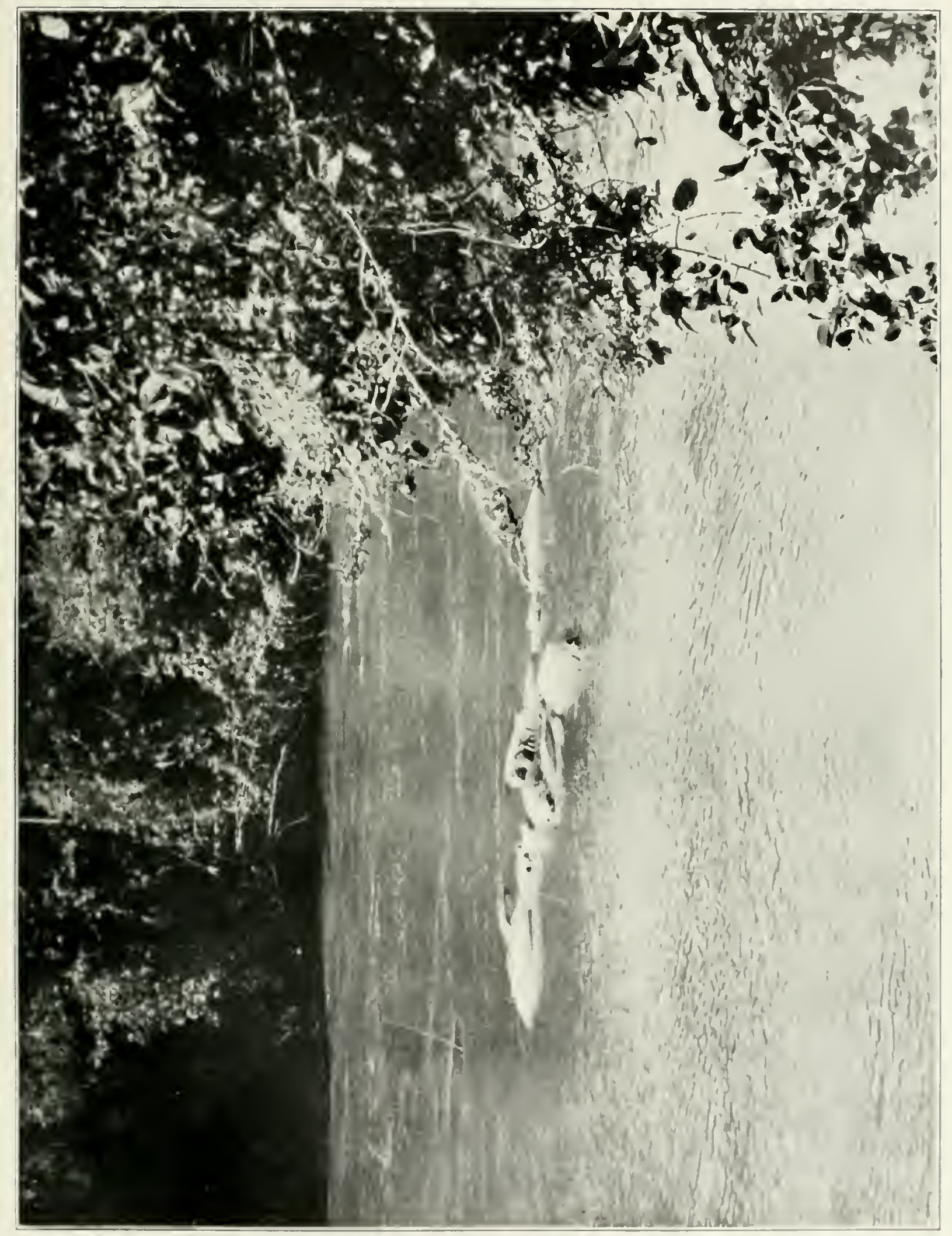



find the shadows prevent you from seeing the sights clearly. What's to be done? To "brown" the party is the only choice left, so you pull the trigger.

You cannot tell if your shot has been successful or not. The great beasts are still apparently in as profound a slumber as before, so, hastily reloading, you take aim again, and pull the trigger. Still neither sound nor movement! One last look at them, and you turn round and make back as carefully and silently as you came.

You remain in ignorance of the result of your shots, and, moreover, must wait three whole months before you can know; that is, until you get back to some civilised part from where you can post the little packet of films to England and then wait until they are returned to you developed.

Will they show your sleeping friends, or will they show only a blank expanse of river, or, worse still, a complete blank, proving that the films have got wet during a fall of rain or whilst crossing neck-deep one of the swollen tributaries of the great river on your return journey?

Meanwhile the great river-horses sleep on, all unaware of the ordeal through which they have passed. 


\section{CHAPTER VIII}

\section{WHAT IS LEARNT FROM SPOOR.}

POOR teaches one (i.) what kind of animals are in a country; (ii.) what they $\checkmark$ eat; (iii.) where they drink; (iv.) when they were at the spot at which the spoor is found; and also a number of other things connected with their mode of living. Spoor, if followed, will also guide one to where the animal itself is.

In the bush and forest a knowledge of spoor and tracking is indispensable to anyone who wishes to meet with any grcat measure of success. In the plains it is not necessary, and indeed, would be of little account, for there is hardly a question of failing to find any particular animal wanted.

In the bush and forests of this country native hunters lay traps and snares, and hunt with dogs and poisoned arrows. In all their hunting they hardly ever do any tracking. They notice by the spoor the places frequented by whatever game they want, and, trusting to the local habits of the game, set their traps and snares there. When following animals to shoot with poisoned arrows they leave it to the dogs to do the tracking and the rounding-up of the game. With elephant a certain amount of tracking has to be done, but there again the native hunter relies chiefly on his knowledge of the animals' habits and haunts, rather than on his power to follow their spoor.

Soon after coming to this country, I was out with a native hunter, and we put up some hartebeests suddenly and they galloped off. According to custom I got on their spoor and commenced to follow them. The native hunter appeared to get very impatient at this proceeding, and continually beckoned me on. So at last I left the spoor and followed him to see what he wanted to show me. After going about ten minutes through wooded country he brought me out into the open again, and there was the same herd of hartebeest. This surprised me greatly for two reasons. First, that it was so unlike the animals I had been accustomed to hunt for a herd to have stopped again so soon after being frightened. Secondly, that the hunter should know where to find them. For a few hours I thought that I had discovered a marvel in the way of a hunter, but I soon found that I was mistaken. The herd of hartebeest wandered backwards 
and forwards between the place at which I had first seen them and where I had seen them later, and hardly ever went elsewhere. So if they left one of these localities it required no great brain fatigue to guess that they would have grone to the other.

A little later I saw a lesser kudu disappear into the bush. Here was something worth taking some trouble over. I asked my hunter where it had gone but he was unable to offer any opinion on the subject, for the lesser kudu does not wander between two places alone. The only thing he could suggest was that we shou'd go back and look at the herd of hartebeest again. When it came to tracking he was perfectly useless and wholly uninterested in the business. This little instance is typical of the native hunter and of the kind of animals usually met with. Game in these parts do not go so far when disturbed as they do in Central Africa, and they nearly always return to the same places during the same seasons. So it cannot be claimed that tracking is of such vital importance in this country as it is elsewhere. If you have with you a native tracker who knows the country thoroughly and the habits of the game of the locality he will be able to do away for you with the lengthy process of tracking. However, to anyone strange to the country, and without the help of a local hunter, the habits and haunts of the game have either to be learnt by experience in the country, or the absence of such knowledge must be supplied by tracking.

The next thing which surprised me in East Africa was, that hunters professedly versed in the habits of game were appallingly ignorant of spoor. When a hunter of a hunting tribe called a hyana's track a leopard's I thought that he must have made some mistake in the Swahili name he used, but since then 1 have heard many Masai, Kikuyu, Ogieg, and other tribes make mistakes just as bad. This particular mistake you would hardly think it possible for a native to make, especially one who lives amid these animals and sees their spoor constantly. For a hyiena's spoor is similar to that of a dog, and a leopard's to that of a cat. The spoor of a hyzena and a cheetah might be confused, but in the case quoted it was manifestly impossible that it could have been the latter, owing to the type of country.

The disadvantage of having a native hunter, such as is found in this country, is that however good he may be at linding game, he will always take you to the game most easily found, and not necessarily to the game you are most desirous of obtaining. Likewise, in the event of an animal being wounded, the native hunter will be found nearly always useless, as he will want to take you to the herd again or some other herd. He will not see the object of 
laboriously tracking up a wounded animal which may have gone far, when there are other animals easy to get at. The Nandi and Wandorobo, or Ogieg, hunters in the forest do a certain amount of tracking, but in the bush or anywhere outside of their own forests they appear to be quite useless. In the forest no great skill is required, as the tracks are all deep and plainly obvious in the soft mouldy floor of the forest.

The difference in ages of spoor will not be at first quite apparent to the sportsman in these regions. He who has not before been in this kind of country will find spooring rather different work to that of a drier country, but after a few days' observation little difficulty will be experienced.

It is quite easy to understand how a Dorobo, who has never done a harder piece of spooring than that of following the deep-cut tracks and line of broken undergrowth made by some forest animal, will not shine at any difficult tracking in the bush or on harder soil. What they are really good at is going softly and quietly in the thickest forest or bush, and for this reason it is a pleasure to hunt with them anywhere. It is advisable to have someone with you when hunting, and a flatfooted, noisy Swahili or Mnyamwezi porter will be found a most trying companion with whom to walk in the bush.

To return to the matter of tracking. It will often happen that there is some particular animal that you are most anxious to come across, such as a sable, kudu, or oxyx. In looking for it you are much more likely to hit upon some part of its night's or morning's spoor than to chance on the animal itself; but having found the spoor and having satisfied yourself that it is that of an adult male, you are almost certain to come up with the animal during the course of the day if you have ability to follow it or have a native with you who can do so. Whether you come up near enough to see it, or only near enough to hear it breaking away, is another matter.

You will always have a greater chance of getting close to the animal when on its spoor than you will have otherwise, for you will be on the qui vive the whole time and expecting to see the animal momentarily. Moreover, the animal will generally be found to be grazing upwind, and so you will follow him as a rule from downwind, while if the wind is wrong you may to a certain extent avoid the danger of betraying yourself by making detours to hit off the spoor. The spoor itself if closely watched will give you a certain amount of clue as to the neighbourhood of the animal and an idea of how near you are getting to it, so that when you judge that you are close you can take extra precautions.

Though tracking is not as useful in East Africa as in Uganda, or in many other 
parts of Africa, it may be taken as being more especially useful under the following circumstances :-

(i.) When any special kind of animal is required.

(ii.) When some animal has been seen and has moved on, or has been frightened away, and it is desirable to find it again.

(iii.) When an animal has been wounded, at which time no effort should be spared to bring it to bag and put it out of pain.

(iv.) When the country is unknown, and there is no native hunter to hand who knows the country perfectly.

(v.) At all times in thick bush and forest.

It is unfortunate that good native trackers for bushwork are so difficult to obtain in this country, for, in following the track of any animal except the elephant, it is most important to keep a constant look-out for the animal. When tracking elephants in thick country it is generally by hearing them that you are made aware of their nearness, so a very sharp look-out is not so essential. With most other animals though, if the greater part of your attention is taken up with tracking, you stand a poor chance of seeing them before they see you. So, when you possess a reliable tracker, you keep him on the spoor, and yourself walk a little ahead of him, doing your utmost to locate the animal. If you prefer it, you can take turns with him at spooring and looking out, calling him back to help you when a check or difficult bit of tracking crops up.

Where speed is essential, such as in following elephants which are travelling, or a spoor some hours' old, it is often a good plan to have two trackers; then, with one of them, you proceed ahead at a rapid pace, and, if you lose the track, cast ahead for it in the hopes of saving time; whilst your second or slow-but-sure tracker worries out the spoor in detail behind. If you hit off the spoor ahead you sign to your second tracker to catch you up, whereas, if you fail in front, there is always the tracker behind to fall back upon. He may have worked out the track whilst you have been on ahead, or, at any rate, he will have worried out a part of it, which will give you a fresh point from which to start.

To be able to track at all well requires not only a tremendous amount of experience, but also constant practice to keep you up to the mark. Also, while similar work in other countries is a help, it requires special practice in the same type of country as that in which you wish to track. 'The art is not only performed by' following the actual spoor-marks, but also by noticing various other signs, such as disturbed dust, broken twigs, bruised plants, trimpled grass, scattered leaves, spots of mud, the brushing off of dew or raindrops, hairs or fur left on thorns and stumps, 
froth, saliva, chewed grass or leares, the marks of browsing, and many other small signs.

It is not my intention here to go into this subject at any length, as I hare done so elsewhere, ${ }^{*}$ and, moreover, this is not so much the country of the tracker pure and simple. I will, however, briefly note a few of the signs to be looked for in different kinds of country.

Taking first the sandy desert with scattered thorn-bushes and mimosas, it is there that tracking is nearly entirely performed by following actual footmarks, which are usually quite easy to see. It is through that sort of country that you have generally to follow giraffe and oryx. Whilst following spoor, occasionally a few leaves dropped during browsing or a piece of stripped bark may be seen at a distance in front and the intervening tracking missed out. In desert or other easily traversed countries the watercourses and river-beds are generally shut in by a dense belt of bush. When the track descends into these, time and trouble may sometimes be saved by keeping to the open and picking it up further on where it comes up again. The sportsman will have to judge for himself as to whether the animal has gone down and up again on the same side or crossed to the other side of the river-bed. If the stream is a fair-sized one and the animal has gone down for its morning drink the chances are in favour of its coming up on the same side by another route. If it has been disturbed and is in flight the probability then is that it has crossed the stream.

In a dry watercourse, or in a watercourse with pools at intervals, there will generally be periodic breaks in the hush-belt, or, at any rate, necks of thinner bush affording an easier crossing.

Where grass is found in a dry sandy, or dry red earth soil, it is usually in tufts and clumps of long and coarse grasses, while between the tufts is bare or sandy soil. Anything passing through such a country naturally finds it easier to push between these tufts, rather than through them. For this reason, following spoor there must be done by following the actual hoofmarks, with but occasional help from signs of trodden grass.

In thick bush-country the path taken by the animal is generally the only feasible one to follow except where other tracks join or cross it, and in such country the fresh track must be distinguished from the older by the freshness or otherwise, of the breaks or bruises in the broken undergrowth, and by occasional spoor-marks or various other little signs; where there is only one track

* "Central African Game and its Spoor," by Captain C. H. Stigand and D. D. Lyell. 
possible for the animal to have taken it will only be necessary to check such signs at intervals.

In green grass-country the trampled grass is followed, and the actual footmarks are looked for only now and again. The freshness of the spoor can be told by the bruising of the grasses. In dead and dry grass the same trampled grass line is followed, but by the time it is dead the tracks are numerous and conflicting. Old tracks may be told from new ones by the appearance of the grass or by mud and gloss on the surface of the flattened grasses. It will be sometimes noticed that the older tracks have broken stems of grass in them with the grass-seeds withered and unmatured, while the seeds of the grass standing round are more mature. Compare, then, the seeds and pods of the trampled grass track with those of the untrodden grass beside it, for with spoor in dry grass this is often the quickest way of telling a comparatively old track from a recent one. With tracks of apparently the same freshness look for the spoormark through the grass to see how clear cut it is. If the spoor-mark has its edges worn away, or has been rained upon, or disturbed by insects or holds fluff and seeds driven in by the wind, it cannot be very new. Just after grass has been burnt tracks can be followed easily, as any burnt grass trodden on is reduced to ashes or powder. In all kinds of earthy and dry countries well stocked with game, so many tracks collect that they become confusing, until a good shower of rain gives a fresh start again. In all thick grass and bush countries fresh spoor can be told easily in the morning by the dew or after a shower of rain, as the dew or raindrops will have been brushed off by the animal's passing. On spoor made early in the night or during the rain, the dew or raindrops will be seen still on the leaves and grass.

When following spoor in grass note carefully any green patches passed and sec if they have been grazed down. By always noling what sort of grass game select to graze on it becomes easier to find marks of browsing. Having found them, a search on the ground will generally slow a scrap which has dropped from the animal's mouth, and by observing to what degree it has withered you get the age of the spoor.

Sometimes the grass is too short and sparse for it to be easily seen whether any has been trampled on, yet the same grass is still quite long enough to make it easy to miss spoor-marks whilst you are walking along. In this sort of country if all the likely tufts of grass passed by are glanced at to see if they have been browsed off, spoor is often found which would otherwise have been passed unnoticed.

Short green grass is often found springing up beneath dead grass, and this 
will be bruised if an animal has trodden on it, even though it be covered by the layer of dry grass on top. In the forest broken twigs on the ground and trampled shoots should be looked for. These shoots are favourite foods of the forest animals, and you should observe if their tops have been bitten off. Owing to the shade and moisture, forest plants, thus browsed off or leaves torn away, retain their freshness much longer than do bush plants.

The next point to consider is the appearance of the spoor-marks of different animals which, as I said before, afford conclusive evidence of the presence in the country of the animal to which they belong. Striking across the spoor of a kudu or other coveted animal will as likely as not cause the hunter to make a stay in that neighbourhood to obtain, if possible, an animal which he would otherwise have missed. If he succeeds in adding the animal to his bag, he has the spoor-mark to thank for giving him the tip.

The localities inhabited by the common animals and the plain-dwelling animals are so well known that the sportsman is not likely to find any difficulty in discovering their haunts. It is in the obtaining of the so-called rarer game, that is to say, the more shy and retiring animals, that a knowledge of the appearance of their spoor is so valuable. These "rarer" animals are, I believe, really much more widely distributed than is generally thought. It is on account of their shy habits and, perhaps, because of the glamour which the better-known and more easily seen plains animals cast over intending sportsmen that these others so often escape observation.

I have always found that white men, who have been through, or heard anything of, any particular plain country to which I may be going, can tell me exactly what animals I shall find there; but this information hardly ever includes any account of the animals to be met with in the bush around, or even the country-bush or forest-that must be traversed to arrive at one's destination. For instance, I might be directed to go to Laikipia Plains, viti a route across the Aberdares. I should be told that I should be able to get all the usual forms of game, and also oryx beisa and a northern form of Grant's gazelle, and also, if I went further north, Grevy's zebra and the gerenug. I should not, as a rule, be told that on the way to these plains there were rhinos in the bush on the lower slopes, also bushbuck and Harvey's duikers; nor should I hear that a few bongo and forest-hog might be had on the hill, or that there were a few lions at the higher altitudes with magnificent manes; that colobus were in the mountain forests, and that occasionally black servals were seen.

Every sportsman says that he is anxious to obtain an animal such as kudu or bongo. Yet will he trek through a kudu and bongo country without a halt, in order 



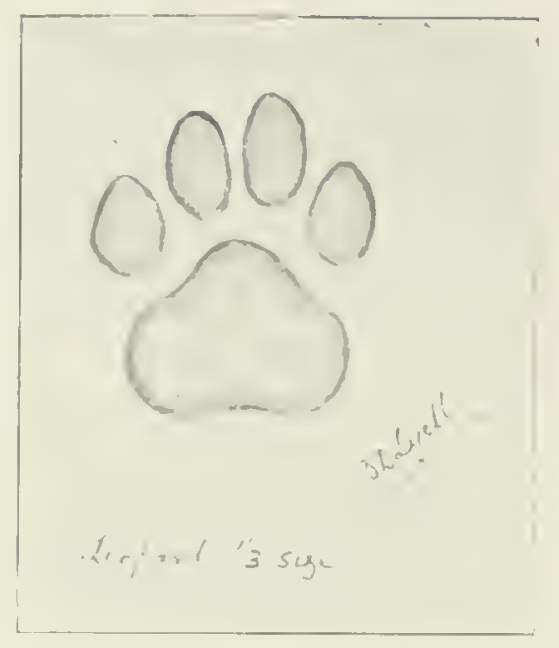

SAI IRIBF.

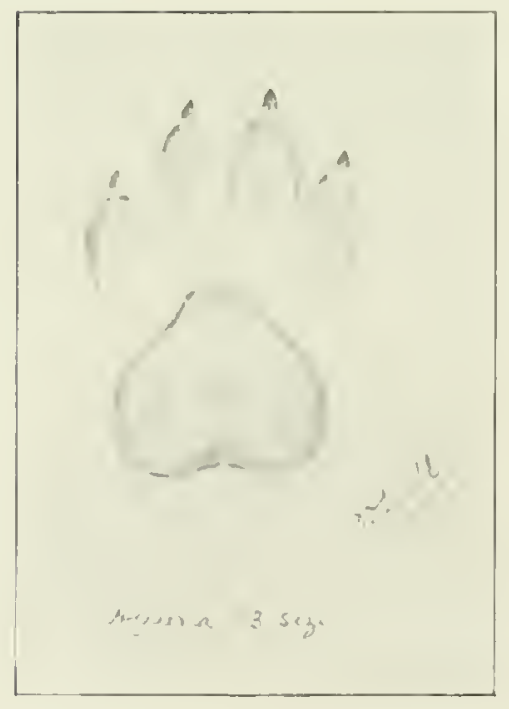

DOG TRIBE. 
to get to some plain where he may shoot zebra and hartebeest and waterbuck. Why is this? Often because he does not know that the other game animals are near. More often though, he finds them too much trouble to hunt, or thinks that all animals ought to be as easily found and shot as are the plain-dwellers.

One hears that Baringo is the only place in the country in which kudu are to be found. This is not true, for there are other places in which these animals may be had if they are sought for with eare. A knowledge of the look of their spoor enables one to do this. To the outdoor naturalist a knowledge of the look of spoor is of as much value as, if not of more value than, to the hunter.

You may go through years of travel and hunting in Africa and yet have never seen a ratel, otter, antbear, genet, porcupine, zorilla, or numerous other little creatures. The reason for this is that these animals are strictly nocturnal in their habits, and in the daytime lie up in safe retreats such as holes, caves, and hollow trees, and therefore are hardly ever come upon or found accidentally, so that, were it not for seeing their spoor about, you would never suspect that such numbers of these creatures existed and were living all round you. Although you never have the chance of observing their doings, you can at least note their spoors and learn from them a great deal about their habits, food, and ways of life.

Perhaps I ought to have omitted the antbear from my enumeration above, for after you have stumbled through the long grass into a few of this creature's holes and nearly sprained your ankle several hundreds of times, you are quite ready to admit its ubiquity without requiring the further evidence obtained from a careful study of its spoor. Other of the nocturnal animals, such as the hyæna, jackal, hyrax, rather thrust themselses upon one's attention by their nightly serenade. It is the more silent creatures which escape notice.

The use, then, of a knowledge of different kinds of spoor is the study of the habits of the most wary, lesser-known, and nocturnal anmals. For the sportsman's purpose, however, the study of only a few of these will suffice.

I will give here a brief description of the different families of spoor, but any sportsman who wishes to learn the size, shape, and appearance of all spoors, such as elephant, rhino, hippo, giraffe, buffalo, kudu, roan, sable, and other kinds, those of many of the smaller mammals, such as porcupine, genet, serval, mongoose, etc., I must refer him to the book 1 mentioned before, namely, "Central African Game and its Spoor."

Between spoors of various members of a tribe, or family, there will generally be found a strong resemblance. So much is this so that, if you know well the spoor of one nember of a species, it is often possible from it to recognise that of another 
member, even though you have never before seen it. For instance, the first time I saw the spoor of the lesser kudu I had little difficulty in recognising to what species it belonged because of its resemblance to that of the greater kudu. I felt so certain of it that $I$ asked a native what was the local name for the animal to which the spoor belonged, and entered it at once in my notebook as the lesser kudu. This name proved to be correct, but of course it was necessary to check it several times afterwards, as must be done with all native names, for natives themselves are apt to tell one wrong names, or names in a language other than that asked for.

My first impression of a bongo spoor was, that it was something like an eland's spoor with a touch of an enormous tragelaph about it. The bongo has, in a very marked degree, the eland characteristic of walking on the forward part of its hoofs, and its spoor has a resemblance to a cattle type of spoor, to which type the eland belongs. Now, this is the exact position the bongo takes in natural history classification, namely, midway between the elands and tragelaphs.

The reader will find a few of the principal classes of spoors given in plate illustrations, reduced in size for purposes of comparison. The first class is an illustration of the cat tribe. There is really very little difference in appearance between the spoors of a lion, a leopard, a serval, and a cat. If any spoor of this tribe is found, it can, as a rule, be easily attributed to the right animal by a comparison of size; though a cub lion's spoor might be confused with that of a leopard, and a cub leopard's with that of a serval, and a cub serval's with a bush-cat. In each case, though, it is probable that the young animal would be accompanied by others and by the mother, which would afford a means of distinguishing to which section it belonged. The serval's spoor would also be distinguishable by the longer stride. The cheetah has a longer stride than either the hyrna or the leopard, though the spoor bears a certain resemblance to both of these. The bush-cat's spoor is smaller than the serval's, and the genet's is still smaller, though resembling the bush-cat's.

Comparing spoors, a member of the dog-like class can be told at once, because of the clawmarks showing. The claws of the cat class, being retractile, only show in the spoor when the animal is about to spring or when they are shot out from some other cause; they then cut deeply into the ground, tearing it up, and are quite different to the blunt clawmarks of the dog class.

The main arrangement of the pads of the dog class are the same as those of the cat class, that is to say, there is one big pad behind, with four smaller pads in front. A comparison, however, will show that they are different in shape, the 




$$
n
$$



four front pads having a tendency to curve inwards, whilst the back pad is rounder in form. Without any knowledge of the shape of the pads, it should be easy to classify at a glance these two types. First look at the arrangement of the pads, and if there is one large back pad, with four smaller pads in front, and no other visible padmarks, the spoor must then belong to one of these two classes. Secondly, if there are blunt clawmarks it belongs to the dog class, but if there are no clawmarks it belongs to the cat class.

There are many animals, chiefly among the smaller mammals, which show clawmarks in their spoors, but with them the arrangement of the pads is different.

Having determined that the spoor is of the dog class, the mext step is to decide to which member of this type it belongs. As one might expect, from the varied membership of this selection, the spoors differ more from each other than do those of the cal tribe. For there is a much greater difference between a hysena, a hunting-dog, and a jackal than there is between a lion, a leopard, and a serval. The hyæna's spoor is about the largest of his class, and so can be recognised from this fact alone, unless, indeed, there happens to be a boarhound in the locality, the spoor of which is wonderfully like that of the hyzena. The jackal's spoor is much smaller than that of the hyæna, and is narrower in proportion. The spoor of the liunting-dog is more in shape like that of the jackal than of the hyæna, and it is midway between the two in size.

The spoor of the civet cat is about the same size and shape as that of the village $\log$.

The next spoor plate depicts that of the greater kudu. The spoor of the lesser kudu is an exact facsimile in a smaller mould. The bushbuck's differs very little from this type, though it is smaller than that of the lesser kudu.

The situtunga, although of the sune family, yet differs considerably in its spoor, for this animal has a hoof specially adapted to its mode of life. Its spoor is long, thin, and graceful.

The next plate shows the cattle class of spoor. The largest of this class is that of a buffalo, and it is exactly like that of some breeds of cattle, but much larger than the ordinary native cattle. Giraffe's spoor is like a very big and enormously elongated specimen of this c!ass. Eland's is slightly smaller, though near enougly in size to be sometimes confused with buffalo, though the eland walks more on the forward part of the hoof than does the buffalo, and does not cut such a clean or such a heavy spoor. From this it is possible to tell the two apart. Where there are females and young the spoor is easily told, for the female and young of buffalo cut a clear-cut cattle track, whilst the female and young of eland have a much more pointed spoor, 
and in this depart from the pure cattle type. An oryx's spoor shows traces of both cattle and hippotragus-like spoor. It is too narrow to be a cattle spoor and too broad to be like that of the roan. The bongo spoor is a type of cattle spoor.

The hippotragus spoor is much narrower than the class above, more pointed than that of the kudu, but not so pointed as that of the hartebeest. The roan's is like that of the sable's, only much larger.

Of the waterbuck type, but differing from each other, are the waterbucks, kobs and reedbucks.

As all the ordinary and common kinds of game inhabiting the plains of East Africa may be obtained with ease without having to resort to tracking or troubling to recognise their spoors, plate examples of their spoors are hardly necessary. The majority of them are more slender and pointed than the types given. The gerenug cspecially is very pointed and very slender near the tips.

I have given an example of a pig-like spoor, to which class belongs the foresthog, the warthog, and the bushpig. The spoor of the little klipspringer is like a miniature of these.

Of pachyderms, the elephant's spoor can hardly be mistaken because of its size. It is as well to remember that an elephant's spoor is practically never worth following if it measures less than eighteen inches in diameter; if possible, it ought to be twenty inches.

In Uganda, if time is no object, and you want a really big elephant, you should look about till you find a spoor of twenty-two inches or over. A small roll steel tape carried in a ticket-pocket will be found convenient for this purpose. Failing this, or in the event of its being lost, then measure by the span from your thumb to little finger, or, what is perhaps even more convenient, measure by the length of your boot. This last method of measurement saves stooping down at intervals, which latter process is tiring when a hot sun is playing on your back and neck. Also make your tracker measure by putting the heel of one foot touching the back of the spoor, and the other foot in front of the first with its heel touching the toe of the first foot. A native can generally get both fcet like this inside a really big elephant's spoor, with an inch or two to spare in front of the toe of his foremost foot.

Even if the spoor has not been measured before, and the elephant is come upon and only wounded, it would be as well to measure the spoor carefully before settling down to track him up. For if a mix-up of spoors takes place, as nearly always happens at some point when following an elephant, and there are no individual peculiarities of the spoor followed, then the measurements taken will be 


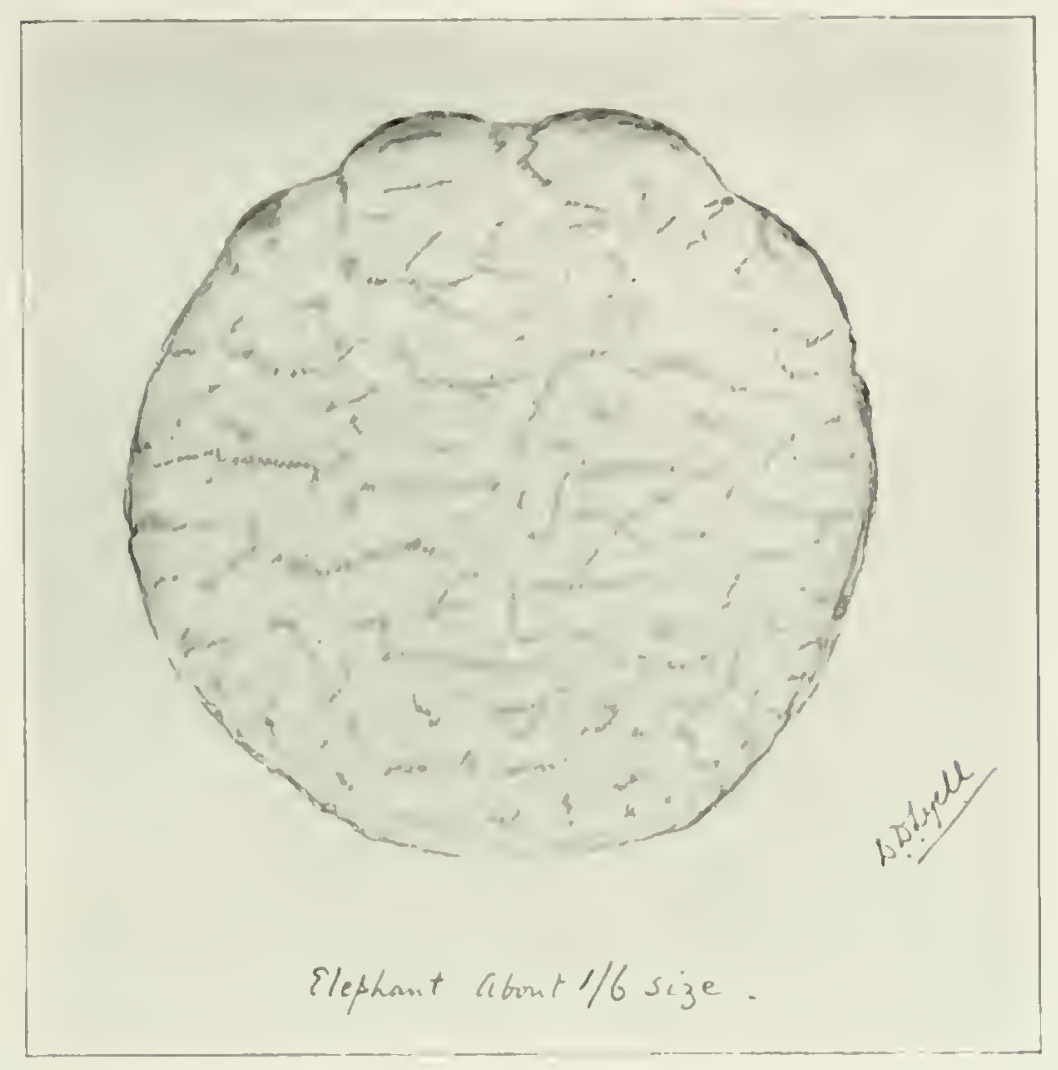

HACHYDERM.

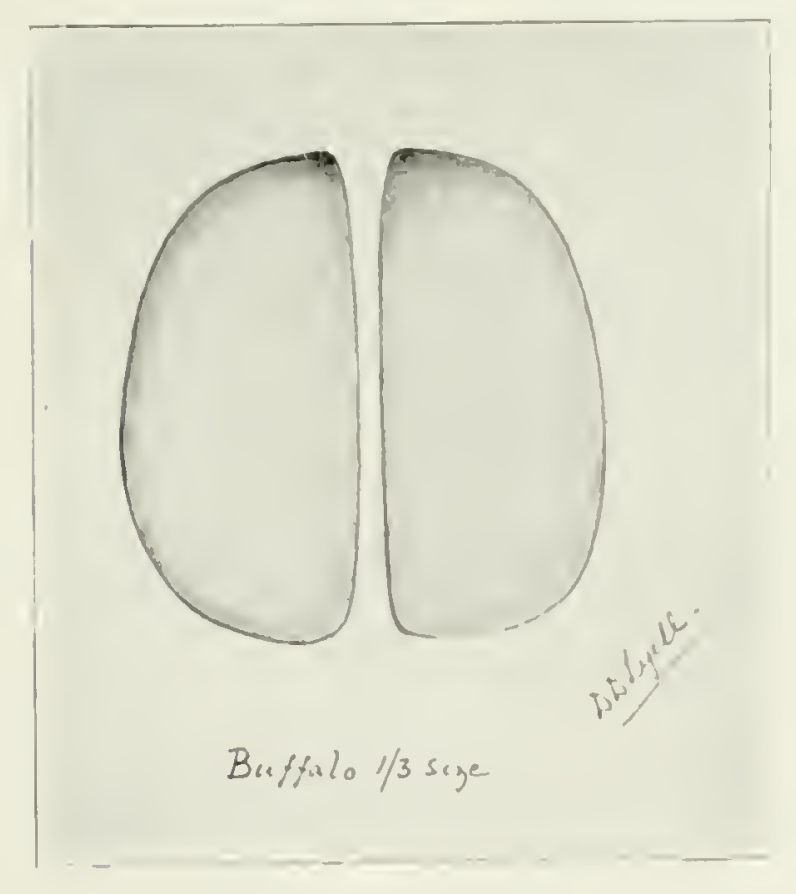



a valuable guide at such points. I have often saved myself a long, worthless walk simply by taking this precaution.

For instance, let us say that a group of elephants is suddenly come upon, and one big tusker is seen and fired at. There follows a wild stampede, and the wounded elephant goes off among the rest. He leaves them almost immediately, and the hunter finds just two drops of blood on the ground or on some leaves. He takes a hurried measurement of the spoor beside which he discovers the blood. The wounded elephant subsequently joins the herd again after going, perhaps, a few hundred yards or so, and from there onwards not a single drop of blood is to be seen anywhere. After a while the herd divides, and the hunter follows one of the two groups. He comes to a soft spot where all the spoors are clearly defined, and after measuring them all carefully, finds that none correspond with the measurement already taken. He then knows that his elephant must be in the other group and congratulates himself on his precaution. The five or ten seconds wasted when he took the measurement now save him hours of fruitless following.

To return to pachydermous spoors considered in general. The elephant, I have said, cannot be mistaken for any other, but it is possible for a beginner to be in doubt as to whether a rhino's spoor is that of a hippo. This point is really easily: solved, for a rhino has three broad toes, each leaving a track almost like a zebra's hoofmark, one pointing forward and the other two on each side of it facing half right and half left, whereas the hippo has four narrow toes, each having a blunt claw at the end.

Of the spoor of the smaller animals there is a class which has, as in the dog class, one big pad, with four smaller pads in front, and claws or nails showing in front of these. In addition to these pads, however, this class has two smaller pads, one on each side and rather behind the big pad. The relative positions and shapes of the pads are all also somewhat different to those of the dog and cat tribes. These two extra pads denote animals such as the mongoose and the zorilla.

There is another class that shows these two extra pads alongside of each other and directly behind the big pad; an instance of which is the ratel.

After these come the more curiously shaped spoors, such as the three long curves of the antbear and the almost human-like spoor of the crocodile, with but one finger less than that of a man. With the apes and baboons there is the characteristic mark of the ball of the thumb.

In spooring, the next consideration is how to distinguish the spoor of a male from that of a female. Once the two have been carefully compared together, there will seldom be any difficulty experienced afterwards, for the spoor of the female is 
almost always much smaller than that of the male, and in most cases is much narrower. With elephant the spoor of the cow is, as a rule, smaller and more oral in shape. In any case its size is an index, and if only spoors of eighteen inches and over are followed there will be no danger of pursuing females in error.

With an eland the spoor of the female is, as before stated, more pointed than that of the male. With kudu it is shorter and smaller. With sable it is smaller.

The track of a hind foot can usually be told from that of a fore foot because of its being longer and narrower. This holds good with most animals, including both the dog and cat classes.

With antelope and buck the hind foot is often smaller altogether than the fore foot, and, in addition to this, narrower in proportion.

As to paces, both the antelope and buck have much the same paces as those of a horse; that is to say, the spoors of the near feet are in pairs, and the spoors of the off feet in pairs, the hind treading a little in front of the fore when the animal is walking. When trotting, the spoors of the hind feet overlap those of the fore, and the stride is much longer.

Cats usually put the hind feet down in exactly the same place as the fore feet, and it is this which makes them so sure-footed and noiseless, as they have only to choose good spots on which to place the fore feet, and the hind follow them naturally. 



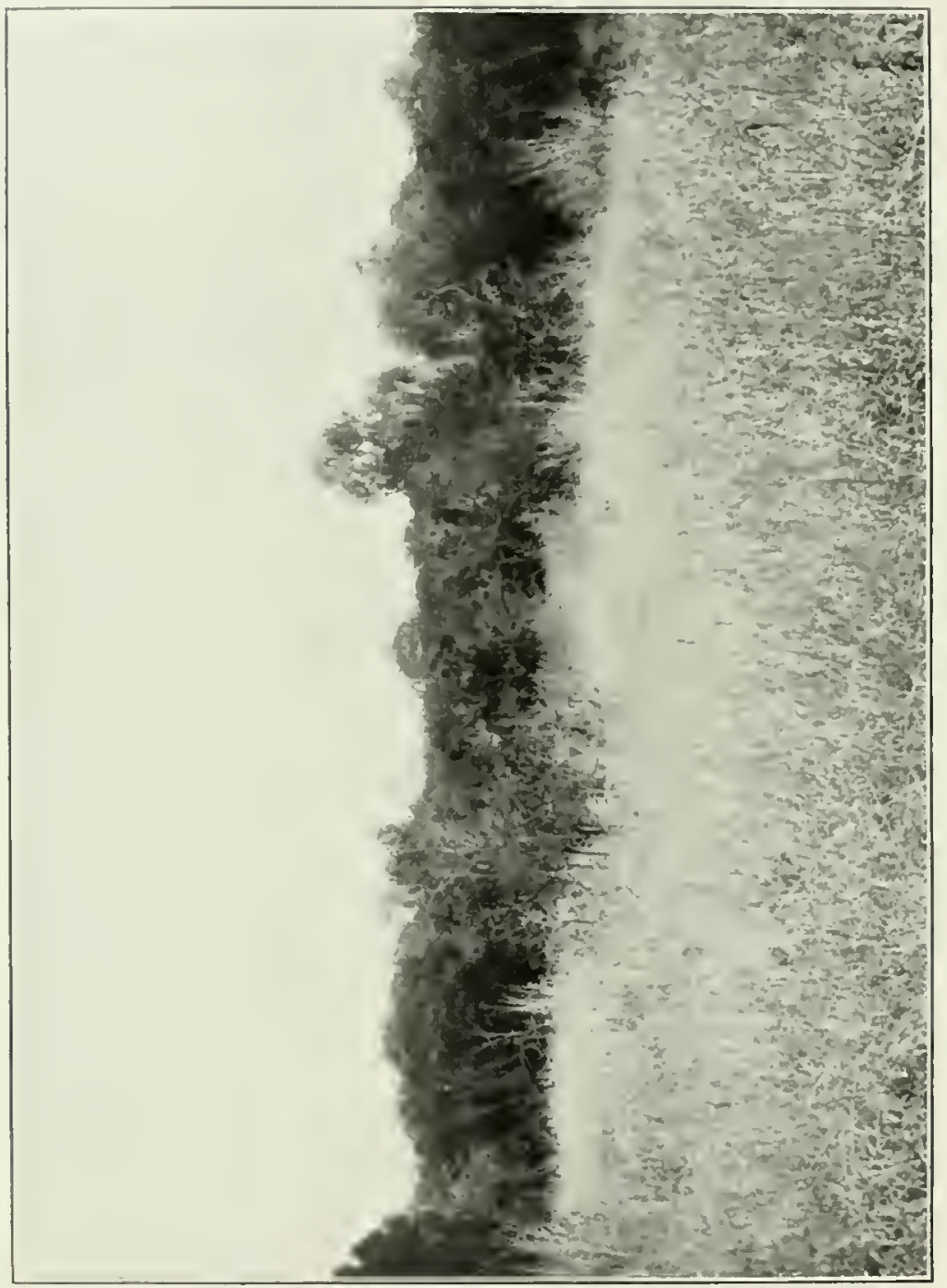

$\overline{\overline{0}}$
$\bar{\Xi}$
$\bar{\Xi}$ 


\section{CHAPTER IX.}

\section{THE BUSH.}

QY the bush I mean country that is not open plain and is not forest, but $B$ is something between these two. I will include under this heading the long elephant-grass country, which is the most difficult country of all in which to approach any game animal.

The sparsely bushed country is perhaps the most pleasant and easy country in which to saunter, and is especially pleasant when a rest is needed after hard days of hunting in thicker country, or after long and fatiguing days in the sun. For in this kind of country all is open between the clumps of bush, and there is no backaching work of crouching under overhanging branches or creepers, nor any tearing of your way among thorns or pushing through thick vegetation. When the grass has been burnt between these clumps the walking is generally very easy and good. However, some of these clumps are very large, and sometimes run in long belts, which, if you do not know the country thoroughly, will prevent you from keeping to any one direction and will necessitate your winding and wisting about and retracing steps to get round them; then, when you wish to return to camp, it will be necessary to return either by the somewhat devious route you have already taken, or you will have to judge the direction of camp and dive through belts of bush and make your way as best you can.

If you can do so, get to the top of a hill or some commanding piece of ground, and from it take note of the country, which will often save you a lot of trouble. For in bush country there is generally some open and easy way from one place to another if that way can be found, though it may be a little circuitous. This is excepting, however, any thickly bushed watercourses which may traverse the country, but even these generally have places where the enclosing bush narrows considerably and affords a fairly easy crossing.

With reference to such watercourses, there is one rule of bushcraft, elementary enough I should imagine, but one which does not always seem to be grasped by the novice. It is, that if on your outward journey you cross any watercourse, it is then impossible to find a way back to camp again which does not recross it, unless you make a complete circle round its source. If you cross the same watcrcourse twice on 
your outward trip, it is obvious that to return to camp it is not necessary to cross it again, but that if you do cross it again once, then you must also cross it a second time. It will not always be easy in thick country to tell if you arc crossing the same watercourse twice (it having taken a bend round), or if you are crossing a second watercourse. By keeping a careful note of the fall and trend of the country, however, you will generally be able to tell. In connection with this there is another very elementary rule which often seems to be lost sight of. It is, that if you cross a watercourse flowing from your right to your left, in whatever position you next meet with the same watercourse and cross it, it must then be flowing from your lcft to your right. If the second watercourse met with is also flowing from your right to your left, it cannot be the same one, but must be another. A careful relegation to memory of all the watercourses crossed during a day, and the direction in which they flow, both by general compass bearing and whether from right to left or left to right of your course, is one of the most important aids in finding your way about a thick bush country. If there is a hill overlooking a bush country in which you intend to hunt, it would be as well to take an early opportunity of ascending it, and thus of learning as much as possible of the lie of the country. Down below, in the midst of the bush, you are in the position of one in a maze; but after ascending a hill from which a good view is to be had, you are in the position of one who has a chart of the maze put into his hands. You may come to a series of turnings or glades, one of which leads by an easy and open path to the spot to which you wish to go, whilst the remainder either wind and turn off or end in culs de sac. It is obviously impossible to tell which is the right one till you have tried.

Some of the watercourses are so thickly wooded with thorns and undergrowth and so broken up with nullahs that it may take an hour or so forcing a way through quite a narrow belt of enveloping bush. If you must cross one of these in an unknown country it saves time and trouble to move parallel with the course, but at a sufficient distance from it to avoid the thick undergrowth, until you meet with game tracks leading down to it. These probably lead to a feasible crossing, and as likely as not to a place where the bush narrows on either side, something in form like the handle of a dumbbell. At worst the tracks must lead to the water or to what in the wet season would be a pool in the river-bed. If, having arrived there, you find that the track returns and does not cross, you have at least performed half the crossing without serious difficulty, and it only remains to push your way from the stream-bed through the belt of undergrowth on the opposite side.

Where a stretch of bush is found on the edge of a plain you have the advantage of being able to camp near the plain, and from there you can make a detour in the 
bush according to the suitability of the wind, and strike the plain again above or below camp, wherever you wish. This facilitates your finding your way back to camp and also enables you to regain it by a more or less direct route in the open, besides giving you the feeling that you are losing nothing, as the wind will then be adverse.

For instance, supposing that you are camped on the edge of the bush, with the plain to your west and the border of the bush running north and south, and supposing the wind to be blowing from the south. You then strike eastwards into the bush and gradually veer round to the south. You continue southwards through the bush until you want to return, at which time you veer westwards till you strike the plain. You will then be upwind of camp, and your walk will be downwind (a thankless task in the bush), and performed across the open with nothing to impede you.

When no particular animal is being sought after in bush country, and you are only sauntering about to see whatever is to be seen, it is none the less necessary to be constantly on the alert; for if you are to see any animal at all, it is necessary to see it either before or at the same moment as it sees you. In addition to this you must always be keeping note of the direction of the wind and of your whereabouts. The latter, and in fact all three of these things, grow on you with experience. The more practice you have, the less strain do they put upon you to be constantly thinking about them, and gradually get to be performed mechanically.

The inexperienced bush-hunter finds it a very severe strain indeed to be constantly forcing himself to keep on the alert whilst looking in every direction, and continually working out his whereabouts and thinking of the wind. Besides which he must always be on the look out for spoor and landmarks, and must be careful about walking silently and negotiating the various obstacles in his way, and most of the time there will be a hot sun shining upon his back. At the end of a long day he will feel very slack and tired, but his fatigue will be as much of the mind as of the bocly, after having had to concentrate his thoughts the whole day on all the small points enumerated, together with a few others of lesser importance. But as time goes on these points will worry him less and less, till he begins to find that he can go along thinking of other things, and yet noticing everything that is to be seen, or, perhaps I ought to say; that he gets to observe everything obvious in the way of landmarks, spoors, and country; but to see every animal in the shadow of the thick bush before it sees him is an impossibility. A hurried shot is usually necessary for an animal once seen, but it will be a shot at close range, for if you get a shot it all, the animal will not be far off.

To the sportsman coming from the plains, animals in the bush will always appear farther off than they actuilly are, for the shadow, the indistinctness of 
an animal, and the vista of undergrowth through which bush animals are seen, increase the idea of distance.

Sportsmen unused to estimating distances in this kind of country would be well advised to put up the one hundred yards sight and decide always to use this, however far off the animal appeared, for unless it was in a long, open glade, no animal will practically ever be scen beyond this range.

The best time for seeing animals is in the morning or the evening, as they are then grazing, whilst during the middle of the day they are generally lying down. At this latter time it will be almost impossible to detect them, for they are usually lying in deep shade, generally with imperfect cover on all sides, through which they can watch your approach, whereas you cannot see them.

When the hunter is a moving object and the game is stationary it is needless to say that the advantage lies very much on the side of the latter, for, besides the advantage of having a moving object to locate they also have the advantage of being themselves silent, whilst, however carefully the hunter mores, he must occasionally make some noise. The preservation of silence is one of the most important points in the bush, and so it would be well for the hunter to wear thick rubber-soled boots, and, in addition, to take every reasonable precaution in treading, and he must likewise aroid rustling branches and leaves. Rubbersoled boots are used by Mr. F. C. Selous in his enterprises, and were also worn by the late Mr. A. H. Neumann.

They are excellent for rocky country and dry ground, but in muddy and slippery places they are of little use, and so should be discarded during the rains for leather-soled boots with nails or bars.

When animals are grazing they are easier to locate than when stationary, but are still often very difficult to sight, for they are but slow-moving objects.

The bush animal when grazing, or any other animal for that matter, as a rule, goes forward only a few steps at a time, and looks up and all round at frequent intervals.

Moreover, it keeps in shade as much as possible, and because of its low stature is able to pass easily under the branches of most bushes, and therefore in the shade. The hunter, on the other hand, unless he crawls under these, must needs go round the branches, thus being in the light.

The lower level of the game animal gives it a further advantage, and that is, that it can look round and between the stems of the bushes and see the lower part of the hunter's body, whilst he, from his superior height, has his line of sight intercepted by the leaves and branches. The great secret of sighting 
game in the bush is to move very slowly so as not to be more noticeable than you can help, and also this gives time to look well in every direction; besides, the slower you go, the more silent will be your advance, which gives the twofold advantage of your being less likely to be heard and of permitting you to hear the better.

The advantage spoken of so far has all been on the side of the game, but, assuming the game itself is moving and the hunter proceeding slowly and in dead silence, he may find that he is able to get the better of the game; for it is very difficult for grazing game-and especially a herd-to move in absolute silence. If they are feeding off leaves and branches they must now and again betray themselves by a cracking twig or the tearing off of a branch, so the hunter should be always listening intently, and when he hears a sound should be more thas ever on the alert. The advantage will then rest all on his side, for he will know of the presence of some animal, whilst it is still in ignorance of his proximity. He can then put himself in the position of the stationary object behind imperfect cover and in shadow watching for the moving object. The object which generally meets his gaze on such occasions is a rump withdrawing behind a bush, or a pair of horns bobbing up and down.

However, the moving object does not necessarily draw towards the watcher, and, after waiting in vain for the animal or some other member of the herd to step into view, he generally finds it necessary to advance if he is to obtain a further glimpse. If he does so, the advantage lies with the game once more, and he himself becomes the moving object. He must, moreover, get into a position from which the greater part of the animal is visible. The animal, on the other hand, needs only to see but the smallest particle of the hunter's person, and an end is put to all chances of success.

So, if the sportsman must advance, he should try to locate by sound or otherwise the exact positions of as many of the herd as possible. He must also keep near bushes, and must not trust to the animal's not seeing him from the other side of any one of them, behind which it has just screened itself. Likewise it would be as well for him to advance in a crouching attitude, so as to be able to see beneath the branches; and such an attitude leaves less of his body to be seen, and also puts him on the same sight-level as the animal, so that if the animal can sec him he ought equally well to see the animal, particularly as he is looking for it and knows, more or less, its exact whereabouts, whilst the animal is keeping a look-out in no one particular direction. Directly the hunter is discovered by the animal, either in the stalk or in walking through the bush, immediately the animal starts up and pauses a moment to look at him, he has to decide in that instant whether he will shoot or leave it alone. 
For the animal, as a rule, waits but for one momentary glance, and then, directly the rifle goes up, turns about and bolts. The shot is but a snapshot, yet it will be at short range. It is during this brief moment that the sportsman must decide whether the head is good enough or not to bring to bag. If the hunter has only seen the animal fairly for the first time at this critical moment, he has then also to decide as to which species and sex the animal belongs before he can gauge the head.

An animal when grazing continually lifts its head to stare in different directions, and will often stare for a considerable time in one particular direction before continuing its grazing. If this lengthy stare happens to be in your direction it often bluffs you into thinking that you have been detected, but an animal when it really does sight something generally stands erect, and usually turns or wheels round either partially or wholly facing the object. So if the animal, when looking towards you, is still crouched over its grazing, but with its head up, you may assume that it has seen nothing to alarm it, and that it is only taking the ordinary precautionary measures of an animal on the look-out. If, on the other hand, when it looks in your direction, it starts bolt upright or wheels round facing you, you make take it that it has seen you; but if you are behind imperfect cover or in deep shadow, you may remain in perfect confidence that it will not see you so long as you do not move.

The only other remark I have to make about this kind of hunting is that you should keep in shadow as much as possible when walking, and pass from the shady side of one clump to that of the next.

Hunting in bush-country, you may spend day after day without seeing a single animal, but it would be unwise to deduce from this that there were no animals in the bush, for it is impossible to estimate how many animals you have just missed seeing, and how many animals have seen you first and so taken to their heels without giving any warning of their presence. You cannot expect to find as many animals in the bush as on the plains, for the grazing is nothing like so luxuriant.

If you were to imagine the plains all covered with thick bush, you could quite realise how few of the many herds of game roaming there would be visible under the circumstances. If you took an imaginary line across and supposed that this was the line you would traverse, and that your vision was restricted to fifty yards on either side of this line, you would find that very few animals came within its limits. Moreover, these very few animals would represent the only ones that it would be possible for you to strike across during the course of a day's hunting. Then from these few you must deduct the animals that might get your wind or hear or see you before you saw them, and you must also remember that the bush is less thickly stocked with 
game than the plains. So there might be quite a number of animals about, and perhaps close at hand, whilst you spend whole days hunting and seeing nothing. It is then that the use of spoor is obvious. For if after several blank days you have seen no fresh spoor, the conclusion is that there cannot be many animals in the locality. If, on the other hand, you find plenty of spoor everywhere, it is always an encouragement to go on in the hopes of doing better next time. In bush-hunting it is the constant failures which goad one on to further efforts, and make success when it comes so well worth the reaping.

The mclancholy return to camp after a long and unsuccessful day, the while ruminating over some lost chance, is so diffcrent from the jubilant return of the successful hunter. With him the long miles seem to slip past with lightning speed. He scems to walk on air, and this notwithstanding that he is possibly carrying a heary head and a pair of horns on his shoulders, whereas had he bcen unsuccessful the miles would have seemed unending and the journey tedious, although he was unburdened with heary spoil.

Now for a little picture of a few days spent in the bush.

You are camped just on the edge of the bush bordering a plain, and directly below camp is a stream-bed to which various game paths descend, thus inarking the places where pools of water have survived the drought of the dry weather. An early start is necessary, to catch if possible some animal out grazing away from cover, and your first step is to skirt along the edge of the plain, keeping close to the bush and inspecting all the little inlets of plain running into the bush, which form farourite places for bushbuck to come out into during the early morning hours. If a bushbuck is scen he should be approached by keeping, if possible, just inside the edge of the bush and thus intercepting his retreat.

I will say, however, that the early morning inspection proves unfruitful; then the next step is to follow the edge of the stream-bed to see if anything has been down to drink at the pools during the night. It is not necessary to descend the steep bank into the nullah to learn this; instead you cross the nullah by the first game track met with, and then pass down the other or bush side, of the watercourse, inspecting carefully all the game tracks leading down into it.

Yesterday after pitching camp the porters who went down to draw water reported having seen a rhino drinking at the pool just below camp. An inspection of the tracks about this pool shows that a rhino did drink there, but it was on the night before you camped, so it is obvious that the porters could not have exactly se'n the rhino. It is, however, a quite pardonable error on their part, for they had thought that the tracks were fresher than they really were, and that the rhino had therefore 
drunk later than he had done. If they had only been drawing water earlier these two times might have coincided, and then they would have seen him drinking, which according to their reckoning is much the same. I do not know if this is the actual working of the native mind-very likely not, but he always puts himself in the position of being a little nearer than he was, and by the time he gets back to camp he imagines that what might have happened has really occurred. For instance, if he hears an animal going away, or if someone else says that he saw one, he considers it just the same as if he saw it himself, and points out most authentically the position in which he saw it. If natives had such things as laws of evidence, "hearsay evidence" would be admitted as every bit as good as any other evidence.

Every African traveller must be familiar with the native who comes in with redhot khabar of game, "having actually seen the animals with his own eyes," and is anxious to show you the spot. After following him for some time there appears to be some sort of difficulty about finding the exact place, and no spoor is visible. When pressed he cheerfully admits that he did not actually see the animals himself; in fact, he has never been to this locality before, so it cannot be expected of him that he should be able to show you the exact spot. However, he as good as saw them, for he met someone who had been told by someone else that he had seen the animals, and this was the spot he described. That someone else probably didn't quite see them, but saw the spoor, or at least someone said it was the spoor, and so if he had passed the day before at the right time he might quite easily have seen the animals.

But I am wandering from the subject in hand. Let us continue our little excursion in the bush. This morning there is no fresh spoor leading down the game tracks in the near vicinity of camp, so the rhino which might have been seen by your porters has betaken himself elsewhere. You are a stranger to this particular part of the country, and thus know nothing of the bush here, so your first step is to try to find out something about the country. There are several little hills rising up out of the bush, so, choosing one which stands more or less upwind and is sparsely covered at the crown, you make it the objective for the first day, and wend your way thither slowly and carefully, taking the line of least resistance by following the open spaces between the clumps and belts. Sometimes you seem to be departing from the hill, and sometimes you are able to steer directly for it; but, in any case, your route will be much longer than it at first sight appeared, owing to the winding and twisting about. On the way you strike a certain amount of spoor, which is cncouraging in itself, but of the animals there is not a sign. At last you reach the hill and toil steadily up, paying little attention to anything except the process of climbing, in 



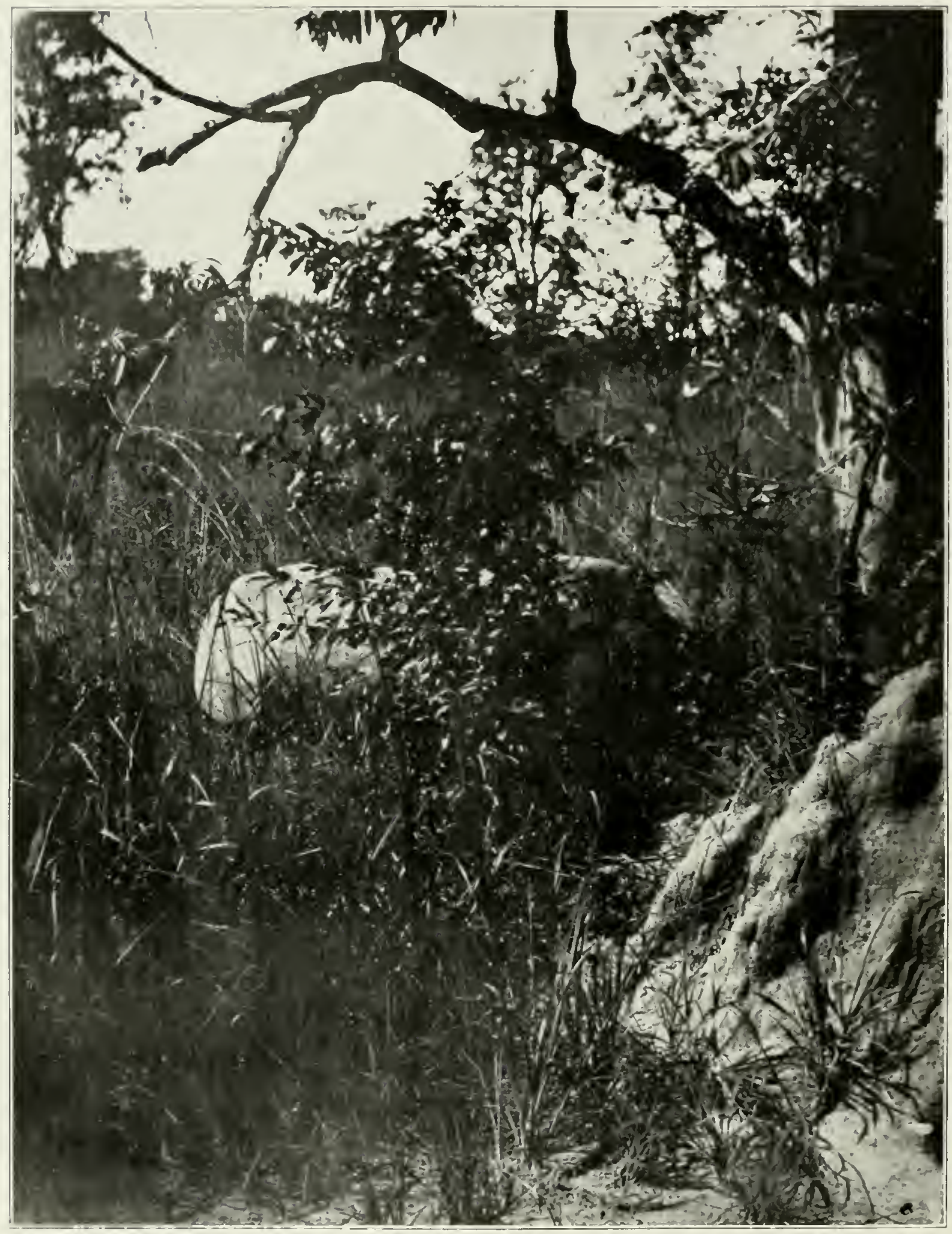


your desire to reach the top. Suddenly there is a breaking of branches on a flank, and, looking round, you catch a fleeting view of a flying impala. You have blundered into a herd just at the only time during the whole day that you have been off your guard. Reaching the top of the hill, a small duiker jumps out of a tuft of grass and scampers off.

The view from the top is good, and you are able to see a great deal of the country, so you note down different likely localities for future use, and also mark out a line for your return journey. On the way back you come to a deep valley-in all probability a watercourse joining your camp stream-and you see something moving at the bottom, which, on inspection with glasses, proves to be a young waterbuck emerging from his midday retreat. This is the only animal to-day which you have sighted before you have been first sighted, and in this spot the ground is favourable for observation. So you creep into the shadow of a bush and watch with glasses. The waterbuck grazes slowly down the valley, but of a sudden cocks up his ears. What has he heard or scented? Looking up above him you see, after a long search, several more waterbuck, hardly discernible against some burnt grass, coming down to the valley bottom. The first one is aware of their approach, having no doubt caught a whiff of their strong smell or heard the rattle of a stone dislodged on the hillside. They at present have not discovered him, and he stands cxpectantly awaiting them. When they get within about eighty yards of him they suddenly see him and halt After looking at him for some time one or two advance little by little towards him and stop again. It reminds one more than anything of the manouvres of strange dogs on meeting.

Presently one of the party reaches the solitary buck, and, after sniffing at him, commences butting with him. Then the others come up and examine him critically, and presently they all stroll off together down the valley, grazing as they go. They are working slowly towards a pool lower down the valley, from which they will take their evening's drink. After watching them you return to camp, and the day's work is finished.

Next morning there seems to be more game about, for, just as you leave camp, you put up a dikdik, which speeds away, and a moment hater you hear the hoarse bark of a bushbuck, which tells you that you have been seen by him. You try to get a glimpse of him, but the crashing of branches tells that he is altogether too sharp for you. You next come across fresh buffalo-spoor, and this you follow, and, as it becomes fresher and fresher, the excitement grows, and you move with extra caution. Then, all of a sudden, there is a rush as of a whirhind, and a crashing of branches and thudding of hoofs. They have nutwited you by their otd trick of lying downind 
of their spoor, after having made a detour.* You spoor them up for the rest of the day, but do not again come up with them, and thus the second day ends uneventfully.

It becomes necessary now to shoot something to replenish the larder, even if it is only a common animal, for the meat problem is getting serious; so, early the next morning, you go down to the water and there find the fresh tracks of a rhino. You follow them up with all due caution, for, as I have said, this animal is dangerous when in the bush. When the spoor leads across the wind it is necessary to keep a constant look-out downwind, for it is unwise to let him have your wind without first seeing him.

This is a point to be very careful about-not only in the bush, but in the long, tangled and matted grass which is such a farourite resort of this beast. Whenever circumstances force you to walk across wind, you should keep a constant lookout over your shoulder downwind. For if a rhino is lying in this stuff he will be invisible as he lies; but, once you have crossed him and he has your wind, he will stand up.

So this morning, as you feel the wind on your left cheeks, you keep glancing backwards over your right shoulder. This caution stands you in good stead, for suddenly from behind a bush looms up the head and horns of a bull rhino sniffing the wind and peering round. There is no time to lose, for in another minute he will be either bolting or coming towards you with a series of engine-like puffs.

It is necessary to decide in a moment whether the horns are a good enough trophy to form one of the two allowed on the licence. If they are not good enough, you had better skip at once, and try to get out of the wind and near a climbable tree. He will probably bolt away, but it is not worth taking the chances, for "the exceptions that prove the rule" are frequent enough, especially in places where rhinos have been much harassed. Presuming the horn is good enough, then, if the sportsman has only a small bore, he should put a bullet diagonally through the forehead and into the brain, taking care that the horn is not in the line of fire, or it may deflect the bullet, and also one of the horns will be spoilt as a trophy. With a big bore, a crashing shot into the chest or shoulder is the safest, as it allows a greater margin for error.

But to resume; I will assume that the horns look a good enough trophy, and that the shot fired goes home, and I will leave the reader to decide according to his

\footnotetext{
* Some people say that they do not do this purposely. I think, however, they do it often enough to show that it is done with intent. Only the day before revising this a Congo buffalo treated me in this fashion, making a wide sweep round and taking up a position some fifty yards downwind of his tracks.
} 



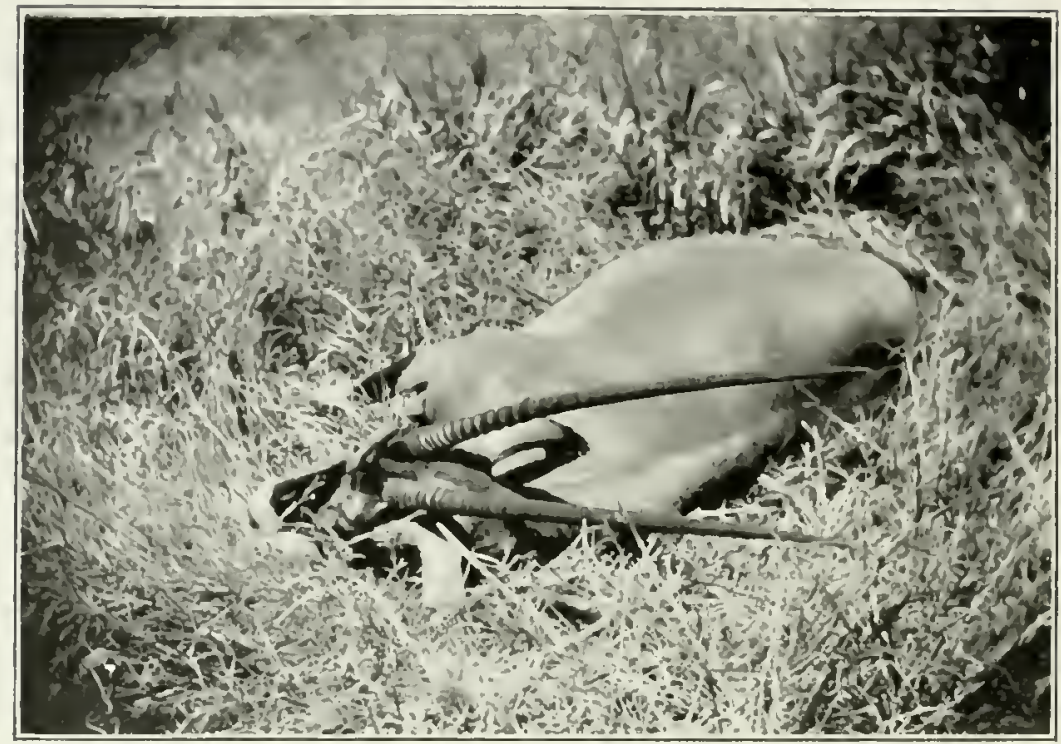

FRINGE-EARED ORYX, LY CIPT. C. R. BICON,

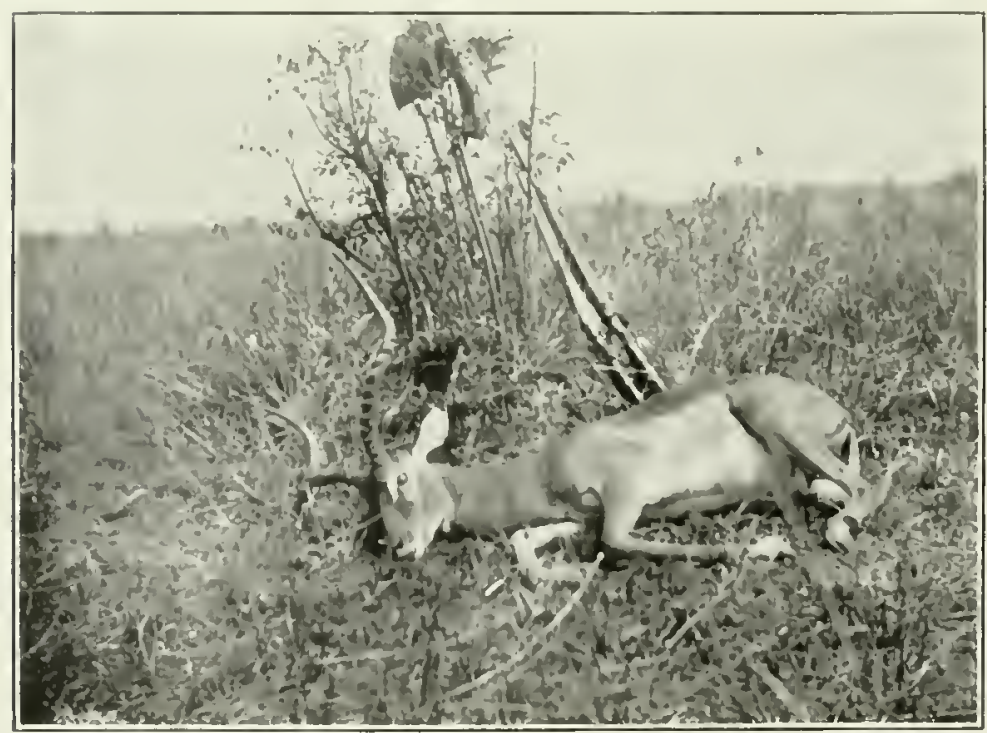

IMP.AL.I, BY C.IPT. C. R. B.ICON. 
individual taste whether it was a big or a small bore which was fired, and so aroid the much-rexed question of bores.

Having brought the rhino to bag you have at least his tongue for the larder to keep camp going until you can get some other meat more toothsome. Also, you have gained some fat with which to cook, and a little biltong can be made out of the meat which will serve for soups. You call the porters and they come screeching through the bush. They are even more noisy than usual in their delight at getting so much meat. You quite regret having shot the animal now, as it means the desecration of your hunting-ground and the scaring away of all the game by this howling rabble of porters. 'The cutting-up operations begin and a revolting orgy' follows, so after making arrangements for the various parts you want to keep, and possibly after having traced the bullet to its destination, you return to camp. Later the porters return, each carrying as much meat as he can stagger under, a ration which he will probably finish in a day or two.* Even the Mohammedan porters, if they have been without meat for some time, will find that they are able to establish their rights to cat the animal although it has not been "hallaled." They will say, "It has no neck, therefore its throat cannot be cut, so it is lawful food." This is a ruling which appears to vary considerably with the length of time since they have had meat, and is what the Wanyamwezi call "Kitowero." $\dagger$

Next day' a change of camp is advisable, so you shift down several miles to get an undisturbed hunting-ground. There, as you stroll along one morning, an enormous pig suddenly makes his appearance from behind a bush and leisurely walks past. You whip out glasses to have a good look at so remarkable-looking an object and watch him stroll out of sight behind another bush. It is only then that you realise that he was that seldom-shot animal, the forest-hog. You tiptoe up to the bush behind which he disappeared, for you have no better route to take, but he has heard vou or scen you through the bush, and has made off.

I have never had time to spend more than a few days in the pursuit of this animal. I hoped to get one in the forests near Nandi and the Ravine, but just as I had finished my work there, I was called away suddenly, and so was not able to spend the couple of days 1 had planned for the hunting of him. He is not entirely confined to forests, as is generally supposed, for I have found traces of him in bush-country in two different localities.

- I am told that many' natises think nothing of ealing a whole sheep at a sitting. "The Winndorobo, after having gorged themselves with as much meat as they can hold, will sleep by their meat cooking by the fire, and wake up at intervals during the night to cram down a little more. or flour.

t The vulgar pronouncialion of the Swahili, "Kitoweo" = meat, fish, or any nawouring eaten with rice 
However, let us continue the stroll. Presently you hear a twig crack, and instantly standing quite still, you see a female impala pass behind a thinly-leafed bush, and on out of sight. You crawl nearer on hands and knees, and when about forty yards distant from the bush another female comes into view. Waiting breathlessly until it is out of sight, you then slowly and silently assume a sitting posture. To right and left you can hear others grazing, and then another one passes; it also is a female. Closely following her is an immature male, and behind him comes another male grazing, head downwards, and only his back is visible. Presently, however, he raises his head and shows a fine pair of horns; but immediately lowers again to resume grazing. That rhino tongue is not very nice, and here is a chance to obtain fresh meat and a good pair of horns into the bargain. It seems to be hours before he moves, and he is so close you feel afraid that he will hear you breathing. At last he moves forward a step, and a shot at the lungs offers. You fire, and he darts off, and the herd also breaks away.

Has a branch deflected the bullet, or what has happened? The shot was too near for you to hear the bullet strike. You now move round to the spot on which the animal stood, and see the deep impress of his hoofs where he leapt away. There is another beyond, and then another, but after that it gets mixed up with the tracks of the herd. You see a wall of bush to the right, and notice that one of the animals has leapt this; looking closer, you find a drop of blood on a leaf, and on pushing through see a large clot of frothy blood, showing that he is hit through the lungs after all. A few yards farther on you find him lying stone-dead, and, what is better, see you have not been deceived about his horns; they are a fine pair, measuring thirty inches. You cut him up with the assistance of one native who has followed you. More natives you could not take with you, for a single native is the greatest number whom you can safely trust not to talk together.

Your native disembowels the animal, and cuts out the kidneys for your morning's breakfast. The quarters are then cut off, some bark is stripped from a neighbouring tree, and the legs are tied together for transit. The head also is taken, whilst the rest of the meat is put up in the fork of a tree to be brought in later. The spot chosen for this reserve meat larder must be at some distance from the remains left on the ground, and the meat should be covered over with branches, so that it may escape the observation of vultures. You then set off back to camp, well pleased with the day's doings.

Now, in one of the little inlets of plain running into the bush you have noticed fresh bushbuck spoor upon several occasions, but early morning visits to the spot have not enabled you to see one of these animals; so the next day, after spending 
the morning attending to heads and skins, you take in the afternoon a pipe and a book and go off to this little inlet and ensconce yourself comfortably in the shade behind a convenient bush and sit there smoking and reading. Towards sunset there is a crackling in the bush, and presently a bushbuck pushes through and looks carefully round. He then lopes out a few yards into the open and starts feeding. Presently a female and a young one emerge from a different quarter. She takes no notice of the buck, as she has already seen him when looking out before leaving the bush. They graze apart, each advancing a few yards at a time in a peculiar crouching way, and looking up timidly from time to time in search of foes. They appear to move with the forelegs bent and crouched lower than their hind. This habit is probably gained from their constant crouching under creepers, branches, and other obstacles in the thick bush and forest. Suddenly the female springs up and darts back into the bush followed by her young one. The buck takes a momentary glance at her and also seeks refuge in the bush. She has got a whiff of your wind. Something else, unnoticed till now, also jumps up and takes to flight. Its glossy yellow side, as it catches the setting sun, shows it to be a leopard, which also had been waiting to see the bushbuck, though more particularly interested in the female and young one.

Having, I think, worked this bit of bush quite enough, let us trek off and take a look at the haunts of the lesser kudu.

These animals almost always inhabit country little watered, so their drinkingplaces are limited in number. By far the best way to hit across them is to get to know all the water-holes in a certain tract of country, and visit these regularly in the hopes of striking fresh spoor. In lieu of native guides, who know the water-holes, these localities may be found by following up old spoor and by observing game tracks. Having found all the likely water-holes in the neighbourhood, these should be visited alternately, choosing each day the ones which lie in a suitable direction for wind from camp. These will form an objective for a day's walk, but look carefully for fresh spoor the whole time, as the chances are you may strike some on the way.

Both the greater and lesser kudus like hilly and stony country, and in that kind of country glades are often at the bottoms of valleys in which the animals come out to graze at night and in the early morning. Kudu-country will generally be a succession of ridges and valleys. On arriving on the top of a ridge it is a good plan to choose a look-out spot from which a good view of the opposite slope may be obtained, and there to sit with glasses and examine earefully piece by piece the whole of the opposite slope. I think that I have seen more kudu by doing this than through 
any other way. Even when following spoor this is advisable, as if you follow the spoor blindly as likely as not you will come on the animal in an unfavourable place or with a bad wind. So whenever the spoor leads you to the top of a rise, carefully examine the opposite slope, remembering that these animals are generally found on the slope of a hill and not on flat ground. Having once seen an animal, if it is in a position unfavourable for a stalk or for wind, you can wait until it moves to some better locality. In any case, it is much better to know exactly where the animal is, than to come upon it suddenly in thick bush. From a commanding position you can generally work out a rery good line for a stalk, after having watched the animal for some time to see which way it is grazing.

Before commencing an approach you should commit to memory as much of the country as possible, and mark down the position of the animal very carefully by a number of landmarks, so that you will have no difficulty later on in telling when you are in its neighbourhood and how far away it is.

The oryx, like the kudu, is an animal which is generally found in waterless country, but which prefers flat and plain bush-country, covered usually with little patches of coarse though not very long grass, and thorn-trees such as acacia and mimosa. As a rule, its tracks are easily picked up and easily followed in the dry sandy or earthy soils usual to the countries it inhabits.

Perhaps I have not been able to convince the reader of the charms of bushhunting. If so, the fault lies rather with the pen that attempts to describe them, than with the undeniable charms of bush-hunting itself.

The rhino, it is true, might be more easily shot on the plains, but shooting him there is very tame work, whilst in the bush there is some excitement and interest about following and bagging him. The impala might be shot in one of the wooded stream-beds of the plains, but in the bush the animal seems to be of a finer size.

The excitement of shooting in the bush is its environment of uncertainty; you never know what you will meet with, or what may be round the next corner-it is not all cut-and-dried shooting as on the plains. You have to be always on the alert, and almost invariably the animal appears when least expected. Moreorer, you must make up your mind in an instant as to what course to pursue, whether to shoot or leave it, or whether to stalk or keep still; and, if you must stalk, then you often have to decide in a moment what route to take, and must likewise appreciate at a glance the possibilities of the country.

The most interesting work of all though, is that of following up an animal; tracking it step by step, always on the look-out and for ever listening for it, 


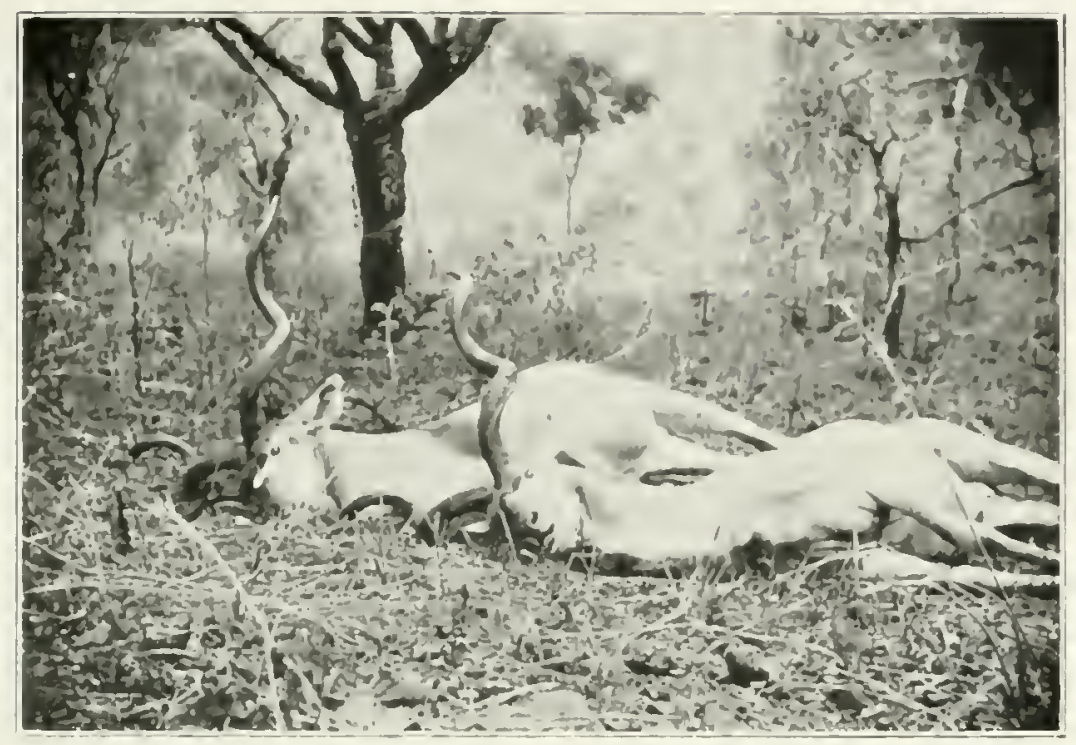

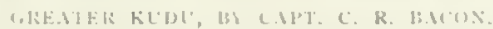

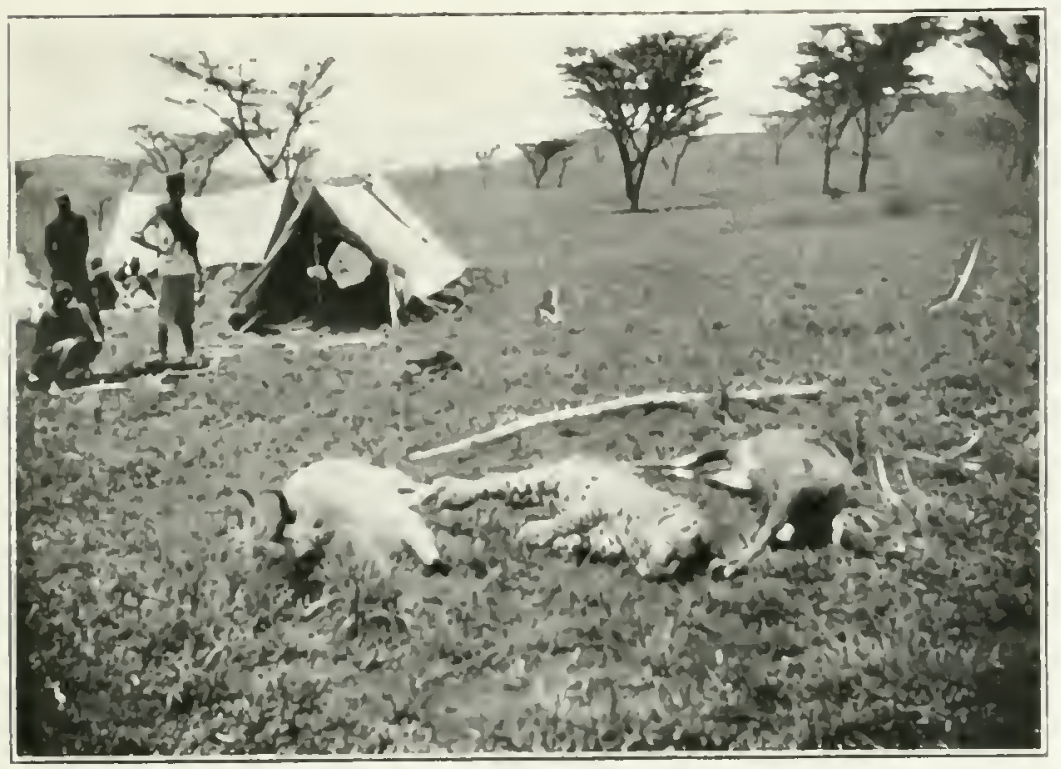

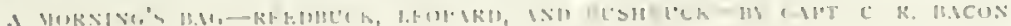



continually thinking how to circumvent it, and bearing in mind the direction and changes of the wind, and a host of other things. This affords an excitement and a pleasure unknown and unobtainable on the plains.

The usual animals frequenting bush-country are:-

Elephant.

Rhino.

Buffalo.

Eland.
Waterbuck.

Impala.

Bushbuck.

Dikdik.
Lion.

I.eopard.

Bushpig.

The rarer inhabitants are :-

Giraffe.

Greater kudu.

Lesser kudu.
Oryx beisa.

Ory:x callotis.

Sable.
IValler's gazelle.

Zanzibar suni.

Forest-hog.

Of the different bush-countries, the Ngong Forest, near Narobi (part of which is bush-country'), contains all the animals mentioned in the first list with the exception of the elephant and the eland. Of these two, the former, I am told, used to exist near Ngong Mountain, but now is no longer to be seen there. Nearly all this country is now included in the reserve.

Then there is the bush-country of the floor of the Rift Valley, between the Mau and Kikuyu escarpments; and there is also some very pleasant bush-country round the upper Kedong stream and under Kijabi, and towards Mount Lonongot. It is in this country that the famous gas-hole is situated, a pit which exhales poisonous fumes. The bones of many buffalo which may be seen strewn round testify to this pit's dangerous nature to these animals.

All the animals on the first list may be had in these parts, and, in addition. there are a few greater liudu if you can find them. Elephants, as a rule, are not found, but very occasionally pass by on their way to the Mau escarpment or elsewhere. Rhino, from all accounts and judging from the number of skulls lying about, used at one time to be numerous, but they have either been considerably thinned down or have betaken themselves to the escarpments.

All round the foot of the mountains, generally known as Kinangop and the Aberdare range, is a belt of bush-country, and a similar country is found on "the moors" on the top. There wander rhino, bushbuck, and Harvey's duiker, but little else in the way of game.

Round Myeri, and especially northwards, north-west and north-east, is some pleasant bush-country lying under the Aberdares, or the Simbara and O-Satima Mountains, and along the border of the Laikipia Plains. In these sections of bush are found the usual bush animals, and, in addition, a few lesser kudu and a few 
forest-hog. The only exception is the buffalo. Myeri Hill itself is a habitat of the lesser kudu and forest-hog, and they also occur, though it is not generally known, in the bush-country to the north-east.

Below the Kenya Forest about Embu, and between the River Dhiba and the Embei country, is a large tract of very easy-going bush-country, in which the usual game are found, buffalo, lion, and eland being especially numerous. Forest-hogs, too, are found there, and the country in parts looks as if it ought to contain lesser kudu, but I have searched in vain for their tracks; neither have 1 been able to obtain any information from natives about the animal, so I suppose that it does not exist there.

At the back of Ol Doinyo Sapuk and in Wakamba-land there is some bushcountry, park-like in parts and in others dense thorn. This country extends to the north towards Punda Milia and Fort Hall, and to the east to the Tana, and on both banks of the Athi River after it has taken its southward bend. In its bush are giraffe, as well as the other bush animals. In the Ithanga Hills, which form part of this section of bush-country, buffalo, eland, and bushbuck are very numerous, and to the southward rhino swarm. Lion are fairly common all over the country.

In Wakamba-land, stretching away behind Machakos and Kitui, and lining both banks of the Tana River, is an immense tract of bush, most of it thorn, and the greater part little or wholly unknown. In the nearer parts giraffe and rhino are common, and so are buffalo and lion. Farther southwards, as the country becomes drier and less watered, the lesser kudu and oryx callotis may be found, and in the little-known and unknown parts they are very numerous. Elephants also are found. Elephants on the Lower Tana are growing scarcer, I believe, from being molested by natives, the Somali and Galla tribes. South of the southern reserve is thin bush, which, farther south, is superseded by the dense and impenetrable bush of the Taru. In these parts are the lesser kudu and the fringe-eared oryx, which also occur in the Kilimanjaro country towards Taveta, and the fringe-eared oryx is reported as plentiful on the German border. Waller's gazelle is also found. Giraffe, too, appear to be plentiful in most of the country.

On the coast, between Malindi and Mombasa, and also near the mouth of the Tana River, is a belt of very thick bush. In both these sections elephants may be found at certain seasons, whilst buffalo are plentiful; lions also are found. The bush is so impenetrable, however, that these animals are most difficult to bag.

On most of the islands of the Lamu Archipelago bushbuck occur, and on some of them the lesser kudu is found. Inland from Gazi, south of Mombasa, some good 


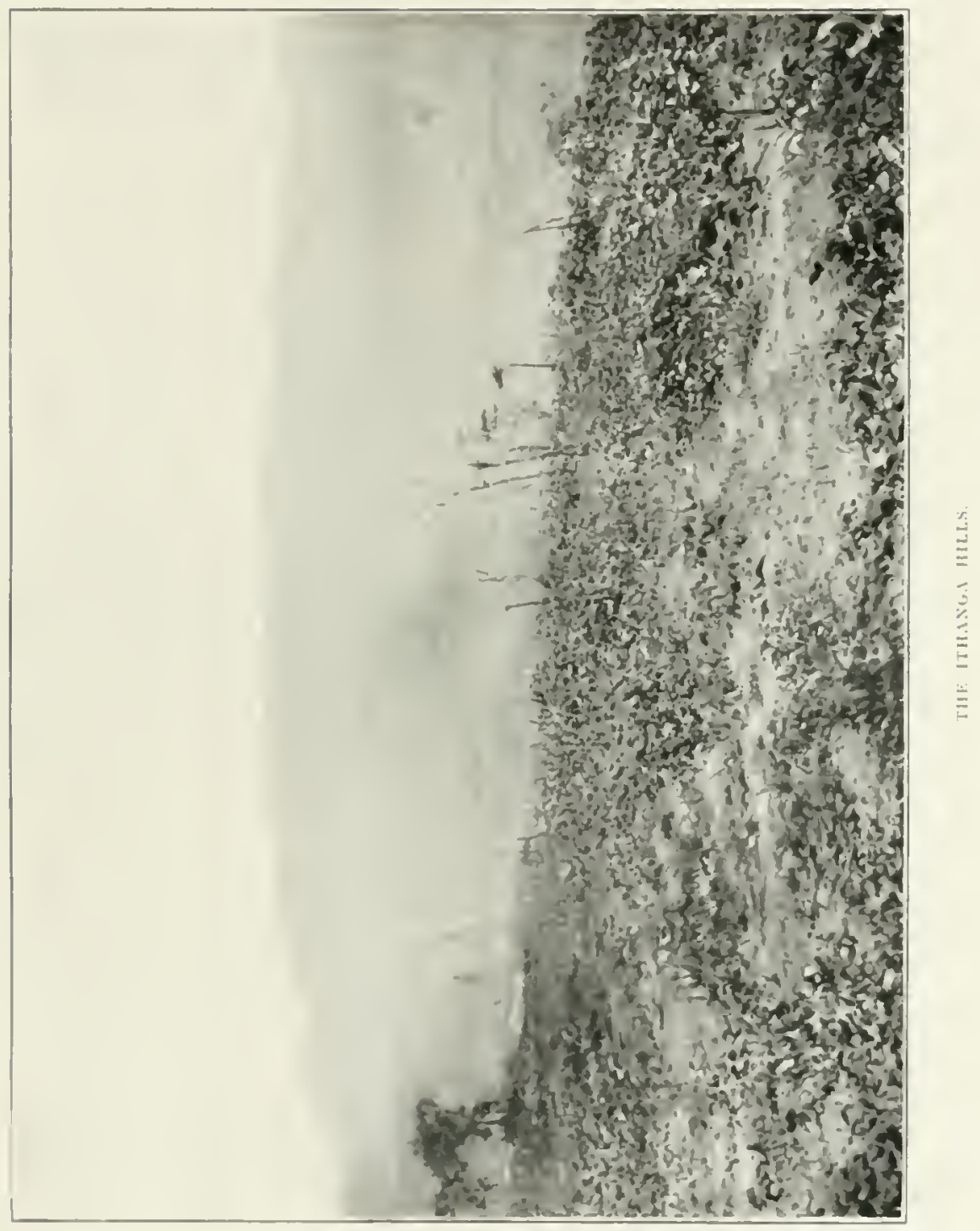



shooting may be had, and it is in this country that sable are found. Some thinner and better bush occurs towards the Shimba Hills, in which are buffalo, eland, sable, the lesser kudu, lion, leopard, and the little Suni antelope. This last is also found in the Kilimanjaro district. Towards Mount Kilibasi some good shooting may be had, and elephants are reported there.

At the back of the Kisii country, on Mount Chamonyeru, is a long-grass bushcountry, and there elephants occasionally appear, as do they also farther back towards the German border, near Karungu. 


\section{CHAPTER X.}

\section{THE GAME OF UGANDA AND THE EASTERN CONGO.}

IRECTLY you cross Lake Victoria and arrive in Uganda you meet with a complete change of scenery and country. Uganda has not the variety and quantity of game to boast of that is possessed by East Africa. Still, it has plenty of the commoner species, such as waterbuck, hartebeest, Uganda kob, bushbuck, and reedbuck; and the country is famous for elephant and buffalo. On the Nile are found many interesting species which do not exist in East Africa-interesting in that they are not commonly obtained by the usual tourist-sportsman.

One thing which forcibly strikes the hunter coming from the plainlands of East Africa is the difference in the habits of the game of this part, and likewise the bushcraft of the natives. The game (as is usual with animals dwelling in bush or long, coarse-grass country) is at once more thinly distributed and more wary; and the natives, who are naturally adapted to the conditions of the country, will be found to be better trackers than natives of the short-grass and open plainlands. They have also a wonderful aptitude for finding their ways about in thick country where no general view is obtainable and no landmarks are visible. In possessing these qualities they are like the natives of the thick-grass countries of North-Eastern Rhodesia and Nyasaland.

The shooting parts of the Protectorate of Uganda are, generally speaking, on the westward side, for the eastern end of Uganda proper, on the borders of Lake Victoria, is thickly populated. On the westward side are situated the two game reserves of the Protectorate, the Budonga Forest reserve and the Semliki or Ruisamba reserve. Both of these are ill-defined in their limits, and in many places it is difficult or impossible to tell where the reserves begin and end.

The famous elephant centres are Masindi and Toro. In the neighbourhood of Masindi the elephants yield soft or "Uganda" ivory-very thick and heary in tusk. This soft ivory is also found on the Nile, on both banks of the Bahr-al-Gebel, and in Buddu. Of the other game of the Masindi district, lions are found, but, like most bush lions, they are wary and hard to bag. Their chief food in this long.grass country appears to be pig. 


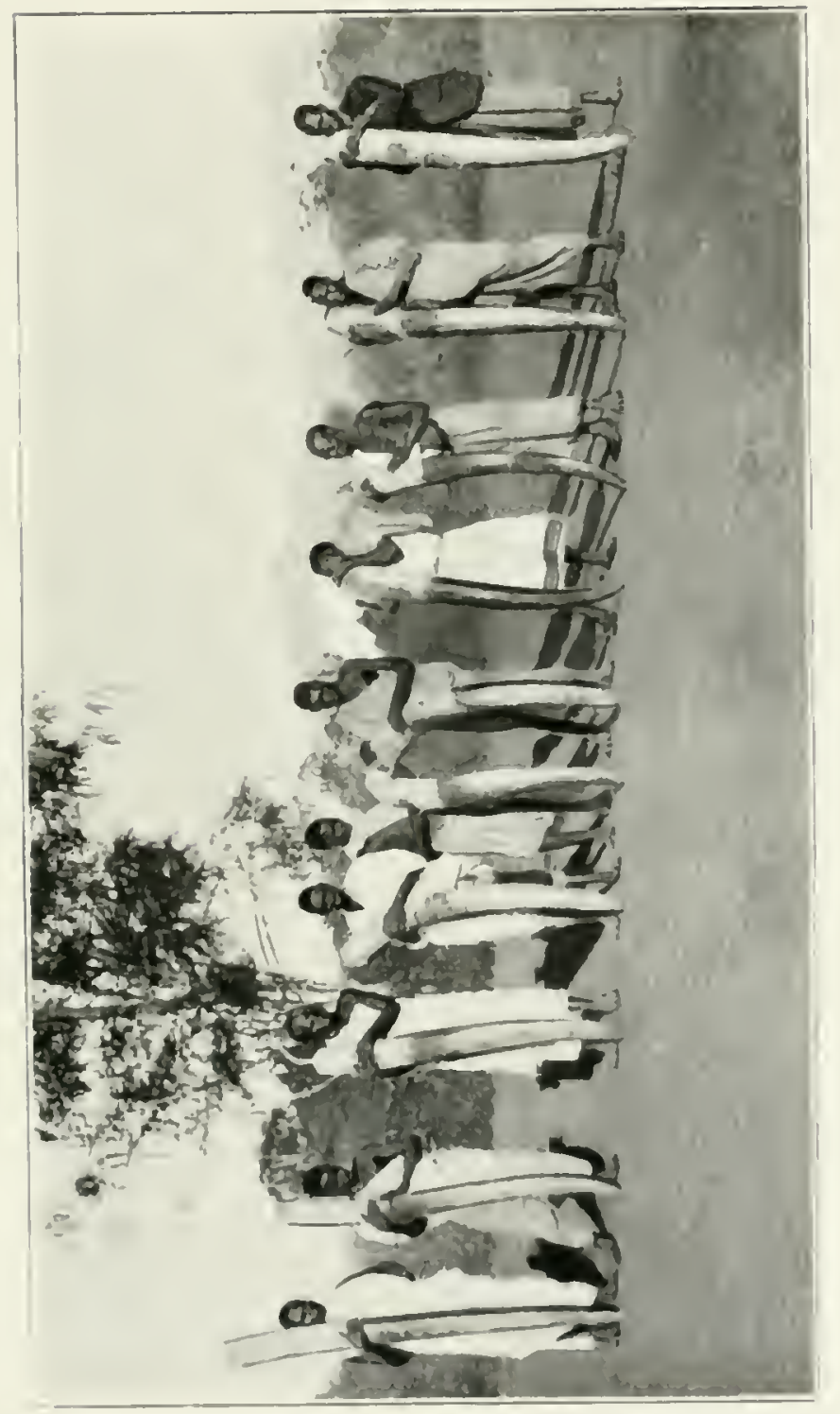






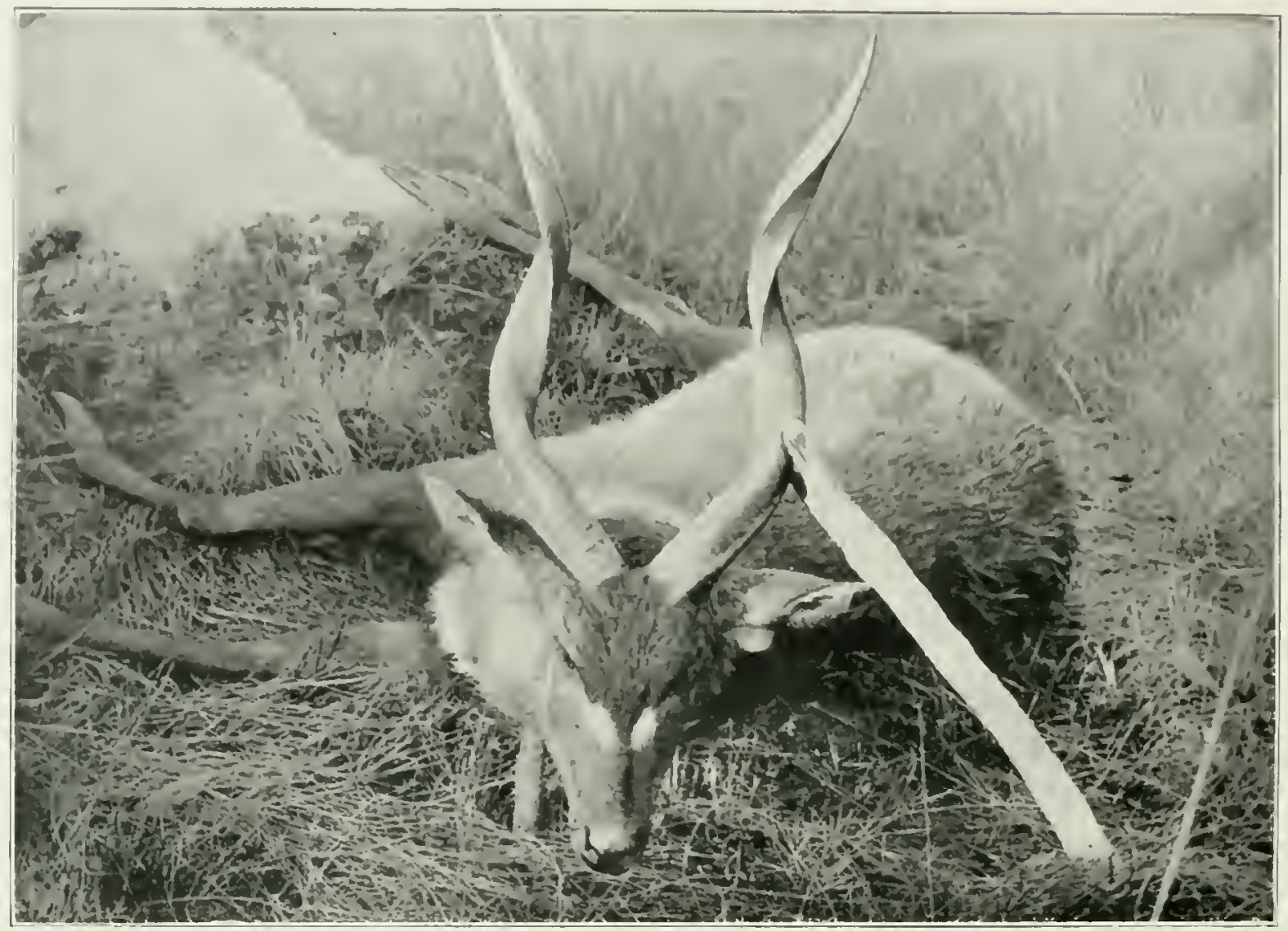

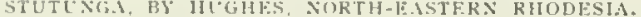

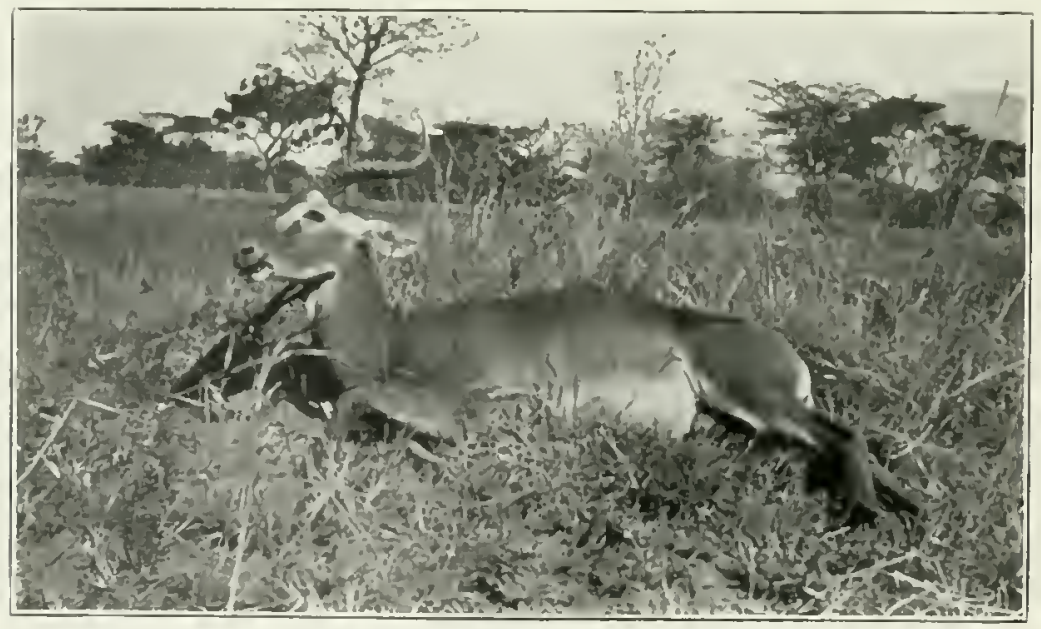

UG.NOA KOB, BY G. R. STONE. 
Situtunga inhabit the rivers of the Kafu and also many other rivers and swamps, and are said to be fairly plentiful. Owing to the swampy nature of the country they inhabit, however, they are practically unobtainable. Perhaps the only way to secure them is to hold a large drive with several hundred beaters driving a swamp. A few animals have been bagged in this way. They live all day under water or in the heart of the swamps, but occasionally come out at night to graze on the grass at the edge of their haunts. No doubt, after a careful study of their habits and spoors, a fair measure of success might be attained by selecting a place in which to sit up for them. However, sitting up for a herbivorous animal, which may graze anywhere, is a very different matter to sitting over a kill for a carnivore, which, if it comes for the kill at all, must come within close range.

In parts of the Sesse Islands the situtunga were at one time common, and there they were easily bagged, having but little natural cover to protect them. Some years ago a party of so-called sportsmen inaugurated a big drive, and are said to have nearly exterminated them in a single day. One of this party gives an account of the slaughter in "Large and Small Game of Africa." After this occurrence these animals were put on the protected list, for it was not then known that they existed in other parts of the Protectorate. Subsequently it was discovered that in almost every big swamp, of which there are many, situtunga are to be found. In view of this they were taken off the protected list, and now two are allowed on a licence.

Of other animals found in the Masindi neighbourhood there are buffalo and, near the Kafu, waterbuck (sing.sing), hartebeest (Jackson's), and kob (Uganda)all fairly plentiful. The grass becomes very long in this district towards the end of the season, and hunting is then difficult and, when out after clephant or buffalo, the work may be said to be dangerous. The early part of the year from February to March is the best for this section of country.

In the Budonga reserve elephants are plentiful, and chimpanzees are said to be there also. South of the Budonga Forest, and between Hoima (Kaoro) and Lake Albert, elephants are often found. Near this lake there exists a peculiar form of bushbuck or harnessed antelope, with horns shorter and thinner than the common kind.

The best shooting-ground in Uganda is supposed to be in Ankole and on the Semliki River. The cattle of Ankole are remarkable for their horns, and it is from this district that the record buffalo trophies come. The waterbuck of the Semliki and west of Lake Albert are remarkable for the size of their horns. From this part and westwards is obtained the "Gendai," "Congo," or forest ivory. It is long, thin, 
and graceful in tusk, and of hard quality, not so valuable as the soft Uganda ivory. In these parts there is also a forest-hog, but I do not know if it is the forest of the Ituri or that of East Africa. The usual common buck as well as buffalo are found here and in Buddu also.

The East African hunter in search of new species will find the Nile far more productire of specimens, for from Nimule to Gondokoro, and especially near the latter place, the shooting is good, and several kinds of animals are found which are not met with in the ordinary shooting-grounds of East Africa. There may be had white-eared kob and likewise Mrs. Gray's kob, also the Abyssinian buffalo, Abyssinian oribi, Rothschild's gazelle, besides giraffe, ostrich, and elephant.

There is a large herd of female elephants which make the neighbourhood of Gondoroko their breeding-grounds. In the Nile (especially in the Bahr-al-Gebel) numbers of hippos are found, and are in this part very dangerous to canoes, accidents being constantly reported. I have never met with them in any other place quite so formidable. On the Zambezi River they occasionally upset canoes, but in most places hippos are looked upon as genial and good-tempered old fellows, mildly curious as to the doings of mankind. The natives of the Bahr-al-Gebel, however, are constantly molesting and hunting them with arrows, harpoons, and muzzle-loaders, and this no doubt has the effect of making them fierce, for it by no means serves to make them shy or fearful of mankind. At sight or smell of a canoe they will, as often as not, approach to investigate at close quarters, rearing head, neck, and chest out of the water. When one of them wishes to upset a canoe it will approach under water, and if not fired at during its preliminary inspection no other chance for a shot will offer. They seem, as a rule, to content themselves with simply upsetting a canoe, but occasionally will maul the occupants in the water. I attended to a native on the Bahr-al-Gebel who had nearly had his arm severed by one of these animals. It had upset his canoe and then caught him by the arm, inflicting two enormous gashes back and front, each several inches long and about two inches deep.

A native of this locality told me that lions occasionally killed young hippos when on land at night, and added that he had heard of two such cases near his own village, and moreover had himself once seen the body of a hippo with the spoor of a lion about it. Very possibly he was telling the truth, as he volunteered the information, and had no object in making the story up. Lions, too, at certain seasons do inhabit both banks of the Bahr-al-Gebel, and are often heard at night. They appear to roam over large areas, after the manner of bush-lions, and feed, as in Uganda, mostly on pig.

Crocodiles are numerous in the Nile, and just below the Murchison Falls at Fajao 



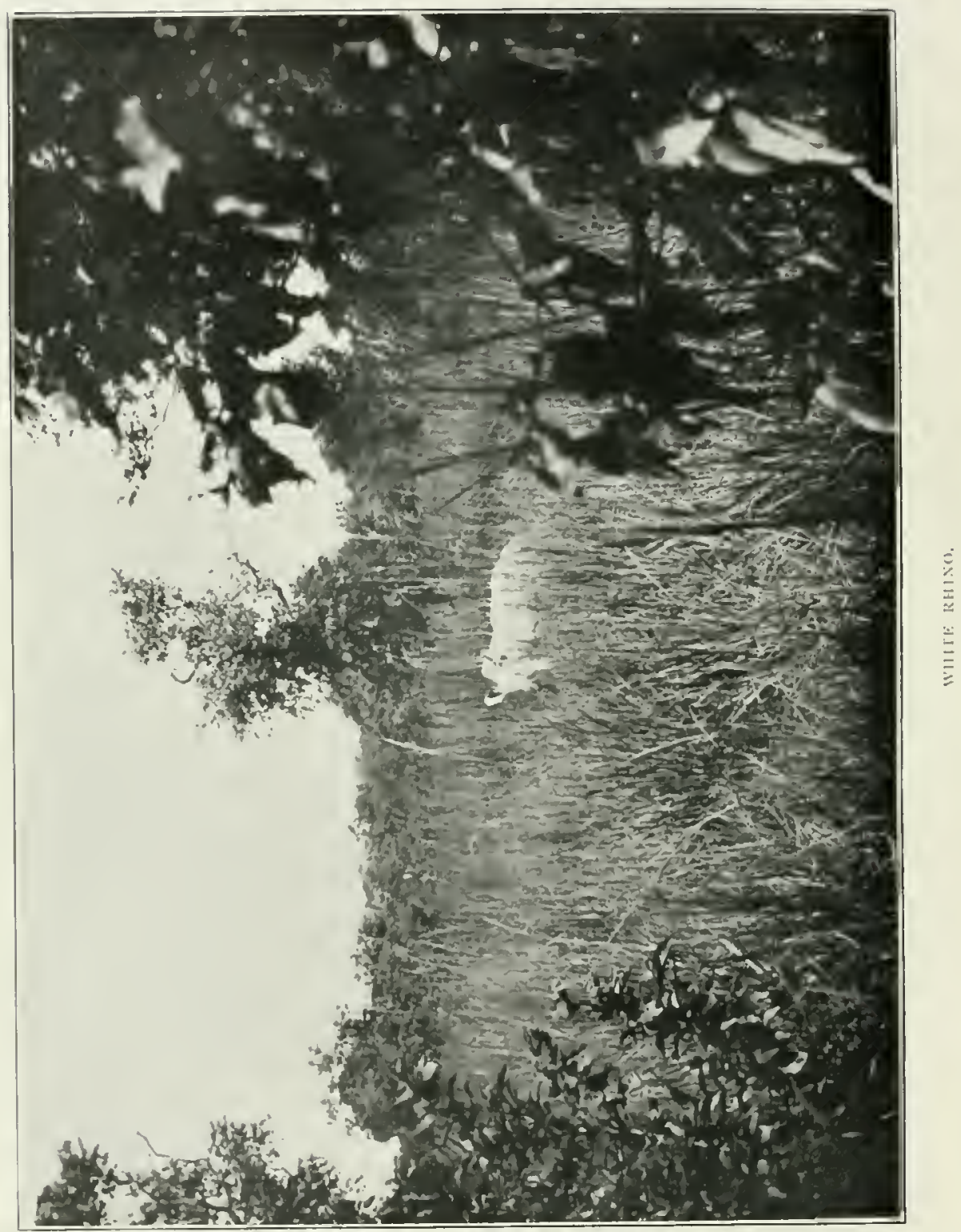


are found in immense numbers. There is there a small bay, along the shores of which some hundreds of these reptiles used to congregate and lie together in a dense mass. By approaching quietly one was able to get within a hundred yards of them before they would take alarm. The whole shore would then appear to be moving down into the river as the hoards scuttled into the water, jostling and pushing each other, stirring up the mud, and making the water seethe and foam.

The commoner buck, such as Uganda kob and waterbuck, are plentiful on the shores of the Bahr-al-Gebel, and a little blue duiker is to be had. On the Congo side of the Nile the Congo buffalo is found near Mahagi, and is plentiful there. This buffalo is redder than the Cape buffalo, the coloration being of marked degree in the young, but not so great in the females.

Elephants are numerous almost everywhere in the enclave, and are found in enormous herds of several hundreds. The old bulls appear generally to be obtained in denser country farther back from the river. The elephants of the enclave are particularly dangerous, as the herds of females do not, as a rule, stampede on being alarmed, but, on the contrary, often appear anxious to investigate and satisfy themselves as to the cause of the alarm. The old bulls, on being disturbed, will often make off downwind for a short distance, and then wait in thick cover scenting and listening for the approach of anything following them. Tusks each of one hundred pounds and over are not uncommon both there and in Uganda.

The white, or square-lipped, rhino is found only on the left bank of the Nile. He ranges, roughly speaking, from Wadelai (Belgian) to the northern border of the enclave, and appears to be found nowlere beyond wo to three days' journey back from the Nile, and in no other part of Africa. I have not heard of a case of a white rhino being seen on the right bank of the Nile, nor have 1 heard of a case of a black rhino being seen in the habitat of the square-lipped rhino. The square-lipped rhino is rery much larger in size than the common rhino. Of other differences, his forehead appears to be higher and squarer, and the base of the horn is square instead of rounded. The most distinctive difference, however, is in the shape of his lips, which are square instead of pointed as with his smaller congener.

It is noticeable that nearly all the elephants of Masindi are covered with old and fresh rifle wounds (inflicted by native muzzle-loaders and European breechloaders), whilst the elephants of the enclave are clean, and seldom bear any signs of wounds upon them.

In the neighbourhood of Belgian Wadelai the grass is short. It grows longer and longer as one proceeds down the river, till at Dufite and inland from there it grows well over the height of an elephant. 
In the Congo forests the okapi, the Ituri forest-hog (Hylocharus ituriensis), the chimpanzee, and many other new and interesting creatures are met witl. North of Lake Victoria, past Mbale, and towards Karamoja and Elgon is some shootingground corresponding more to the East African type of country than to any other. There elephants are plentiful, and the commoner kinds of buck, the lesser kudu, and the oryx beisa. I have heard it rumoured that the greater kudu also is to be found in the locality. 


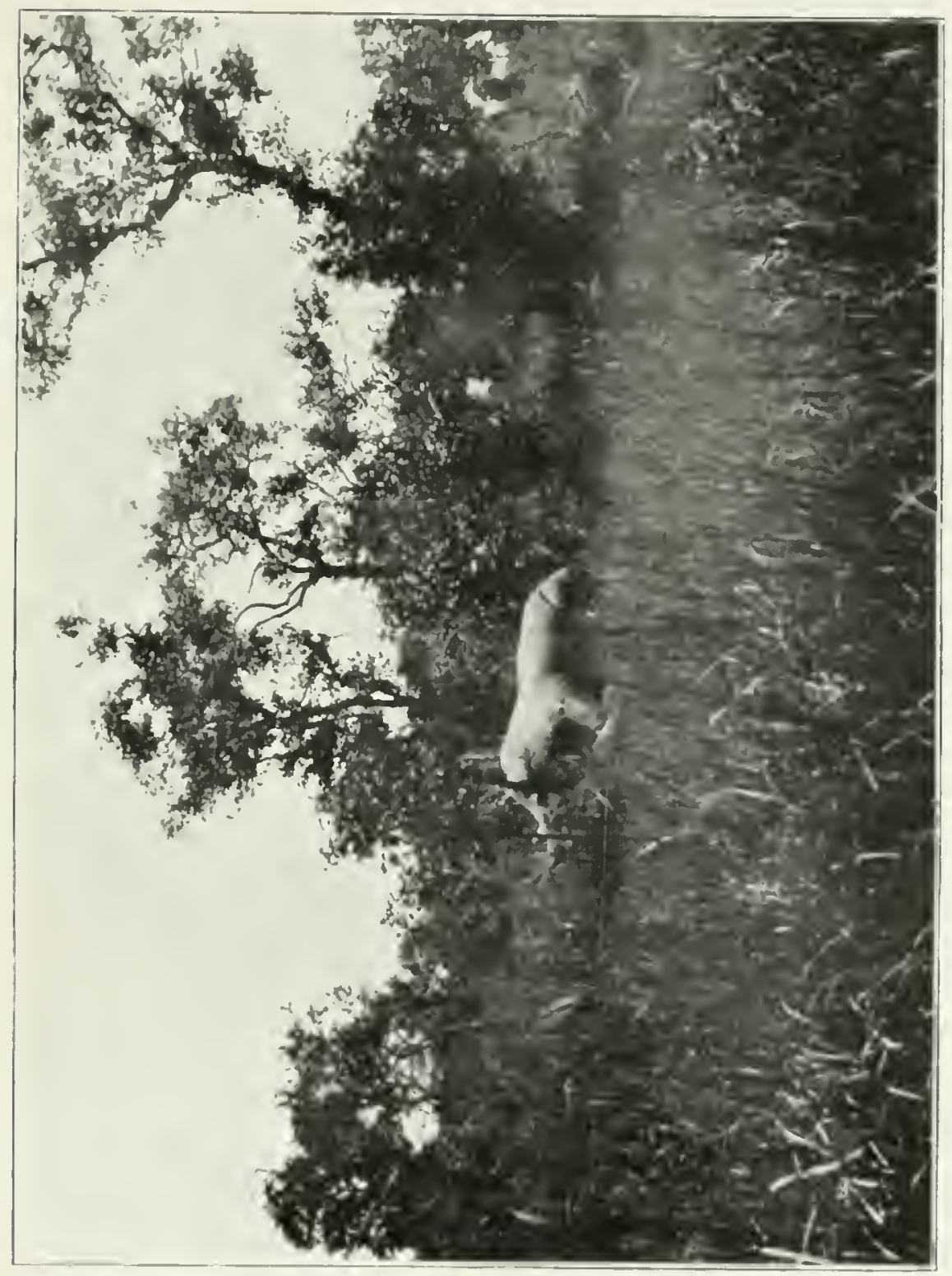





\section{CHAPTER XI.}

\section{THE FOREST.}

THl: forests of British liast Africa are mostly at high altitudes. The great juniper forests, such as those of Kenya and the Aberdares, do not exist below an altitude of six thousand feet, and are usually considerably above this level. Most of the lower forests are so tangled with undergrowth that progression through them is difficult. The forests of greater trees are, however, frequently more or less free from impediments below, excepting for broken branches and various shoots and fallen trees, and these are comparatively easy to walk through.

Passing from the bush and plain to these great forests, one enters quite a different kind of country and climate-it is as if a new land had sprung around one. Everything has altered, the whole aspect is different, and all vegetation and animal life seems to have ehanged.

On the plains and in the bush one experienced sun and glare, but in these forests there is everywhere cool shade. Whilst before all was dry and parched, now one has entered a land of moisture and running streams. The forest animals are most of them unknown clsewhere, and the birds even are different. The cold morning mists hang about the forests, and it is difficult to believe that one is close (1) the equator. In the early morning can be heard the croaking of the colobi, uttered and answered all over the forest. The sound appears to start from far away and then comes rolling nearer and nearer, passes swiftly orerhead and away into the deepest recesses of the forest. This seeming movement is given to the sound by the croak being taken up by numberless colobi, and as the cry reaches each indiridual it is passed on to others beyond. This wave of sound probably passe's the length and breadth of the forest like the wave of cocks crowing which passes across England from east to west, day by day, as the westward cocks take up the call from their brethren eastward. The piping of the different suernons and other monkeys sounds from all sides, whitst the lond rustling of leares and branclues above tells of parties making their way along their roads. Or it may be that a party of colobus have been disturbed, and the crashing of branches is heard as lhey recklessly throw themselies from tree to tree.

At midday the forest is generally silem, there is neither sign nor sound of life, 
but towards evening it wakes up a little, and the monkeys start twittering and piping again, whilst parrots and other raucous-voiced birds screech and call.

Night is the time of activity in the forest. As dusk falls all the forest animals begin stirring; the bircls only are hushed, and have all gone to roost an hour since with shrill cries, hoarse screechings, and nuch comnotion of flapping wings and hustling flutters about the selection of their night perches. As night closes, the shrill trilling of the hyrax begins from a thousand different places and continues without cessation until dawn. The colobus croaks and other nocturnal sounds proceed from the forest. Stately elephants stalk silently about with noiseless palded feet, and only a breaking branch now and again or the crashing fall of some small tree broken down tells of their presence, or perhaps a shrill trumpet or loud-gurgling stomatic rumble denotes that one of their number is angry or pleased, as the case may be. When they go down for their midnight drink it is then that they become noisy. If the stream they visit is of any size their splashings, gurglings, and trumpetings wake the echoes of the forest.

The bongo and the bushbuck are busy feeding, moving from place to place by their little paths broken through the undergrowth. The former is busy browsing off the shoots that grow on the floor of the forest, laying his horns flat against his back and stretching out his head to crouch through the undergrowth. Early in the morning a party will make their way by a well-beaten path to the lone stump of a rotten tree. The paths leading to and from this tree and the hoof-trodden ground about it show that it is a favourite resort. They will then tear off the rotten bark and gnaw the decayed pith of the tree, and alterwards will make their way down to the stream for their morning drink, then back again to the dark recesses of the forest, grazing as they go. Occasionally some old male will uproot a sapling so as to get at the leares or bark. This he will do by digging and levering up the roots with his massive horns. Soon after dawn the herd will have reached some secluded retreat in the denser undergrowth in which to pass the day.

The forest-hog is poking and ferreting about hither and thither, grubbing up roots and eating shoots and other dainties. The leopard also is busy prowling round to see what he may procure. Almost anything is acceptable that comes his way, though he would like best of all a baboon, a monkey, or a colobus, and, in point of fact, these animals form his staple food in the forest. He is also very partial to the little duiker and dikdik, which patters along the floor of the forest, or even a female or young bushbuck if he can catch one. I do not think he often tackles an adult male bushbuck, for this buck is very handy with its horns, and has, moreover, plenty of spirit. When the above-mentioned dainties fail, the leopard has then to fill 



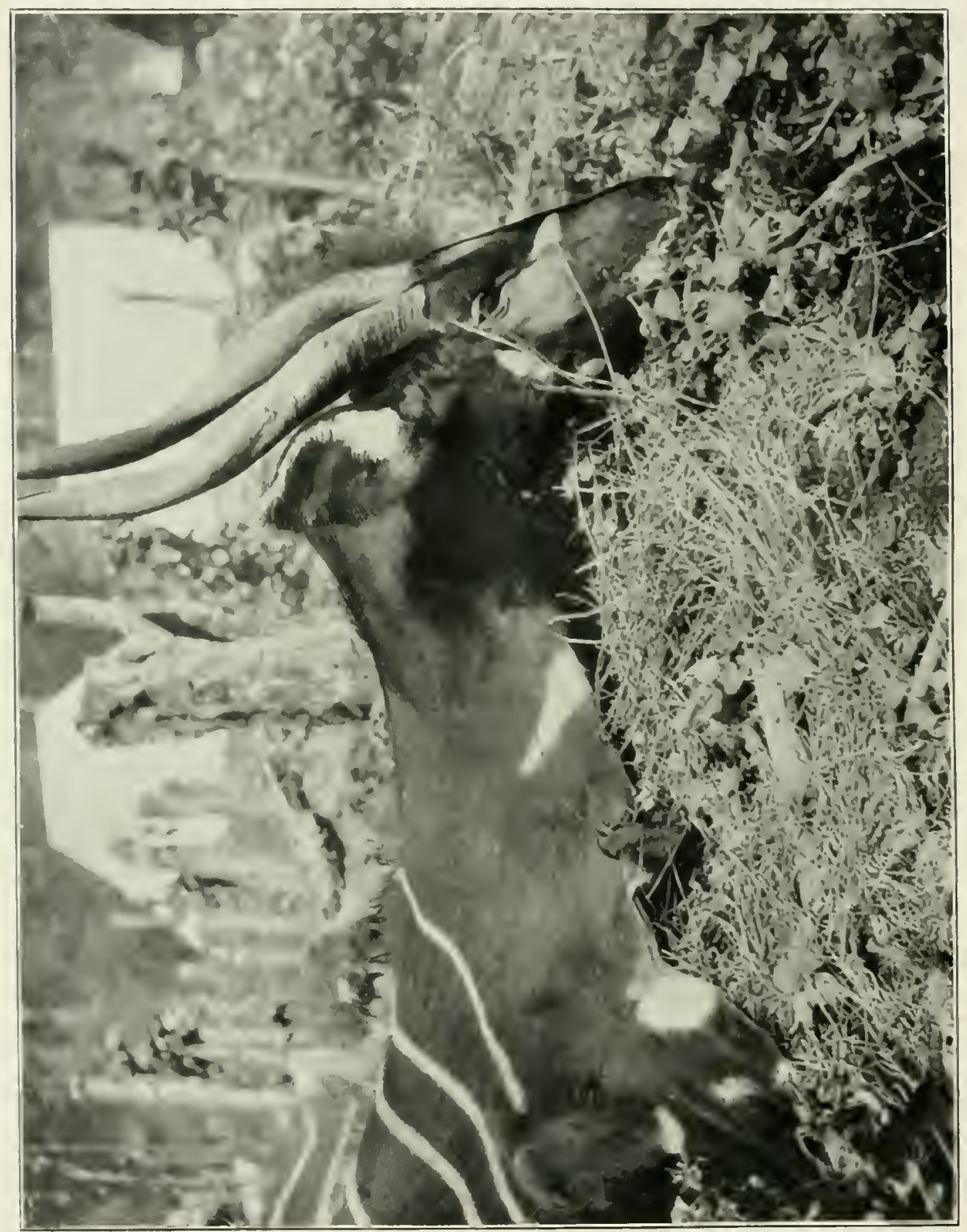


his empty stomach with rats, shrews, and, perhaps, a hyrax or two, or some other small mammal-anything he can catch, even if it is only a bird.

The forest is intersected with tracks and game paths broken by bongo and forest-hog. The bushbuck, unlike the bongo, does not push under or through obstacles, but usually jumps over them. The bongo, on the contrary, will practically never jump anything higher than three feet, preferring to push under it.

Sometimes during the night in the forest one hears the dull crashing and rending of branches, which grows louder and louder, and ends in a splitting burst as of thunder. For a moment one is bewildered, and imagines that some great convulsion of nature is taking place, and waits expectantly for further developments; but all remains still, more silent than usual, for the hyraces have been momentarily hushed into silence. It is some massive forest giant which has at last succumbed to the insistent attacks of the termites about its roots, and has fallen with a crash down the hillside. Such is night in the forest, a time of activity for all its furred denizeiss.

Dawn and day come rather late in the forests, for the morning mists and clouds hang heary, and the light is long in penetrating. The hyrax takes itself to its hole in a tree trunk, the leopard finds some safe, hidden retreat in dense bush, or lies stretched full length along a lower branch, ready to drop on any unsuspecting animal that passes.

The cluikers and dikdiks funish their morning meals, and then as the day advances, lie down in some hidden nook. The elephants have perhaps been up to the bamboos after their drink of the early evening. "They have there been snapping and twisting the stout bamboos as if they were blades of grass. Possibly the herd has also visited one of the salt-licks near the sources of some of the forest streams and there dug their tusks into the soft red earth and caten sreat lumps, for in the forests there are no red termite hills as in the bush. As the day adrances the herd returns to the forest and its members stand in a little group round one or two tree trunks, and there doze, lazily flapping prodigious cars from time to time or rubbing themselves against a tree. The eow elephant may be seen standing with her trunk over her young one as if to keep it out of harm's way. Others may be seen rubbing tusks together or exchanging similar courtesies.

Such is life in the forest. It camnot be elinmed that there is il steat variety of game to be found. It is in its tree-life that the forest is so rich, for such animals as volobus, monkeys, genets, byraces literally abound, and numberless other small mimmals as well als al great variety of birds. The grame in the forests are only :-

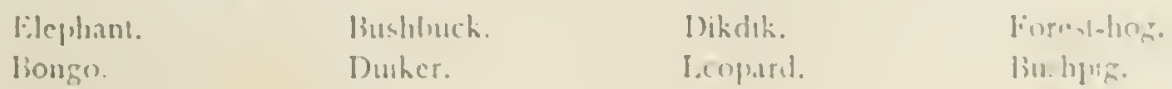


In the thicker forests, more matted with undergrowth, rhino love to roam, and regard their retreats as safe. A wounded or disturbed rhino will often fly to the forest. One of its special retreats may be seen in a patch of thick forest north of the NairobiFort Hall road just after crossing the Ndurugu stream. This patch affords a harbour of refuge to the much-harassed rhinos of all this section of the plains."

The hunting of the forest is practically entirely done by tracking. For the game of the forest is not so plentifully scattered as to allow for much chance of ever meeting with animals when casually strolling round. Further than this, as I have already said, nearly all the denizens of the forest are nocturnal in habits, so, unless one obtains by following their tracks a very good idea of where they may be lying up, there will be no hope of discorering them.

The greatest of all reasons why tracking is so necessary in the forest is that its floor is carpeted with dead sticks, whilst undergrowth and creepers bar the way in every direction. 'To move noiselessly, therefore, necessitates one's going at a snail's pace. If you are walking thus in the hopes of fluking on some anımal, the distance covered during the day's hunt will be infinitesimal. When on fresh spoor you can afford to go with all due caution, for, as the animal will probably be lying down the greater part of the day, there is a good chance of coming up with it.

Again, the animals of the forest are among the most crafty of all game; so, when you are following up some spoor step by step and going infinitely slowly, there is more chance of sceing the animal, or at least of getting near it bcfore it sees you; for when following spoor you know that the animal has passed, and also that he cannot be very far distant, and so your precautions will be greater and your outlook keener than if you were aimlessly wandering about on the off-chance of seeing something.

The best method of procedure in forest hunting is to work round the edge of a forest and dive into it now and again, along elephant tracks, goat tracks, or any paths you may find. Sometimes quite feasible paths enter for some distance into the forest, having been made by natives for the purposes of cutting wood. There are also in many places regular elephant roads, known to native hunters, which lead in every direction through the forest. These will often be found to lead to the tops of mountains or hills of any prominence. The main roads traverse the tops of ridges and necks, and up and down spurs, forming an easy method of progression when compared to the rest of the forest. I have never seen it stated to what altitude elephant tracks are found. On the Aberdares and Mount Kenya I have

* I believe, however, that since this country has been so much taken up by setllers the thino is almust unknown lierc. 
seen elephant roads at thirteen thousand feet above sea level, but it is probable that they ascend to greater altitudes than this.

When you have found some sort of a path by which to enter the forest, you should next examine carefully the ground in its immediate neighbourhood, and, if possible, any streams near at hand running through the forest. After careful examination of many such pathways and the streams close by them, you may find one with enough spoor about it to warrant your making that section of forest your hunting-ground. If you are able to get some of the native hunters of the forest to join you, so much the better, as they will be able to lead you straight to a good locality.

Having selected your proposed hunting-ground, you must take every precaution not to alarm the game, for if once you are known to be in the neighbourhood, all the wary forest animals will clear straight out of the district. So you should camp outside the forest if your hunting-ground is near the edge, or, at any rate, you should take care 10 be some way back from wherever you intend to hunt.

Your site being chosen, the next thing to do is to find the lie of any streams in the forest near your hunting-ground. You start in the morning from camp and roam about looking for fresh spoor. If you cannot find any the first day, you try to locate the streams and any drinking-places so as to visit them on the morrow. By "visiting a drinking-place" I do not mean going down and looking at the water, for this is generally but a waste of time. I mean, you pass upwind of it with a view to cutting across the spoor of any animal which may have passed down to the stream or back from it.

In the forest spoor will be casy enough to see, as the hoofs sink deep into the soft and rotten floor of the forest, and the shoots and leaves are easily trampled down. It is just after the rains that tracking is so easy in the forests, as the shoots have sprung up everywhere and the ground is not then covered with a network of tracks going in every direction. Later in the year the tracks grow somewhat confusing.

Harmg found a fresh track the next step is to decermine if it is fresh enough to follow up. 'This is by no means easy to tell when you are unused to forest spooring. for there is so much damp and moisture about that the trampled shoots keep fresh-looking for several days. Examine carefully, therefore, any trampled shoots, and, if needs be, follow the tracks some way to find marks of browsing and dropped leaves.

You will probably be searching for tracks in the flatler country and above the stream-banks, for in those parts the "groing" is citsicr. Such parts, ton, form usually the nighlit's grazing-grounds for game, so, when you stant following a 
particular track, it will probably lead you for a while through similar easy country. It will be best to follow up without wasting too much time, though still using of course all the care compatible with an advance not too slow; for it may be assumed in such country that the animal was feeding at night, so will be some distance ahead. When the track begins to take to the thicker and more tangled country, such as may be found on the little hills in the forest or alongside the watercourses and in mullahs, then is the time to begin to follow in earnest. It will be necessary for you to exercise all possible care and to proceed stealthily and noiselessly. Every step will have to be tested before the foot is put down, to learn if the twigs will crack or not. Every branch will have to be carefully pressed back as you pass and replaced with the same caution afterwards to prevent rustlings. Creepers will have to be lifted over your head and brambles unhooked from your clothing. However careful may be your advance there will always be every now and again some twig that will scrunch or some decayed piece of timber that will collapse as you climb orer it. Very back-aching work it will be found besides, for what with crossing branches and creepers, etc., you will hardly ever find a place in which you can stand upright. The path you will be following will be one that has been forced through the undergrowth by an animal of much less stature than yourself, and one, moreover, adapted by nature to make itself into the shape of a wedge, so that it can push through overhanging obstacles.

Some of the places through which a bongo or a forest-hog have passed it is quite impossible to conceire how such a large animal managed to get through. It is the great body-weight however that has been turned to account, and the branches and creepers have fallen back again into their old places after the animal has passed.

During the uncomfortable process of squeezing yourself along your selected narrow trackway, and crouching or crawling under obstacles, or unhooking yourself from thorns, you will have cause to think often and bitterly of the unadaptibility of the ordinary human frame for passing through sucl country. The human foot appears as if it was specially designed to hook into every creeper and trailer in the path so as to trip one up, and the human back does not appear to be endowed with the suppleness necessary to bend in and out from under overhanging branches. Moreover, the human skin is absurdly sensitive to the thorns and noxious plants met with in the way, and the human head does not seem to be designed for pushing itself into thick places in advance of the body.

The great secret of going quietly in pursuit of an animal is to go slowly. However slowly you may have to go it is better than going a little faster and making a little more noise. Your quarry must be lying down, and if it is lying near, 
you will sooner or later come up with it, if it is lying some distance off you will not. But if you do not come up with it nothing is lost, for you have not disturbed it, and so are just as likely to find it or another of its kind on the morrow. If you push on rashly so as to make sure of reaching it the same day, you will succeed in disturbing not only the animal sought after but the whole countryside. If you do this you will most certainly fail to get anything at all in the locality or anywhere near it. If you do not come up with the animal sought for one day, you return to camp and look for its fresh spoor on the morrow, and hope for better luck or an easier stretch of country to traverse.

Having succeeded in following up the track step by step, the long expected at last happens. There is a noise just ahead of you, you have bcen heard, and the quarry is just preparing to bolt. Be ready for this, and directly it happens rush forward as hard as you can in the hopes of catching a glimpse of the animal as it clears; or you may succeed, if there are several animals, in seeing one which has not been so quick to rise as its companions. Your shot will be but a snapshot, and in any case must be fired through thick undergrowth. You must be always ready and on the alert for the critical moment to arrive. There is one thing in its favour, and that is that it is never a long shot, but morc usually at thirty or forty yards, for the simple reason that in the forest you are lucky if you can see ahead even this distance.

So much for the foresthog, bushbuck, and bongo. The duikers and dikdik may be found grazing in the morning and late afternoon, or lying up in the middle of the day. Even when lying up they may be bagged with a snapshot, for they do not, as a rule, take alarm from a distance like the other animals. They rely for protection more on their small size and in the taking of cover, and you may pass within twenty yards or so of many in a day's hunting without being alware of their proximity, for they give no sign. However, if they think that you are approaching too near they will spring up and makc a dash for it; then, if you do not secure a smapshot at once, watch carefully as they go and see if they do not stop for another look at you before finally going off; for these little buck are very inquisitive and almost always stop for just one more look. If you follow their spoor you will see where they have done this, and it is more often than not just where they were out of your sight, but could still see you through the undergrowth.

One of the greatest difficulties met with in forest hunting is the treachery of the wind. There is never any steady breese blowing from any one quarter. Usually a stillness prevails, whilst if any breeze grets up, it comes puffily from contrary directions. However carefully you may move, you camot count on being righte 
with the wind, and time after time you are betrayed through no misjudgment of your own.

Now, lastly, let me touch on the most magnificent sport which Africa, or, for that matter, any country in the world, has to offer, namely, elephant-hunting. Any sportsman who has ever shot elephants admits this to be undeniably the case, though what the exact reasons are for its being so would perhaps be difficult to state. To start with, it is distinctly a dangerous pursuit, and becomes more so as time goes on and elephants grow less unsophisticated and take to thicker and thicker country. In some places in East Africa where they have been much peppered, it is as much as a man's life is worth to venture near a herd of females and young. In other parts where the hunter is still little known elephants are harder to move to anger, and the old bull, which it is the hunter's particular desire to bag, is generally an easy-going old fellow. Wherever an old bull is met with there are always females, some of which are subject to sudden fits of rage on getting one's wind at close quarters. Even the old bull, when wounded, may show a burst of anger, and, from the many bullet wounds and native missiles often found in his hide, it is small wonder that he gets rather bored with being shot at.

The few elephants I shot in Uganda I found covered with wounds, and the natives who cut up the carcasses extracted a number of iron native bullets.

However, in spite of the way that the bull is in some parts molested, it is still the female which is always the more dangerous. Though one's desire may be only to meet the bull, it is not always possible to find him apart from females and young; or, to be more accurate, it is not always possible to miss running into females and young when in pursuit of a bull. It is the same with most animals, the females are usually the worse-tempered. If from a couple of lions the lion is shot, it is the lioness's charge one has to fear, whereas, if one shoots the lioness first, the lion is unlikely to charge. The cow buffalo is a more dangerous customer when she gets wild than is the bull. The reason for this is that with her lighter head and horns she is more agile than the bull. The bull's massive horns and blind charge appear to be especially designed for strife inter se. It is the female which protects the young, and so it is the female that is quicker at seeing and turning upon an adversary. The bull, on the other hand, would possibly go and toss an imaginary victim before he discovered that it had escaped, and would then look round to see where it had gone.

Some people seem to be grossly lacking in a sense of humour concerning the attacks of dangerous game. They will shoot hundreds of inoffensive and harmless animals, and a sprinkling of dangerous animals. When one of the latter suddenly 
turns upon them, perhaps without much provocation, they will express themselves as decply injured that any creature could be so bloodthirsty and ferocious as in try to do them bodily harm. Ferocious, savage, vindictive brute are terms freely used of such animals, but these terms could be applied just as becomingly to describe the hunter. It is only once in a way that an animal will try to harm a human being, and then it has very heavy odds to contend with. The hunter kills harmless and dangerous animals indiscriminately; he does not wait for them to attack him first, and he has, as a rule, suffered nothing at their hands when he commences his hunting. He has neither right nor justice, then, in resenting that any animal should try to retaliate on him.

But to return to elephant-hunting. From my own experiences, I am inclined to think it is a more dangerous pursuit than any other kind of hunting. For, in the brief experience of elephants falling $10 \mathrm{my}$ rifle, I have on three occasions very narrowly missed being had by them, not to mention the many times I have been forced to run out of their paths. On one of these occasions I was kicked aside by a young elephant, and crawled away on all-fours, whilst he was busily engaged in pounding the ground on which I had been standing, evidently believing that I was beneath him.

The consensus of opinion and the casualty list gives the verdict to the lion as being the most dangerous. The latter is more certain to damage you if he means business, but I should think the proportions of narrow shaves with elephants would be much more numerous. An elephant is not destined by nature for the capture and killing of a little pigmy ereature like man. When he gets angry he rushes for the object of his rage with the intention of doing him some sort of damage. If he tramples on him or runs a tusk through him, or catches him up with his trunk and throws him against a tree, the chances are that there will not be much left of the hunter. Owing, however, to his own ponderous body and the smallness of his adversary in proportion, and also because of his defective eyesight, he as often as not makes a bad shot for his victim, either with trunk or tusk; or, again, he may lose the wind and pass by apparently without seeing him.

I do not suppose that when he gets angry he has any very clear idea of what he intends to do. After relieving his rage by one or two vigorous prods which may do no more harm than disturb some earth, the lurking fear of mankind at the back of his mind reasserts itself, and whether or no he has finished his victim, he clears off. Many a sportsman has lived to tell the tale of some great elephant having stood over him as he lay on the ground, and of its making bad shots for him with its tusks. Some have been caught up and thrown into soft bushes, others have had elephants 
passing right over them and have yet escaped unhurt, when but one second of pressure beneath one of the four feet would have meant instant death. Other sportsmen have been less lucky; of these some have been torn limb from limb; many have been speared through the lungs or head by a tusk or crushed to death by the weight of the animal, and, again, many more have been caught up by the animal's trunk and had their brains dashed out against trees or their arms or legs broken.

So one of the charms of elephant-shooting may safely be said to be due to the danger run. Another is the hard work and constant disappointments involved, for elephants travel immense distances, especially during the night, and have generally to be tracked for miles before one comes up with them, whilst many more miles are covered looking for spoor. A day of hard going from before sunrise till after sunset is quite an everyday event with the elephant-hunter, and, moreover, often leaves him at the end of the day hungry, tired, foodless, tentless, and disappointed.

Next comes the pleasure of tracking an elephant. Although the actual tracking is not so hard or difficult as that entailed by spooring up many other animals, it yet offers many subtle and interesting points not met with when following other game. Elephant country is generally a mass of tracks of all ages, and to pick out the track you wish to follow from amongst all the others is a very difficult matter, more especially when the grass is dry. A very common experience in elephant-hunting is to find the tracks of one or more large-sized bulls, which, when followed up, lead into the spoor of an enormous herd of females and young. The herd will have passed over the same spot as the bulls either an hour or two before or an hour or two after them. All the tracks are so inextricably mixed up together that, if it is in difficult country, it is practically impossible to find the spot at which the track of the bulls leaves those of the herd again; for there are but a few bulls, whilst the herd numbers perhaps several hundred, and their spoors cover the countryside.

Another of the charms of elephant-hunting is the excitement of having to be constantly on the look-out, and also listening and smelling for the animals. Elephants are nearly always found in forest, thick bush, or long elephant-grass. In places where they cannot get grass-food they will occasionally wander out on to the open plains, though more usually at night than in the day. They are essentially forest and bush animals, and in such localities amply make up to the sportsman for the deficiency of other game. In the forest the best way to hunt them is to pitch your main camp either outside the forest or at some place in it where there are paths or beaten tracks, and then to send out natives in all directions to look 
for spoor and locate the animals; for in the forest elephants will at different times take up their quarters in altered localities.

It is as well to make the natives you send out bring in a stick cut to the size of the spoor, so that you are not led away after females and young. When you get good khabar start off with about two or three carriers bearing a little light tent, or waterproof shect to rig up for shelter at nights, and take also a few stores, such as biltong, flour, salt, pepper, cocoa, saccharine, tobacco, and matches, also a canteen, in the body of which you can cook soup made from biltong, and in the top of which you can brew your cocoa. The natives will also have a few day's' supply of food and a cooking-pot

'Thus lightly equipped you can start off to locate the elephants, not forgetting to take a small axe and a billhook with you. These will not only be useful to cut firewood, but will also serve to cut out the tusks of the elephants, if you are fortunate enough to bag any.

The next proceeding is to follow your native guide to the place where he has found the fresh spoor, have a look at it, and decide whether it is good enough to follow up.

Here I might say that if the spoor denotes the presence of a large herd in the thick forest, or, worse still, in the thick bush or bamboos, it is, in these days of stringent game regulations, not worth the following; more especially is this the case in a place where the elephants have been much molested. For in the bamboos (the home of the forest elephant) the females and young move about in vast herds, with perhaps but only one shootable male with them. The chances, then, that you will strike this one big male out of the whole herd, whilst you are walking in the thick undergrowth, may be said to be infinitesimal.

Moreover, if you meet an animal face to face in such country the situation is awkward, and often results in your having to shoot the animal whether you like to or not, and there goes one of the two elephants allowed on your licence for a worthless tusk.

What is still more dangerous, however, is when the elephants become alarmed, which must happen sooner or later when elephants are all around you and you are still hoping to strike up against your shootable male, and then they stampede up and down, crashing through the bamboos as if the stems were se much grass. When this sort of pinic starts, most penple would be willing to grive all they possessed for a big tree behind which to stand, instead of the indecently insulficient shelter of a bamboo stalk, which is the only arailable cover. In these days of stringent licences and much-peppered elephants, which have been drisen into all 
the thickest and worst country in Africa, shooting is much more dangerous than it used to be.

But to resume our examination of the spoor found. If it proves to be that of several bulls together you are in huck, and should lose no time in getting on the tracks. These you will follow, up hill and down dale, through thick and tangled nullahs, and up into easier-going forest again, till either the spoor begins to show fresher or sunset compels you to choose a place for the night's camp, and you make yourself as comfortable as circumstances permit.

If by the spoor you see that the elephants are trekking straight on, and this straight trekking has continued all day, it would be as well to give up following them. In such a case you would return to camp and await fresh khabar, or try to strike tracks elsewhere where they are fresher. If, however, the tracks you are following show signs that the elephants are spreading out and feeding much by the way, it is a hopeful sign, and you are probably orerhauling them rapidly. Elephants if they have been alarmed will travel cnormous distances the same night, and it is then, as a rule, hopeless to follow them. If they have not been alarmed it is often possible in the early morning to get on their spoor of the previous day, and by following it up to come upon them the same day, but it generally means walking. Sometimes, however, they remain in the same locality for several days together, making much the same round each day. That is to say, that they will drink at night from different parts of the same stream, and be found on the same hill in the morning and move on to another place for midday, and again move on in the afternoon to their night's grazing-ground, returning to the same stream to drink later on. If this is the case you may find them quite close to the place in which your native scout has seen or heard them. After a few days in one locality they will suddenly trek off for no apparent reason.

When following the spoor, and it begins to get quite fresh, it is as well to leave your carriers behind.

Once on fresh spoor the points to notice are, the wind and the obtaining of as early a warning as possible of the elephants' presence. The wind is the allimportant point about elephant-hunting. A little bag of flour to shakc out from time to time, so as to learn its exact direction, is a most valuable aid. So long as you can keep the wind right and do not make any very violent noise you are all right. But it is just this keeping of the wind right which is so difficult in these forests. Also, you can see only such a short distance that it is hard to locate the animals, and you may be passing them at any moment, for they frequently double on their tracks. 
To locate them quickly you must always be listening for them. When they are feeding they can be heard breaking branches, and when standing still they may be heard blowing, stanping, and rumbling. Whenever the spoor leads you down a valley, pause before descending and try to hear them below you or on the opposite side. Then, once you hear the crack of a branch or the unmistakable scrunch of a bamboo, all precautions should be redoubled. Having located an elephant by sound, if he is feeding do not be in a hurry; but try to locate all the rest of the party. If they are on the opposite side of a valley you may be able to catch a glimpse of a tusk. After you have located your elephants you must approach slowly, listening from time to time to learn of their movements, and testing the wind carcfully at intervals.

So you gradually draw nearer, taking care that you do not pass any onc of them which might get your wind. If, when at last they come into sight, the nearest one is a small tusker, and a big tusker is farther away, you have to decide whether you will wait in the hopes of getting a chance later or see if you can get round the neatrer one without giving him your wind. Sometimes, when they are restless, and show signs of going off, desperate measures hare to be resorted to, such as running past the nearer one and taking a rapid shot at the farther before he has time to get the alarm, or as he is just preparing to bolt. Even as he goes off, sometimes a deadly shot may be had from a little to one side at the back of the head near the earhole, glancing forward into the brain. More usually, howerer, a broad expanse of rump is all that offers itself as a target.

As to the question of shots; with a small bore the brain-shot is more effective. but for this, the position of the brain must be known exactly. One adrantage of a small bore is that it disturbs the animals less, and so often allows one to have a steady second and even third shot. If the animal falls to the brain-shot in amy other posture than it collapse into a kneeling position, make certain of him by putting a shot into his brain at close range. To do this, however, approach him from behind-not round by his trunk-and shoot at the back of his head, raking forward into the brain. Very often one is compelled to forego this chance nf linishing him through the kindly offices of his friends, who gather round him directly he falls, effectively blocking the view till they have helped him to rise. They life him to his feet, and he sones off, never to be angin seen by you; for at shot which just misses the hrain, its al rule, only stums the animal for ibout twenty seconds, and once he has regained consciousmess he gnes off litele the worse for the small fonllet-lunte in the massive bene of his skull. If you could see the tusks of those helping him up you might shont another, but, ats 
a rule, only the massive rumps are viewed, and the tusks, always difficule to see in thick country, even from thirty or forty yards, remain invisible.

With a big bore the safest shot to go for is the heart, as it allows more margin for error. A heart-shot, however, is not always instantly fatal, and if the elephant comes for you a shot fired at close range in his face should turn him.

It is nearly always a female that proves truculent, or a worthless tusked young male that becomes playful, and when tied down by stringent game regulations it is a very difficult matter to decide, on the spur of the moment, what to do. If you shoot the animal it is one lost on your licence, as well as, possibly, a rebuff from official quarters. Charging female and young elephants are often looked upon by the ignorant as myths of the imagination, and the small size of the tusks, when compared to those of a well-grown bull, adds to the delusion that the animal in question was not really very formidable. Female tusks may be small, but they are very sharp-sharp enough to drive right through a man's skull, as has been proved many times-and the tusks are not the only things to be feared, there is the trunk and also feet to reckon with.

The best advice, then, is, leave the females and young alone, even if there are bulls with them.

There is one denizen of the forest I have not yet described, and that is the professional native hunter. The Wandarobo is the name of the tribe, but among themselves they are known as the Ogieg. One hears sometimes of Masai Wandarobo in contradistinction to Kikuyu Wandarobo. The former have a tradition that they were formerly derived from the same source as the Masai, and they refuse to admit that there are any Wandarobo other than themselves. The Kikuyu Wandarobo are merely Kikuyu who have taken to hunting as a means of livelihood. They live, to all appearances, just like the Ogieg, but their language is Kikuyu, and they are always liable to revert to the ordinary state of an agricultural Kikuyu. The Ogieg, on the other hand, have a language of their own, which, though it bears certain resemblances to other non-Bantu languages, such as Nandi, is yet just as much a distinct language as is the Kikuyu language distinet from other Bantu languages. Moreover, an Ogieg never reverts to any other sort of life, once an Ogieg he remains one always. The tribes' ranks are sometimes swelled by Masai who have been driven to a hunting life by hunger induced by cattle sickness. A Masai once adopting this profession never reverts to the pastoral life again, but remains and intermarries with the Ogieg and virtually becomes one of them.

These hunters are practically nomads in the forests following the game about. When they kill an animal they build their little huts near the carcase, and remain 
there till the meat is finished, when they again start off in search of game. The chief animals they hunt are elephant, rhino, forest-hog, bongo, and bushbuck. A big animal such as an elephant or a rhino is, of course, much prized by them, as it enables them to sit down and do nothing for a considerable time till all the meat is finished.

Their methods of hunting are:-

\section{(1) Game Pits.}

These are dug in the animal's pathways. They are narrow and deep and taper to a point at the bottom so as to wedge in the legs of an animal, preventing it from springing out. They are grenerally made in three sizes, vi\%, elephant, bongo, and bushbuck, and are cunningly covered over with leaves or grass. For this reason anyone walking in localities where $W$ andarobo are known to be, should always carefully take, of two paths forking, the round-about path rather than the direct path. He should also always prod any doubtful-looking ground with a stick before stepping on to it. When leaving a locality the Wandarobo generally uncover their pits.

\section{(2) Poisoned Arrozis.}

The hunters creep up near to an animal, such as an elephant, and shoot at it with a poisoned arrow, aming to hit it anywhere. The animal is then tracked up, and when the poison has had time to work it is found dead. They say that if the animal eats as he groes he has recorered from the poison and will not die. If he drinks it means either that he has completely recovered, or else if the poison is still working he will be found dead by the water.

Bows and arrows are largely used for the shooting of monkeys, colobi, and other tree animals, for the Wandarobo to a great extent subsist on the flesh of these creatures.

\section{(3) Drop Spears.}

These also are poisoned; they are hung above elephant-tracks in such a way that they are released when an animal passes underneath, and thus drops on its back.

$$
\text { (4) Dogs. }
$$

With dogs they bring to bay such animals as the bongo; they then shoot at them with arrows.

$$
\text { (5) Nooses. }
$$

These contrivances are made of a rery strong liana called by the IV andarobo "faragwet." The nooses are set in it run attached to a spring bow arrangement, 
conmon in the country. The arrangement is only a larger edition of what the children in all the villages use to catch grumea-fowl or partridge witl. It is used in all parts of the country, from the coast inland. It is curious to note that it is an altogether more simple and easier made trap than that in common use in Central Africa. The latter consists of a thin mesh or net into which the animal must run before the bow is released. The illustration of this trap is taken from "Central African Game and its Spoor."

The Wandarobo drink the blood of the animals they kill. For this reason if an inmal has been shot with an arrow they will never cut its throat or finish it with a

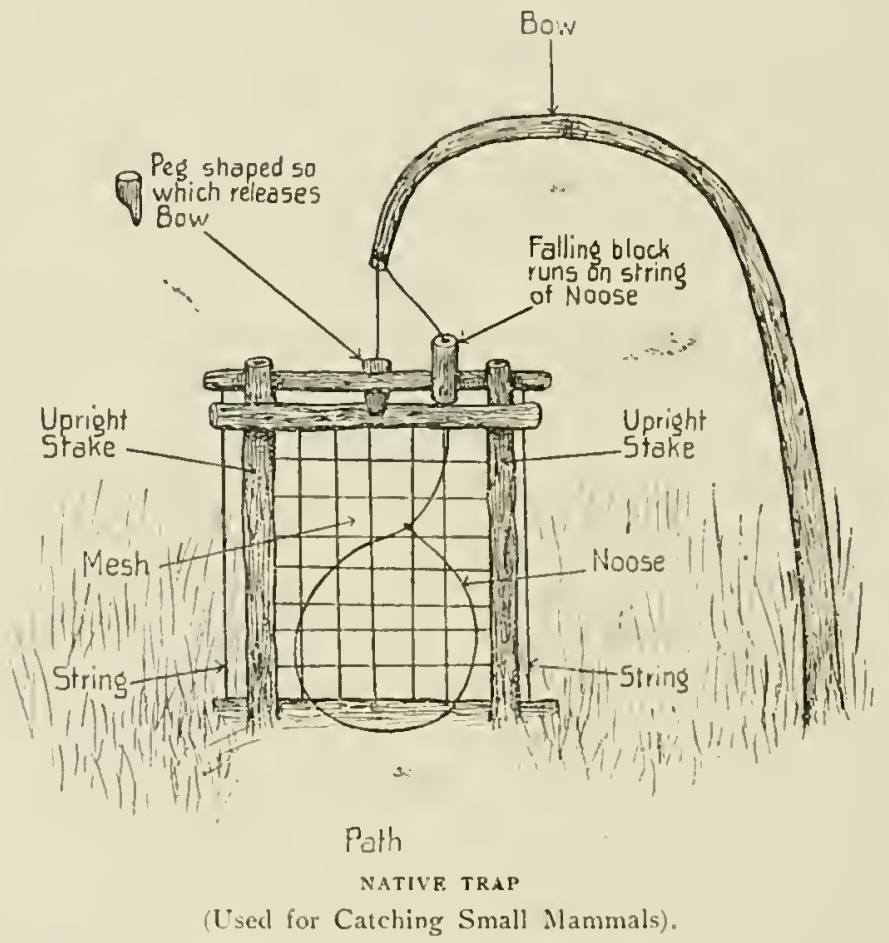

knife or spear, for fear of losing the blood. If it is a small animal they may stifle it to death by holding its mouth and nostrils, but if a large animal they leave it to die of its arrow-wound or the poison.

Once out of their own country the Wandarobo is of little use at tracking or hunting. Moreover, it is only possible to hunt with them when they are hungry. Directly an animal has been killed they will secure as much of the meat as possible, and nothing will then induce them to go out hunting or to take any interest in anything until they have finished it all.

As to the different forest areas of the Protectorate, first in order come the 
great strips along the sides of the escarpments that shut in the Rift Valley. These areas in parts extend back from the tops of the escarpments and clothe the hills and mountains beyond them. The lower parts of the escarpment forests are more bushy in nature, and give shelter to rhino and buffalo coming up from the valley below: On the top, at a level of about seven thousand or eight thousand feet, the bongo and forest-hog make their home. At the southern end of the forest on the Kikuyu escarpment elephants appear to be creatures of the past, but they still linger north of the railway line and on the Mau escarpment. Farther back in the dense Mau Forest they are said to be fairly numerous. On both these escarpments, but more particularly on the Mau, a number of Wandarobo roam.

Above Naivasha, the escarpment on the eastern side goes up in two shelves, or terraces, each with its escarpment, the greater and the lesser escarpment. These are both forested, but appear to contain few animals cxcept bushbuck. Elephants pass occasionally, but only in travelling to or from the Nguzeru and Simbara ranges. Farther north, however, elephants are found on these escarpments. The lower slopes of the mountain range beyond are forested or clothed with bamboo from an altitude of about eight thousand to ten thousand feet or more, both on the Naivasha and the Nyeri sides. These large tracts of bamboo above and amongst the forests form favourite feeding-grounds for elephants, but the animals have been so hunted by white and black sportsmen that there are very few decent tusks left amongst them. There are a few bongo and forest-hog found in the forests, and in the lower parts rhino wander. Bushbuck are found round its edges; a certain number of Wandarobo also hunt these hills, and it is they who are the chief molesters of the elephants. Southward of the range the tribe appears to be Kikuyu Wandarobo, but northward the true Ogieg is met with.

The whole way round Kenya there is a belt of forest about ten miles in thickness, which contains a certain number of bongo and forest-hog, but nothing like the quantity found on the escarpments. Elephants are numerous in parts, whilst other parts scarcely ever seem to be visited by the hords. Meru, on the eastern side, appears to be a noted place for them, but at present sportsmen are not allowed to visit that side nor the Embu side either, where al gond number of clephant herds roam.

Kiliuyu fields cut into the Kenya and the Niruzeru forests in all directions. Between these two great lorest-clad momntains is the thickly populated Kikuyu country almost barren of trees, except where little round hills dotted about are thickly forested. These hills, on which the trees have been left, are sacred groves in which 
the Kikuyu offer sacrifices for rain, etc. 'The uniformity with which these little forestclad hills spring up the whole way across this cultivated region leads one to suppose that once upon a time, before the Kikuyu came with axe and fire to devastate the land, the whole of this region was corered with a vast forest extending from Kenya to the Aberdares.

A curious circumstance is that on a few of these isolated hills colobus are found, left as it were on a little island, presumably at some time past cut off from the main forests by the inroads of plantations in all directions.

The little patches of forest left to them probably dwindled year by year, till now they have only a space limited to the summit of sacred hills to inhabit. Finding themselves unmolested they have probably preferred to remain where they were rather than make a trek of perhaps ten or twenty niles to the nearest part of the forest. Moreover, I doubt very much if a colobus would be able to perform such a journey on terra firma, for they practically never leave the branches of trees as do other monkeys. The above circumstances, to my mind, afford sufficient proof that Kenya and the Aberdares were at one time connected by either a strip or a wide stretch of forest. Colobus are not very common either in the Aberdares or Kenya. In the escarpment forests, however, they are found in vast quantities.

On Kilimanjaro there is a great belt of forest land containing elephants, colobus, and other forest animals. The scaly manis is said to be found there, also the Zanzibar suni.

Above Loldiani (Londiani), Lumbwa, and Fort Ternan on the railway line are great forests stretching into the Nandi country, and bordering on the Guas Ngishu to the northwards, and stretching into the Lumbwa and Sotik country southwards. Also about the Ravine and northwards towards the Kamasia the country is thickly forested. In all these parts forest-hog, bongo, bushbuck, and colobus are plentiful, but elephants are scarce.

Nearly all the administrated portion of British East Africa is poor in elephants. Northwards, outside the administrated area herds are more numerous. Such unadministrated parts are the bush-country of Saragoi, Elgon, Karamoja, and the Turkana country, and (at certain seasons) the Lorian swamp, also parts of Tanaland and Jubaland. 


\section{CHAPTER XII.}

TREK AND CAMP.

A LIFE of trekking and camping is a most enjoyable one. Exactly why this should be so I cannot say, for the petty worries and discomforts connected with such a life are countless. It would be easy to fill several chapters on these trifles, but the charm of camp life is less easy to describe. It consists in the absence of all the restraints of a super-civilised existence and surrounds one with the presence of wild life. It is this close touch with wild nature that prevents the outdoor existence from ever becoming monotonous; it is no small thing to walk in paths made by elephants, drink from streams reserved for the beasts of the forest, and to hear the lions roar at night. Trekking with porters has many disadvantages, including the usual annoyances of travelling in uncivilised countries, and adding a few which are especially its own. To compensate for these latter it also possesses advantages which other forms of travel lack. Not the smallest of these is the complete freedom of movement that is enjoyed. You can start at whatever hour you please, halt whenever and wherever you like, move in any direction, and bring all your belongings required for a temporary home to any spot selected as suitable, the only necessities to allow for being the water supply and firewood, and having a comparatively flat spot on which to pitch your tent.

With any form of whecl-trinsport you are confined to the actual roads or flat country, and with pack-transport you are hampered to some extent by the requirements for zarebaing and grazing the animals, and besides, certain types of country are impractical even to pack-transport. Travelling with porters is a slower mode of transit of course, but you obtain a very intimate knowledge of the country passed through.

1 must admit that continually "footing it" is apt to become boresome after a lime, especially on a return journey of any distance, or when there is litule game about or other objects of interest. But then, what journey performed for the mere sake of arriving at a particular place, is not apt to become dull?

To the student of nature, or the student of the customs and linguages of different peoples, there is seldom a moment that does not produco something fresh 
or worth noting. The more he learns about the objects around him the less boring is the actual walking part of the trek.

Some of the grcatest interests in travelling are the choosing of routes and the calculating of your positions and the working out of the way to some place you wish to reach. Local guides have generally to be resorted to for showing the actual paths in a neighbourhood, but for finding the way to any distant place they are generally rather useless, and the more you can do without them the greater independence you gain. The best way is to decide for yourself what hill or landmark you should pass by, and you should then get a local native to show you a path leading to it. Directly he gets a few hours from his village you will generally find that he knows nothing about the country, and so he can be sent back and another obtained farther on.

The worst place I have travelled in yet for local guides is a section of the Lado enclave. In one part of this the natives know nothing of the district, either by hearsay or otherwise, beyond an hour or two hours' journey from their own village. At every village I came to I was told a similar tale, "At the other side of the valley there was a village, and the people in it wcre very bad and killed anyone who went there, and beyond that village there were no more villages, it was just bush." I could procure guides to show me half-way to the next village, representing a journey of perhaps one and a half hours, and they would then hurry back in case they should meet with the bad people. At the next village I was surprised to hear that "the people whom I had just left were a very fierce and warlike people whom it was not safe to go near, and that on the opposite side of the next valley lived an equally ferocious and warlike tribe, and beyond them it was all bush."

From all accounts the same state of things used to prevail in the Kikuyu country; and each little slope between the hundreds of little streams running down from the Aberdares used to possess a village or group of villages hostile to their ncighbours on the slopes on either side of them. Even now most Kikuyu have a strong objection to moving from their own little section of country, and a still stronger dislike to moving into country inhabited by any other tribe. Each little community is in great dread of its neighbours, and never discovers that they are held equally in dread themselves, and so bloodshed is most uncommon.

This state of things was general with the timorous agricultural tribes which now occupy such a large area of Africa, though there were, and are, other and more warlike tribes, generally speaking pastoral tribes. When these latter felt a desire for outward expansion or the working off superfluous energy, they must have found the more cowardly and split-up tribes completely at their mercy to kill 
and raid as they pleased. The only thing which must have saved the weaker tribes from total annibilation or from being merged into the stronger tribes was, that directly the warlike tribes felt themselves expanding they almost invariably started fighting amongst themselves, and such fights were often rather bloody affairs.

The difference between the courage of some African tribes and the cowardice of others is most marked, and one wonders how the latter have ever managed to survive. You meet with two tribes living alongside of each other, and whilst nembers of one will face a lion with spears and shields, the members of the other will run away in herds at sight of a single man, even without waiting to see if he is armed or is hostile or friendly.

But to return to the native guides; they generally refuse to accompany you singly or without their weapons, though the latter are generally merely ornamental curiosities, for they are thrown away at the slightest hint of danger.

Two guides will generally accompany your party, and this number is useful, as, if you wish to temporarily leave the path, one guide may be taken with you, whilst the other is sent on with the caravan. Before separating, great care should be taken that both guides understand the place at which they are to re-meet. All such arrangements should be thrashed out very thoroughly, as names of places, distances, etc., seem, from minute to minute, to have a curious way of changing.

The best method of arriving at distances is to take one of the gruides out of hearing of the other, and ask him, "If we were to start from here at dawn, where would the sun be when we got there?" or, for long distances, "How inany days is it to such and such a place?" Note then what part of the heavens he points to with his spear, and afterwards take the other guide aside, and ask him the like question.

If they only disagree by a few hours, a mean may be taken, remembering that their calculation is for a man walking without a halt, and that a caravan will take longer. But if one guide says that the journey will take three days, matrehing eastwards, and the other says three hours westwards, or if one stoutly contends that there is no such place, the question will have to be gone into at greater length.

However, I have found these interminable discussions about places waste so much time and are so trying to the temper that I prefer nut to start them, and on most occasions I tell the headman or my cook about how many hours he is 10 so, and that he is to stop at the first water and suitable site for camp after about that number of hours, and I also tell him to block the paths on the way. I then show the gruide the direction in which 10 go, and trust to eutting in on the track of the prorters, and following this up when I wish in get bick in camp. 
If you already know the country the matter is of course simple enough, but standing in the hot sun and trying to make two savages agree about an unknown place, the name of which and likewise the direction and distance of which have all changed since yesterday, and when you know only a few words of their language, and want to be off following fresh elephant-spoor, you are only ncedlessly trying your temper. If you are not pressed for time the best plan is to tell the caravan to follow the path and camp at the first water or village ahead.

I make it a rule with my people that if I have not returned by dusk a party is to leave camp and take the path by which I turned off, or they must travel towards the spot at which I left them, taking with them a lamp if there is one, otherwise they must shout. I almost always arrange in returning, to cut my outgoing tracks, and after a long day following elephants it is a most cheering sight when stumbling along in the dark, and somewhat uncertain of finding camp, to see the light of the search party's lamp bobbing about in the distance, and to know that one will have no more difficulty in finding the way.

The usual kind of porters are Swahili, Wanyamwezi, and Manyema. The ivory and slave-raiding caravans which used to penetrate in every direction into the interior of Africa used to start chiefly from Zanzibar and the mainland opposite, and were composed mainly of the two first of these tribes.

The Manyema is a later arrival on this coast, and came from the Congo Free State. In East Africa one is able to obtain the old professional porters of these three tribes, men who have spent their lives carrying loads with different caravans. As such they take pride and pleasure in displaying their prowess in marching distances and carrying heavy loads, and they are points above the porters obtained in other parts of Africa. The professional porter is also an old hand at camping arrangements, such as pitching tents, cutting wood, and generally making things comfortable, and he sets to work directly he arrives in camp to do all that is necessary without having to be told. Very different are the ordinary scratch lot of porters obtained in ather parts of Africa, to whom the pitching of a tent or the digging of a trench round it to drain off the rain-water are matters of profound mystery.

The Wanyamwezi are practically a race of professional porters, than whom there are no better in Africa. Their strength and endurance in carrying loads is wonderful, and, in addition, they are willing, cheerful, and never idle. They have one very aggravating drawback, which often makes their employer forget their many good points; they are about the most noisy and boisterous individuals it would be possible to find. All African natives I have as yet met are peculiarly and noisily 
garrulous. However smart they may be at bushcraft, they almost always give themselves away by loud talking and wrangling. I have located natives hundreds of times by this trait of theirs, whilst they have been in ignorance of my presence. On many of these occasions it has been greatly to their disadvantage to make a noise, such as when they have been stealing the meat from an animal shot or when trying to shirk work.

I should have the utmost confidence in making a bolt alone through the couniry of the most hostile of African tribes, feeling certain that I should always hear a party talking before I was myself seen, or at any rate, if surprised, I should hear them arguing as to who should shoot first. The Wanyamwezi are no exception to this rule, and on the line of march shout and sing without cessation, and if they see any game yell at it; one would think that their chief ambition was to scare all the game out of the neighbourhood. However much work they have done during the day and however tired they ought to feel, they are still able to sing and dance far into the night, and to beat tins and play all manner of devilish noise-producing instruments calculated to drive the average person insane. Their knowledge of country is poor, ridiculously poor for African natives, and if left to themselves they are in danger of being lost.

As to game, they are generally ignorant of all animals' names, habits, spoors, or anything about them. I have often marvelled how it is that some of these porters having spent their whole lives with different caravans, many of which were big-game-shooting expeditions, yet have learnt nothing about the game which has been all about them. It is no exaggeration to say that many of these natives do not know the difference between a buffalo and an eland or a bushbuck and a lesser kudu.

Of the more local and untrained porters there are the Wakikugu and the Wakamba. These generally prefer to carry a load on the back fastened by a strap round the forehead. The former are good in hilly country, but neither of these tribes are capable of carrying the weight or marching the distances that the Wanyamwezi can accomplish. Moreover, they are unreliable and frequenty run away, sometimes during the first few diys and at other times owing to a sudden panic or for no seeming cause whatever towards the end of a journey when pay is due to them. In either case it is most provoking, as one may be left stranded anywhere with no porter to take the loads.

The Wakikuyu are about the most undecided people it is possible to find. A party' will trek an inmense distance to some Government station to get work, where they may get "written-on," given food and a place to sleep, and in the 
morning it will be discorcred that they have all run away. They appear to be subject to peculiar fits of alarm and apprehension, only needing someone to tell them that they are groing to be takin to a far-off country or something equally fictitious, and they decamp.

The Baganda and Banyoro porters are also unreliable, but these often appear to have no intention whaterer of working. They come in and get themselves signed on and receive an advance of pay and then disappear, knowing full well that they will never be caught.

Thus it is evident that for comfort and almost every other consideration the staid old professional porter is the man to gret hold of, and although his wages are twice as much as some of the local porters, he is often the most economical. For he will march twice the distance in a day that local porters will accomplish, and carry a bigger load the while, and there will be no danger of trek delay owing to his suddenly disappearing.

In Nairobi, most unfairly, the porter's wage is the same, no matter from what tribe he comes, and the wild Kikuyu, who carries forty or fifty pounds, and may run away at any time, draws as much salary as the stalwart Mnyamwezi carrying his seventy or eighty pounds.

There is in force a regulation by which one is compelled to give a porter an advance of pay and a blanket on enlistment. With the professional porter this is sound enough, as the pay enables him to make provision for his wife during his absence, and he is accustomed to the use of a blanket, and also uses it as a turban on which to rest his load, but with the wild porter the enforcement of this regulation is absurd; his wife he has left in his village looking after his fields, and he has never had a blanket before, or anything more than a patch of skin to cover him; moreover, there is no guarantee that he will not run away. The interests of the professional porter are bound up in his work; he hopes to get employment for several months, and he is dependent on his wages for his living; but with the wild porter matters are very different, for he makes his living out of the hoeing and tilling of his fields, and he has no desire whatever to leave his village if he can avoid doing so. He has practically been compelled to leave his fields to raise sufficient money to pay his hut-tax; so that, after some confiding white man has given him enough to cover this hut-tax and a blanket into the bargain in exchange for a fictitious name and address, he really sees no inducement to stop and do work distasteful to him, when he might be sitting in his village.

I suppose some of these runaway porters are caught and punished, but I must say that, although I have come across many hundreds of cases of porters disappearing 
directly they have received their advance, or during the first few days of the trek, I have very rarely heard an authentic case of any one of them being punished for so doing. Provoking as the case is, I really cannot blame them, for I think that most people would do the same under similar circumstances.

As to discipline, there is seldom any difficulty with the porters, for they are almost invariably checrful and obedient. If you have the ordinary cararan leader's powers of punishments these will gencrally suffice; in fact, they will hardly ever be required to be brought into force. So long as the men know that you have power to punish them and are quite prepared to do so, you will seldom or never havc cause to make use of any punishment. However, like all African natives, if they think that you are without authority or inclined to be lenient, they are almost certain to give trouble, and will, anyhow, try to impose on you. It is, therefore, as well to correct. any mistaken ideas on this subject from the start, and an infinity of trouble in the future will be saved. I have always found it advisable, with a new set of porters who do not know me, to watch them most carefully for the first few days, and deal with the slightest offence most harshly. Having done this, I can afford to treat all trivial offences in the future with the utmost leniency, and serious offences then practically never occur.

I have generally found with natives that it never pays to show oneself too solicitous about their welfare, or to show that you wish to treat them better than they are accustomed to being treated, for they are certain to interpret it as a sign of weakness and ask for more; so, excepting when I want to reward them for specially arduous work, I never allow that it is my concern for them which prompts me to give them anything more than their dues. For this reason when I wish to give them extra rations, lighter loads, or any similar concession, I always pretend that it is a purcly personal or selfish reason that actuates my doing so, and in no way is my change of treatment connected with any consideration for then.

During the last few years, most of which have been spent on trek, I have found that the only offences I have had to deal with are thefts and misdeeds against the inhabitants of the country passed through. These are excepting a few petty cases of insubordination occurring during the first few days of a trek, but which when once dealt with never again oecur. Offences against natives should be dealt with most severely, as for every one discovered probably a dozen have taken place undetected. You are, as a rulc, largely dependent on the goodwill of village inhabitants for the obtaining of porters' food and supplies, so that in many places, if a porter steals from a friendly native or maltreats him, nothing will induce any other of his tribe to even come near your camp, and much less to 
bring in supplies. In unadministrated countries lawless action on the part of porters is apt to cause infinite trouble, and is a source of danger to the whole caravan.

When travelling through little-visited country natives may be hostile, but more usually they run away at the sight of a white man and a large party. It then requires great patience and tact to persuade them that your intentions are friendly and to induce them to bring in supplies. The average native is frightened at the sight of any other native of another tribe until he sees him run away, and then he suddenly discovers what a brave fellow he is himself, and wants to rob and loot his adversary.

The greatest vigilance has to be exercised to guard against your followers helping themselves to the belongings of the flying inhabitants of a village, for the language of the village native will most likely be strange, and even if you have an interpreter he will as likely as not conceal any cases of theft reported.

It is not only your own people who are offenders in this respect however, for a native of the country is often every whit as bad. If you have any local guides with you they will as likely as not take the opportunity of robbing their friends, for they know that they will not be themselves suspected. Not long ago I killed an elephant, after having followed its spoor to a spot which I imagined far from any village. The time when I shot the animal was about four o'clock in the afternoon, so I then returned to camp, walking for about two and a half hours. Next day I resolved to camp by the elephant, so that 1 could exchange the meat for porters' food at some village. I wanted to get to the kill before any natives got wind of it, so I made an early start and reached the neighbourhood of the elephant about seven o'clock. Loud wrangling and talking at once made me aware of the state of affairs, and creeping up to the elephant 1 found a party of natives just clearing off, having made an absolutely clean sweep of every atom of flesh. It turned out that there was a village comparatively near, and the natives having heard my shots had set off to discover the cause. Having found my elephant they camped by it all night, and cut it up and were just making off, evidently not expecting my return so early. Directly they saw me they bolted into the bush, leaving spears, bows, arrows, and knives lying about in all directions. I was very annoyed, as meat was in that locality about the only thing that it was possible to exchange for other food, and I had counted on this elephant for the men's rations. The last elephant I had killed had been too far away from villages for me to be able to effect an exchange, and so the natives had had the meat for nothing.

When the party bolted into the bush I managed to catch one poor old man who was not so quick or slippery as his fellows. I then collected all the weapons 
in a heap with the help of a native guide who was with me, and who belonged to the same tribe as the thieves; then when the porters came up I made them pass by at a distance so that they could not lay hands upon anything. The native guide assured me that he knew the people well and that there were relations of his in the village, so I sent him and the old man off into it to say that I had all the weapons, and that these could be had back as soon as flour was brought for my porters in exchange for the meat that had been stolen. Presently the chief appeared with a very meagre supply of flour, and I gave him back the weapons and also gave him a present.

He then complained that the contents of a small skin bag he had left hanging on a tree had been stolen, and that they consisted of an axe-head and some rupees. As the local guide was the only person who had been near the place besides my'self, I knew that if anything had been stolen it must have been taken by him. On being searched, although he protested loudly that he would never dream of robbing his brothers, an axe-head was found in his bag of food. No rupees were forthcoming, and if there ever had been any he must have buried them at once. However, it was most unlikely that any native from the part I was in would be in possession of money, as no money was in that country, nor were there any likely means of obtaining it. Most probably, according to true native fashion, the old chief had invented the rupees so as to rub in the magnitude of his loss.

Having caught a native of the country robbing his fellows in this manner, it is a rather difficult matter to know how to deal with him; for if you punish him there and then, you are punishing one of the tribe whose fears you are anxions to allay, whilst if you let the fellow go, he returns to his own village, where his version of the story will be believed. If he had robbed a member of his own particular village the matter would be simple, for then he could be handed over to his own chief to be dealt with according to local customs.

If you hand him over to the chief of the other village, for all you know there may be hostility between the two villages, in which case directly you trek off the man will probably be murdered.

But I must return to the trek with porters. All loads which remain the same throughout the journey, such as tent, cooking-pots, table, and bed, etc., should have men selected for them whose special duties should not be changed. When every man knows beforehand what constitutes his load it facilitates getting atway quickly in the morning. for each then knows exatefly how to do up his particular luad and exactly what to do with it and where to put it when lee grets into camp. At the first start off on trek there is a lengthy sorting and arranging of lwhe which takes 
most of the morning, and so the first day's trek is often confined to just getting out of a station. On the next morning, however, directly the word is given every porter rushes for his load of the day before, and has it done up in no time, and without further trouble all the loads have found porters. Here again the professional porters show to advantage, for they know by experience that wasting time in packing up and in wrangling over loads means wasting the most valuable marching hours of the day, whilst with the unprofessional porters a wearying repetition of the first day's sorting and apportioning of loads takes place, and there is a general fight for the lightest packs, and when everyone has done up his load there will still be seen other loads lying about without owners, due either to deserters who have decamped during the night or through men dividing up their packages of the day before and only taking half. Finally, when all is ready, the sun is high in the heavens, and the march must be performed through the hottest part of the day.

The tent should be given to men who habitually arrive first in camp. Nothing gets straight till the tent is put up. During the rains it is exasperating to have the greater part of the loads lying about and getting sodden by the rain owing to the tent not having arrived.

The usual pace of a good porter is from three to three and a quarter miles an hour, exclusive of halts. The spirits of the men make an enormous difference to the pace. They appear at their best during the last few days of a homeward march, when they will often be quite indignant if they are not allowed to march thirty miles or more during the day.

The longest march by "time" that I have seen Wanyamwezi perform was a day commencing at 6.30 a.m. and ending after sunset, with only four brief halts of from five to ten minutes for water. The whole of the journey was performed across country of very thick rank vegetation, with no paths, and up and down steep hills. Although the actual distance covered was not more than thirty miles, the thickness of the regetation* and the steepness of the hills must have been very trying to men carrying loads.

When travelling by paths the route to be taken is generally indicated to the porters behind by blocking all paths not to be taken. This is done by throwing down a handful of fresh leaves or grasses, or by placing a branch in the mouth of all paths not to be taken. However, such signs may be kicked aside by other passers-by, and so, if one has nothing else to do, it is advisable to wait at stated intervals for the caravan to catch you up. For in a doubtful case it never appears

* The vegetation was matted long elephant-grass, which left one at the end of the day with rags in place of the comparatively new pair of breeches one started in. 
to occur to the coast porter to look for the track of your boot, however obvious such tracks may be.

In East Africa all the natives are very poor in tracking, but in bush and thick countries like Uganda and Nyasaland it is generally possible to march straight on to your new camp, even if part of the way is across unbroken country. Upon the new site a man is left with directions as to camping whilst you go off hunting, feeling quite assured that the porters will find no difficulty in following you to camp.

Shooting-caravans, or safaris, are generally considered incomplete without the addition of from one to three munificently paid and imposing individuals referred to as "gun-bearers." I have never quite been able to understand exactly how they come to be considered worth the enormous salaries they often receive, or what they do to earn them. They certainly carry a rifle or a gun, and possibly a bag of cartridges, but any porter would be glad to exchange his eighty-pound load for a ten-pound rifle without increase of increment. The gun-bearer cleans the rifles, but so will a porter if he is shown how to do them, and both types of native are equally likely to leave a piece of flannelette jammed in the bore. If you have a native to clean your rifles it is a wise precaution to look down the barrel before going out to shoot, for most natives think that an obstruction of the flannelette kind will be removed the first time the rifle is fired without its ever showing any indication of the blockage having existed.

But to return to the gun-bearer; from the few I have chanced to meet I would not consider their bushcraft or knowledge of game of any very high order. So far as I can see, most of them prefer to wear white coats, red tarbooshes, and squeaky boots or noisy sandals when in pursuit of game. Moreover, their masters are constant in their complaints of their cowardly concluct in the presence of dangrerous game, so for what reason they are employed I cannot imagine.

Some natives are very cowardly and timorous, and some are quite the reverse. If you want to secure a native to stand by you in emergencies with a spare rifle you must very carefully select the tribe he is to be chosen from. Many natives, knowing well the habits of game and exactly how far they can go without putting themselses into any real danger, appear stalwart enough on most occasions until some unexpected event happens, and then they bolt. With the majority of savage tribes it is considered no discredit to a man to run away and leave a companion in the lurcis. He would say, "I saw the animal looked fierce, and so I ran away," and his companions would think it very wise and proper conduct, and that the man who stopped to get mauled was rather a juggins. It is just as a boxer would say, "I saw that he was about to swing" 
his right, and so I ducked." No one would think him cowardly because he did not stand up and receive the blow. However, there are a few tribes who have different codes, and who consider it a great disgrace to show cowardice or to leave a companion in the lurch.

Amongst the coast porters there are many such men, and in any caravan of professional porters I have had I have never found any difficulty in getting a man to stand by me with a second rifle, and no doubt I could have found several such. If one of these porters is supposed to have shown himself insufficiently staunch he is unmercifully chaffed by his fellows for a long time afterwards. As, however, the men are hopelessly weak in bushcraft, it generally happens that you have some raw native guide with you who knows the locality thoroughly and can help in tracking and finding game. When you have only one such with you it is as well to be entirely independent of him when you approach a dangerous animal. On such occasions I take in my pockets sufficient ammunition for an emergency, and the guide can then make himself scarce up a tree with the rest of the porters, or do anything else he likes without causing me inconvenience.

Sometimes, though, amongst these raw savages are found very stalwart men, who insist on standing by you, but it would be very unwise to assume that a man is one of the exceptions to the rule until he has been absolutely proved. The tribes that frequently turn out courageous men are the Sudanese, the Wanyamwezi, Manyema, Swahili, Makoa, and Yao, all of which contain numbers of undoubtedly staunch men, while the Somalis and Masai have often proved their bravery, especially against lions.

I have shot dangerous game with members of all these tribes, and I must say that it is a very comforting feeling to have a man beside you upon whom you can rely to hand you a big bore in the event of a rush from a wounded animal, or at any rate to do something to help you in a mishap.

However, in most cases of my bagging dangerous game, I have not had one of these men with me. I have then found it best to trust entirely to a magazine small bore, as with such a rifle you practically always have a cartridge ready, whilst with a double bore you generally expend both cartridges either on the same animal or in trying to secure a right and left, and then a critical delay takes place whilst the gun is reloaded.

For elephants I sometimes take the big bore from the man carrying it, when the animals are located, and advance with a rifle in either hand, subsequently resting the big bore against a bush whilst I fire with the small bore. However, this is rather a wearying proceeding, especially if the animals are moving, and moreover, in thick 
country they may suddenly appear close at hand or stampede past, when it is difficult to find a place in which quickly to rest one of the rifles.

But 1 appear to be wandering somewhat from my subject, which was that a gaudily dressed, be-booted, cigarette-smoking loafer of a big town like Nairobj does not know enough about game or bushcraft to be worth from forty to eighty rupees a month (which salaries are common for the professional gun-bearer to recerve). If you want a man of pluck to follow you, take almost any one of your Wanyamwezi or Manyema porters at a salary of twelve rupees, and he will think himself handsomely paid; if then you take him into any dangerous position you can always make him a present afterwards if he behaves himself well. If you want a man skilled in bushcraft he will be harder to find, but raw savages can generally be picked up who are fairly useful for local work. When you leare the man's district you can give him a present, large or small, according to the services he has rendered. In most parts of British East Africa it is very easy to find your way about; especially is this so in the highlands. There is no long grass over the head, and a good view is generally obtainable, whilst there are numbers of landmarks easily recognisable.

If the sportsman is not used to finding his way about he should take careful note of all landmarks, especially those near camp. He should also mark down all streams, watercourses, and valley's crossed, and their directions.

The only way to learn to find your way about is by constant practice in trying to work out the way, even at the expense of taking a longer route or wandering farther afield than if directed by a native. There is a good Swahili proverb, "To lose the way is to know the way," meaning that if you lose a path once you will remember that way for ever afterwards. It is by the failures and not by the successes that you gain experience.

The difficult places in which to find your way are in the thick bush, such as round $\mathrm{Voi}$, and dense forests such as on the escarpments. In both these countries it is not at all an easy matter to locate your camp. The dense forest is often the harder country, as in the highland forests the mists may last well into the afternoon and the sun never come out to guide you.

Noting detail, whether it is of country, spoor, or anything else, is only a matter of bringing the mind to bear on the subject. Almost everyone has the gift of being observant of detail to some extent, and people develop this gift, consciously or unconsciously, on different subjects, generally confining themselves to those things which especially interest them.

I have met many men who have spent years in wild countries and yet have not the faintest conception of finding their way about or of observing the details of a 
country. Others have spent long periods in places and yet have hardly picked up a dozen words of the language and know nothing about the inhabitants. The reason of this is not that they are incapable, but that such things have not interested them. Many of these men are wonderfully observant of anything which is of interest to them. Some will be able to tell you after a few minutes in a bar exactly what bottles and drinks were exposed; others can remember the exact pattern and colour of any necktie they may happen to have seen.

After several years spent in the wilds, constantly training myself to observe details of country and various other signs which go to make up the science of bushcraft, I returned to England imagining that I was more observant of detail than my fellows, owing to this training. I soon found, however, that I was quite mistaken. I perhaps observed more general details than the average, but the average person had specialised in one or more subjects just as I had specialised in bushcraft, and in their subjects I had not the technical knowledge to compete with them. For there is nothing more difficult than to observe well several perfectly strange or unfamiliar objects and remember their details. So some people can come out of a church with a mental picture of the exact shapes, materials, and constructions of perhaps a dozen different hats, because it is a subject they have studied; and in like manner an architect can in a few moments commit to memory the plan and relative positions of doors, windows, and a multitude of other details connected with his building craft.

Practically everyone has the gift of observation in some special line, and so almost anyone could turn this talent to account in learning to obscrve country were he so minded.

The reason why the observation of country is found so difficult at first is that all the objects seen are strange and unfamiliar and difficult or impossible to commit to memory. When, however, you learn that one kind of tree is called a mkuyu and another a mbuyu, and when you get to know what they look like at a distance, you have laid the foundations for recognising them as landmarks. You will next notice that all mkuyus are not alike, and then any of very quaint shapes will begin to impress themselves on your mind.

Although an eye for country is to a great extent more or less of a gift, anyone who cares to take the trouble can learn a great deal-at any rate enough to take them about most parts of East Africa. It is much more interesting to strike your own line than to trust implicitly to native guides, and also it gives you a sense of freedom impossible to realise when dependent on natives.

There are two little pieces of advice that I should like to suggest to the beginner if he finds himself alone or lost in a difficult country. 
The first is, that he should not make blind shots, as people are apt to do when they feel themselves lost, for after a series of wanderings he will be more at seal than ever. He should rather sit down and light his pipe, collect his thoughts, and think out the way he came and his best way back. Of all subsequent movements he should take very careful note.

Secondly, he should plan to hit off some landmark, or series of landmarks, the longer the series the better, such as a path, river, ctc., so as to leave more margin for error. When he has finally decided what he will make for he must persevere in that direction for some time after he thinks that he ought to have reached his landmarks, for it will hardly ever happen that he will overestimate the distance to a landmark; on most occasions he will begin to expect it long before it is due. It is then the case of the "watched pot," and it will seem an infinity of time before he reaches it.

One of the greatest charms of the trek is the loneliness which it entails. Some of us are gregarious by nature, and others are not. To the latter constant jostling and elbowing with crowds is a source of continual annoyance, if not of actual pain. On trek, when once you have got past the ever-spreading fungus of civilisation and have reached the "beyond," all the cares and worries of a super-civilised life fall away and are completely forgotten.

There is a never-failing yet ever-differing charm about the wilds which must be known to be appreciated. To be out of touch with civilisation, or, better still, to be in a totally uninhabited country, is to lead a very pleasing existence.

There are, it is true, the drawbacks of noisy porters who spoil the peace and beauty of the solitudes with hideous rows, but if your tent is pitched at a little distance from them you are spared a certain amount of the noise, and as time groes on you get more or less hardened to the constant babel, or perhaps notice it less, though it must always remain a source of petty worry.

In spite of the very constant and real annoyance I feel at this continual row, I never attempt to put a stop to it, or, like many men, insist on silence after a certain hour. For so long as I hear them wrangling together and shonting at each other I know that they are happy, contented, and well fed. Solong as they do their work well I let them matic all the noise they like, excepting only when I am camped near a spot which I expect clephant to visit cluring the night. "lo impose silence on a native is to him a very real hardship.

After all, you escape from the noise cluring the whole day, when gon are frencrally in the open. I usually choose for my companious for the day one porter, who will carry water-bottle, camera, and anything else required, and one local nutive, who will show me paths and give me any information required about the country. 
As these two will at most have only a few words in common, no very sustained conversation can ever be held.

I must say, however, that often when I have been struggling back to camp in the dark, or when trying to strike the camp and am uncertain as to its position, I have been very glad to hear the loud talking of the porters in the distance, and know that food and rest were at hand.

Although most of the noise is wrangling and arguing over childish matters or is the singing of obscene songs, it is often possible to hear quite interesting and amusing conversations. Among a "safari" of coast or professional porters there are certain to be a certain number who have been on all sorts of interesting and, perhaps, historic expeditions, and their accounts and versions of the different events are most quaint and entertaining.

You may hear about the old days when the trek up to Uganda used to be performed on foot, or you may hear of the fights against Kabarega and the Soudanese Mutineers, or of expeditions to the Lorian, Rudolf, and many out-ofthe-way places, and all manner of other thingss. These accounts are generally so profuse in minor details and so haphazard as to the aims, objects, names, and clates of the expeditions, that it is often some time before you can gather the drift of affairs.

For instance, a native might commence, "When I was with Bangusi (or some other nicknane), the white man who paid the Government for permission to take war up to such and such a country." This might mean anything. It might refer to some trader who was seen paying money for his licence (hence the paying to the Government), and who subsequently fired off a rifle to frighten away some hostile natives, or it might equally well refer to a shooting expedition or some small punitive expedition.

At times I have taken my chair round to the porters' fire, to listen to the headman or some other telling stories, either of the fairy-tale description or of folk-lore. Sometimes I have been asked to contribute something in the way of a story, and on such occasions I have found that any of the "Thousand and One Nights" permits readily of being translated into Swahili, and is greatly appreciated, so long as any very subtle points or matters referring to local customs not likely to be understood are omitted. With the higher-class Swahilis of the coast these stories can be told rerbatim, as their modes of living and ways of thinking are almost identical with those of the Arab.

These story-telling occasions, however, are in the minority, for the almost nightly recreation consists of singing obscene or topical improvised songs in a 
monotonous scale to the accompaniment of beaten tins, sticks and boards, or the shaking of grain in a wickerwork or wooden receptacle. The topical songs are improvised from time to time and touch on the events of the trek. I give here two examples :-

I.

When we climbed up Nguzeru

The tears came forlh because of the cold.

For necessities we were hard pul to it.

'Then came forth Hasan Ali and said:

"My children, when you return to Nairobi you will forget all this."

II.

The Bwana (master) has shot a marua (bongo).

The Bwana has shot a marua.

When he told us we thought he was playing with us,

Bul now we see it is true.

Behold he is a son of wealth.

liast Africa is becoming more and more settled over from day to day, and nowadays to find solitude, peace, and quiet, you have to go far afield. In any unoccupied country near at hand you will find, perhaps, a dnzen shooting-parties following one another round like foursomes on a crowded golf-link. However, for the ungregarious, there are still the unheallhy or waterless tracts, shumned by the many, to fall back upon.

To conclude this chapter, I will endearour to give a few tips conducive to comfort when on trek. I have often met with people who, with exactly the sanc means at their disposal, live a life of discomfort because they have never been shown how to improve matters.

Some of the little expedients used in the bush are so simple that a child ought to be able to invent them; yet it is a fact that they are seldom thought of before one has been shown them by someone else. I claim no originality for my tips, as they have almost all been suggested to me by others, and any conclusions not so suggested have probably been arrived at by humelreds of sportsmen.

First of all, as to the selection of a site for camp. A flat surface is required on which to pitch the tent, but not a storry or rocky surface, or the peess cimnot he driven in. If travelling in very rocky country iron pegs should be taken. A pleasant addition to the camping site is a big shady tree, if such can be found, and the tent should be placed so that it is shaded from the midday sun, otherwise it becomes unbearably hot inside, to the detriment of stores. It should also be arranged so that 
you can sit outside on return to camp shaded from the afternoon or erening sun; in other words, the tent should be placed under the tree, with the door to the cirst of the trunk.

Any formation of the ground which might prove to be a watercourse after rain, or any depression which might fill with water, is to be avoided in the immediate vicinity of the tent.

If it is the rainy season, let the back or side (according to pattern of tent) be towards the prevailing wind, so that rain is not driven into the tent. If, however, it is the hot weather, then arrange the door of the tent to face the prevailing wind, so as to obtain a cool breeze flowing through the tent, and have all the tent side-flies rolled up during the day. If there is no shady tree the door must be juggled so as to face away from the afternoon sun, which is alwajs possible unless the prevailing wind is from the west.

Having a lot of firewood close at hand is another important consideration, and seeing a fallen dead tree in a convenient spot is often an inducement to make it a camp-site, especially after a long march or when there is little daylight left. If the water supply is to be obtained from a swamp, then camp some distance from it or above it, for the neighbourhood of a swamp is unluealthy, and if in low country is bound to be full of mosquitoes.

It is easier to bring water from a distance than it is to carry firewood.

The tent having been pitched, make it a rule to have a trench dug round it as soon as possible to carry off rain-water. It is too late to dig trenches when the rain has started or a sudden thunderstorm has burst. The trench should be in such a position as to catch all the water from the roof of the tent, and the earth of the trench should be banked against the tent.

A waterproof sheet put up as an awning at the door of the tent gives pleasant shade, and makes a cool place to sit under, as the wind percolates freely beneath. Nor does such a sheet weigh much, and it may be easily fixed up by one upright bamboo stuck into the ground and another pole tied between it and the tent-pole. Over this the sheet is slung and is fastened to the ground by cord and pegs. Spare loads can be placed under this shelter safe from the rain and sun.

Having arranged the site for your tent, it is advisable to put the porter's camp some little distance downind. By so doing the noise nuisance is somewhat mitigated, and you do not get the smoke from their fires, but, above all, you are less troubled with the stench which emanates from their camp. A collection of raw porters is, as a rule, very strong. The coast porters are fairly clean, and do not smell much, but there is generally some decaying meat in their possession, 
whiffs of which are very unappetising during meal-times. Some of the coast natives are very cleanly in their persons and habits, but even with them their houses are dirty and unclean. Most inland natives are filthy in their habits and manner of living. Some of them never wash at all, smear themselves over with fat or odoriferous oils, and if they have any clothes these are practically never taken off, night or day, till they drop off with age.

There are people with whom it is a mania to try to make out that the black man is equal to, if not superior to, the white man in both morals and habits. These people maintain that it is only a difference of habit whether one cleans oneself with water or plasters oneself with fat and mud, and that if we think the black man smells, he also thinks we smell equally badly. That we may smell to the black man I am quite ready to admit, but there is this distinct difference all the same, for whereas the strong smell of black man is most offensive to the average white man, I have never been able to cletect a native show the least discomfort at the near presence of a white man. The odlour of raw natives close round one, packing up the tent and loads in the early morning, is quite sufficient to prevent one from eating any breakfast when not feeling very fit; but with natives, on the contrary, once they have got over their first feeling of shyness at the presence of the white man, they seem rather to prefer his proximity than to avoid it.

I have often been out on a very hot day with a couple of local savages and sat down to rest under the shade of some small bush, and they have come and huddled themselves close up against me, one either side, although there was plenty of other shade to be had. On getting up and groing to another tree they have followed me and again sat quite close to me. No doubt they have been prompted purcly by a spirit of friendliness, but it was none the less trying on a hot day, when one wanted to get all the air possible.

Obtaining food for porters always involves intervals of delay and trouble. If visiting uninhabited parts or places where the natives are pastoral or awerse to selling food, the simplest plan is to have a few donkeys, and packs of food slung on cach side of the animals. These loads can be obtained at the last Indian store touched at, and are generally fairly cheap. 'Though more expensive that they" could be bought from natives of the country, the delay and worry in inducing natives to bring in food is not worth the few extra rupees insolved. Buans and peas keep best, and can be packed in sacks, though the men like flour fur a change of diet, and for packing this a few green waterproof rotproof bigs atre imaluable.

When you are long away from all stations, and intend going farther alicled, foud must be obtained from natives. To procure such necessaries, it is essential that 
you should know the exact articles required for barter, as native tastes differ exceedingly among different tribes, or even sections of tribes. White calico and brass wire are alway's safe things to take, but are none the less awkward things to barter in exchange for food, for the local natives turn up in a long file, each man with, perhaps, a cupful of flour, for which he expects remuneration, and to give out a piece of calico or wire big enough to be used by each individual is, of course, absurd. Beads and salt are useful things, as a small string of the former or a spoonful or two of the latter can be given to each man. However, for both these articles you must be certain of the market, as there may be a local salt manufactory, when your packages will be found useless; and then beads differ from time to time and in different localities. As a rule there is only one particular sort of bead that is acceptable, whereas any of a hundred other kinds will not be looked at. So unless you are certain of the particular bead required, these are things better left alone, or you will find yourself saddled with loads of perfectly useless ware. Tribes cliffer so materially in custons, ornaments, and in their ways of regarding the white man, that unless you have visited the spot before, or have first-hand and recent information, it is impossible to tell what may be required.

Along the banks of the Upper Nile in certain parts, the most valuable things it is possible to possess are empty plain glass bottles, as the natives break them up and chip lip-ornaments from them. I have been offered two and even three chickens for a Worcester sauce bottle, and an empty jam tin fetched another. Inland, bottles and tins are perfectly useless. Most savages are very independent, and unless you can find something they are very anxious to possess, then food will be almost impossible to obtain.

Some natives seem to have the greatest mistrust of the white man, and can never be persuaded to do anything for him. Directly they are asked to bring food or to produce a guide they all disappear into the bush. Other tribes that might be expected to be much wilder often show the greatest confidence in the white man from the beginning, or, rather, directly they find that he has not come to kill or rob them.

Every now and then a native will ask for medicine, but it is not a very usual occurrence, and so 1 grenerally take only sufficient for myself and porters. The natives of one tribe, whose confidence I was anxious to win so as to simplify the food question, used to flock in for medicine, and some used to be carried in from miles away to have enormous sores, the size of saucers, dressed. If I had been aware beforehand that this might take place, I would have taken on trek large bottles of iodoform, salts, and other simple remedies. 



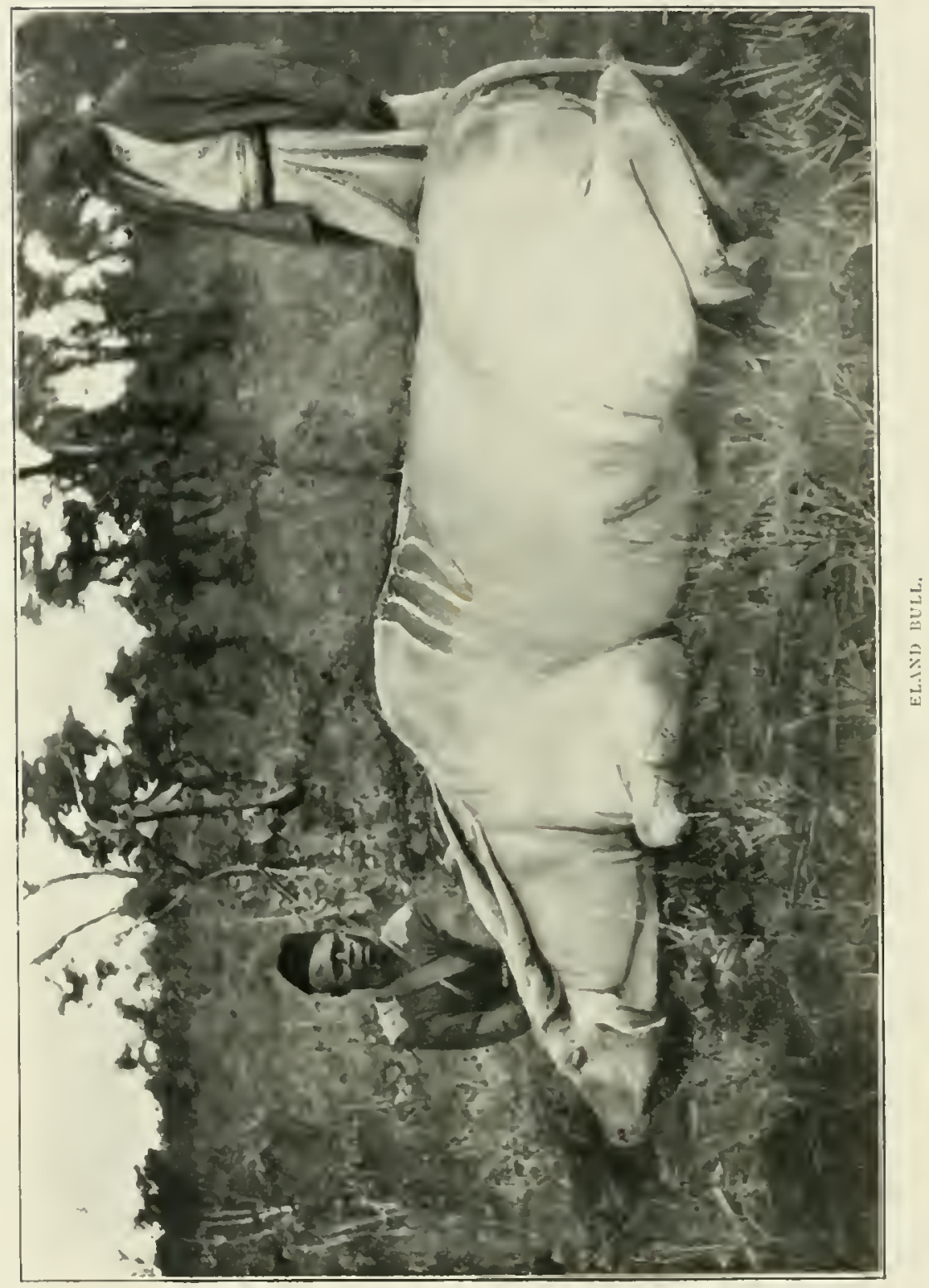


Some of those I attended had spent a night stealing the meat from an elephant I had hoped to convert into flour, and had fought and slashed at each other with their knives. When they had stripped the carcase bare, they came back and coolly strolled up to my camp to have cut fingers and various other wounds, received during the night, attended to. However, the tribe were on the whole a very fair lot, for when it was explained to them that they had had all the meat for nothing, and that I now wanted flour for nothing, they quite saw the justice of the argument. So the hat, in the shape of my bath, made a tour of the villages and received contributions of flour. The natives' ideas of the amount of nour an clephant was worth was rather smaller when half the animal was eaten than it would have been if 1 could have approached them when suffering from meat hunger.

The first time that the flour was stored for the night in the bath (for want of a sack), I watched my Uganda headman levelling the top of the flour and making little patterns and impressions on the top with one of my cups before stowing it under the flies of the tent. Now, you never see a native do a thing like that without some good reason, and it struck me immediately that the designs were executed for a purpose, and that the dodgre was one of those very simple little precautions which no one ever thinks of for onc's self. For if the llour was just piled up anyhow in the bath someone might come during the night and belp himself to it without anyone else being much the wiser; but with the simple precaution of the cup designs it would be impossible for anyone to take even a handful without disturbing the patterns, and it would be equally impossible for anyone to make similar patterns again in the dark or without the lrelp of my cup.

In unhealthy countries if the traveller does not do himself fairly welt in the way of food-stores, he quickly gets run down and covered with veldt sores. It is a very false form of economy to try to do himself cheaply, as it lays him open to fevers and many other tropical ailments. However, on a long trek, far from civilisation, the inevitable day must arrive when nearly all his stores are finished, and he has then to live as best he can on the resources of the country. A knowledgre of these resonrces (which resources are always poor), and of how they can be turmed to account, is invaluable at such times.

The anount of food-stores you can carry with yeu is enencrally decided by the number of porters your funds enable you to engrage, or the number it is feisible to take with you, From twenty to thirly porters are grenerally ats many as com be laken with comfort. The greater your following the greater the difliculy you have in feeding them; hesides, the tronble and delay ealused by collecting fond connterbalances the extra toads it would be pressibli. to take. 
When you are six months or a year absent from any depôt or station, it is manifestly impossible to carry enough food for the men for even a quarter of this time. If every man carried nothing but his own food, he could only take enough to last him for a litule over a month. For this reason you have, when on long treks, to depend on local supplies.

As regards your own food, it is as well to arrange, if possible, for enougl stores to do yourself fairly well for as long a period as possible; and after that time to still have at least enough tea, salt, and tobacco to last you through the whole journey.

As to local supplies, sometimes you can get practically nothing at all, and at other times, if you are constantly on the look-out, you can manage fairly well. Of regetables, whenever you find any you should lay in a stock at once, for it does not follow that because at one village there happen to be pumpkins and sweet potatoes that there will also be pumpkins and potatoes at the next. Sometimes you arrive at a cultivated country and find a few vegetable commodities, but as the natives are unwilling to sell them, you pass on, thinking that you will obtain plenty of opportunities further on, but, on arrival at the next place, you find that there is nothing ripe or that there are none at all.

Of regetables, there are pumpkins, sweet potatoes, yams, bananas, tomatoes, beans, and peas, obtainable in different localities, though seldom all together, and then they only ripen at certain seasons. If the bananas are unripe they may be used as a vegetable, cooked in a mash. Pounded cassava root, also cooked in a mash, makes a good eating regetable. Natives always wait until the peas are hard and dry before picking them, but if secured in the young green pods, they may be eaten as French beans. An excellent mash is made by soaking the ordinary broad beans, then pounding them and cooking with chillies. Then the green tops to the sweet potato may be used as a spinach, and there are also several other leaves, some cultivated and some wild, known to the natives, that form a good spinach.

Fairly good chupaties may be made from a dough of red flour* and fried in fat. A porridge also can be made from the same flour as, too, from the coarser flour of the millet (mtama) and Indian corr (mahindi).

Your cook will always be bothering you for fat. I do not know what he does with it exactly, but plenty of it seems to keep him happy, and if he does not get it the cooking deteriorates. Some people issue tins and tims of marrow fat for cooking purposes. It must be very nice to be rich enough to be able to afford such a luxury, but it strikes me as rather a waste of money. Before starting on a trek I generally send the cook to buy a couple of fat sheeps' tails, which he melts down and uses 
for cooking. This supply is soon exhausted, but from time to time I am able to kill a sheep to replenish the supply, or else I give him the fat from an elephant, rhino, hippo, eland, or giraffe to melt dowm, other animals appearing to have none. When very hard up I have cut the yellow fat from under the skin of a \% bra, but this flavours the cooking unpleasantly. Sometimes the fats of the pachyderms are excellent, whilst at other times they are strong and unpleasant. The oil of the semsem (ufuta) is excellent for cooking, and very good stews may be made with pounded semsem, or better still pounded ground nuts (njugur), which give a very pleasing flavour.

When I have run out of most tinned provisions I always make my cook manufacture Swahili dishes. If he persists in trying to turn out dishes which he fordly imagines are white man's food, not having the means to make them, he only serves up dull, watery stews and plain roasts. Of local products several very palatable Swahili dishes can be turned out of the curry and mashed-vegetable order, having rich gravies and plenty of chillies. Some Swahilis have an excellent way of slowly cooking meat with salt, which makes it very tender. It takes one or two days to prepare; still, a cold huffalo tongue prepared in this fashion is first-class.

Most game-meats seem to vary considerably; sometimes a particular kind of animal proves to be coarse and unpalitable, and at other times is quite good eating. The meat varies so much that it is very difficult to say which particular kind of animal produces the best meat; nor is it as a rule possible to guess correctly as to what animal any particular dish of meat belongs. Waterbuck is always supposed 10 be strong and uneatable, but I have often eaten the meat of this buck and been under the impression that it was some other animal. The meats that I have found best are those of cland, Thomas's kob, reedbuck, and Thomson's gazelle; these are nearly always good. Many other meats also are very good, but not perhaps as uniformly good as those I have named.

Fresh milk makes a most welcome addition to the camp table, but it is not often obtainable. If, as a stranger, you pass by a Masai or other kranl, you will find it, as a rule, difficult to make them sell any milk. If you do suceed in overcoming their objections, then the arrangements for obtaining the milk in a clean and pure state are so complicated that as often as not the whole concern falls through. Natives seem to object intensely to pare milk, and to use every artifice at their disposal to make it umpleasant.

The milk is generally drawn from the cows into gnurels dressed with ait. smelling fats and contaning a wash of old and putrefied mille. The inside of the 
gourd is also prepared with the charred wood of a certain tree, which I belicre curclle's the milk. Other pleasant native customs are those of mixing the milk with blood or urine, or else they will put it by until it has curdled, and grown a fungus on top. So unless the native can actually be caught milking his cattle, and made to milk into one of your own utensils, it is not much use trying to obtain milk otherwise. Some natives are very willing to oblige, but even with these it takes perhaps a two days' stay in a place before you can obtain drinkable milk.

On arrival at a place the chief will perhaps immediately come down with presents, including a gourd full of curdled, putrefied milk, which has been put by perhaps for months for some great occasion such as your coming. When he is told that you camnot eat it he often sits down and eats it limself with the greatest gusto. In the evening when the cattle come in he sends you down fresh milk in a gourd smelling most abominably; and with bits of old and decayed milk floating about in it, hoping this will satisfy you.

Next morning you send a utensil to him to put the milk into, and he milks into the gourd just the same, and then pours it into your utensil. He is very concerned when he finds that this does not suit your fastidious palate, and so in the evening a man is sent to superintend. He returns with the milk and reports that it has been milked directly into your tin. Even then it is strong and unpalatable, and you imagine that it must be something to do with the grazing. Your boy, however, suggests that it is, maybe, caused by the dirty hands of the man who milked, a most revolting thought, but which none the less proves correct, for when the boy makes the herdsman first wash his hands and then the cow's' udders, you at last obtain pure, sweet milk.

Having once obtained your fresh milk, it is such a godsend to drink with tea and mix with your porridge made from native flour that if you are trekking on the next day you will wish to preserve it for as long as possible.

You should put aside what is required for immediate use and boil the remainder immediately. It will then last throughout the next day, both for breakfast and the evening meal.

When using tinned milk, in spite of the very urgent exhortation on the lid to punch two holes, I have found it advisable to punch only one. The milk can easily be induced to come out by sliaking the tin or by squeezing the top and bottom. When the trek is resumed, a little plug can be put in the hole and none of the milk will then be lost in transit. With two holes though, however carefully they are plugged up, there is sure to be a little air leaking into one which allows of the milk escaping from the other, as the tin among the porter's load rocks with each step. 
This is a very small matter, but one which counts for a great deal when you are trying to eke out your last tin as long as possible.

A camp firc close to your tent is a very cheering sight, especially on cold nights. The direction of the wind should be observed before making your fire, so that the smoke may not be driven into your tent. In the dry season, when the grass is dead, a large space should be cleared around the firc or otherwise you may suddenly find the whole camp in a blaze. It is also as well to sce that the porters take similar precautions, as they are very careless in the matter. When you go to bed cverything may seem to be all right, but a log when it has burnt back may catch a tongue of grass which leads to a large patch of dry grass, and suddenly you will awake during the night to find clouds of smoke and the crackling of fire all around. All hands rush out with sticks, and, if lucky, beat down the grass before any damagre has been done.

When camping in the mountains or on the very high plateaux it is often bitterly cold at nights, and, with kit prepared for a tropical climate, you may feel very miscrable. If, too, there is a searching cold wind, it is most umpleasant. Where plenty of firewood is obtainable, the stalwart Wanyamwezi will bring in enormous logs of wood and trec-trunks, till presently blazing fires will be kept going all round. However, the chicf disadvantage of a big fire in the open is that if you get near it the heat is so intcnse that the side next the fire gets scorched, whilst the side away from it remains colder than ever. When you turn round and the cold air strikes your scorched side, the difference is so great that the cold feels more intense than erer.

Some of the firs and junipers of the forest produce the most splendid red embers, which remain glowing for an immensc time. When I sit and write, or when I am at meals, a spadeful or tinful of red-hot cmbers is brought and scattered under my chair and table, and the warmth thus created is most comforting.

At night your toes are apt to become untucked and protrude at the fout of the camp bed. I suffered at nights from cold feet for some time before I thought of the very simple cxpedients of not laking off my socks when in cold localitics, or even of putting on a second pair.

Many sportsmen will, without doubt, think that my camp-tips require no great ingenuity to devise, and many who have had experience will probably have thought of most of them for themsclves, together with many more besides. Still, it is a fact that, as a rule, the simplest and most obvious things are those which escape notice, and so a few of those that I have given may not have oceured to some of my: readers.

When the nights are so cold that sleep is almost impossible in a camp-bed 
placed in a chilly tent, I then have a hole dug under the bed or at the back of the tent. This hole is a foot or a foot and a half deep, and is filled to the top with glowing embers, and the tent then remains warm and snug almost until the next morning. It is a simple enough device, but I know that many men have felt cold in the mountains without thinking of the remedy. Some trees produce embers which grow for a long time, whilst others will dic out quickly, so you must carcfully select your trees.

Of all the troubles which aflict the traveller, the discomforts and sickness caused by different insects are far the most constant and maddening. An enumeration of all the different insects whose special mission in life scems to be the worrying of mankind and animals would make a very long list; then, in addition to these pests, there are the many other insects which, without the least intent, also cause annoyance. Such are the hundreds of moths and beetles which insist on committing suicide in your tca, soup, and gravy, the ants and other insects which madden you by aimlessly crawling over you or that eat your stores, besides hosts of others.

\section{The Mosquito.}

Of the more noxious insects, the mosquito is a pretty bad fellow. You get so used to being bitten by this pest that in localities where it occurs only in small quantities you would not be much troubled if it were not for the fact that some kinds give fever. The anopheles, the fever-giving kinds, can at once be distinguished from other mosquitoes when seen at rest, because their bodies stick out at an angle from whatever they are sitting on. The ordinary mosquito sits close to the wall like a fly.

The mosquito nuisance can be mitigated to some extent by placing a fire so that the smoke is driven into and fills the tent, or by making a small fire within the tent itself. These methods considerably lessen the quantities of mosquitoes which otherwise invade the tent, especially when the tent is pitched in such localities as along the banks of the Nile. Unfortunately, neither method quite does away with them; moreover, the discomfort caused by the smoke is almost as great as that caused by the mosquitoes. The fever resulting from bites may be obviated to a great extent by taking five to ten grains of quinine cvery third or fourth day whilst in a mosquito country and for about a fortmight after leaving it.

\section{Tsetse Fly.}

Where tsetse flies are numerous you can keep a certain amount off by continually swishing a branch round about and by beating the back of the head with it. 


\section{Sleeping Sickness.}

This sickness very rarely appears to attack Europeans. I have met officials calnnly residing in sleeping-sickness areas and receiving only a modest salary of $f 200$ or so a year, when onc would imagine that $f 2000$ would be a poor enough remuneration for the risk run. I have seen only a very few times the fly which is the cause of the sickness. It is to all intents and purposes it tsetse fly. A favourite trick of the tsetse is to settle on the coat collar and then hop quictly on to the back of the neek, where it will not be noticed till it bites. If it were to alight from flight straight on to the skin it would be felt and driven away. So whenever I have been in a known haunt of the sleeping-sickness fly (as when in a canoe on the Nile) I have always fastened a bandkcrchief at the back of my head and neck, tucked into my hat and also under my coat.

Perhaps many people who have seen more of the fly will laugh at my precautions, but I must say that I think the risk of being gored or stamped to death by an elephant is a much more preferable risk to run than that of being killed by a small ny.

\section{Sandfies, Horseflies.}

These flies and a multitude of other stinging and biting flies I will pass over for want of adequatc terms in which to describe them.

\section{The Figger.}

This pest generally makes its presence felt by a feeling as of a chafe or blister on the foot. It is generally only after it is extracted that there is any itching. However, if it has entered a part of the foot which does not rub the boot perhaps the itching will then be the first symptom of its presence. Directly there is an itching or hot feeling about the foot, look carcfully for a little black spot surrounded by a white patch. When found, remove the skin from orer this spot carefully with a needle and scoop out the interior, which consists of a little bag of eggs. When extracted, put in a drop of carbolic oil or some disinfectant and the operation is completed.

I have never suffered the misfortune of awaking suddenly in the middle of the. night to fund myself covered with siufu, the large biting ant, but I should imagrine it to be a most unpleasant experience. I have, nevertheless, often discovered an army of them advancing on my camp at night or commencing to imvade the temt. The best way to get rid of them on such occasions is to watch which way they are trekking, then light a fire in the way or strew red embers across their path. They will then turn round and trek back again. Sometimes you will find that during an hour or two 
a box of stores has become filled with myriads of the small ants (tungu). The best way then to induce them to leave is to place the box near a fire so that the smoke and heat drive into it and out they go.

Perhaps sone of the most unpleasant experiences of trekking are the continual wettings received, either from rains or in crossing swollen rivers and marshes, or from the dew on the long grass, which last is of daily occurrence. Not only do the constant wettings and subsequent dryings in the sun spoil one's boots and make them crack, crinkle, and perish, and likewise the sewing rot, but the boots themselves make the feet sore when they dry so hard. In East Africa, where the grass in most places is short, it is a good plan to start the day in sandals or sandshoes, in which kit you will suffer no discomfort from the feet getting wet. Of course a man follows carrying boots and socks, which are put on as soon as the dew has dricd off the grass. In countries of long, coarse grass, as in Uganda, the troubles from dew are very great, as you get wet every morning from the neck or waist downwards, and the dew talkes longer to dry off the long grass. If sandals or shoes are worn, the ankles and legs get cut by the coarse grass, and rubbed sorc by the continuil friction, and scratched by thorns, for it is impossible in such country to see where you are stepping. In countries where the grass is not too long, then a mule or horse, ridden during the first few hours of the morning, solves the problem of how to keep dry.

During the rainy season you should try to arrange your treks so as to miss the actual rain, but, with all precautions, you will often be caught by sudden showers or thunderstorms. If, when trekking along with the caravan, one of these sudden downpours occurs, there is no reason whatever why you should get soaked through, and all your loads sodden by the rain. You can often hear the rain in the trees some time before it reaches you; then, if the tent has been, as before suggested, given to a strong porter who leads the caravan, the inner fly of the tent can be rapidly put up and the loads placed bencath it, whilst you can sit on a box and read and smoke till the rain ceases. The porters, if they are professional porters, have also their tents, one or two of which they can put up if they like to take the trouble. If your porters are naked savages, the rain will trouble them little; it is only to anyone wearing clothes that rain is such a discomfort. When wet through after a sudden storm I have often envied the naked savage, for, directly the rain ceases, he is dry again, whereas I have had to tramp on, feeling the discomfort of wet clothes for scveral hours afterwards.

Baganda porters are very quick at rigging up a shelter from the rain. They draw downwards a few boughs of some tree and tie the ends, and then pull up armsful 
of long grass by the roots and throw these on top, and in a few minutes a very tolerable shelter is obtained. Bunches of long grass, with a waterprof sheet thrown over, make a very comfortable bed should anything happen to your camp-bed.

When yon hive as many loads as your train can carry, and are still collecting more in the shape of heads or ivory, it is with great relief that you cast away usetess or broken articles-empty tins, and all manner of things, thinking how much you are reducing the overweighted loads. However, you are in reality effecting nothing at all, for everything thrown away is carefully picked up again by one of your porters and carricd on by him, the only difference being that it is then carried amongst his effects instead of amongst yours. The raw porter especially cannot leave anything behind, but collects all odds and ends, and then carries what the Swahilis call "mzigo wa fisi," a hyana's load. So anything useless that you wish to get rid of should be taken out at night or else carefully hidden in the long grass, otherwise it will reappear again.

Once a chief complained of having been robbed by my porters, who were Bagandas, so I ordered a general inspection of loads. The articles alleged to have been stolen were not found, but the collection of other things that were turned out was rather surprising. The greater part of each native's private effects consisted of discarded rubbish; nothing had been considered so worthless that it could be left behind. Even pieces of torn paper or cardboard, tin discs from tobacco tins, lint which had dressed sores, and other equally worthless articles had been hoarded up, whilst quite half the men had helped themselves to either potatoes or onions.

A very simple expedient for making a stand for a washing-basin is to cut three sticks and arrange them tripod fashion. The ends of the sticlis should be stuck into the ground and a piece of string licd round the middle, when a very serviceable receptacle for a basin will result. The contrivance also saves the usual stooping over a box.

Many people think that a bath is essential if a good wash is to be enjoyed. However, if anything happens to the bath or if it is temporarily used for other purpose's (such as in forming a receptacle for flour), a very good substitute for a bathe is 10 wash after the mamner of Orientals, i.e, to take a bucket of water and a cup and pour the water over the body with the cup, then soap thoroughly, and afterwarcts sluice down again with the cup. Swahilis use hall a coconnut attached to a hong wooden handle for this purpose, which is a convenient arrangement, as it permits of water being poured down the back.

1)irectly you arrive in camp you usually see the porter, whose duty it is to help the cook, wandering round looking over the ground. He is searching for "mafiga," or the 
stones on which the cooking pots are to rest. If these cannot be found, then lumps of earth, broken off the side of a white-ant's hill, will have to serve. It is seldom that neither one nor the other of these useful camp properties cannot be found. Occasionally you strike localities where neither one nor the other are to hand. A simple device then may be constructed as follows: Dig a trench narrow enough to permit of the pots resting across it, and opposite each position for a pot dig another little trench sloping down into the main trench. The firewood is then placed in the big trench and the pots stood over it in position, and when lighted the fire is kept going by bits of stick being shoved down the little trenches or ramps, under their respective pots.

There are many other simple contrivances that I might describe, but they will have to keep for another time, as this chapter has already grown too long. For all I know to the contrary, most of the devices I have given may be stale news to my readers, but I shall hope that a few at least may prove of service to him. 


\section{CHAPTER XIII.}

\section{THE PRESERVATION OF GAME.}

THIS is a subject which of late has come very much to the fore. Talking warning from the sad destruction or utter extermination of game in many parts of the world, there is a strong morement on foot to strictly preserse the game still left. Whilst it is impossible to underestimate the value of this movement, I cannot help thinking that some of its supporters go so much to the anti-sporting extreme that they are in danger of defeating their own ends.

For a really permanent movement to save game from extermination, the true sportsman should be the most useful man to enlist. This is obrious, for his interests lie in the same direction, and therefore afford a more permanent inducement for the preservation of game than any wave of popular indignation or scntiment. Moreover, no preservation can be strictly maintained without a certain expenditure of money, and this money comes from the sportsman's pocket in the shape of the amounts paid for licences. It is not the tax-payers, but the sportsmen of England who preserve our game, aided, of course, by suitable laws.

I cannot help thinking that the freely expressed opinions of many arm-chair faddists and stay-at-home sentimentalists are more calculated to alienate the true sportsman from their schemes than to draw him into them. The game-bird shooter at home who kills thousands of birds in a season is allowed to enjoy his sport in peace, but the big-ganle hunter who accounts for a few hardly-earned trophies is, as often as not, classed with the man who kills hundreds of easily-shot animals (usually slaughtered for their meat or hides), and is condemned as a butcher or murderer.

Sonce of the bigrgame animals in certain countries are as easy to bag as sheep, but a collection of good trophies always means patience and skill in hunting, qualities which are not much ealled into requisition when merely shooting at birds. Perhaps the bird-shooter will be posted by the head gamekeeper, and, without further exertion, knowledge of woodcraft, or trouble, may account for a few hundred lives, and be able to piss through the fire of criticism with in unblemished character. "The only requisite is that he must be a good shot with a gun. He knows neither hunger, thirst, fatigue, nor privations, or, at least, not in their reality.

On the other hand, we have the much abused elephant-humer, who hunts in 
shoot a fair number of good bulls. I will try to give a description of what he generally has to undergo before bagging a single animal.

First, there is the long march to the hunting ground, generally performed on foot. This may be anything from a few days to a few weeks, during which time he will daily be pushing through thick grass that reaches high above his head and quitc conccals his path and prohibits all vicws. Every morning he will get wet to the skin with the dew that falls from the orcrhead grass as he pushes it aside, and his boots will get sodden and cut to pieces by the edges of the same grass. Later in the day the sun will beat down so fiercely that the exertion of pushing through the grass will be redoubled. Underfoot will be stones, stumps, and holes, forming regular traps for unwary feet, and hard to avoid, as they will be inrisible by reason of the all-pervading grass. As soon as his boots become hard and cracked with the heat, as likely as not he will find that his path leads him through a swamp of evil-smelling black mud, or across a swollen river, and so he must renew the discomforts of wet feet and clothing.

On arrival at his hunting-ground he will realise of what inestimable value, after all, was the much-abused track he has been following. For then he will have to push through the thick vegetation in earncst; through grass entwincd with creepers, convolvulus, and buffalo beans, and brambles, together with occasional thorn-bushes, often hidden from view, and all manner of scratching, tearing, and stinging things that impede his progress.

He then settles down to search for fresh spoor, and the time he takes to find it will be proportionate to his luck, skill, and the distance he covers. At last, having found some, he will then have to decide if it is worth the following up or not, and when once his mind is made up that the track is fresh enough to afford a reasonable chance of his orertaking the quarry he must be prepared to spend a night away from camp if necessary.

Sometimes only a few hours may elapse before he overtakes the animal, at other times he may find himself at nightfall, hungry, tired, disappointed, and many miles from camp.

Hunting in tropical Africa is very different to hunting in the northern and southern ends of the continent, which are more healthy. So in unhealthy climates the hunter must do his utmost to regain his camp during the night, as sleeping in the bush and possibly getting wet-through is conducive to all manner of ills, which will quickly put an end to his prospective hunting, or at any rate will seriously delay it.

Once on an elephant track the going is easier, but by no means can it be called "easy going," for although the elephant will have crushed down the grass to some 
extent, there will still be the spaces between his footprints, with grass often the more difficult to pass through from having been pushed sideways across the track. There the hunter will have the added exertion of raising his knees to the level of his waist at every step, an action most trying after an hour of it. If the elephant has passed through a forest it will have pushed aside branches which will have sprung back again across the track, and the hunter will have to go round these or crawl under them.

Perhaps the most trying part of the "following up" performance is the strain of having to keep on the alert the whole time, for there is constant occupation for all the senses. The hunter will find that his eyes are for ever being strained to sce through the grass or the branches; his ears constantly listening for the sound of a flapping ear, a stomach rumble, or the stamping of a foot, or even the breaking of a bough. The great beast may be standing still in his tracks only a few yurds away, so even the sense of smell must be used when amid thick grass, as the scent of the elephant is often the only indication of his presence. Nor is this all, for the constant labyrinth of tracks will have to be sorted out, the elephant's movements pondered over, and the direction of the wind frequently tested and alway's kept in mind.

At last perhaps the Rapping of an ear will be heard, and the hunter will then steal forward, taking the wind incessantly and straining his ears to catch another sound.

Let us say that he reaches at length what he supposes to be the spot, and there waits for another sound. He anxiously tests the wind again, and finds it gusty and then still. Suddenly a shrill trumpeting sounds from twenty yards away, and three elephants burst out and crash past within a few yards of where he stands. The wind has changed and they have got a whiff of him. They are gone in a second or wo for grood, and until he examines the tracks he is unable to tell if they were bulls or cows, for the high grass and the animals' own large ears have concealed from him all but the merest glimpse of their tusks. An examination of the ground to his front shows him that the whole herd had been close by before the alarn was given. So he turns round and sorrowfully returns to camp, hoping for better luck next lime. Anylhow, he has come well out of it, which he might not have done hatd he beers standing a few yards more forward.

The description of a week of hard walking and larder luck woukl afford but dismal reading, so we will pass this over, and make our hunter more lucky on his next venture. We will saly he his had a long and trying day after reported elephants, and has only met with old spoor. However, on his way back to camp in the afternoon he is met by natives, who say that they lave just seen some elephants. 
Led by these, he arrives at a place where elephants have certainly been standing that day, but as it is now past their siesta time, they have already moved on. Throwing caution to the winds he hurries down the spoor, hoping to overtake them. At sunset he is about to give up, when he hears the sound of a heavy body moving through the undergrowth somewhere ahead. Running in the direction of the sound he finds the spoor of one big bull, which has separated himself from the rest of the party, but which has evidently got his pursuer's wind. There is only one chance, then, of getting a shot before dark sets in, and for this he must sprint down the tracks and overtake the animal before it is aware of his proximity.

For the usual custom of elephants on getting the wind of a hunter is to stampede for about four or six hundred yards, and then stand perfectly still and silent, listening and sniffing for any sound of danger. If, after standing a few moments they hear or smell nothing to further alarm them, they make off at a rapid walk, and do not stop for several hours, during which time they cover a considerable distance, varying from five to twenty or more miles. If, however, they hear or smell anything that alarms them, they then stampede again, but in a new direction, going for a distance of, perhaps, a third of a mile, and then stop for a few minutes to listen and scent for danger.

So our hunter runs rapidly down the track till he comes to an abrupt turning, where the elephant has stopped, evidently located him, and made a second stampede. Turning with the track he continues to run as fast as he can, when suddenly there sounds a roar of anger, and an immense body comes dashing towards him through the bushes. He cannot see the animal owing to the bushes, but to his right, and a little behind him, is a more open space of about twenty yards wide, so he turns back and flies across it and pulls up on the opposite side ready to receive his visitor. A huge elephant, with great brown-stained tusks, appears at the same moment on the very spot on which he had been standing a few seconds before. There it halts and sniffs, trying to locate its adversary. The old fellow evidently became bored with being chased round, and resolved to put an end to affairs.

The hunter notes the huge tusks and raises his rifle, trembling with excitement and the effects of his twelve hours' hard going in the sun. He pulls the trigger, but no answering report rings out. Feverishly he reloads and fires again, with the same result. This must be one of the bad dreams in which big tuskers stand to be shot by a rifle that will never go off, it cannot be a reality. The elephant turns to go off, and the hunter, having reloaded once again, fires a hurriedly aimed shot. This time the rifle blazes forth, and the elephant stumbles. Ah! Those tusks are to be his, after all! He reloads again to make sure of the animal, but 
again a miss-fire takes place. He shouts for his second rifle, but gets no response. He rushes towards the spot at which he last saw his native followers disappear, and shouts again. He looks behind him and sees the great beast slowly pick itself up and walk off with slow and stately steps. Then, after what appears an infinite delay, one native appears and sets out in search of the trusty bearer of the big bore. At last the rifle is produced, and the hunter, grasping it, scts off down the tracks at his best pace, but unhappily the sun has set, and soon he is reluctantly forced to turn back, and starts a three-hour stumble in the dark back to camp, cursing himself and the natives and the rifle and the gunmaker, thereby gaining some relief.

An inspection of the rifle shows that a heavy fall of rain just after he left camp in the early morning was the cause of the disaster, drops of rain having rolled down the bore and entered the interior of the bolt around the striker, thus rusting the pin and hindering it in its forward action.

The three-hour stumble in the dark develops into four hours before he arrives back in camp, exhausted and weary, only to make the delightful discorery that the parties sent out to buy chickens have not been successful, and so dinner inust consist of mashed beans and native flour.

Next morning he is about to move camp to the scene of his last night's adventure, when a native rushes in to say that he has just seen two elephants passing close by. In this case the native khabar turns out, by way of novelty, to be wonderfully accurate. He has not actually seen two elephants, but he has seen the fresh spoor of one which he has mistaken for that of two. The hunter loses no time in getting on the trail, and soon recognises by the spoor that by some extraordinary luck it is his last night's elephant he is after, which, having probably walked round in semicirles during the whole night, has chosen this direction in which to trek off.

The spoor leads our hunter for the whole diy through long grass and through thick bush; nuly twice has the elephant stopped, and then but for a moment. At last, in the afternoon, the spoor passes into very thick dense grass, the track left being but a narrow lane between two immense walls of grass.

Suddenly, as he approaches a tree, he starts, and his heart stops beating and then throbs on with a great rush. For there, under the tree, just discernible between the grass about fifteen yards away, is a great bulky form A moment later he recognises that it is but a termite-hill under the tree and, though his hopes sink, he has still some crumbs of comfort left, for the hill will make a suitable place from which to recomnoitre. He approaches $i t$, and when he has proceeded another few yards he stops agrain in sudelen doubt. Surely it is 130 all ant-hill? Ile then sees 
that not ten yards from him, though standing the other side of the hill and nearly concealed by it, is the great beast he has bcen following all day.

His position is hopeless; he can neither retreat nor advance, nor can he leave the patl without breaking down the wall of grass on either side; so he must fire from where he stands-not at all a favourable shot. The elephant is a quarter facing him, and, with part of its head, shoulder, and one huge tusk showing, all other parts are concealed from view. The shoulder-chest shot is the only shot to go for, but unluckily this shot is partly masked by the huge tusk. However, something must be done, so, aiming so as just to miss the tusk, he fires. The elephant crosses his front, and in a moment is swallowed up in thick grass, affording only time for a rapid second shot in the flank. He hears the elephant fall, and then various other sounds. Rapidly reloading, he runs towards the spot, and finds that the elephant has trodden on the side of an ant-hill, has fallen, and picked himself up and proceeded. He hastens after it, and, after going for half an hour, reaches a thinner bush-country, and just catehes a glimpse of the hind view of his elephant stalking along ahead of him. He hurriedly puts a couple of shots into this expanse, and then, as the animal disappears, runs as hard as he can after it, trying to reload as he runs.

Then the unexpected happens. There suddenly sounds a scream of rage, and before he quite knows what is happening the huge elephant is bearing down on him with ears outspread, offering about three yards of frontage and going at a ponderous sort of gallop. It seems impossible to avoid or get round the great mass which is but a few yards from him, so, taking his chance, he shrinks behind the insignificant cover of a small thorn-bush. The elephant passes his thorn-bush within hand's reach, and goes on for some fifteen yards before it halts and looks about for its adversary. The hunter hurriedly reloads and takes a rapid shot, and then increases the distance between himself and the elephant, which is unpleasantly little.

The animal goes off before the hunter can find another clip and effect a reload, so there is nothing left to do but to follow the spoor again. This he does for a short time, and then, in a thunderstorm, returns to camp to make preparations for what he realises will be a long business, and so en ts the second day's hunting.

The next phase is the slow and steady following up of the night's spoor, which pans out to an immense walk occupying the whole day, and towards sunset he finds that the spoor is older than when he started, showing that the distance between himself and his quarry has increased instead of diminished. Presently, however, fresh tracks, made within the last few minutes, cross the spoor he is following, so, changing on to these, he shortly conjes up with a large herd of bull elephants. 


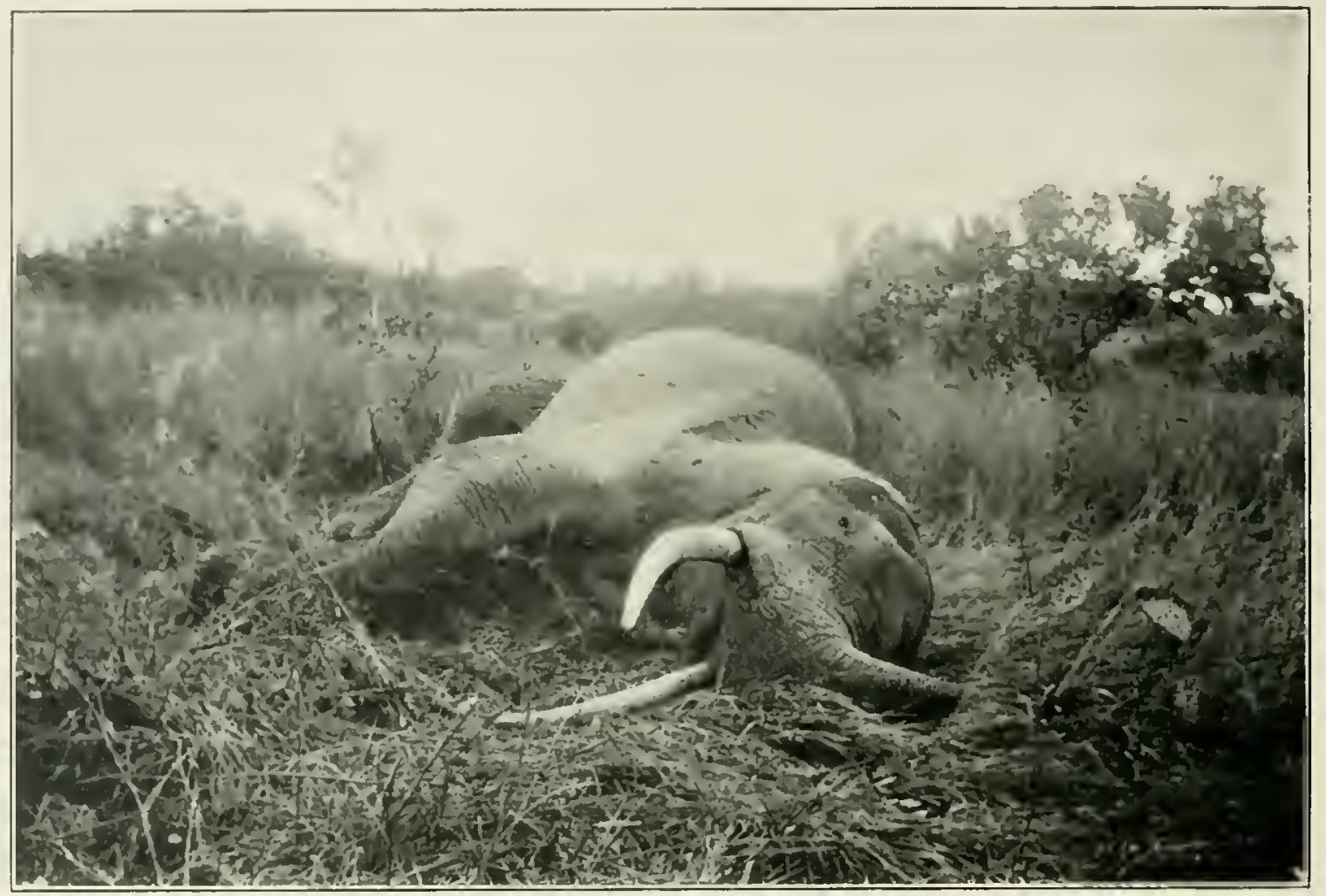

IBNORMAL TUSKER,

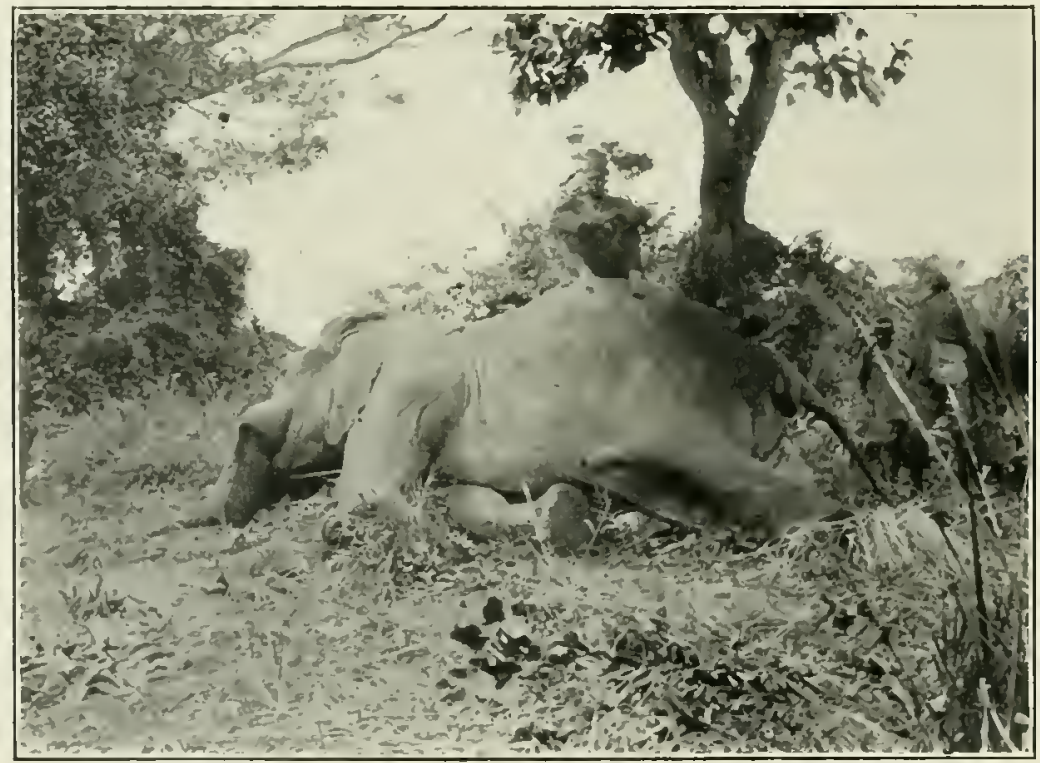

ONE TUSKER, BY WRIGHT. 
Some are taking a mud bath, and some are walking clown to the bath, and some are leaving it.

He creeps up close to the bath, and, selecting the biggest bull, fires. The whole herd turns and gallops past him, and as they pass he fires twice, one shot at the one he previously hit, and which is lagging, and one shot at another elephant. One animal falls dead, but the other rushes on. As it is close upon nightfall the hunter decides to camp where he is, and stops the next day cutting out tusks, whilst natives are sent after the newly wounded bull and after the old one.

The one that was last wounded is found dead not far away, and proves to be a one-tusker, whilst, after a delay (which the hunter spends in unsuccessful hunting), the natives sent after the older bull return to say that the wounded animal has crossed a big river and is now in a tract of bush on the other side. So camp is at once moved there, and fresh tracks are found and followed.

'Towards the afternoon the hunter suddenly sees his old enemy standing under a tree. He takes careful aim and fires, and the animal comes towards him with staggering gait. He fires agrain, and it staggers to one side and then stanls rocking. He fires again, and a third and fourth time, and it rocks more and more, till with a tremendous crash it falls to the ground, and he rushes to the spot in triumph to take stock of the tusks.

Such is elephant-hunting-periods of bad luck and periods of good luck, but the bad luck is generally out of all proportion to the good luck. Yet, curiously enough, when recalling his experiences it is only the good luck which will be remembered, the hunter will treat all the long blank days, hard work, and privations as if they had never been.

In the hunting I have stictched, our hunter has been rery lucky, three grood etephants having fallen to his rifle within as many day's. He will probably begin building castles in the air on this basis as to his future achierements. He will altogether forget to include in his calculations the fifteen blank days spent before the first of the three elephants fell. To assert that a hunter of elephants is a slaughterer or no sportsman is mnfair and unjust, for no form of sport calls for such endurance, nor is there any sport in which fatigue, hunger, thirst, privations, and dangers have to be faced in so extreme a degrce.

It bores me to hear people crabbing a man like the late $A$. H. Neumann because of the number of elephants he has shot. The people who are so ready to criticise are, as a rule, they who know litte or nothing of elephant-hunting, but who are quite ready to fire fusillades at the sheep-like animals of the plains.

As to the number and the size of elephants that it is advisable to allow any one 
man to shoot, this can be effected by legislation without its being necessary to abuse hunters who used to shoot over the samc ground before such legislation was enforced.

From all accounts of elephant-hunting, however, though always a hard pursuit, I cannot help thinking that the elephant used to be more accessible than he is now. Comparatively speaking, it is only recently that such great store has becn put on his tusks. Since that time, however, the animal has been hunted without respite by both white and black sportsmen all over Africa. It would have been odd if such continued persecution had not had the effect of making him more cautious, more dangerous, and more addicted to thick country. That after all this hunting he still survives in most parts of Africa, and in some parts in great numbers, testifies amply to the difficulties attending the hunting of him and the way he is able to take care of himself. If only some cheap and perfect substitute could be offered by the chemical world to take the place of ivory, there would be practically no danger whatever of this animal ever becoming extinct or even of ever dwindling in numbers.

The modern tendency is to cry out against all killing of big-game, whether performed in a sporting or an unsporting manner. If adverse criticism were confined to those who grossly infringe sporting codes all good sportsmen would acknowledge the justice of the criticism. The ethics of sport as to whether it is wrong or not to take animal life does not affect the question under consideration, for if it is wrong to kill a kudu or sable it must be equally wrong to kill a red deer. What the sentimentalist fails to realise is that sport properly controlled affords animal life greater security than does criticism or even ill-controlled legislation. It is sport alone which has saved the red deer from becoming extinct on Exmoor, and the same factor keeps this animal in undiminished numbers in Scotland and in many of the European forests.

As civilisation advances into the heart of Africa the big-game will become reduced in numbers from a variety of reasons. Sentimental considerations alone are not likely to produce the requisite funds for their preservation, a matter which will become more expensive and more difficult as civilisation envelops their haunts and the land they occupy becomes more valuable. Things may alter very greatly before such a state is reached, but it appears at present as if the sportsman is the only man who will be found to subscribe towards the maintenance of what will eventually be looked on as a number of useless mouths grazing over land which might otherwise be sold or disposed of.

I cannot imagine any legislation likely to be popular by which settlers and colonists could be forced to keep on their lands numbers of animals which would eat their crops and break down their fences. Nor can I imagine such settlers submitting 
cheerfully to a tax for the preservation of this game elsewhere. No, sad though it may appear, the safest way to preserve these animals from extinction (at any rate in a country like East Africa) would be to hand them over to some great syndicate of sportsmen who would undertake the responsibility of preserving them.

However, I am looking a long way ahead, for it is certain that for many years to come they will not feel the crush of civilisation over their present vast areas. In the meanwhile as great a number of sportsmen as possible should be enticed into identifying themselves with all movements having the preservation of game as their objective. For it is the sportsmen who know about the game, their habits and characteristics, and the likely effects of any experiments in any particular line, moreover it is the sportsmen's interests which are most deeply concerned.

Now as to what exactly characterises a sportsman in matters relating to big game. Opinions, of course, differ on the subject, but let me try to lay down a few broad rules.

A sportsman, I take it, is a man who wants to shoot a few selected heads (generally of males only) of each of certain animals. To obtain these he is prepared to go to infinite trouble and to conform to all the game-laws. He learns as much of the habits of his game and the lore of wooderaft as he is able to work up in the lime at his disposal. Ite is a good marksman with a rifle, but, in spite of this, he uses every art in his power to get near his game, so as to stand as little chance as possible of only wounding an animal. If he fails to approach sufficiently near for a safe shot, he knows that it is generally owing to want of skill on his part, and so he does not try to score off the animal by taking a long shot, but only makes up his mind to achieve better stalking next time. He is one who follows a wounded animal either until he has finished it or until all possible chance of recovering it is lost.

Every shot fired should be within a maximum range of, say, two hundred yards, and should be a steady and carefully aimed shot at some vital spot. There is no reason why a traveller or sportsman should not kill occasional animals for meat where game is plentiful However, in consideration for his successors, he ought to shoot is moderatcly as possible. To ensure this he should only shont males when possible, as by so doing he does not lessen the output of that species, for, if he kills a female, he may take two lives, one of these in embryo, besides losing all the animals which might be bred from that female subsequenty. He should not shout when he has already a supply of meat, unless he is just approaching a grameless region; and he should allow himself il limit of range beyond which be does not fire. If he has not the time, opportunity, or inclination to get near shy animals, it should be to their good fortune, so he should not fire at longer ranges. 
In out-of-the-way countries, very pressing needs of the stomach may occasionally make the sportsman do what he otherwise would not do, but if everyone acted up to these few simple rules, there would hardly be any necessity to make any game-laws. Unfortunately there are great numbers of people who seem to be endcavouring to establish reputations as big-game hunters, simply by killing large quantities of perfectly harmless and easily shot animals. There are also numbers of other persons who, taking advantage of the accessibility of British East Africa in modem times, and knowing nothing about shooting, are yet let loose annually on the game with rifles and unlimited ammunition to wound or scare game as they think fit.

I am sure that most of these people offend through pure thoughtlessness or ignorance. They see plenty of game and think it inexhaustible, and they do not realise the amount they are wounding or the harm they are working. Moreover, they base their ideas of what is "sporting" and what is "non-sporting" either on the shooting they have been accustomed to indulge in at home, where numbers alone make a good bag, or from what a native or Somali gun-bearer tells them.

One of the most common malpractices is the long-range independent firing at game. Parties of so-called sportsmen turn up and go out in a drove together, each followed by several gun-bearers carrying weapons of assorted sizes, when, directly game is seen, without any pretence at a stalk, fire is opened, and it is positivoty dangerous to be anywhere in the vicinity. Before coming to East Africa I could not have believed that a party could go out and expend perhaps fifty or a hundred rounds of ammunition in a day and come back brazenly in the evening to be congratulated on bagging an undersized gazelle. No attempt is made to follow wounded animals, and the number of these must be very great. If a man kills one animal out of fifty shots it is not within reason to suppose that whilst one bullet out of the fifty hit a vital spot the other forty-nine all completely missed the animals fired at. Even an experienced hand firing at medium ranges is sometimes at a loss to know if he has hit an animal or not. It is only on the open plains that such performances can be indulged in.

The best training for a sportsman is to commence in thick bush-country, and, when he has mastered the bushcraft, required in such parts to obtain a certain measure of success, he will feel no inclination for the very tame shooting of the plains. At most, if he is very keen on heads, he will only take toll of a few selected ones, but he will ridicule the idea of anyone considering himself a hunter on the plains. "Browning" herds is an error not so common. In this case the firer trusts to the most prodigious fluke to bring down an animal. Again, this fluke is still more prodigious if the animal brought down is a good one. 
The vital parts of an animal are so very small in comparison to the rest of the body that a shot roughly aimed at an animal stands about a ten to one chance of missing a vital spot. Therefore, aim should only be taken at some vital spot, and at a range close enough to make one fairly certain of hitting it.

After a first shot which misses, young sportsmen are apt to lose their heads or tempers, and pour in a succession of rapidly aimed, unsteady shots in the hopes that one will strike home. Some men are so lazy and callous that they will not take the trouble to follow a wounded animal; whilst other men, owing to their long range and erratic shooting, do not know how many animals they have hit and wounded. Some, after wounding an animal, if they are anxious to obtain a head of its kind, give a native a rifle and tell him to go and secure the animal for them, promising him a reward. The native naturally comes back if possible with a head of the same species rather than miss his reward, and the sportsman fondly imagines that he has shot the animal. Why people who are content to obtain heads like this ever go out shooting I cannot imagine, it would save them a deal of trouble if they paid someone to make their whole bag for them.

Some sportsmen (generally foreigners, I am glad to say) think it just as grood fun to shoot a lion in a trap as outside of one. This trapping and also the poisoning of big game seems to me a most unworthy practice. I have heard it urged that it is excusible with settlers who have their caltle to look after, and I have been told that I should change my views if I was a settler. All I can say is that I have been in the position of a settler, that is in an isolated station or on trek with stock. The conclusion that I have come to is that to build proper kraals and take ordinary precautions is all that is necessary for the security of stock. The Masai, who have neither rifles nor poison, seldom lose an animal; and, moreover, the lions of East Africa usually prefer game.

Most settlers who have anything in them welcome the chance of a day after lions as a pleasant change from their other dutics. Others are great hunbers where plain-dwelling buck are concerned, but they are not interested in shooting lions.

You will always find plenty of men looking for lions in East Africa, who would be only too glatd to get the tip that the animals had been seen ur lucated in any particular place, so there is really no excuse for anyone who does not want to shoot them himself indulging inste.ld the evil practice of poisoning on his land. $I t$ is a bit sickening to hear that someone within easy reach has found it lion's kill, and that instead of sitting up orer it or visiting it at dawn, or asking somebody else to do so for him, he: has injected strychume inte the curcase and 
accounted for a whole family of lions, several hyenas, a few jackals and vultures, besides a favourite dog.

Some people think that their prorress will be judged by the number of heads obtained in a shoot, or by the gross weight of horns amassed, and that the quality of the heads and the species are quite minor points. To obtain numbers, often large quantities of females and immature animals are killed, and then they say, "Oh, we got three hundred and six head on our trip!" as if it had been a pheasant drive! Sportsmen on short trips think that they ought to shoot up to the limit allowed on the licence for each animal, or else that they are not having their money's worth.

A number of the points I have mentioned are so obviously unsporting that it may hardly seem worth while pointing them out. Yet such unsporting acts are not only frequently indulged in, but many sportsmen naively describe them in their writings as if they were quite the right things to have done. There is one constantly recurring phrase with which sportsmen often excuse themselves for making some big battue, viz., "The meat was not wasted." The number of times this phrase is used would lead anyone to suppose that sportsmen, as a rule, go out to kill animals for the benefit of the hyæna and vulture.

The question involved is, what is to be considered as waste? If being left to rot on the ground or being eaten by beasts of prey alone constitutes waste, whilst being removed by human agency is not waste, then meat will practically never be wasted, because almost always people may be found to eat it, whatever the quantity. I claim, however, that if numbers of animals are shot in a day for their trophies or for sport, and the meat goes to porters already overgorged, or is given gratis to villages of grain-feeding Africans, that meat is as much wasted as if it had been left for the hyænas. Therefore the phrase by which sportsmen wish to whitewash themselves after their battue is really valueless.

As the true sportsman is one of the greatest supporters of game preservation, so the bad sportsman is one of its greatest menaces. The latter offends chiefly through ignorance and inexperience. If there was a proper code of big-game sporting rules as definite as those of the partridge fields at home, it would go a long way towards checking unsporting practices. Big-game shooting is a more or less solitary pursuit, and so a sportsman guilty of unsporting practices seldom gets dropped on by his brother sportsmen. A proper code of rules, however, would at least prevent men bragging about gross breaches of sporting etiquette, as they now so often do.

If we were to lave the big game of Africa preserved for the sportsman and the naturalist, and if we were to have both these parties concerned in its 
preservation, and furthermore if we were to have the former anxious to conform to a stringent code of sporting rules, failing the observation of which he would be considered not a sportsman, but a poacher, we would then have gone a long way in the right direction. The main essence of this code of sporting rules ought to be the same in all countries, but for the actual preservation of different species special rules should, of course, be drafted for different countries.

Such special rules or game regulations, I am glad to say, are already in force in most countries, and in British East Africa a very wise set has been framed. They chiefly concern game reserves and licences.

As to game reserves, there is the Southern Reserve and the Northern Reserve (including the Sogota Reserve). The Southern Reserve contains the following game:-Rhino, hippo, giraffe, buffalo, eland, oryx (fringe-eared), gnu, lesser kudu, bushbuck, roan, waterbuck (common), hartebeest (Coke's), gazelles (Grant's, Peter's, Waller's, Thomson's), reedbuck (Chanler's), oribi (Haggard's), impala, duiker, klipspringer, steinbuck, dikdik, lion, leopard, chcetah, zebra (Burchell's).

The Northern Rescrve contains many of the above, and also elephant, oryx (Beisa), gazelles (Grant's northern form, Söemering's, and Waller's), greater kudu, waterbuck (Sing-sing), oribi (Abyssinian), reedbuck (Bohor), topi, zebra (Grevy's).

Although the Northern Reserve has never been more than a reserve in name, but too often a happy hunting-ground for Somalis, Baluchis, Abyssinians, and all manner of straying peoples, it was thought that the move of making this country a reserve was good and sound. Although this country was not occupied by us, and the idea of a reserve was by many considered premature, the making of this reserve (on paper) was a guarantee that whenever the country should be occupied this reserve should stand; but now that the administrated portions of the country show signs of expanding towards this reserve, there is an outery to abolish this Northern Reserve before it has ever become anything more than the reserve in name which it now is.

Nor is this all, for in some quarters there is dissatisfaction that there should be a Southern Reserve, and it is urged that the game should be killed off and the whote country thrown open to settlers. Probably most of the people who ery out loudty that the reserves should be abolished have given but litule thought or study to the question, and they seem to imagne that the advisers of the Govermment in this matter have given even less.

In both the Northern and Southern Reserves there is at great scarcity of water, and in addition to this a large purt of the country is covereel with dense thorm, and has been proved unsuitable for settlers.

The Masai who inhabit the Southern Reserve and a part of the Northern have 
to be continually trekking about in search of grazing and water-a nomadic life which would hardly be agreeable to settlers, even if they were able to make their cattle thrive in this way. A great portion of the Northern Reserve is a camel country, and still less adapted to the use of settlers. As to the inhabitants of these countries, the Masai, not being a hunting tribe, are peculiarly adapted to the requirements of a game reserve, and graze their herds alongside the game herds without molesting them.

When the Masai were moved from such places as the Rift Valley and parts of the Guas Ngishu plateau (places they had inhabited for hundreds of years, as the deeply scored cattle-tracks in rock will testify), so as to make room for white settlers, an agreement was made between them and the Government that they should move out of these places and restrict themselves to the Southern Reserve, and Laikipia in the Northern Reserve, so as to remove themselves from contact with Europeans. In return for this, and in recognition of the good spirit in which they complied with the wishes of the Government, they received the above-mentioned tracts of land (which, by the way, had always been Masai-land) to live in with their flocks and herds, they and their descendants for all time.

Barely three years after this agreement was made, a movement began to try to break through this treaty. It will be seen that, without breaking faith with the Masai, it is impossible and undesirable to throw such lands open to colonisation by Europeans. As Masai Reserves they are admirably adapted to fulfil the extra function of game reserves, and there is no reason why they sloould ever be made shooting-grounds for European sportsmen. As to the other portions of the Northern Reserve, no doubt, when we finally occupy and administrate that country, it will be found that its size is rather larger than necessary, and so it will be cut down. As we have not yet been brought into contact with the natives, however, and know little about them, it is rather early to decide what our subsequent policy in those parts will be, and what portions will be found necessary for native reserves.

As to the preservation of the different kinds of game in the country, it will be seen by the lists given above that no arrangement has been made for the preservation of the bongo, stutunga, sable, Hunter's antelope, Neumann's hartebeest, and Thomas's kob.

To take these in order, the first-named is well able to take care of itself. The stutunga and Thomas's kob is preserved in the Uganda Reserves. The sable is preserved in many other parts of Africa, and in British East Africa, although it is scarce, it is not much sought after, as it inhabits difficult or unhealthy country. Ilunter's antelope is at present amply provided for, as there are numbers of 
these animals in what are at present quite inaccessible hunting-grounds in Jubaland.

There only remains, then, the not uninteresting Neumann's hartebeest. The area inhabited by this animal is by no means large, being bounded roughly east and west by the Aberdares and Lake Nakuru, and north and south by Lakes Solai and Naivasha.* The whole of this land has been apportioned out to settlers, and so the administration have now practically no hold over the preservation of this animal. It is to be hoped, however, that the Neumann's hartebeest will be preserved by the private enterprise of some of the settlers on whose land it occurs.

Next as to licences. These are mainly of two kinds, a comparatively cheap one for settlers, to allow them to procure a meat supply by the killing of certain quantities of the commoner game animals, and a more expensive licence on which sportsmen may shoot a selection of both the rare and the common animals for trophies. The traveller must take out the sportsmen's licence whether he wants trophies or not, as the settler's licence does not apply to him.

The game animals allowed on a settler's licence are of so common a kind that at present there is no danger of their extermination.

There is another licence, the landholder's licence. This allows a holder of land to kill practically anything on his own land. Many of the landholders are Boers, and many others take little interest in grame, but on the contrary regard it as a menace to their crops, so it is not to be expected that by their own enterprise they will go to the trouble of preserving any animals. No doubt a few large landholders will make rules for the shooting and preserving of game on their lands, but the majority will shoot, and let their employés shoot, without thought for the future. This means that in course of time the majority of the game animals occupying private lands, and especially on small holdings, will disappear. Therefore we must look to lands not yet settled on and the reserves for the future preservation of game. As the sports. man cannot shoot over private lands, the districts that will interest him will be those unsettled-on lands that are ever becoming less and less.

British liast Africa is so rapidly being covered by settlers that it seems to me that the Government will shortly have to take some sort of steps to establish shooting-rescrves for the benefit of sportsmen, in addition to the game-preservation reserves already extant; for all available land is being apportioned to settlers, to reserves, and to native cultivations, and there will soon be no land for the sportsman to shoot over; thus the administration will lose the revenue they nuw recuive from licences, and a very considerable sum it anounts to. Moreover, it is presumably

- Excepting, of course, the country in which it was originally discovered, now dbyssinian territory. 
this sum which at present affurds the inoney for the patrolling and upkeep of the reserves, a duty which it will become more difficult and more expensive to perform efficiently as time goes on.

It is for this reason that I say that sportsmen should be persuaded to as great an extent as possible to identify themselves with game preservation in East Africa; for the lime will ineritably arrive when the question will arise of who is to support the expense of keeping up the game reserves, and an arrangement with sportsmen will probably be the only satisfactory way of solving the problem.

As to the present sportsman's licence, personally I think the amount allowed is much too generous, especially as regards the scarcer animals. Many sportsmen come out with the idea of obtaining as many heads as possible, irrespective of sex or age. Such men consider that they have not had their money's worth if they have not shot their full allowance of each kind of animal.

Now, I do not suppose it was ever the intention of the framers of game-laws that the maximum number of animals allowed should in every case be reached.

For instance, you are allowed ten hartebeest, ten waterbuck, ten gnu, ten impala, and ten of a number of others. I take it that this number ten is an outside number, fixed so as to allow for disappointments, mistakes, and want of meat in certain districts. A sportsman, especially a beginner, might have very bad luck with one kind of animal and fail to get a good head after many efforts. Or he might stop a long time in some district where there was only one common animal and it might be necessary to kill his full allowance for meat. With the greater part of the game, however, he should have secured good heads after shooting about four animals. It is not then necessary to shoot six more just because they are allowed.

As to the meat problem, its difficulties are not felt so much by the sportsman who only stops a short time in the country and whose business it is to be constantly shooting different kinds of game. He is never without meat, and generally has an abundance with which to glut his porters. It is the traveller or those who spend long periods in the country and who have not the time or opportunity to go out of their way to hunt, for whom arrangements should be made to facilitate their shooting for meat. Such travellers generally shoot the most common animals they can find, but they have to pay the same amount for shooting a few of these animals for daily needs as if they wanted a large bag of rare animals, for, as I said before, a traveller has to take out a sportsman's licence.

For the benefit of such men then, and to save as much as possible the rarer animals at the expense of the commoner, I should like to see some little different 
arrangement made. I would suggest that the most common animals in the country should be carefully listed, and of these a licence should allow a number not exceeding forty to be shot, irrespective of any proportion of each. These animals should be so chosen that they are common, are widely distributed, and have no appreciable trophies, so that they would not be likely to appeal to the sportsman.

Zebra should certainly be included in this category. They are about the commonest animal in the country, are never likely to be sought after as a trophy, and in some parts are practically the only animals to be found. Moreover, they are alleged to do considerable damage. Although their flesh is strong and unpleasant to the white man, they are much appreciated by the native. At present only two are allowed on a licence. If more were allowed, then zebras would often be killed in place of rarer animals, for the zebra is very fat, and contains a quantity of meat, almost twice as much as the skinny hartebeest. Perhaps this is owing to its superior teeth, which allow it to crop the grass shorter.

In certain districts special rules might hold where any different animal was especially common. Of the animals selected for the common and useful purpose of supplying meat to the white man and his porters, I would suggest zebra, Coke's hartebeest, Jackson's hartebeest, common waterbuck, sing-sing waterbuck, and in Jubaland the topi. All these animals are very common, and none of them except the waterbuck has any appreciable trophy. Forty of these animals should, with an occasional other animal, keep both porters and white man fairly provided for. As, however, none of the animals named can be considered as very tasty meat, the white man will probably be glad to make use of various small or other buck for his personal use when occasion offers.

It must not be forgotten that meat will only keep at most about four days, and generally not so long. Of the other buck he should have no difficulty in securing a sufficient quantity if his licence permits him to shoot four of all the other very common kinds, such as gnu, Grant's and Thomson's gazelle, impala, bushbuck, reedbuck, oribi, duiker, stcinbuck, dik dik.

So much, then, for the cheaper licence, on which the holder only wishes to supply himself with meat. In many places where it is impossible to obtain the supply other than from game such a licence is imperative.

As a rough guide, I might say that during a year's trek in East Africa I found it necessary to shoot up to my full amount in only two of the common kind of animals, viz., ten Coke's hartebeest and two zebras. However, I had a number of other animals to depend on in supplying food for the men, such as elephant, rhino, eland, and many others. Had I but possessed such a meat-shooting licence as I have 
just described, no doubt I should have completed up to ten or more waterbuck and zebra, shot more hartebeest, and so saved more uncomnon animals.

Next, as to the expensive, or sportsman's licence. This should include all the former animals, and, in addition, two or one of all the rarer animals, excepting any particular species of animals that showed signs of becoming very scarce. These latter might be included only on special licences, for which an extra fee should be paid, or they could be preserved from time to time, as thought fit.

Arrangements ought also to be made so as to permit of the sportsman's shooting any additional animal over the number allowed, on payment of fees varying according to the rarity or size of the animal. He cannot want multitudes of each kind of easily shot buck and antelope. It is only with dangerous game, where the sport is exciting, and with very wary game, where the sport requires skill, that any real interest can be sustained to go on shooting any one sort of animal. By the arrangement I have suggested, if the sportsman failed to get a good trophy by the time he had exhausted the number allowed of any species, he could always take out a special licence and shoot another and another of the animals until he had secured what he wanted. Moreover, the shooting of a number of animals not really required, but just shot to make up the number allowed, would thus be obviated, and so the number of animals sared would exceed the number killed on special licences, and the revenue accruing would be greater.

If a sportsman can, as at present, afford to pay $£ 5^{\circ}$ for a licence, besides the outlay required to undertake a shooting trip, he can easily afford a few extra pounds for an extra head or two of some animal he is very keen to possess. He must not think that he is being fleeced because he is a well-to-do sportsman, but must remember that such an arrangement was made so as to keep out the men who really only shoot for the sake of shooting, and who are not keen enough on a single trophy to pay extra for it. The latter would shoot a kudu or eland if he could get it for nothing, but as he cannot he shoots another zebra instead.

The sportsman, by paying some few extra sums, would be helping to keep enough of the desirable picked trophies in the country to give sport both to himself and to his brother sportsmen.

However, in the existing state of affairs, the sportsman has no guarantee that by paying expensive licences and shooting moderately he is doing anything to preserve picked animals for the future either for himself or for brother sportsmen. Rather is it the reverse, for the land which he is paying to shoot over to-day may to-morrow be divided up into farms, in which case his temperate and moderate shooting will have benefited no one and he might as well have shot the best trophies himself. So the 
tendency is undoubtedly to "make hay whilst the sun shines" and take the pick of the trophies, for the next comer may be a farmer who will shoot the picked trophies for meat or simply because they are a menace to his crops, and will care nothing for the heads.

Some land or area definitely set aside for the benefit of sportsmen, or even run by a syndicate of sportsmen, would ensure that every sportsman would reap the advantages of his brother sportsmen's moderation in shooting.

1 have often heard surprise expressed that the Government should be so stony-hearted as to claim the trophy of any animal shot in self-defence. Supposing. for instance, you have already shot two rhinos, and a third charges the safari and is killed in so doing, the trophy must be handed in to the Government, which certainly seems rather hard luck. However, rules are framed for weak mortals, and game-rules are no exception. If everybody in this world was absolutely incorruptible, there would be no need for this or many other rules. Unfortunately, even as rules stand, it requires only a slight flaw in any one of them, and there will always be found people ready to profit by the slip. If a sportsman was allowed to keep the trophy of any rhino that charged him, just think of the number of men who would annually be charged several times by rhinos, and also think what an evil reputation this already blackly-painted animal would gain.

There is one great enemy of game I should like to see "got at," and that is the rash, long-range, bad shot who wounds many animals to obtain a single head. Such an one generally manages to fairly well fill up his licence, as regards the plaindwellers, by sheer expenditure of ammunition. He is really in the position of one who has considerably over-shot his licence, for he has killed or caused the deaths of many more animals than his licence allows. Y'et no legal action can be taken against him.

In places where much shooting groes on, I have often been attracted by rultures to the carcase of some animal which has evidently been killed by bullets, but which has never been recovered by the shooter, and hence has not been counted on his licence.

I should like to sec some arrangement by which, in place of so many animals being allowed on a licence, only so many shots at each of certain species should be permitted. Such an arrangement would effectually put a stop to the long-ranger and the rash shot. It would, indeed, tend to make everyone more careful of their shots and make them shoot to kill only, and not fire vaguely in the hopes of hitting an animal somewhere. I am afraid, though, that such a rule is impracticable unless every shooter had a detective at his heels. Failing this, however, in the interests of game l think that everyone who takes out a licence shoukt pass some sort of a shooting: 
test before he is allowed to fire at game. I have seen some atrociously bad shots disporting themselves on the veldt. I think it very hard on game to let loose on them some of these bad and irresponsible shooters. Moreover, such men are a danger to others besides game.

Prospective sportsmen should be made to pass a shooting test before being granted a licence. Such a test could take place in the country in which the licence is granted, and also in England, so that intending sportsmen from home could be saved any possibility of disappointment by being tested before they started. Such a test might be arranged at a dummy buck, say an impala, set up partly concealed by bush and grass. The figure could be made solid on the side facing the firer, but hollow on the other side, with an arrangement for placing a target representing the heart and lungs in this hollow in their exact positions relative to the body. These would, of course, be invisible to the firer. The sportsman would then be allowed to approach not nearer than a line one hundred and fifty yards from the animal. He would be prohibited from crossing this, but might move his position to right or left so as to get a better view of the animal. He should also be allowed field glasses.

He might then be allowed a specified number of shots at the animal broadside on, a similar number facing, and again another lot half facing or three-quarter ways on. He should be required to make a certain percentage of vital hits out of these shots, say, three out of five through heart or lungs and the remainder well placed. This would not be a very severe test. 


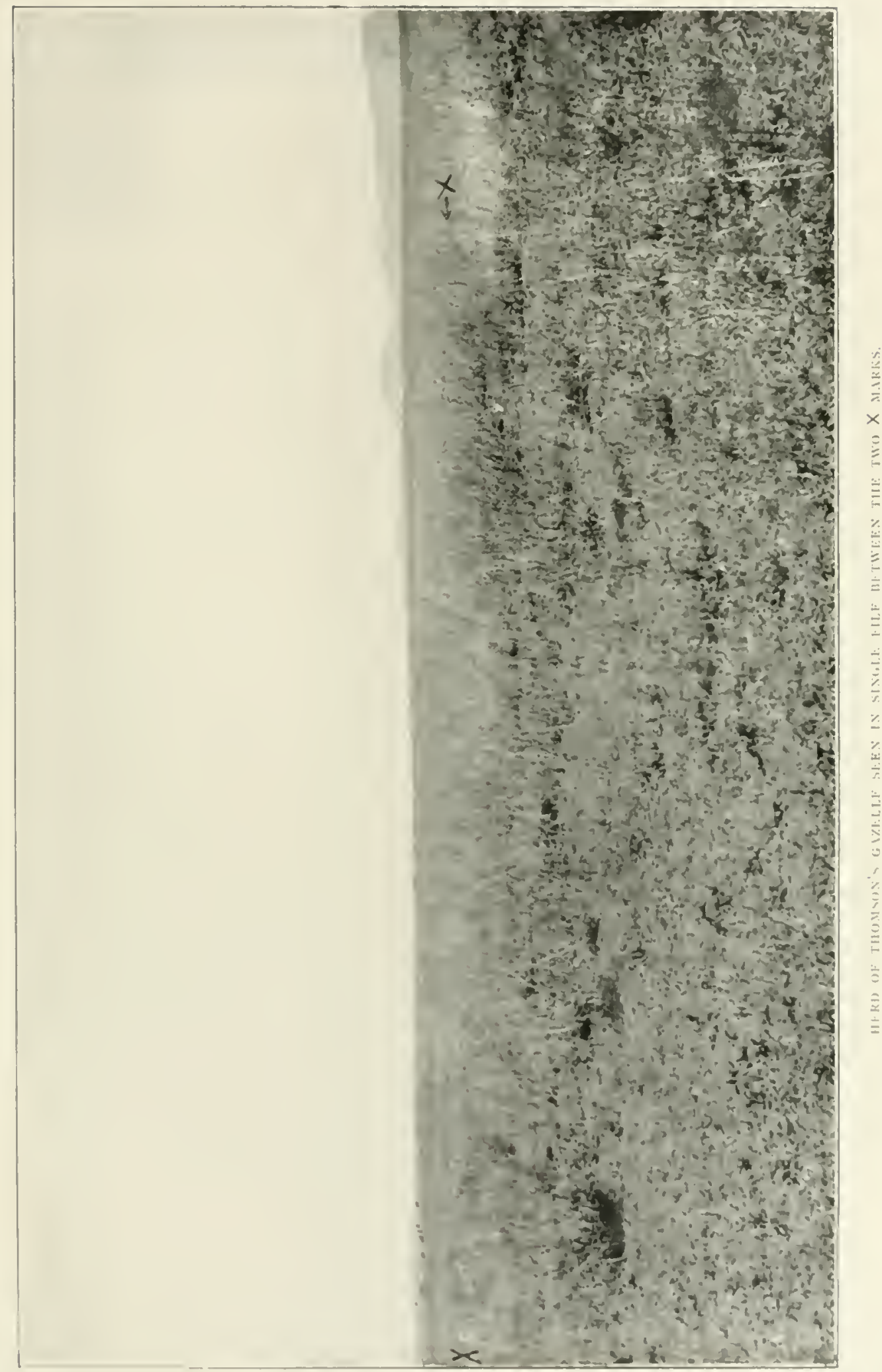





\section{APPENDIX.}

\section{NOTES ON THE GAME ANIMALS IN ALPHABETICAL ORDER.}

\begin{tabular}{|c|c|c|c|c|c|c|c|c|}
\hline Ant-Bear & & $\begin{array}{r}\text { PAGE } \\
\ldots .237\end{array}$ & Eland... & $\begin{array}{l}\text { PAGE } \\
247\end{array}$ & Hyrena, Str & $\begin{array}{l}\text { PAOR } \\
264\end{array}$ & Recdbuck, Bohor & $\begin{array}{l}\text { PAGE } \\
279\end{array}$ \\
\hline Antelope, Hu & unter's & ... 237 & Flephant & 248 & Impala $\quad .$. & $\ldots 264$ & Chanler's & 279 \\
\hline Bongo & $\ldots$ & ... 237 & liorest-Hog $\ldots$ & 257 & Jackal, I3lack-backe & ed 265 & " IVard's & .. 279 \\
\hline Buffalo, Cape & & ... $24 i$ & Galago (see l. enurs) & & Klipspringer ... & .. 265 & Rhino, Burchell's & ... 280 \\
\hline "Cong & & .. 2.42 & Gazclle, Grant's . & 257 & Kob, Mrs. Gray's & ... 265 & " Black ... & .. 280 \\
\hline Bushbuck & ... & ... 243 & "I Peters' & 258 & "l'homas's & .. 265 & Roan ... ... & $\ldots 28_{3}$ \\
\hline Busl:-pig & $\ldots$ & ... 244 & Rothschild's & 258 & "I'hite-cared & ... 266 & Sable ... . .. & ... $28_{3}$ \\
\hline Chectah & ... & ... 244 & Sœmmerring' & 's $25^{8}$ & Kudu, Greater & ... 266 & Scaly Manis ... & ... 284 \\
\hline Chimpanzec & ... & $\ldots 2+5$ & Thomson's ... & . 258 & "L.esser & ... 266 & Serval... $\quad .$. & ... 28 \\
\hline Civet Cal & $\ldots$ & ... 245 & Waller's ... & $25^{8}$ & L.cmurs & ... 266 & Stut unga & ... 28 \\
\hline Colobus & $\ldots$ & ... 245 & Giraffe & 259 & L.copard & ... 267 & Stcinbuck ... & $\ldots 28$ \\
\hline ," Red & $\ldots$ & ... 245 & Gnu ... .. & 259 & l.ion... $\quad \ldots$ & ... 267 & Suni, Zanzibar & ... 28 \\
\hline Crocodile & $\ldots$ & ... 246 & Hartebecst, Coke's ... & 260 & Oribi, Abyssinian & ... 277 & Topi . ... & ... 285 \\
\hline Dik Dik & $\ldots$ & $\ldots 246$ & ". Jackson's & 261 & " Haggard's & ... 277 & IVarihog & ... 286 \\
\hline Duiker, Blue & $\ldots$ & ... 246 & Neumann' & $s 261$ & Oryx, Bcisa ... & .. 278 & Waterbuck, Commo & \\
\hline "Com & mon & $\ldots 246$ & Hippo $\quad \ldots$ & . 262 & $\therefore$ Fringe-cared & .. 278 & 11 Sing-sir & ing \\
\hline Harv & vey's & ... 247 & Hunting.Dog & .263 & Ostrich $\quad \ldots$ & $\ldots 278$ & 7ebra, Chapman's & $\ldots$ \\
\hline Isaac & & ... 247 & Hyana, Spotted & .263 & Porcupine & .. 279 & ", Grevy"s & \\
\hline ugong & .. & ... $2+7$ & & & & & & \\
\hline
\end{tabular}

\section{ANT - BEAR.}

\section{Native Names.}

Swahili......... Mohanga. Kikuyu (Korori's). Ngări ya Kithaka. Kikuyu (Kinanjui's) ... Nyama. Kikamba ..... Luma.

This animal is purely nocturual in habits, and so is rarely seen. It is very common however, and its burrows and night's spoor may be seen almost everywhere. Its dung is something like that of the porcupine; and natives say that it digs a hole in which to deposit its dung, and afterwards covers up the hole.

The Yaos say that to catch this animal a certain medicine must be obtained, which the hunter must put into a horn and carry about with him, then, when he digs for the animal, the medicine will prevent it from noticing that it is being lug out.

\section{ANTELOPE, HUNTER'S.}

This interesting animal is one of the most local animals in Africa, being only found in one part of Jubaland and on the left bank of the lower 'Tana, some few days' journey' from the coast.

\section{BONGO.}

Native Names.
Swahili . Márua (same as the kudus).
Ogregg........... Osiruwet.
kikuyu. . Ndongoro.
Ogiek (Ravine) ....... Solgoita.

Spoor.-Shaped much like the spoor of small native cattle, but has the eland tendency of walking on the forward part of its toes, only in a much greitter degree. On the soft floor of the 
forest the fore-part of the spoor often sinks in a couple of inches, whilst the back part is level with the surface. I an referring to walking-spoor ln galloping-spoor the whole foot sinks in decply; but the toes are still the deeper part. The dropjings are light coloured, something like those of the waterbuck in shape, but they are occasionally stringy. The usual droppings are soncthing like those of eattle, but much lighter in colour, whilst the drier droppings and occasional droppings are like the dry-weather droppings of the waterbuck, only lighter in colour.

Food.-The bongo eats a great variety of foods, amongst other things, rotten bark and pith of decayed trees. When a tree in the forest dies or falls it is soon affected by the damp and becomes soft and rotten. Wood-borers attack the dead trees, and the holes they make facilitate the entry of rain or moisture. It is then that the bongo likes to gnaw the decayed wood under the bark.

Other foods are the charcoal and charred woods of the burnt trees of the forest; the animal probably eats these to get the salt contained in them; the barks of certain trecs, which it strips off in the same destructive way as does an eland in bush-country; roots of various trees which it digs up with its horns. There is a plant in the forest the lcares of which are of much the same texture and shape as those of a primrose, but of gigantic size, being a foot long. The bongo occasionally eats these lcavcs. The floor of the forest is largely carpeted with a plant much like the stinging nettle in shape and appcarance, but the leaves are not so dull. There are also patches of stinging nettles growing amongst this plant. Just at first it is difficult to pick out and avoid the stinging nettles from amongst the masses of this plant through which you have to walk. However, when you have been stung several times, you quickly learn to distinguish them. These two fplants, the nettle and its innocuous facsimile, form the farourite foods of the bongo. The animal also eats bamboo leaves.

Habitat.-The animal inhabits thick forest, such as the forests of the Kikuyu and Mau escarpments and those about the Ravine, Lumbwa, and Fort Ternan. In these localities it is very plentiful. It is also found, but scarcer in numbers, in the Murasi forests of Kinangop and the Abcrdares, and also in the forest belt of Kenya.

As the floor of the forest is covered everywhere with a laycr of brittle twigs, which crack when stepped upon, this animal generally has ample warning of the approach of an enemy. Moreover, in the places in which it loves to lie up there is generally an abundance of noxious vegetation, brambles, gigantic nettle-bushes, as well as a network of branches and lianas. Any creature (such as man) that is not specially built for moving about in this sort of country, will find these obstacles very difficult to pass, and almost impossible to pass amongst in silence, or to get through at more than a snail's pace. The bongo, however, slips through, over, and under such obstacles easily enough, or, if needs be, crashes through the slighter obstructions, such as brambles, thorns, and creepers. The vines and creepers are really worse than the thick pendant lianas hanging crosswise and in loops from the tall trees, for the latter can be parted or pushed aside, stepped over, or crawled through, as the case may be; but the all-pervading vines and convolvulus-like creepers hook up your feet, knees, ears, hat, buttons, rifle, and every conceivable angle of the person. Whilst disentangling yourself from a mass of these, as likely as not you will brush up against a giant-nettle, which stings through your clothes, and is said to make even the eleplant "sit up."

Parts of the forest are carpeted with flowers and small shoots, which are pleasant to walk anong. There you may see the bongo's spoor, but you know that you will not find the animal 
itself. It has only been there to feed at night; by day it will be concealed amongst the dense undergrowth of the forest. Followng the animal to its lying-up place is trying and backaching work, constituting a continual crouch and crowl, with only an occasional spot in which you can stand upright.

The forest-hog inhabits the same kind of country as does the bongo, and where the latter is found the former is almost certain to occur. The converse does not follow, as the forest-hog is occasionally found in bush-country, while the bongo never appears to quit the recesses of the forest.

Mabits.-The bongo feeds chiefly at night, and also a little in the early morning and late evening. 'Throughout the day it lies down, listening intently for sounds. Like the kudu, it has cnomous ears, and is quick of hearing. Moreover, the breezes of the forest are very treacherous, ind whatever precautions are taken, a change of breeze or a local current cannot be calculated "lpon, and as often as not the animal gets a whiff of a pursuer, for it has a well-dereloped scuse of smell, like most bush and forest animals. Very seldom in the innermost recesses of the forest is there anything like a strong breeze; as a rule there are only local currents, varying and intermittent, and it is therefore very difficult to make out the direction. Should there be any. Well-defined breeze, then, that would be a most favourable time to attempt to approach the animal, as not only are you less liable to be betrayed by scent, but also the rustling of the leaves of the tall trees may prevent small noises made cluring approach fro:u reaching his acute ears. For the same reason, a good time to approach is during rain, for the pattering of the drops on the leaves drown lesser sounds. However, during the rains the bongo is said to wander farther alield, and so a longer approach to its lying-up place would generally have to be made.

As you cannot foretell where it will be lying up, you have to endeavour to move as silently. the whole time as if you were expecting it to be lying up close by. Half-measures are of no use; you must always move as if the animal was round the next conner, for it may" be there or may be several miles away.

To move silently enough to give yourself the slightest chance of success, it is necessary to travel at about half a mile or less per hour, and you will also have to move every branch or crackling twig out of the way, besides testing every piece of ground, before bringing the weight of your body upon it, and take numerous other precautions. Following fresh spoor is, of course, the only method of coming up with an animal, and the finding of fresh spoor is the signal for commencing these precautions, whereas, whilst looking for spoor, you only take precautions compatible with covering a certain amount of ground.

These animals move about in small family parties of three or four, although a male occasionally wanders by himself.

The spoor is, as a rule, easily seen and easily followed in the soft floor of the forest. Where the ground is carpeted with shoots, the trampled shoots are obvious enough. Where they are sparse the spoor-marks themselves are easily seen. Marks of hrowsing shoulel be lonked for, as these signs will tell of not only fresh spoor, but also where the amimals are in the habit of feeding. With nettles and the nettle-like plant they bite off the tops, and the white serered tips may be noted.

The bongo is aceustomed to uproot small trees and saplings with its horns. It digs its horns into the soft ground under some: of the roots and then levers them up. It is, I belicece, chiefly the males that do this, with the object mainly of eating the ronts and stripping of the barks, but not to get at the leares. 
It is almost incredible what small spaces this animal manages to pass through or under in its pathways cloked with undergrowth and fallen trees. It puts its head low down, lays its horns along its back, and crouches its legs to pass along. In this attitude the whole forepart of its body is slaped like a wedge, with the nose as the point. It seldom seems to jump obstacles, but prefers to push through or under them, differing in this respect from the bushbuck, which will jump over obstacles that the bongo will crouch his large body bencath. It will almost always go under an object rather than over. For instance, fallen trees are strewn plentifully about the forest, some lie on the ground, but most are raised a little way off the ground in the centre or at one end by their branches. If a tree of this sort is lying across the path and there is a space underncath it of about two and a half feet, the bongo will probably go underneath rather than jump or climb over the trunk.

In the thick undergrowth in which they live their paths afford the only means of passageway. These old paths appear to be used by the animals when moving about, though whilst feeding they generally make new paths so as to get at fresh vegetation. They do wot scem to frequent salt-łicks as do other animals, but just jaw up any red earth and eat it. Where they have done this little shallow basins in the ground may be seen. They will often return again and again to some favourite tree for its pith when it is rotting. A beaten track may be seen to the tree, and hoofmarks all round. They gnaw off all the bark and decayed wood they can get at, and then leave the tree for a while until it has decayed further. If the dead tree is still standing they will, when they have caten all they can get within reach, then stand up on their hindlegs and put their forelegs against the tree to reach up farther. In this way they will obtain feeding at a height of eight feet or more.

With regard to this, an instance has come into my mind that shows what facile liars are natives. I used to wonder why whenever natives went out by themselves they were pursued by rhinos and buffaloes, or saw a lion, a kudu, or other rare animal, whereas when they went out with me such things rarely occurred. It was some time before I realised that a native sees no difference whatever between direct and indirect evidence. Therefore, if he saw a lion, or if he saw some spoor of a lion or the kill of a lion, he would equally well come back and say that he had seen a lion, and no other native would call him a liar, because to their mind it is the same thing. That is, if there was a spoor there must have been a lion at some time. Only in the first case, if he had really seen a lion he would have probably returned and said that it chased him. Again, it would not occur to a native that he was a liar, because lions sometimes do chase people and so he might have been chased, and so he has a right to say that he was chased by a lion.

Well, I noticed in the forest a tree as described above to which bongo used to go at night to gnaw the bark. I noticed it very carefully; there was a broken dead tree standing, and round it a little trodden circle of bongo hoofmarks, whilst it was gnawed to a distance of rather over my. height. The spoor was several days old.

An old man in my camp was despatched next day to get something from some villages outside the forest. On his return he told me that on his way he had seen seven bongo playing round a tree, and that he had watched them for upwards of an hour, and that they had finally gone off without sceing him. I asked him to take me to the place where he had seen these animals, and he took me to my tree, which I again examined carefully and found no fresh spoor whatever, but only that which I had observed on the day previous. The only excuse the old man gave was that he thought that the spoor was fresh. 
The hongo comes midway between the bushbuck group and the cland group. "The female has horns as has the female eland, and the horns of the former are not unlike those of the latter, cxcept for the curve and for the white tips. These ivory-like lips are also possessed by the bongo's relations, the kudu and the stutunga. The bongo does not bark as does the bushluck family, but makes a snuming noise more like that of the eland.

An old male is said to have no hair in the centre of its back. from the rubbing of the horns when they are thrown back in passing through obstacles.

Like the eland, the bongo's stripes fade, become merged, and are lost as the animal grows old. In the young adult animals the colouring is very effective, the body being of a rich chestnut red with bright white stripes. The Wandorobo catch this animal by means of game-pits, or by rounding it up with dogs and then shooting it. They tell me that they are unable to stalk and shoot it, as they are sometimes stated to be able to do.

The meat is most excellent, and so is every part of it, the marrow, the tongue, and even the tail for soup. It is a very fat meat, and much superior even to eland.

\section{BUFFALO, CAPE.}

\section{Native Names.}

Swahili...... Mbogo. Nyati.
Ogiegr ..... Ng'wesit (?).
Kavirondo . . . . Joi.
Kitaita . . . . Mbogo.

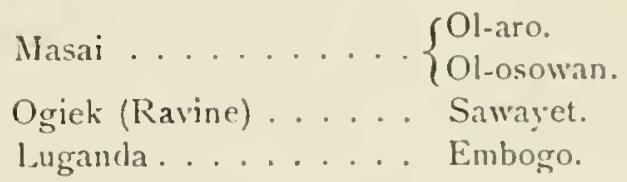

This animal has sadly diminished in numbers since the rinderpest. Before that discase it is said that countless herds might be seen on the Athi Plains; whilst below the Nandi Hills, near Lake Victoria, numbers used to roam. Von Höhnel describes great herds met with by Count Teleki in the Rift Valley, near Baringo, where now hardly a head is to be seen. Owing to strict preservation this animal has of late years recovered slightly from the devastation caused by the rinderpest, and in sonse places is fairly mumerous. However, wowhere are such vast herls to he met with now as in the days prior to the wholesale destruction caused by this disease.

As a dangerous animal it has in recent times much declined in popular estimation. This is only natural, as where sportsmen used to be able to shoot hundreds, they may nowadays only look at a few from a distance or shoot but one on a licence. So to-day the risks run, and therefore the accidents occurring, are reduced a humdrediold.

A herd of buffaloes, when alarmed, conveys the idea of a heaving sea of horns and tails, a sufficiently formidable-looking mass, although you know that they will practically always stampede away from you. When lying down, there are generally a few cows standing up as sentinels; at least, this has been my experience, although Von Höhnel, who must have seen many more herels than I have or am crer likely to see, states that it is the males who stand as sentrie's.

Buffalo and gnu, when at a distance, may be distinguished from a lierd of zebra from the fact that the latter graze with their heats all in one direction, whilst the former generally feed facing in various directions. If it were not for this peculiarity they would look very like one another when in the far distance, as at that range they both look big, black, bulky auimals when the sun is not shining on their flanks. 
Buffalo are amongst the most keen-scented of game-animals, being, perhaps, only sccond to the elephant in this respect. They are also very keen of sight and hearing.

In old times, when they were amongst the most common of game animals, it would appear, from all accounts, that they were much less suspicious and more casily approached than they are at the present time. Now they are generally difficult to stalk and have seemingly left the open plains for the bush, which circumstance converts them into animals that have to be hunted, tracked, and stalked. I have seen either buffalo or buffalo spoor in the following places:Ngong Mountain, one herd; Kedong Valley, one large herd; these wander between Kijabe Station and Mount Lonongot and down the Kedong. They come to a salt-lick close to Kijabe Station.

On the lower slopes and foot of Kinangop on the western side.

About the Ithanga Hills and 'lana River east of these hills (plentiful).

On Ol Doingo Sapuk (Kilima cha mbogo = the buffalo hill), a herd.

At the edge of Athi Plains north-east of Nairobi.

On the Fort Hall road near Embu, a large herd ranging backwards and forwards across the road from north to south.

Near Malindi on coast.

On the mainland opposite Manda Island, in the Lamu Archipelago.

On east shore of Rudolf (plentiful).

Buffalo are also reported from the Beskaya Plains, Jubaland. The German border west of game reserve, and also higher up west of Kisii.

Kiunga on coast near Lamu.

Near the Shimba Hills.

In Uganda they occur plentifully in most districts, and there they are not on the restricted list owing to their numbers and the damage they do.

The Cape buffalo has lately been divided into a number of sub-species chiefly determined by the shapes and features of the horns. As horns of animals found in the same district, or cren the same herd, differ so materially from one another, it seems to me that a comparison of two or three horns from each district would be of little value in judging which of these differences was constant to a type, and which was only an individual variation or a variation hereditary to the offspring of one animal. It seems to me as if the roundness or smoothness of a horn is no guide to determining a variety, as nearly all bulls not fully matured have round and smooth horns which with age become flatter and more crinkled. Again, the breadth of bare skull between the horns would be of little use as a guide, for this space not only differs with age, but also differs with buffaloes of approximately the same age. Yet some of the subspecies have been determined on such evidence as this.

\section{BUFFALO, CONGO.}

This animal differs from the Cape buffalo in that the horns are less massive and point upwards, instead of spreading at right angles to the head. The colour of the body also differs, for it is more of a reddish colour; especially is this the case with immature animals, and in a lesser degree with the females. The animal is found plentifully on the west bank of the Nile and around Lake Albert, especially about Mahagi. 


\section{BUSHBUCK.}

\section{Native Names.}

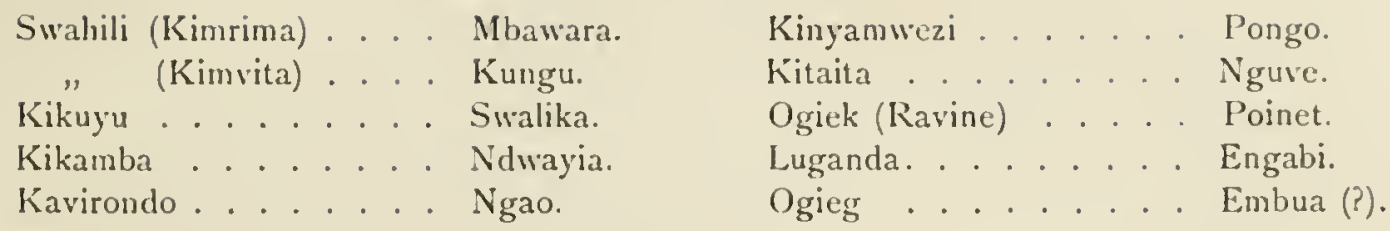

These animals are bush and forest dwelling animals, and are usually rery shy, so that they are interesting to hunt and stalk. They may often be seen out of cover just about sunset, when they graze round the edge of the bush-belts, and also after rain, especially at high altitudes. They come out presumably to escape the dripping of the trees and bushes in cover.

The male often passes obstacles in thick bush by laying back his horns and breaking through or jumping over. The lemale and young push through and under obstacles. From this pushing through and under bush they nove in a peculiar crouching fashion with the forelegs bent. Whilst feeding they go forward a few yards at a tine, frequently raising the head to listen, but keeping the legs and body crouched. Inmediately on being alarmed they lope back into cover.

The female and young are of a bright rufus red with white spots or stripes, but the old male has often lost his bright colour and white markings, and in the distance appears perfectly dark or black. There is a variety of bushbuck found on the Ithanga and Doinyo Sapuk having a white chevron on the nose (see photo, page $6 r$ ).

When on the look-out for spoor at the edge of the forest or bush you should follow round the edge and take note of the game-paths leading out Irom the bush: these will soon show you if the animal is in the neighbourhood or not.

The male bushbuck is often almost bare of hair about the neck or has only very short hairs about that part with the skin showing through. This circular patch covered with short hair round the neck is often distended or swollen.

When a bushbuck sights anyone it will often utter a sharp, hard, raucous bark, provided that it is standing at the time in thick cover.

liy following round just inside the edge of a forest or patel of busl you can sometimes spot an animal out grazing and approach it unobserved.

A smaller variety of the bushbuck is found on the shores of Lake Albert. It is a kind of harnessed antelope and is covered with stripes instead of spots, and the horns are smaller amel often are close together at the tips.

The bushbuck occurs in most bush and forest tracts of the country. On Ol Doinyo Sapuk and the Ithanga Hills it is very common, also on the top of the Aberelares and again in the bush on the foothills. It is plentiful on the coast-folt and in the Lamu Archipelagn, at the Ravine, Guas Ngishu, and in the Kamasia Ilills.

It is also common in the hushiest parts of L'ganela, and occasionally in the long grass. "The anmal has a very strong smell. 


\section{BUSH-PIG.}

\section{Native Names.}

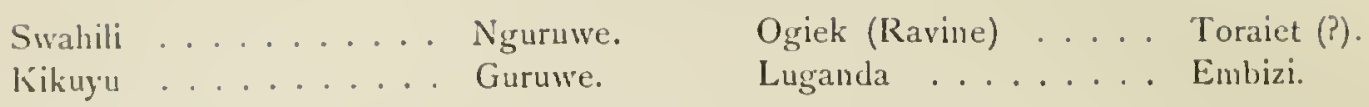

This animal is exceedingly common in nearly all the forest, bush, and thick-grass country in British East Africa, Uganda, and the Lado Enclave. As it is a nocturnal animal, it is seldom seen, though its burrows may be seen in most places in great numbers. It is especially common in the coast bush-belt and in the Uganda long-grass countries, as also that of the Lado Enclave, in all of which places it forms the staple food of the bush-lion.

\section{CHEETAH.}

Native Names.

Few natives appear to distunguish between this animal and the leopard.

Somali....... Wer. Masai...... Engingyalasho.

Samburr ...... Engingyalasho.

These animals are found in small parties on most of the plains of British East Africa. $A$ single animal seen at a distance on the open plains is not at first easy to distinguish from a lioness. I have known Masai and other plain-dwelling natives make this mistake. The coat, in the distance, looks of a uniform yellowish colour like that of a lion.

The distinguishing points to observe are:-

(i.) The shininess of the coat in the sun. (Lions' coats are not so glossy.)

(ii.) The smallness of the head.

(iii.) The height of the shoulder blades.

(iv.) The long waving tail. This last is a most distinguishing mark, and can be seen from afar. Lions, as a rule, keep their tails dragging behind them.

The differences between a cheetah and a leopard are, that the cheetah has but single spots on its coat, whilst the leopard has groups of spots just as if someone had dipped his fingers into black paint and, without spreading out the fingers, had left finger-prints. The cheetah has a short mane and its legs are very much longer than those of a leopard or even than those of a hunting-dog. The body, head, and tail are of the cat type, whilst the legs and claws are more of the dog type. The foot looks like that of a hyena, with large, blunt, dog-like claws. The typical cat foot is not capable of standing much hard usage; cats are only capable of going fast for very short bursts, at other times they walk carefully and daintily. The dog type of foot is one more capable of standing long runs and hard wear and tear, and this kind of foot is essential to such a hunting animal as the cheetah. I have seen cheetahs on the Athi Plains, the Guas N̈giro Plains, and near Nyeri, and also on the Tana River east of the Ithanga Hills. They are reported to occur on most other plains in the Protectorate.

The animals appear chiefly to hunt small game. I have several times seen them passing close to, or in amongst, a herd of grazing zebra, and the latter did not show the least alarm or concern at their proximity. 


\section{CHIMPANZEE.}

Native Names.

Swahili ......... Sokwe. Luganda ........ Ezike.

This animal occurs in the Budonga Forest in Western Uganda and in the Ituri Forest, Eastern Cougo.

\section{CIVET CAT.}

Native Names.

Swahili (Zanzibar) ... Ngawa. Swahili ..... Fungo.

This animal does not appear to be at all common in British East Africa. It seems to occur fairly plentifully on the island of Zanzibar, especially about Maweni.

Its neat is brought into the bazaar and sold, and is much appreciated by the natives.

\section{COLOBUS.}

\section{Native Names.}

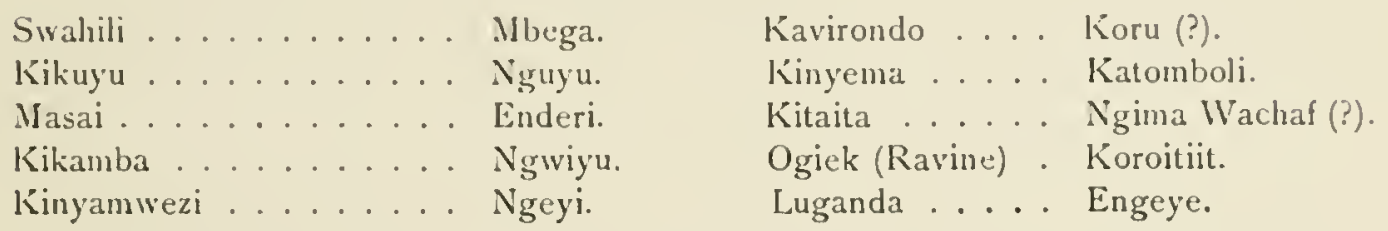

These animals feed on leaves and do not come down to the ground as clo the "kima " and other monkeys. When alarmed they often descend quickly from the higher branches of a tree, so as to obtain concealment in the thicker foliage below. They will sometimes pull branches and leaves around so as to hide themselves. This is done particularly by a female carrying in her arms a young one, which does not want to take flying leaps to the adjoining trees. The females carry their young hugged against the chest. Colobus nake a peculiar croaking sound, especially in the early morning, when waves of their sound pass across the forests, the cry being taken up by those in advance and carried forward. These animals are found in most of the elevated forests in the country, such as :-

Nandi and Mau forests, very plentiful.

Kikuyu escarpment, plentiful.

Aberdare forests, less plentiful.

Kenya forest and Kilimanjaro forest.

They also occur plentifully in the Budonga and other forests of Uganda.

\section{COLOBUS, RED.}

There is a red colobus found plentifully in the forests of Western Uganda and the lisatern Congo. 


\section{CROCODILE.}

\section{Native Names.}

Swahili . . . . . Mamba.

Swahili (Mombasa) \& Giriyama Ngwena.

Embci............. King'ani.

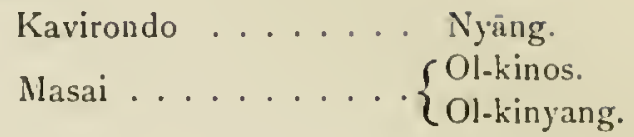

This reptile is not plentiful in the Protectorate. It occurs on the Tana and is said to be plentiful in the Juba.

Some thousands of these animals were left high and dry in Jubaland by the drying up of a swamp, and for a long time afterwards some were found lying about in the bush. On the Victoria Nile crocodiles are found in thousands. Just below the Murchison Falls the numbers secn are incredible, and masses of several hundreds may be seen lying out of the water packed closely together. They are also numerous, but not to such an extent, lower down on the Nile.

I had always imagined until recently that the crocodile crawled flat with its stomach almost touching the ground, as generally depicted in illustrations. In reality, when on land or making its way back into the water, it stands up high on its legs, and the head or belly is a good foot or foot and a half off the ground. In this position it reminds one of the way a chameleon or a lizard stands up with straightened legs and head raised, in an attentive attitude. The reason why the crocodile is usually depicted crawling flat is that it is generally seen on marslyy ground, in reeds, or just crawling into the water, in which position the mud, grass, or water lides most of its legs.

\section{DIK DIK.}

Native Names.

Rendile ......... Sagarr. Somali.......... Sakaro.

There are, I believe, four different kinds of dik dik to be found in British East $\Lambda$ frica, viz., Guntlier's, Kirke's, Hinde's, and Cavendish's. The dik diks are distinguished by having no kneepads, but a thick growth of hair on this part. They are generally found in dry country, and occur plentifully along the Tana and northwards towards the Borana.

\section{DUIKER, BLUE.}

I have seen several little blue duikers in the Lado Enclave, close to the Nile. 1 believe they also occur on the Uganda side. I do not know to what species of duiker it belongs. Probably the same as the Sudan blue duiker.

\section{DUIKER, COMMON.}

Native Names.

Swahili. No name but Paa for all the little buck.

Kikuyu. Sia. (?)

This little forest-dwelling animal does not appear to be very conımon in British East Africa. It occurs, as a rule, in lower-lying country than the Harvey's duiker. The female has a long black tuft on the head, which at first sight looks like a horn, and so the animal is liable to be mistaken for a male. 
The common duiker is of a much duller colour than the Harrey's. Its food consists of pods, beans, and shoots. This animal sometimes appears to be so preoccupied with other things that it forgets to be on the alert. I have twice got to within ten yards of one: once in the Ngong Forest and once in Nyasaland. As a general rule, however, it is alert enough. Females are occasionally found with horns.

\section{DUIKER, HARVEY'S.}

\section{Native Names.}

Kikuyu ....... Sia. Kikamba ....... Mweyana.

Found plentifully on the Aberdares and in other high localities. Its body is of a bright chestnut colour. It can readily be distinguished by a black vertical stripe down the centre of the face. It is said to also occur in Uganda.

\section{DUIKER, ISAAC'S.}

This animal is said to be found in British East Africa. I have not come across any of the species.

\section{DUGONG.}

Native Name.

Swahili ............... Nguva.

This mammal is caught fairly often by native fishermen off Mlombasa and in the Lamu Archipelago. Its meat is highly appreciated by the coast Swahilis and Arabs, who pay high prices for it, and so the lucky captor turns over a good sum. It is generally sold outright to a buyer, who then sells it retail in small portions. Its flesh is excessively tender and succulent, tasting something of the quality of veal or sucking-pigr. It occurs also at Aden, and at various other places on the coast of the Indian Ocean. The corresponding mammal of the Atlantic is the manatee. The natives are wont to exaggerate its likeness to a human being, especially when talking to others who have never seen one. No doubt, as alleged, this animal is the original of the mermaid.

\section{ELAND.}

Native Names.

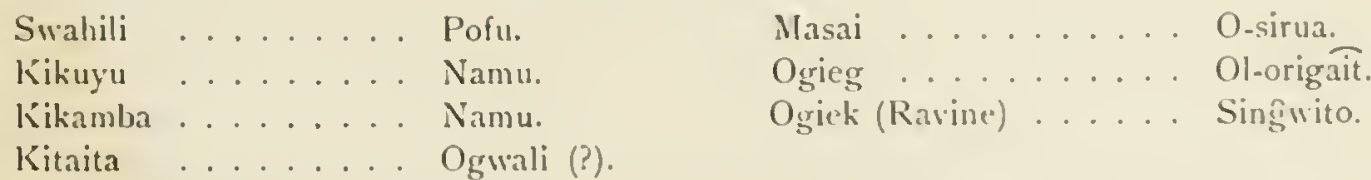

This animal, and especially the cow, looks in the distance very like the ory. When the latter, however, is looking towards you, the white markings on the face distinguish it, and also (where the grass is short) the white stockings. The rland has a brown blaze on the face instead of the white markings. Both the above animals can often be distinguished from other amimals by the cow-like switchings of the long tails. The stripes on the eland, like those of the bongo, appear to decrease in number, facle, or disappear with age. The tip of the tail is black; there is 
also a black patch on the inside of the forelegs above the knees. This animal is both a bush and a plain dwelling animal, and occurs in the following places:-Shimba Hills, Athi Plains (scarce ontsicle the reserve), Ithanga Hills (plentiful), north of Nyeri and on the Guas Nigiro; Guas Ngishu, near Baringo (plentiful), north of Guas $\tilde{N}$ giro (plentiful); Embu and south of Embu, and in various other localities being fairly common, but of ten shy.

\section{ELEPHANT.}

Native Names.

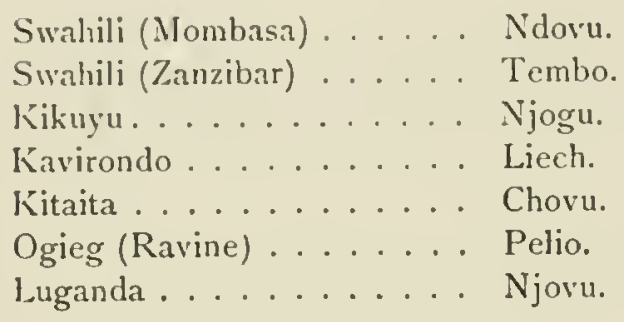

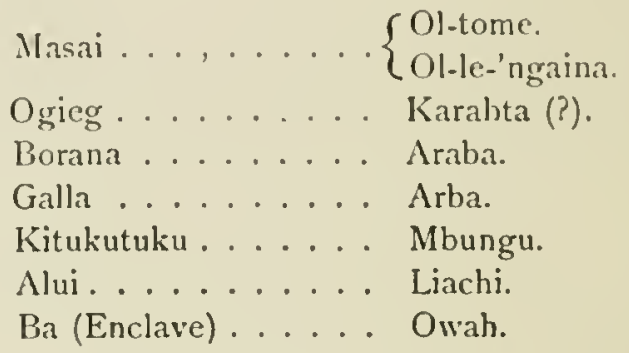

Types.-There are a number of different types of elephant, easily recognised by ivory experts by the difference in their tusks. The coast ivory is small and of poor quality, whilst the hill ivory is closer grained and of better quality. The "Uganda" type of ivory, short, thick, and heavy in tusk, is found in Masindi, the Budonga Forest, and on both the British and Belgian banks of the Nile. It is a soft irory, and of greatcr valuc than hard ivory. The "Congo" varieties, long, thin, and graceful tusks, weighing light, are met with on the Semliki and in the thicker country, back from the Nile, in the Congo. These are hard ivories.

Food.-In addition to the usual foods of grass and the leaves and barks of various trecs, elephants eat bamboo. The usual procedure is to bend over the stem of the bamboo bow fashion, six or eight feet from the ground, until it gives and hangs over. The animals then strip off the leaves.

In bamboo-country it can be seen at a glance where elephants have been, as there will be banboos in every direction in the shape of arches, and several together resemble the framework of a bower. When convolvulus and other creeping plants have crept up the broken stems and covered in the top the rcscmblance is complete. Besides eating the leaves of the bamboo, elephants often break off young shoots and chew the stems, afterwards spitting them out again.

Below the forest levels of the Aberdares and Kenya there is, in the belt of bush, a shrub called by the Kikuyu masasumua. This grows in profusion, and is also a favourite food. The elephants, as a rule, in these parts leave the higher levels of forest and bamboo only at night to go down to eat the masasumua and also the grass of the plains. The bush is, I believe, a kind of wild tea.

In Uganda and the Congo, elephants often at night get into the fields and feed on the crops and the young banana-trees. A large herd will sometimes completely destroy an outlying field during a single night, and pull up all the young banana-trees. On the site of an old and deserted field may generally be found remains of millet or other crops which have gone to seed. These spots are favourite resorts for elephants, as they can there leed without having to approach near any habitation. 
Elephants are very fond of aloes, which they pull up and chew and then throw away again. In the Enclave they often eat the small thorn-bushes growing on the hills by the Nite, which is unusual in elephants, as in most places they do not eat the leaves of acacia-like thorns, though they sometimes strip off the barks. In the same locality these animals are also very partial to a bush, hearing a very pleasant edible berry about the size, shape, and colour of a blach cherry, called hy the Alui, ashuga.

Meight.-There lsas always been considerable difference of opinion and much uncertainty as regards the maximum height of African elephants, and there probably will always continue much uncertainty on the point.

Sume people talk fuently of twelve-foot elephants, and others consider anything over eleven feret at the shoulder to be abnormal. The reason why such uncertainty prevails is that a fullgrown African "lephant has probably never been seen in Europe, and possibly never will be.

Whe'n an elephant is killed he usually falls in one of two postures-either a kneeling position (the result of a clean brain shot) or a lying position. Sometimes, however, he falls in a crumpled-up sitting position, the result of a shot other than a brain shot. It is obvious, then, that only in the lying position can an animal be measured for its height. In this position the forc-legs are usually slighty bent, and then the united efforts of half-a-dozen men are not sufficient to absolutely straighten a leg whilst a measurement is being taken. If such measurement is not taken immediately after death, it will be found impossible to straighten out this leg afterwards to secure even approximate measurements.

There are, however, other difficulties attending the taking of such measurements, for uprights have to be found at least five feet long, though six feet are better. The usual articles used for this purpose are the spears of the local natives who have accompanied you. These spears have to be arranged by eye, and to ensure that they are perpendicular the grass must be cut back to the distance of about ten yards from the head of the clephant so as to enable you to see them from that distance. Then the horizontal distance between the spears must be taken, and as you cannot move the elephant, it is obvious that this distance must be taken across the upper part of the uprights. lou will have to judge by eye if the string is horizontal, but this time you will not be able to step back to mark it from a distance, for you will be holding one end of the string yourself and a raw savage will be holding the uther. If, then, in conjunction with such untrained assistanes you succeed in taking a measurcinent of the height of the elephant with only a matter of two inches of error, 1 consicler that you have done well.

1 do not know if other people have developed a better method of measurement, but, so far as I can see, rough-and-ready methods are the only ones generally available.

From the approximate measurements (as regards height) that I have taken, I can say that, to the bist of my belief, clephants of eleren feet four inches at the shoukler are not uncommon both in Uganda and the Lado Enclave. Possibly such an animal as a twelve-foot clepplant does exist, but such an onc wonk be abnormal. Many full-grown make elephants are only deven feet, and some even, with large tustis of, say, sixty ponnds, may be found only ten feet, or, at any rate, but a fow inches over this measurement. The usual 7.00 and menagerie elephlants arc such pignies compared to the full-grown African bulls that people who have only secen the former would be inclined to think that cleven feet was an impossible size for an elephant. I believe that Jumbe was ten feet seven inches. It is clamed that he could not have been a very: big elephant or he would not have been able to pass through the tunnel at the Zoo. Speaking 
from memory, I shoukl certainly say that the tunnel is nothing like thirteen feet in height-the approximate height of a big African bull elephant's head or back above the ground.

$\therefore$ rougl-and-realy calculation of the height of the luead of a big bull, or, perhaps, the height of its back (i.e., at the edge of the small, flat plateau which is found on either side of the spine), can often be makde by observing trees against which an elephant has been standing and rubling himself. If he has just been having a mud bath, the line of the lighest part of his back touching the tree (this is lower than his spine) can often be seen clearly marked on the trunk. Bclow the line is soliel mud; above, only a few splashes. Often, when following a solitary bull, 1 have, on passing such a tree, stood underneath and reached up to the spot with a spear and just touched it (the spear being my own height in length). I have also measured by eye, roughly, twice my own height on the tree, i.e., I have macte a mark at the height of my cye-nearly six feet-and then stepped back to see if it was half the height of the high mud mark, or less than that. By such rough-and-ready methods I have often come to the conclusion that the highest part of a very big elephant was about thirteen feet or a trifle uncler.

Judging by eye, 1 should think that there was no comparison between an African hull elephant and an Indian bull elephant, the latter appearing as small as, or smaller than, an African cow.

1 can trace no relationship between the height of an elephant and the weight of its tusks, nor between the size of its foot and its height. A distinct relationship, however, appears to exist between the size of the foot and the weight of the tusks, and I am inclined to think that the tusk and the foot continue growing long after the animal has reached its maximum leiglt.

Weight.-Jumbo was said to weigh about four tons. Small menagerie Indian cleplants weigh, I believe, about two to two and a half tons. Taking a large performing clephant, the height would probably be about eight feet, and the weight two and a half tons. An African bull is half as high again, and so its weight should be about double. I should think five tons "rould not be an excessive estimate for an elephant of eleven fect four inches.

Reading the Weight of Irory. - The weight of tusks largely depends on the amount of hollow inside them, and as this cannot be ascertained until after they have been cut out, the estimate of weight from outside measurement can only be approximate. However, if the animal is an old one the hollows will be small; if a young one, they will be large. Again, the amount of curve in the tusk affects the reading. Straight tusks look longer than curved, but in the same lengths of straight tusks and curved tusks the straight will weigh the heavier, provided the girth is the same and the hollows are of equal size.

Tracking.-There are a few points in tracking which I have not mentioned elsewhere.

During the early hours of the morning just before dawn, and for a few hours afterwards, elephants leave few droppings and sometimes none at all. Early morning spoor of a herd may often be recognised from this fact. In the daytime numbers of flies settle on the droppings of elephants immediately they are deposited, then if a cloud of fies rises with a loud buzz as you pass, it shows the spoor is absolutely fresh, within a few minutes. If there are only a few flies the spoor is perhaps half an hour old. Notice should be taken of the number of beetles there are about which make it their duty to remove the droppings. If these are very numerous, and if they arrive quickly on the scene, they will break up a dropping in the course of an hour, when a powerful sun shining on the remains for from four to six hours will completely dry. them up and make them look like droppings of the day previous. Their real age can, however, be ascertained by kicking the dried part off the top and looking underneath. If the 
bectles have already buried their balls of manure, they must have been at work for an hour or two.

Fresh spoor in grass shows a shininess on the grass not seen with old spoors. Old spoor in grass can be told from fairly recent spoor by sceds on the crushed grass of the old spoor having been arrested in their development, and so not showing so ripe as the seeds of the surrounding grass. This observation is uscful when on passing through a country you wish to know if elephants have lately been in the vicinity, or have not heen present for several weeks or a month.

Where spoors cross, the fresher spoor can as a rule be told, by the overlapping of the grasses. The spoor which has crushed down the top layer of grass is, of course, the more recent. Where old spoors or elephant roads cross, matters sometimes become complicated. There may be at layer of dead grasses pointing up onc spoor, another layer crossing this from a second track, and again a few fresh blades from the edge of the first path will be trampled across the second again by a more recent elephant; and perhaps over all these there will be one blade crossing from the second spoor again, which will show the latter to be the most recent of all.

Sometimes there will be an old track with its line of flattened dead grasses; crosing this will be a newer track flattening a layer of green grass across. An elephant then passing down the old track would show few signs of having passed until it came to the green grass, which would reveal signs of having been pushed a little on one side, and not laying dead straight across the path.

The above remarks refer to tracks crossing at right angles. With tracks overlapping, converging, or joining, the same principles are observed, but the more recent tracks are more diffecult to tell merely by the overlapping of grasses, and are then generally told by observing which track has disturbed or slightly brushed asicle the grass of an older.

Ekphants, after rolling in a mud bath, or whilst climbing up a steep bank, often help themsolves up with their tusks, and the approximate grirths can often then be estimated from the impresses on the ground. These impresses can also be secn at a saltelick.

liange of Vision.-It is rather difficult to tell exactly how far elephants can see. Sometine"s they appear unathe to see anyone at a few yards, but that may be because they do not know what man looks like. Their experienec of him must as a rule, be contined to his secnt and the noise he makes, such as natives shouting, the cutting of trees, and the reports of rifles.

() the other hand, upon certain occasions, I am convinced that I have been seen at thirty yards and even lifty yards. If a hunter appeared against the skyline, such as on the top of an ant-hill, they probably coukl ste lim at this latter clistance-lifty yards.

liange of Sucll.- likphants can smell human beings at enormous distances, the range depenting, of course, on the kind of hreeze blowing and on the thickness of the country. I believe elephants can smell human beings at a greater listance than any other animal, not excepting huffalo. Linder favourable conditions they can scent man at quite six hundred yards, and probably much farther.

As to scenting water or mud, I should not like to state how far away they are not able to detect its presence, possibly many miless.

Vilephants, owing to the lengths of their noses and the power they possess of focussing a brewe hy extending their ears and flapping them forwards, are better epuipped than any other animal

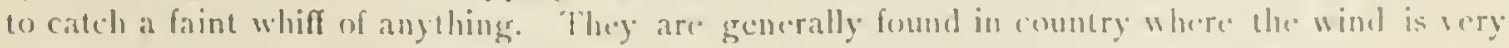
treacherous; but even allowing for this, there is no animal the pursuit of which leads to so many disappointments, and no animal which so habitually letects by wind the presence of the hunter. 
Ilcaring. - They are often credited with very bad hearing, but this is not quite correct. They are very slow to hear anything before having been alarmed, but this is the result of many reasons. Firstly, they are not on the alert and listening for strange sounds, and, morcover, are making such at variety of sounds themselves, such as breaking branches, stamping on the ground to loosen earth, flapping ears, rumbling stomachs, and blowing hard through the trunk, that any other sounds are apt to pass unheard. When, however, they are once on the alert or get suspicious, they stand perfectly still and silent, and then they are very quick at picking up sounds; they are remarkably quick at hearing the sound of a distant rifle, and for this reason elephant-hunters go without meat rather than run the risk of disturbing elephants by shooting at other game.

Once they have becn alarmed, they stop all other noises and listen intently, and when they stampede they stop at intervals and stand perfectly silent, listening.

It is at this time that they are so dangerous, as anyone following rapidly on an elephant's tracks will be heard, whereas the elephant itself, if in thick bush or grass, will not be visible. The first warning the hunter often has that his quarry has stopped and is not still stampeding, is to pass round a corner and suddenly find himself only a few yards away from his animal, or, worse still, he hears an angry trumpet and the sound of a great body crashing towards him from somewhere close by.

Stomachatic Rumblings.-Elephants seem to be able to stop these rumblings at will. When you are close to a herd and suddenly all these sounds ceasc, you know that you have been scented or heard, or at any rate that the animals are suspicious. However, they do not seem able to hold them in indefinitely, and sometimes after they have been alarmed and whilst making off a stomachatic rumble will be heard. A wounded animal also will often make this sound, perhaps when standing still unable to procced, or about to fall.

Size of Herds. $-\lambda$ herd generally consists of from ten to forty animals. A very large herd usually consists of a number of herds of about twenty or thirty animals, each herd grazing apart, and standing apart at midday. Occasionally, however, large numbers are seen moving as one herd, and as many as two or more hundred elephants may be seen trekking in onc compact mass and also standing together in a mass.

Salt-licks.-White-ant hills are generally used, the earth being removed by digging with the tusks or kicking with the fcet, and then it is eaten in lumps. Very occasionally a flat surface is scen, having the appearance of having been licked with the tongue. Sometimes the overhanging bank of a spring or of a watercourse is used, and these are occasionally excavated far back from their original positions. The ground underneath them is pounded and trampled by many elephants, and serves as a mud bath. Many of these places nay be seen among the ravines and watercourses of the Aberdares, especially near the sources.

Elephant Paths. - Those to distant places generally go in a very straight line and do not wind and twist about as do human paths. They are also broader than the latter.

Whilst generally making his own path during a day's or a night's grazing, an elephant will, as a rule, when trekking from one place to another, take an old path. In mountainous country inhabited by elephants, almost every peak, however seemingly steep, every ridge, well-marked spur, and col will be found to have an elephant road following its line of watershed. At the highest parts of the Aberdares paths may be seen at an altitude of 13,000 feet. The highest point of linangop is a steep-sided block of rock, perhaps 60 feet in height. Elephants, apparently, have not succeeded in climbing this, but close underneath it, and running past is a well-defined path used by elcphants and rhinos. What they do up there l cannot imaginc, as 
the place is very rocky and the chief plants are strange rock and mountainous plants anr] lichens. However, there is a certain amount of grass, so possibly it is that which tempts them there, as they can graze on it in the open with little chance of being disturbed by men in these rocky solitudes.

On the paths along the ridges old bamboos may be seen with their glaze rubled off by the constant passing and repassing of elephants.

Elephant there do not stampede on such a broad front as they do in other places. Where there is a steep hill to be negotiated they may be seen pushing and jostling each other to get the path to which they are aceustomed.

Old Bulls. - The old males shun the society of the females and young, so for this reason big tusks are selelom obtained by approaching a herd. Occasionally an animal with Golb. tusks may be found running with a herd, but the ustal weight of the biggest males with a herd is 3 olb. to 4 olb. In examination of the tusks of these herd-bulls will grenerally show that the hollows are large, proving that they are young animals. Thus an animal with Goll). tusks may be found with large hollows. If such an animal had lived it would probably have become a very hig tusker. On the other hand, an animal with forty-pounders may be found to have very small hollows, showing that he is an old animal and not likely to grow tusks nuch bigger. Such an old 4o-pounder will as likely as not be found to have left the herd and taken to a solitary hife, wher'as, perhaps, the young sixty-pounder may still be running with the herd.

The actual weight of the tusts is no indication of the animal's age, except that the immense tuskers, such as over toolb., are almost certain to be old aninals, and thus be found apart from the herds. These old males, viz, males with small hollows to their tusks, are gencrally either solitary or wander about in small parties, the usual number being from one to five. Larger parties will generally consist of younger animals. I have met with a party of between twenty and twenty-five large bulls together, with tusks running from about 3olb. to 65lb. These I believe, however, were all youngish males. The very big tuskers seem gencrally to go with but one to three companions. These old males are generally cunning old fellows, and, as a rule, live in very thick country and never leave it for more open kinds. They wind and twist so in their day's wanderings that they always stand a very good chance of winding anyone following them, whilst the hunter remains unaware of their presence when they are standing still until he has almost run into them.

Abnormal Tusks. - By page 223 is a photograph of an elephant bull with abnormal tusks of a very peculiar shape. The measurements of the tusks were as follows :-

Right tusk (slightly curved): Length, 6 feet 6 inches; girth, 6 inches; Weight, $53^{\text {ll. }}$.

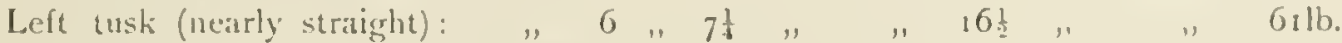

The height of the animal was 10 feet 10 inches at shoukler.

The tail was abnormally long, being $57 \frac{1}{2}$ inches from the root to the commencement of the hairs.

The ear was 70 inches in length from top to botton.

The right tusk curved forwark, hut was enusiderably straighter than most male chephant's tusks.

The left tusk grew straight dowmwatrels, slighty behind and in line with the trunk, so that it was only noticeable when the trunk was swumg forwards, whon it was visible behind it. The animal was covered with sores and wounds from the tusks of his fellows, so it would appear that he was net wry popular, althougls lie was anongst a lange herd of males. 
Young Elephants. - On the birth of a new calf the mother does not drive away the old calf as do most other animals. I have never seen a female rhino with more than one calf following it. With elepliants, however, two and even three calses of different sizes may be scen following nne female. W'ben three calves of different sizes follow one female, the largest must he at least four years of age to allow for the subsequent hirths of the two others. I have often observed three animals follow the movements of one old cow; but on most occasions the biggest of the three calves was a female; possibly females remain longer with the mother than do males. When a cow is killed, the calves, unlike the rhino calf, remain only a short time with the borly of their mother, they then leave to rejoin the herd. One small calf by itself would probably: remain, like the rhino calf, for a day if not disturbed, but being accompanied by older calves it would naturally follow their movements and leave when they did.

Elephants Fighting Inter Se.-It is gencrally considered that elephants are very amiable and good-natured. I have not noticed in the works of any writer any description of the licree conflicts which must occur between the bulls. Old bulls are always covered with scars, recent and old wounds dealt by the tusks of others. Ears are torn and holes punched througl them. I found on one elcphant, on the tusks being cut ont, the broken tip of another clephant's tusk deeply embedded in the gums.

Broken-tusked and One-tusked Elephants.-Elephants with the tip broken off a tust are commonly met with. This may be caused by fighting, as in the case I have just mentioned, or by various other causes. The broken end of a tusk was brought in recently by natives, who averred that they found it sticking in a tree.

One-tusted elephants have, I am of opinion, often lost a tusk from an old wound in the nerve at the base of the tusk. Such a wound is generally caused by a native missile passing through the thin ivory at the base of the tusk, and lodging in the nerve. "The nerve decay's and the tusk splits at the place which the missile enters. The tusk decays and, gradually becoming brittle, breaks and crumbles away. I have seen elephants with just the stump of a decayed tusk, and I have seen elephants with no sign showing of the prosence even of a stump, spongy bone alone occupying the space which should form the tusk socket.

Elcphants Charging Trees.-I was told by a resident in East Africa that an clephant charged a tree behind which lee was standing and completely smashed up one tusk against it. The pieces were picked up and fitted together, forming the complete fore-part of a tusk that weighed about 2 olb.

A native who was brought to me on a litter to have wounds dressed stated that some elephants came into his lields, and he climbed up a tree and from there shot an arrow at one of them. It immediately charged the tree in which he was perched and knocked it down. A tree of about a foot in diameter was pointed out as being of similar girth to the one in question.

I luave been told by a brother officer of an instance in which an elephant he wounded in the liead fell down and then rose again and charged the nearest trce, which happened to be a very big one, and so half stunned itself.

A wounded elephant will sometimes rush, trumpeting, at a tree, and tear off a branclı or beat with its trunk the branches above its head.

1 was told of a case in which a wounded elephant, on being followed up, was found to have torn up almost every tree it had passed by.

Elephants Charging.-Elephants seem only to charge for comparatively short distances. When 
stampeding and seen at close quart'rs they have the appearance of charging, but they keep straight on, and it is their intention to get away. However, should the hunter be in their way, he will stand a good chance of being trampled upon, unless he is able to divert their course by firing at close quarters, or, if the country is open enough, he runs to a flank. A boni fide charge directed at the seent of the hunter or at the sound of his rifle or footfall, such as the charge made ly an old bull waiting in his tracks, or a cow when she turns and leaves the herd, is seldom made for a greater distance than fifty yards or so. If the animal misses its object after galloping this distance, it generally stops and listens again or tries to get a fresh scent by raising its trunk ahove its head. The reason for this is that the animal does not, as a rule, charge unless it believes its objective to be close at hand. If the animal sees its objective, or hears it again, it may then continue the pursuit.

The elephant's main object is to get away from the molestation of the hunter. If the hunter continues to follow it after it has tried to get away, and it still finds itself elosely pursued, it may charge or may wait quietly until the hunter comes near enough for a charge.

Sometimes eleplants charge the first time they scent or hear the hunter. It is probable: then that they have recently been wounded or molested. It is, indeed, seldom that any of the dangerous game animals make a charge of any great distance. Wounded buffalo usually wait for the hunter in thick bush, and, if he follows them, charge from elose quarters, or else go off again. Lions and leopards, as a rule, only turn on the hunter when they are wounded and he has come elose to them in thick country. Occasionally animals charge from longer distances, but as a rule $t$ is only at close quarters that they assume the offensive. If it was never necessary to approach nearer to clangerous game than one hundred yards the casualties in liunting them would he infinitesimal.

An clephant rising after falling experiences some difficulty in getting up, and has to assist himself by his tusks and his trunk.

In at mud bath, where an elephant has rolled, the marks of his tusk may often be seen on the "elge where he assisted himself to rise.

When an clephant falls, the hunter should have no fear of running in to finish him whilst on the ground, provided the country is not so thick and tangled as to make it liflicult to move. If the (ephant commences to rise again there is just time to reach a safe position downind and out of his ranger of sight before he has completed the process. It is, of course, understood that in such approaching the hunter keeps out of range of the elephant's trunk.

Dificulty of Secing Tusks. - In l'ganda and the usual long-grass countries in which elephants are found, it is a matter of great diffeulty to see an animal's tusks. An clephant keeps his head low, and the tusks are completely concealed by the grass. It is only, as a rule, when he tosses lis head up or reaches up for a loranch that a glimpse may be had of them. As the sportsman naturally rloes not wish to bagr a small pair, it sometimes hecomes neecssary for him to wait at close yuarters for hours, until he has macle certain. During this time, as likely as not, the wind changere or the animal moves off, and the opportunity is lost. Moreorer, it is exceedingly dillieult to judge the dimensions of the tusks of an elephant when no other animal is in sight, as the hunter has often to do when in long grass. A small elcphant with comparatively hig tusks may "asily be mistaken for a big-tuster; similarly a female, when the tusks are not visible, may casily be mistaken for a male. If the spoor has been observed, the hunter can at least tell that it is not a female, and, by the size of the sper, he may make a tolerably guod guess as to whether the tusks are worth having. 
When elephants are standing at rest they kick up the ground with their feet from time to time, to loosen the dust. They gather up this dust and also grass and place it on their heads or backs, presumably to shield themselves from the sun.

On hard ground, where the size of the spoor is often difficult to determine, such places generally yicld a good impression in the loosened soil.

Continual reachings-up for branches above their heads appear to tire elephants, and they find it more convenient to feed off the ground. Thus, even small trees will be torn up and laid on the ground, or branches will be torn off so that they may feed off the leaves at leisure when resting at midday.

Superstition concening Elephants. - The wide-spread superstition that the nerve from the inside of an cleplant's tusk must not be looked upon is also believed in Uganda and Unyoro. There they say that it can be used as medicine by which to kill people, and so it is removed out of sight and buried.

Elephants Kneeling.-It has often been stated that elephants never kneel or lic down. This is untruc. Elcphants occasionally kneel in nature in the same way as do tame clephants when receiving a load. It is, however, very rarely that wild clephants have been seen in this position.

Lungs of Elcphants. - A writer in the Field has lately pointed out that the African elepliant shares with its Indian congener a peculiarity which separates these two from all other known mammals. This difference is that the lungs, instead of being enclosed in a bag, are attached to the vertebre and to the walls of the chest.

Elephants in a Thunderstorm. - I had occasion to watch a herd during a thunderstorm, and was very surprised to notice how nervous they appeared. At cvery clap of thunder they started and ran a few steps. I do not know if this was their usual bchaviour. Thunderstorms werc numerous enough in the locality, occurring daily during a great portion of the year, so they ought to have been accustomed to them.

Haunts of Elephants. - The usual East African shooting-grounds are poor in elephants. There is a large herd or group of herds on the Aberdares and Kinangop. They are chicfly females and small tuskers, most of the large tuskers having been shot off. They occasionally trek towards the Mau, where there are other elephants, and I have seen the tracks of such a trek on the waggon road close to Naivasha.

At Kibagori there is a herd which consists chiefly of females.

Elephants occasionally visit the Kikuyu Escarpment north of the railway line in the Rift Valley. At Saragoi (Sirgoi) and north of the Guas Ngishu they are found on occasions fairly plentiful. Near the German border they occur north of Sotik and west of the Kisii country and the Kuja Valley. They also occasionally visit the Kisii Hills. Near Karungu on the Nyanza they are found in very thick country. They are also found at certain seasons in very thick bush between Mombasa and Malindi, two or three days inland from Malindi, and near Witu and the mouth of the Tana River; but in all these localities the tusks are notorious for their small size and are of poor quality. Farther up the Tana large elephants are found, especially in the neighhourhood of Korokoro, but they are alleged to have become much scarcer there of recent years. Still higher up the Tana, near the Mumoni Hills, they are said to be found. Also, at certain seasons, along the Tsavo River. On Kilimanjaro and its slopes they are found, and also appear in the game reserve in the Nyiri Marshes. East of Kenya, about Meru, they are said to be plentiful, and likewise south of Kenya, on the lower slopes, though less plentiful. They are said to be very plentiful about the Loriani Swamp at certain seasons. Near Mount Elgon large 
bulls are found, and the closed country of Karamoja is said to contain numerous clephants. Both Uganda and the Lado Enclave arevery fine elephant countries, and there the ivory is of the rery best quality and the tusks of great size. In Uganda the best distriets are Masindi, Toro, and the Semiliki. Mlso between Mbale and Karamoja, north and east of Hoima, and north of Nimule. Near Gondokoro there is a vast herd, consisting chiefly of females and young. In the closed Bukedi country numerous elephants are reported. In the Enclave the best localities are near Mahaji, Wadelai, Dufile, and inland near Mount Watt. On the west bank of the Nile chormous herds are often met with, consisting of several hundreds of animals.

\section{FOREST-HOG.}

\section{Native Names.}

$\begin{array}{lll}\text { Kikuyu .... Numera. } & \text { Ogiek (Ravine). Tomda (Pl. Tumik). } \\ \text { Ogriegr . . . Tomda (Pl. Tumik). } & \end{array}$

This animal occurs in the highland forests and also in some bush-countries. It scems to prefer very thick country, and its paths and lying-up places can be seen where there is an undergrowth to the forest. For lying up it chooses a thick patch of bush, and in this makes a form in which it is, more or less, screened from view.

There are, it is said, three different species of forest-hog at jresent known in Africa, one indigenous to the Cameroons, onc to the Ituri Forest, and one, the meinertzhageni, to East Africa. I believe these two latter are both to be found in Ugancla, the last near Elgon, and the Ituri or some other forest-hog to the west about Ruwenzori.

In British liast Africa the forest-log is found in the following localities:-The forest of Nandi, near Loldiani and the Mau (plentifuJ), the Kikuyu Escarpment, the Aberdares (scarce), Nycri Hill and in the bush near Nyeri, in the bush near Embu.

\section{GAZELLE, GRANT'S.}

Native Names.

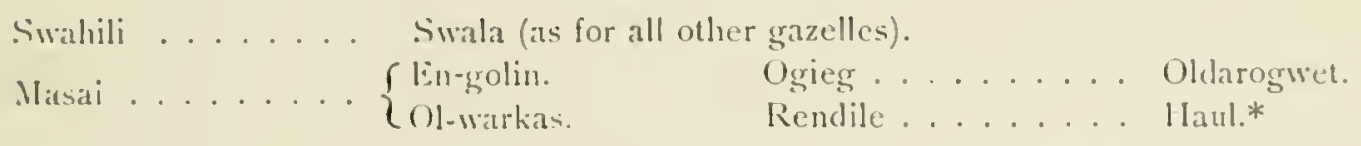

This animal's head is one of the best trophies of the plains. The length of horns in proportion to the size of the head is exceptional. These gazelle are practically never found on any but level ground or anjwhere but in the open plains. They nerer go into busls, and seem even to shun its proximity especially in the evening, probably from fear of leopards.

There are two well-defuned varieties found in British East Africa-(i.) Ruberts' Grant's gazelle, lound both in the Keelong Valley and on the German border; (ii.) the Northern form, found about the Guas Nigiro.

"lhe first of these two kinds has very widely spreading horns, whilst the second kind has the dips mearer together and the horns less curved, being more like the l'eters's grazelle in shape.

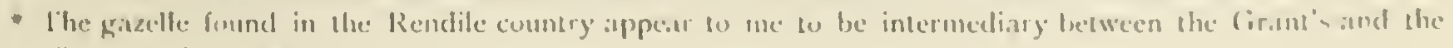
Somali (Siemmerring's gazclle). 


\section{GAZELLE, PETERS'S.}

Said to be found in parts of the Taru Desert, on the lower Sabaki, and in a part of Jubaland.

\section{GAZELLE, ROTHSCHILD'S.}

This little gazelle is reported to live near Gondokoro, on the Sudan border.

\section{GAZELLE, SCEMMERRING'S. \\ Native Names. \\ Somali ............... Aul.}

This animal occurs in part of the north-east of the Borana country.

See note under "Grant's Gazelle" of a type called by the Rendile "Haul."

\section{GAZELLE, THOMSON'S.}

\section{Native Names.}
Swahili .......... Swala
(same name for all gazelle).
Kavirondo...... Barai.
Mlasai ....... Ol-oilii.

Kikuyu .......... Endaratali.

Markings.-Black stripe on each side extending from centre of shoulder to the beginning of the launch. This stripe is about two inches broad at the shoulder and increases to about four inches at the hip. Above this stripe the body is fawn-coloured, whilst bclow the belly is white. The neck, throat, and chest are white and the tail is black. The rump is white, with a faintly darker linc at the top. The face is white with a brown blaze and black snip, and a dark line from eyes to mouth. The animal has also tear glands and glands in the groin.

This little buck is very common on most plains, especially on the Athi, the Guas Ngiro, and the Rift Valley. It is seen sometimes in pairs and sometimes in herds of twenty or thirty, with one adult buck. It is sometimes extrcmely tame.

\section{GAZELLE, WALLER'S.}

Native Name.

Rendile........... Tange.

This, like most of the gazelles, is essentially a waterless-country animal. It feeds on mimosa and other kinds of thorn, which its long neck and legs especially adapt it to reach.

I believe it was Teleki who first named this animal the giraffe gazelle. It is found on the Serengeti Plains, in parts of Jubaland, and the lower Tana, and also in the Rendile and Samburr cuuntries and in the Borana. 


\section{GIRAFFE.}

Native Names.

\begin{tabular}{|c|c|}
\hline $\begin{array}{l}\text { wahili } \\
\text { (occ: }\end{array}$ & onally Tigwa is heard). \\
\hline & \\
\hline
\end{tabular}

Kitaita ..... Ndiga.

Masai .... Ol-o-ado-kiragata.

Luganda..... Entuga.

This animal is essentially a dry thorn-bush-country dweller. The maximum height of an adult bull is, perhaps, 18 feet. When alarmed it moves off at what appears to be a slow, stately: gallop, lut which, in reality, is a rapid pace. It possesses exceptionally good cyesight, and is a difficult animal to stalk when shy. In many East African haunts, however, it is so seldom shot at that it is fairly tame. Giraffe are found in the following localities:- thi River, right bank and east of OI Doingo Sapuk; west of Ithanga Hills; right bank of Tana, toward Mumoni, (common); the waterless tracts between the railway and the middle Tana; edge of Taru Desert; in the reserve near Makindu; in the reserve on German border; Lemek Plains; near Rudolf, both sides.

The reticulated giraffe is found in the Borana country and in Northern Jubaland; Beskaya Plains, Jubaland; Niddle Tana; north and north-West of Elgon; east of Nimule; near Gondotioro, and near Rejaf, on the Nile.

\section{GNU, WHITE-BEARDED BRINDLED.}

\section{Native Names.}

Swahili ............ Nyumbu

(this word also means a mule).
Kavirondo ......... Eriwo (?).

Masai........... O-engat.

The East African variety of the brindled gnu is called the white-bearded brindled gnu. Firon all accounts, it used to occur in great numbers in this country, especially on the Athi l'lains. It is now much more scarce, and, moreover, seems to have fully appreciated the walue of the game reserve as a sanctuary. This animal, of late years, more than any other animal perhaps, has left the north-eastern side of the railway line for the south-western. At any rate. herels are often seen in the reserve, whereas they are seldom seen out of it.

The: colouring and markings of a bull are as follows :-

Mouth, nostrils, and face jet black (the Nyasaland variety has a white blaze on the face). Grey beard and long grey hairs on throat. Black and grey manc. Tail with very long black hairs. Main colour of body, dark grey with streaks of brownish hair.

The animals inhabit open plains and are never seen in bush-country. They graze in compact herds, with solitary sentinels several hundred yards from the herd on exposed sides. (Hn being alarned these sentincts gallop hate to the herd. Often when a herd is grazing in a hollow onc or more of these sentinels may be seen standing on the top of ridges and out of sight of the herd. At such times they might casily be mistaken for solitary bulls. If, however, they are put to flight and followed, they will be found to have joined a herd.

The horns of young gnus grow verticall! upwarls at the commencement, and it is not until 
they are several years of age that they commence to grow out sideways and finally assume a horizontal dircction.

The animals are very playful and frisky, and may often be seen indulging in the most absurd antics and contortions. In the distance one of these, with his heavy mane, looks rery much like a lion. The scent of the animal exercises a most disturbing influence upon horses. Gnu-tail makes a most excellent soup, and the tongue also is rery good.

I have seen gnu in the following places:- Three-mile Trec, Nairobi; Juja Farm, Stony Athi Pools (Reserve), Athi River, west of Ithanga Hills, near Simba Station, and various other parts of the Athi and Kapiti Plains.

\section{HARTEBEEST, COKE'S.}

Natiz'e Names.

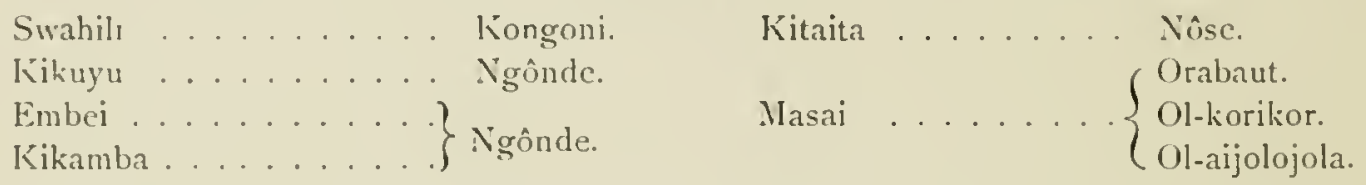

The Coke's and Jackson's hartebeests are by far the most common of game animals in British East Africa. Of the two, perhaps the Coke's is the more numerous, but if Uganda is included then perhaps the Jackson's would be the more numcrous.

Hartebeest in East Africa are csscntially plain-dwelling animals, and practically are ncver seen in bush or in shade; they seem even to mistrust the proximity of bush. They are sometimes seen in large herds of upwards of a hundred, especially just before dark, when they pack together cither for warmth or for safety. The usual number in a herd is about twenty-five. A single hartebeest is often seen accompanying herds of other animals. I have noticed, for instance, one hartebeest grazing with a large herd of zebra, and seen the same herd later in a different placc still with the single hartebeest. These animals on being alarmed make a kind of spitting sound something like the noise made when a Westinghouse brake is uncoupled between two carriages, only the noise is shriller. The sound can be heard distinctly for long distances, especially during the night. The animals often move up to the military lines at Nairobi at night, and graze on the parade ground. This is probably for safety from lions.

Next to the zebra it is the animal most commonly killed by lions.

The colour of the pupil of the eye is dark blue, and is about the size of a large marble. The iris is a bright opalescent yellow: Outside this is the white, which can only be seen by drawing back the lids, or when the animal turns its eyes round before death takes place. The only sections of the white of the eye which show naturally are at the corners of the eyes, and there they are blackish brown in hue.

A wounded kongoni almost always lingers behind for a little while, and thus gives a chance for another shot. To make certain of such an animal another shot should be fired at once, for if it is followed and is not vitally hit, it will, as a rule, join the herd again. When it las mingled with the others it will be difficult or impossible to distinguish again. In this respect it is very unlike a wounded bush animal, which will leave the herd and go off to lie up by itself. Hartebeest have very long sight, and are quick to pick up moving objects at long distances. They are slow to see anything immovable or in shade. They do not seem to have a very keenly. Jeveloped sense of smell, as they rely almost entirely on eyesight to pick up an enemy. Their 
intelligence appears to be of the slightest, and they fall an easy prey to lions. They occur practically on every open plain east of the Rift Valley, excepting some of the dry, waterless plains to the north; they also occur south of the Rift Valley, from Naivasha to the German borler. They meet with the Jackson's hartebeest north of Solai and Olbolossat, and also near the German border at the back of the Kisii country.

\section{HARTEBEEST, JACKSON'S.}

\section{Natize Names.}

(The natives do not appear to distinguish between this and Coke's hartebeest.)
Ogick (Ravine) ..... Rokoyuct.
Masai ......... Ol-korikor.
Vandi Kimigrosict.

This animal is slightly darker than the Cohe's hartebeest, and is casily distinguished from the latter by the horns which grow verticilly upwards from the head instead of outwards The horn pedicles are very high, which make the face look even longer than with most hartebeests.

In the Rift Valley all three kinds of hartebeests are met with, viz., Coke's south of Naivasha, Jackson's morth of Solai, and Neumann's between these two places. The Jackson's and Coke's are divided from each other by the Neumann's where this latter animal exists, but north and south of the area occupied by Neumann's they meet without any intermediate type separating them. The Jackson's hartebest is the commonest game animal in East Africa north and west of the Rift Valley. It also occurs plentifully in Uganda and the Lado Enclave. It inlabits equally well some of the hottest and some of the coldest parts of these countrics, occurring on the Nile near Gondokoro, and on the Mau summit and Guas Ngishu plateau, over Sooo fect in altitude.

\section{HARTEBEEST, NEUMANN'S.}

\section{Natia'e Names.}

(The natives do not appear to distinguish between this animal and the kongoni.)

This animal is very local, occurring only in a small area in the Rift Valley, viz., bounded on north by Lake Solai, west by Lake Nakuru, south by Jake Naivasha, and east by the Aberdares and Kipipiri. In this locality it divides the areas inhabited by Jackson's and Coke's hartebeests. It is evidently an intermediate type between these two, and is, no doubt, the result of former hybrid breeding inter se. The horns are exactly mid-way lotween the high, vertical horns of the Jackson's and the more horizontal horns of the Cole?'s. The coat is of a colour intermediate between these two species, being not quite so dark as the Jachison's nor so light as the Cuke's. The horns are often very massive for hartebeests, and seen to be on an average more bulky than either of the other two. Cases have often been observed of one of these animals rumning in a herel of Jackson's or Coke's, or onc of the latter rmuing in a leerd of Neumann's. Intermediate types between Neumann's and one of the other hartebeests are reported from time to time, which tends to prove that these animals occasionally loreed with either of the other two types. The area occupied by these animals is all taken up as private or syndicate land, and so to obtain specincus leave would have to he obtained from some landholder in the Rift Valley. They occur in considerable numbers north of Lake lilementaita and east of Lake Nakuru.

Sionth of Olbolossat and on the Kinangop platcau they also occur, but are searee. 


\section{HIPPO.}

\section{Native Names.}

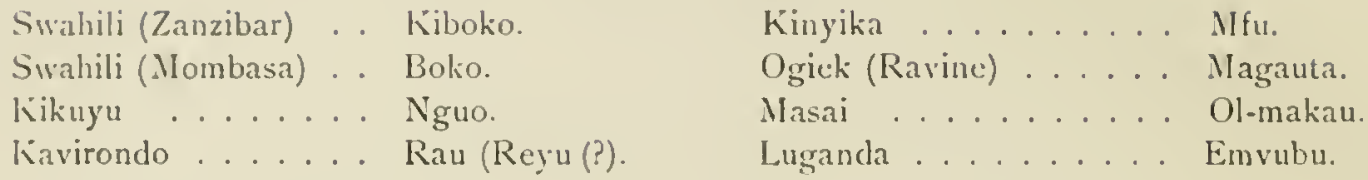

The hippo is usually a shy, and, at the same time, a very inquisitive animal.

Tusks.-I have seen no good tusks from East Africa other than from the Lake or Tana River. In its other East African haunts it runs small and is very careful to kecp out of danger, no doubt because it has been much peppered. In Uganda and on the Nile good specimens are occasionally obtained.

Abnormal Tusks. -The longest tusks are always abnormal tusks, viz., tusks which, by some mischance, do not play upon the tusks opposite, and so have no wear and tear to check their growths. I measured an abnormal tusk of this sort which it was said came from Uganda. It measured $54^{3}$ inches on the outside curve, and formed a complete circle and a half. On the Nile these animals are very dangerous to canoes, frequent cases occurring of them upsetting these craft, and occasionally mauling the occupants. For this reason they are not protected in the locality. Very probably the reason that they are so dangerous about there is that they are continually being hunted and harassed by the natives the whole length of the Bahr al Gebel. Even a genial animal like the hippo must get bored in time with continually having arrow-heads, harpoons, spears, and native bullets launched at him.

Hippo Fat.-Hippo fat is excellent for cooking purposes, and as dubbing for boots or leather, likewise as a substitute for rifle-oil. When procured for cooking, care should be taken that the fat is cut out and boiled down as soon as possible after the body of the hippo has come to the surface. Shooting hippo is usually a most uninteresting and unsatisfactory pastime. It is generally necessary to go in a canoe to get near them, as they are usually found in places where are miles of marsh and sudd between the shore and water. The heads bobbing up and down make difficult marks, whilst the unsteadiness of the canoe often precludes accurate shooting. As this is the case there is not much interest in pursuing them once you have obtained a specimen or two. They are interesting and, as a rulc, inoffensive animals if left alone and not worried.

The tongue, salted and cooked, makes an excellent dish.

For boots, in wet weather, the fat should be mixed and boiled down with beeswax.

Hippos have a peculiar way of learing their droppings scattered about on bushes. The Swahilis explain this hy saying that it is the result of a quarrel with the bird tipi-tipi, about which they have a story. I have often wondered how the dung is so scattered and why so often found at such a height above the ground. Mr. Jackson tells me that the reason is that the animal during process vibrates its tail rapidly, which suffices to send the droppings flying in different directions.

The hippo is found almost everywhere in East Africa and Uganda where there is a river of any size or a swamp. I have seen these animals or their spoor in the following places:-

The Tana River, near its mouth, higher up, and where it is called the Kililuma, and also where it is called the Sagana.

Thika, Ziba, and Namindi Rivers. 
Athi River (Nto wa maboko=the Hippo River). In this a few are found even in the small swamps near its source, but the animals are very small.

In the Olholossat Swamp. Lakes Naivasha and Nakuru. Lake Rudolf.
Lake Victoria.

Vietoria Nile and Bahr al Gebel-very numerous. Kafu River (Uganda).

\section{HUNTING-DOG.}

Native Names.

Swahili ...... Mbwa wa Mwitu. Kavirondo ............... Sudthi.
Kiboudei. .... Mbwizi.

Packs of hunting-dogs soon appear to clear the game out of any locality, and so they do not ever remain long in any given spot. They prefer the bush to the plains; possibly the scent is better there and the game animals not so swift. Game seem to fear them very much more than they clo either lions or leopards. Recently a pack appeared in the Lamu Archipelago and visited many of the islands, clearing out all the game. I believe both the dogs and game must have swum short distances to reach or leave some of the islands, although the water is shallow between most of the islands at low tide.

Most people who have met with these animals have been convinced that they needed but little provocation to attack a man, but I have never actually heard of a case where they have flone any damage to a luman being. I have always been singularly unlucky in finding these animals, and so can speak of them with but little personal knowledge.

\section{HYÆNA, SPOTTED.}

\section{Native Names.}

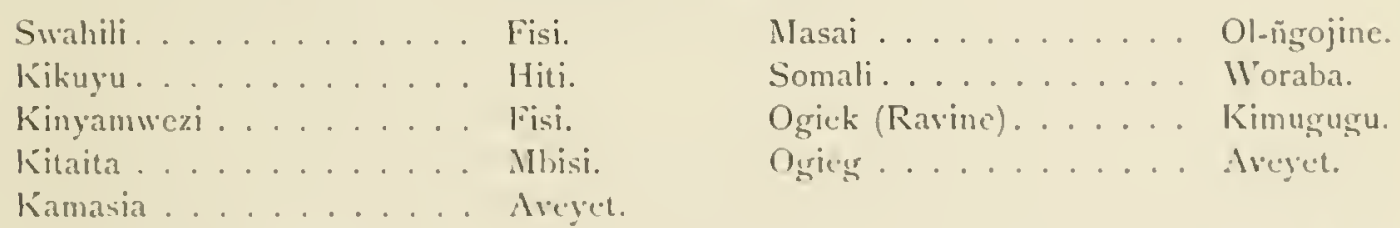

This animal is extraordinarily numerous on the plains. In some of the precupitous, rocky, bush-clad nullals which run down into the plains, colonies of them make their hones, and numbers of them may be seen trekking home about sunrise. "They lice very close during the daytime, but if anyone passes close to the bush or chump in which they are lying they will generally dash away. They do not seem to frequent the same lying-up places as lions. Some of the caves on the Athi Plains seem to be used exclusively by lions, and others by hyenas. A hyena on the move is easy to recognise in the distance by his shambling gait and the way his himelyuarters fall away, as if he was wounded and dragging his hindeuarters. When he is sitting up it is not so easy to tell his species until lue looks towards you, when his chegrlike ears will show that he is not a leoparel or cheetah, besiles which, with the latter, the long waving tail sheuld be looked for.

Both males and females have well-developed manes, and this, togrether with other peroliarities of their structure, makes it often elificult to tell 20 which sex an animal belongs. In fact, with natives it is a common superstition that they are sexless. The animals appear to vary rery much in colorition. 
Many of the tribes of East Africa leave their dead out to be devoured by hyanas. I have not noticed, however, that this fact makes them any more addicted to eating human flesh, or any bolder in attacking human beings than in other countries. Several instances lave occurred in British East Africa, as elsewhere, of their having attacked slecping men or horses at niglit. In Somaliland they used to prefer the dead horses to the men; and in British East Africa they seem to rather avoid human flesh; at any rate, they often do not touch a body the first night.

The hyena, not only in this country, but in most parts of Africa, is regarded with strange veneration and superstition by the natives, and is practically never killed or in any way molested by them.

In thickly populated Kikuyuland they take up their abocles on the sacred hills or groves, small patches of thick bush or thickets preserved for religious sacrifices and ceremonials from the cutting and clearing which takes place everywhere else. In these parts practically their only food must be the bodies of the dead and a few bones of goats and sheep, for the country is so thickly populated that there is no game.

I have never been able to make out why they howl, especially when prowling round liuman habitations. When heard at very close quarters their howl seems to develop into a long moan or wail. They are most impudent on a dark night, and will take skins or meat out of one's tent or house, and are excessively cunning at slinking about in the shadows without being seen. When a lyana suddenly howls near camp natives always laugh, the reason for which I cannot quite follow. Similarly, when a lion roars at night, natives often begin grunting and talking in their sleep like dogs having bad dreams.

The animal is very common indeed on the plains, but is comparatively rare in the bush, in Uganda, and the Enclave. It is very fond of walking on pathways at night, and so its presenco may easily be detected by its spoor, besides by its howling.

\section{HYÆNA, STRIPED.}

Native Name.

Somali . . . . . . . . . Didar.

This animal is unknown in the usual East African hunting-grounds. He occurs on the German border and also northwards on the Borana border, and is smaller than his spotted congener. He is, however, generally given credit for greater ferocity than the latter. Instances of small parties having attacked zarebas and killed camels are fairly well known in the north.

\section{IIMPALA.}

Native Names.

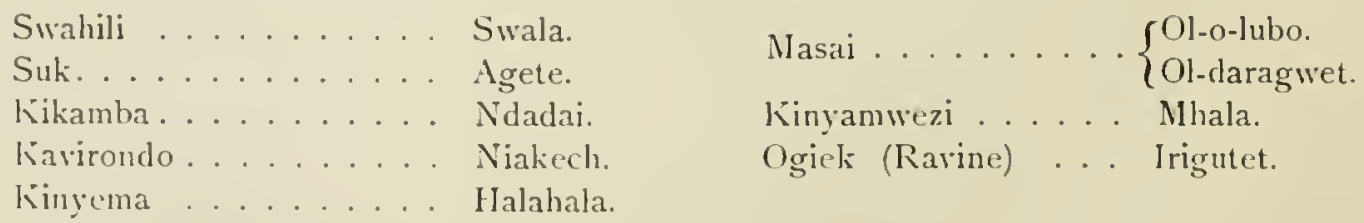

Athough often seen on the plains the animal is more of a bush animal than a plain-dwelling animal. It is peculiar amongst buck in that it possesses glands behind the pasterns; above these 
Muhoroni. On the plains between this place and Kisumu, however, the animal is common, esprecially about kibos. It is also found at the mouth of the Kibigori or Baganoyo stream on the shores of Iake Victoria. In Uganda it is, perhaps, the commonest of buck, while it is also common on the banks of the Nile in the Lado Enclave.

\section{KOB, WHITE-EARED.}

Mabitat, sec "Mrs. Gray's Kob" above.

\section{KUDU, GREATER.}

\section{Native Names.}

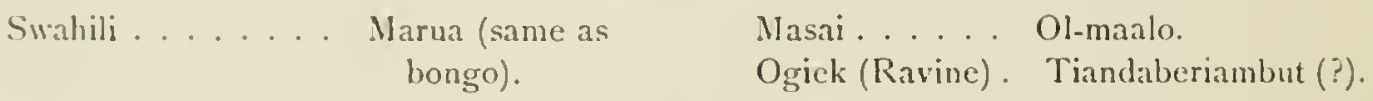

This animal is rare or non-existent in the greater part of the administrated portions of the Protectorate. Near Baringo it occurs, but is there protected. It is occasionally met with in the Rift Valley south of Baringo, where the country is suited to it. I have seen jt at Legisinan. It is reported to be fairly common north of Elgon, and it is also found near Marsabit and near the shores of Rudolf, and also, probably, in many other parts of the Borana country. The animal haunts, for preference, the sides of story and steep bush-clad hills.

\section{KUDU, LESSER.}

\section{Native Names.}

Swahili...... Marua mdogo. Kinyika ........ Sakwa.

This animal is fairly common in many parts of the Protectorate. Like the greater kudu it prefers dry, stony, and broken bush-country, and both species are often found where water is scarce or mon-existent. The lesser kudu is found in the Taru Desert, and plentifully in the waterless tract between the railway line and the Tana. It also occurs in the Shimba Hills, some of the islands of the Lamu Archipelago, and in some of the coast bush-belt. It is fairly plentiful in parts of the Borana country and in parts of the Turkana country. There is also a small herd near Nyeri.

\section{LEMURS.}

Lemurs occur in Zanzibar and along the coast. The common lemur is the galago, called by the natives komba, while any other kind is often referred to as komba wa bukini=the Madagascar lemur.

Lemurs are nocturnal animals, and can be heard making their croaking noises at night. They generally lie up amid thick date, cocoa, or other palms, and cause great consternation to the matives, for they are said to help themselves out of the cocoanut bowls placed in the palm; to catch the toddy as it oozes out. 


\section{LEOPARD.}

\section{Native Names.}

Swahili . . . . . . . . C Chui.
Kikuyu . . . . . . . Ngāri.
Ogicg . . . . . . . . Nilildo.
Kikamba. . . . . . Ngó.

Kavirondo...... Kuăch.

Food.-The chicf foods of the leopard are baboon, monkey, suni, dik dik, guinea-fowl, and rats and mice of all sorts. The animal is essentially a forest and bush aninal, being practically. never seen in the open. Although they exist almost in all localities where there is bush or cover, they are practically never secn. The reason for this is that they are so wonderfully cunning and wiry, and morcover are very clever in making use of any cover that exists and in moving from cover to cover. They lie very close and never give themselves away by moving. You may pass within a few yards and a leopard will give no sign of its presence.

A wounded leopard is, perhaps, more dangerous to follow up than a wounded lion, for it will lie even closer than the latter, and is more difficult to detect and far more agile and active. Although so seldom seen, leopards are really very plentiful, as may be noticed by their spoors. for almost every path in bush-country is scattered with their droppings. "They" are nocturnal in their habits, and at night use pathways extensively. They occasionally take to man-killing, and may then continue in one locality for years, taking toll of lyuman lives and defying all efforts made to kill or capture them. A famous leopard used for many years to haunt the Sheikh Pass in Northern Somaliland, and would drop from above on solitary passers-by.

As these animals exist in nearly every bush and forest in British East Africa and Uganda, there is no need to enumerate the localities in which they occur. They are particularly plentiful in the latter country, and are occasionally found in Zanzibar.

Melanism.- Two cases of melanism, I believe, have been obtained in this country.

In Uganda it is alleged that two varieties occur in addition to the typical leopard, viz., the leopard of German East Africa, called suabilica, and the leopard of Ruwenzori, called ruwenzorii.

\section{LION.}

\section{Native Names.}

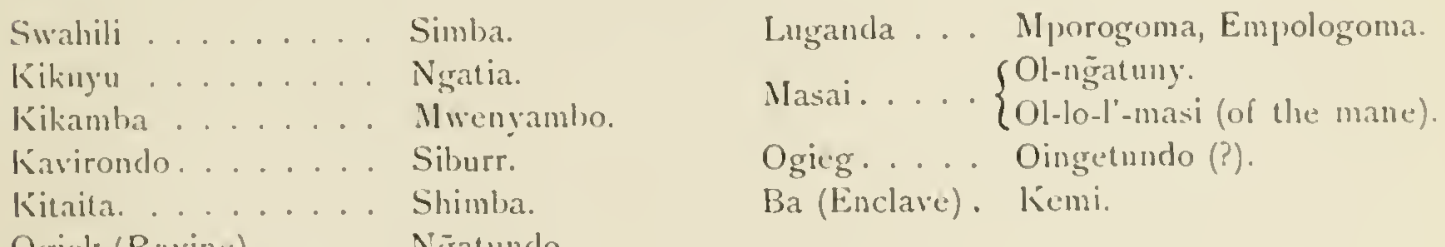

Ogrick (Ravine)..... Nğatundo.

Types. - The only type differing from the ordinary is the variety known as the maneless or Matsat liun. The question of varieties imongst animals is a very diffeult one to decide. A "variecy" is supposed to be a type of animal differing from the typical form, but not differing sufficiently to form a separate species. The formation of a variety is supposed to be a step in

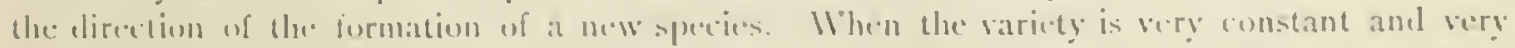
well elelined it becomes no longer a varsety, hut a new species. Sume peculiarity or irregularity 
in atl anmal is often elescribed as a varicty, whereas it is but an individual variation in that one animal.

Some authorities describe black-maned, tawny-mancd, and red-maned lions as three different varieties, whilst others gyo even further, and divide up almost every shade of mane into a separate varicty.

It secms as if there ought to be another word in use to denote a bond fide varicty and a variation which in but of an individual or of an occasionally recurring variation. An animal such ar the northern form of Grant's gazelle might be considered as a bona fide variety. If one finds in at certain locality herds of animals all differing in some slight degree from the type of the species they are distinctly a variety. It seems to me that a boni fide variety must be local to fulfil the requirements of its being a stepping-stone in the formation of a new species. Judged by" this standard, the Masai lions might possibly be considered a variety, but black or other coloured maned lions are types which may occur wherever lions are found, and, moreover, different types may occur in the sane troop or the sane litter. Such differences in colour are possibly caused by the same influences that cause melanism, either partial or complete, and are in no way confined to local races.

Apart from the colours of their manes, lions may be roughly divided in to two types, differing to a certain extent in their habits and habitat. These are the plain-dwelling lions and the bush-dwelling lions. The former live almost entirely on zebra and hartebeest, whilst the latter appear to rely for existence chiclly on bush-pig, though they occasionally kill buffalo and also small buck that live in herds, such as the impala and kob.

The Plain-daclling Lion.-This animal always has plenty of game upon which to feed, and the game are so foolish and easily caught that it never has much difficulty in catching them; for this reason the plain-dwelling lion has many characteristics which it does not share with the bushdwelling type.

Foremost of these characteristics is that, not having to work so hard for its living, it is less cunning and of lazier habits than its bush congener. It seldom has to go far for water, and, having drunk, it seldom goes far to lie up for the day, and often takes a position in a reed-patch or grass close at hand. It is seldom tempted to kill stock, as that would be more trouble than the simple killing on the plains, and besides there is always plenty of its favourite food about, namely; zebra. As there is always plenty of food, these lions often go about in large troops. I have never seem more than nime full-grown lions together, but much greater numbers have been reported. Some people, however, count cubs in the total, so if two lionesses happened to be together with fitters, this would at once makc a total of fourteen or so. In consequence of going about in larger numbers, and also because of the number of hyxnas and vultures frequenting the plains, and the ease with which the latter can detect a kill, there is seldom anything left of a kill twelve hours or so after it has been procured. Thus it is unusual and almost unknown for these lions to return to a kill the following night. I have seen two lions picking the bones of a kill one or two nights old, but this is an exceptional instance, and probably they had remained lying ncar the kill during the previous day.

The game of the plains seem almost fearless of lions during the day, and let them pass through their miclst or at quite elose quarters. I think the funniest sight I have ever seen were two belated lions slinking home looking very" self-conscious and ashamed of themselves, whilst a small herd of kongoni followed them, trotting after them a little way, and then standing and staring at them till they passed on, and then trotting after them again. 
I remember once putting up a lion and lioness in a reedy river-bed. They broke away on the opposite side, and made up a bare stony rise, so that I could see them perfectly well. One was very full of meat, and almost dragging its stomach along the ground. Half-way up the rise was a Thomson's gazelle, which had seen me and was staring in my direction over the heads of the lions.

1 was watching the Thomson's to see when it would notice the lions and how soon it would move out of their way, as they were making directly for it. They drew nearer and nearer, and still the gazelle stared at me and took no notice of them. At last the lions were only a few yards from it, and still it never took its eyes off me, but skipped a few yards to a flank and still stared. The lions must have passed over the actual spot on which it had been standing, yet it never turned to look at them, either as they passed or after they had passed behind it.

I could quote many instances of lions having passed close to game, though not quite so near as in this particular instance, and of the game having remained absolutely indifferent to them.

I have never heard of a case of a man-eating lion on the plains, and the few accounts one hears of lions attempting to take stock near the plains, I fancy, are generally, in point of fact, bushlions which have travelled up from their usual habitats. As all the upland natives are quite immune from attacks by lions, they do not hold the animal in the same superstitious dread as do such peoples as the natives of Nyasaland and North-eastern Rhodesia. It is to this that I attribute the fact that the natives of the former comtries are always ready to bring in khabar of lions, if encouraged to do so, whereas the natives of the latter countries, in which places numbers of them are annually devoured by man-eaters, cannot be induced to betray the animals' whereabouts.

The plain-dwelling lions, as already remarked, prefer zebra to any other animals, this animal always being extraordinarily fat and in good condition. Failing zebra they will kill a hartebeest or waterbuck, and are also fond of an occasional warthog. If there are buffalo in the bush near their particular plain they may sometimes hust them, but this is rather outside their province. They will eat impala, but do not go out of their way to kill the animal.

The amount they eat varies. I once killed two impala as bait for lions. They started on the first soon after sunset, and I found them just finishing the second before sunrise, the party consisting of four, two lions and two lionesses. They had killed and finished a zebra the day before, so they could not have been very empty.

One of the two impala I killed within too yards of eamp just about sunset. Close by the spot there was a great mass of rocks, covered with vegetation, and I saw a lion poking his head out from the top of this watching me, but he withdrew quickly directly he saw that I was lookingr at him. So soon as night fell, he came down and went straight to the impala, uttering loud roars, no doubt to call his friends. Of this animal they only left the horns and the hoofs. "The other impala ! killed, in a little grassy dip between two walls of rock, twenty or thirty feet high. My intention was to climb up on one of these walls, the one nearest camp, and erawl along the top' until I arrived at a place overlooking the kill, and about forty yarels from it, from which it would have becn easy to take a quiet shot at anything feeding on the kill. Moreover, from this commanding position I should have been alle 10 get in a second and a third effective shot at close range, for to escape the lion would have hat to bolt up or down the little grassy glade loedween the walls of rock.

llowever, they were not quite so simple as I gave them credit for heing, for as I reached the rocky wall in the morning, and was about to pass on to the place at which 1 intended to climb up, I heard a low rasping purr from the top. Climbing ciutiously up, I leard a scrumching 
of lone just ahove me, and on looking over the top saw that one lion was just linishing his meal and two lionesces were descending, whilst I saw shorly afterwards another lion going off below, he having been the first to leave. They had taken the impala bodily up from where it had dropped, to the top of the rock to feed on it there.

The plains lions seem very fond of water, and often lice up in the centre of some reed-bed which is mostly under water, and to approach which they must pass through swamp. I believe that they are in the habit of erossing the Tana River, at a place where it is at least a hundred and lifty yards broad. Of this 1 am not certain, but they certainly cross its tributaries, such rivers as the "Thika and Ziba, the last a swift-flowing river lifty yards or more in widtl.

It is cxtroodinary how lions will often return to some farourite hant, even if they are constanty disturbed and shot at there. Such a place is the famous stony Athi reed-hed, which must have heen driven for lions dozens of times, and yet they still return there. Where lions are constantly disturbed and shot at they seldom ruar. The reed-bed just referred to is an instance in point, for the lions which lie up there are perfectly silent. A lion, lying in a big reed-bed such as this one, if disturbed will take refuge in another part of the bed, or if induced to break out will try to break back again into another part. When disturbed lying in a small clump or patch of cover they will generally' bolt out on the opposite side and malic off. "They" will then, as a rule, cross several rises and dips till they are out of sight, when they will take cover in it thick bed or nullah.

When wounded a lion almost invariably retıres to some thick cover, and if followed up, seldom, or practically never, tries to bolt, but awaits its pursuer concealed in cover, confident that the advantage lies all on its side.

Lions appear to be almost fearless of man at night, and should occasion offer pass quite close to human habitations. As a rule their pursuit of game takes them away from civilisation, but occasionally animals will come in close to houses at night for protection, or when pursued will bolt through even a town such as Nairobi. The lion then has no compunction in following them. $\triangle$ party of lions are recorded to have killed and eaten a zebra one Christmas within a few yards of the railway offices at Nairobi, and not many months ago a lion killed a zebra 150 yards from the military lines and demolished it there. Cases used to occur fairly frequently of lions pursuing zebra into the town of Nairobi, but now one hears less of them. In some places they find the footpath alongside the railway line convenient for either setting out upon, or returning from, their niglut's rambles. Cases have occurred when they have been run down by an engine, for they do not trouble to move out of the way of a train, nor do they trouble to walk round a station, preferring to march straight through on the line. In a train 1 was once in the driver said that he had ran against some animal during the night, and on inspecting the cow-catcher 1 found caught in under a nut some unmistakable lion's hairs which I have kept as a memento. Even a shot fired at night seems to cause them no anxiety; on the contrary, if they are walking along they will stop to reconnoitre, but will not bolt. During the construction of the railway many coolies and workmen fell victims to lions, especially whilst passing through the thick bush. A lust of man-killing, which has not since becn equalled or in any way approximated, seemed to take possession of the lions in the neighbourhood of the railway. Since those days authenticated cases of man-killing have been most rare and isolated. Lions are also said to have killed workmen on the line when working through the plain, though not to such an extent as in the bush. I have found human skulls in recd-beds near the line, which I have becin told belonged to workmen killed by lions. Whether these were lions of the 
plains or bush-lions which had followed up the camp at the rail head as the work was pushed forward, I do not know.

Anyhow, the lion appears since to have quite reformed in this locality, although occasionally one hears of a man-eater in the bush-country between Makindu and Voi.

In the open plains lions are casily overtaken on lorseback; in fact, when pursued in this way they seldom make a serious attempt to escape, but sit down and await the horseman.

Bush-diwelling Lions. - These animals have to work much harder for their food than do the lions of the plains. Game is scareer and warier in the bush, and so they have often to cover enormous distances in pursuit of it. They do not hunt together in large parties, but generally: singly or in pairs. They have no lairs or favourite haunts, for they must always be changing localities to find fresh game, or game that has not been alarmed. When they kill they make the most of the meat, and often lie near the lill during the following day. Hyanas are scarcer in the bush, and rultures do not often see the kill amongst the trees, and so the lions are often able to return the following night and every subsequent night to their kills until finished. II'hen game is difficult to obtain, often two or three will organise a drive of small game, two lying in wait whilst, perhaps, one drives.

The bush-lion often passes many days without being able to kill. It is on such occasions that he is constrained to look for man or for stock. Whereas the lion of the plains is almost always fat and full when killed, an inspection of a bush-lion often shows that he is in poor comlition and has not fed for many days. This is the more often remarked on as it is often after sucl periods of hunger that he falls a vietim to the rifle whilst trying to break into a kraal, or, biving killed an animal and having been frightened, he subsequently tries to return to the kill.

On killing, a lion generally first sucks the blood of its victim. After this a bush-lion will sometimes leave the animal and return later for the meat. Perhaps after a long fast it linds this method is more healthy than that of at once filling its stomach, or it may be that after drinking the blood it feels thirsty and treks off to water. The plain-lion is unable to leave the kill in this way, for the moment its back is turned the hyienas will make a clean sweep of the carcase, or, failing their presence, the vultures will strip the carcase the next day.

The District Commissioner at Malindi told me that a lion broke into a kraal near that place and killed something like lifty goats, drinking the blood of each, but did not touch the meat. Neither dic it return for the meat afterwards. It is seldom that a lion kills wantonly in this manner, though I have heard cases of leopards killing a number of groats after breaking into a kraal.

On the coast and in parts of Uganda the chief food of the bush-lion is bush-pig, and in the Eastern Congo it is almost entirely dependent on that animal. Where other game is plentiful in the bush the lion fares better, its farourite food being buftalo, but it is also partial to cland, and, when able, kills various kinds of buck, such as waterluck, impala, and kob.

A hungry lion may try to kill anything, but it appears unable to bring down such animals as giraffes and the kudus. Cases lave oceurred of the former being killed by a party of lions, hut, as a rule, they are immune from attack, whilst the latter are too wary and too yuick over bid comnty to fall easy victims. "The usual methor by which a lion kills a large animal is to spring from one sicle on to its neck, seixing it with one of its fore paws over the nostrils and the other over neck or shoulder, while it finishes the animal cither by wenching the head downards and backwards or by biting it on the neck behind the ears or by a combination of the two. "1"he" lion's hind legs generally remain on the ground the while. Of course, if it sees that the animal 
is about in nutdistance it and escape, it will seize it wherever it can, by the rump or tail, in an concleavour to check it.

The bush-lion, owing to its greater cumning and more roving habits, is most difficult to bag, and, as it seldom leave's thick cover, is seldom seen. It is generally only when it has killed stock or man that it is obtainable, and then only when the khabar is fresh, by following the trail if it has dragged the carcase away, or by sitting over the borly the next night, if it has been left.

Size of Lions.-The only accurate methorl of measuring a lion is to measure the animal as it lies after having been killed. All measurements of skins afterwards are practically valueless, as their size depends on the weather at the time they are drying and the amount they have been stretched in pegging-out.

There is a story told about an official in this comtry who had just killed a lion and the skin was being dried and stretched at the back of his house. During this process a visitor called and was met at the donr by the offecial, and they stoot there talking.

On being asked what the measurement was, he called out to his wife, who was at the back of the house, "My dear, what is the measurement of the lion I shot yesterday?" Unaware of the presence of the visitor, she answered, "It is 10 feet 6 inches now, but it is still stretching."

The general method of measuring a lion is to take it just as it lies and to tape from its nose to the tip of the tail, the measure passing over the head between the ears and down the spinc.

Such a measurement does not really convey an idea of the actual size of the body, for a small lion with a long tail might measure more than a larger animal with a shorter tail. However, this is the recognised method by which the sizes of lions are compared.

I an inclined to think that red-maned lions run bigger than do the darker-maned types. In any case, the largest amongst those I have measured have belonged to this type. One of them measured 9 feet 6 inches, which 1 take to be a very large measurement. Unfortunately, 1 did not record the length of this animal to the root of the tail-a measurement which would afford an indication of the size of the body. His photo, also, was a failure. The black-maned lion shown in the photograph by page 6 measured 6 feet 2 inches from the tip of the nose to the root of the tail.

Six and a half feet would be a very big animal measured in this way. Unfortunately, measurements taken in this way must necessarily be taken by different individuals, and so are not of the same value as a basis of comparison as are measurements of horns all taken in the same way and by the same man, as are found in "Records of Big Game."

Two settlers who have measured a number of lions, both killed by themselves and by sportsmen in their neighbourhood, tell me that the biggest measurement they have ever taken was 9 feet 5 inclies.

If the tape is pulled across from the head to the root of the tail, instead of being made to follow the hollow of the back, a reading of one to two inches less would be recorded. The correct method is to follow the spine.

Size of Tecth. - The size of the canines differs in a great degree. Natives have toll me that lions dwelling in caves have larger teeth than those that lie up in the open. There seems to be no reason why this should be so, but the only two cave-dwellers I have obtained had larger canines than those I obtained elsewhere.

Lion Fat.-This is much prized as a medicine among Swahilis and also Indians. It is boiled down and sold in bottles, fetching at Mombasa as much as twenty to thirty rupees a bottle. 
The genuine article is said to be recognised by the smell. It is used for ear-ache, rheumatism, and varions other maladies. It forms a good substitute for rifle-oil, should the sportsman run short of it.

The Lions' Amulet.-There is a belicf amongst the Swahilis that the lion possesses a charm or amulet (Herizi) which it carries about in its mouth. This is said to be about the size of a walnut, and to consist of hair and bone (perhajss a ball of matted hair lodged between the teeth). This the lion is supposed to bury when he goes hunting, and after dirinking he returns, scratches it up, and carries it off again to wherever he intends lying up. When he is about to die he is said to propel this out of his mouth to a great distance to avoid its being found. I have never seen this substance or 1 slould start a manufactory of it and open a shop in Mombasa, for it fetches (normous prices amongst the peoples of the coast. A small fragment wrapped up and worn round the neck makes one immune from the attacks of lions or other wild beasts, and it also has various other propertics. Whenever a lion is killed, porters are seen anxiously searching the ground all round the body, and from that spot back to the place at which the lion was lirst seen. The Masai have no faith in its properties, but allege that there is such a substance, and that it is expelled from the mouth before death.

Methods of Hunting.-A single lion will generally locate its herd of game and crawl up as near as possible, then make a sudden dash for an animal. It may watch which way they are gazing, and lie in wait on a flank so as not to give them its wind.

Generally on the plains parties of lions hunt together, and when so doing they have various devices for driving game to each other, such as roaring or stampeding a herd by giving them their wind, when others will be in readiness to waylay them as they go off. Lions may be heard in full pursuit of an animal, during which time they make a continuous grunting sound. l'resumably they have not much chance of catching the animal when it is in full flight, but they are trying to drive it to their fellows, and the grunting is to show their whereabouts. When the animal is exdrausted by its first wild stampede, the others, fresh to the pursuit, have more chance of catching it. They often apply the same tactics to stock, and will pass upwind or roar so as to stampede cattle. This is more likely to be effective when cattle are being moved from one: locality to another, and so are only enclosed in a light zareba.

During the day lions often take up al concealed position in some little patch of cover near a drinkingr-place, and when herds come to drink they spring out on them. This they often do during the daytime, and the number of skulls frequently found near these little reed-patches, or lying-up places, afford abundant evidence of the success of the scheme.

The lions of the plains will often kill in this way by day. A case occurred near Embu, when I was in that locality, of a lion springing out of cover and taking a calf whilst the catte were out grazing.

The lush-lion, before he tries to kill stock or before he attacks a hut, has, as a rule, reconnoitred the spot thoroughly first. Sometimes he will visit the place on a succession of nights locfore he finally breaks into a kraal.

When addicted to man-eating, I have often been told by natives that a lion will jump on to the roof of a hut, and then part the grass-thateling with a paw and plunge through. If he effects an entrance through the wall he will generally scrateh a hole, and then, pressing back the wattle, insert his nose and force a palssage.

The seratching and the preliminary widening of the aperture is, from all accounts, generally performed cautiously and without undue noise or blows from the paw. A setuler told me that a 
iriendly lion, after prowling round his log-cabin for a while, came to the door and began gently acrotuhing. Finding that it was solid wood he centualfy left it, although a crashing blow from the pan would almost certainly have staved it in.

I have hearl it stated, however, that a lion will never rain blows on a hut, but will always reatele and then slowly foree a passage. "This is not true, as 1 am able to testify. I was once camped alongrite a native village, and during the night I was aroused by my boys to be told that there were lions about. Going out of my tent, l was able to hear some lions paying a round of calls on a number of villages near. I could hear easily the monent of their visit to a village, from the noise made by the inhabitants, which commenced and continued long after the animals had left. A few roars followed each visit, and then silence, and presently shouts, drums beating, and various noises from a new direction would proclaim that the lions had arrived at nother village. After one of the periods of silence a double crash suddenly came from a hut near by. Ifter this the band which started (every man in his hut contributing some music hy beating sticks, drums, tins, or anything which rame handy, joined with vocal accompaniment) drowned all other sounds. After a while, however, louder than the concert, were heard the roarings of the lions as they left and went off elsewhere. As the night was absolutely black, I could see nothing of their methods, but from a careful inspection on the morrow and questioning the natives I was cnabled to gather exactly what had happened.

The double crasl I had heard was caused by two blows, onc on either side of the doorway of a hut, and one of these had staved in a portion of the wall, with the exception of some strong uprights, about 5 inches thick, which had held firm. These blows were not preceded by any scratchings. The lion, seeing that this hut was too strong for him, had proceeded to another, to reach which he had to pass two others. There he had made a large breach in the wall and passed in. From the look of the hole and the strength required to break the staves, 1 concluded that this had also been caused by a blow. The blows given to the first hut would in all probability have effected a breach if they had been delivered anywhere but upon the strong uprights on either side of the door. Having made a hole in the second hut he had forced his body through, breaking back the withies of the wall, and had passed round the centre-pole of the hut and out again, having, to his disappointment, found noone inside. This secmed rather an error of judgment on his part, as probably that hut was the only empty one in the village, the onner having left it that day. However, from the number of times 1 have heard of a woman or man being alone in a lut and falling a victim, 1 fancy that a lion generally selects an almost empty hut for preference, and that if he smells many people in a hut he is inclined to leave it.

That he did not attempt to touch one of my porters, although we were standing in a group in the open whilst he passed on a path close by, seems to show that lions will avoid a group of people, though they will attack a solitary man or two men together.

Although from the roaring 1 gathered that there were two animals, only one came into the village, passing my tent to do so, as we found by the spoor in the morning. The second must have been waiting quite close by, as they joined up again directly he left the village. This is the only occasion on which I have actually heard a lion breaking into a hut, although I have several times arrived on the scene the next day, and so seen the spot and obtained first-hand information from natives present.

Spur on Lion's Tail.-1 have never heard an explanation concerning this extraordinary appendage, or a suggestion as to what function it could serve or has served in bygone times.

I take it that it is now in a rudimentary state, as it only occasionally occurs. When there 
is no spur there is a little, harel lump of stin, about the size of the head of a match. Leopards also occasionally possess this appendage.

Spots on Lions. - Nearly all the African beasts of prey are spotted, viz., heopard, chectah, and serval, and other carnivorous animals also are spotted or blotched, such as the spotted hyaena and the hunting-eg. The lion also possesses this characteristic, the culys being spotted, and even adult animals sometimes show signs of spots, especially on the belly. I killed a young but full-yrown lioness in which these spots were very marked on the under side, especially when the skin was lreld in certain lights. It would thus seem as if all members of the cat tribe, it least, have descended from a spotted ancestor, and that the lion was not always of his present colour.

The Lion's Roar.-In inspection of the wonderful organ in the lion's throat is sufficient to convince me that this reverberating apparatus does not take its origin by elunce. It is absurd to contend, ats many people do, that it only serves the useless purpose of making a noise after the anmal has fed, and that it is not used during hunting. Such a statement is undoubtedly a miscepresentation. Morcover, it is unlikely that an animal should possess an organ which, if used, serves only to frighten the game and leave him supperless. I have seen it stated hy many people that the lion does not roar before or during hunting, and to prove the statement they do not adrluce facts, but always add the corollary, "For if he roared before hunting he would frighten away the game." However, I have so often heard lions roaring both before and during hunting that I camnot agree with the statement that they do not do so. Lions can often be heard roaring almost mcessantly from sundown until they have made their kills. Often, however, they will become silent before killing. Having killed, they are usually silent until they have finshed cating and are on their way to water.

Wherever there are lions which have been unmolested, there can they almost invariably be heard roaring soon after sunset. It would, indeed, be curious if this nightly performance was mot merely uscless, but adrerse to the ir chances of success in the hunt.

Lions make various kinds of roaring sounds. The commonest is the well-known sound commencing with a low moan, gradually swelling in volume till a clepp-throated roar is produced. After one or two of these, the last one terminates with a wood-sawing noise in sharj) jerks, growing shorter and fainter till it dies away. This roar on a dark night is undoubtedly a very unnerving sound, and I doubt if anyone could hear it under such conditions wholly umored. Yet this sound is the finest music on carth, and, once heard, the listener is always anxious for a repetition.

When lions try for stock they sometimes approach in silence and sometimes they roar. When they roar they will generally roar from one side and then pass on and roar again from another direction, till they have, perhaps, roared from three or four different directions. After this they will approach from anew direction in silence.

The object undoubtedly appears to perplex their victims and make them uncertain as in which direction in which to latie flight. I presume this is the reason for which they roar on the plains before hunting, namely, to utterly confuse the game, or make them imagine that there are lions on every side.

The roar of the lion is ventrilopual only on that it is difficult or impossible to judge law far rlistant is the animal. The direction, howerer, ean always be judgecl. A lion roaring close hy sounds very near, and a lion roaring in the distance also sombls close. A lion roaring perhaps a mile away sounds as if he were but a few humeled yards off. Ciame might be grazing on the 
1)ain and leare a listant roaring from the north; shortly afterwards they might hear a nearer rowrimg upwind from the east, and presently another from the south. Then they might hear a rour again (loser from the cast, and again what they would imagine to be quite near from the morth. They would then perlazps get a whilf of lion from upwind and would stampede westwards, where a lion miglt be awaiting them, having sent his lioness to do the roaring.

The roaring of the lion, deseribed in an earlier passage, that came down to feed off the impalis, was probably to call his fellows, and doubtless, by some indication in the roar, they were able to know that they were being called.

Joweser, there is a certain kind of roar, a moan followed by three short, sharp syllables, which 1 have seldom heard, lut which 1 imagine to be a call, either of a male for a female, or for a party wishing to join another party. I have heard it given by parties in different directions approaching each other, either at sunset or in the morning before lying up.

Igain, by roaring at intervals, lions are able to inform one another of their whereabouts, and sn (1) act in concert. When actually in pursuit of an animal they employ a series of short, sharp grunts. These can be heard at a considerable distance, and are presumably to keep the others informed as to the progress of the chase, so that they can join in when they are able to.

I belive, however, that the chief use of roaring is for the purpose of driving game to one another, and often in such cases the fact that the roar sounds as if the lion was much nearer than he actually is serves to unduly frighten the game and make them stampede wildly in the required direction without taking precautions for wind.

Again, a lion, laving stalked an animal, may suddenly spring out on it with a loud roar or growling sound, calculated to terrify it into momentary inaction. A wounded lion will roar on being approached, or will throw himself with a loud roar at his adversary. "This is presumably a roar of anger, and is intended to terrify his opponent into submission, serving the same purpose as the growl with which a dog falls upon another. These are, however, ixceptional roars. With the ordinary roars the usual procedure on the plains is as follows:-

At sunset and for an hour or two afterwards roars are heard from different directions. This is followed by a period of silence. Later, if one happens to be in the neighbourhood of the hunt, the pursuing grunt, grunt is heard, and then all is silent again till carly in the morning when roaring is again heard, and often lasts for an hour or two after sunrise. Presumably the first rouring perplexes the game or herds them into the required position. After this probably a stalk is made, and some animal is marked down and pursued in the required direction, other lions joining in and rounding up the animal. They then fecd, and leaving the kill in the carly morning proceed to water, and after that to their lying-up spots, roaring meanwhile.

At other times, and especially where herds of small game are concerned, a drive is held, ancl the lion that is to drive roars intermittently the whole time, whilst the others, which post themsclves like guns for a grouse drive, remain silent. Why lions should almost always roar when going to water I do not know, unless it is for practice. They cannot roar whilst fecding, nor is it advisable to do so during the day, or they would disclose their retreat.

Vultures. - When vultures are circling in the air it usually means that they are waiting to lescend to a kill, but that there is still some animal over it. When a number of vultures are seen in a trie it means that they have funished a kill and are digesting the food.

Polyandry in Lions.-I lave on several occasions seen one lioness accompanied by two lions, and am inclined to think that this condition is not unknown amongst them.

Cannibalism.-I have observed two cases of lions cating the dead bodies of others, and have 
heard and read of many others. However, the instances noticed have always been after the skin lad been removed, and so the body would not be recognisable to others as a lion's body. It would certainly smell of lion, but a lion's hill would also smell much the same. I have never seen it stated definitely that a lion has fed off an intact carcase of another.

Lions when lying up appear to be less on the alcrt than are buck lying up, and hence are casier to stalk than are most buck. The reason for this is that they are not, as a rule, so suspicious of danger, and if lying up after a lieav' meal are feeling lazy and sluggish. When in the open, however, or on the move, they are very quick to notice a sportsman.

Ilabitats.-I have seen or heard lions or noticed their spoors in the following places:-

Athi Plains. Very common sometimes, and at other times rare. Good localities are both the Athi and Stony Athi rivers for their whole lengths on the plains. The lions lie up in the reed-beds and amongst the trees on the banks; also in the hills to the north, which contain a number of rocky nullahs; these are favourite spots. Lion rocks. Between the Thiririka and Thika rivers, south of Fort Hall road. Punda Milia and the neighbourhood of OI Doinyo Sapuk. They occur plentifully also in the reserve, and are said to be plentiful at certain seasons near Wami and kiu.

They occur at Simba and in the bed of the river, which the line crosses just above the station, and from there downwards.

In the Rift Valley, the Kedong River, and are also said to be numerous towards Matapato and Lake Magadi, in the reserve, the Ndabibi Plains, and occasionally seen near Naivasha.

Kinangop Platcau (occasionally).

The moors on the top of the Aberdares (occasionally). Here they are said to have very fine manes.

Upper Tana, Sagana or Kilifuma River, both banks from below Fort Hall downward.

Ithanga llills and Athi River, after leaving plains.

Lower Thika and junction of Thika and Tana.

Embu, and from there southwards to Tana. Banks of Ziba and Namindi rivers.

Plains north of Nyeri and streams coming from north end of Aberdares.

On the opposite side of the hills at Lake Olbolossat (said to be a man-eater there).

Guas Ngishu Plateau. Said to be numerous northwards towards Sirgoi.

Mainland opposite Lamu Archipelago.

In Uganda they occur mear Hoima and Masindi; also said to be found at Yailo.

Uceur occisionally near Wadelai (Belgian) and inland from there, and also from Dufile.

Both banks of the Nile from Wadelai to Gondokoro at certain scasons.

\section{ORIBI, ABYSSINIAN.}

Natize Name.

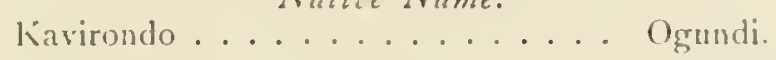

This animal occurs on the .Hau and Guas Ngishu; also at Gondokoro.

There is an oribi which occurs south of the Kisii country which is probably of this species

\section{ORIBI, HAGGARD'S.}

"his animal is at once distinguisheel from other oribis by the great thickness and latge corrugations of the horns. It is found in the Taru Desert. 
ORYX, BEISA.

Natize Names

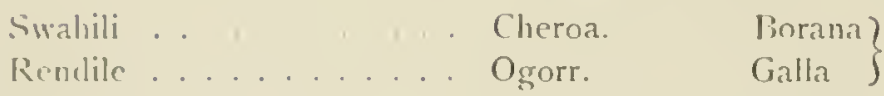

Sala.

This animal is an inhabitant of waterless tracts. It is first met with, going northwirrl, just to the south of the Guaso N̈giro. On the north side of this stream it is plentiful, and from there northwards it is met with in the low and dry countries of the Samburr, Rendile, and Borana.

$\triangle$ female roan facing one might at first sight be mistaken for an oryx, for in that position the horms of the former often appear to be straight. Both have black and white markings on their faces. With the roan the ground colour of the face is black, with white streaks under the eyes. The oryx, on the other hand, has white for the ground colour, and on this is a black blaze and black stripes under the eyes.

\section{ORYX, FRINGE-EARED.}

Native Name.

Swahili .................... Cherna.

This animal is distinguished from the beisa by the hairy fringes at the extremities of its cars. Its horns, also, are shorter and more curved than those of the beisa. It is a close relation of the roan and sable. The horns of all these animals named tend to curve backwards. 'The extreme case in the hippotragi is the sable, the horns of which are sometimes three-quarters of the circumference of a circle. In the ory the extreme case is the sabre-horned oryx. The gemshok and the beisa have the straightest horns of this group, but even these tend to curve hackwards slightly, and with some individuals it is more apparent than with others. So with the fringe-cared oryx and the beisa, a straight-horned specimen of the former would not curve to a greater extent than a particularly curved specimen of the latter.

The fringe-cared oryx is found in the game reserve ncar Simba Station and at Laki Jipi and about the Nyiri Swamps. It is also plentiful in the Taru Desert, especially in the waterless 1 ract between the railway line at about Makindu and the Tana River, and again is found in the neighhourhood of the Serengeti Plains.

The oryx and gazelle families are especially fitted for life in waterless places, the oryx more so, perhaps, than the gazelle. It is almost a sure sign that wherever oryx are seen that there water is scarce or non-existent in the vicinity.

\section{OSTRICH.}

Natize Names.

Swahili........... Mlburi.

Ogick (Ravine) ..... Tiasongol.

Kikuyı............ Nyaga.

Masai ......... E-sidai.

Kitaita

This bird is very common on the plains. It is now preserved from being shot, but, under special liccnce, the eggs may be collected or the young may be caught for the purposes of ostrichfarming. Large herds of about forty birds are occasionally seen. A single male grazing alone gencrally means that there is a nest in the vicinity. An occasional unfertile egg is dropped by 
itself without being laid in a nest. Sometimes an enormous number of eggs are seen in a nest, perhaps thirty in number. Where this occurs something has probably gone wrong with one clutch, and another has been laid on the top of them. The hen occasionally gets bored with the actled eggs which come to nothing and kicks them out of the nest, as can be seen in the photograph by page y1.

\section{PORCUPINE.}

\section{Nalive Nanes.}

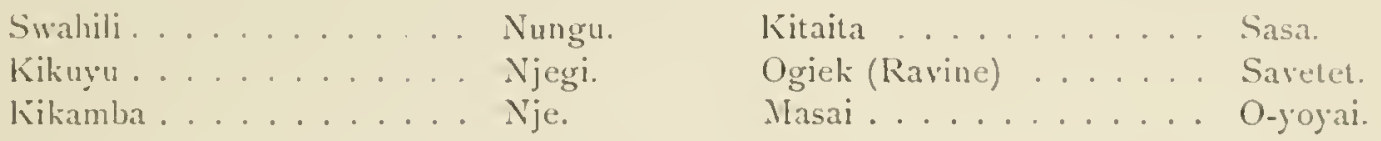

This nocturnal animal is practically ncver seen excepting occasionally when it is hunted out by dogs, but by the frequent signs of its presence on pathways and around native plantations it appears to be a very comnon animal. It commits great depredations on the fields at night, and is most unpopular amongst agricultural natives.

\section{REEDBUCK, BOHOR.}

Native Names.

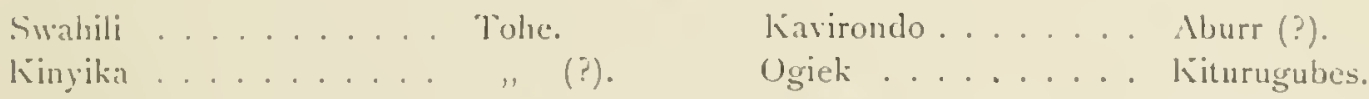

'This animal is much larger in size than Chanler's reedbuck. The horns rum much smaller than those of the common reedbuck, although the animal is much the same size. It is found on the (juas Ngishu, Nandi, and the Rift Valley north of the line. It is also said to exist on the Mau. Fither the Bohor reedbuck or the Abyssinian reedbuck occurs on the Nile, in Uganda, and the Lato binclare, but 1 am unable to state which species.

\section{REEDBUCK, CHANLER'S.}

\section{Native Names.}

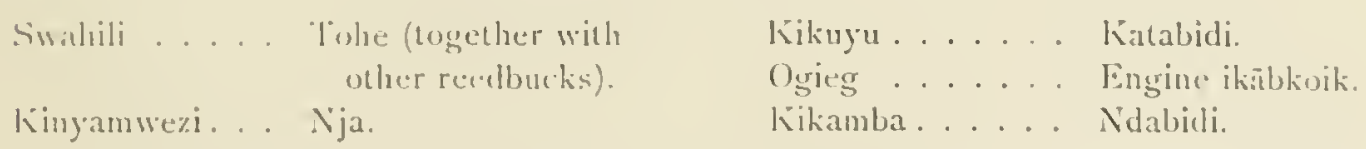

These animals inhabit both rocky hills and mountains, and also the steep banks of some of the ravines on the plains. They go about in family parties of three or four, or sometimes a dozen or more may be secu together. It is very diffeult to distinguish male from female.

Phey weur on the Athi Plains in various places, such as on Lukenya, and between the Ndurugu and Plikia rivers, and in the Kedong Valley; the Ithanga Ilills, very plentiful; Ol Boinge Sapuk, very plentiful; the Kisii country, south of Ndube's, and on Chamonyeru: the Kikamba llils, south of (1) lnimo Sinpuk; the hills south of Eubu and on cither hank of the T:ana.

\section{REEDBUCK, WARD'S.}

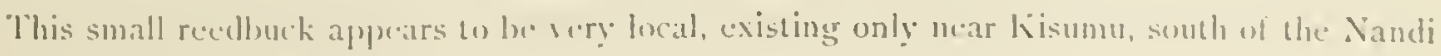
llills, and in part of the liarenclo comntry. 


\section{RHINO, BURCHELL'S.}

Habitut.-This animal, so far as is at present known, occurs only in a very limited area of the fado Enclave. (This is, of course, excepting the few specimens still known to exist south of the Zamlezi.) It is found a few miles north of Wadelai (Belgian), and extends from there along the Nile's left bank as far, I believe, as the border of the Soudan. It does not appear to wander far from the river, and 1 have not observed it or its spoor beyond three days' journey inland from the vile. I have not heard of a case of the animal having been found on the right bank of the Nile, nor have I heard of a case of a black rhino ever having been found on the left bank of the Nile, at just this part, viz., Wadelai to Lado or Kiro.

Burchell's rhino differs from the black rhino; firstly, in that it is square-lipped, whereas its congener is prehensile and pointed-lipped. It is also of much greater bulk, probably weighing about a ton more than the other. It stands perhaps six to eight inches higher at the shoulder, and its head is much more massive. Its horns grow to greater dimensions, and are square instead of rounded at the basc. As to colour, it seems perhaps a shade lighter than the other spccies.

Rhino scem to vary much in the colour of their skins, and it is often difficult to tell what their real colour is unless the skin is washed. The rhino shown in Chapter X. was certainly a very light-coloured one, and this effect was not entirely produced by white mud. Others I saw were slightly lighter in hue than the average black rhino. Individuals of the latter species, howerer, are occasionally secn of a much lighter shade than their fellows.

Burchell's rhino is a grass feeder, whereas the other rhino is chiefly a thorn and bush feeder. As the present habitat of the square-lipped rhimo is a long-grass country, it is better fitted to survive than the ill-fated South African variety.

\section{RHINO, BLACK.}

Natize Names.

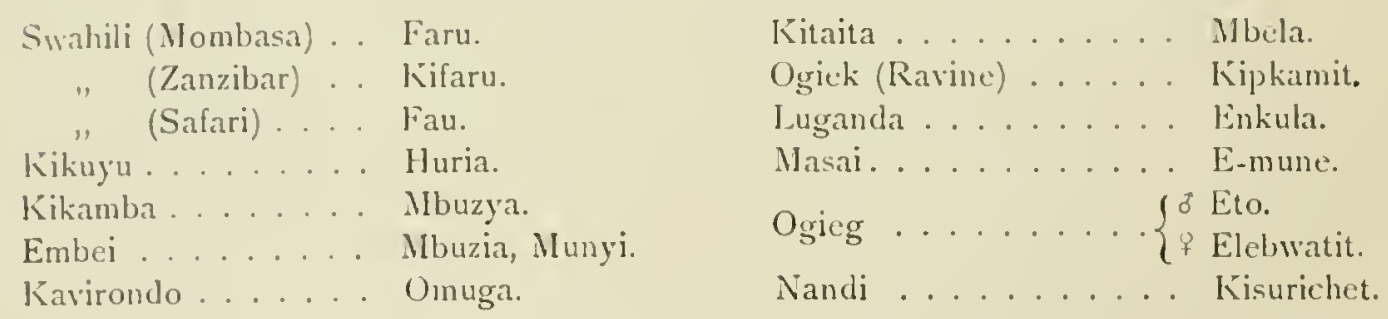

Mabitat.-The rhino of East Africa takes naturally to the open plains. As the grass is short and there is but little cover, he is as defenceless and vulnerable as the Burchell's rhino of South Africa used to be. Fortunately for his chances of survival in this country, there are also large tracts of dense thorn in which he is accustomed to wander. Those animals that inlubit this latter country are as dangerous and inaccessible as the rhino of other parts of Africa.

Food.-The usual diet of the black or bush-dwelling rhino is a mixture of thorn-bush and grass. In parts of Africa where the grass is long, tangled, and matted he is as safe wandering in such grass-country as he is in the bush. In East Africa, however, owing to the shortness of the grass, directly he leaves the bush-country he becomes a conspicuous object. In parts of the 
country where the thorn is dense he seldom need leave the thick bush, as patches of grass occur mingled with the thorn. In other parts, however, he appears to spend much of his time in the open or to live in thornless forest or bush, feeding on leaves and thistle-like plants.

Range of Sight.-Range of vision of the rhino in all probability does not cxceed thirty-five yards. I have often been within this distance of rhinos facing me, and have been convinced that they have not seen me.

Sense of Hearing.-He is also not very quick at hearing, being considerably below the average game animal in this respect.

Sense of Smell.-He has, however, an acute sense of smell, though inferior in this respect to the elephant and buffalo.

Ferocity. - The rhino is undoubtedly a fairly plucky animal, and on occasions gives way to unreasoning lits of rage. I have heard of many instances of rhinos charging objects as various as a train, a tent, a horse, and a hencoop. With reference to the well-known instance of a rhino having charged a train, a friend of mine has called ny attention to the disgraceful way the train nust have been overcrowded on that day. A first-class coach is only supposed to seat twelve people, but he himself had met nearly twenty men who told him that they had been on that occasion in the carriage that was charged.

It is very likely that the majority of rhinos which make themselves unpleasant have been at some time wounded, and so have good reason to resent mankind and all that pertains to him. I have never noticel that they make themselves objectionable to game, but if they did so, no doubt the animals could get out of their way easily enough. Neither have I ever heard of their doing any harm to Masai or their cattle, although these people often graze their herds in spots abounding with rhinos. This is noticeably the case just north of Nyeri, where the Masai graze their cattle amongst clumps and patches of thick bush notorious for dangerous rhinos.

Wherever rhino are common there may be observed numbers of rhino privies to which they go to deposit their droppings. After this action they scrateh backwards with their hind legs, generally breaking up the droppings. The only explanation I have ever heard given for this proceeding is that offered by the Wanyamwezi in one of their folk-lore stories. This is, that the eleplant becomes angry if he finds a whole dropping belonging to the rhino, as it is so like his own, and so he compels the rhino to break up his.

Mud Bathing. - The rhino is very fond of mud baths. Tracks leading from these baths will often be found with all leaves, twigs, trees, and branches close to the track plastered thickly with mud. When such a track is met with the direction of the mud-hole can easily be seen, as the mud will be plastered on the sides of trees and branches nearest the bath, for the rlinos, of course, only leave mud on then when coming from the bath.

Rhinos are generally found either singly or in pairs. A single rhino is generally a male, while a pair constitute a female and young. When the young has grown up somewhat, a male will often join the pair, but frequently grazes a little apart. So when three are scen together they are generally male, female, and young.

Linlike the elephant, the rhino calf leaves the mother just before another is born. I have never scen a rhino with two calves. When more than threc rhinos are seen together the probability is that two or more parties happen to be grazing in the same spot.

Rhinos puff loudly when charging or when running away, and so one is generally warned when they are disturbed. They schlom seem to lie down for any length of time, but stand up every now and again and sniff and turn round, and then lie down again, or move on to another 
place. When they gret up and stand they have a habit of peering downwind as if they were louking at something. They are probably listening for danger, but if the sportsman is advancing from that direction he is liable to be bluffed into thinking that the animal has seen lim. Rhinos are sery fond of lying in thick and tangled long-grass country. When lying down in such grass they are not visible, but when they get your wind they generally stand up at once. It is risky following spoor downwind in such country or in bush.

If circumstances compel the sportsman to move across the wind in this kind of country a constant look-out should be kept downwind and over the shoulder. For one may pass quite close to a party of rhinos lying down without seeing them, and if they are downwind of him they will prohahly get his wind and stand up just after he has passed them.

Rhinos, whether hit in brain, heart, or lungs, are more often found dead in a sitting position than lying on the sides.

$A$ lemale will often leave a young calf lying down whilst she grazes round for a little while and then returns to it.

Sharpening Horns.-A rhino can sharpen both back and front horns on a stone. The long, thin anterior horns of the females are constantly getting broken, and are then gradually sharpened again.

This is the reason that old females are so often seen with short horns only a fool or so long.

In hilly country rhinos will often choose a spur on which to lie when the wind is blowing down the spur. In such a position they can probably hear better anything approaching from downwind or from a flank.

Sores on Underside. - They almost invariably have open sores on the undersides of their bellies where the skin is thin and soft. Drops of blood from these sores may sometimes be seen where the animals have been lying. The friction of thorns and grass, logether with the gigantic ticks which are generally found on this part of the body, are probably the cause. Schillings speaks of one sore about the size of a crown which is always found in the same spot. I have never been able to find this particular sore, but have always noticed a sore or sores varying in size from a sixpence to a dessert-plate, and varying in number from one to three or four. The same writer mentions that long rertical gashes are found on the sides of hippos and rhinos, but not on elephants.

Elephants fight by prodding with the tusks, and on occasions when they have caught a hunter they generally try to prod him when on the ground. Wounds and scars on elephants are generally circular or short gashes. A rhino fights by tossing his head, an action which produces a ripping wound. Hippos also tear long straight gashes with their teeth. In the distance a rhino looks more like a great pig than anything else. When alarmed, it sticks its tail straight up in the air as does a warthog. Where they have not been much disturbed they often graze on the plains by day and retire to the forest by night. Where they have been disturbed they often reverse this proceeding. The sight of rhinos strolling about unconcernedly in the open plains is year by year growing more unusual in the neighbourhood of familiar shooting-grounds.

The game-ranger's report of 1903 speaks of rhinos as being numerous on the Athi l'lains. At the present day they are practically never seen in the unreserved portion of these plains, while they are seldon seen in the open even in the game reserve. As time goes on, doubtless they will become rare objects even on the more remote plains. However, in the bush bordering the plains they are still common.

Rhino Birds.-In the more civilised parts of the Protectorate the rhinos appear to have 
learnt how to tell the approach of man by the behaviour of the tick-birds accompanying them. In uncivilised parts, however, they are still wonderfully unsophisticated, and will sometimes stand all unconscious or unsuspecting of danger long after these birds have flown away. These birds I believe to be responsible to a large extent for the many sores often found on the rhinos. They pull off the ticks and with them small pieces of skin, and they also appear to peck at old and festering sores.

I have noticed rhinos or the spoor of rhino in the following parts of British East Africa:-

Alhi Plains. Now confincl to a few in the reserve.

In the bush near Kiu and Of Doinyo Sapuk.

In a forest near the Ndurugu River, just north of where it is crossed by the Fort Hall road.

Neng Forest and Mountain.

Kedong Valley, formerly plentiful, but now almost entirely conlined to the forests on the escarpments.

The Aberdares and Kinangop (Nguzeru) Mountain.

lthanga Hills, very plentiful.

On both banks of the Tana, below its junction with Thika River, very plentiful to Mumoni, and probably beyond.

West of Embei country; plentiful.

In Ukamba country, between Tana and Kitui, and on the lower Athi, plentiful.

North and east of Nyeri, plentiful.

Baringo and northwards and east shore of Rudolf, very plentiful.

It is also reported from almost every part of the Protectorate where thick thorn and bush is found.

In Uganda it occurs plentifully northwards towards Elgon, but is scarce or non-existent iin most parts.

It occur: plentifully on the right bank of the Nile, and inland from Nimule and Gondokoro. 1 have not heard of it, however, as occurring on the west bank of the Nite at this part.

\section{ROAN.}

Native Names.

Kavirondo......... Omuga. Ogiek (Ravinc)..... Lalgotiet.

This animal is fairly local in British East Africa. I have seen it near the lthanga Hills, on the Guas Ngishu, and in the low country round Muloroni, in the latter place plentifully. A herd is said to be near Machakos. A variety, Baker's roan, occurs in Uganda, on the Nile.

It is also found on the German border near the Kisii country.

I found a considerable quantity of bits of bone in a roan's stomach which I obtained near the Ravine. I have never noticed that these aninals ate hone before.

\section{SABLE.}

$$
\text { Kinyika ............ Kalungungu }
$$

The only part of the Protectorate in which this animal is known to exist is in the Shimba Hills, and inland from Gazi on the coast. 


\section{SCALY MANIS.}

'These aninals, I belicve, are occasionally found in the Protectorate. I hase been told that they have been found near Taveta. They also occur in Uganda.

\section{SERVAL.}

\section{Native Names.}

Swahili........ Mpaka wa mwitu or chui (viz., same as either Kaffir cat or leopard). Masai ........ Ol-ogwaru mara (generic name for all spotted felines).

Kikuy̆u (Njchu) ... Kibao.

Kikuyu ....... Kirumi.

Embci ....... Kenge.

Kikauba ...... Timba.

Ogiek (Ravine) .... Lilwot.

Somali ....... Harama'at.

Food-Rats and mice and especially the burrowing ground-rat often referred to as a mole.

Varictics.-Individuals differ tremendously in markings and ground colour of coats. One variety with little black spots all over the body in place of all stripes excepting those of the neck, is referred to as the servaline cat, and is illustrated in Sir Harry Johnston's "Uganda."

Mclanism.-Several black servals have been shot in this country, two from the neighbourbood of Nyeri; and I have seen on the Aberdares above this station what I took to be a black serval.

The length of tail differs enormously in different individuals. The serval's body is not really much bigger than that of a large cat, it is the length of legs which makes the animal look so large. It often stands or sits with one joint of its legs bent, and is then about the lieiglut of an ordinary cat.

These animals, like the leopard, sit very tight. Whilst out with a dorobo one day, we saw a serval peer out at us and then crouch down in a small tuft of long grass. The dorobo walked on as if he had not seen it, and passing close to the tuft hit it with a heavy leather rifle bucket he was carrying.

These animals are not quite so nocturnal in their habits as are leopards, and may often be seen out just about sunset. At a distance their spots are not visible, a peculiarity which the serval shares with most spotted animals; it then looks much the colour of the caracal.

At the coast and in the Lamu Archipelago servals often go down on to the beach and there dig for the multitudinous crabs whicl live in little holes in the sand. They are fairly common in most parts of British East Ifrica, and inhabit both bush and plains. They like to lic up in the bush bordering on the plains and come out to hunt on these at night. When living in the open plains they lie up either in a reed-bed or in holes in rocks. In bush and forest countries thay often live up trees. I was wandering in the forest once with some Kikuyu honey-hunters. One of them detected a bees'-nest in a tall tree and commenced to climb it. A serval which had been lying up in a sheltered fork of the tree took a leap down about thirty feet, landed in a bush, and darted off none the worse.

The Ogieg of the Kikuyu Escarpment appear to have no name for the serval, but call it "the leopard's young one." They say that a leopard turns one cub away out of its litter and does not suckle it. This goes off by itself and never grows up. This is the serval, whilst the others which are suckled grow up into leopards. They do not explain how the serval gets its long legs. 


\section{STUTUNGA.}

This animal is supposed to cxist, and probably does so, plentifully amongst the reeds and papyrus on the shores of lake Victoria, near Karungu, and in many other parts of the lake coast. As this part of the lake shore is full of slecping-sickness and fevers, it would require a very ardent naturalist to investigate the truth of the rumour. On the Uganda side of the lake the animal is known to exist, and also in the comparatively open waters of the Sesse Islands. A specimen was recently obtained from a swamp on the Guas Ngishu, a locality in which it was not before known to exist. It also occurs in many of the swamps of Uganda, but it is there so inaccessible that it is practically never obtained except by "driving" a swamp. This even is generally accompanied by ill-success owing to the impossibility of making any way in the deep water, and so of preventing the animals from breaking back, as they will always try to do rather than be driven out into the open.

\section{STEINBUCK.}

\section{Natia'c Names.}

Swahili ......... Paa

(same as all other small buck).
Kikuyu ......... Thiya

(th as in English "the").

Ogieg .......... Olwargoi.

This animal is just like a small oribi, excepting that it has not the black knec-pads of the latter. It is exceedingly common on the open plains, and also on open hills. It will often sit very tight in long grass and allow anyone to pass quite close. Directly, however, it thinks it has been detected, away it darts. Like most small buck it generally stops for a last look round before finally making away.

\section{SUNI, ZANZIBAR.}

\section{Native Names.}

Swahili......... Paa.

Kikuyu.......... Kasuni (?).

Ogieg ............... Chinjet.

The Zanzibar suni, or Grave Island gazelle, is a small bush-dwelling animal. It occurs on the island off Zanzibar, and on P'rison Island, Bawi Island, and Grave Island, likewise near Kilimanjaro, and near lava and other parts of the Slimba Hills. Mr. Jackson tells me that it also occurs in the Ngong Forest, and I have heard a peculiar, lip-smacking cry of alarm on the escarpment below Kijabe, which probably denoted the same animal. I have also heard the same noise in the forest between escarpment-station and Kinangop.

In the Shimba Hills this animal is a favourite food of the leopard.

\section{TOPI.}

This animal takes the place of the hartebeest in point of numbers in some parts of the Protectorate. It is found in great numbers in Jubiland, and also in the low country between Inhoroni and Kisumu. It also occurs on the German horder and in parts of Uganda, and on 
the lower Sabaki and near the moutls of the Tana, also east and north of Lake Rudolf. It has in life a beantiful, glossy coat, like its relation the sassaby; but the shine and gloss yuickly disappear after death. Herds of these animals are found numbering from twenty to forty.

\section{WARTHOG.}

\section{Native Names.}
Swahili.... Ngili, Mnjiri, Mngiri.
Kavirondo ........... Mbithi.
Kikamba .... Ngrili.

These animals are common enough on the plains. They seem to feed by day and lie up in holes or caves by niglat, whereas the bushpig does just the reverse. Lions seem fairly addicted to the warthog, probably because it generally las a certain amount of fat on it. I fancy that a lion would probably kill one when he wanted to take the body away, so as to feed young cubs lying up in cover, for he could easily carry the animal some distance. When the warthog goes into his hole he generally enters backwards, so as to have his head towards the opening instead of his more assailable spots, with a view to tackling anything which might attempt to enter. I killed an old warthog once that had probably escaped from a lion, as he was mauled behind and had no tail left. As they always stick their tails straight up in the air when alarmed and making off; a lion might easily get hold of it if he missed any other part. From the number of times that 1 have seen animals with no tails, or only stumps mauled by lions, I am inclined to think that a lion, if he misses the body, often catches hold of the tail to try to bring the animal up with a round turn before it escapes him.

The warthog is very common to the north of the Athi Plains and in the Kedong Valley, both places near forest country; but it is !ess common in the middle and other parts of the plain. I am inclined to think that it does not like the open plains without cover, but prefers the erges of the plains, so that it can lie up in bush or forest if it wishes to, whilst retaining the plains on wich to feed. The animal's characteristic method of going down on the fore-knees to grub with its snout, while pushing with its hind-legs straight out behind it, can be well seen in the photo by page 89 .

It occurs commonly enough in most open country in the Protectorate, provided that there is cover in the vicinity.

\section{WATERBUCK, COMMON.}

\section{Native Names.}

(The names for this and the sing-sing waterbuck are the same.)

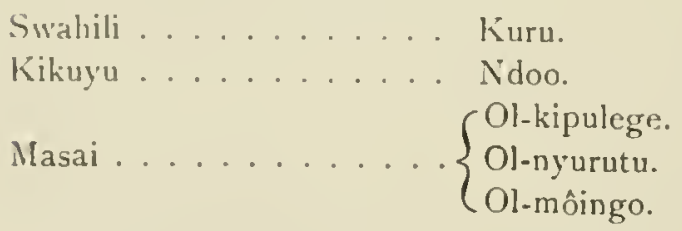

Embei.......... Ndopo.

Kikamba ......... Ndoo.

Karirondo ........ Apol.

Ogiek .......... Tiaponaret.

Luganda ......... Nsama.

This animal is a bush or long-grass country animal, though often scen on the plans, especially in the mornings and evenings, and near the banks of rivers. It is greyer in colour than the sing-sing, though its most distinguishing difference is the marking of the rump, which 
has nearly a complete narrow, white ring. This circular marking has a break in the upper portion of it about six incines broad, and through this break comes the root of the tail. The buck has also white nose and ears. Its eyc has a dark blue pupil with a mottled orange-coloured iris. The animal has a powerful pungent scent which remains where he has been long after he las moved. It appears to be seldom found far from some river or swamp. When alarned in the open it generally takes to thick country.

When finishing off a wounded buck on the ground be careful of the cow-kicks from the hind-legs, as the animal is very active with these limbs.

It occurs east of the Rift Valley plentifully, and in most watered parts of East Africa. On the opposite side of the Rift Valley is found his congener the sing-sing. The two species meet at Ngong Nountain and the Aberdares.

\section{WATERBUCK, SING-SING.}

Native Names.

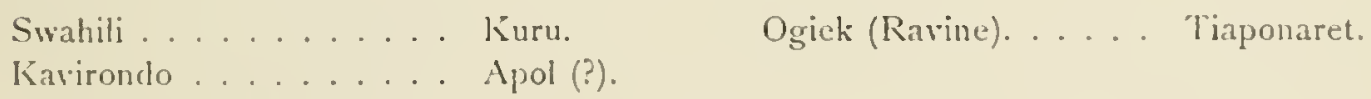

This animal differs from the common waterbuck in that the coat has a reddish tint about it and the horns run longer.

Roughly speaking, the Kikuyu Escarpment forms the boundary between the defassa and the common waterbucks. In places on the escarpment the two species meet, whilst eastwards the common only is found, and westwards only the defassa. It occurs on the sides of the Rilt valley, on the Guas Ngishu, plentifully, and in the Nandi and Kavirondo countries, and also in Uganda. The horns of thesc animals run to great lengths in the Semliki Valley, and also west of Lake Albert, where $3^{6-i n c h}$ horns have been obtained. It is also found in the Lado Enclave.

\section{ZEBRA, CHAPMAN'S.}

Native Names.

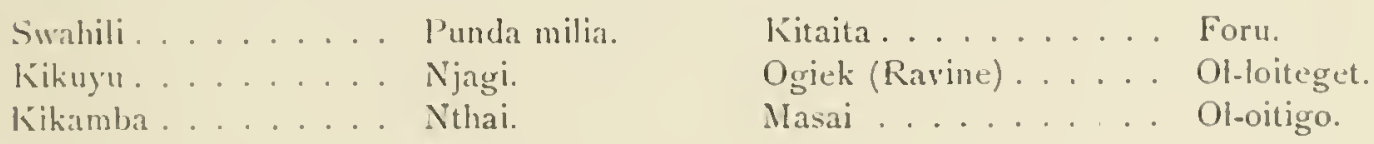

Kavirondo...... Magwarr.

These animals are one of the most numerous kinds of game animals in British East Africa, and, as they are but seldom shot, they are also one of the tamest. They appear to be very. inquisitive, and often come up close, sometimes as near as lifty yarels, to inspect a person. A number of zebrat escaped fron the zelora-ranch on the Athi Plains, and many of these were quite tame, so this may account for the confidence with which sone zebra approach anyone. On the plains north of the Guas Nigiro the zebra, although not shot at by sportsmen, are much wilder. This may be because they are hunted by the Wandorobo of those parts.

Zebra appear to be much more intelligent than the average plain-dweller. They are always very fat and well fied, and unler the skin maty generally be found a layer of yeliow fat. As they hase teeth on hoth upper and lower jaws, they can graze closer 
than the hollowhorned ruminants, and so can feed where other animals would get little or no nourishment.

Zebra form the favourite food of the plain-dwelling lions. They occur almost all over British liast Africa wherever there are plains, until a latitude of about two degrees north is reached, and then the Grery's zebra takes the place of this type.

\section{ZEBRA, GREVY'S.}

Native Names.

Masai ............ Kanga.

Rendile............ Kango.

Swahili.......... Kangaja.

This animal is much larger than Grant's zebra. It also makes a sound much resembling the braying of a donkey.

It is found plentifully in most of the low-lying country of Samburr, Rendile, and the South Borana. It is also found in Turkana country, north of Elgon. So far as I am aware it is not found south of the Lorogai Mountains, or south of parallel one degree of latitude. It is plentiful north of the Lorogai, and between this range and Doto (Mathew's Range). 


\section{N D EX.}

A Byssivia, South and Eastern, Rainy season of, 29. Abyssinian buffalo, 166 .

Hunting-dog, 64 .

Oribi, 106, 166 .

Animals: Abilities in finding one another, 61 .

lllood spoor of, 94.

Bush and forest animals, 22.

Jush animals' sense of hearing, 57 .

Characteristics of mountain animals, 3 r, 32.

Characteristics of plains animals, 32 .

Comparisons in approaching several, 68 .

Deception in coloration of, 53 .

Glands zersus smell, 62 .

In long, thick grass, 57 .

Kinds of, in each country, 31 .

Maimed and ailing, 93, 94 .

Mystery surrounding lives of, 22.

Observations of plains animals, $4,22.99$.

Plain-dweller and lion, 57 .

Plains animals' intellect, 32, 57 .

Plains animals' ideas of safety, 32 .

l'oisoning of, 7, 227.

Remarks on rare and common, 4 .

Seeing in the dark, 61 .

Sense of smell, 5 fi, 62 .

Shot in self-defence, 235.

Taking to difficult country, $3^{\text {ho. }}$

Tameness of plains animals, $1,39,68$.

Vital parts of an, 227.

Wariness of, 39 .

Ankole. 165.

Ant-bear, 95.

Native nanies for, 237.

Nocturnal habits of, 237 .

Spoor and dung of, 237.
Antelope (Harnessed), 165.

Hunter's, 107.

Iabitat, 107, 237.

Preservation of, 230.

Ants, 214.

Author's attitude towarls plain and busli shooting, 22 .

BABOONS, 35, 126.

Baboon and leopard, 36, 127.

Crossing a river, 126,127 .

Food of, $3^{6 .}$

Habitat, 35.

Bactrian camel, 27.

Bahr-al-gebel, $164,166,167,262,263$.

Bamboo, 31, 106, 171, 179, 184, 248, 252.

Barbary deer, 31 .

Barbary sheep, 27, 31 .

Baringo, 106, 241, 257, 266.

Beginner's luck, 82 .

Beisa, 27.

Beskaya Plains, 242 .

Bongo, 7, 80 .

Bongo tree, 170, 240.

Coloration, 53, 241 .

Dificule to bag, 7 .

Droppings of, 238 .

Fairly common, 7 .

Feeding in the forest, 170.

Following up the, 239.

Food of, $23^{8 .}$

Habitat, $35,184,185,186,238$.

Habits, 239 .

IJorns of, 241.

Native hunters of, 7 . 
Bongo, Native names for, 237.

l'assing through undergrowth, 171, 174, $23^{8}$, 240.

Prescrvation of, 230.

Salt earth, 240.

Spoor of, 142,237 .

Boer settlers, 107,231 .

"Browning," 66, 133.

Buck, Small (in gencral).

Coloration. 50 .

Fars of, 33 .

In short grass, 114.

Sitting tight, 49 .

Buddu, $164,166$.

Budonga Forest Reserve, $164,16,5$.

lBudonga Rescrve (see "licserve").

Buffalo, 7, 73,80, 129, 161, 166, 167, 154, 229.

Nlarmed herd, $2+1$.

As dangerous game, $87,2+1$.

Cape buffalo. $2+2$.

Charge of cow, 176 .

Distance at which shot, 85 .

Distribution, 87 .

Drinking. 73 .

Gas-hole and, 161 .

Ilabitat, 104. $107,161,162,163,16_{4}, 165$, $2+2$.

Horns of, 242 .

Licence for, 7,87 .

Manner of grazing, $2+1$.

Naulings by, $s_{7}$.

Native names for, $2+t$.

lowers of scenting, 242 .

Record buffalo trophy, i65 (see "Errata ").

Rinderpest and, $24 \mathrm{r}$.

Sentinels, 24 I.

Sight and hearing of, $2+2$.

Spoor of, 143 .

Strong smell of, 62 .

Trekking, is 8.

Trick of lying downwind, $16_{5}$.

Uganda buffalo, 7,242 .

Wariness of, 74,242 .

When wounded, 85 .

Congo, 242.

Coloration of, $167,2+2$.

Habitat, 242.
Bush, The, 147 .

$A$ few days in, 153 to 160 .

Belts of bush, $1+7,148$.

Burnt grass of, $\mathrm{r}+7$.

Camera in, 109.

Consistent goodl luck in, 7 .

Difficulty of secing long distances, 76 .

lixcitement of shooting in, 160 .

Fatiguc in, 149.

Getting througls, 131, 132 .

High ground in, $147,148,154,155$.

Ilunting in, 152,153 .

Indistinciness of animals in, 149.150.

Inspecting water-courses, 153 .

Knowledge of lunting neccssary in, 70, 134.

List of animals in, 161 .

Making detours in, 149 .

P'ools in, 13 S.

Preservation of silence in, 150, 151 .

Quickness of cyc in, 121,151 .

Sleeping in, 218 .

Sparsely bushed country, 147.

Tracks to the river bed, 148 .

IIind in, 149,156 .

l3ushbuck, $4,159,161,164,170,171,184,186,233$.

Approaching the, 153 .

Coloration of, $53,2+3$.

Difficult to bag, 4,243 .

Female and young of, $12 \mathrm{x}, 243$.

Habitat, 243.

Hoarse bark of, $155,243$.

Hours of grazing, $2+3$.

Leopard and, 170 .

Native names for, 243 .

Peculiarities during grazing, $2+3$.

Skin and horns of, 34 .

Small variety of, $2+3$.

Spoor of, $1+3,2+3$.

Strong smell of, $62,2+3$.

With white cherron, 243 .

Bushcraft (see also "Spoor," "Stalking," and "Tracking ").

Advance, The, 151, 160.

Alertness, 136,149 .

Arts of, $70,7:, 174$.

Broken boughs and fallen leares, 75,123 , I 37,174 . 
Bushcraft, Copious old spoor, 71.

Crossing watercourses, 147,148 .

Experience in, 149.

Eye for country, 200.

Fall and trend of country, 148 .

Finding one's way about, 199.

ir resh spoor, $71,136,139$.

Fresh tracks and the animal, $123,136$.

Great points in, 7 .

Interest of spooring, 72 .

Keeping in the shadows, 152 .

L.earning habits of bush animals, 76 .

Listening for elephants, $\mathbf{I} \mathbf{I}$.

Map making, 72 to 76 .

Obliterated tracks, $7 \mathrm{I}$.

Observations from high ground, 147,148 .

Observations of detail, 199, 200.

Of natives, 164 .

Paths in forest, $172,173,174$.

P'iecing together of information, 72, 76 .

Plan of campaign, 71,72 .

Secret of sighting game, 151 .

Silence, 150, 151, 174 .

Site for camp, 72 .

Spoor about waterholes, 69,74.

Spoor in rainy season, 71 .

Spooring bushbuck, $2+3$.

Spooring in the bush, $70,7 \mathrm{I}$.

Stalking and tracking, 123.

Stalking for camera shot, rog.

Use of flour-bag, 180.

Water, 72.

When lost, 201.

Wind, $124,149,156,175,1$ so.

Bush-dwelling game, 33 .

Activity of, 33 .

I'leeting glimpses of, 79, 8o.

Forcing passage-ways, 34 .

Hours of leeding. 33 .

Inupracticable paths, 34.

Intelligence of, 33 .

kecping in the shate, 150.

List of, 80.

Lying up, 33.

Sellse of hearingr, 33,57 .

Sense of smelling, 33.99 .

Shape of horns, 63 .
Bush-dwelling game, Sight of distant hunter, 110.

Size of ears, 33 .

Thickness of hides, 34 .

When grazing, 150 .

Bushpig, 80, 16r, 171 .

Habitat, 24.

llabits, $2+4$.

Native names for, $2+4$.

Spoor of, 144.

CAMERa: A snapshot, 132.

Damp and the, roy. 10 .

Light and shadic, 109.

Telephoto lens, 1 ro.

Warping, 1og.

Camp, 149.190.

A few tips for comfort in, 203 to 216 .

After elephant, 179.

Camp fire, 211.

Camping in the mountains, $21 \mathrm{t}$.

Charm of camp life, 187.

Discomforts of insects, 212.

Firewood, $187,204,211$.

In the busl, 153 .

In the forest, 173 .

Noise of porters, 202.

Porters' camp, 204.

Porters' loads, 195.

Position of tent, 204.

Professional porter and, 190, ryo.

Scarch partr, 190.

Selecting site for, $72,187,203$.

Tene and porters, 196,201 .

Tent by the river, 127 .

Tent on the plains, 119.

Trek ard camp, 187 to 216.

W'ater, 72, 187, 204.

Waterproof shcet, 204.

Candlearbra euphorbia, I 2.

Canoes, 132.

Hippo and, 86, เ66.

Carnivora. 33 .

liyes in the dark, or.

Family ties, 99.

Hunting by scent, 53. 5t.

Intelligence of, 33 . 
Carnivora, Sitting over kill for, 165.

Chania lialls, 105.

Chectah, 49, So, y2, 104, 105, 229.

Ancestors of, 49 .

Behaviour of, 86 .

Coloration of, $49,244$.

Food of, 244.

General peculiarities of, $2+4$.

Length of leg of, 49 .

Native names for, 244.

Spoor of, $135,142$.

Chevrotain, 35 .

IJabitat, 35 .

Chimpanzee, 35 .

IIabitat, $35,165,168,245$.

Native names for, $2+5$.

Civet cat, $1+3$.

Flesh of, 245.

Habitat, 245.

Native name for, 245 .

Coast belt, 89 .

Coloration of game animals, 40.

Animal life of lower scale, 41,125 .

Birds taking butterflies, 43 .

Butterfies, shrews, and lizards, 43 .

Cheetah, 49.

Climate and environment, 46 .

Colours in the distance, 50 .

Complex laws, 52 .

Desert birds, 46 .

Determining factors, 40 .

Different colours, 47 .

Difficulty of sighting animals, $5 \mathrm{I}$.

Distinguishing colours, 59 .

Eggs, young, and females, 46 .

Eyesight of early man, 55 .

Faulty theories, 45.

General reasons for, 47 .

Ground colour of buck, 53 .

Human variation, 47 .

Hunting-dog, 49.

Influences of environment, 56 .

Investigation of theories, 40 .

Iridescent lizards, 45 .

Larger game and particular colours, $4 \mathrm{I}$.

Leopard, 48 .

Light-coloured bellies, 53 .
Coloration, Lion, 48 .

Lion observing game, 54 .

Male and female, 45 .

Mammals, 46 .

Jan as a hunter, 54,55 .

Outline of animals, 53 .

Paclyderms, 55.

Prevalent conditions of country, 54, 55 .

Protective theory, $42,56,61$.

Reptiles, 44 .

Rhinos resembling rocks, etc., 55 .

Savage in London, 51 .

Savages and civilised races, 45 .

Selous' conclusions, 4r, 50, 56 .

Sense of "lightness and darkness," 60 .

Sense of safety, 49 .

Sense of smell, 54 .

Severed wings of butternies, 43 .

Sexual selection, 46 .

Short-lived insects, 43 .

Spotted hyana, 48 .

Theory of utility, 46 .

Tropical insects, 42 .

Wallace's theories, 40.

White rumps of buck, 53 .

Zebra and hartebeest, 52 .

Colobus, $169,183,185,186$.

Concealment, 245 .

Croaking of, 169,245 .

Female and young, 245 .

Food of, 245.

Habitat, 245 .

Native names for, 245 .

On the sacred hills, 185 .

Red, 245;

Habitat, 245 .

Congo, 245 .

Buffalo of, 167 .

Chevrotain found, 35 .

Forests of the, 35,168 .

Game of the, 164 to 168 .

Porters from, 190.

Tropical belt, 26 .

Conviction and subsequent experience, 10.

Countries-

Boran country, 106, 258, 259, 266, 278, 288.

Bukedi country, 256. 


\section{Countries-}

Embei country, 105, 162.

Kavirondo country, 279, 287.

Kikuyu country, 185.

Kisii country, 105, 163,242, 256, 277, 279 (see "Errata").

Nandi country, 186.

Rendile country, $258,277,288$.

Samburr country, 258, 277, 288.

Sotik country, 105, 186.

Turkana country, 266, 288.

Country (types of) : Plains, The, $8 y$.

Sparsely clad bush-country, $121,1+7$.

Thick and tangled bush-country, 123 .

Thorn-bush and desert, 105.

Critics and the "sporting chance," 5 .

Critics on big-game shooting, 4, 5, 223, 224 .

Crocodile, 44, 86, 166.

Coloration of, 44 .

Food of, 92, 127 .

Game, Manlind and, 128.

Habitat, $2+6$.

Lying in wait, 92 .

Manner of walking, 246

Mlasses of, $167,2+6$.

Native names for, $2+6$.

Shooting of, 86, 128.

Cutting up an animal, 158 .

Desert (Taru), 30, $162,258,259,266,277,278$.

Red dust of, 89 .

Water supply, 3 o.

Deserts: Plains and, 119.

Spoor in the, 138 .

W'orld's belt of, 26 .

Dik-dik, 80, 170, 171, 229, 233.

Different kinds of, $2+6$.

rood of, 126.

llabitat of, 246 .

Hours of grazing, 175 .

Kinecpads of, $2+6$.

Native names for, 246 .

Sitting tight, 175 .

Stopping to look back, 175.

Carendish's, $2+6$.

Guntlier's, $2+6$.
Dik-dik, Hind's, $2+6$.

Kirk's, 246.

Dufile, 167,256 .

Dugong, Neat of, $2+7$.

Native names for, 247 .

Origin of mermaid, 247 .

Where caught, 247 .

Duiker, $49,64,80,170,171,229,233$.

Coloration of, $53,2+7$.

Female of, 246,247 .

Food of, 126, 247 .

Glands of, 62 .

Hours of grazing, 175 .

Native names for, $2+6$.

Sitting tight, 49,875 .

Stopping to look back, 175 .

Blue, $2+6$.

Harvey's, 161.

Coloration of, $2+7$.

Habitat, 247 .

Native names for, 247 .

Isaac's, $2+7$.

East Africa (British), 244, 246, 247, 257, 261, $265,284,287$.

A white man's country, 6,7 .

Administrated portions, 19, 186 .

Agricultural tribes, $2 \mathbf{I}$.

Area, 19.

Boundaries, 19.

Elephant-hunting in, 176 .

Forests of, 35,169 .

Gane in high altitudes, 31.

Game regulations of, 229.

I.azy habits of game, 29.

Local habits of game, 20.

Nasai tribe, 37 .

Natives tracking, 65, 197 .

Pasturage, $28,29,64$.

Picked trophy of usual hunting-grounds in, 70 .

Quantity of game in, 29.

Rainfall and dew, 2 S.

Rank grass of, 64 .

Kapid occupation of land, 21,231 .

Rare game, 4.

Rich in gane, 19. 
Kast Africa, Sable in, 230.

shooting and hunting in, 4 .

Slrooting of, 64 .

Shooting parties in, 203.

Southern Game Reserve, 19.

Stalking in, 124 .

Swamp-dwelling game of, 35 .

Tameness of game, 1,65 .

Town-hreal sportsmen, 2.

Tracking in, $13^{6 .}$

Trophy bunter in, 22.

Types of country in, 31,64 .

Inadministrated lands and native tribes, 102.

Uninteresting shooting of, 29.

Water in, $3 \circ$.

Waterluck of, $2 \mathrm{~S}$.

Egret, I 28.

Eland, $38,64,104,161,162,163,229$.

Coloration of, 53,256 .

Habital, 257 .

Inferior and superior horns of, 28 .

Native names for, 256 .

Spoor of, $142,143,146$.

Strong smell of, 62 .

Elephant, 5, 73, 80, 105, 106, 124, 160, 185, 186, 229.

A kingly sport, 5, 176 .

Alarmed, 180, 181, 251.

Approaching, 181 .

As a dangerous quarry, $176,177,251$.

Assisting wounded comrade, ISI.

At night in the forest, 170 .

At the salt-licks, 171 .

Breeding-grounds of, 166 .

Charging, IS2, 254.

Charms of hunting, 178 .

Dangerous elephants of Fnclave, i6 7 .

Description of hunting, $219,223$.

Difficulty of seeing tusks, 255 .

Distance at which shot, 85 .

Distribution, $64,8 \mathbf{1}$.

Elephant country, 5, 88,2 I 8.

lilephant rising, 255.

Elephant roads, 172, 252 .

Elephants of Enclave, 167.

Elephants of Masindi, 167.

Elephants more accessible formerly, 224 .
Elephant, Elephants winding the liunter, 220, 251 , 252,254 .

Enraged, 177,178 .

Extremes of labitat, $28,178$.

Famous elepliant centres, 164.

Favourite feeding-grounds, 184 .

Female, $171,176,182,253$.

Fighting inter se, 253,282 .

Finishing off an, 255 .

lits of rage, 176 .

Food of, 75,8 I 248,255 .

Grazing by night, $8_{1}, 107,170,248$.

Habitat, $105,106,107,162,164,165,166$, $167,168,185$.

Hair-prolucing power, 28.

llardships in hunting, 6, 176.178, 218.

llaunts of, 256.

Hearing of, $25 \%$.

Height of, 248,249 .

Herds' siesta, 171, 255 .

Highland and lowland ivory, 28 .

Hunting in the forest, $178,179$.

In a thunderstorm, 256 .

In bamboo, 171,179 .

Kineeling of, 255 .

Licence, 179, 223.

Listening for, $1 S_{1}, 219$.

I.ong walks after, 5, 178, 180, $218,222$.

Lungs of, 255.

Measuring an, 248,249 .

Native names for, 247 .

Native traps for, 183 .

Old bull, $176,252,253$.

On the plains, 107 .

Positions in falling, $18 \mathrm{I}, 248$.

Question of shots, 181,182 .

Range of smell, 251.

Range of vision, $25 \mathbf{I}$.

Reading weight of ivory, 250 .

Salt-licks, 252.

Separating and rejoining, 61 .

Shots at, $181,222$.

Size of foot and weight of tusks, 249 .

Size of herds, 252 .

Spoor of, $144,146,180,250,255$.

Spreading and feeding, 180.

Stampeding, 179, 251 . 
E.lephant, Stomachatic rumblings in, 251, 252.

Stores and canteen when hunting, 179).

Strong smell of, 62 .

Superstition concerning, 255 .

Tracking up of, $88,137,145,180,181,219$, 250.

Tracks of single eleplant and herd, 178, 179.

Trekking of, 118 , 1 So.

Trees and mud-bath, 249 .

Tusk impressions and inud-bath, 251, 255 .

Tusks, $169,252,253,254,255$.

Types of, 247.

Use of flour-bag, 180.

Weights of, 250.

Wind, 1 So, $219,220,251$.

Young eleplants, 253 .

Elephant-hunter, 124 .

Difficulties of the, 219,219 .

Elephant charging the, 254 .

lilephant, Fallen, and the, 255.

Nuch-abused, 217, 218, 223.

Rapid judgments of, 124 .

Elgon, 186, 257, 259, 266.

limbei (see "Countries").

Eimbu, 162, 242, 257 .

Enclave, 167,264 .

Lado, $188,244,246,256,261,266,279,287$.

E-uaso X̄giro, 105.

Fasso, 166.

Flies: Horsefy, 213.

Mosquito, 212.

'T'setse, 212.

Sandfly, 213 .

Sleeping-sickness $\AA_{y}, 213$.

Food and water supply, 28 to 3 .

Forest, Altitude of, 31,169 .

At midday, $169,170$.

Birds in the, 170 .

Break of day, 171 .

British East African, 169 .

Colobi in the, ifog.

Crafty game, 172, 173 .

Description of, 169 .

During the night, 170,173 .

Fallen giant tıces in. 171 .
Forest, From Kenya to Aberdares, 185.

Hewing down of, 21.

llunting in the, $172,173,178,239$.

IIunting tribes of the, $3^{8}$.

Interests of, $35,3^{\text {h. }}$.

Juniper forests, 169 .

Knowledge of spoor in the, 134 .

List of animals in the, 171 .

Progress and patience, 174, 175, 239 .

Quantity of game, 171, 172 .

Rhino in thick forests, 172 .

Spooring in the, 174 .

Tracking in the, 136,172 .

Tracks and paths in the, $171,172.173$.

The "going" in the, $35,85,169,173$.

Unclergrowth, $35,169,238$.

Visiting drinking-places, 173 .

Forest-dwelling game. 35 .

List of, 80 .

Forests: Aberdare, $2+5$.

Budonga, 245,248 .

Ituri, $26,168,245$.

Kienya, $162,185,2+5$.

Kilimanjaro, 245 .

Masindi, 248 .

Nau, 184,245 .

Nandi, 245, 257.

Ngong, 161, 247, 283, 285.

Nguzeru, 185 .

Forest-hog, So, 157, 161, 162, 166, 170, 1,1, I $\$$. . is6.

Habitat of, 239, 257.

Native names for, 257.

Paths of, 174.

Spoor of, 144 .

Three species of, 257 .

Fort Hall Road, $162,172,242,277,2 S_{3}$.

Fort Ternan, 186.

Fresh milk, 209.

Gase: Appearing on a flank, 121.

Bush and long-grass country, 104 .

Bush fires and grazing, y6.

Coloration of young. $5 \kappa$.

Daily round of, $y 6$.

Dillicult to see in bush, 51. 
Game, Disappearance of, 19, 20, 24, 106, 217.

liffect of cold on horns, 27,28 .

Family ties of, 100 .

Flight upwind of, 57 .

Game and the stationary object, 56, 60, 150.

Game of Uganda, 164.

Game on the plains, 89 .

Grazing upwind, 57.

Ilarmony with surroundings, 55 .

Joys and dangers of, 96 .

List of British East African, 39.

List of game in reserves, 229.

Lying up, $12 \mathrm{r}$.

Neumanı's liartebeest, 106.

Night grazing, 93 .

On sighting the hunter, $121,151$.

One method of approaching, 69 .

Packing together for protection, 95.

Peculiar glands of, 62 .

Plains-dweller and lion, 96 .

Precautionary measures of, 152.

Preservation of, 217 to 236 .

Range of approach, 68.

Scarcely visited haunts of, 108.

Sense of colour of, 60 .

Sprecial causes affecting changes in, 26 to 28 .

Sportsman's attitude towards, 1.

Stalking gamc, 109 .

Swamp and water dwelling. 34.

The leeward side and the foe, 55 .

The sportsman on the path, 68 .

Uncertainty in hunting big game, 5 .

What game rcly on for escape, 49 .

Wounded game of plains, 66, 130.

Dangerous: Ancient way of hunting, 83 .

Attacks of, 176 .

Charge of buffalo, 176 .

Charge of lioness, 176 .

Difficulty of bagging, 87 .

Enumeration of, 86.

Hazards run in hunting, $81,86,87$.

Ideas about, 82 .

Mauling by lions, 87 .

Modern way of hunting, 83 .

Native support, 198.
Game, Dangerolis, Sportsman's respect for, 82 .

The muzzle-loader and, 85 .

Writers at variance, $8, y$.

P'lurals of rhino and hippo, 17.

Protective colours and, 51 .

Statements, 10.

Tempcrament affecting observations, 18 .

Theories of arm-chair naturalists, 62 .

Views on thino charges, 15 .

Gas-hole, 161.

Gazelles, 258.

Glands of, 62 .

Clarke's, Rivalry of, 37 .

Grant's, 27, 63, 68, 80, 90, 104, 229, 233.

Habitat of, 27.

Horns of, $69,257$.

Native names for, 257 .

Northern form of, 105, 229, 257.

Peter's, So, 229.

Habitat, 258.

Roberts Grant's, 105.

I Iabitat, 105, 257.

Horns of, 257.

Rothschild's, 166,258 .

Habitat, 258.

Scemering's, 27, 229.

Habitat, $27,258$.

Native names for. 258 .

'Thomson's, 27, 68, 80, 90, 104, 229, 233.

Approaching, 69 .

Flesh of, 209 .

Habitat, 27.

Markings of, 258.

Natice names for, 258 .

Tameness of, $68,258$.

Waller's, 80, 105, 107, 161, 162, 229, 258.

Native names for, 258 .

Rivalry with Clarke's, 37 .

Specialised feeding, 34,258 .

Gazi, 162,283 .

Genets : Habitat, 35 .

Spoor of, $1+2$.

German boundary, 105, 106, 162, 163, 242, 256, $259,261,283,285$.

Giraffe, 34, 51, So, 129, 161, 162, 166, 229.

Coloration of, 50,53 .

Eyesight of, 259. 
Giraffe, Habitat, 104, 105, 107, 162, 259.

Height of, 259 .

Making off, 129,254 .

Native names for, 259.

Reticulated giraffe, 106, 259 .

Specialised feeding, 34 .

Spoor of, $1+3$.

Spooring the, 138.

Survival of fittest, 37 .

Glands in the groin, 62 .

Under the eye, 62 .

Gnu, 62, 63, 80, 92, 98, 104, 229, 233, 259.

Antics of, 259 .

Colourings and markings of, 259 .

Glands of, 62.

Habitat, 259.

Horns of, 259 .

Manner of grazing, $2+\mathrm{I}$.

Native names for, 259.

Number allowed on licence, 232.

Scent of, 260.

Sentinel of herd, 91, 259 .

Gondokoro, 165, 166, 256, 258, 259, 261, 265, 283.

Gorilla, 35 .

Grass, Length of, 167 .

Guas N̈giro, $257,258,278$.

Guas Ngislu, 26, 186, $229,243,256,257,261,277$, $279,283,285,287$.

Lion manes, 27 .

Roan found, 26 .

Situtunga reported, 36 .

Guernons, s 60 .

Guinea-fowl, 94, 184 .

HAвITS: Effect of human neighbours, $3^{6}, 37$.

Grass-eaters', 5 6).

Modification of, $3^{6}$.

1Jartebeest, in general, $63,68,98,134,164$.

Coloration of, 52,53 .

Food of lions. 52.

Glands of, 62 .

llorns of, 67 .

Number allowed on licence, 232.

Resemblance to ant-hill, 56.

spitting cough of, yo, 260.

Variations, 64.
Hartcbecst-

Coke's, 27, 64, 80, 104, 229, 233 .

Coloration of, 260.

Habitat of, 27, 106, 261 .

Ilorns of, 63 .

Intelligence of, $26 \mathrm{I}$.

Large herds of, 260.

Native names for, 260.

Quantities in reserves, 67.

Sense of sight, 260 .

Sense of smell, 260.

Spitting cough of, 260.

Stalking the, 68 .

W'ounded, 260.

Jackson's, 27, 64, 80, 233, 260, 261.

Coloration, 261 .

IIabitat, $27,107,165,261$.

llorns of, $63,26 \mathrm{I}$.

Native names for, $26 \mathrm{I}$.

Neumann's, 80.

Colour of coat, 64 .

Ilabitat, 10 h, 231,261 .

Horns of, $63,261$.

Preservation of, 230, $23 \mathrm{I}$.

Settlers and, 106.

Heads, Collecting, So, $\delta_{1}$.

Gem of plains-animals', 70 .

Lack of obtaining big, 2, 70 .

Highland country, Nature of, 21.

Hippo, 86, 95, 229.

Blowing of, 128.

Canoes and, 86, 166, 262.

Distribution, $64,262$.

Droppings of, 262.

Fat of, 262.

Fceding at night, 95.

Fighting between, 282 .

Ilippos" siesta, 132.

In the Nile, $86,262$.

Lions and, 166.

Native names for, 262.

Nature of, 166, $26_{2} 2$.

Shooting of, S6, 262 .

Spoor of, $1+5$.

liusks of, 262 .

Pigmy, 64.

Iloima, I 655,256 . 
Illorns: Cattle of Ankole, 165.

Difficulty of sceing size, 77 .

Diverse number of, 6z.

Grant's gazelle, 6y, 105.

llarnessed antelope, 165 .

Ilarteheest trophy; 6\%.

Ilollow-horned ruminants, 62 .

Indication of relationships, $6_{3}$.

Inter-male strife, $6_{3}$.

Onc-horncl, 63.

Ilunting dog, So.

Coloration, 49 .

Game and, 263.

Native names for, $26_{3}$.

Packs of, 263.

Spoor of, $1+3$.

Variation in types, $f_{4}$.

I Iunting zersus tracking and shooting, 1 .

llunters of ancicnt times, 83 .

llyæma (in general) as scavengers, 90.

Attacking slecping man, 86 .

Distribution, 64 .

Hyana cave, 90.

Hyæna valley, 90.

laugh of, 95 .

Mechod of killing wounded game, 67.

Spoor of, $13 \overline{5}, 1+3$.

Strong smell of, $6 z$.

The lion's kill and, y4.

Brown, 64 .

Spotted, 263 .

Coloration, 48,263 .

Distribution, 263 .

Family vault, 49,264 .

Howling of, 264 .

Lying up of, $26_{3}$.

Manes of, 263 .

Native names for, 263 .

Native reneration for, 264 .

Sleeping men and, 264 .

Striped, $64,264$.

Habitat, $26_{4}$.

Native Name, 264.

Hyrax, 35 .

Concealment of, $17 \mathrm{I}$.

Habitat of, 35 .

Trilling of, 170.
IIEX, $27,31,121$.

Impala, So, 92, 104, 105, 155, 158, 161, 229, 233.

Coloration, 53, 264 .

Distribution, 265.

l.yesight of, 92 .

Herds and males, 265.

llorns of, 265 .

Native names for, 264 .

Peculiar glands of, 62,264 .

Pig-like noises of, 265.

Superior and inferior horns, $28,160$.

Ithanga IIills (see "Mountains").

Ituri Forest (see "Forests").

Ivory: from Buddu, 164.

From the Bahr-al-gebel, 164 .

From the Nile, 164.

"Gendai" or "Congo," 165.

Highland and lowland, $28,248$.

Hollows in tusks, 252.

Ivory-hunter, 6.

Ivory profits and expenses, 6 .

Old caravans, 190.

Reading the weight of, 250 .

Tusks of 10olb., 167 .

JACKAL, 265 .

Cry of, 94, 265.

Distribution, 265.

Native names for, 265 .

Spoor of, 143.

The lion's kill, 95 .

Jigger, 213.

Jipi (see "Swamps").

Jubaland, 25, 186, 231, 257, 258, 259, 286.

Escort required in, 107.

Haunt of topi, 25.

Hunting tribes, 38 .

plains and bush of, 107.

Juja Farm, 260.

KAFU, 165.

Kamasia, 186.

Karamoja, 186, 256 .

Karungu, 163,256 .

Kavirondo crane, 94 . 
liedong valley, 106, 2\$2, 257, 277, 279, 283, 286 .

Kibagori, 256 .

Kijabe, $161,2+2,285$.

Kikuy'u escarpment, 38, 106, 126, 161, 18 4,188 , $245,256,257,264,287$.

Kilimanjaro (see "Mountains").

Kisii country (see "Countries").

Kisumu, 266, 279, 285 .

Kitui, 162 .

Kiu, 277,283 .

Kiunga, $2+2$.

Klipspringer, $31,120,229$.

Distribution, 31,64 .

Glands of, 62 .

Habitat, 31, I 20, 265.

Head of, 120.

Native names for, 265 .

Spoor of, $14+4$.

Kob (Mrs. Gray's), 166, 265.

Thomas's, $80,265$.

Coloration of, 265 .

Flesh of, 209.

Habitat, 107 .

Preservation of, 230.

Spoor of, 144.

Uganda, $164,165,167$.

White-eared, $166,266$.

Korokoro, 256.

Kuja Valley, 256.

Kudu (Greater), 7, 80, 106, 142, $161,168,229$.

kars of, 33.

Habitat, 31, 159, 266 .

Native names for, 266 .

Protected area, 7.

Skin and horns of, 34 .

Spoor of, $1+3,1+6$.

Lesser, $7,80,106,107,135,142,146,161,162$, 163,168 .

Distribution, $64,26 \%$.

Female and young, 121,14 .

llaunts of, 159.

Native names for, 266.

Spoor of, $1+3,14^{6}$.

LAkes: Albert, $28,165,242$.

liuslibuck of, $2+3$.
Lakes, IJarnessed antelope of, 165.

W'aterbuck of, $28,165,287$.

Bangweolo, 25.

Isolated sassaby, 25.

Reported water rhino, 34 .

Ellementeita, 261 .

Jipi, 278.

Magadi, 106, 277.

Naivasha, 20, 106, 231, 263 .

Allotted lands, 20.

Grant's gazelle, 20.

Nakuru, 231, $261,262$.

Rudolf, $27,262,266,29_{3}, 286$.

Beisa, 27.

Grevy's zebra, 27.

Oryx, 27.

Sœmering s gazelle, 27.

Waterless tracts about, 30 .

Solai, 106, 107, 231, 261.

Victoria, 107, 164, 168, 241, 262, $266,285$.

Lamu Archipelago, $162,2+2,243.247,263,266,284$.

Lechwe. 53.

Legisinan. 266.

Lemurs, 266.

Habitat, 266.

Habits of, 266 .

Native names for, 266 .

Leopard, So, 159, 161, 163.

IBaboon and, 127.

Coloration of, 48,244 .

Dangerous, $87,267$.

Distribution of, $64,267$.

Eiffect of habits of other animals, 36 .

Food of, 170, 171, 267, 2S5.

Habitat, $45,159,161,163,267$.

In short grass, 114 .

Lying up, 171, 267 .

Melanism, 267.

Native names for, 267 .

Rarity of secing. +8.

Shooting of 110,85 .

spoor of, $135,142,143$.

Spur on tail of, 275 .

licences: I meat-shooting licence, 233 .

Ainount of game allowed, 232 .

Buffalo, 'lie, 7,87 .

Elephant, The, 179. 
I.icences, Kinds of, 231, 234 .

I'rices for, 234 .

Situtunga, 'The, 165 .

Lion, So, 82, yo, 104, 129, 161, 164, 226, 267 .

Amulet of, 273 .

Attack and stalk, 48 .

Black manes of, 48,268 .

Bush-lion, 271.

Cannibalism, 276 .

Charge of, 176,177 .

Coloration and hunting, 47 .

Coloration of cubs, 49 .

Description of a shoot, $130,131$.

Distance at which shot, 85 .

Distribution of, $6_{4}, 6 y$.

Driving game, $57,98,273,275,276$.

Effect of mankind on, $3^{6}$.

Estimated success with, 5 .

liamily ties between, 100 .

Fat of, 272 .

Fearlessness of, 83,270 .

Food of, 268,271 .

Food of plains-lion, 52, 268.

Game following, 97, 268.

Going for stock, 11.

Habitat, 105, 107, 161, 162, 163,164, 166, 276.

Hippo, 166.

Hunting grunt, 11, 95, 273.

Hunting hours of, 97 .

Hyxna and, 94.

Incessant roaring of, $11,275$.

In reed-beds, 69,273 .

In the open, 69 .

Intelligence of, 33 .

Lion-men and non-lion-men, 9 .

Lions entering huts, 274.

Loudest roars of, 98 .

Lying up, 11, 12, 28, 90, 270, 277 .

Man-killing, 270, 273.

Maneless Masai lion, 27, 267 .

Mauling by, $s_{7}$.

Measuring a, 272 .

Method of hunting, 273 .

Nethod of killing large game, $27 \mathrm{I}$.

Native names for, 267 .

Night's kill of, $58,67,93$.

Of Masindi district, 164 .
Lion, Old liaunts of, 270.

On the warpath, 97.

Outclistancing the, 57 .

Passing close to game, 97 .

Plain-dweller and, 268.

Poison and traps, 7 .

Polyandry in, 27 א.

Railway train and, 270.

Reasons for roaring, 98 .

Returning to kills, 271 .

Roar of, 275,276 .

Roaring apparatus of, 11,275 .

Roaring before hunting, 11, 275

Seeing in the dark, 59 .

Seldon roaring, in.

Sense of smell, 59 .

Separation and re-joining, $6 \mathrm{~s}$.

Shot at long ranges, 85 .

Shot in twos and threes, 99 .

Size of teeth, 272.

Spoor of, 143.

Spur on tail of, 274.

Strong smell of, 62 .

Supcrior manes of, 33 .

Tail of, 244 .

Troops of, 268 .

Types of, 267 .

Upland and lowland, 27.

Vultures and, 276 .

Wanton killing by, 271.

Ways of shooting, 6 .

Wounded, $85,130,270,276$.

Wounded comrade, 99.

Loldiani (Londiani), 186.

Lumbwa, I 86 .

Machakos, $105,162,283$.

Mahagi, 167,256 .

Makindu, 259,278 .

Nalindi, $162,242,256$.

Maps: Mapping an unknown locality, 72 to 76 .

Man: An outsider, Sg.

Dressed for stalking, 125 .

Game and distant sight of, 96 .

Qualities of man in adversity, 99 .

'The black and the white, 205. 
Man, The only animal that hunts to excess, 9 f.

Tracking in the forest, i 74 .

Narkhor, $12 \mathrm{I}$.

Marsabit, 266.

Marsh mongoose, 93.

Food of, 93 .

Spoor of, $1+5$.

Time of feeding, 93.

Masai (see "Tribes").

Masindi, 164,165 .

Matapato, 277.

Mau Liscarjment, 38, 106, 161, 184, 257, 277, 279.

Maweni, 245 .

Mbale, 168,256 .

Measurements: Lion, 272 .

No proof of skill, 2 .

Tape measurementi, $\mathbf{i}, 2$.

Meat: Coke's hartebeest, 68.

keeping of, 233 .

Meat problem, 2, 3, 67, 232, 233.

Storing in a tree, 158 .

To obtain on trek, 68 .

Zebra, 69.

Meru, 256.

Mombasa, $162,247,256,272$.

Mosquito, 2 I 2.

Fever-giving kinds, 2 i 2 .

Ordinary, 212.

Mountains: Aberdare, 39, 106, 107, 161, 231, 247 .

$$
252,256,257,28_{3}, 287 \text {. }
$$

Hunting tribes of, 39 .

Forests of, 169, i $S_{5}$.

Known as Simbara, 106.

Nguzeru, 106.

Chamonyeru, $163,279$.

Doto Range, 288.

Elgon, $256,283$.

lthanga, $162,242,257,259,260,274,283$.

Buffalo, 162 .

Bushlouck, $162,2+3$.

Eland, s6r.

Giraffe near, 104.

Roan found, 26.

Kamasia IJills, $2+3$.

lienya, 39, 105, 126, 827,256 .

Vilephant roads, 173 .

Forests, ifig, 185.
Mountains: Kenya, Hunting tribes of. 39.

Kikamba, 279.

Kilibasi, 107,163 .

Kilimanjaro, $107,162,163,172,185,256$.

Kinangop, 39, $161,242,252,256,283$.

Kisii, 256 .

Lonongot, $2+2,26$ i .

Lorogai, 288.

Lukenya Hill, in .

Mumoni, 256, 259, 283 .

Nandi, 107, 157, 241.

Ngong, 104, 161, 2ł2, 287 .

Nguzeru, I 26, 127, 184 .

Nyeri, 257.

O] Doinyo Sapuk, $89,105,162,224,259,277$. $279,283$.

O-Satima, I61.

Simbara, I6 $1,163,1 S_{4}, 242,257,266,2 S_{3}, 2 S_{5}$.

Wakamba-land, III.

Watt, 256 .

Muhoroni, 107, 266.

Murchison Falls, I 66,246 .

NajRobi, $161,199,260,270$

Porters' wages in, 192.

Naivasha, 106, 181, 161, 277.

Natives: Abilities as hunters, 39,159 .

Burial customs, 49 .

Bushcraft of, 164 .

Courage of tribes, I89, 197 .

. in emergency, $58, \varsigma_{4}$.

Cultivations of, 21 .

Dogs of, 134,183 .

Filthy habits of, 205.

Game, Dangerous, $S_{3}, \delta_{4}, 134$.

Garrulous, 191.

Guides, : 87,189 , iyo.

Hy:ina and, 2fł.

ldeas of seeing game, 153, 154 .

Ideas of whispering, 72 .

"Khabar" of gime, 154, 179, 221, 240, 269.

Languages of, $\%, 10,5 y$.

I.eniency with, :93.

lions, Anulet ant, 273.

lion's roar, 58 .

Mleasuring spoor, 14f, 17y. 
Natives: Missiles in elephants, 17 h.

Nimbleness of. $s_{3}$.

Of Bahr-al-Gelel, 166 .

Of Lado Finclave. 187.

Ot North-lisstern Rhodesia. I 64.

Of Nyasaland, Ifot.

Orgies of, 157 .

Poisoned arrows of, $128,134,166,183$.

Sense of colour, fio.

Superstition concerning elephants. 255 .

The skilled hunter, I 82.

Tracker, 39. 70, 135, I 37, I 84,164 .

Tracking. 39. 134, $135,164,184,197$.

Traps and pits, 134. 183 .

Wounded game and the, 136 .

Wrong names given by, $1+2$.

Narrow escape, The, S6, 177.

Nettles, Giant, 23 S.

Ngongo Bagasi, 105.

Nimule, $166,259$.

Nile. 164. 166, 167, 206, 242, 256, 259,279, 280 , $2 S_{3}$.

Crocodiles of the, $2_{\downarrow} 6$.

Slecping sickness, 213.

Square-lipped rhino of, 167,280 .

Thorn-bush and Elephants by, 248 .

Nyasaland, 29, 247, 269.

Grazing of, 29 .

Natives tracking in, 65, 164, 197.

Rainfall of, 29 .

Wandering game, 29.

Nyeri, 161, 162. 1 84, 24t, $257,266,283$.

OKAPI, 35 .

Habitat, 35,168 .

Olbolossat, $26 \mathrm{I}$.

Ol Doinyo Sapuk, Sy, 105, 162, 2ł2, 259, 277 . $279,2 s_{3}$.

Bushbuck of, $2+3$.

Bush-countıy beyond, 104 .

Masai zarebas, 103

Oribi, 50, 64, 80, I66, 233.

Coloration, 50.53 .

Cover and concealment, 50.

Glands of, 62.

Habital of, $105,106$.
Oribi, Abyssinian, 106, $229,277$.

1 Iabitat, 277.

Native names for, 277 .

Haggart's, 107, 229, 277 .

Habitat, 277 .

Horns of, 277 .

Oryx (in general), 27, 64, 80, $107,136,256$.

is a trophy. 70 .

Habitat of, 106.

Hide of, 34 .

Markings of, 256 .

Spooring, $13 S$.

Spoor of, 144,160 .

Stalking, 70 .

Beisa, 80, 16 1, 168, 229.

Coloration of, 278 .

Female of, 278 .

Habitat of, $105, \mathrm{I} 68,278$.

Native names for, $27 \mathrm{~S}$.

Callotis, So, 105, 107, 161, I62.

liringe-eared, $162,229$.

Habitat, 278 .

Horns of, 278 .

Native names for, 278 .

Ostrich, So, 104, I66, 278 .

Collecting eggs of, 278 .

Habitat of, 278 .

llerds of, 278 .

Native names for, 278 .

Single male, 278 .

Sitting hen, 90 .

Unfertile eggs, 279 .

Otter, spotted-necked, 95 .

Ovis Poli, I 2 I.

Plains, 89 .

Charms of, 69, 1 i 9 .

Dawn over, 89 .

Deceptive look of, i 10.

Heat haze over, 91 .

$M$ ists of, $g 0$.

Most interesting occupation of, 69 .

Nature of, 89 .

Night on the, 94.95 .

Plains and the desert, I 19.

River of the, 126. 
Plains, Scavengers of the, 9o.

Seen from a hill, 110.

Stalking on the, $70,117$.

Termite hills of, $9 \mathrm{I}$.

The Sussex Downs and the, int.

Athi, 244, 257, 258,260,263,265, 277, 279, 283,286 .

Buftalo of, $2+I$.

Division of, 20.

lilephants on, 105.

I Lill of Lukenya, i I .

Maneless lion of, 27.

Rhinos of, 24.

Rough boundaries of, 104 .

Vastness of, 89 .

Zebra ranch on, 287 .

Beskaya, 107, 259.

Kapiti, 260.

Rough boundarics of, 104 .

Station, 111.

Vastness of, 89 .

Laikipia, 105, 161 .

Lake Victoria, 107.

Lemek, 105, 259 .

Mwea, 105.

Ndabibi, 106.

Rudolf, 105, 259.

Serengeti, 107, 258, 278.

Plain-dwelling game: Approaching water downwind, 57 .

Characteristics of, 32, 59 .

Daly routine of, i I 9 .

Fright and grazing, 58 .

Grachual grazing of, 119 .

Intellect, $32,57,58,97,9^{8}$.

List of, $8 \mathrm{o}$.

Sight of distant hunter, I1 O, I 20.

looking past an object, 99 .

l'lain-dweller and lion, 57,58 .

Powers of scenting, 98,99 .

Powers of sight, 99.

Seeing in the dark, 59.

Sumptuous existence of, 99 .

Stalking the plains-dweller, fog.

The lion's roar and, 97 .

Time spent in eating, 99.

Wariness and open country, 6y.
Plateau : Laikipia, 106.

Kinangop, 106.

Ngishu, Iof, 107.

Poisoning, 227.

Porcupine, 95, 279 .

Native name, 279 .

Nocturnal habits of, 279 .

Porters, 3, 58.

Advance of pay, syz.

Alarm of, I 29, I 31, I 97.

Authority with, 193.

Baganda, 192, 214 .

Banyoro, 192.

Camera and, 110.

Cooking Mbaazi, 3 .

Discarded articles and, 215.

Discipline among, 193.

Good work and, 3 .

Gun-bearers, 197.

Inability to track, 65, 191, 197, 19S.

Lion's Amulet and, 273 .

Load carrying by, 65, 190, 192.

Masai, ios.

Makon, 198.

Manyema, Iyo, iys.

Mnyamwezi, 136, 192.

Muhainmadan, 157.

Noise of, 72, 157, 190, 191, 202.

Of big-game expeditions, 191, 202.

Ofiences by, 193.

Orgies of, 157 .

Passing rhino, 13

l'rofessional porter, 65, 190, 192, 196 , I1) 8 .

Rations for, 3, 157, 205.

Reports of seeing game, 153,154 .

Rhino charge and, 14.

Runaway, 1yz.

Selection of, Iyy.

Shooting meat for, $3,65,233$.

Somalis, 198.

Soudanese, Iys.

Story telling among, 202.

Swahili, $13^{6}, 190,198,202,215$.

Topical songs of, 203 .

Trekking with, 187.

Unteliable, 191, 192. 
Porters, Usual pace of, $19^{\text {K. }}$

Village inhabitants and, 193.

Wiages of, 193 .

Wakamba, ry.

Wakikuy u, ryt.

Wanyamwezi, 190, 196, 198, 211.

Yao, iys.

Puku, 53

Punda milia, 105, $162,277$.

Rat (giant), 95.

Long-teethed ground, 95.

Ratel, 145 .

Ravine, $157,186,243$.

Reedbuck (in general). 64, 80, г64, 233 .

Flesh of, 207.

Lying up, 92.

Bohor, 106, 229. 279.

Habitat, 106, 279.

Horns of, 279.

Native names for, 279 .

Chanler's, 229 (see "Errata").

Found on hills, 3r, 279.

Native names for, 279 .

Peculiar glands of, 62 .

Mountain, 17, 91, 120.

Habitat of, 120 .

Head of, 120.

Ward's, 279.

Habitat, $107,279$.

Rejaf, 259.

Reserves, 89, 104, 105, 106, 277.

Budonga, 165 .

Coke's hartebeest in Southern, 67 .

Congestion of Southern, 20, 21 .

Dense thorn of, 229.

Masai in the, 101, 102.

Northern, 229.

Patrolling and up-keep of, 232.

Rhino, 104.

Scarcity of water in, 229.

Settlers and the, 229, 230.

Sogota, 229.

Semliki, Ir $4,164$.

Southern, 229.

Uganda, 164,230 .
Rifle: In the hands of the hunter, $S_{4}$.

Range and safety, $s_{4}, \delta_{5}$.

The heart-shot, 84 .

The magazine, 85,198 .

The question of bores, 157,1 y8.

Rift Valley, 24, 68, 106, 161, 184, 229, 241, 256, $258,277,279,287,261,266$.

Haunt of topi, 25.

Rhinos of, 24.

Roan found, 26 .

River : Athi, $162,259,260,263,277$.

Dhiba, I 62 .

L-uaso స̃giro, 104, $105,106$.

Juba, 246 .

Kafu, 263 .

Kedong, 161 .

Namindi, 262.

Ndurugu, 172,283 .

Nile, $164,166,167,206,213,242,246$.

Semliki, 28.

Stony Athi, 277.

Tana, $103,105,107,123,127,129,162,242$. $244,245,246,25^{6}, 259,262,270,278$, $279,283,286$.

Thika, 103, 262, 277, $28_{3}$.

Tsavo, 104

Victoria Nile, $26_{3}$.

Zambezi, 25.

Hippo and canoes, 166.

Sassaby, southward of, 25 .

Ziba, 262.

River of the Plains: At night, 2 S.

Fish in, 126.

General characteristics of, 126,129 .

The cool breezes of, 128 .

The edge, 126.

Thorn bush on banks of, 129.

Rhino, So, 91, 104, 118, $184,185,229,280$.

A galiant foe, 13,14 .

Agility of, 16.

Alarmed, 282 .

Approaching, 12, 13 .

Back shuffle of, 10, 281 .

Being on the alert for, 14,282 .

Biltong of, 157 .

Blind charges, 15 .

Charging "bald-headed," 14. 
Rhino, Coming for your wind, 14.

Difficult shooting, 14.

Distance at which shot, 85 .

Distribution, 64 .

Ease of shooting, $8,68,87$.

Ferocity of, 28 .

Figluting, 282 .

Food of, 280 .

Grass food of, 24,280 .

Habitat, 280,283 .

Hair producing energy, 27.

Inducing rhino to move, 12.

Infested country, 17 .

In pairs, 16,281 .

In thick forests, 172 .

Licence to shoot, 8.

Making détours, 13.

Making off up wind, 13.

Mrs. Rhino, 92.

Much molested, 12.

Mud-bath of, 92, 281 .

Native names for, 280 .

Numbers of, 8.

Open and bush country, 16, 160 .

Overdrawn hunting accounts, 12.

Peculiarities of square-lipped, 167 .

Peering down wind, 282.

Puffing of, $131,156,281$.

Resemblance to rocks, etc., 55 .

Retiring-places, 11,28 r.

Returning to droppings, 10, 11 .

Rift valley and Athi plains, 24.

Rhino calf, 281 .

Rhino path, 75 .

Rhino reserve, 104.

Sense of hearing, 281 .

Sense of sinell, 281 .

Sharpening horns, 282 .

Shortness of sight, $13,44,28 \mathrm{t}$.

Skulls of, 106.

Sores on underside, 282.

Sproor of, 145.

Strong smell of, 62 .

l'ongue of, $15 \%$

Uncertainty of lirection, 13.

Undergoing gradual clange, 23.

Walking across wind of, 156 .
Rhino, When dangerous. $8,23$.

White rhino, 167,280 .

Wounded rhino, 172, 281 .

Burchell's, 167, 280 .

$A$ grass-feeder, 280 .

I Jabitat, 280 .

Rhino birds, 282.

Sores caused by, $2 \delta_{3}$.

Stalking the, 12.

Rhodesia, North-eastern, 2y.

Grazing of, 29.

Native trackers of, 164 .

Rainfall of, $2 y$.

Roan, 80, 229, 283 .

Coloration, 278.

Habitat, 26, 105, 106, 107, 283 .

Native names for, 283

Spoor of, 144

Ruwenzori, $257,267$.

SАвакт, $258,286$.

Sable, $80,82,136,161,163,283$.

Coloration of, 56 .

Habitat, $28_{3}$.

Horns of, 278 .

P'reservation of, 230 .

Spoor of, $144,146$.

Salt lick, 96, 252.

Description of, 96 .

Samburu station, $107,288$.

Sandgrouse, 93.

Saragoi, Sirgoi, 107, 186, 256.

Sassaby, 25.

Isolation of, 25.

Where found, 25.

Scaly manis, 185,284 .

Secretary bird, 94 .

Semliki Reserve (see "Reserves").

Semliki valley, 287.

Serval, $80,104$.

Food of, 95, 284 .

Length of tail, 284 .

I.ying up, $2 s_{4}$.

Mlanner of sitting, 284 .

Melanism, $2 S_{4}$.

Native names for, 284 . 
Serval, Patrolling patlis, 95.

Sitting tight, $2 s_{4}$.

Spoor of, 142,143 .

Varieties, $2 S_{4}$.

With young, 93 .

Sesse Islands, 165,285 .

Shooting-

Dangerous game, 87 .

During a year's trek, 233.

Lack of future grounds for, 21 .

Long.range shooting, 120, 226.

Moderate, $23+$.

Modern short-shooting trips, 4 .

Plains animal and bush animal, 77 .

shooting en roule, 67 .

Shooting in Jubaland, 107.

Shooting in the bush, $149,150,152,160$.

Shooting in the forest, 175 .

Shooting meat for porters, 3 .

Shooting meat for pot, 3,226 .

Shooting two or more lions, 100.

Shooting zersus hunting, 66 to 88, 119.

The "sport" of plains shooting, 70 .

The sportsman in, 225.

Usual procedure in shooting game, 66.

Waiting at water-holes, 69 .

Sight and stationary objects, 42, 99 .

Simba station, 105,107,260, 277, 278 .

Situtunga, 285 .

A herbivorous animal, 165 .

Foot of, 34 .

Habitat, 165,285 .

Licence for, 165 .

Peculiarities of, 34,165 .

Preservation of, 230.

Spoor of, 143.

Skulls, 106.

Sleeping sickness, 213.

Solai, $26 x$.

Somaliland: A famous leopard of, 267.

Giraffe of, Io6.

Rainy season of, 29.

Sotik country (see "Countries").

Species: Formation of new, 23, 268.

Horns of, 63 .

Rivalry between, 36,37 .

Splitting up of, 64 .
Spoor, 69, 74, 134 .

Antelope and buck, $1_{4} 6$.

Classed spoors, $1+2$.

Comparison of various, $142,143,144,145$, 146.

Dead grass and new grass, $139,140$.

Early night spoor, 139 .

Elephant, 144, 178, 1 So, 181, 255.

Forest paths and, 173 .

Fresh spoor, $71,136,180$.

Hind and fore foot, 146 .

Hyxna, 135.

In green grass country, 139 .

In the desert, $13^{8}$.

In the forest, 136,173 .

Nale and female spoor, 145,146 .

Measuring, 144,145 .

Morning spoor, 139 .

Old tracks and new, 139 .

Rhino and hippo, 145.

Search for kudu, $159,160$.

Special points in spooring, $137,138,139,173$, 174.

Sport: Dangerous game shooting, 87 .

Luck and success, 77 .

So-called "sport," 70, 228.

Sporting codes, 77 .

The preservation of game and, 224 .

Sportsmen: A favourite resort for, 107.

A shooting test for, 235 .

Advancing on game, 151 .

Amassing heads, So, $117,228,232$.

Anusing stalking, 67 .

An untouched country, 107.

Animal bluffing, 152,282 .

Animals crossing river beds, 138 .

Arts of bush-craft, 70 .

Best training country for, 226 ,

Big game shooters, 226.

Bringing the rifle to bear, I 21

Carried to game, 67 .

Code of rules for, 229 .

Definition of a, 225 .

Elephant hunting, 175,177 .

Exaggerations, 81.

Game-bird and big-game shooter, 217.

Hunting lion by day, 69 . 
Sportsmen, Licences, 231, 232, 234 .

Long range shooting, $120,226,235$.

Naking sure of a shot, 117 .

Methods of shooting game, 66, 69 .

Native and wounded animal, 27.

Native tracker and, 135, 136, 159.

Of the plains, irg.

Preservation of game, 217.

"Safaris" and, 197.

Securing good heads, 232.

Shooting reserves, $231,235$.

Sighted by game, 151 .

Situtunga and, 165.

Stalking and tracking, 123.

Stampeding elephants and, 179 .

Standing still, 122.

The bush-game hunter, 77 .

The novice in tracking, 124 .

The sportsman unarmed, 85 .

The stalking enthusiast, 120.

The true sportsman, 228 .

Unsporting methods of, $70,226,228$.

Visiting drinking places, 173

Wasting meat, $228,232$.

Wounding game animals, 68 .

Stalking: Animal coming into view, 116,121 .

Animal on sighting hunter, 121.

Appearing on the skyline, $\mathbf{1} 20$.

Appreciation of cover, 110, 112, 119, 123 .

Appreciation of lic of country, $110,111,119$.

Approaching, 110, $111,151$.

Barking of knees and clbows, 117 .

Committing objects to memory, if 2.

Crawling, $117,118,150$.

Disturbed game herds, 1 i 8.

Drawback to plains-stalking, 120.

Dress for, 124,125 .

Easiest country for, 123.

Erratic movements of animal, 115 .

For a camera shot, rog.

Forgetting the legs, 115.

Folds in the ground, I 10, III, II 8.

Game on a flank, 12 r.

Glades and recesses, 12 r.

Glasses an aicl in, 116,119 .

lland and knec approach, 117.

Heat of the sun, 17.
Stalking, In long grass, 117.

Keeping a straight course, 115 .

Keeping to the shade, 121 .

Iateral and oblique movements, 122 .

Leather knec pads for, 17 .

Locating other animals, i $6,122$.

Long crawls and waits, 117 .

Long open spaces, 122

Movements in, 121, $122,125$.

On drawing out of sight, 122.

On standing still, $122,125,158$.

On the plains, $70,117$.

Perfect and imperfect cover, II $, I_{1}, I_{4}$, $117,122$.

Plane of sight, i 22.

Practice in, 111, 115.

Quickness of eye, 121 .

Rubber soled foot-gear, $120,150$.

Running towards cover, 114.

Screened objects, 111 .

Short grass country, II 4 .

Study of lrabits of game, irg.

The bush on the ant hill, 117, is

'The deep-cut watercourse, i 12.

The clliptic curve, $115,16$.

The secret of success, 177 .

The shady side of cover, $116,120$.

The stalker's true country, 119 .

The stationary animal, 115,151 .

'Time and patience in, IIO, 117.

Topping a rise, 119 .

Understanding "distance," 113,115 .

Understanding of light and shadow, $113,114$.

Stcinbuck, 53. So, 104, 229, 233.

Coloration, $53,285$.

Glands of, 62 .

Native names for, 285 .

Sitting tight, 285.

Stony Athi pools, 260.

Reed-bed, 270.

Strife between males, 63 .

Suni (see "Zanzibar").

Sursi antelope, 163 .

Swamps: Jipi, 105.

Loriani, 106, 186, 256.

Nyiri, 105, 256. 278.

Olbolossat, 263. 
Taxaland, $186,259$.

Ilaunt of topi, 25.

Hunting tribes of, $3^{8}$.

Tape, Roll-measure, 144 .

Tapirs, 52.

Taru desert (see " Deserts ").

Tareta, $107,162,284$.

Termite hills, 91 .

Termites, 171 .

Thorn bush, 160.

Three-mile-tree, 260 .

Topi, 8o, 105, 285.

Coat of, 286 .

Habitat, 25, 105, 107, 286.

Herds of, 286 .

Prescrvation of, 230.

Toro, 164.

Tracking, 88.

Among grass tufts and sand, $13^{8}$.

Attractions of, $4,70,160$.

Branches across the path, 124 .

Droppings of elephants, 250.

Dry countries, 139.

Fresh tracks and the animal, 123.

Game in near neighbourhood, 123,136 .

Going tip-toe, 123.

In green grass country, 139 .

In the desert, 138 .

In the forest, 172 .

Leaves and twigs, 123.

Making detours, 136 .

Method of spcedy tracking, 137 .

Native inabilities in, 39, 65, 197 .

Old tracks and new tracks, 139 .

Special points in tracking, $137,138,139$.

Special uses of, 137 .

Testing each step, 123 .

The tape measure in, 144.

Tracking elephants, $137,250$.

Tracks into river-bed, 138 .

Types of country for, 123 .

Transport: Pack-transport, 187 .

Wheel-transport, I 87 .

With porters, 187.

Trek, 187 to 216 .

A few tips for comforts, 203 to 216 .

Amount of food stores, 207.
Trek, Arranging details with guides, $187,190$.

Articles for barter, 206.

Authority with porters, 193, 194.

"Blocking" paths, $19^{6}$.

Charms of, $187,201$.

Continual wettings, 214.

Dealings with villagers, $194,195,206$.

Discarded articles and porters, 215.

Discomforts of insects, 212,213 .

Finding one's way, 199.

Firewood, 187.

Game meats, 209.

Guides of Lado Enclave, 187.

In the rainy season, 214.

Local guides, $187,189,195$.

Local supplies, 208.

Medicine for natives, 206.

Milk-fresh, 209, 210.

Nilk-tinned, 2 Io.

Mosquito nuisance, 2 I 2.

Native cooking, 208.

On "doing oneself well," 207, 208.

Porters' loads, 195, 196.

Search party, igo.

Slight description of, 129 to 132 .

Storing flour, 207.

Supply of cooking pots, 209 .

Tent on, 196.

Transport, Pack, i 87.

Transport, Porters, 187, 188, 190, 191, 192, 193.

Transport, Wheel, 187.

Use of donkeys, 205.

Washing, 215.

Water supply, i 87 .

When lost, 201.

Tribes: Abyssinians, 229.

Baluchis, 229.

Galla, 162 .

Kienya, 2 I.

Kikuyu, $25,3^{8}$.

An agricultural people, $3^{8}$.

As hunters, 38,135 .

Hunting grounds of, 39 .

Kikuyu Wandorobo, 39 .

Masai, 21, 2 27, 244.

A pastoral people, 100 . 
Masai, Ancient origin of, $37,230$.

As hunters, 38, 135, 182 .

As porters, 198 .

Buffalo-hide shields, roo.

Courage of, 58, 100.

Food of, 37, 100, 103.

Government agreement, 102, 230.

Healing of wounds, 100.

Huts of, 103.

Ideas of fresh milk, 209.

Lion's mane and, 100.

Lions near kraal, 101.

Masai problem, $10 \mathbf{r}$

Masai Reserves, ror.

Masai zarebas, 102.

Northern Reserve, 106.

Organisation, 101.

Relations with game, 38, 100, 101.

Rinderpest and, ro3.

Rhinos and, 28 s.

Tail hairs of giraffe, 100 .

Tobacco, snuff, 103.

Trekking for water, 230.

Wandorobo or Ogieg, $3^{8 .}$

Weapons of, 103.

Women and loads, 103.

Nandi, 136.

Prolific African, 2 .

Rendile, 102.

Samburr, 102.

Somali, 162, 198, 22y.

Sudi, 58 .

Waboni, 38 .

Wandorabo (or Ogieg), 38, 39, 103, 135, 1 82, 185.

As forest hunters, $38,65,135,136$.

Food of, $1 s_{4}$.

Language of, 103,182 .

Nethods of huming, $183,24 \mathrm{I}$.

Ogieg and Masai, 103, 182 .

Serval and, 284.

\%ebra and, $2 S 7$.

Zulu tribes: Angoni Zulus, 25.

Courage of, 58 .

Tsetse-1ly, 212 .

Trophies, 81, 233, 234, 235.

Turkana, 866.
UGANDA, $2+3,244,245,256,261,266,267,279$, $28_{3}, 28_{4}, 285,287$.

Best shooting ground in, 165 .

Buffalo, $7,2+2$.

IElephant tracks in, 144 .

Elephants shot in, 176 .

Forest hogs in, 257.

Forests of, 35 .

Game of, 164 to 168 .

Game reserves of, 164 .

Horns of cattle, 28 .

Hunting in Masindi, 165.

L.eopards of, 267 .

Porters of, 197.

Shooting parts of, 164 .

Situtunga, 35 .

Tracking in, 136.

Tropical belt, 26.

Uganda kob (see "Kob").

Ukambaland, 89, $10_{4}$.

Vol, 107.

Country round, 123.

Vultures, 235,276 .

WanELAI, I 67, 256 .

Wakambaland, 162.

Wami, 277.

Wart-hog, So, 104, $2 S 6$.

A "sounder" of, 92.

Distribution, 64, 286.

Ilabits of, 286 .

Method of entering hole, 286 .

Method of feeding, y3, 286 .

Native names for, 286 .

Spoor of, 144 .

Strong smell of, 62 .

Tail of, 92, 256 .

Waterbuck, 28, 50, 91, 107, 155, 161, 164, 165, 166.

$$
22 y, 233 .
$$

Coloration, 286

Cow-kicks of, 287 .

Flesh of, 200.

Ilabitat, 287 .

kind meeting kind, 155.

Native names for, 286 . 
Waterbuck, Number on licence, 232.

Spoor of, $1+4$.

Strong smell of, $6 z$.

Sing. Sing, 107, 229, 233.

Colorition, 287 .

Habitat, $107,165,287$.

Horns of, 287 .

Native names for, 287 .

Watercourses, $112,138,1+7,1+8$.

Inspection of, 153 .

Water-holes, 129.

Bleached skulls by, 90,98 .

Looking for, 75,76 .

Spoor about, 67,74 .

Visiting, 173 .

Water supply, 28 to $30,108,229,278$.

Wind, $124,149,156,175,180$.

YAYA, $2 S_{5}$.

Yellow-barked thorn-trec, 126.

ZaNZ1Bak, 190, 245, 266.

Zanzibar Suni, 80, 161, 285.

Habitat, $107,185,285$.

Native names, 285 .

Zebra (in general), 68, 80, 98, 104, 105, 120.

Allowance on licence, 233 .

Zebra, Ancestors of, 52 .

Cheetah and, $2+4$.

Cont of the, 50.

Easy to approach, 68.

Flesh of, $233,287$.

Food of lions, 52, 288.

Intelligence of, 99,287 .

Manner of grazing, $24 \mathrm{I}$.

Mistaken for rhino, $5 \mathrm{I}$.

Protective coloration, 50, 52 .

Stripes of, 53.

Strong smell of, 62 .

Teeth of, 233,287 .

The plains from a zebra's point of view, 90 .

Yellow fat of, 287 .

Burchell's, 229.

Chapman's, 287 .

Habitat, 288.

Inquisitireness of, 287 .

Native names for, 287 .

Grani's, 27.

Grevy's, 27, 105, 229, 288 .

Braying of, 288 .

Habitat, 27, $105,298$.

Native names, 288.

Size of, 288 .

Zorilla, $1+5$.

Spoor of, 145. 

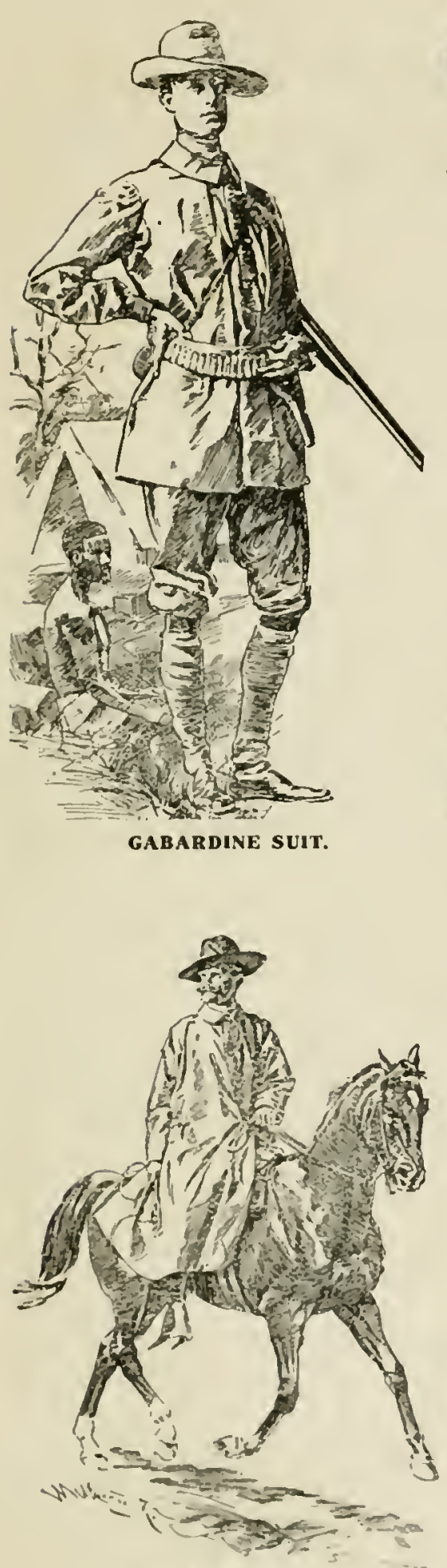

TIIE BURBERRY (Rlding Pattern).

\section{GA B ARDINE}

The Registered name of Burberry Material, which has done more than any other item of Exploration Equipment to bring the darkest recesses of the earth into the light of human knowledge.

In Gabardine a Sportsman can face the cruellest thorns and heaviest rains, the Mountaineer can scale the steepest heights.

Everywhere between Petersburg and Gibraltar or Cape Town and Cairo, from Bombay through Tibet to Pekin, across the great islands of Australasia and the lonely atolls of the Pacific to the two Americasfrom farthest South to Farthest North, Gabardine has afforded protection and comfort to pioneers of Science, Sport, or Civilisation. For the less hazardous purposes of Shooting and Fishing at home, or for Winter Sports in Switzerland, Gabardine is "facile princeps."

Light-in-weight, Air-free and Weatherproof, Warm in the cold of IVinter, Cool in the heat of Summer. No more cogent evidence of Gabardine's extraordinary qualities could be instanced than the fact that all Polar Expeditions have been fitted out with the tropical texture of this fabric-thinner than that recommended for the regions of the Equator.

July, I 909 , Mr. Bede J. B. Bentley says:-

"I am returning one of your Justly tamous Burberry Coats used by me on my recent automobile tour across Somalliand and Abyssin:a. It has had twelve manths of the roughest work it was pussibte to put it to-in lact, unjustly so; but it stIII retalns allits waterproot propertles.

To glve you an Idea as to how roughly It was used-I used to put four stlcks in the gruand, the up the corners, and use it as a bath. On several occeslons. when crossing rlvers with my car, I used to cover the front of the radiator with if ta prevent the rush of water to the engine. I have used it to store water In when In camp. Alter losing all my blankets I used to sleer in It.

"During part of the Journey thraugh Somalliand, where we had to cut a passage through the heavy scrub, my clothes got so torn tbat I had it to grotect myself. The drIving aprons I made Into a Blvouec, but they were stolen by natlves on the latter part of the trlp.

$\because$ My tents were a great success in the tropical ralns. I have trled many so. CALLED waterprojis in varlous parts of Africa, but they only remain 80 for the llist lew weeks.

"MY MOTTO NOW IS, IVEAR A BURBERRY AND KEEP DRY."

\section{Patterns and \\ full \\ particulars \\ of \\ Gabardine \\ Burberry-Kit \\ sent post-free}

to any part

of the World.

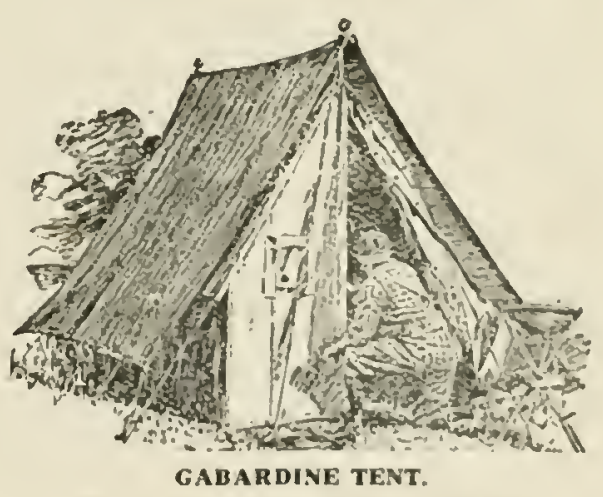

Extremely Light, Imperishable, and Non-Absorbent.

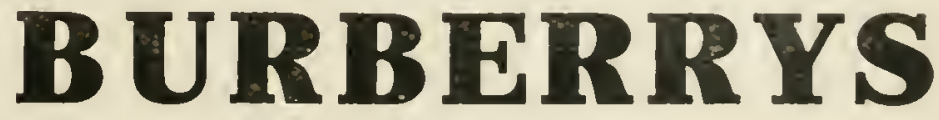

30 to 33, Haymarket, LONDON. 10. Bvd. Malesherbes, PARIS. BASINGSTOKE and Provincial Agents. 


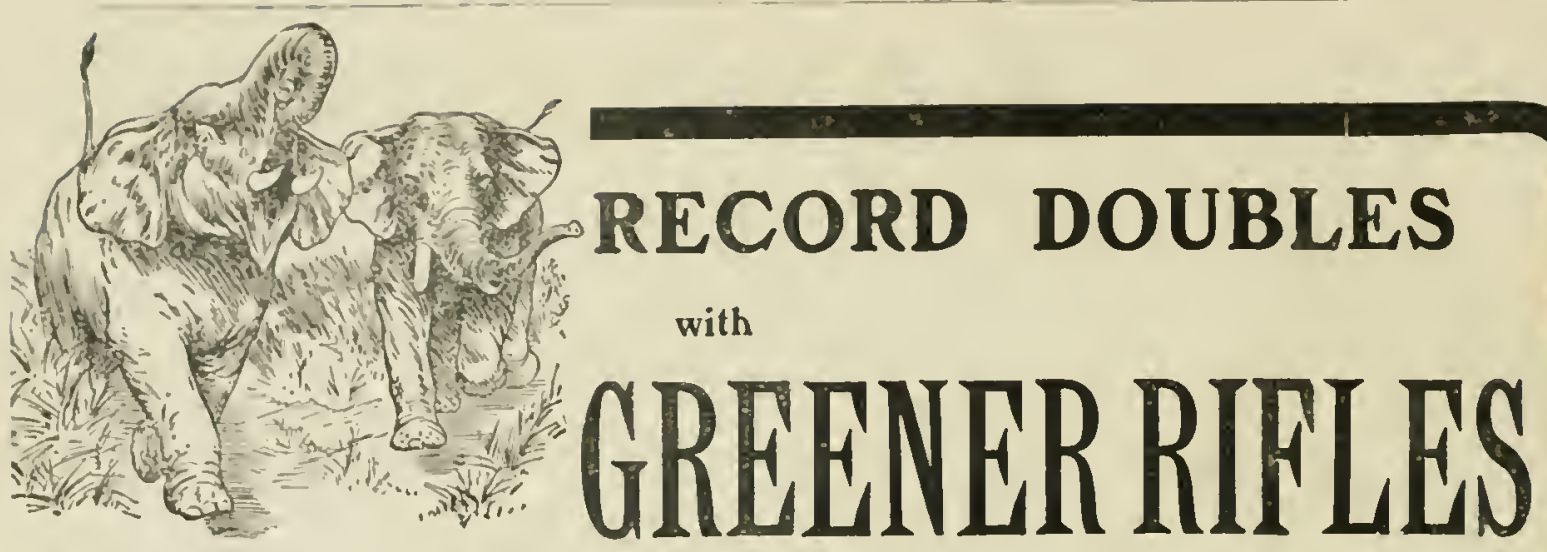

The unsolicited commendation of disinterested Sportsmen carries greater conviction than columns of self-laudatory descriptions.

"I got two rhino, right and left, with the $450 / 400$ you made me.-Kedong Valley, B.E.A. 1/2/09."

"Elephants were at lijijabi about thirty miles from here. I borrowed a double-barrelled rifle made by GREENER, carrying 30z. bullets, each hitting with a weight of 50olb., and started after them. I believe this rifle saved my life. I have not time for details now, but I may say that I got below the elephants on the side of a hill. Something above must have frightened the herd, and about fifteen came thundering down upon me. Fortunately they were scattered, and only two saw me. Both charged-one in front and one on the right. I dropped the front one at six yards and the second at ten yards from where I stood. The first was stone dead, and a ' 303 finished the other. Both were males. It had been considered almost an impossibility to kill an elephant from the front with an ordinary heavy rifle.-C. C., Limoru, March 21, 1905."

"As regards the shooting qualities of the guns you made me, they were absolute perfection. $M y$ best record was twenty-five buck and a pig out of twenty-seven shots ( 5777$)$. Mly sixteen hippopotam out of seventeen shots is a matter of history in the Shinte-Highlands.-CHiNDE."

W. W. GREENER RIFLES have been famous since the days of G. P. Sanderson and Sir S. Baker. Rifles made then are STILL doing good work.

W. W. GREENER'S DOUBLE-BARRELLED, HIGH-VELOCITY RIFLE, Hammerless Treble Wedge Fast Action, made in $303, \cdot 375 \cdot \cdot 450 / 400$, and 475 calibres,

Price

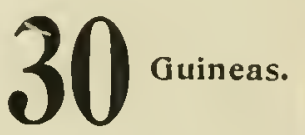

W. W. GREENER'S SINGLE-BARREL, HIGH-VELOCITY RIFLE, Martini Action, Simplest and Strongest extant. 303 or 375 calibre. Delivered Free in British Empire

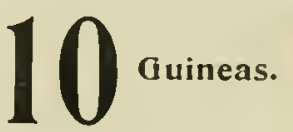

Price LIsts of Shot Guns, Single and Double Rifles, Choke Bore Rifles, etc., Post Free.

\section{W. W. GREENER,}

THE ENGLISH GUN MAKER,

\section{8, HAYMARKET, LONDON, S.W.}

Head Office and Works: ST. MARY'S SQUARE, BIRMINGHAM. 


\title{
LANG'S :470 SPECIAL HIGH VELOCITY RIFLE FOR BIG GAME. Muzzle Velocity, 2,III f.s. Striking Energy, 4,943 ft. Ilos.
}

\author{
(More powerful than an s.liore Black powder rifle).
}

This cartrifge as originally designed did nut, in our opinion, cume up to at sulliciently high standarl, and in conseppence our expert visited Messrs, liynoch's works, and in eonjuntion with their experes cunducted a si:ries of experimenth extending wer three weeks, whis ately designing the bullets now in use from this popul $r$ rifle J. L. \& S. (herefure

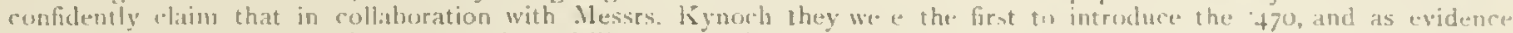
submit the following extrase from the Field, and illustration of the actual diagram made lu.fore $t$ e editor of that journat.

Fiveld, March 23, 1907: "A very" viluible adıane has been ach eved, and Messers l,itng are to be congratulated on their enterprise in so promptly bringing forward a rifle and cartridges, o mplying with the qwo must pressing demands in Sporting Rifles, viz, a weapon to take the place of the pruhibited +50 , and a car ridge which shows an adbance in flatness of irajectory, with il diminution of recoil and pressure."

THE BEST DIAGRAM male before the Editor of the "Fivld" with a rifle of this bore.

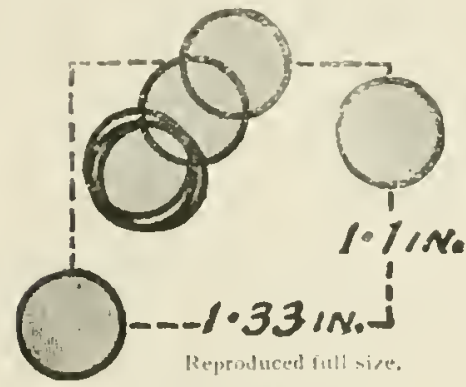

7 Shots st 100 yards with Lang's 470 Sporting Rifle.

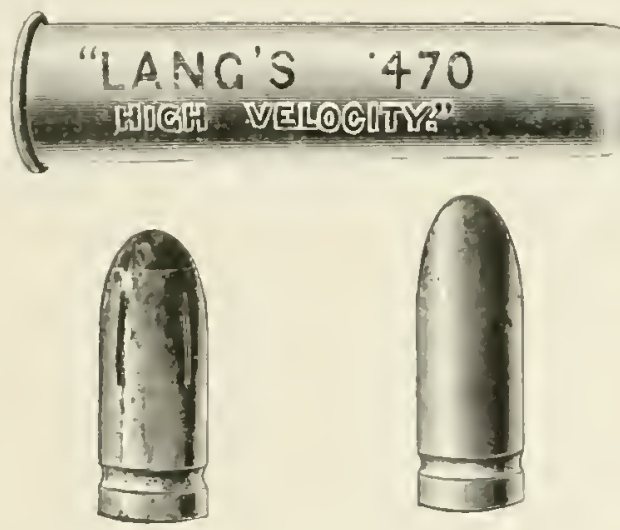

Soft-nosed split bullet.
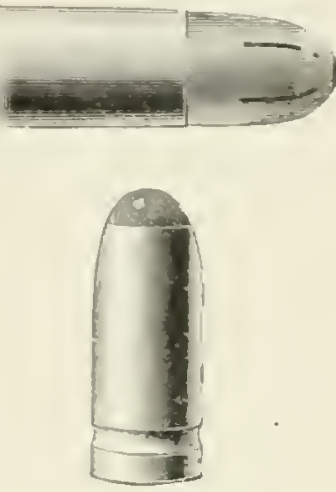

Solld bullet.

Solid soft-nosed bullet.

\section{No. $2 \cdot 360$ Bore.}

In comparisun wath the $400 / \cdot 3$ bn the muzate selocisy of this new

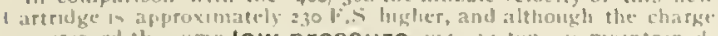

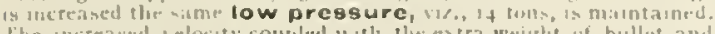
The increared lelocity coupled with the extra weight of bullet and practicalls the stopping power of a 450 or $500 \mathrm{Black}$ Powder Exprosg, all is cuncequents an ideal weapon for deor stalking and for snooting heavier forms of deor staking and tor snooting heavier forms of non-dangorous game: moremer, lis cenciplestere withe

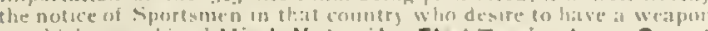
in whichinciombincd High Velocity, Flat Trajectory, Great Striking Energy, Minimum Recoll, and in whlil, throms.t,

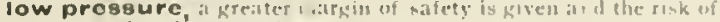
jammsag reducedio a musuimum.

Velocily 2,150 F.S., Striking Energy 3,280 ft, Ibs. PRICES OF BOTH TIIE ABOVE:

Single Barrel Falling Islock...

Dushle Harrel IIn mumer

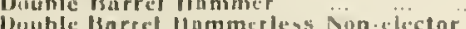

bouble in-rel IInmmerliso Iijecior

$20,25 \div 30$

27,40 , 50

35,60 \&5

$35,50 \& 55$
$\ldots 40,55 \& 70$

" Rifle" Catalogue", contarning full particulars of abone and others from "256 to "o00 bore", pest freit on application.

\section{JOSEPH LANG \& SON, LTD. Estnbllshed 1821 .}

102, NEW BOND ST., LONDON, W.
The accuracy is of the higlyest ordere, ats will be seentl by the atrompanying diagram mate by the listitor of the Fiseld and not by a profensional expe-

"FIELD."

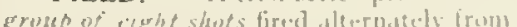
inaret to bint

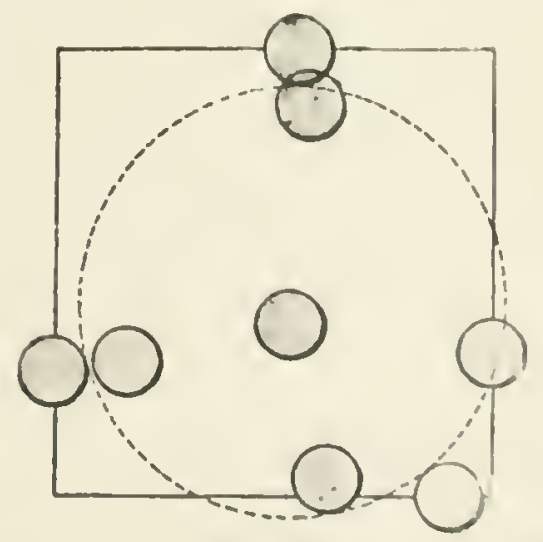




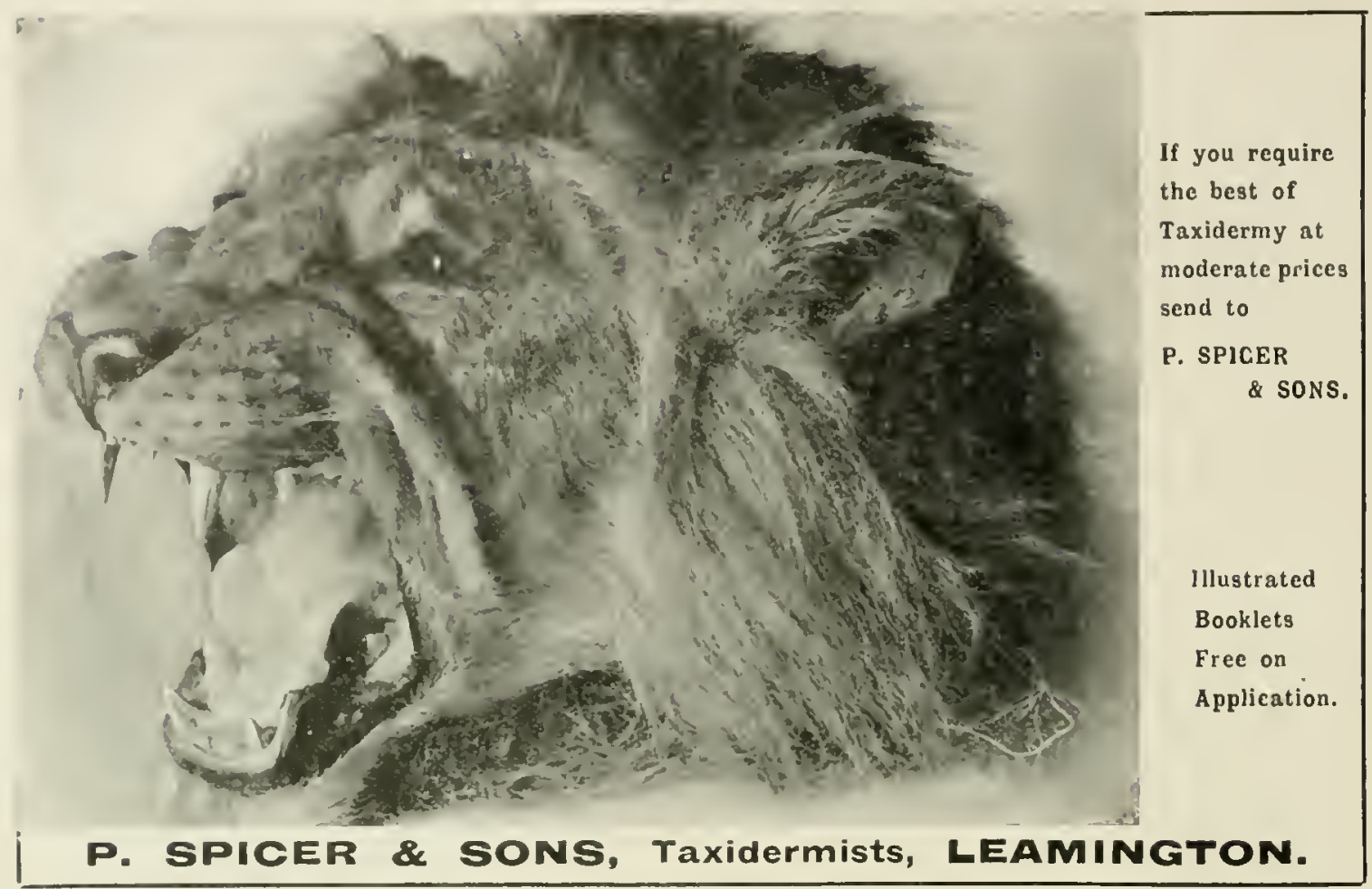

\section{EVANS' Hammerless GUNS \& RIFLES.}

EJECTORS from 20 grineas to $\mathbf{5 0}$ guineas. NON EJECTORS from 10 guineas. DOUBLE HAMMER GUNS from 8 guiness. COROITE BALL and SHOT GUNS - HAMMER from 20 guineas, HAMMERLESS from 25 guineas.

EVANS' HIGH VELOCITY CORDITE RIFLES.

HAMMERLESS from 25 guinens.

HAMMER from 20 guneas. 360 to $\cdot 500$ bore.
SINGLE from 15 guinens.

MAGAZINE from 14 guiners.

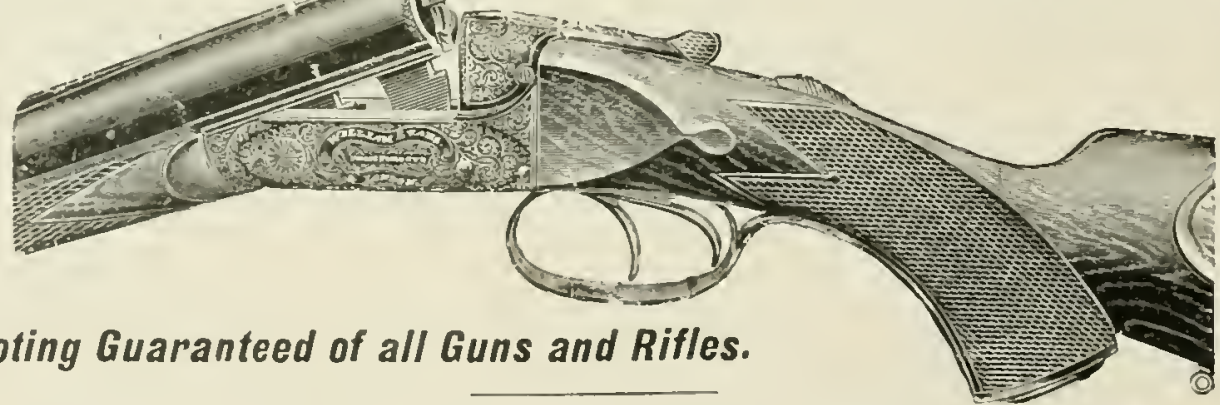

Own Private Shooting Ground close to London for Testing and Improving One's Shooting.

THE LARGEST STOCK OF SECOND-HAND GUNS AND RIFLES IN LONDON. LISTS ON APPLICATION.

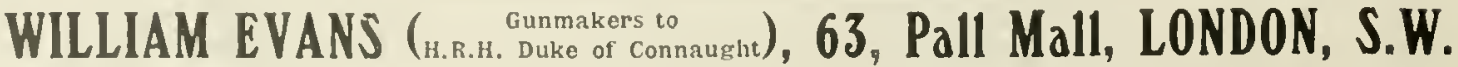




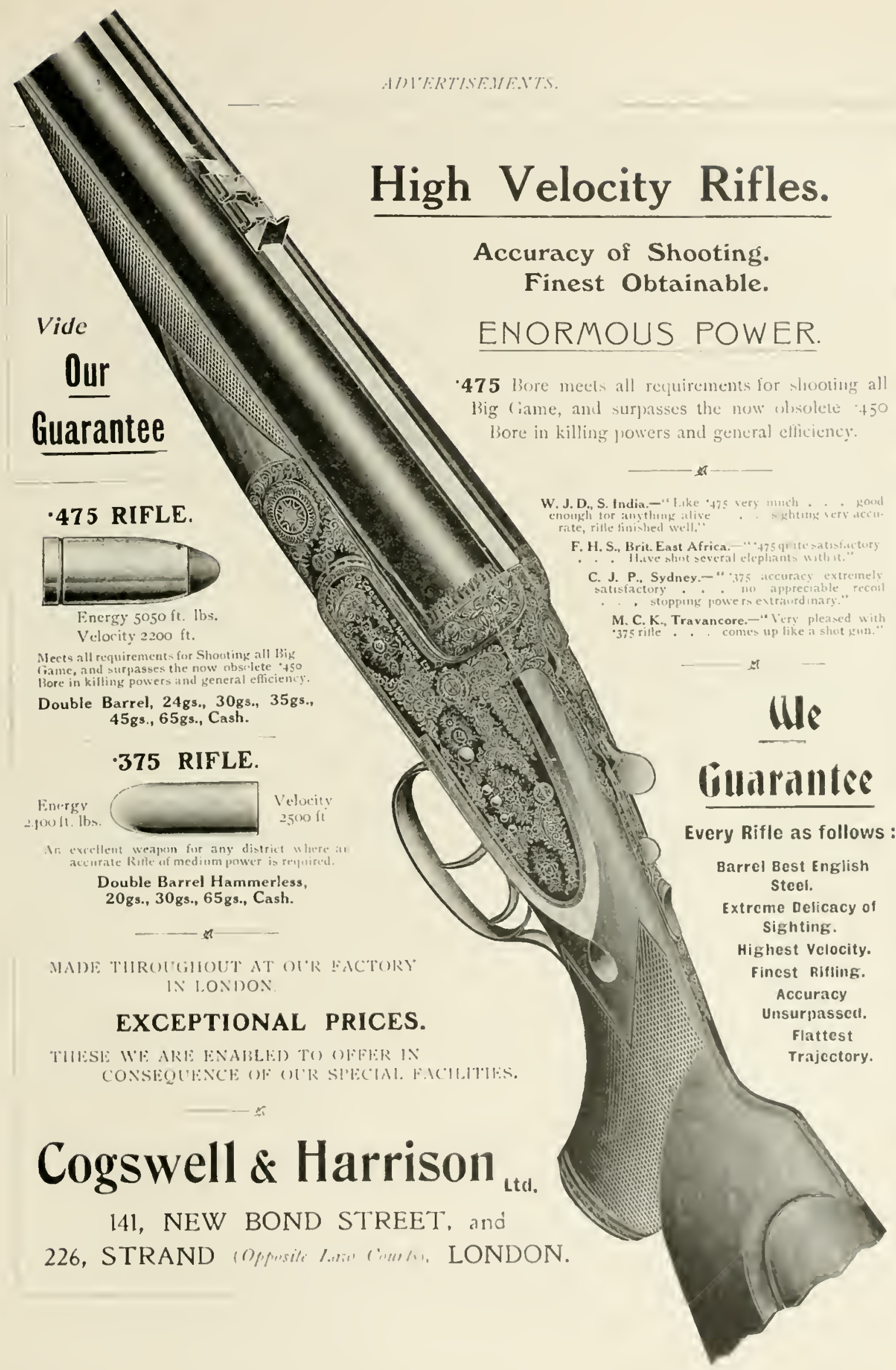




\section{RICE BROTHERS \& CO.}

Sporting and Military Tailors.

Makers of the Celebrated

WESTBURY COAT

for SHOOTING and GOLFING.

lavaluable to Sporismen. Rainproof Without Rubber.

Fixtriet irom FIFI.D of Derember .3, 1004

"It will werve equally well the sheoter. the fisher, and the follfer, the

leacling idea being that it mus sleld to the shoulder when the gun,

rod, or chub is in actom, and at all times give the maximum of case

and frecelnm. "Thin it certisinly does, and the result is achered ly a

s.ries of expanding pleats that are most effective without heing

wheler how the me of an earlier generation endured the hide. bound

contumen whuch are $(t)$ be seen in nld pictures of tield spent"

29, George St., Hanover Sq., LONDON, W.

Northern Nigeria, Southern Nigeria, Gold Coast, Sierra

Leone, British East Africa, B.S.A., Uganda, Nyassaland.

WAY

THE
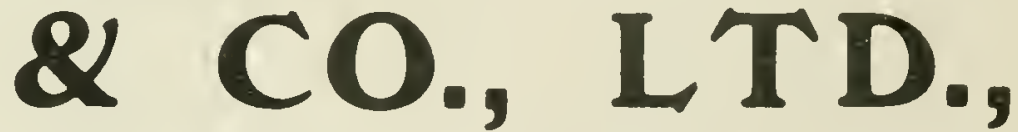

AFRICAN TRAVEL,

Will be pleased to supply any Information and Advice regarding necessary Equipment, Route, and Transport, \&c., to Sportsmen.

For the convenience of Sportsmen, Military Officers, Civil officials and others going abroad

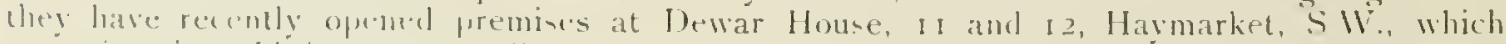
comprise, in atdlition to a well-arranged suite of genteral and private offices, a spacious Warehouse, containms an extensive and comprehensive astorment of impedimenta typical (s) the repuirements of sojourners in Iropical countries.

MESSRS. WAY \& CO., LTD., have special facilities for the mounting of HORNS and TROPHIES. Careful and artistic mounting combined with first-class workmanship.

Goods purchased and sent out to Customers.

WAY \& CO. act as buying Agenls for Firms on lowest possible Commission.
All kinds of Insurance effecled :

LIFE (with special rales for Africa). FIRE, MARINE, and ACCIDENT.

DEWAR HOUSE, 11 \& 12, HAYMARKET, LONDON, S.W. 


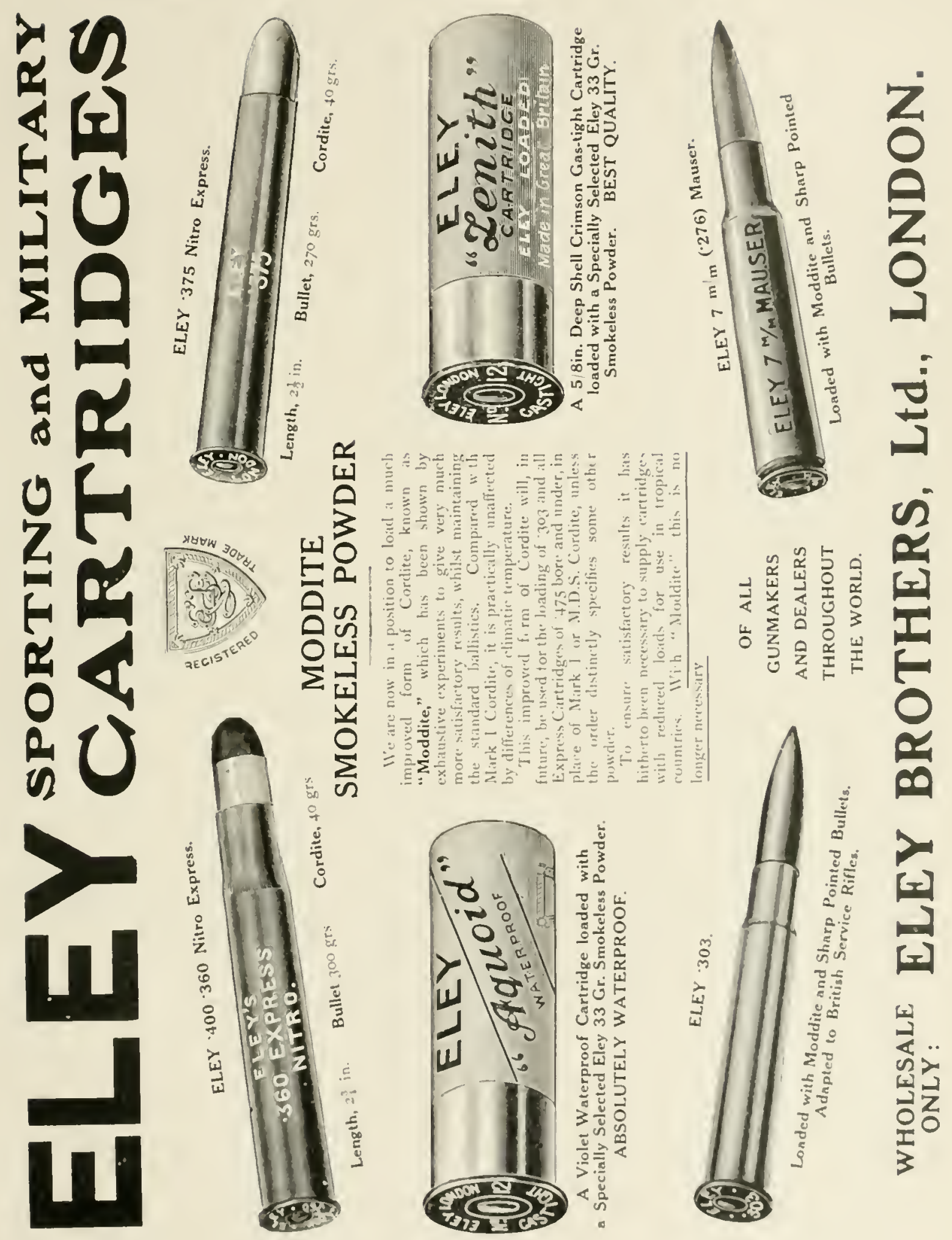




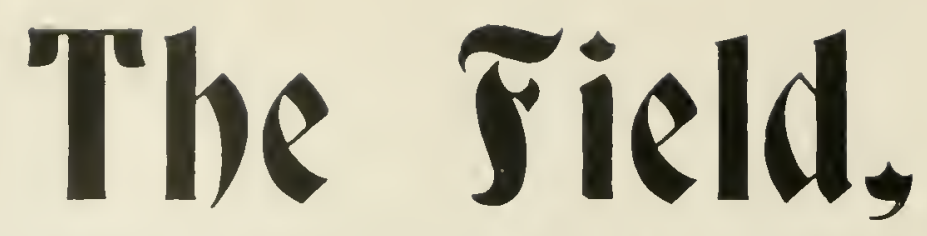

THE FARM, THE GARDEN, THE COUNTRY GENTLEMAN'S NEWSPAPER.

PUBLISHED EVERY SATURDAY, PRICE SIXPENCE, BY POST 6:d.

This paper is devoted entirely to the interests of Country Gentlenen, and is the largest and most lnfluential of its kind in the United Kingdom. The subjects are treated in the fullest manner by the foremost writers of the day, and comprise:-

SHOOTING.

CRICKET.

VETERINARV.

FARM.

PASTIMES.

BEE-KEEPING.

ACCLIMATISATION.

FISHING.

RACING.
WILD SPORTS.
GARDEN.
BRIDGE.
WHIST.
POULTRY.
PISCICULTURE.
HUNTING.

RACING.

GARDEN.

BRIDGE.

WHIST.

PISCICULTURE.

HUNTING.

\author{
YACHTING. \\ STABLES. \\ COUNTRY HOUSE. \\ CHESS. \\ PIGEONS. \\ TRAVEL. \\ COURSING. \\ ROWING.
}

\author{
KENNEL. \\ ATHLETIC SPORTS. \\ DRIVING. \\ NATURAL HISTORY \\ LAWN TENNIS. \\ CYCLING AND \\ MOTORING. \\ \&c., \&c., \&c.
}

Where thought advisable subjects are illustrated in the best manner possible.

THE FIELD is additionally interesting to Country Gentlemen, Sportsmen, Naturalists, and others, as it is the Established Medium for ADVERTISENIENTS in connection with the following matters :-

Shooting, Fishing, and Hunting Quarters; Estates and Farms for Sale or to Let; Poultry and Pigeons; Gamekeepers, Bailiffs, Gardeners, and other Servants; Yachts for Sale and to Let; Horses and Carriages for Sale; Dogs, Stud Horses, Stud Dogs, Farm Implements, Farm Seeds, Garden Seeds, New Books, Hotels, Housekeeping, and Miscellaneous Articles.

Subscription to Foreign Countries: Yearly. fl 19s. 6d.: Six Months, 19s. 9d.: Three Months. 9s. 10d.

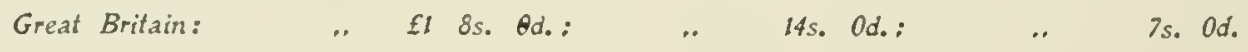
.
14s. Od.:

TENTh AND New EDition. In Super-royal Svo, with more than a hundred and twenty Plates, price EI 5s. net; by post is. 6d. extra.

\title{
DIXON KEMP'S MANUALL OF YACHT AND BOAT SAILING.
}

\author{
EDITED BY B. HECKSTALL-SMITH, \\ Associate Institution of Naval Architects, Secretary Yacht Racing Association, etc.
}

(THE LORDS COMMISIONEIRS OF THE ADMIRALTY HAVE BEEN PLEASED TO DIRECT THAT THIS BOOK SHOULD BE ISSUED TO SHIPS OF THE ROYAL NAVY.)

HORACE COX, WINDSOR HOUSE, BREAM'S BUILDINGS, LONDON, E.C. 


CENTRAL UNIVERSITY LIBRARY

University of California, San Diego

DATE DUE

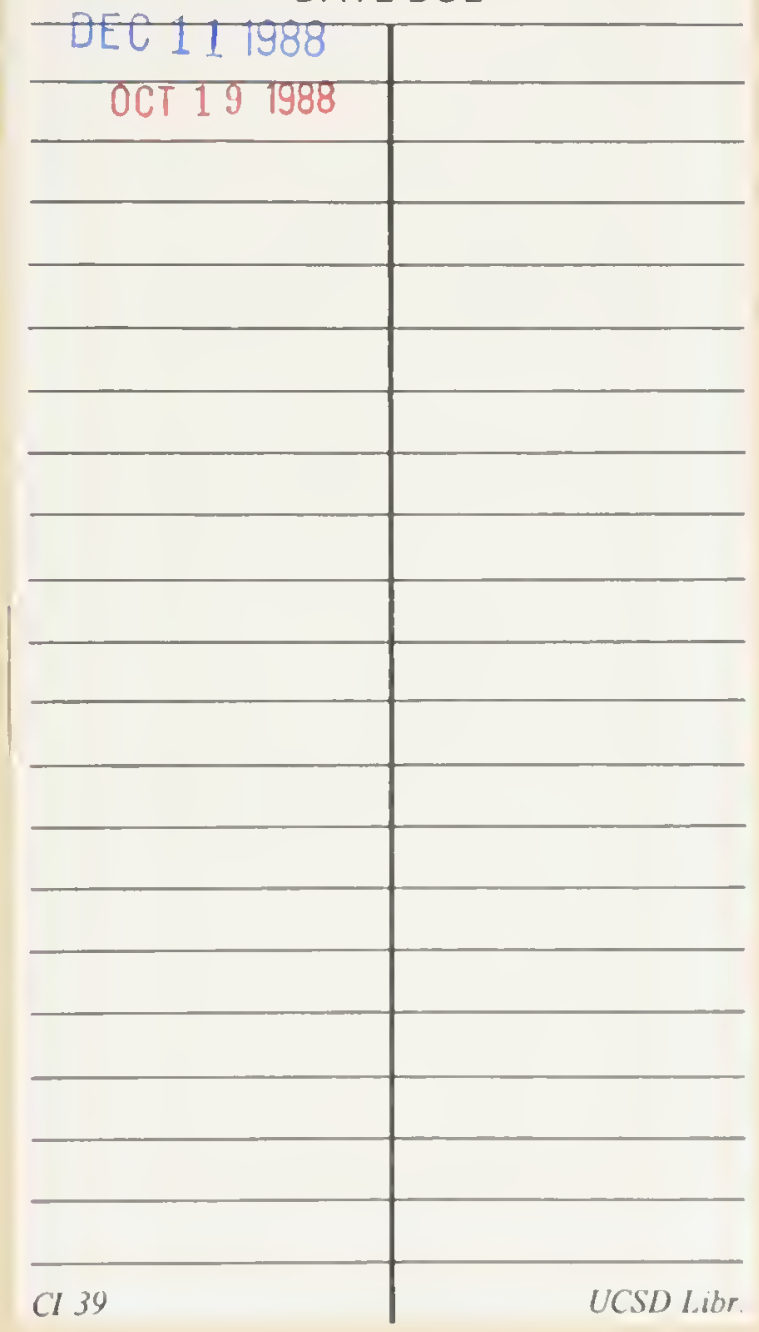




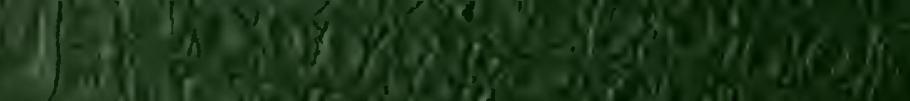

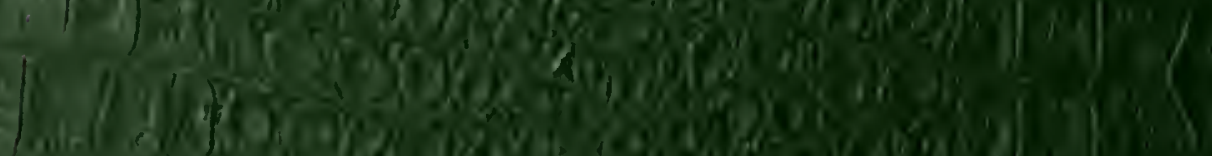

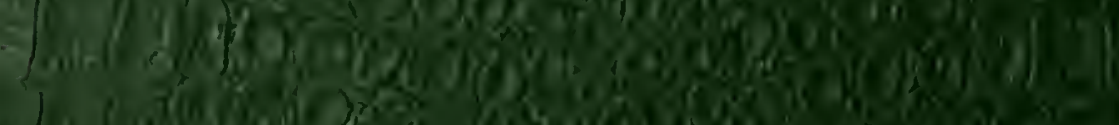

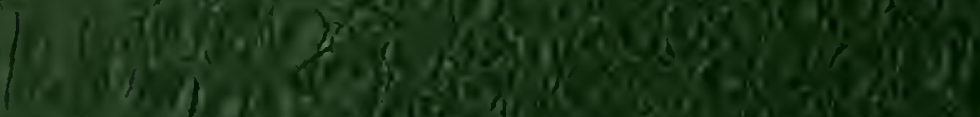
1.7.4 wow

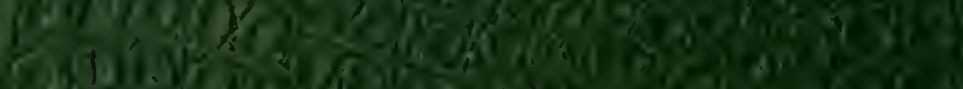

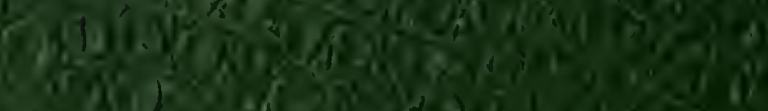

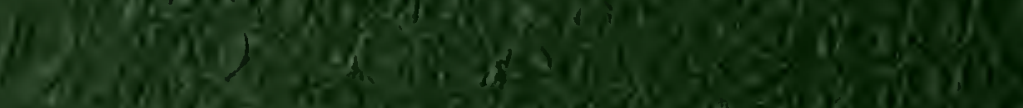

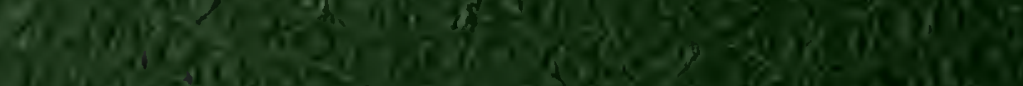

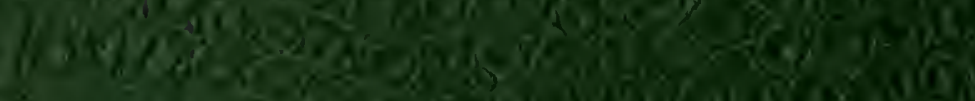

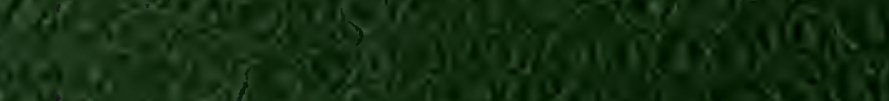

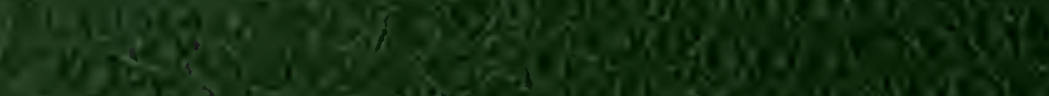

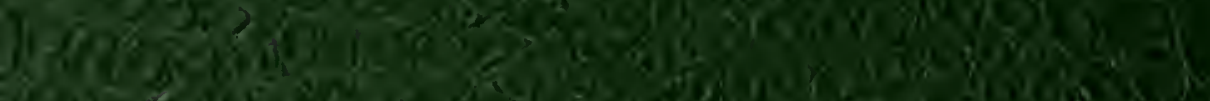

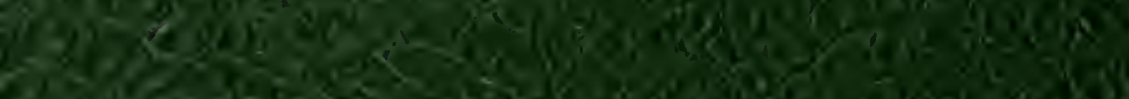
Qs

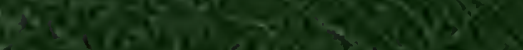
Pans

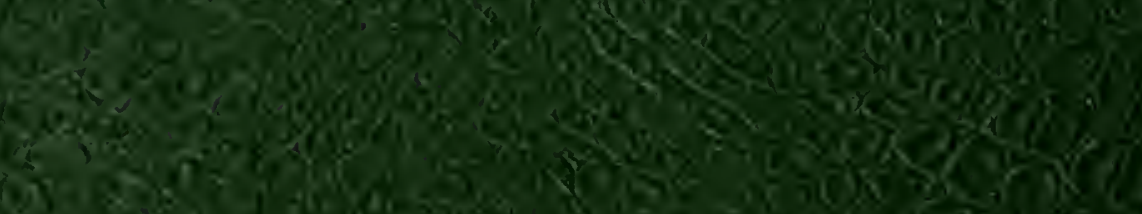

(5)

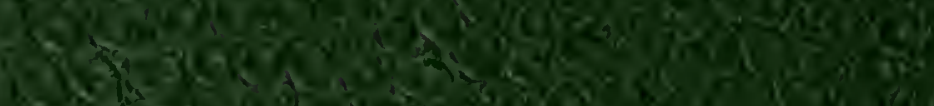

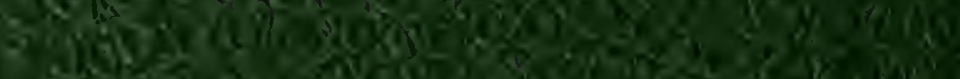

18

roves

Sive

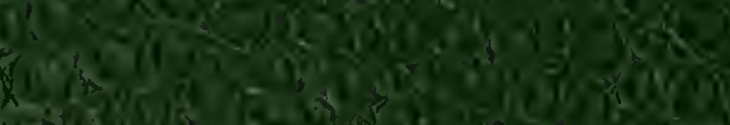

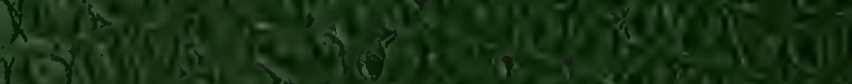

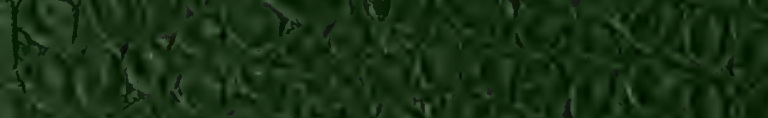

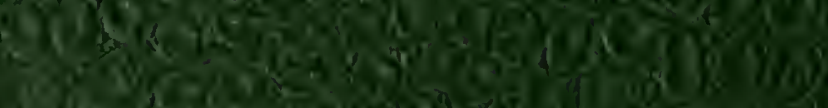

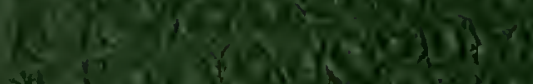

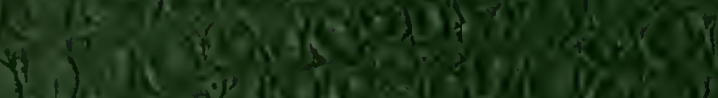

- whe

S. 302

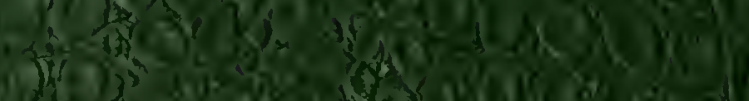

-

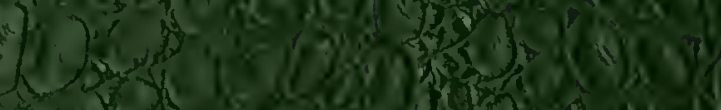

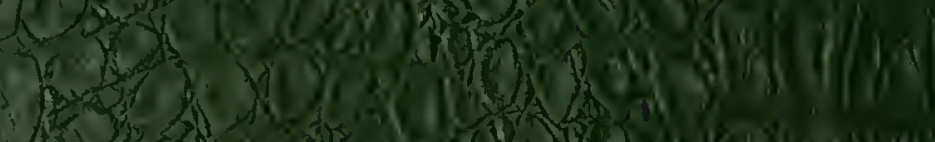

Wu

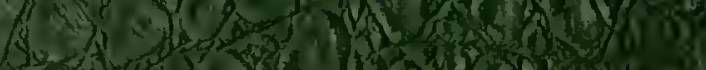

